\title{
Site response analysis and seismic surveying of high contrast soil profiles for the city of Ottawa
}

\author{
A thesis submitted to \\ the Faculty of Graduate Studies and Research \\ in Partial Fulfillment of the requirements for the degree \\ Doctor of Philosophy
}

by

\section{Kasgin Khaheshi Banab}

\author{
Department of Civil and Environmental Engineering \\ Carleton University
}

Ottawa-Carleton Institute of Civil and Environmental Engineering

September 2010

(C2010 Kasgin Khaheshi 
Library and Archives

Canada

Published Heritage

Branch

395 Wellington Street

Ottawa ON K1A ON4

Canada
Bibliotheque et

Archives Canada

Direction du

Patrimoine de l'édition

395 , rue Wellington

Ottawa ON K1A 0N4

Canada
Your file Votre référence

ISBN: 978-0-494-70525-4

Our file Notre référence

ISBN: 978-0-494-70525-4
NOTICE:

The author has granted a nonexclusive license allowing Library and Archives Canada to reproduce, publish, archive, preserve, conserve, communicate to the public by telecommunication or on the Internet, loan, distribute and sell theses worldwide, for commercial or noncommercial purposes, in microform, paper, electronic and/or any other formats.

The author retains copyright ownership and moral rights in this thesis. Neither the thesis nor substantial extracts from it may be printed or otherwise reproduced without the author's permission.
AVIS:

L'auteur a accordé une licence non exclusive permettant à la Bibliothèque et Archives Canada de reproduire, publier, archiver, sauvegarder, conserver, transmettre au public par télécommunication ou par l'Internet, prêter, distribuer et vendre des thèses partout dans le monde, à des fins commerciales ou autres, sur support microforme, papier, électronique et/ou autres formats.

L'auteur conserve la propriété du droit d'auteur et des droits moraux qui protège cette thèse. $\mathrm{Ni}$ la thèse ni des extraits substantiels de celle-ci ne doivent être imprimés ou autrement reproduits sans son autorisation.
In compliance with the Canadian Privacy Act some supporting forms may have been removed from this thesis.

While these forms may be included in the document page count, their removal does not represent any loss of content from the thesis.
Conformément à la loi canadienne sur la protection de la vie privée, quelques formulaires secondaires ont été enlevés de cette thèse.

Bien que ces formulaires aient inclus dans la pagination, il n'y aura aucun contenu manquant. 


\section{Abstract}

Seismic surveying and site response analysis of several sites in the city of Ottawa were studied. The motivation for this research arose due to two main reasons: First, Ottawa is rated third in terms of highest seismic risk in Canada. Second, some sparse earthquake recordings in the region along with the surficial geology of the city accentuate the hazard. The surficial geology of the city consists of high velocity contrast soilbedrock formations that can trap seismic waves and lead to large seismic amplification.

A fast seismic surveying method, the multi-channel analysis of surface waves, was implemented to discern the high shear wave velocity contrast in Ottawa area and the capability of random search inversion was verified for most of the examined profiles. The reflection/transmission coefficients method for site response analysis, which can simulate the internal wave reverberations, was modified using a shaking-intensity damping scheme.

Site response analysis using the finite element method confirmed the observed large amplification ratios from the weak motion recordings, but on the other hand, indicated limited peak amplification ratio for the shaking intensities used in geotechnical/structural engineering practice. It was also noted that the variation in the peak amplification for a given shaking intensity is not significant when soil-bedrock velocity contrast ratio exceeds about twelve. Strong correlation between low and high frequency amplification ratios with the average shear wave velocity in top thirty meters was obtained in the examined sites. These amplification ratios are comparable with the values specified in the 2005 edition of the National Building Code of Canada (NBCC) for the Ottawa region.

The peak amplification values obtained from two-dimensional site response analysis of a deep valley in the study area were in good agreement with those obtained for a nearby one-dimensional site. At higher frequencies, minor discrepancies between two-dimensional and one-dimensional cases occurred. 


\section{Acknowledgements}

First, I would like to sincerely thank my supervisors, Professor Siva Sivathayalan and Professor Dariush Motazedian, for their unrestricted support. They inspired me in every step of my work from the very early stages to the end and enhanced my knowledge as a student and a researcher.

I would like to thank Dr. James Hunter from Geological Survey of Canada for his technical support and collaboration in this research.

I am also thankful to Professor Gail Atkinson for her guidance and help in providing the seismic data input throughout this research.

I also wish to thank S. E. Pullan, A. Pugin, T. Cartwright, R. A. Burns, R. L. Good and M. Douma from the Geological Survey of Canada, for their comments and assistance, and Carleton University students, A. Duxbury and V. Ter-Emmanuilyan.

I am also grateful to Professor Peter Shearer from the University of California, San Diego, for providing us with the useful subroutines of his wave propagation program.

I would like to express my gratitude to Dr. Choon Park for his help and guidance during the seismic surveying part of this research.

I would like to convey my special appreciation to my family, especially to my father and mother, who have been supporting me from the beginning of my life. They steadfastly encouraged me to pursue my academic studies in the doctoral level and I owe an unforgettable debt of gratitude to them.

The financial and technical supports provided by NSERC (Natural Sciences and Engineering Research Council of Canada), ORDCF (the Ontario Research and Development Challenge Fund) and POLARIS (Portable Observatories for Lithospheric Analysis and Research Investigating Seismicity) are greatly appreciated. Funding for a part of this work also came from the Eastern Canada Hazards of the Geological Survey of Canada. 


\section{Table of Contents:}

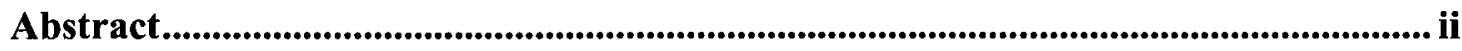

Acknowledgments ......................................................................................................................... iii

List of Figures.......................................................................................................................... $\mathrm{x}$

List of Tables .......................................................................................................................... xxviii

1. Introduction ....................................................................................................................... 1

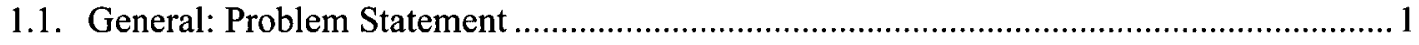

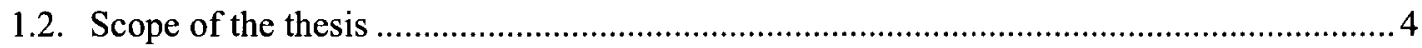

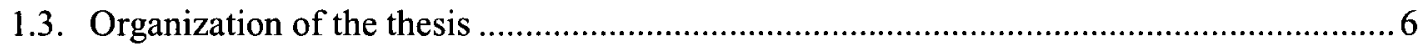

1.4. References....................................................................................................

2. Seismic Surveying using the Multi-Channel Analysis of Surface Waves

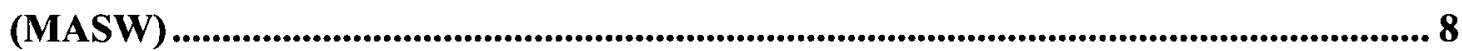

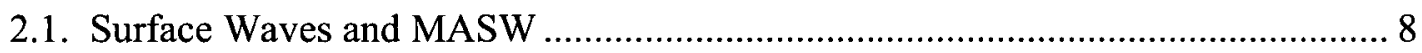

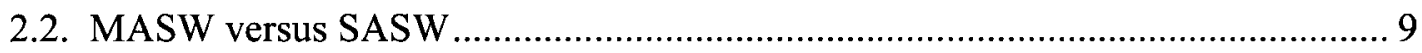

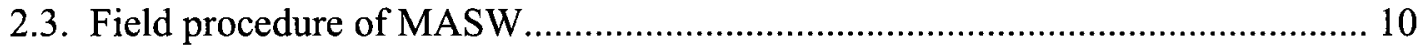

2.4. Essential Parameters and Important factors of MASW ………………………..... 12

2.5. Criteria of the Source, Receiver and Offset selection in MASW ........................ 13

2.6. Construction of the dispersion curve ............................................................. 15

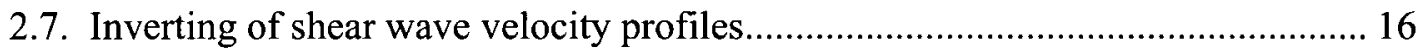

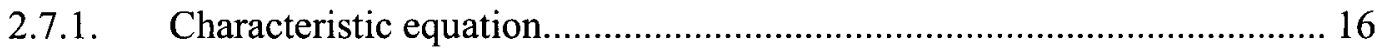

2.7.2. Inversion techniques to discern the high shear wave velocity contrast between soil and bedrock formations ................................................................. 19

2.8. Errors occurred in the inverted shear wave velocity ........................................ 21

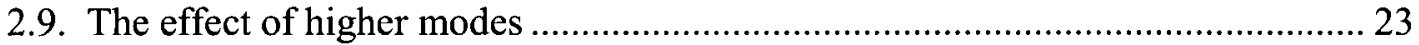

2.10. MASW applications; review of reported successful case studies....................... 24

2.11. Appropriate inversion technique to distinguish the high shear wave velocity

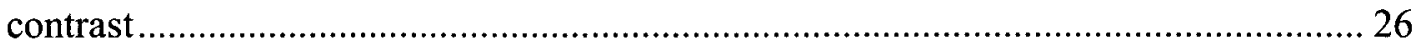

2.12. Investigated sites in Ottawa area and MASW results ...................................... 27 
2.13. Sensitivity of the inversion results to input parameters of initial model in

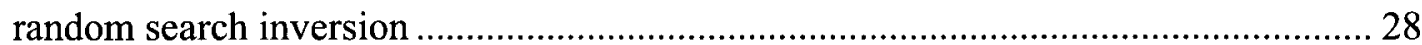

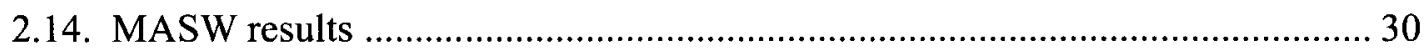

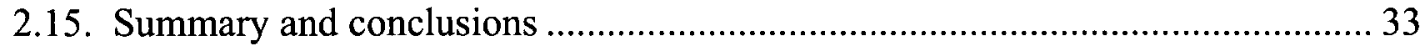

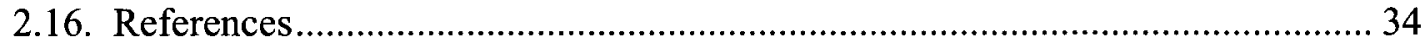

3. Site Response Analysis Using Modified Reflection/Transmission Method ...... 52

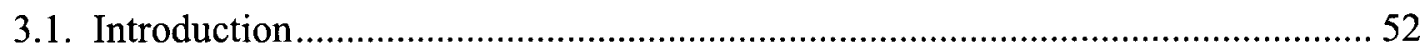

3.2. Matrix method for site response analysis................................................... 55

3.3. Development of the generalized reflection/transmission $(R / T)$ coefficient method for plane wave incidence on multilayered medium ............................................... 58

3.3.1. Scattered plane P-SV waves: Reflection and transmission of seismic waves 58

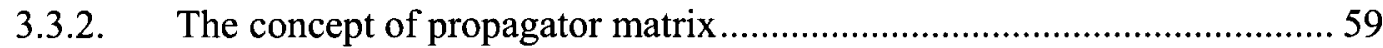

3.3.3. Generalized method of reflection/transmission .................................6 60

3.4. Seismic response of a stack of layers to the plane P-SV waves using R/T method:

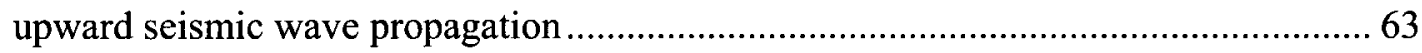

3.5. Site Response Analysis using the Equivalent Linear Method (ELM) .................. 64

3.6. Results of R/T site response analysis; Discussions......................................... 65

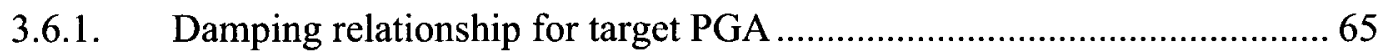

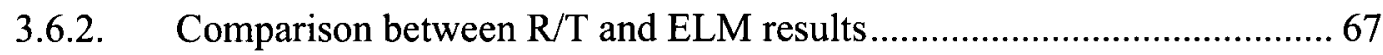

3.6.2.1. Seismic amplification results using damping modified R/T method 67

3.6.2.2. Seismic amplification results using damping-modulus modified $R / T$ method 68

3.6.2.3. Comparison of damping modified $\mathrm{R} / \mathrm{T}$ method with damping-

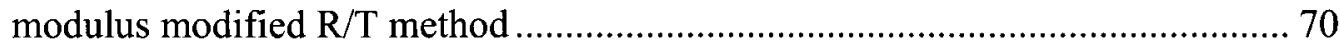

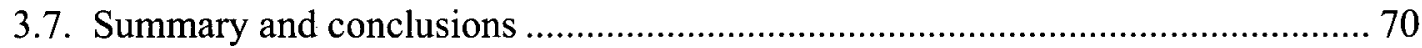

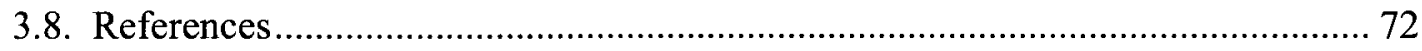

4. Site Response Analysis using Finite Element Method ....................................93

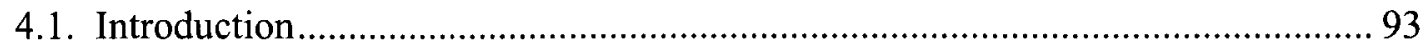

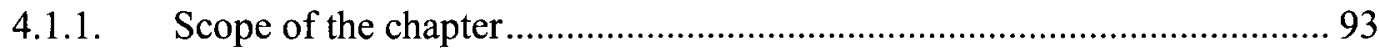

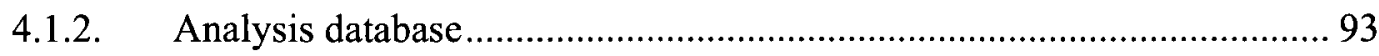


4.1.3. Amplification factors in National Building Code of Canada.................. 95

4.1.4. Finite element method (FEM) for site response analysis....................... 97

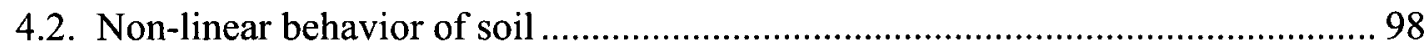

4.2.1. Hysteretic model and the subsequent effect on soil mechanical properties 99

4.2.2. Dependency of non-linear soil response on frequency and shaking intensity 101

4.3. Variable Shear modulus and damping ratio for dynamic analysis .................... 102

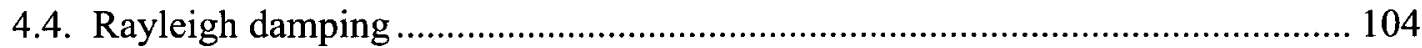

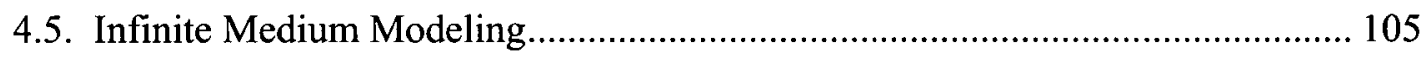

4.6. Numerical seismic amplification simulation for the city of Ottawa; Concerns. 107

4.7. Seismic amplification simulation for the weak motion recordings ................... 110

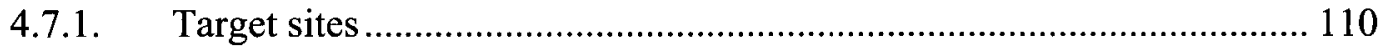

4.7.2. Comparison of observed and modeled seismic amplification using weak motion recordings

4.8. Effect of the contrast ratio and the shaking intensity on the seismic amplification variation

4.8.3. Target sites and input motions

4.8.4. Variation of the seismic amplification ratio with the shaking intensity (level of shaking)

4.8.5. Variation of the seismic amplification ratio with the contrast ratio

4.8.6. Mathematical models for peak amplification ratio $\left(\mathrm{F}_{\mathrm{fo}}\right)$ variation

4.8.6.1. Accounting for the contrast ratio effect on the peak amplification variation 119

4.8.6.2. Accounting for the shaking intensity effect on the peak amplification variation 119

4.8.7. Proposed model for combined effect of contrast ratio-shaking intensity on peak amplification variation 120

4.8.8. Validation of the proposed models for $F_{f 0}$ using scaled records 120 4.9. Verification of the applied site response analysis method (by FEM) for recommended amplification factors of NEHRP, 1994 
4.9.1. Generating of Depth-velocity configurations

4.9.2. Comparison of the obtained amplification factors with NEHRP 1994

recommendations

4.10. Development of high and low frequency amplification factors/equations for different soil classes in Ottawa area.

4.10.1. Low frequency amplification factors based on Fourier spectra, $\left(\mathrm{F}_{\mathrm{V}}\right)_{\mathrm{FFT}} 127$

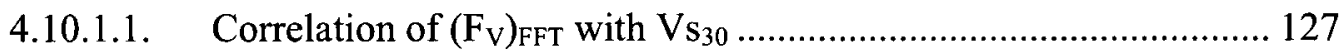

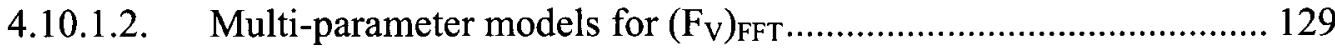

4.10.2. High frequency amplification factors based on Fourier spectra $\left(\mathrm{F}_{\mathrm{a}}\right)_{\mathrm{FFT}} \cdot 131$

4.10.3. Low frequency amplification factors based on response spectra $\left(F_{\mathrm{V}}\right)_{\mathrm{RS}} 132$

4.10.4. High frequency amplification factors based on response spectra $\left(F_{a}\right)_{R S} 133$

4.11. Region-specific amplification factors for Ottawa area; Foundation factors for Ottawa area in analogous format of NBCC, 2005

4.11.1. Developing of low and high frequency amplification values for Ottawa region for different site classes; Comparison with the foundation factors of NBCC, $2005 \quad 134$

4.11.2. Peak amplification values for a target fundamental frequency 136

4.12. Concluding remarks on the obtained low and high frequency amplification factors for the city of Ottawa

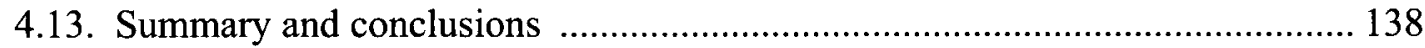

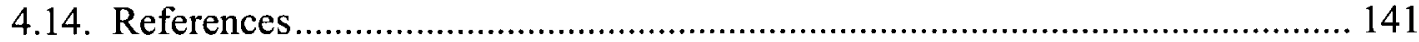

5. Two-dimensional site response analysis using explicit finite difference

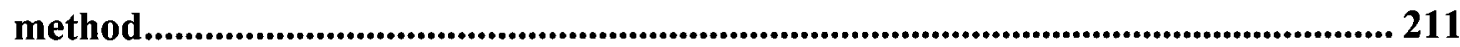

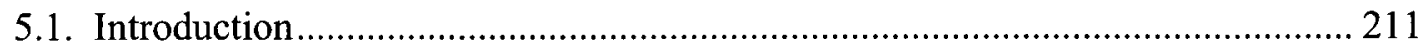

5.2. Dynamic relaxation technique for the solution of finite difference formulation in

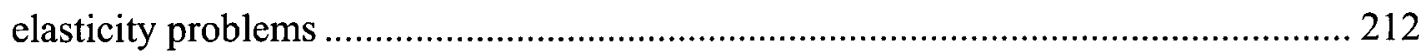

5.3. FLAC (Fast Lagrangian Analysis of Continua) program ............................. 213

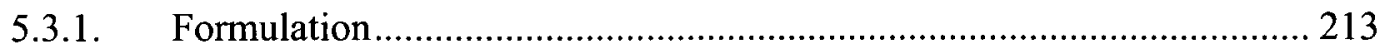

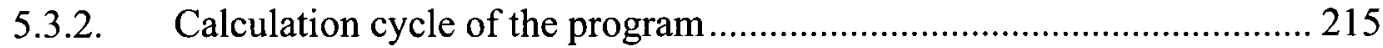

5.4. Constitutive law/model for stress-strain relationship; Modified Cam-Clay Model (MCC) 


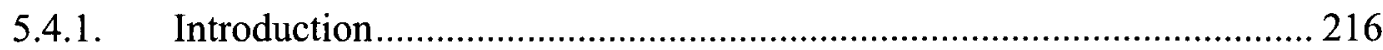

5.4.2. Critical state mechanics; General concepts........................................... 216

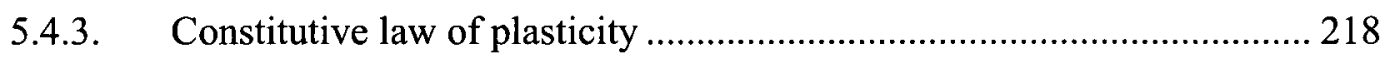

5.4.4. Parameters of modified Cam-Clay (MCC) model .................................... 219

5.5. Leda Clay; General and geotechnical properties ............................................... 220

5.6. Verification of modified Cam-Clay model using the results of drained triaxial test 223

5.7. Infinite Medium Modeling............................................................................ 224

5.8. Implementation of Rayleigh damping in two dimensional models .................... 225

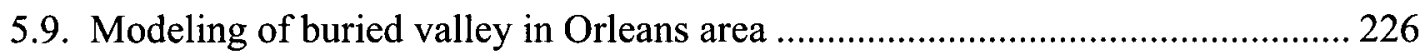

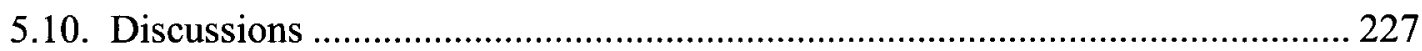

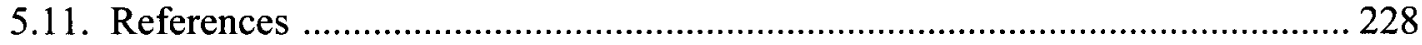

6. Conclusions ................................................................................................................................ 242

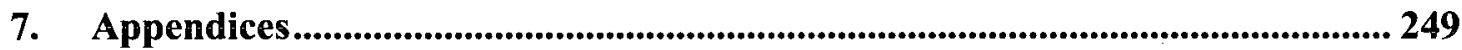

7.1. Appendix A: Amplification curves from Fourier spectra definition for Heritage Park site in Ottawa area. These sites (real and the generated profiles) are subjected to the artificial Eastern Canadian Earthquakes (10\% in 50 years records). 249

7.2. Appendix B: Peak Amplification value variation versus contrast ratio for Heritage Park site in Ottawa area.

7.3. Appendix C: Amplification curves related to site $\# 31$ in Ottawa area. This site (real profile and the generated ones) is subjected to the scaled records obtained from the artificial record having PGA of $23 \mathrm{gal}$ 258

7.4. Appendix D: Samples of Amplification curves obtained from similar depthvelocity configurations to those used by NEHRP, 1994. Each curve is shown for a specific site class subjected to the records having similar target peak ground accelerations.

7.5. Appendix E: Sample of Amplification curves (Fourier spectra definition) for the sites in Ottawa area for the low and high frequency amplification determination. The input records were chosen from the artificial Eastern Canadian Earthquakes 
7.6. Appendix F: Sample of Amplification curves (response spectra definition) for the sites in Ottawa area for the low and high frequency amplification determination. The input records were chosen from the artificial Eastern Canadian Earthquakes. 275 7.7. Appendix G: Extracted low frequency amplification values for 19 sites in Ottawa area subjected to different ground motions. Amplification values are based on the Fourier spectra definition of seismic amplification and are shown versus average $V_{s 30}$ of the examined site. 280

7.8. Appendix H: Extracted high frequency amplification values for 19 sites in Ottawa area subjected to different ground motions. Amplification values are based on the Fourier spectra definition of seismic amplification and are shown versus average $V_{s 30}$ of the examined site. 283

7.9. Appendix I: Extracted high frequency amplification values for 19 sites in Ottawa area subjected to different ground motions. Amplification values are based on the response spectra definition of seismic amplification and are shown versus average $V_{s 30}$ of the examined site. 286 


\section{List of Figures:}

Fig. 2.1: City of Ottawa and the investigated sites.

Fig. 2.2: Sample shot gather from the MASW method for the Brantwood site located around the Rideau Canal in the city of Ottawa.

Fig. 2.3: Comparison between shear wave velocity models based on MASW method using multi-layer soil model and borehole data (downhole shear wave velocity measurement in a borehole located $30 \mathrm{~m}$ away from MASW site) for NRC site.

Fig. 2.4: Layer models of depth-shear wave velocity for NRC site. Shear wave velocity profiles for different contrast ratios of the initial model, shown at the end of each profile. In the initial models, bedrock depth and average soil velocity values are fixed. 42

Fig. 2.5: Layer models of depth-shear wave velocity for NRC site. Shear wave velocity profiles for different bedrock depth of the initial model, shown at the end of each profile. Contrast ratio and average soil velocity values are fixed. 42

Fig. 2.6: Layer models of depth-shear wave velocity for NRC site. Shear wave velocity profiles for different bedrock velocities (in $\mathrm{km} / \mathrm{sec}$ ) of the initial model, shown at the end of each profile. Contrast ratio and bedrock depth velocity are fixed..... 43

Fig. 2.7: Sample overtone image of the dispersion curve from the combined MASW method for the NRC site located in the southern part of the city of Ottawa....... 43

Fig. 2.8: Extracted dispersion curve of the fundamental mode for NRC site showing the participation of active and passive MASW tests.

Fig. 2.9: Continuous representation of dispersion curve for the fundamental mode of the MASW method for NRC site. The part of curve that is located inside the dashed ellipse $(\leq 5 \mathrm{~Hz})$ comes from the passive roadside test. 44

Fig. 2.10: Comparison between shear wave velocity values of MASW results and borehole data for the GSC Anderson Road site.

Fig. 2.11: Dispersion curves of the fundamental mode and a higher mode (first mode) of the Rayleigh wave obtained from the combination of active and remote passive MASW methods for the soccer field of Carleton University. 
Fig. 2.12: $\mathrm{V}_{\mathrm{s}}$ profile for the soccer field of Carleton University, based on random search inversion. The great velocity jump is obvious at the depth of $5 \mathrm{~m}$. 46

Fig. 2.13: 2-D Shear wave velocity profile for NRC site in Ottawa area....................... 47

Fig. 2.14: 2-D Shear wave velocity profile for NRCan site in Ottawa area.

Fig. 3.1: Three examined sites in the Orleans area located in the eastern part of the city of Ottawa. 76

Fig. 3.2: Shear wave velocity variation for Barrington Park Site from reflection/refraction tests (Hunter et al., 2010). 77

Fig. 3.3: Shear wave velocity variation for Chapel Hill site from reflection/refraction tests (Hunter et al., 2010). 77

Fig. 3.4: Shear wave velocity variation for Longleaf Park Site from reflection/refraction tests (Hunter et al., 2010). 78

Fig. 3.5: R/T: method scheme showing the reverberations inside the soil layers for upward wave propagation. $\mathrm{R}$ and $\mathrm{T}$ denote the reflection and transmission matrices and $U$ and $D$ stand for the up-going and down-going waves.

Fig. 3.6: Upward SH wave propagation scheme and the model parameters of ELM in a 3layer model. P and Q show the amplitudes of the advancing and the reflected Swaves. $h, \rho$ and $G$ stand for the layer thickness, density and the shear modulus of the layer material respectively.

Fig. 3.7: A sample of simulated acceleration time history with the PGA of $0.4 \mathrm{~g}$ for eastern Canadian earthquakes (Atkinson and Beresnev, 1998).

Fig. 3.8: Peak ground acceleration from simulated time histories (generated for eastern Canada) versus effective shear strain (from ProShake program). The best fit equation is $\varepsilon=0.4752$ PGA $\left(\mathrm{R}^{2}=0.9289\right)$. $\varepsilon$ and PGA are the effective shear strain and the peak ground acceleration, respectively. 80

Fig. 3.9: Damping curve for clayey soil from Sun et al. (1988). The best fit equation is $\mathrm{D}=17.308 \varepsilon^{0.2537}\left(\mathrm{R}^{2}=0.9586\right) . \mathrm{D}$ and $\varepsilon$ are the damping and the shear strain, respectively.

Fig. 3.10: Horizontal amplification ratios for the Barrington Park site using dampingmodified generalized R/T method for the vertical incidence of the SV wave. 
Solid line and dashed line illustrate the amplifications for the damping ratios compatible with PGAs of $0.2 \mathrm{~g}$ and $0.4 \mathrm{~g}$ respectively

Fig. 3.11: Horizontal amplification ratios for the Chapel Hill site using damping-modified generalized R/T method for the vertical incidence of the SV wave. Solid line and dashed line illustrate the amplifications for the damping ratios compatible with PGAs of $0.2 \mathrm{~g}$ and $0.4 \mathrm{~g}$ respectively.

Fig. 3.12: Horizontal amplification ratios for the Longleaf Park site using dampingmodified generalized $\mathrm{R} / \mathrm{T}$ method for the vertical incidence of the SV wave. Solid line and dashed line illustrate the amplifications for the damping ratios compatible with PGAs of $0.2 \mathrm{~g}$ and $0.4 \mathrm{~g}$ respectively.

Fig. 3.13: Amplification curves for the Barrington Park site: Comparison of damping modified generalized $\mathrm{R} / \mathrm{T}$ method (solid line) with the equivalent linear method (dashed line). In the R/T method, the vertical incidence of the SV wave and the damping ratio compatible with a PGA of $0.2 \mathrm{~g}$ are considered. In the equivalent linear method, the multilayer model is subjected to a simulated strong motion for eastern Canada with a PGA of $0.2 \mathrm{~g}$.

Fig. 3.14: Amplification curves for the Barrington Park site: Comparison of damping modified generalized $\mathrm{R} / \mathrm{T}$ method (solid line) with the equivalent linear method (dashed line). In the R/T method vertical, the incidence of the SV wave and the damping ratio compatible with a PGA of $0.4 \mathrm{~g}$ are considered. In the equivalent linear method, the multilayer model is subjected to a simulated strong motion for eastern Canada with a PGA of $0.4 \mathrm{~g}$.

Fig. 3.15: Amplification curves for the Chapel Hill site: Comparison of damping modified generalized R/T method (solid line) with the equivalent linear method (dashed line). In the R/T method, the vertical incidence of the SV wave and the damping ratio compatible with a PGA of $0.2 \mathrm{~g}$ are considered. In the equivalent linear method, the multilayer model is subjected to a simulated strong motion for eastern Canada with a PGA of $0.2 \mathrm{~g}$.

Fig. 3.16: Amplification curves for the Chapel Hill site: Comparison of damping modified generalized R/T method (solid line) with the equivalent linear method (dashed line). In the R/T method, the vertical incidence of the SV wave and the 
damping ratio compatible with a PGA of $0.4 \mathrm{~g}$ are considered. In the equivalent linear method, the multilayer model is subjected to a simulated strong motion for eastern Canada with a PGA of $0.4 \mathrm{~g}$. 84

Fig. 3.17: Amplification curves for the Longleaf Park site: Comparison of damping modified generalized $\mathrm{R} / \mathrm{T}$ method (solid line) with the equivalent linear method (dashed line). In the R/T method, the vertical incidence of the SV wave and the damping ratio compatible with a PGA of $0.2 \mathrm{~g}$ are considered. In the equivalent linear method, the multilayer model is subjected to a simulated strong motion for eastern Canada with a PGA of $0.2 \mathrm{~g}$. 84

Fig. 3.18: Amplification curves for the Longleaf Park site: Comparison of damping modified generalized R/T method (solid line) with the equivalent linear method (dashed line). In the R/T method vertical, the incidence of the SV wave and the damping ratio compatible with a PGA of $0.4 \mathrm{~g}$ are considered. In the equivalent linear method, the multilayer model is subjected to a simulated strong motion for eastern Canada with a PGA of $0.4 \mathrm{~g}$.

Fig. 3.19: Strain-dependent shear modulus reduction curve for clays ( Sun et al., 1988). 85

Fig. 3.20: Amplification curves for the Barrington Park site: Comparison of dampingmodulus modified generalized R/T method (solid line) with the equivalent linear method (dashed line). In the R/T method, the vertical incidence of the SV wave and the damping ratio compatible with a PGA of $0.2 \mathrm{~g}$ are considered. In the equivalent linear method, the multilayer model is subjected to a simulated strong motion for eastern Canada with a PGA of $0.2 \mathrm{~g}$.

Fig. 3.21: Amplification curves for the Barrington Park site: Comparison of dampingmodulus modified generalized R/T method (solid line) with the equivalent linear method (dashed line). In the $\mathrm{R} / \mathrm{T}$ method vertical, the incidence of the SV wave and the damping ratio compatible with a PGA of $0.4 \mathrm{~g}$ are considered. In the equivalent linear method, the multilayer model is subjected to a simulated strong motion for eastern Canada with a PGA of $0.4 \mathrm{~g}$.

Fig. 3.22: Amplification curves for the Chapel Hill site: Comparison of dampingmodulus modified generalized R/T method (solid line) with the equivalent linear method (dashed line). In the R/T method, the vertical incidence of the SV wave 
and the damping ratio compatible with a PGA of $0.2 \mathrm{~g}$ are considered. In the equivalent linear method, the multilayer model is subjected to a simulated strong motion for eastern Canada with a PGA of $0.2 \mathrm{~g}$.

Fig. 3.23: Amplification curves for the Chapel Hill site: Comparison of dampingmodulus modified generalized $\mathrm{R} / \mathrm{T}$ method (solid line) with the equivalent linear method (dashed line). In the R/T method, the vertical incidence of the SV wave and the damping ratio compatible with a PGA of $0.4 \mathrm{~g}$ are considered. In the equivalent linear method, the multilayer model is subjected to a simulated strong motion for eastern Canada with a PGA of $0.4 \mathrm{~g}$

Fig. 3.24: Amplification curves for the Longleaf Park site: Comparison of dampingmodulus modified generalized R/T method (solid line) with the equivalent linear method (dashed line). In the R/T method, the vertical incidence of the SV wave and the damping ratio compatible with a PGA of $0.2 \mathrm{~g}$ are considered. In the equivalent linear method, the multilayer model is subjected to a simulated strong motion for eastern Canada with a PGA of $0.2 \mathrm{~g}$.

Fig. 3.25: Amplification curves for the Longleaf Park site: Comparison of dampingmodulus modified generalized R/T method (solid line) with the equivalent linear method (dashed line). In the R/T method vertical, the incidence of the SV wave and the damping ratio compatible with a PGA of $0.4 \mathrm{~g}$ are considered. In the equivalent linear method, the multilayer model is subjected to a simulated strong motion for eastern Canada with a PGA of $0.4 \mathrm{~g}$. 88

Fig. 3.26: Amplification curves for the Barrington Park site: Comparison of damping modified $\mathrm{R} / \mathrm{T}$ method (dashed line) with damping-modulus $\mathrm{R} / \mathrm{T}$ method (solid line) for the target PGA of $0.2 \mathrm{~g}$. The Fundamental Frequencies are obtained 0.6 $\mathrm{Hz}$ and $0.45 \mathrm{~Hz}$ from the damping modified and damping-modulus modified methods respectively.

Fig. 3.27: Amplification curves for the Barrington Park site: Comparison of damping modified R/T method (dashed line) with damping-modulus $\mathrm{R} / \mathrm{T}$ method (solid line) for the target PGA of $0.4 \mathrm{~g}$. The Fundamental Frequencies are obtained 0.6 $\mathrm{Hz}$ and $0.3 \mathrm{~Hz}$ from the damping modified and damping-modulus modified methods respectively. 
Fig. 3.28: Amplification curves for the Chapel Hill site: Comparison of damping modified R/T method (dashed line) with damping-modulus R/T method (solid line) for the target PGA of $0.2 \mathrm{~g}$. The Fundamental Frequencies are obtained 0.4 $\mathrm{Hz}$ and $0.35 \mathrm{~Hz}$ from the damping modified and damping-modulus modified methods respectively.

Fig. 3.29: Amplification curves for the Chapel Hill site: Comparison of damping modified R/T method (dashed line) with damping-modulus R/T method (solid line) for the target PGA of $0.4 \mathrm{~g}$. The Fundamental Frequencies are obtained 0.4 $\mathrm{Hz}$ and $0.25 \mathrm{~Hz}$ from the damping modified and damping-modulus modified methods respectively.

Fig. 3.30: Amplification curves for the Longleaf Park site: Comparison of damping modified R/T method (dashed line) with damping-modulus $\mathrm{R} / \mathrm{T}$ method (solid line) for the target PGA of $0.2 \mathrm{~g}$. The Fundamental Frequencies are obtained 1.2 $\mathrm{Hz}$ and $0.9 \mathrm{~Hz}$ from the damping modified and damping-modulus modified methods respectively.

Fig. 3.31: Amplification curves for the Longleaf Park site: Comparison of damping modified R/T method (dashed line) with damping-modulus $\mathrm{R} / \mathrm{T}$ method (solid line) for the target PGA of $0.4 \mathrm{~g}$. The Fundamental Frequencies are obtained 1.2 $\mathrm{Hz}$ and $0.6 \mathrm{~Hz}$ from the damping modified and damping-modulus modified methods respectively.

Fig. 4.1: Scheme of finite element mesh for site response analysis. The seismic waves propagate from elastic bedrock. Applied boundary conditions $\left(\rho V_{p} w \cdot\right.$ and $\rho V_{s}$ $u \cdot)$ make the infinite medium a roughly perfect absorber. These boundary conditions are explained in section 4.5.

Fig. 4.2: A typical hysteresis loop that is used to describe the stress-strain $(\tau-\gamma)$ behavior of soil materials for loading-unloading during the earthquake shaking. For a point shown on the loop, secant modulus $\left(\mathrm{G}_{\mathrm{sec}}\right)$ and tangent modulus $\left(\mathrm{G}_{\tan }\right)$ are illustrated. 150

Fig. 4.3: Extended Masing's rule (a) shear stress variation with time (b)shear stressstrain behavior (from Kramer, 1996). 
Fig. 4.4: Threshold acceleration of soil non-linearity versus frequency for a Ottawa soil with average shear wave velocity of $150 \mathrm{~m} / \mathrm{sec}$ and shear strain of $10^{-4}$

Fig. 4.5: Variation of damping ratio of clayey soil from Seed and Sun (1989)

Fig. 4.6: Variation of shear modulus of clayey soil from Seed and Sun (1989)

Fig. 4.7: Locations of ORHO and ORIO stations in the eastern part of the city of Ottawa. ORIO station is located on the rock and is close enough to ORHO. The stations are $1.3 \mathrm{~km}$ far from each other; this distance is small enough relative to the epicentral distance of recorded local and regional earthquakes.

Fig. 4.8: Horizontal component of the acceleration time history recorded on ORIO station (from the earthquake of Christmas Eve, 2008).

Fig. 4.9: Horizontal component of the acceleration time history recorded on ORHO station.

Fig. 4.10: Comparison between the simulated acceleration time history for ORHO station and the acceleration record on ORIO station. 155

Fig. 4.11: Amplification curve on ORHO station from FEM using the weak motion recorded on ORIO station. Soil profile (profile \#1) includes loose Leda clay with the depth of $81 \mathrm{~m}$.

Fig. 4.12: Amplification curve on ORHO station from FEM using the weak motion recorded on ORIO station. Soil profile (profile\#2) includes the loose deposit of $81 \mathrm{~m}$, Leda clay, underlain with $10 \mathrm{~m}$ of glacial till.

Fig. 4.13: Comparison of the observed and the modeled amplification ratios for ORHO station (profile \#1). The agreement between the peak values is satisfactory (amplification ratio of 86 from observation and 83 from modeling) although the fundamental frequency shift relative to the fundamental frequency of the site occurs (shift is shown with the arrow above the Figure). Fundamental frequencies are obtained $0.54 \mathrm{~Hz}$ and $0.75 \mathrm{~Hz}$ from the modeling and observation, respectively.

Fig. 4.14: Comparison of the observed and the modeled amplification ratios for ORHO station (profile \#2). Not only the agreement between the peak amplification ratios is good but also the fundamental frequency of modeling is obtained $0.7 \mathrm{~Hz}$ that is close to the fundamental frequency of 0.75 from observation. 157 
Fig. 4.15: Three investigated sites in the eastern part of the city of Ottawa. These sites were studied for the combined effect of shaking intensity and soil/bedrock contrast ratio on the seismic amplification variation. 158

Fig. 4.16: Artificial acceleration time history of Eastern Canadian EQs (10\% in 50 years) with: (a) PGA of 23 gal; (b) PGA of 41 gal; (c) PGA of 70 gal; (d) PGA of 81 gal.

Fig. 4.17: Artificial acceleration time history of Eastern Canadian EQs (10\% in 50 years) with: (a) PGA of 147 gal; (b) PGA of 208 gal; (c) PGA of 349 gal................ 160

Fig. 4.18: Acceleration time history at ground level for Heritage Park site subjected to record having (a) PGA of 40 gal; (b) PGA of 70 gal; (c) PGA of 147 gal; (d) PGA of 349 gal.

Fig. 4.19: Amplification curves at Heritage park site for different contrast ratios. The site is subjected to the acceleration time history having PGA of $23 \mathrm{gal}$. 162

Fig. 4.20: Amplification curves at Heritage park site for different contrast ratios. The site is subjected to the acceleration time history having PGA of 41 gal. 162

Fig. 4.21: Amplification curves at Heritage park site for different contrast ratios. The site is subjected to the acceleration time history having PGA of 70 gal. 163

Fig. 4.22: Amplification curves at Heritage park site for different contrast ratios. The site is subjected to the acceleration time history having PGA of 81 gal. 163

Fig. 4.23: Amplification curves at Heritage park site for different contrast ratios. The site is subjected to the acceleration time history having PGA of $147 \mathrm{gal}$. 164

Fig. 4.24: Amplification curves at Heritage park site for different contrast ratios. The site is subjected to the acceleration time history having PGA of 208 gal. 164

Fig. 4.25: Amplification curves at Heritage park site for different contrast ratios. The site is subjected to the acceleration time history having PGA of 349 gal. 165

Fig. 4.26: Variation of the fundamental frequency of site \#31 versus PGA. The frequencies from FEM are compared with fundamental frequency of the site obtained from average shear wave velocity. The best-fit equation to non-linear part (PGA > 81 gal) is: $\mathrm{f}_{0}=0.89 \mathrm{PGA}^{-0.04}$ 165

Fig. 4.27: Variation of the fundamental frequency of site \#41 versus PGA. The frequencies from FEM are compared with fundamental frequency of the site 
obtained from average shear wave velocity. The best-fit equation to non-linear part (PGA>81gal) is: $\mathrm{f}_{0}=0.87 \mathrm{PGA}^{-0.03}$ 166

Fig. 4.28: Variation of the fundamental frequency of Heritage park site versus PGA. The frequencies from FEM are compared with fundamental frequency of the site obtained from average shear wave velocity. The best-fit equation to non-linear part $(\mathrm{PGA}>81$ gal $)$ is : $\mathrm{f}_{0}=0.86 \mathrm{PGA}^{-0.08}$ 166

Fig. 4.29: Variation of the reflected energy percentage $\left(E_{R}\right)$ of the seismic waves with the contrast ratio of soil-bedrock formation.

Fig. 4.30: Variation of the peak amplification ratio versus contrast ratio and PGA for site \# 31. Saturation behavior of amplification ratio (in a constant PGA) is observed when the contrast ratio exceeds high values.

Fig. 4.31: Variation of the peak amplification ratio versus contrast ratio and PGA for site \# 41. Saturation behavior of amplification ratio (in a constant PGA) is observed when the contrast ratio exceeds high values. 168

Fig. 4.32: Variation of the peak amplification ratio versus contrast ratio and PGA for Heritage Park site. Saturation behavior of amplification ratio (in a constant PGA) is observed when the contrast ratio exceeds high values. 168

Fig. 4.33: Residual plot for the simulated $\mathrm{F}_{\mathrm{fo}}$ values versus equation (4-38) 169

Fig. 4.34: Variation of the peak amplification ratio $\left(\mathrm{F}_{\mathrm{fo}}\right)$ versus contrast ratio and PGA for site \#31. The scaled records are used to obtain $F_{f 0}$ for a pair of $(P G A, z)$. Similar to Figures 37 to 39 the saturation behavior of amplification ratio (in a constant PGA) is confirmed when the contrast ratio reaches exceeds high values. 169

Fig. 4.35: Residual plot for the simulated $\mathrm{F}_{\mathrm{fo}}$ values (using scaled records) and the equation (4-38) at site \#31.

Fig. 4.36: High Frequency amplification values for class $\mathrm{A}$ of different soil-bedrock configurations subjected to shaking intensities from $0.1 \mathrm{~g}$ to $0.5 \mathrm{~g}$. 170

Fig. 4.37: High Frequency amplification values for class B of different soil-bedrock configurations subjected to shaking intensities from $0.1 \mathrm{~g}$ to $0.5 \mathrm{~g}$.

Fig. 4.38: High Frequency amplification values for class $\mathrm{C}$ of different soil-bedrock configurations subjected to shaking intensities from $0.1 \mathrm{~g}$ to $0.5 \mathrm{~g}$. 
Fig. 4.39: High Frequency amplification values for class D of different soil-bedrock configurations subjected to shaking intensities from $0.1 \mathrm{~g}$ to $0.5 \mathrm{~g}$

Fig. 4.40: High Frequency amplification values for class $E$ of different soil-bedrock configurations subjected to shaking intensities from $0.1 \mathrm{~g}$ to $0.5 \mathrm{~g}$ 172

Fig. 4.41: Low Frequency amplification values for class $\mathrm{A}$ of different soil-bedrock configurations subjected to shaking intensities from $0.1 \mathrm{~g}$ to $0.5 \mathrm{~g}$.

Fig. 4.42: Low Frequency amplification values for class B of different soil-bedrock configurations subjected to shaking intensities from $0.1 \mathrm{~g}$ to $0.5 \mathrm{~g}$. 173

Fig. 4.43: Low Frequency amplification values for class $\mathrm{C}$ of different soil-bedrock configurations subjected to shaking intensities from $0.1 \mathrm{~g}$ to $0.5 \mathrm{~g}$.

Fig. 4.44: Low Frequency amplification values for class $D$ of different soil-bedrock configurations subjected to shaking intensities from $0.1 \mathrm{~g}$ to $0.5 \mathrm{~g}$. 174

Fig. 4.45: Low Frequency amplification values for class $E$ of different soil-bedrock configurations subjected to shaking intensities from $0.1 \mathrm{~g}$ to $0.5 \mathrm{~g}$. 174

Fig. 4.46: Average high frequency amplification values for class $\mathrm{A}$ of different soilbedrock configurations subjected to shaking intensities from $0.1 \mathrm{~g}$ to $0.5 \mathrm{~g} \ldots 175$

Fig. 4.47: Average high frequency amplification values for class B of different soilbedrock configurations subjected to shaking intensities from $0.1 \mathrm{~g}$ to $0.5 \mathrm{~g} \ldots .175$

Fig. 4.48: Average high frequency amplification values for class $\mathrm{C}$ of different soilbedrock configurations subjected to shaking intensities from $0.1 \mathrm{~g}$ to $0.5 \mathrm{~g} \ldots 176$

Fig. 4.49: Average high frequency amplification values for class $\mathrm{D}$ of different soilbedrock configurations subjected to shaking intensities from $0.1 \mathrm{~g}$ to $0.5 \mathrm{~g} \ldots 176$

Fig. 4.50: Average high frequency amplification values for class $E$ of different soilbedrock configurations subjected to shaking intensities from $0.1 \mathrm{~g}$ to $0.5 \mathrm{~g} \ldots 177$

Fig. 4.51: Average low frequency amplification values for class A of different soilbedrock configurations subjected to shaking intensities from $0.1 \mathrm{~g}$ to $0.5 \mathrm{~g} \ldots 177$

Fig. 4.52: Average low frequency amplification values for class $B$ of different soilbedrock configurations subjected to shaking intensities from $0.1 \mathrm{~g}$ to $0.5 \mathrm{~g}$.... 178 Fig. 4.53: Average low frequency amplification values for class $\mathrm{C}$ of different soilbedrock configurations subjected to shaking intensities from $0.1 \mathrm{~g}$ to $0.5 \mathrm{~g} \ldots .178$ 
Fig. 4.54: Average low frequency amplification values for class D of different soilbedrock configurations subjected to shaking intensities from $0.1 \mathrm{~g}$ to $0.5 \mathrm{~g} \ldots 179$

Fig. 4.55: Average low frequency amplification values for class $E$ of different soilbedrock configurations subjected to shaking intensities from $0.1 \mathrm{~g}$ to $0.5 \mathrm{~g} . . .179$

Fig. 4.56: Artificial acceleration time history of Eastern Canadian EQs ( $2 \%$ in 50 years) with: (a) PGA of 181 gal; (b) PGA of 256 gal; (c) PGA of 304 gal; (d) PGA of 422 gal. 180

Fig. 4.57: Artificial acceleration time history of Eastern Canadian EQs ( $2 \%$ in 50 years) with: (a) PGA of 512 gal; (b) PGA of 607 gal; (c) PGA of 707 gal; (d) PGA of $813 \mathrm{gal}$ 181

Fig. 4.58: Artificial acceleration time history of Eastern Canadian EQs (2\% in 50 years) with: (a) PGA of 942 gal; (b) PGA of 1000 gal. 182

Fig. 4.59: Pseudo-acceleration (PSA) values for the target PGA of 0.42g in Ottawa area. (Probability of $2 \%$ in 50 years). A similar Table is given at NBCC, 2005. This graph was based on values given in the Appendix of NBCC (2005).

Fig. 4.60: Variation of low frequency amplification ratios in terms of the thickness of the examined sites in Ottawa area subjected to the input motion having PGA of 422 gal. The large amplification ratios $\left(F_{v}>3.3\right)$ are observed for the sites having depths from $30 \mathrm{~m}$ to $41 \mathrm{~m}$ which have natural frequencies ranging from $0.8 \mathrm{~Hz}$ to $1.3 \mathrm{~Hz}$. 183

Fig. 4.61: Variation of low frequency amplification ratios in terms of thickness of the examined sites in Ottawa area subjected to the input motion having PGA of 707 gal. The large amplification ratios $\left(\mathrm{F}_{\mathrm{v}}>3.5\right)$ are observed for the sites having depths from $30 \mathrm{~m}$ to $41 \mathrm{~m}$ which have natural frequencies ranging from $0.8 \mathrm{~Hz}$ to $1.3 \mathrm{~Hz}$. 183

Fig. 4.62: Low frequency amplification values at the PGA of 422 gal for different $f_{n}$ values using equation (4-42)

Fig. 4.63: $\left(\mathrm{F}_{\mathrm{V}}\right)_{\mathrm{RS}}$ amplification values versus average $\mathrm{V}_{\mathrm{s} 30}$ for 19 sites using the record having (a) PGA of 181 gal; (b) PGA of 256 gal; (c) PGA of 304 gal; (d) PGA of $422 \mathrm{gal}$ 
Fig. 4.64: $\left(\mathrm{F}_{\mathrm{V}}\right)_{\mathrm{RS}}$ amplification values versus average $\mathrm{V}_{\mathrm{s} 30}$ for 19 sites using the record having (a) PGA of 1512 gal; (b) PGA of 607 gal; (c) PGA of 707 gal; (d) PGA of $813 \mathrm{gal}$.

Fig. 4.65: $\left(\mathrm{F}_{\mathrm{V}}\right)_{\mathrm{RS}}$ amplification values versus average $\mathrm{V}_{\mathrm{s} 30}$ for 19 sites using the record having (a) PGA of 942 gal; (b) PGA of 1000 gal.

Fig. 4.66: Amplification curves for different site classes and spectral accelerations in Ottawa area (a) site class A subjected to PSA of $0.5 \mathrm{~g}$; (b) site class B subjected to PSA of $0.2 \mathrm{~g}$; (c) site class $\mathrm{C}$ subjected to PSA of $0.75 \mathrm{~g}$;(d) site class C subjected to PSA of $0.4 \mathrm{~g}$;(e) site class D subjected to PSA of $0.25 \mathrm{~g} ;(\mathrm{f})$ site class E subjected to PSA of $1.25 \mathrm{~g}$.

Fig. 5.1: Overburden thickness in meters in the Orleans suburb of Ottawa, based on combined borehole and shear wave seismic site measurements.

Fig. 5.2: Transverse and longitudinal cross sections of the Orleans buried valley with a vertical exaggeration of $\sim 10: 1$. (BH: borehole, $\mathrm{SH}$ : Seismic site).

Fig. 5.3: Location of the critical state line (CSL) in the (lnp'-v) space.

Fig. 5.4: Configuration of rectangular finite difference model for a strain-controlled drained triaxial test 233

Fig. 5.5: Comparison between the results of MCC and experimental data in a drained triaxial test for (a) slightly overconsolidated sample; (b) highly overconsolidated sample. 233

Fig. 5.6: A simplified two-dimensional non-scaled scheme of a deep valley located in the eastern part of the city of Ottawa. Lines "ae" and "ec" illustrate the boundaries between the valley sediments and the underlying bedrock. The valley has a gentle slope from points " $\mathrm{e}$ " to " $a$ " that can be approximated by a linear boundary. 234

Fig. 5.7: Amplification curves for a 2D (two-dimensional) valley in Orleans area and an adjacent 1D (one-dimensional) site, GSC site \# 23 , having depth of $81 \mathrm{~m}$. The amplification curve of 2D valley was obtained at the deepest part with the depth of $70 \mathrm{~m}$. Both sites are subjected to the same input motion having PGA of 181 gal. 
Fig. 5.8: Amplification curves for a 2D (two-dimensional) valley in Orleans area and an adjacent 1D (one-dimensional) site ,GSC site \# 23 , having depth of $81 \mathrm{~m}$. The amplification curve of $2 \mathrm{D}$ valley was obtained at the deepest part with the depth of $70 \mathrm{~m}$. Both sites are subjected to the same input motion having PGA of 256 gal.

Fig. 5.9: Amplification curves for a 2D (two-dimensional) valley in Orleans area and an adjacent 1D (one-dimensional) site, GSC site \# 23 , having depth of $81 \mathrm{~m}$. The amplification curve of $2 \mathrm{D}$ valley was obtained at the deepest part with the depth of $70 \mathrm{~m}$. Both sites are subjected to the same input motion having PGA of 304 gal.

Fig. 5.10: Amplification curves for a 2D (two-dimensional) valley in Orleans area and an adjacent 1D (one-dimensional) site, GSC site \# 23 , having depth of $81 \mathrm{~m}$. The amplification curve of $2 \mathrm{D}$ valley was obtained at the deepest part with the depth of $70 \mathrm{~m}$. Both sites are subjected to the same input motion having PGA of 422 gal.

Fig. 5.11. Amplification curves for a 2D (two-dimensional) valley in Orleans area and an adjacent 1D (one-dimensional) site, GSC site \# 23 , having depth of $81 \mathrm{~m}$. The amplification curve of 2D valley was obtained at the deepest part with the depth of $70 \mathrm{~m}$. Both sites are subjected to the same input motion having PGA of 512 gal.

Fig. 5.12: Amplification curves for a 2D (two-dimensional) valley in Orleans area and an adjacent ID (one-dimensional) site, GSC site \# 23 , having depth of $81 \mathrm{~m}$. The amplification curve of $2 \mathrm{D}$ valley was obtained at the deepest part with the depth of $70 \mathrm{~m}$. Both sites are subjected to the same input motion having PGA of 607 gal.

Fig. 5.13: Amplification curves for a 2D (two-dimensional) valley in Orleans area and an adjacent 1D (one-dimensional) site ,GSC site \# 23 , having depth of $81 \mathrm{~m}$. The amplification curve of $2 \mathrm{D}$ valley was obtained at the deepest part with the depth of $70 \mathrm{~m}$. Both sites are subjected to the same input motion having PGA of 707 gal. 
Fig. 5.14: Amplification curves for a 2D (two-dimensional) valley in Orleans area and an adjacent 1D (one-dimensional) site, GSC site \# 23 , having depth of $81 \mathrm{~m}$. The amplification curve of $2 \mathrm{D}$ valley was obtained at the deepest part with the depth of $70 \mathrm{~m}$. Both sites are subjected to the same input motion having PGA of 813 gal.

Fig. 5.15: Amplification curves for a 2D (two-dimensional) valley in Orleans area and an adjacent 1D (one-dimensional) site, GSC site \# 23 , having depth of $81 \mathrm{~m}$. The amplification curve of 2D valley was obtained at the deepest part with the depth of $70 \mathrm{~m}$. Both sites are subjected to the same input motion having PGA of 942 gal. 238

Fig. 5.16: Amplification curves for a 2D (two-dimensional) valley in Orleans area and an adjacent 1D (one-dimensional) site, GSC site \# 23 , having depth of $81 \mathrm{~m}$. The amplification curve of $2 \mathrm{D}$ valley was obtained at the deepest part with the depth of $70 \mathrm{~m}$. Both sites are subjected to the same input motion having PGA of 1000 gal.

Fig. 5.17: Residual plot (Difference between the peak amplification values) for $1 \mathrm{D}$ and 2D methods for different input motions. Each input motion is represented by its peak ground acceleration (PGA) 239

Fig. A1: Amplification Curve for Heritage Park site subjected to the record having PGA of 23 gal using: (a) contrast ratio of 4; (b) contrast ratio of 8; (c) contrast ratio of 12 ; (d) real contrast ratio 249

Fig. A2: Amplification Curve for Heritage Park site subjected to the record having PGA of 41 gal using: (a) contrast ratio of 4; (b) contrast ratio of 8; (c) contrast ratio of 12 ; (d) real contrast ratio 250

Fig. A3: Amplification Curve for Heritage Park site subjected to the record having PGA of 70 gal using: (a) contrast ratio of 4; (b) contrast ratio of 8; (c) contrast ratio of 12 ; (d) real contrast ratio 251

Fig. A4: Amplification Curve for Heritage Park site subjected to the record having PGA of 81 gal using: (a) contrast ratio of 4; (b) contrast ratio of 8; (c) contrast ratio of 12 ; (d) real contrast ratio 252 
Fig. A5: Amplification Curve for Heritage Park site subjected to the record having PGA of 147 gal using: (a) contrast ratio of 4 ; (b) contrast ratio of 8; (c) contrast ratio of 12 ; (d) real contrast ratio 253

Fig. A6: Amplification Curve for Heritage Park site subjected to the record having PGA of 208 gal using: (a) contrast ratio of 4; (b) contrast ratio of 8; (c) contrast ratio of $12 ;(d)$ real contrast ratio 254

Fig. A7: Amplification Curve for Heritage Park site subjected to the record having PGA of 349 gal using: (a) contrast ratio of 4 ; (b) contrast ratio of 8 ; (c) contrast ratio of 12 ; (d) real contrast ratio 255

Fig. B1: Application of contrast ratios to Heritage Park site; Maximum amplification values for simulated contrast ratios using the record having: (a) PGA of 23gal;

(b) PGA of 41 gal; (c) PGA of 70gal; (d) PGA of 81 gal. 256

Fig. B2: Application of contrast ratios to Heritage Park site; Maximum amplification values for simulated contrast ratios using the record having: (a) PGA of 147gal; (b) PGA of $208 \mathrm{gal}$; (c) PGA of 349gal. 257

Fig. C1: Amplification Curve for site \#31 subjected to the record having PGA of 23 gal using: (a) contrast ratio of 4; (b) contrast ratio of 8 ; (c) contrast ratio of 12 ; (d) real contrast ratio 258

Fig. C2: Amplification Curve for site \#31 subjected to the record having PGA of 41 gal using: (a) contrast ratio of 4 ; (b) contrast ratio of 8 ; (c) contrast ratio of 12 ; (d) real contrast ratio 259

Fig. C3: Amplification Curve for site \#31 subjected to the record having PGA of 70 gal using: (a) contrast ratio of 4; (b) contrast ratio of 8 ; (c) contrast ratio of 12 ; (d) real contrast ratio 260

Fig. C4: Amplification Curve for site \#31 subjected to the record having PGA of 81 gal using: (a) contrast ratio of 4 ; (b) contrast ratio of 8 ; (c) contrast ratio of 12 ; (d) real contrast ratio 261

Fig. C5: Amplification Curve for site \#31 subjected to the record having PGA of $147 \mathrm{gal}$ using: (a) contrast ratio of 4 ; (b) contrast ratio of 8 ; (c) contrast ratio of 12 ; (d) real contrast ratio 
Fig. C6: Amplification Curve for site \#31 subjected to the record having PGA of 208 gal using: (a) contrast ratio of 4 ; (b) contrast ratio of 8 ; (c) contrast ratio of 12 ; (d) real contrast ratio

Fig. C7: Amplification Curve for site \#31 subjected to the record having PGA of 349 gal using: (a) contrast ratio of 4; (b) contrast ratio of 8 ; (c) contrast ratio of 12; (d) real contrast ratio

Fig. D1: Amplification Curve using different time histories ;(a) for target PGA of 0.1g at site class A of Config.1; (b) for target PGA of $0.3 \mathrm{~g}$ at site class $\mathrm{E}$ of Config.1; (c) for target PGA of $0.4 \mathrm{~g}$ at site class B of Config.2; (d) for target PGA of $0.5 \mathrm{~g}$ at site class $\mathrm{D}$ of Config.2.

Fig. D2: Amplification Curve using different time histories ;(a) for target PGA of $0.2 \mathrm{~g}$ at site class D of Config.3; (b) for target PGA of $0.5 \mathrm{~g}$ at site class C of Config.3; (c) for target PGA of $0.5 \mathrm{~g}$ at site class B of Config.4; (d) for target PGA of $0.1 \mathrm{~g}$ at site class $\mathrm{C}$ of Config.4.

Fig. D3: Amplification Curve using different time histories ;(a) for target PGA of $0.4 \mathrm{~g}$ at site class A of Config.5; (b) for target PGA of $0.2 \mathrm{~g}$ at site class B of Config.5; (c) for target PGA of $0.4 \mathrm{~g}$ at site class C of Config.6; (d) for target PGA of $0.3 \mathrm{~g}$ at site class B of Config.6.

Fig. D4: Amplification Curve using different time histories;(a) for target PGA of 0.5g at site class B of Config.7; (b) for target PGA of $0.2 \mathrm{~g}$ at site class A of Config.7; (c) for target PGA of $0.1 \mathrm{~g}$ at site class D of Config.8; (d) for target PGA of $0.5 \mathrm{~g}$ at site class D of Config. 8 268

Fig. D5: Amplification Curve using different time histories ;(a) for target PGA of $0.2 \mathrm{~g}$ at site class E of Config.9; (b) for target PGA of 0.4g at site class E of Config.9

Fig. E1: Amplification Curve for site with $10 \mathrm{~m}$ deposit using the record having: (a) PGA of 181 gal.; (b) PGA of 256 gal; (c) PGA of 304 gal; (d) PGA of 422 gal...... 270

Fig. E2: Amplification Curve for site with $10 \mathrm{~m}$ deposit using the record having: (a) PGA of 512 gal.; (b) PGA of 607 gal; (c) PGA of 707 gal; (d) PGA of 812 gal....... 271 
Fig. E3: Amplification Curve for the site (a) with $10 \mathrm{~m}$ deposit for target PGA of 942 gal.; (b) with $10 \mathrm{~m}$ deposit for target PGA of 1000 gal; (c) with $20 \mathrm{~m}$ deposit for target PGA of $181 \mathrm{gal}$; (d) with $20 \mathrm{~m}$ deposit for target PGA of $256 \mathrm{gal}$......... 272

Fig. E4: Amplification Curve for site with $20 \mathrm{~m}$ deposit using the record having: (a) PGA of 304 gal.; (b) PGA of 422 gal; (c) PGA of 512 gal; (d) PGA of 607 gal....... 273

Fig. E5: Amplification Curve for site with $10 \mathrm{~m}$ deposit using the record having: (a) PGA of 707 gal.; (b) PGA of 813 gal; (c) PGA of 942 gal; (d) PGA of 1000 gal..... 274

Fig. F1: Amplification Curve for site with $15 \mathrm{~m}$ deposit using the record having: (a) PGA of 181 gal.; (b) PGA of 256 gal; (c) PGA of 394 gal; (d) PGA of 422 gal...... 275

Fig. F2: Amplification Curve for site with $15 \mathrm{~m}$ deposit using the record having: (a) PGA of 512 gal.; (b) PGA of 607 gal; (c) PGA of 707 gal; (d) PGA of 812 gal....... 276

Fig. F3: Amplification Curve for the site (a) with $15 \mathrm{~m}$ deposit for target PGA of 942 gal; (b) with $15 \mathrm{~m}$ deposit for target PGA of $1000 \mathrm{gal}$; (c) with $81 \mathrm{~m}$ deposit for target PGA of 181 gal; (d) with $81 \mathrm{~m}$ deposit for target PGA of 256 gal........ 277

Fig. F4: Amplification Curve for site with $15 \mathrm{~m}$ deposit using the record having: (a) PGA of 304 gal; (b) PGA of 422 gal; (c) PGA of 512 gal; (d) PGA of 607 gal........ 278

Fig. F5: Amplification Curve for site with $15 \mathrm{~m}$ deposit using the record having: (a) PGA of 707 gal; (b) PGA of 813 gal; (c) PGA of 942 gal; (d) PGA of 1000 gal...... 279

Fig. G1: Low frequency amplification values versus average $V_{\mathrm{s} 30}$ for 19 sites using the record having: (a) PGA of 181 gal; (b) PGA of 256 gal; (c) PGA of 304 gal; (d) PGA of 422 gal. 280

Fig. G2: Low frequency amplification values versus average $V_{\mathrm{s} 30}$ for 19 sites using the record having: (a) PGA of 512 gal; (b) PGA of 607 gal; (c) PGA of 707 gal; (d) PGA of 813 gal. 281

Fig. G3: Low frequency amplification values versus average $\mathrm{V}_{\mathrm{s} 30}$ for 19 sites using the record having: (a) PGA of 942 gal; (b) PGA of 1000 gal. 282

Fig. H1: High frequency amplification values versus average $V_{s 30}$ for 19 sites using the record having: (a) PGA of 181 gal; (b) PGA of 256 gal; (c) PGA of 304 gal; (d) PGA of 422 gal. 283 
Fig. H2: High frequency amplification values versus average $V_{\mathrm{s} 30}$ for 19 sites using the record having: (a) PGA of 512 gal.; (b) PGA of 607 gal; (c) PGA of 707 gal; (d) PGA of 813 gal. 284

Fig. H3: High frequency amplification values versus average $V_{s 30}$ for 19 sites using the record having: (a) PGA of 942 gal.; (b) PGA of 1000 gal. 285

Fig. I1: High frequency amplification values (RS-based) versus average $V_{s 30}$ for 19 sites using the record having: (a) PGA of 181 gal.; (b) PGA of 256 gal; (c) PGA of 304 gal; (d) PGA of 422 gal. 286

Fig. I2: High frequency amplification values (RS-based) versus average $V_{s 30}$ for 19 sites using the record having: (a) PGA of 512 gal.; (b) PGA of 607 gal; (c) PGA of 707 gal; (d) PGA of 813 gal. 287

Fig. I3: High frequency amplification values (RS-based) versus average $V_{s 30}$ for 19 sites using the record having: (a) PGA of 942 gal.; (b) PGA of 1000 gal. 288 


\section{List of Tables:}

Table 2.1: Main field parameters for different MASW tests.

Table 2.2: Comparison between estimated MASW results and borehole data for shallow bedrock sites (canal sites).

Table 2.3: Estimated bedrock depth and velocity using MASW for some sites located in the downtown area of the city of Ottawa.

Table 2.4: Comparison between estimated MASW results and those of the reflection/refraction methods (GSC preliminary map, 2007) for deeper bedrock in the Orleans area. 51

Table 3.1: Physical model parameters of the Barrington Park site located in east Ottawa.

Table 3.2: Physical model parameters of the Chapel Hill site located in east Ottawa. .... 92

Table 3.3: Physical model parameters of the Longleaf Park site located in east Ottawa. 92

Table 4.1: Site Categories in NEHRP Provisions and NBCC, 2005 188

Table 4.2: Input parameters of the finite element model for the profile in ORHO station (weak motion modeling). 190

Table 4.3: Physical parameters of three sites in the eastern part of the city of Ottawa. . 191

Table 4.4: Peak amplification factors at Site \#31 using the FEM seismic response analysis and the scaled records.

Table 4.5: Application of Logarithmic-Linear model (equation (4-38)) to ( $\mathrm{z}$, PGA) data at site \#31. Peak amplification factors are calculated for site \#31 using different contrast ratios and peak ground accelerations.

Table 4.6: Shear wave velocity ranges of soil and the underlying bedrock for nine different profile configurations. These configurations are used to generate NEHRP,1994 velocity profiles.

Table 4.7: Low frequency amplification factors $\left(F_{v}\right)$ from NEHRP 1994. $S_{1}$ is the spectral acceleration at the frequency of $1 \mathrm{~Hz}$.

Table 4.8: High frequency amplification factors $\left(F_{a}\right)$ from NEHRP 1994. $S_{0.2}$ is the spectral acceleration at the frequency of $3 \mathrm{~Hz}$. 
Table 4.9: GSC sites (depth $>30 \mathrm{~m}$ ) used for low and high frequency amplification analysis in Ottawa area and the corresponding depth-velocity parameters and $\mathrm{Vs}_{30}(\mathrm{~m} / \mathrm{sec})$. $\mathrm{d}$ is the depth of the site.

Table 4.10: Sites (depth $\leq 30 \mathrm{~m}$ ) used for low and high frequency amplification analysis in Ottawa area and the corresponding depth-velocity parameters and $\mathrm{Vs}_{30}$ $(\mathrm{m} / \mathrm{sec}) . \mathrm{d}$ is the depth of the site.

Table 4.11: Low frequency amplification values (Fourier spectra definition) for the 19 examined sites in Ottawa area. Site depth, average shear wave velocity in top thirty meters and fundamental frequency calculated based on the average shear wave velocity are illustrated in the first, second and third columns. The amplification values are given for 10 intensities of shaking (PGA).

Table 4.12: Values of low frequency Foundation Factors $\left(F_{v}\right)$ in NBCC, 2005. 200

Table 4.13: Constants of $a, b$ and $c$ in equation (4-42) for the determination of low frequency amplification values, $\left(\mathrm{F}_{\mathrm{V}}\right)_{\mathrm{FFT}}$. These constants were obtained based on the multiple linear regression at the specific shaking intensity $(\mathrm{PGA}=\alpha)$.

Table 4.14: High frequency amplification values (Fourier spectra definition) for 19 sites in Ottawa area. Site depth, average shear wave velocity in top thirty meters and linear fundamental frequency are illustrated in the first, second and third columns. The amplification values are given for 10 intensities of shaking (PGA). 202

Table 4.15: Values of high frequency Foundation Factors $\left(F_{a}\right)$ in NBCC, 2005. 203

Table 4.16: Low frequency amplification values (Response spectra definition) for the nineteen examined sites in Ottawa area. Site depth, average shear wave velocity in top thirty meters and fundamental frequency (calculated from average shear wave velocity) are illustrated in the first, second and third columns. The values are given for ten intensities of shaking (PGA).

Table 4.17: High frequency amplification values (Response spectra definition) for nineteen sites in Ottawa area. Site depth, average shear wave velocity in top thirty meters and linear fundamental frequency are illustrated in the first, 
second and third columns. The values are given for ten intensities of shaking (PGA).

Table 4.18: Depth and average shear wave velocity values in top $30 \mathrm{~m}$ for the examined sites in Ottawa area. These sites provided the source profiles to obtain the low and high frequency amplification values similar to those given in NBCC, 2005

Table 4.19: Low frequency amplification values for Ottawa area for different configurations of site classes. 206

Table 4.20: High frequency amplification values for Ottawa area for different configurations of site classes 207

Table 4.21: Average Low frequency amplification values for Ottawa area. 207

Table 4.22: Average high frequency amplification values for Ottawa area. 208

Table 4.23: Proposed average low frequency amplification values for Ottawa area. The amplification values were normalized to the values of site class $\mathrm{C}$ 208

Table 4.24: Proposed average high frequency amplification values for Ottawa area. The amplification values were normalized to the values of site class $C$ 209

Table 4.25: Peak amplification ratios for target fundamental frequencies in Ottawa area.

Table 5.1: Minimum frequency and damping values for a sites having fundamental frequency of $0.75 \mathrm{~Hz}$. Depending on the dominant frequency of input motion the minimum frequency is changed. Corresponding damping ratio of this minimum frequency is determined based on the shaking intensity of input motion.

Table 5.2: Fundamental frequencies of the $2 \mathrm{D}$ valley compared to the adjacent $1 \mathrm{D}$ site for different input motions. 


\section{Introduction}

\subsection{General: Problem Statement}

Seismic hazard represents the potential for the occurrence of an earthquake and the associated ground hazards in a given location. However, the risk to population and property depends on the exposure, and hence seismic risk is determined based on a combination of the hazard and exposure. In terms of highest seismic risk, Ottawa is rated third in Canada since this populated city is located in the Western Quebec seismic zone that extends from Montreal, Quebec to Ottawa, Ontario (Adams and Halchuck, 2003). This seismic risk can be further elevated with potential soil amplification due to surficial geology. Surficial geology of the city consists of very loose and low shear wave velocity ( $<180 \mathrm{~m} / \mathrm{sec}$ ) post-glacial deposits (Holocene age sediments) underlain by very high shear wave velocity $(>2300 \mathrm{~m} / \mathrm{sec})$ bedrocks.

The current version of the National Building Code of Canada (NBCC, 2005) uses seismic soil amplification as one component of the specifications for earthquake design loads in engineering practices. The NBCC specifies amplification factors for soil sites that are classified according to the measured shear wave velocity of a site from surface to a depth of $30 \mathrm{~m}$ and/or based on other geotechnical parameters. Site amplification is an important concern in geotechnical practices in the Ottawa area as the majority of the eastern and southern parts of Ottawa is located on loose post-glacial sediments with very low shear wave velocities overlying a very firm bedrock with high 
shear wave velocities (Adams, 2007; Hunter et al., 2007; Motazedian et al., 2006; Motazedian et al., 2007; Motazedian and Hunter, 2008; and Pugin et al., 2007).

The active Western Quebec seismic zone extends from Montreal, Quebec with a population of 3.3 million to Ottawa, Ontario with a population of about one million people. Significant earthquake hazards exist in this zone and in Eastern Canada. It was in this zone that the 1935 Temiskaming earthquake (magnitude M6.2), and the 1944 Cornwall-Massena earthquakes (magnitude M5.8) occurred. In addition, ample evidence of large scale paleo-earthquake-triggered ground deformation exists in this region (Aylsworth et al., 2000). Most events in this zone concentrate along the Ottawa River and in the West Quebec seismic zone striking northwest from Montreal. The recent magnitude M5.0 earthquake in the Outaouais region on June 23, 2010 was located at about $50 \mathrm{~km}$ away from the city of Ottawa, and highlights the hazard potential that needs to be taken into consideration in this city.

Furthermore, past earthquakes have demonstrated the dramatic effects of soil response that can cause damage to property and public safety. The phenomenon of seismic soil amplification by soft sediments has been observed in several locations in the Ottawa area (Adams, 2007; Hunter et al., 2007; and Motazedian et al., 2008). Sparse earthquake recordings in the Ottawa area show that the soil amplification is large relative to typical amplification factors being used in geotechnical practice. This unusual high soil amplification for the weak motion is a serious concern in microzonation studies for the Ottawa area. The nonlinearity of soil behavior decreases the level of seismic soil amplification for strong ground motion. Due to lack of strong ground motion data, a theoretical approach often becomes necessary. 
The research reported herein is part of the microzonation study of the Ottawa area initiated by Carleton University in 2005. Geological Survey of Canada (GSC) recognized the importance of this project and joined in the efforts in 2006, which resulted in a strong collaboration in order to conduct field work using various geophysical techniques to obtain shear wave velocity measurements $\left(V_{s}\right)$ in the near-surface within the City of Ottawa.

The results of this research over the last few years highlight unusual seismic soil amplifications for weak motions possibly due to the very high contrast between the shear wave velocity of the post-glacial sediments and the shear wave velocity of the bedrock in the Ottawa area. The presence of the loosely consolidated sediments, often called Leda Clay in the literature, leads to a very high shear wave velocity contrast between the bedrock and overlying soil (Pugin et al., 2007; Motazedian and Hunter, 2007); and Hunter et al., 2006). This contrast can be described by the acoustic impedance factor, $\mathrm{Z}$ :

$Z=\rho \mathbf{v}$

where, $\rho$ and $v$ indicate the density and shear wave velocity, respectively.

The ratio of the acoustic impedance of the bedrock to that of the overlying soil, termed impedance contrast ratio, determines the nature of the reflection/refraction of seismic waves at the interface. The typical values of density and shear wave velocity of Leda clay in Ottawa area are around $1700 \mathrm{~kg} / \mathrm{m}^{3}$ and $150 \mathrm{~m} / \mathrm{sec}$, respectively. The average bedrock density and shear wave velocity are about $2500 \mathrm{~kg} / \mathrm{m}^{3}$ and $2700 \mathrm{~m} / \mathrm{sec}$ respectively. Thus, the acoustic impedance contrast ratio at the soil and the bedrock boundary is more than 20. Motazedian et al. (2007) showed that this acoustic impedance value gives the reflection coefficient and reflected energy coefficient of 0.9 and 0.8 , 
respectively. Furthermore, they concluded that the critical angle for the incident waves is just a few degrees implying that the incident waves with the angles more than few degrees are totally trapped.

Weak motion observations from sparse earthquake recorded in Ottawa show large seismic amplification values compared to the amplification factors given by the National Building Code of Canada (NBCC, 2005). As an example, for $\mathrm{M}=4.2$, Dec. 7 , 2006, Cochrane earthquake very large amplification values $(\sim 143)$ were reported at the fundamental frequency of the ORHO seismic station (Motazedian et al., 2007). In addition, Pugin et al. (2007) obtained high amplification values up to 75 for the same site using $\mathrm{H} / \mathrm{V}$ spectral ratio method (Nakamura technique). These studies suggest that a comprehensive study on site response and seismic amplification factors is needed throughout the city.

\subsection{Scope of the thesis}

The high impedance contrast ratio implies that comprehensive seismic surveying and site response analysis for the city of Ottawa is critical to understand the main issues associated with seismic design in the city. The research program presented in this thesis is concentrated on two main categories to address the aforementioned issues:

Firstly, it is essential to establish velocity-depth functions for Leda clay and distinguish the high impedance contrast boundary between the soil and bedrock in the city using different seismic surveying methods. As one of the geophysical methods, multi-channel analysis of surface waves (MASW) method is applied to detect the bedrock and to determine the impedance contrast ratio. It should be mentioned that Carleton University and Geological survey of Canada (GSC) have been surveying the Ottawa area 
using other geophysical/geotechnical methods, which are not discussed in this thesis, but their results are used for comparison and as input parameters in the seismic soil modeling.

MASW method benefits from fast data acquisition and powerful analytical processes. In addition, this method enables engineers and geophysicists to perform a seismic survey on pavements in busy urban area where other methods such as seismic reflection/refraction may not be practical. The MASW application in this research is a part of "seismic microzonation studies and measurements for city of Ottawa" program conducted by Carleton University in collaboration with Geological Survey of Canada (GSC).

Secondly, extensive site response analyses are performed to understand the issues associated with soil amplification in the city. These analyses include i) method of generalized reflection/transmission $(R / T)$ coefficients, ii) one-dimensional finite element method (FEM) and iii) two-dimensional finite difference method (FDM). The research reported in this thesis has investigated the wave trapping issue, shaking intensity-dependant damping formulation, weak motion amplification, amplification models based on shaking intensity and impedance contrast ratio, low and high frequency seismic amplification equations and two-dimensional amplification of a deep valley.

This research provides a better and more reliable formulation/understanding of the seismic amplification phenomenon in different parts of the city. Moreover, the differences between NBCC recommendations and weak motion observations are explained by appropriate analyses. 


\subsection{Organization of the thesis}

To address the high impedance contrast issue and to obtain the shear wave velocity-depth functions chapter 2 is devoted to the seismic surveying. These velocitydepth profiles are one of the essential inputs to seismic response analysis. In that chapter, the investigated surveying method, which is the multi-channel of surface waves (MASW), is calibrated against reflection/refraction and borehole results and its capability to differentiate the high shear wave velocity is studied.

In chapter 3, reflection/transmission (which is called $\mathrm{R} / \mathrm{T}$ ) method is used to investigate on reflection and transmission characteristics of seismic waves in soil layers. This method provides a scheme for analyzing the probable internal reflections of seismic waves because of the high impedance contrast ratio in the Ottawa area. The studied $\mathrm{R} / \mathrm{T}$ method is calibrated against the widely used equivalent linear method (ELM) by implementing an intensity-dependent damping formulation and adjusting the shear modulus. Chapter 4 presents extensive one-dimensional finite element analyses for several sites across the city. In that chapter, weak motion amplification simulation, analyses of seismic amplification ratios based on combined effect of shaking intensity and impedance contrast ratio, and finally development of high and low seismic amplification equations/correlations are presented. In chapter 5, using explicit finite difference method, a deep valley located in the eastern part of the city is subjected to an artificial input motions and the seismic soil amplification curves are obtained and compared with those obtained from an adjacent one-dimensional site. 


\subsection{References}

Adams J., and Halchuck S., 2003, Fourth generation seismic hazard maps of Canada: Values for over 650 Canadian localities for the 2005 National Building Code of Canada, Geological Survey of Canada, Open File 4459, 155p.

Aylsworth J.M., Lawrence D.E., and Guertin J., 2000, Did two massive earthquakes in the Holocene induce widespread landsliding and near-surface deformation in part of the Ottawa Valley, Canada? Geology, 28, pp. 903-906.

Hunter J.A. and Motazedian D., 2006, Shear wave velocity measurements for soft soil earthquake response evaluation in the eastern Ottawa region, Ontario, Canada, SAGEEP Conference Bulletin.

Hunter J.A., Burns R.A., Good R.L., Aylsworth J.M., Pullan S.E., Perret D., and Douma M. , 2007, Borehole shear wave velocity measurements of Champlain Sea sediments in the Ottawa-Montréal region, Geological Survey of Canada Open File 5345, Geological Survey of Canada, Natural Resources Canada, Ottawa.

Motazedian D., Hunter J.A. and Khaheshi Banab K., 2007, Using a railway train as a seismic source to observe trapped waves in a low Vs soil layer overlying a High Vs bedrock, submitted to the Bulletin of the Seismological Society of America.

Motazedian D. and Hunter J.A., 2008, Development of a NEHRP map for the Orleans suburb of Ottawa, Ontario, Canadian Geotechnical Journal, 45, pp.1180-1188.

Pugin A., Hunter J., Motazedian D. and Khaheshi Banab K., 2007, An application of shear wave reflection land streamer technology to soil response evaluation of earthquake shaking in an urban area, Ottawa, Ontario SAGEEP conference. 


\section{Seismic Surveying using the Multi-Channel Analysis of Surface Waves (MASW)}

\subsection{Surface Waves and MASW}

In this chapter, multi-channel analysis of surface waves (MASW) technique, among different seismic surveying methods, was used to distinguish the high shear wave velocity contrast between the bedrock and the overlying soft soil. This method was also applied to detect the depth of the bedrock, and to delineate the velocity-depth profiles of the examined sites.

Surface waves are dispersive because different wavelengths have different penetration depths, and consequently the seismic wave propagates with different velocities at different depths. This characteristic of the surface waves is commonly used to obtain the dispersion curve that is the relationship between phase velocity and frequency. The obtained dispersion curve is then analyzed and inverted to estimate the variation of the shear wave velocity with depth (Nazarian et al., 1983; Stokoe et al., 1994; and Park et al., 1998). Rayleigh wave can be generated easily in comparison with the other types of seismic waves. In near-surface seismic surveying using vertical sources, the energy of Rayleigh waves is about two thirds of the total seismic energy (Richart et al., 1970) and is very prominent on the multi-channel records.

Hence, high signal to noise ratio can be attained and guaranteed by using Rayleigh waves. If multi-channel system is used, body waves and higher-modes of the 
Rayleigh wave can be distinguished by their different resolutions on multi-channel record, and their different patterns on the associated dispersion curve (see section 6 for the definition of the dispersion curves).

Multi-channel analysis of surface waves (MASW) is a quick method to evaluate the shear wave velocity profile compared to the other surface wave methods, such as the spectral analysis of surface waves (SASW) (Nazarian et al., 1983; and Nazarian, 1984) since there is no need to change the configuration of source and receivers to reach different depths. Three steps are taken in an MASW method: a) data acquisition or collecting the required shot gathers, b) construction of the dispersion curve for the fundamental mode of the Rayleigh wave using an appropriate technique (e.g. the wavefield transformation technique was used in this research), c) and non-linear inversion or random-search inversion to obtain the shear wave velocity-depth function.

\subsection{MASW versus SASW}

SASW method uses only two receivers to record ground roll that is usually generated by impact sources (like sledge hammer), and therefore, the test should be repeated with multiple field setups (different source and receiver spacings) to cover different depths of investigation. SASW test is also performed in two directions to cover effect of any internal phase shifts due to receivers and instrumentation (Nazarian et al., 1983). The necessity of the repeated tests furthermore exists for the purpose of reducing the influence of random noise. Following the field procedure, the collected data are analyzed to establish the dispersion curve using a spectrum analyzer (Stokoe et al., 1994). This method is time consuming due to the requirement of repeated tests with different field configurations and it usually takes several hours to complete the entire process. 
Moreover, since only two receivers are used, all the possible adverse effects that may cause errors in the results cannot be detected and handled properly. These effects are the inclusion of body waves, higher-modes and non-planar surface waves. Because of these issues, quality control of the acquisition and processing is difficult and the accuracy of the SASW results may be diminished.

On the contrary, in MASW method, multiple number (usually twelve or more) of receivers (geophones) with multi-channel seismograph are used. Field configuration of MASW is very similar to that for body-wave surveying and some extra criteria are required to have acceptable data-acquisition (see next section).

\subsection{Field procedure of MASW}

Field procedure of MASW can be performed in different manners: Active, remote passive and roadside passive. To carry out the field procedure of the active MASW, multiple receivers (geophones) are positioned along a survey line (spread). These receivers are located with even spacing and connected to a seismograph. A seismic source (a sledge hammer or a vibratory machine which operates vertically) generates seismic waves which are gathered by a seismograph and recorded on a computer. In this research, a 24 channel Geometrics Geode seismograph, and vertical $4.5 \mathrm{~Hz}$ geophones were used. Geophones are mounted on the land streamer plates, which simply lie on the ground, or the geophones are coupled to the ground by their spikes to satisfy the required coupling. Land streamer plates are connected with a strong rope allowing the shift of the entire spread in order to cover a long profile in a short time.

Passive surveying methods usually use waves generated by traffic to increase the investigation depth (Park et al., 2006; Okada et al., 2003; and Louie et al., 2001). The 
necessities of passive surveys are greatly justified since the active methods fail to cover sufficient depth of investigation in urban areas. In the passive roadside MASW method (Park and Miller, 2008), a conventional linear geophone array is adopted and the surface waves, generated by local or simulated traffic, are utilized. In this method, moving sources (traffic) are employed parallel to the spread line and the offline distance between the moving source and the survey line is kept fairly constant throughout the surveying. In addition to the waves from traffic, surface waves generated from natural or cultural sources with low frequency content provide a wide range of penetration depths. Therefore, there is a strong motivation to use them in passive MASW method, usually called the passive remote MASW. In this passive method, one-dimensional arrangements of the receivers cannot capture all the characteristics of the passive sources because intensity and the modal nature of the waves are unknown. Thus, as long as the symmetric shape of the two-dimensional geophone array is kept, any common array of geophones deployment including circular, cross, square, or triangular configuration may be utilized. To achieve the main goal of passive methods, which is higher depth investigation, it is generally recommended to increase the dimension of the geophones array (e.g. Park et al., 2005) because the array dimension is directly related to the longest wavelength that determines the maximum depth of investigation.

In summary, the key differences between the field procedure of active and passive tests are as follows:

In active tests, linear geophone setup and impact sources or vibratory machines are used but in remote passive tests, two dimensional symmetric geophone arrays should be utilized and the source is the ambient noise. In roadside MASW, although the spread is 
linear but the source would be the traffic moving parallel to the geophone array. Time of recording and the geophone spacing are increased for both types of the passive tests compared to the time and spacing of active tests. Larger spacing leads to greater spread length that enhances the depth of the investigation.

\subsection{Essential Parameters and Important factors of MASW}

Essential parameters of the MASW method are:

1. Type of receivers which are relatively low frequency geophones,

2. Spacing between two successive geophones,

3. Total length of spread,

4. Offset between the source and the first geophone,

5. Total time of recording,

6. Sampling rate.

In active tests, source of energy is usually a heavy sledge hammer striking vertically on a rigid and heavy plate to produce $\mathrm{P}$ waves. In passive roadside MASW and passive remote MASW tests the moving traffic (heavy cars and trucks) and the ambient noise are the seismic sources respectively. In the MASW field procedure, some important factors should be noted. First, an appropriate coupling between the plate and the ground is essential, because the seismic wave should be transmitted properly. Both, spikecoupled and plate-coupled geophones have their own limitations and advantages, and hence extra considerations are needed depending on the corresponding site conditions. Second, the natural frequency of geophones should be low, since high frequency geophones will limit the depth of investigation. Third, the length of the spread is equal to or comparable to the maximum resolvable depth of investigation. Fourth, the spacing 
between geophones that controls the depth-velocity resolution should generally be between 0.5 and $1.5 \mathrm{~m}$ for the active tests. For the passive tests, the spacing is increased to investigate higher depths. Fifth, the distance between source and the end of spread (offset) is usually between $10 \mathrm{~m}$ and $100 \mathrm{~m}$ for the active tests. The minimum value of the offset avoids the non-linear propagation of Rayleigh waves at shorter distances. At offset distances larger than $100 \mathrm{~m}$, the dominance of body waves or the ambient noise is probable.

\subsection{Criteria of the Source, Receiver and Offset selection in MASW}

Sources: A sledge hammer heavier than 10 -lb is a good source for MASW tests at the most of the sites. A heavy metal hammer plate is preferred over other types (e.g., aluminum plate) for a better coupling at low (e.g. $<10 \mathrm{~Hz}$ ) frequencies. A swept source (a vibrator, for example) or an impulsive source (a sledgehammer) will generate surface waves.

Offset between the source and the first geophone: Although surface waves are dominant on seismic data, they require acquisition parameters which are well-matched to record the planar form of the fundamental mode of Rayleigh waves. Due to adverse nearfield effects, Rayleigh waves can be considered the "horizontally traveling plane waves" only after a certain propagation distance from the source point (Richart et al., 1970). Therefore, the source to the first receiver distance (called $x_{1}$ ) must be large enough to have horizontally traveling plane waves.

On a multi-channel record displayed in a swept-frequency format (offset versus frequency), the above mentioned near-field effects manifest themselves as a lack of linear coherency in phase at the lower frequencies. Different researchers have reported some 
optimum ratios between $x_{1}$ and maximum wavelength $, \lambda_{\max },(e . g$. Stokoe et al., 1994; and Gucunski and Woods, 1991). For example, Stokoe et al. (1994) suggest the following equation:

$\mathrm{x}_{1} \geq 0.5 \lambda_{\max }$

Depth: Penetration depth of the surface wave is approximately equal to its wavelength $(\lambda)$ (Richart et al., 1970), while the maximum depth $\left(\mathrm{z}_{\max }\right)$ for which $\mathrm{V}_{\mathrm{s}}$ can be reasonably calculated is about half the longest wavelength $\left(\lambda_{\max }\right)$ measured (Rix and Leipski, 1991). Rewriting equation (2-1) to represent maximum imageable depths,

$$
\mathrm{x}_{1} \geq \mathrm{Z}_{\max }
$$

Equation (2-2) also provides a good rule of thumb for selecting the near-offset distances.

It has been suggested that the lowest frequency $\left(f_{1}\right)$ determines the maximum depth of investigation,$z_{\max }$, through the subsequent inequality:

$z_{\max }>\mathrm{C}_{1} /\left(2 \mathrm{f}_{1}\right)$

where $C_{1}$ is phase velocity for the lowest frequency $f_{1}$ (Rix and Leipski, 1991).

Receivers: Receivers of $4.5-\mathrm{Hz}$ and $10-\mathrm{Hz}$ usually do not make much difference as long as depth of investigation is not more than $30 \mathrm{~m}$. Receivers with plate coupling (not coupled to the ground) also can generate results comparable to those obtained by the using of spike coupling. The lowest frequency $\left(f_{1}\right)$ recorded is usually limited by the natural frequency of the geophone and source type. If $z_{\max }$ is not sufficient for a desired depth, a different type of source that can generate more energy at lower frequencies and/or followed by lower-frequency geophones should be used.

High-frequency (short wavelength) components of surface waves attenuate rapidly in comparison with low-frequency components (Bullen, 1963) and therefore the 
selection of large receiver offset may reduce the dominancy of the high-frequency components of surface waves. This attenuation of high frequency waves can cause body wave contamination. Also far-offset effects can be followed by the amplitude decrease of some frequencies or the linear coherency reduction in the arrival waves.

The mentioned far-offset effect limits the highest frequency $\left(f_{\max }\right)$ at which the phase velocity can be measured. Stokoe et al. (1994), used $f_{\max }$ to designate the top thickness $\left(\mathrm{H}_{1}\right)$ for a particular phase velocity:

$\mathrm{H}_{1}>0.5 \lambda_{\min } \quad\left(\lambda_{\min }=\mathrm{C}_{\min } / \mathrm{f}_{\max }\right)$

where $C_{\min }$ and $\lambda_{\min }$ are phase velocity and wavelength, respectively, which correspond to a particular $f_{\max }$. Equation $(2-4)$ is a rough estimation of the minimum definable thickness of the shallowest layer.

\subsection{Construction of the dispersion curve}

The wavefields of horizontally traveling ground roll are recorded by receivers (geophones) laid at the surface with certain spacing, $\mathrm{dx}$. Then, recorded wavefields are analyzed at different frequencies $(f)$ for the phase velocities $\left(C_{f}\right)$ based on the difference in the arrival times $\left(\Delta t_{f}\right)$ of ground roll at two receivers. Therefore, $C_{f}$ is obtained using the following equation:

$\mathrm{C}_{\mathrm{f}}=\mathrm{dx} / \Delta \mathrm{t}_{\mathrm{f}}$

This analysis produces a set of data ( $f$ versus $C_{f}$ ), which is the dispersion data, that are the input data for the next step of MASW, the inversion process.

A number of methods have been introduced for extracting of the dispersion curves (Zhang et al., 2003; Ashiya et al., 1999; Zywicki and Rix, 1999; Park et al., 1998; McMechan et al., 1981; Jones, 1962; and Heukelom et al., 1960). 
During recent years, older methods based on steady-state Rayleigh waves (Jones, 1962; and Heukelom et al., 1960) were shown to be inappropriate for layered models. Another method, the frequency-wave number (F-K) method (Zywicki and Rix, 1999; and Ashiya et al., 1999) is based on the imaging of the stacked energy in (F-K) space. Zhang et al. (2003) showed that the extracted velocities from the (F-K) method are apparent velocities, rather than fundamental mode ones, and can cause erroneous outcomes in the inversion process.

In this study, I applied the wavefield transformation technique (McMechan et al., 1981; and Park et al., 1998), which aims to get the dispersion spectrum from multichannel surface wave data. Zhang et al. (2003) showed that this technique gives a better representation of the dispersion behavior of the Rayleigh waves than the previous techniques. Transformation steps and theory were explained by Park et al. (1998). After a mathematical manipulation, these researchers suggest a transform function whose maximum values (for each intended frequency) give pairs of frequency-phase velocity that provide the image of the dispersion curve.

\subsection{Inverting of shear wave velocity profiles}

\subsubsection{Characteristic equation}

Sensitivity analysis of the parameters affecting the Rayleigh wave phase velocity is determined by a characteristic equation, $\mathrm{F}$, in its nonlinear, implicit form:

$F\left(f, V_{R}, V_{P}, V_{S}, \rho, H\right)=0$

In this Equation, the parameters are: frequency vector ( $\mathrm{f}$ in $\mathrm{Hz}$ ), Rayleigh wave phase velocity vector $\left(V_{R}\right.$ in $\left.\mathrm{m} / \mathrm{sec}\right), \mathrm{P}$-wave velocity vector $\left(V_{P}\right.$ in $\left.\mathrm{m} / \mathrm{sec}\right)$, density vector $(\rho$ in 
$\left.\mathrm{kg} / \mathrm{m}^{3}\right)$ and layer thickness vector $\left(\mathrm{H}\right.$ in meter). Given a set of model parameters $\left(\mathrm{V}_{\mathrm{P}}, \mathrm{V}_{\mathrm{S}}\right.$, $\rho, H)$ and a specific frequency, $f$, the roots of this equation are the phase velocities. Accuracy of the partial derivatives is the key point in the calculation of the variation of the mentioned parameters. This accuracy dramatically affects convergence of the inversion procedure required to determine the target parameter (Xia, 1986). The practical way to calculate the partial derivatives of this equation is by evaluating finite-difference values because the equation is in an implicit form. Xia et.al (1999) developed an inversion algorithm and used Ridder's method of polynomial extrapolation (Press et al., 1992) to calculate the partial derivatives (Jacobian matrix) during the inversion.

For implicit functions in general, evaluating the accuracy of partial derivatives may not be possible because they are calculated using a finite-difference formula. However, the accuracy of partial derivatives may be evaluated with respect to densities ( $\rho$ ) since in characteristic equation (Equation 2-6), density terms appear in the form of $\rho_{i+1} / \rho_{i}$ (Schwab and Knopoff, 1972). Mathematically, this form of density $\left(\rho_{i+1} / \rho_{i}\right)$ shows that the direction of the partial derivative vector with respect to density (shown with Jacobian, $\mathrm{J} \rho$ ) is perpendicular to density vector, $\rho$. This feature can be expressed by the following equation:

$\mathrm{J} \rho \cdot \rho=0$

where $(\cdot)$ denotes the dot product. Xia et al. (1999) state that the Jacobian matrix calculated in a high-frequency range $(>5 \mathrm{~Hz})$ by Ridder's method is stable. The other way to estimate the Jacobian matrix is to use variational techniques. These techniques require computation of Eigen-functions but generate stable estimates of partial derivatives. 
As shown in Equation (2-6), Rayleigh-wave phase velocity is the function of four parameters: S-wave velocity, P-wave velocity, density, and layer thickness. Each parameter contributes to the dispersion curve in a unique way. A parameter can be disregarded from the inverse procedure if contributions to the dispersion curve from that parameter are relatively small in a certain frequency range. Xia et al. (1999) evaluated the contributions to the Rayleigh-wave phase velocity in the high-frequency range $(\geq 5 \mathrm{~Hz})$. Their results show that the variations in S-wave velocities have a dramatic effect on Rayleigh-wave phase velocities in the high-frequency range $(>5 \mathrm{~Hz})$. Jacobian matrix equation is written in the following form:

$\mathrm{J}_{\mathrm{s}}=\left(\partial \mathrm{F} / \partial \mathrm{V}_{\mathrm{S}}\right) /\left(\partial \mathrm{F} /\left(\partial \mathrm{V}_{\mathrm{R}}\right)\right.$

This equation indicates that multiplying $\mathrm{J}_{\mathrm{s}}$ by the changes in phase velocities will give the changes in S-wave velocities. For the other parameters, the mentioned authors used the same procedure and concluded that S-wave velocity variation, the variation of the layer thickness, density and P-wave velocity have the most effect on the phase velocity respectively. Therefore, inverting the Rayleigh-wave phase velocity for layer thickness is more reasonable than for P-wave velocity or density because the sensitivity indicator is greater for thickness variation than for P-wave velocity or density variation. On the other hand, since the subsurface can always be subdivided into a reasonable number of layers, each having a constant S-wave velocity, thickness can be eliminated as a variable in the inverse procedure and consequently only S-wave velocity is left as unknown. In conclusion, the S-wave velocity has the highest sensitivity indicator and it can be reasonably inverted from phase velocity data. 


\subsubsection{Inversion techniques to discern the high shear wave velocity contrast between soil and bedrock formations}

In the third step of MASW processing, the shear wave velocity is inverted from the dispersion curve of the Rayleigh wave. It has been shown that the inverted onedimensional (1-D) shear wave velocity model is an average of the earth material beneath the geophone spread, and it is reasonable to locate an inverted 1-D shear wave velocity model in the middle of the geophone spread (Luoa et al., 2008). There are two different inversion techniques used in the MASW method: (i) Monte Carlo or random search inversion, and (ii) generalized non-linear inversion. In both inversion techniques, forward modeling is applied on an initial model. Then, using the extracted dispersion curves, one of the inversion techniques is applied to provide the shear wave velocity values at different depths.

A summary of the generalized inversion technique is presented here. In linear inversion, the relation between the matrices of observed phase velocity matrix (C) and model parameter (x), which is the shear wave velocities of the layers, is expressed by the following form:

$$
\mathrm{x}=\mathrm{G}^{-1} \mathrm{C}
$$

where $\mathrm{G}$ is the model matrix.

In contrast, it is assumed in the non-linear inversion approach that the variation of the observed phase velocity, $\Delta \mathrm{C}$, is proportional to the variation of model parameters, $\Delta \mathrm{x}$, (shear wave velocity here) that means:

$$
\Delta \mathrm{x}=\mathrm{G}^{-1} \Delta \mathrm{C}
$$


For a variable function of $\mathrm{C}(\mathrm{x})$, which is differentiable at least $\mathrm{n}$ times from the points $\mathrm{x}$ to $\mathrm{x}+\delta \mathrm{x}$, the Taylor expansion can be written:

$$
\mathrm{C}(\mathrm{x}+\delta \mathrm{x})=\mathrm{C}(\mathrm{x})+\mathrm{g}^{\mathrm{T}} \delta \mathrm{x}+0.5 \delta \mathrm{x}^{\mathrm{T}} \mathrm{H} \delta \mathrm{x}+\ldots
$$

where $\mathrm{g}^{\mathrm{T}}$ is the transpose of the gradient vector and $\mathrm{H}$ is the Hessian matrix.

Levenberg and Marquardt (Marquardt, 1963) considered both of the introduced terms $\left(\mathrm{g}^{\mathrm{T}}\right.$ $\delta x$ and $\left.0.5 \delta x^{T} H \delta x\right)$. Knowing that $C(x+\delta x)-C(x)=\Delta C$, using Equations (2-10), (211) and applying the least squares method, $G^{-1}$ is obtained:

$$
\mathrm{G}^{-1}=\Delta \mathrm{x} /(\mathrm{C}(\mathrm{x}+\delta \mathrm{x})-\mathrm{C}(\mathrm{x}))=-\left[\mathrm{A}^{\mathrm{T}} \mathrm{A}+\lambda \mathrm{I}\right]^{-1} \mathrm{~A}^{\mathrm{T}}
$$

where $\mathrm{A}$ is a Jacobian matrix containing the partial derivatives of $\Delta \mathrm{C}$ relative to $\Delta \mathrm{x}$, and $\lambda$ is the eigenvalues of the matrix $A^{T} A$ (Lee et al., 1981).

Thus, the inversion algorithm can be implemented: $\Delta \mathrm{x}$ is obtained using Equations (2-10) and (2-12), knowing that, in Equation (2-10), $\Delta \mathrm{C}=\mathrm{C}_{\text {observed }}-\mathrm{C}_{\text {model }}$, where $\mathrm{C}_{\text {observed }}$ is the phase velocity in the extracted dispersion curve and $\mathrm{C}_{\text {model }}$ is the phase velocity obtained from the model using the method introduced by Schwab and Knopoff (1972). $\mathrm{C}_{\text {model }}$ is a function of $\mathrm{x}$ (shear wave velocity) and a suitable initial profile is needed to start the inverse algorithm. A new $\mathrm{x}$ (where $\mathrm{x}_{\text {new }}=\mathrm{x}_{\text {previous }}+\Delta \mathrm{x}$ ), which is the shear wave velocity profile, is updated in each step until the least squares errors are minimized.

The other inversion technique is the random search inversion approach. The generalized or nonlinear inversion techniques rely on analytical solutions, while the random search inversion approach takes a suitable initial velocity profile as the initial guess of the inversion and uses a random search algorithm to revise the initial profile. The advantages of random search algorithms have been studied by a few researchers. For instance, Ryden and Park 2006 used the fast simulated annealing (FSA) global search 
algorithm (Szu and Hartley, 1987) that seeks the best match between the measured and modeled phase velocity spectrum. Ryden and Park (2006) indicate that random search inversion method is less likely to get trapped in local minima, which may occur with a generalized inversion method.

A number of researchers studied the accuracy of the inversion models in seismic surveying. For instance, Zhang and Chan (2003) studied the effects of sample interval and truncated frequency range on the accuracy of the inversion models. Their study shows that the accuracy of inversion models is improved by: (i) choosing small sample intervals over a wide frequency range, and (ii) proper identification of the fundamental mode. According to this study, the sensitivity of the inversion model is highly dependent on the acquired dispersion data of low frequency range, because low frequencies related to long wavelengths provide the information of deeper layers. These findings justify the application of combined active and passive MASW tests, as performed in the present research, that give the information associated with the low frequency range of the dispersion curves.

\subsection{Errors occurred in the inverted shear wave velocity}

Some researchers (e.g. Zhang and Chan, 2003) have studied the errors affecting the inverted shear wave velocities. A part of errors also originate from misidentification of higher modes, truncated frequency range and the reduced sample intervals. These studies emphasize that the inversion methods need a clear identification of data points related to the fundamental mode of the dispersion curve. The following factors cause difficulties in identifying of the mode order of the data points: 
1- Heterogeneous ground conditions make it difficult to predict the energy distribution of different modes. At large distances, higher modes become significant. In that case, an entire higher mode dispersion curve may be misinterpreted as the fundamental mode

2- In certain ground conditions, higher mode signals might be enhanced.

3- Due to the sensitivity and frequency range of geophones, some receivers do not respond equally at different frequencies. This characteristic might lead to the sensitivity of the system to the higher mode data.

4- Overlapping of the dispersion bands (in dispersion curve) can lead to misidentification of the different modes.

Rayleigh wave inversion is based on the minimization of misfits both in the phase velocity and the S-wave velocity. The misfits in the two velocities are related to each other through a Jacobian matrix, $\mathrm{J}$ :

$\Delta V_{R}=\left(\partial V_{R} / \partial V_{S}\right) \Delta V_{S}=J \Delta V_{S}$

As pointed out in the inversion section, it has been shown that the influence of shear wave velocity on the Rayleigh wave inversion is more significant than the other parameters such as P-wave velocity and density. Errors in the S-wave profile are controlled by the values of $f$ and $V_{R}$ :

$\delta \mathrm{V}_{\mathrm{S}}=\left(\partial \mathrm{V}_{\mathrm{S}} / \partial \mathrm{V}_{\mathrm{R}}\right) \delta \mathrm{V}_{\mathrm{R}}+\left(\partial \mathrm{V}_{\mathrm{S}} / \partial \mathrm{f}\right) \delta \mathrm{f}+\mathrm{O}\left(\delta \mathrm{V}^{2}{ }_{\mathrm{R}}+\delta \mathrm{f}^{2}\right)$

$\delta \mathrm{V}_{\mathrm{S}}, \delta \mathrm{V}_{\mathrm{R}}$ and $\delta \mathrm{f}$ include the errors in shear wave velocity, phase velocity and frequency respectively. In the equation above, small error term, $O\left(\delta V_{R}{ }^{2}+\delta f^{2}\right)$ can be ignored and we have:

$\delta V_{S}=\left(\delta V_{R}+\left(\partial V_{R} / \partial f\right) \delta f\right)\left(\partial V_{S} / \partial V_{R}\right)$ 
Since the partial derivative of $V_{S}$ with respect to $V_{R}$ in Equation (2-15) depends on the model structure (Aki and Richards, 1980), the inaccuracy in the inversion is proportional to the errors in the extracted phase velocity $\left(\delta V_{R}\right)$ and the partial derivative of phase velocity with respect to frequency $\left(\partial \mathrm{V}_{\mathrm{R}} / \partial \mathrm{f}\right)$.

Low frequencies are associated with higher $V_{R}$ values and therefore, partial derivative in equation (2-15), $\left(\partial \mathrm{V}_{\mathrm{R}} / \partial \mathrm{f}\right)$ is greater at relatively low frequencies. On the contrary, at high frequencies, a dispersion curve tends to be stable and $V_{R}$ and consequently $\left(\partial \mathrm{V}_{\mathrm{R}} / \partial \mathrm{f}\right)$ converges towards a minimum value. Therefore, the errors in the inversion of S-wave velocities are strongly dependent on the errors in the phase velocity at low frequencies.

Some errors occur in the interpretation of dispersion curves that contain withinmode errors and cross-mode errors. Within-mode errors are related to the inaccuracy for the particular mode. These errors are mostly related to missing data at low frequencies, which contain the information of deeper layers, and therefore reduce the depth of investigation. Cross-mode errors are caused by misidentification of the modes of dispersion curve.

\subsection{The effect of higher modes}

Developing algorithms for the inversion of higher modes is difficult for the following reasons:

1- The absence of a generic relationship between higher-mode dispersion and the fundamental-mode

2- Difficulties in the determination of the mode order of data points collected in the field and the confusion due to the cross-mode error issue. 
Xia et al. (2000) have studied the advantages of using the higher modes. Highermode data have a deeper investigation depth. These authors conclude that the fundamental mode phase velocities, when calculated with high accuracy, can generally provide reliable Vs velocities $( \pm 15 \%$ of error).

Supranata et al. (2007) achieved the following results for multi-modal analysis:

1) For regular profiles, the use of higher modes does not significantly improve the accuracy of the inversion compared to inversion using the fundamental mode only.

2) For irregular profiles, inclusion of the second mode in the inversion, gives more accurate inversion result.

3) Use of a third mode in the inversion does not significantly improve the accuracy of the inversion for regular or irregular profiles.

Because the majority of the profiles encountered in Ottawa area are regular profiles (increasing shear wave velocity with the increasing depth), this research will concentrate on the fundamental mode analysis. Consecutively, in order to enhance the accuracy of results, improve the dispersion curve images and increase the depth of investigation, the combined active and passive MASW will be used.

\subsection{MASW applications; review of reported successful case studies}

Many applications of MASW have been reported in the literature. For instance, MASW has been employed to locate buried structures (Tallavo et al., 2008) and to detect and image underground cavities (Nasseri-Moghaddama et al., 2007; and $\mathrm{Xu}$ and Butt, 2006). In addition to geophysical/geotechnical applications, MASW has been employed in infrastructure engineering. For example, Cascante et al. (2008) used MASW to assess the conditions of the masonry sidewalls of the Navigli channels in downtown Milan, 
Italy. As a significant geotechnical engineering application in earthquake prone areas, MASW provides a tool for soil classification maps (e.g. Kanli et al., 2006) based on the average shear wave velocity values for the top $30 \mathrm{~m}$ of the soil. In summary, popular applications of MASW include imaging of near surface heterogeneity, evaluation of rigidity of near surface materials and estimation of shear wave velocity.

Many successful MASW case studies have been reported in the literature. For brevity, just a few of them are mentioned here:

1. To validate the MASW method, MASW shear wave velocity profiles were statistically compared to shear wave velocity profiles measured in eight boreholes in unconsolidated sediments of the Fraser River delta, near Vancouver, British Columbia, Canada. The agreement between the methods was good, and an overall difference of $15 \%$ or less was observed between the shear wave velocities derived from the two methods (Xia et al., 2002). The database of the mentioned borehole-derived shear wave velocities can be found in Hunter et al. (1998).

2. MASW method tests were carried out at eight Norwegian research sites (Long and Donohue, 2007); and, it was shown that the MASW shear wave velocity profiles are similar to those of other techniques, such as the cross-hole seismic test and the seismic cone penetrometer test (SCPT).

3. Richwalski et al. (2007) used MASW, in parallel with four geophysical techniques, for the estimation of the local site effects in Germany and achieved consistent results from the dispersion curves of the Rayleigh wave.

4. Thitimakorn et al. (2005) carried out 2-D interpretations of MASW to estimate the shear wave velocity profiles and bedrock depths in downtown St. Louis, 
Missouri, USA. They compared their interpreted results with borehole, cone penetrometer and seismic cone penetrometer data and found good correlation between these geotechnical data and the MASW results.

5. Hoffman et al. (2006) compared shear wave velocity data from MASW method tests with SCPT, cross-hole and ultrasonic pulse velocity methods and recommended the MASW method as the quickest and most economical technique.

\subsection{Appropriate inversion technique to distinguish the high shear wave velocity contrast}

In the current MASW surveying for the city, due to the high impedance contrast interface in the study area, an attempt was made to find the most efficient method of inversion to accurately differentiate the soil from the bedrock in the shear wave velocity-depth function. Between the two aforementioned conventional inversion methods, random search inversion was found to be the most efficient in locating the high impedance contrast interface in the study area. The success of this method is due to two probable reasons:

1. There is only a slight possibility that this inversion method may get trapped in local minima (Ryden and Park, 2006).

2. This technique benefits from extra flexibility in updating of both variables of depth and velocity. This feature does not exist in the generalized inversion method. 
In random search inversion, the forward modeling is performed based on an initial velocity-depth model constructed within a reasonable range of velocities. The initial velocity-depth model prevents the divergence of the velocity values from the real profile. This simply means although this method provides good results, there should be some initial information on the geology of the area, which is useful in all geophysical methods. Random search inversion can then be set for the different velocity increments around the initial model. Using random search, theoretical dispersion curves of the velocity depth functions are compared with the extracted dispersion curves; and profiles get updated iteratively until the errors reach the desirable minimum values.

\subsection{Investigated sites in Ottawa area and MASW results}

I investigated 33 sites in the Ottawa area (Figure (2.1)) to evaluate the capability of both passive and active MASW methods in the determination of the shear wave velocity-depth functions. These locations include: one site at the GSC Anderson Road Site, four sites in the eastern part of the city (Orleans sites), ten sites around the Rideau Canal (canal sites plus the site located in the soccer field of Carleton University), one site that is located in the south (NRC Geotechnical Site No. 1) and seventeen sites in downtown area of the city. These sites were selected for the following reasons:

1. Two sites (NRC Geotechnical Site No. 1 in the south and GSC Anderson Road Site in the east) were chosen due to the availability of accurate data from nearby boreholes and seismic refraction/reflection measurements. The main objective was the calibration of passive and active MASW methods with other reliable geophysical/geotechnical methods. 
2. Nine sites (canal sites) were chosen due to the presence of shallow bedrock. The objective was the evaluation of capacity of this method in the recognizing of shallow bedrock.

3. Four sites (in the Orleans area) were chosen due to the presence of deep bedrock (the majority of that part of the city is mostly covered with thick soft clay). The main objective was the evaluation of the ability and reliability of combined passive and active MASW methods to detect the deep and high velocity bedrock.

4. One site (the soccer field of Carleton University) was chosen for two-dimensional tests and passive remote MASW, due to the availability of a large field.

5. 17 sites in the downtown area of the city were surveyed to determine the MASW capability in detecting of the expected shallow bedrock in the region.

Modeling parameters given in Table (2.1), and the Surfseis software (Park, 2004) were used to construct the dispersion curves and to obtain the shear wave velocitydepth functions for all these MASW sites.

\subsection{Sensitivity of the inversion results to input parameters of initial model in random search inversion}

Active and passive MASW methods were applied to 33 sites in the city of Ottawa (shown in Figure (2.1)). After obtaining the shot gather data (a sample shown in Figure (2.2)), the analysis procedure of MASW is performed to obtain the shear wave velocity profiles. For one of the sites with available borehole information and the presence of bedrock in the top $18 \mathrm{~m}$ (NRC site), the sensitivity of the inverted depthvelocity profile was evaluated for the variation of different input parameters in the initial 
model of random search inversion. The comparison benchmark (target profile) was the borehole site, which is $30 \mathrm{~m}$ away from the NRC site. According to the borehole data (see Figure (2.3)), which shows downhole shear wave velocity measurements, bedrock was detected at the depth of $18 \mathrm{~m}$ and is overlain by a loose soil with the average shear wave velocity around $100 \mathrm{~m} / \mathrm{sec}$. Also the bedrock velocity was measured $2,300 \mathrm{~m} / \mathrm{sec}$ using the reflection/refraction method (Hunter et al., 2007). Figure (2.3) illustrates the MASW results using multi-layer soil model. As shown in this Figure, shear wave velocity gradient from $100 \mathrm{~m} / \mathrm{sec}$ to $150 \mathrm{~m} / \mathrm{sec}$ were obtained from MASW and the agreement between these results and the borehole shear wave velocities is acceptable.

To carry out the sensitivity analysis of the initial soil model, I applied the random search inversion technique and instead of multi-layer soil model I chose 2-layer model (one layer for the entire soft clay and one for the underlying bedrock). Shear wave velocity contrast (ratio of bedrock velocity to average soil velocity), as the first input parameter of the initial model, was given different values, while the bedrock depth and average shear wave velocity of soil were kept constant in the initial model. In other words, while keeping the deposit depth of $18 \mathrm{~m}$ and the corresponding average shear wave velocity of $100 \mathrm{~m} / \mathrm{sec}$ constant, the shear wave velocity of the bedrock was increased by the factors of 1, 5, 10, 15, 20 and 25 (velocity contrast ratios). Figure (2.4) illustrates the final inverted 2-layer velocity-depth profiles for the different values of shear wave velocity contrast. As shown in Figure (2.4), using the shear wave velocity contrast ratios equal or greater than $\mathbf{1 0}$ for the initial model, the utilized random search inversion delivers the bedrock velocity values within a relatively reasonable range $(2100$ $\mathrm{m} / \mathrm{sec}$ to $2800 \mathrm{~m} / \mathrm{sec}$ compared to $2300 \mathrm{~m} / \mathrm{sec}$ in the nearby borehole). 
As the second input parameter, the bedrock depth was given different values, while all other parameters were kept the same. As shown in Figure (2.5), the final bedrock depth is close to the borehole data, although the bedrock shear wave velocity can sometimes be underestimated. Different values were also given to the bedrock shear wave velocity, the third input parameter, while all other input parameters were kept unchanged, as shown in Figure (2.6).

Figures (2.4) to (2.6) indicate that the input parameters in the initial model can make a difference, depending on the expected accuracy from the MASW. I conclude that, in the majority of cases, reasonable results were obtained for bedrock depth (from $14 \mathrm{~m}$ to $20 \mathrm{~m}$ compared to the bedrock depth of $18 \mathrm{~m}$ in nearby borehole) and average shear wave velocity for loose soil (from $90 \mathrm{~m} / \mathrm{sec}$ to $96 \mathrm{~m} / \mathrm{sec}$ compared to the average shear wave velocity of $100 \mathrm{~m} / \mathrm{sec}$ in the nearby borehole).

\subsection{MASW results}

NRC site: Borehole information is available for NRC site and bedrock is in the top $30 \mathrm{~m}$. Figure (2.3) shows good agreement between the borehole data and the MASW results. Figure (2.7) illustrates the overtone image of that site that contains the image of the extracted dispersion curves. Figures (2.8) and (2.9) show the constructed dispersion curve of the fundamental mode for that site. At NRC site, the passive roadside MASW was combined with active MASW to improve the results at lower frequencies. The phase velocity values between $2.2 \mathrm{~Hz}$ and $4 \mathrm{~Hz}$ (see Figures (2.8) and (2.9)) are from passive MASW; and, the higher frequency $(>4 \mathrm{~Hz})$ values are from active MASW.

GSC Anderson road site: Borehole data and refraction/reflection measurements are available for that site, which is located in the eastern part of the city of 
Ottawa, but the bedrock is not in the top $30 \mathrm{~m}$. The obtained shear wave velocity values from MASW are close to borehole data up to 25 meters, as shown in Figure (2.10). For the MASW shear wave velocity profiles in Figures (2.3) and (2.10), the confidence limit range, which is root mean square (RMS) errors, varies from $2 \%$ to $8 \%$.

Sites with shallow bedrock: For sites with shallow bedrock (located around the Rideau Canal in the central area of the city), the random search inversion method was used to invert the depth-velocity function from the corresponding dispersion curves. Table (2.2) provides the MASW results and borehole information for the canal sites that are located on shallow bedrock. As shown in Table (2.2), the efficiency of MASW was confirmed for detection of the shallow bedrock in that area. The bedrock shear wave velocities resulting from MASW lie in an acceptable range (from 2,200 m/sec to 3,000 $\mathrm{m} / \mathrm{sec}$ ), although underestimations arose for some sites. The depth of bedrock is also reasonably estimated by the MASW method. The errors in depth estimations are $14.5 \%$, $15 \%, 5 \%, 15.8 \%, 18 \%, 10 \%, 20 \%, 4 \%$ and $17.3 \%$ (compared to the adjacent borehole) for sites in Table (2.2), from the top to bottom, respectively. The discrepancies may be related to the reference boreholes, because they are located at least $100 \mathrm{~m}$ away from the examined sites. Thus, based on Table (2.2), the random search inversion technique can provide a reasonable estimation of depth (difference is typically less than $15 \%$ ) and shear wave velocity in areas where the bedrock is shallow $(<30 \mathrm{~m})$. Table $(2.3)$ illustrates the results of more MASW sites of similar bedrock condition performed in the downtown area of the city. Depth of upper level of bedrock layer is shown in this Table.

The site for the 2-D tests (Carleton University soccer field site) provides a large area for passive remote MASW measurements. In this site, the passive remote MASW 
method was combined with the active MASW method to increase the frequency range of the dispersion curve and improve the reliability of the total frequency range. For this site, two different inversion methods were applied to investigate the applicability of MASW for the high contrast interface between the soil and the bedrock.

For Carleton site, the extracted dispersion curve and the inverted shear wave velocity (using the random search inversion) are shown in Figures (2.11) and (2.12) respectively. The estimated bedrock depth, as shown in Figure (2.12), is $5 \mathrm{~m}$, which is very close to the results of the other geophysical measurements, such as near surface refraction/reflection methods and available local geological maps. The nearby GSC borehole (Natural Resources of Canada online maps, 2006) with a $5.4 \mathrm{~m}$ bedrock depth confirms the results of the random search inversion. Furthermore, the inverted shear wave velocity was determined to $2,698 \mathrm{~m} / \mathrm{sec}$ for the bedrock, which is quite close to shear wave velocity obtained from reflection/refraction methods $(2,500 \mathrm{~m} / \mathrm{sec})$. Thus, the random search inversion technique provides reasonable results for the cases with high contrast velocity, as well as for the shallow bedrock sites.

Sites with deep bedrock: These are mainly located in Orleans area (eastern part of the city) with bedrock at depth of more than $40 \mathrm{~m}$ overlain by a very loose layer of soil (Motazedian and Hunter, 2008; and GSC preliminary map, 2007). The combined passive roadside and active MASW methods were applied to estimate the bedrock depth and shear wave velocity using the random search inversion method. As shown in Table (2.4), although the velocity values seem reasonable (generally, the shear wave velocity is larger than $2,500 \mathrm{~m} / \mathrm{sec}$ ), the estimated depths are quite different from values obtained from the reflection/refraction method. This depth issue may be resolved if more sensitive 
geophones and stronger sources are taken into account (improved signal-to-noise ratio). It would be beneficial to increase the dispersion information regarding the low frequency range (down to $1 \mathrm{~Hz}$ ) for these deep and loose soil profiles.

To map two-dimensional profiles, MASW can be repeated along a line of surveying by moving the source and the spread. Using all the inverted shear wave velocity profiles, it is possible to correlate the one-dimensional shear wave velocity profiles and derive the two-dimensional profiles by interpolating methods. Two samples of these two-dimensional shear wave velocity profiles are illustrated in Figures (2.13) and (2.14).

\subsection{Summary and conclusions}

Thirty three sites in the city of Ottawa were chosen to investigate the efficiency of MASW for high contrast shear wave velocity profiles and to study the suitable inversion techniques applicable to the velocity models. Results of the sensitivity analysis for the initial model indicate that, except for the case of very low contrast in the initial model, the velocity-depth data obtained from the random search inversion are in good agreement with the borehole data. In high contrast shear wave velocity profiles, like the majority of sites located in Ottawa, I recommend using random search inversion over analytical generalized inversion. Random search inversion is less likely to become trapped in local minima and benefits from the flexibility to search for the best match in velocity profile. Because the sensitivity of inversion techniques is dependent on the low frequency part of the dispersion curves, I recommend applying the combination of active and passive MASW methods to obtain this low frequency data at sites where deep layers of soil are examined. 
In summary, apart from the partial deficiency of the utilized MASW for very deep bedrock detection, it is concluded that MASW is capable of estimation of shear wave velocity-depth profiles, although this method can benefit from geological and geotechnical information for the input parameters in the initial model. The results of MASW can be useful for the determination of site classes throughout the city. It should be mentioned that NHERP site classes of NBCC (National Building Code of Canada), 2005 are based on the shear wave velocity for the top $30 \mathrm{~m}$ of soil, and the MASW method utilized here is capable of providing reasonable results to that depth.

\subsection{References}

Ashiya K. K., Yoshioka O., and Yokoyama H., 1999, Estimation of phase velocities of multiple modes by inversion of frequency-wave number spectrum and its application to train induced ground vibrations, Geophysical Exploration Journal, 52(3), pp. 214-226.

Bullen K. E., 1963, An Introduction to the Theory of Seismology, Cambridge University Press.

Cascante G., Najjaran H., and Crespi P., 2008, Novel methodology for nondestructive evaluation of brick walls: Fuzzy logic analysis of MASW tests, Journal of Infrastructure Systems, ASCE.

Crice D., 2005, MASW, the Wave of the Future, Journal of Environmental and Engineering Geophysics, 10, June, pp. 77-79.

GSC preliminary map of Holocene thickness for the Orleans area, 2007, Geological Survey of Canada.

Heukelom W., and Foster C.R., 1960, Dynamic testing of pavements, Journal of Soil Mechanics and Foundation Division, ASCE, 86, Part I. 
Hoffman D., Stephenson R.W., Luna R., and Anderson N.L., 2006, Non-destructive testing of earthquake hazard mapping, Southern Missouri, USA, Ground modification and seismic mitigation, ASCE publications, pp. 433-440.

Hunter J.A., Burns R.A., Good R.L. and Pelletier C.F., 1998, A compilation of shear wave velocities and borehole geophysical logs in unconsolidated sediments of the Fraser River delta, Geological Survey of Canada, Open File No. 3622.

Hunter J.A., Burns R.A., Good R.L., Aylsworth J.M., Pullan S.E., Perret D., and Douma M. , 2007, Borehole shear wave velocity measurements of Champlain Sea sediments in the Ottawa-Montréal region, Geological Survey of Canada Open File 5345, Geological Survey of Canada, Natural Resources Canada, Ottawa.

Jones R., 1962, Surface wave technique for measuring the elastic properties and thickness of roads: theoretical development, British Journal of Applied Physics, 13, pp. 21-29.

Kanlı A.I., Tildy P., Pronay Z., Pinar A. and Hermann A., 2006, Vs s $_{30}$ mapping and soil classification for seismic site effect evaluation in Dinar region, SW Turkey, Geophysical Journal International, 165, pp. 223-235.

Lee W.H.K. and Stewart S. W., 1981, Generalized inversion and nonlinear optimization section in principles and applications of microeathquake networks, Academy Press, pp. 105-128.

Long M. and Donohue S., 2007, In situ shear wave velocity from multi-channel analysis of surface waves (MASW) tests at eight Norwegian research sites, Canadian Geotechnical Journal, 44(5), pp. 533-544.

Louie J. N., 2001, Faster, better: shear-wave velocity to 100 meters depth from refraction microtremor arrays, Bulletin of the Seismological Society of America (BSSA), 91, pp. 347-364.

Luoa Y., Xiab J., Liua J., Xua Y., and Liua Q., 2008, Research on the middle-of-receiverspread assumption of the MASW method, Soil Dynamics and Earthquake Engineering, in press. 
Marquardt D.W., 1963, An algorithm for least-squares estimation of nonlinear parameters, Journal of the Society for Industrial and Applied Mathematics, 11, pp. 431-441.

McMechan G.A. and Yedlin M. J., 1981, Analysis of dispersive waves by wave field transformation, Geophysics, 46, pp. 869-874.

Motazedian D., and Hunter J. A, 2008, Development of a NEHRP map for the Orleans suburb of Ottawa, Ontario, Canadian Geotechnical Journal, 45, pp.1180-1188.

Nasseri-Moghaddama A., Cascanteb G., Phillips C., and Hutchinson D. J., 2007, Effects of underground cavities on Rayleigh waves-Field and numerical experiments, Soil Dynamics and Earthquake Engineering, 27, pp. 300-313.

NBCC 2005, National Building Code of Canada, Canadian commission on building and fire codes, National Research Council Canada.

Natural Resources Canada online maps, Urban Geology of NCR (Surficial Boreholes), 2006, Copyright of the Geological Survey of Canada, Available through: http://tsdmaps.gsc.nrcan.gc.ca/website/_urbgeo_natcap/surficial_boreholes_e.htm.

Nazarian S., Stokoe II K. H., and Hudson W. R., 1983, Use of spectral analysis of surface waves method for determination of moduli and thicknesses of pavement system, Journal of the Transportation Research Board, Transportation Research Record No. 930, pp.38-45.

Nazarian S., 1984, In situ determination of elastic moduli of soil deposits and pavement systems by spectral-analysis-of-surface-waves method: $\mathrm{Ph} . \mathrm{D}$. Dissertation, University of Texas at Austin, Austin, Texas, U.S.A.

Okada H., 2003, The microtremor survey method, Geophysical Monograph Series, no.12, published by Society of Exploration Geophysicists (SEG). 
Park C. B., Miller R .D., and Xia J., 1998, Imaging dispersion curves of surface waves on multi-channel record, Technical Program with biographies, SEG, 68th Annual Meeting, New Orleans, Louisiana, pp.1377-1380.

Park C.B., 2004, Surfseis software for active and passive MASW, Kansas geological survey, Kansas.

Park C.B., Miller R. D., Ryden N., Xia J., and Ivanov J., 2005, Combined use of active and passive surface waves, Journal of Environmental and Engineering Geophysics, 10(3), pp. 323-334.

Park, C.B., Miller, R.D. and Ryden N., 2006, Roadside Seismic Survey Utilizing Traffic Noise, Proceedings of the 6th International Symposium on NDT in Civil Engineering (NDT-CE), St. Louis, MO, 14-18 August, pp. 317-324.

Park C. B., and Miller R. D., 2008, Roadside Passive Multi-channel Analysis of Surface Waves (MASW), Journal of Environmental and Engineering Geophysics, 13(1), pp. $1-12$.

Press W.H., Teukolsky S.A., Vetterling W.T., and Flannery B.P., 1992, Numerical recipes in Fortran 77: The art of scientific computing, Cambridge University Press, Cambridge, MA.

Richart F. E., Hall J. R., and Woods R. D., 1970, Vibrations of soils and foundations, Prentice-Hall, Inc., Englewood Cliffs, N.J.

Richwalski A.M., Picozzi M., Parolai S., Milkereit C., Baliva F., Albarello D., Kabir Roy-Chowdhury K., van der Meer H., and Zschau J., 2007, Rayleigh wave dispersion curves from seismological and engineering geotechnical methods: a comparison at the Bornheim test site (German), Journal of Geophysics and Engineering, 4, pp. 349-361.

Rix G. J., and Leipski E. A., 1991, Accuracy and Resolution of Surface Wave Inversion, Recent Advances in Instrumentation, Data Acquisition, and Testing in Soil 
Dynamics, ASCE Geotechnical Special Publication No. 29, S.K. Bhatia and G.W. Blaney, Eds., pp.17-32.

Ryden N., and Park C. B., 2006, Fast simulated annealing inversion of surface waves on pavement using phase-velocity spectra, Geophysics, 71(4), pp. R49-R58.

Schwab, F., and, Knopoff L., 1972, Fast Surface Wave and Free Mode Computations, Methods in Computational Physics, 11, Academic Press, New York, pp. 87-180.

Stokoe, K. H., II, Wright, S. G., Bay, J. A., and Roësset, J. M. ,1994, Characterization of geotechnical sites by SASW method." Geophysical Characterization of Sites, ed. R. D.Woods, Oxford \& IBH Pub. Co., New Delhi, India, pp.15-25.

Supranata, Y.E., Kalinski, M.E., and Ye Q., 2007, Improving the uniqueness of surface wave inversion using multiple-mode dispersion data International Journal of Geomechanics 75, pp.333- 343.

Szu H., and Hartley R., 1987, Fast simulated annealing, Physics Letters A, 122, pp.157162.

Tallavo F., Cascante G., and Pandey M., 2008, Experimental and numerical analysis of MASW tests for detection of buried timber trestles, Soil Dynamics and Earthquake Engineering, in press.

Thitimakorn T., Anderson N. L., Stephenson R., and Liu W., 2005, 2-D shear wave velocity profile along test segment of interstate I-70, St. Louis, Missouri, Site Characterization and Modeling, ASCE publications.

Xia J., 1986, Some problems in interpretation of two-dimensional magnetic anomalies by nonlinear programming: M.S. thesis, Symposium of Geophysical and Geochemical Prospecting, P. R. China, in Chinese, pp.174-187. 
Xia J., Miller R. D., and Park C. B., 1999, Estimation of near-surface shear-wave velocity by inversion of Rayleigh waves, Geophysics, 64(3), May-June, pp. 691-700.

Xia J., Miller R.D. and C.B. Park , 2000, Advantage of calculating shear-wave velocity from surface waves with higher modes. In: Technical Program with Biographies, SEG, 70th Annual Meeting, Calgary, Tulsa, pp. 1295-1298.

Xia J., Miller R. D., Park C. B., Hunter J. A., Harris B., and Ivanov J., 2002, Comparing shear-wave velocity profiles inverted from multi-channel surface wave with borehole measurements, Soil Dynamics and Earthquake Engineering , 22(3), pp. 181-190.

Xu C., and Butt S. D., 2006, Evaluation of MASW techniques to image steeply dipping cavities in laterally inhomogeneous terrain, Journal of Applied Geophysics, 59 , pp. 106-116.

Zhang S. X., Lung S., Chana L. S., Chang Y., Chenb C. Y., Daic F. C., Shenb, X. K., and Zhong H., 2003, Apparent phase velocities and fundamental-mode phase velocities of Rayleigh waves, Soil Dynamics and Earthquake Engineering, 23, pp. 563-569.

Zhang S.X., Chan L.S., 2003, Possible effects of misidentified mode number on Rayleigh wave inversion, Journal of Applied Geophysics, pp.17-29.

Zywicki D.J. and Rix G.J., 1999, Frequency-wavenumber analysis of passive surface waves, Proceedings of the Symposium on the Application of Geophysics to Environmental and Engineering Problems (SAGEEP), pp. 75-84. 


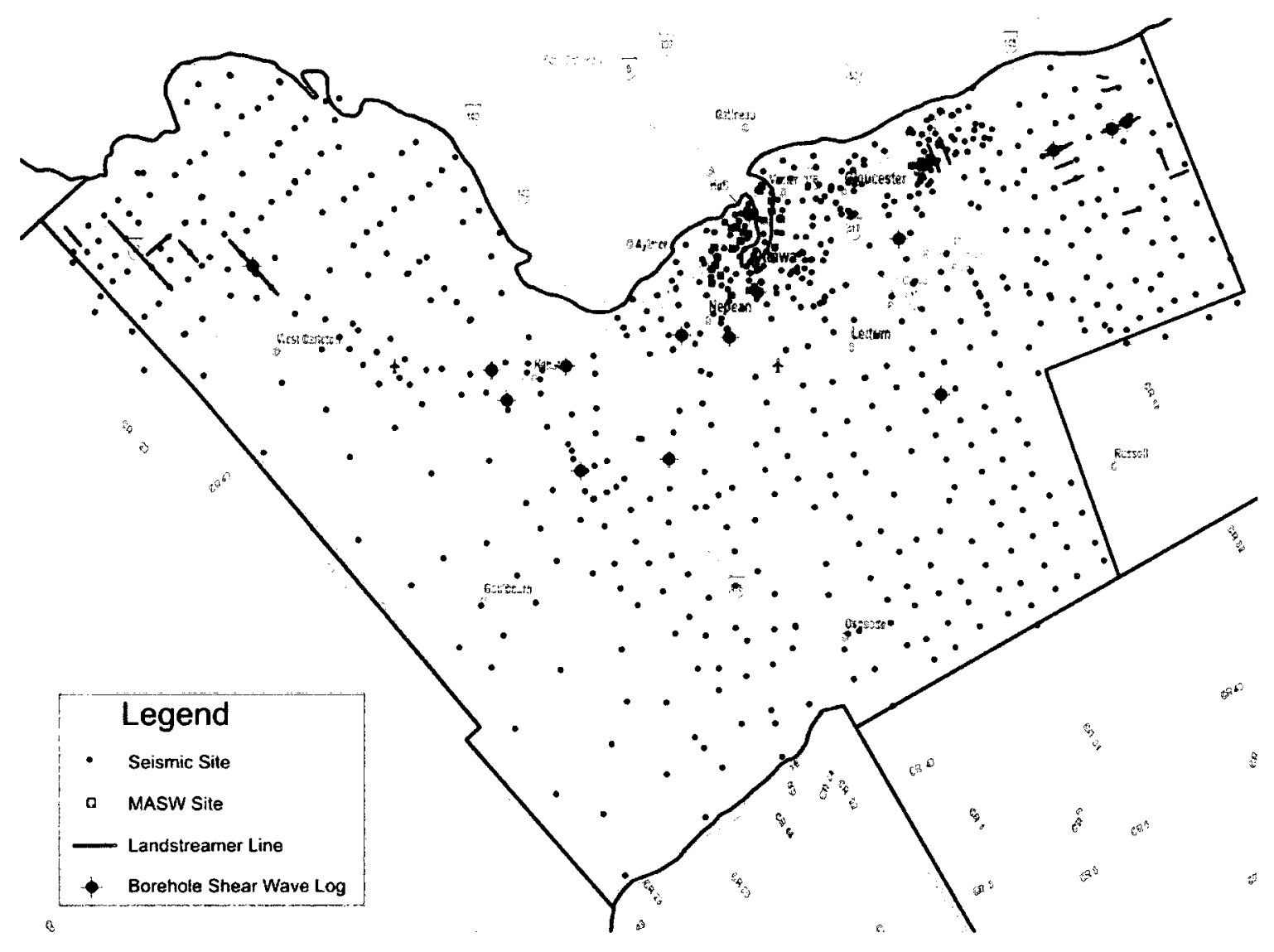

Fig. 2.1: City of Ottawa and the investigated sites. 


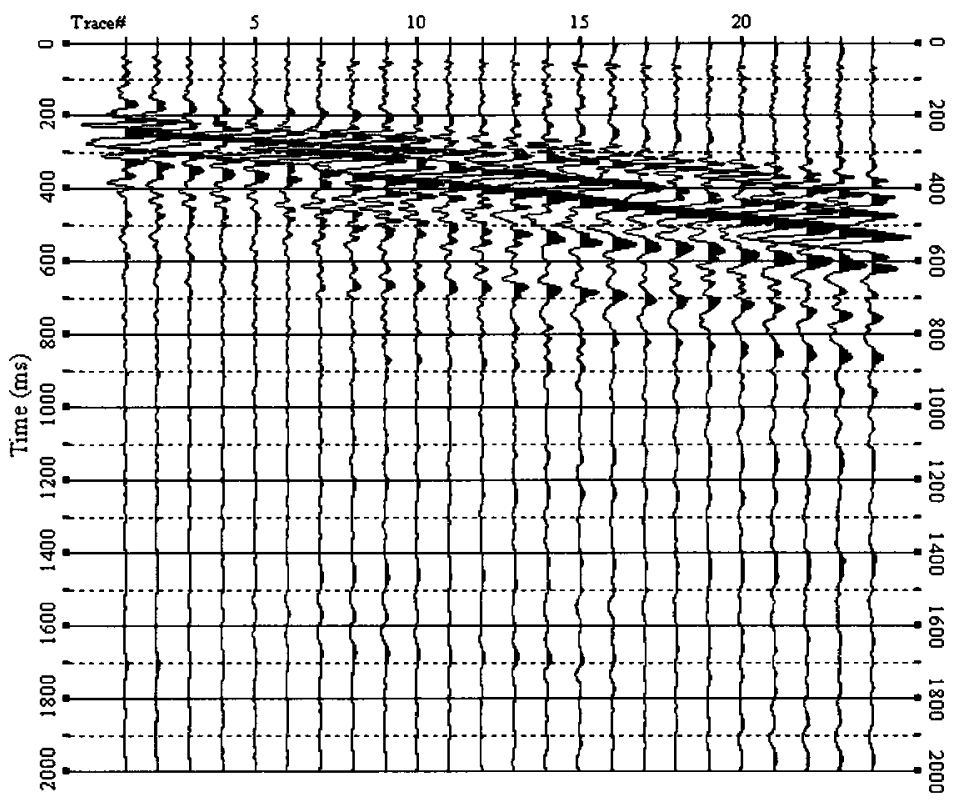

Fig. 2.2: Sample shot gather from the MASW method for the Brantwood site located around the Rideau Canal in the city of Ottawa.

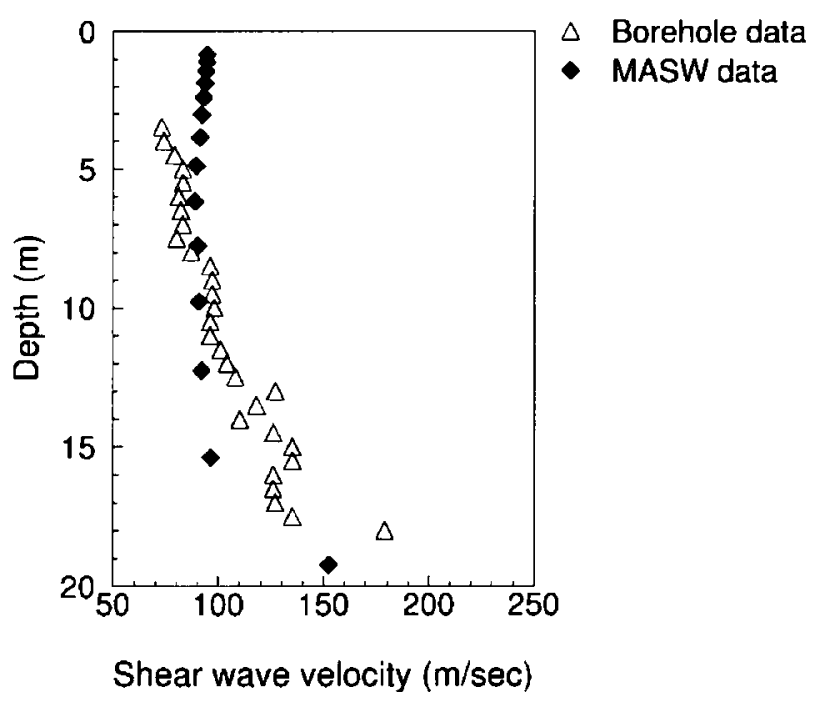

Fig. 2.3: Comparison between shear wave velocity models based on MASW method using multi-layer soil model and borehole data (downhole shear wave velocity measurement in a borehole located $30 \mathrm{~m}$ away from MASW site) for NRC site. 


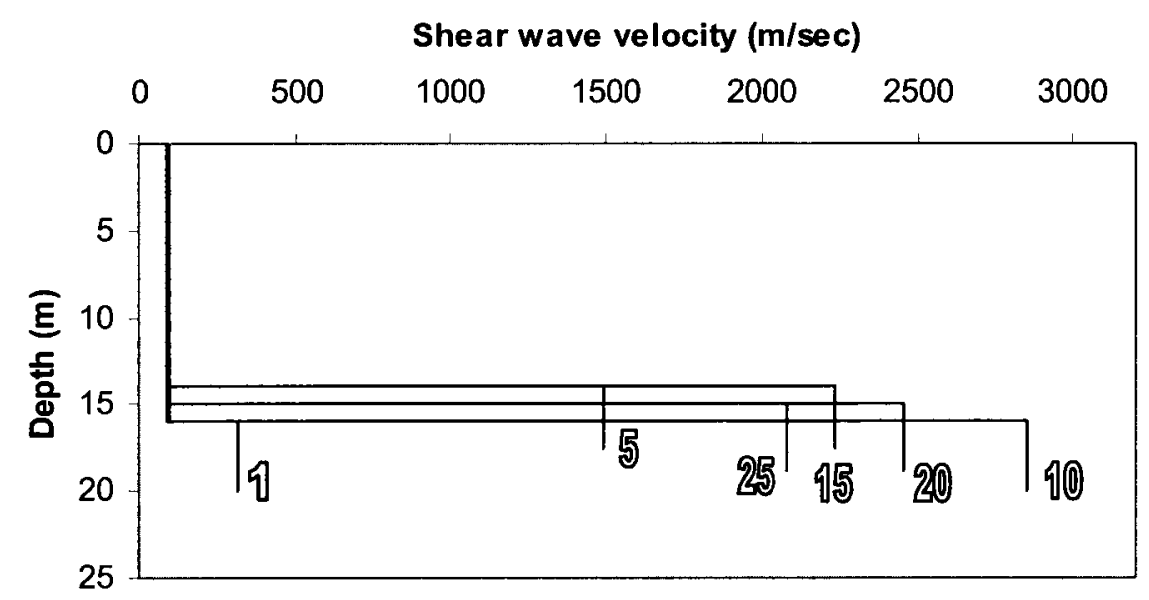

Fig. 2.4: Layer models of depth-shear wave velocity for NRC site. Shear wave velocity profiles for different contrast ratios of the initial model, shown at the end of each profile. In the initial models, bedrock depth and average soil velocity values are fixed.

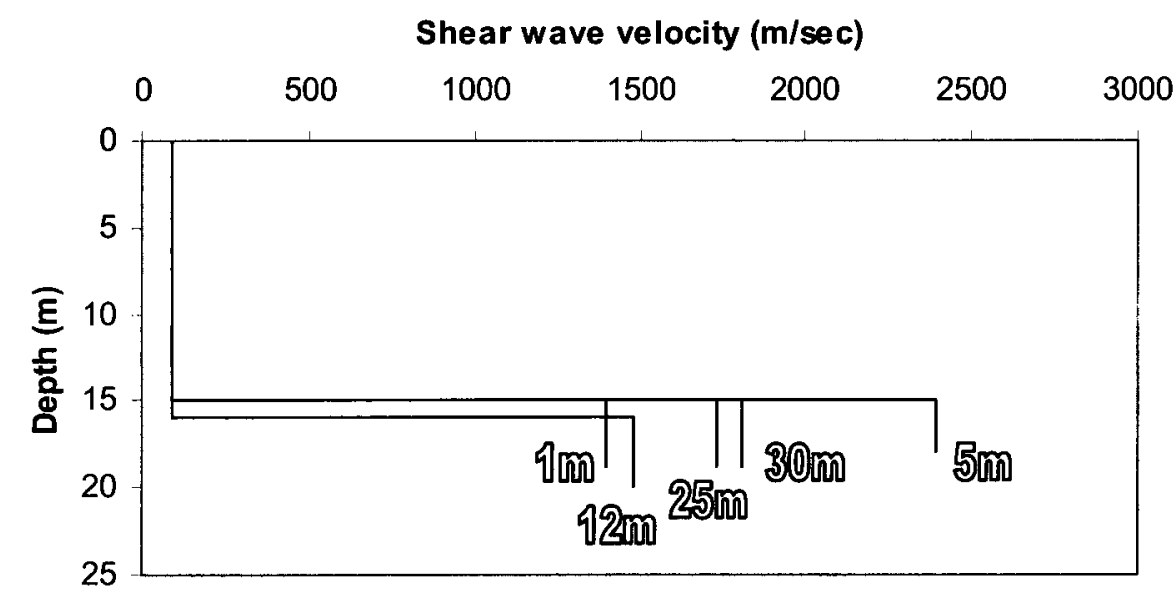

Fig. 2.5: Layer models of depth-shear wave velocity for NRC site. Shear wave velocity profiles for different bedrock depth of the initial model, shown at the end of each profile. Contrast ratio and average soil velocity values are fixed. 


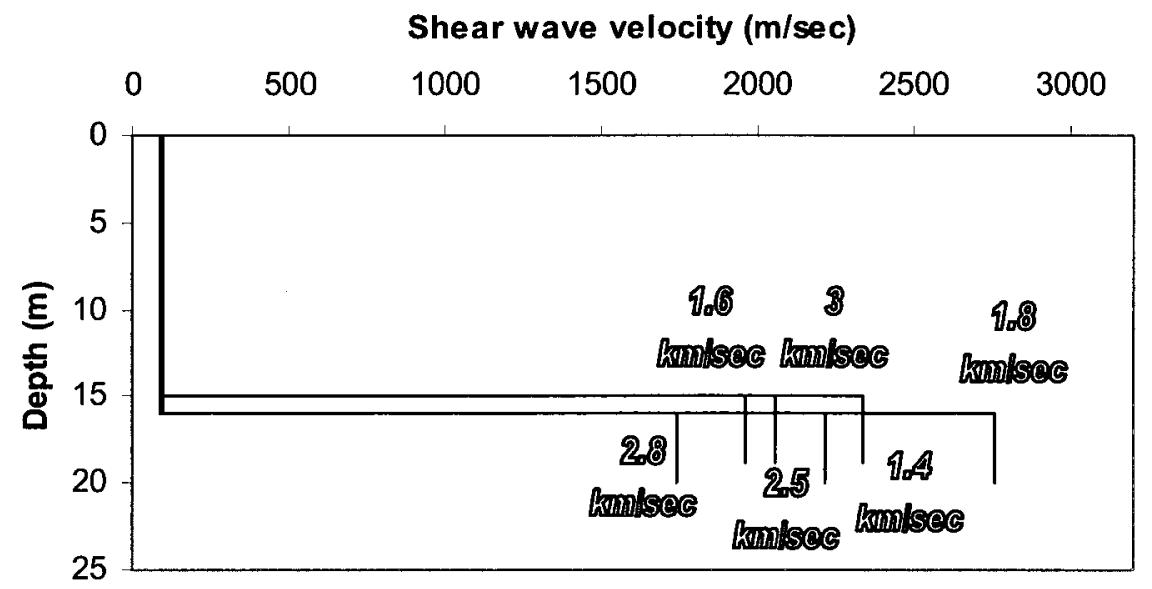

Fig. 2.6: Layer models of depth-shear wave velocity for NRC site. Shear wave velocity profiles for different bedrock velocities (in $\mathrm{km} / \mathrm{sec}$ ) of the initial model, shown at the end of each profile. Contrast ratio and bedrock depth velocity are fixed.

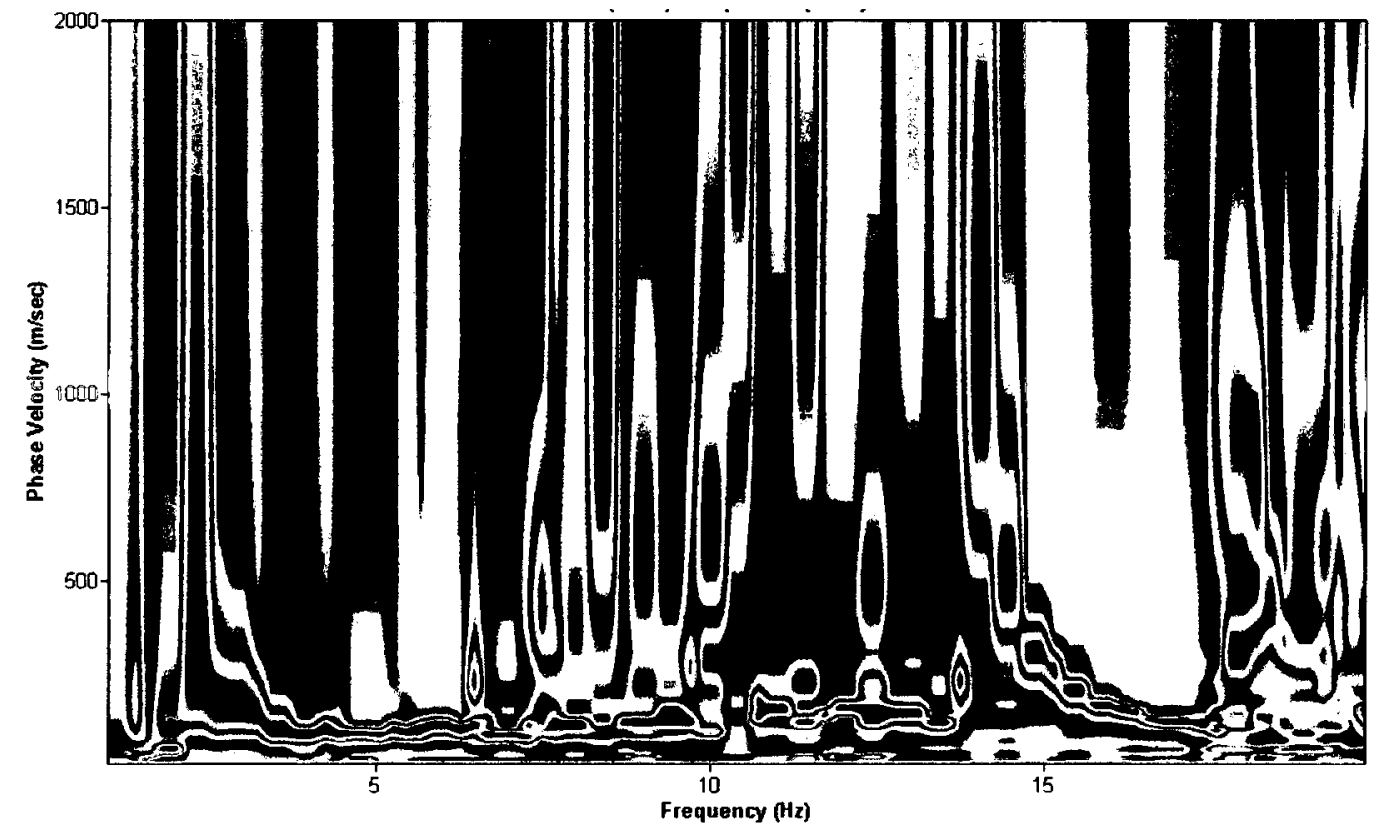

Fig. 2.7: Sample overtone image of the dispersion curve from the combined MASW method for the NRC site located in the southern part of the city of Ottawa. 


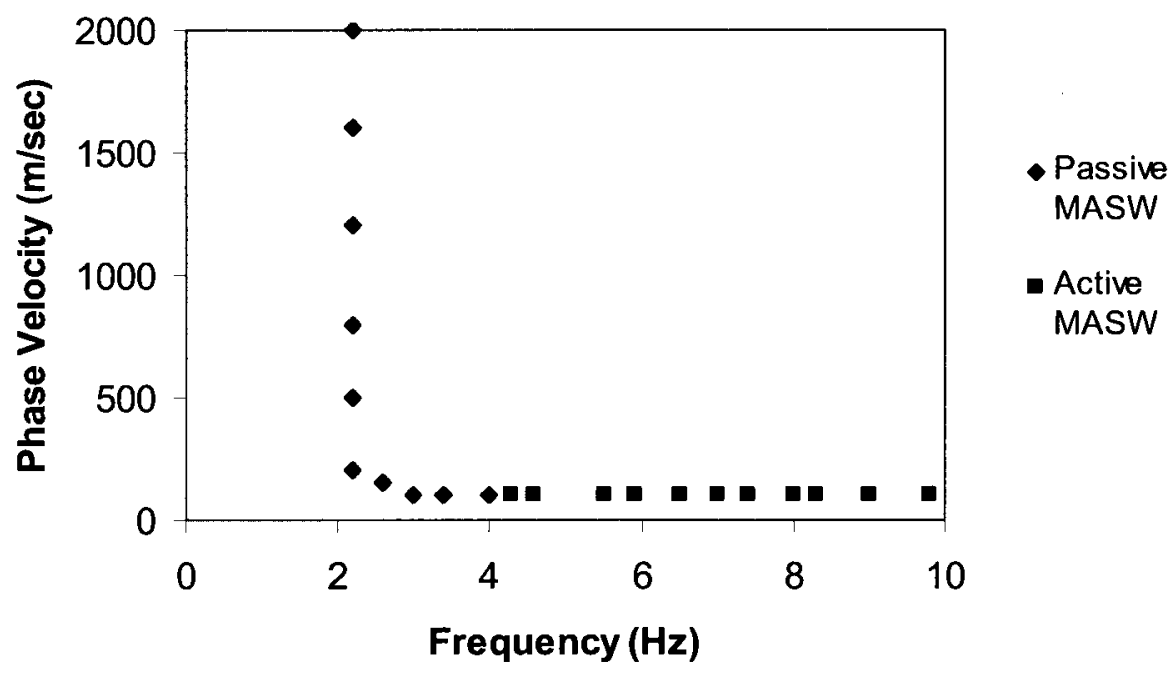

Fig. 2.8: Extracted dispersion curve of the fundamental mode for NRC site showing the participation of active and passive MASW tests.

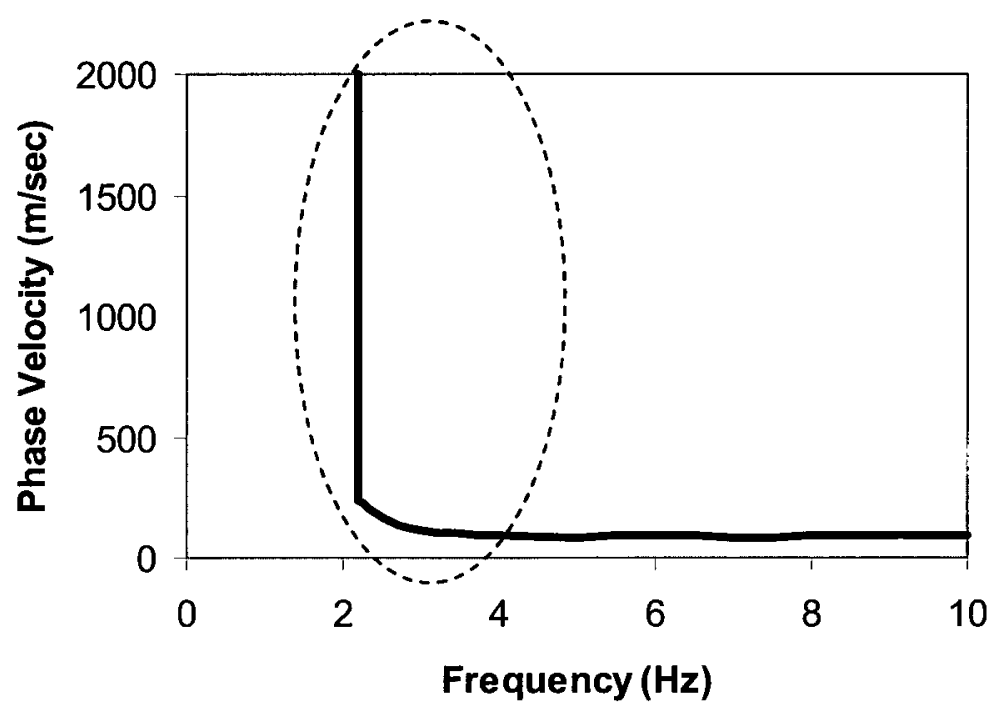

Fig. 2.9: Continuous representation of dispersion curve for the fundamental mode of the $M A S W$ method for NRC site. The part of curve that is located inside the dashed ellipse ( $\leq$ $5 \mathrm{~Hz}$ ) comes from the passive roadside test. 


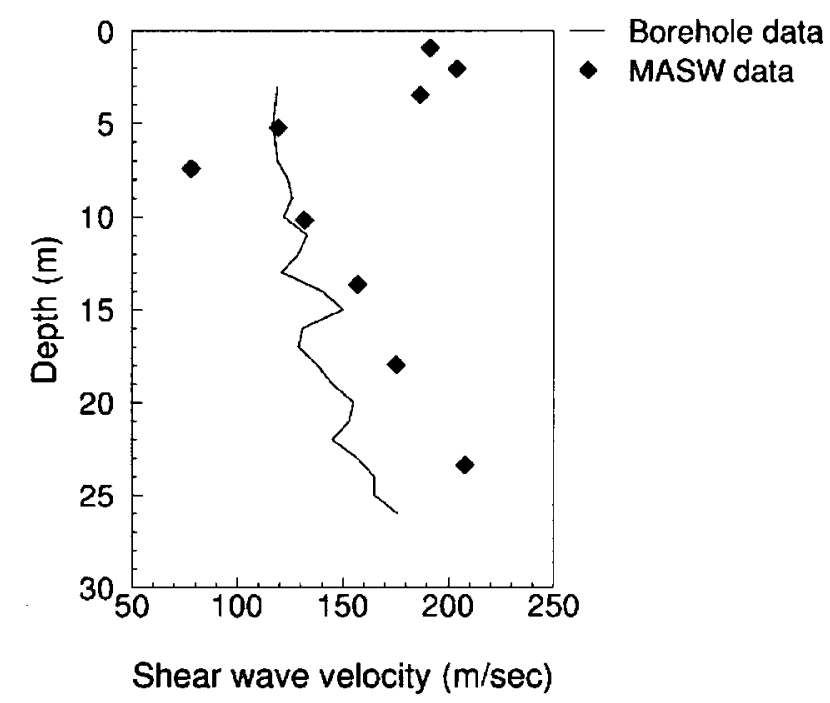

Fig. 2.10: Comparison between shear wave velocity values of MASW results and borehole data for the GSC Anderson Road site.

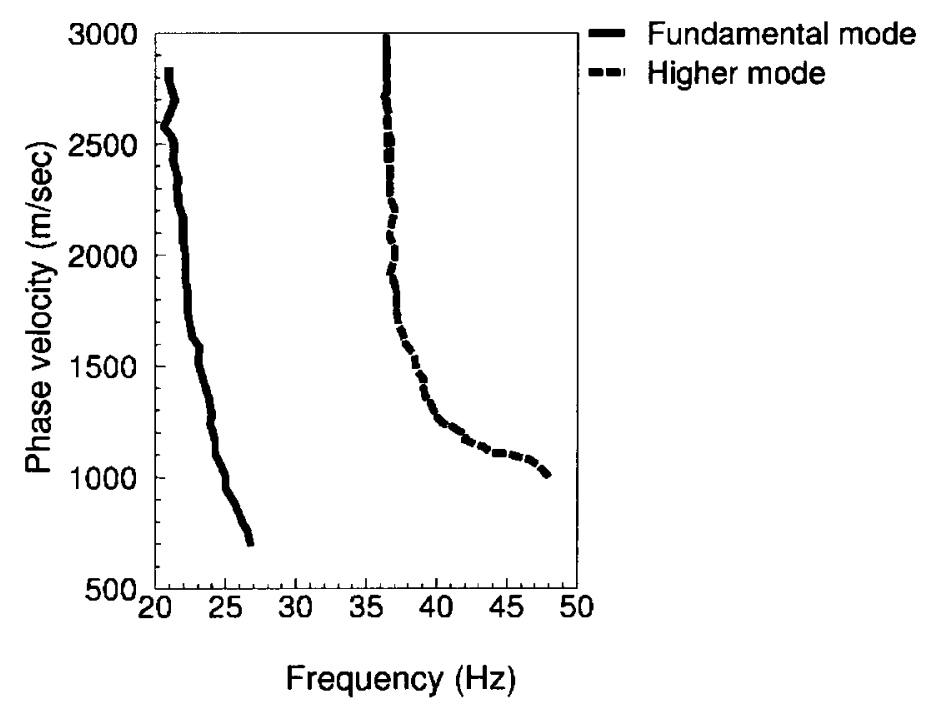

Fig. 2.11: Dispersion curves of the fundamental mode and a higher mode (first mode) of the Rayleigh wave obtained from the combination of active and remote passive MASW methods for the soccer field of Carleton University. 


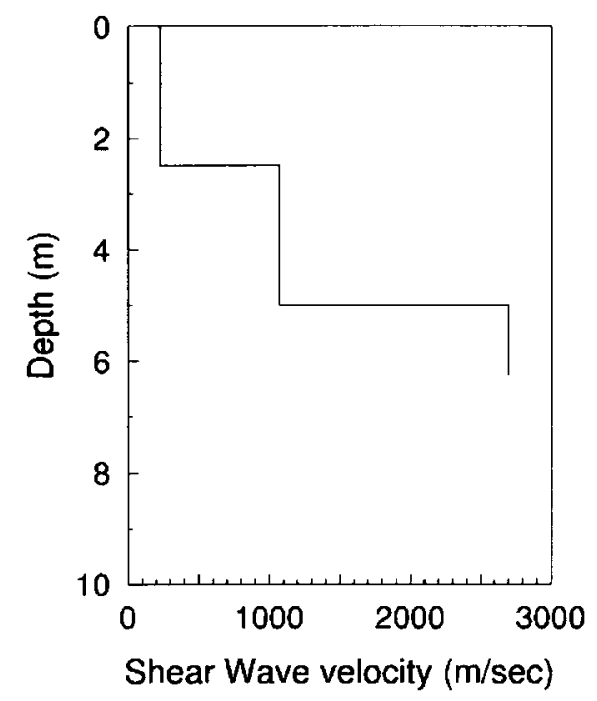

Fig. 2.12: $V_{s}$ profile for the soccer field of Carleton University, based on random search inversion. The great velocity jump is obvious at the depth of $5 \mathrm{~m}$. 


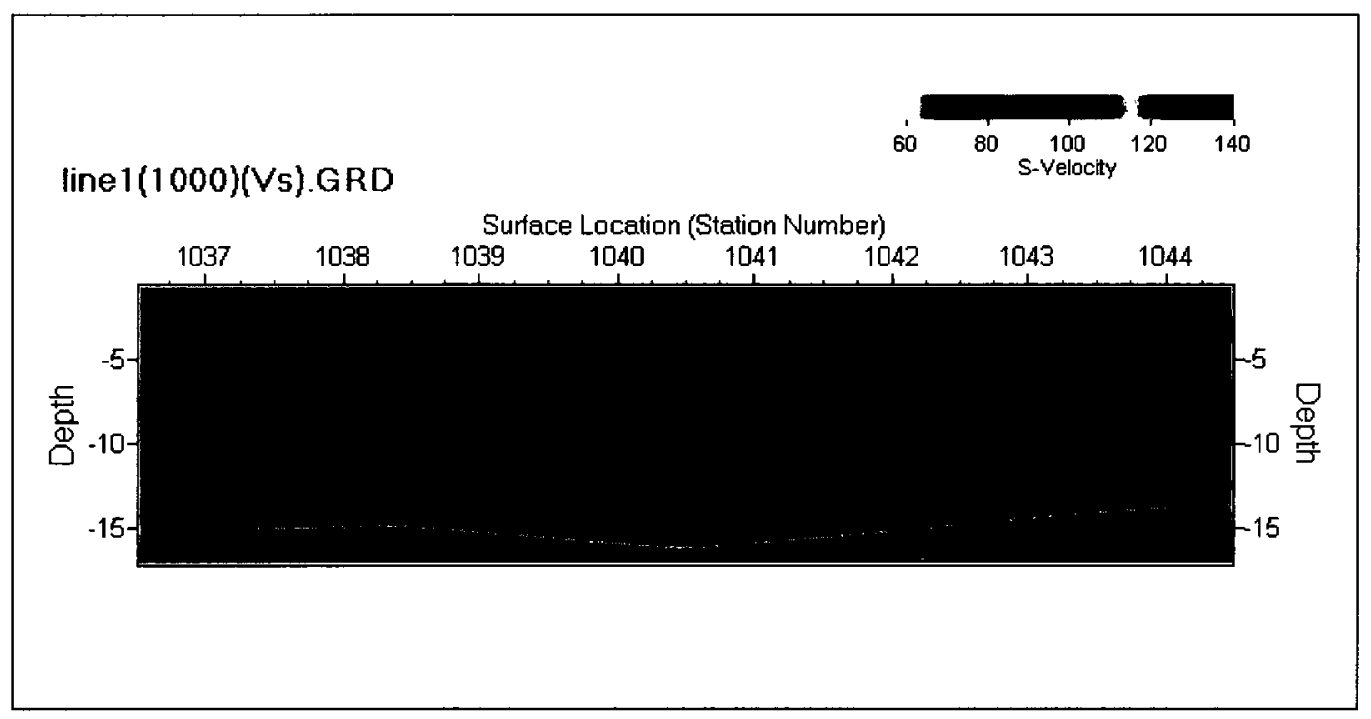

Fig. 2.13: 2-D Shear wave velocity profile for NRC site in Ottawa area.

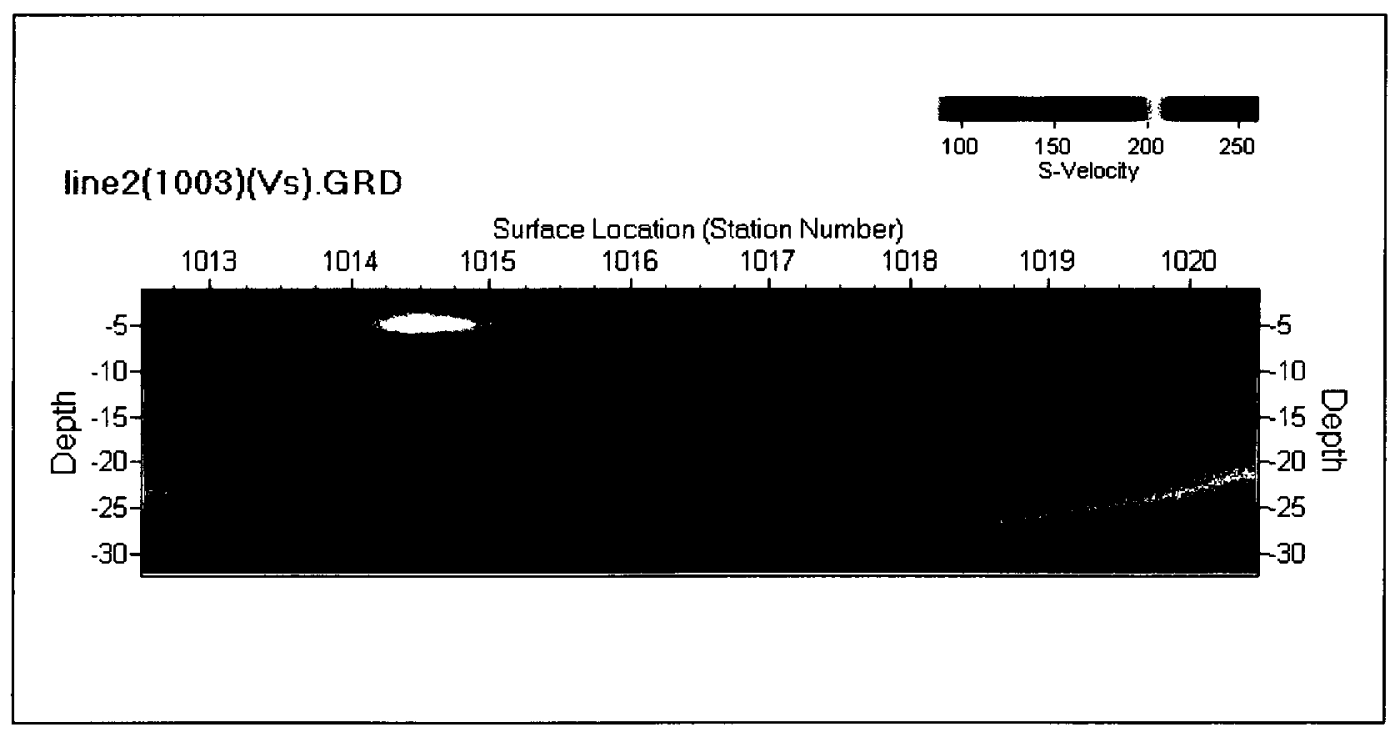

Fig. 2.14: 2-D Shear wave velocity profile for NRCan site in Ottawa area. 
Table 2.1: Main field parameters for different MASW tests.

\begin{tabular}{|c|c|c|c|c|c|c|c|c|}
\hline $\begin{array}{l}30 \\
\sum \\
\sum\end{array}$ & 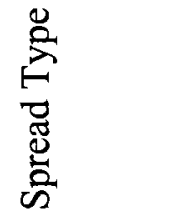 & 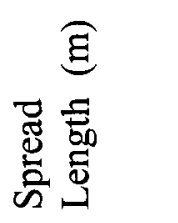 & 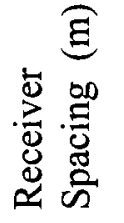 & 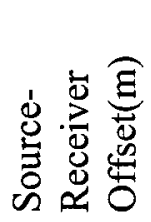 & 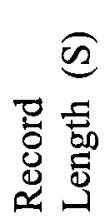 & 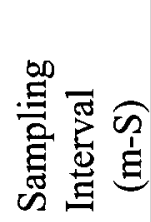 & 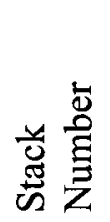 & 离 \\
\hline Active & Linear & $11.5-46$ & $0.5-2$ & $10-35$ & $1-2$ & $1-2$ & 5 & $\begin{array}{l}\text { Spike/ } \\
\text { Plate }\end{array}$ \\
\hline $\begin{array}{l}\text { Passive } \\
\text { Roadside }\end{array}$ & Linear & $34.5-80.5$ & $1.5-3$ & NA & 30 & 4 & 5 & $\begin{array}{l}\text { Spike/ } \\
\text { Plate }\end{array}$ \\
\hline $\begin{array}{l}\text { Passive } \\
\text { Remote }\end{array}$ & Triangular & 40 & 1.5 & NA & 60 & 4 & 5 & Spike \\
\hline
\end{tabular}


Table 2.2: Comparison between estimated MASW results and borehole data for shallow bedrock sites (canal sites).

\begin{tabular}{|c|c|c|c|c|}
\hline 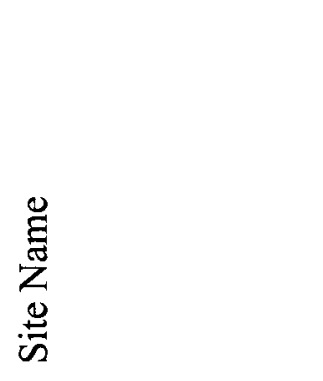 & 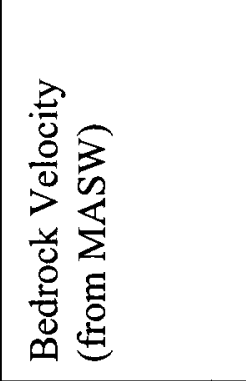 & 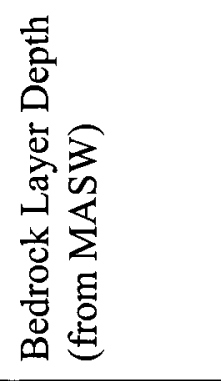 & 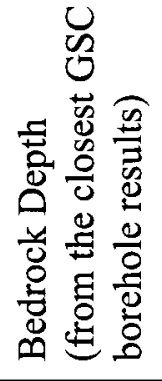 & 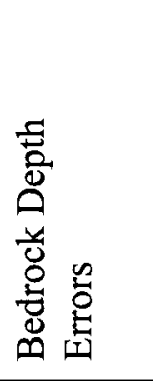 \\
\hline Brantwood Park & $2,943(\mathrm{~m} / \mathrm{sec})$ & $9-11.25 \mathrm{~m}$ & 7.7 & $14.5 \%$ \\
\hline Bordeleau Park & $2,662(\mathrm{~m} / \mathrm{sec})$ & $4-5 \mathrm{~m}$ & 4.7 & $15 \%$ \\
\hline McDonald Park & $2,326(\mathrm{~m} / \mathrm{sec})$ & $10-12 \mathrm{~m}$ & 9.5 & $5 \%$ \\
\hline Robinson Park & $2,584(\mathrm{~m} / \mathrm{sec})$ & $7-8.75 \mathrm{~m}$ & 5.9 & $15.8 \%$ \\
\hline $\begin{array}{l}\text { New Edinburgh } \\
\text { Park }\end{array}$ & $2,245(\mathrm{~m} / \mathrm{sec})$ & $5-6.25 \mathrm{~m}$ & 4.1 & $18 \%$ \\
\hline Browns inlet Park & $2,433(\mathrm{~m} / \mathrm{sec})$ & $1-2 m$ & 0.9 & $10 \%$ \\
\hline Windsor Park & $2,772(\mathrm{~m} / \mathrm{sec})$ & $4-5 \mathrm{~m}$ & 5 & $20 \%$ \\
\hline Brewer Park & $1,953(\mathrm{~m} / \mathrm{sec})$ & $5.2-6.5 \mathrm{~m}$ & 5.4 & $4 \%$ \\
\hline Rideau River Park & $1,890(\mathrm{~m} / \mathrm{sec})$ & $11-13.75 \mathrm{~m}$ & 9.1 & $17.3 \%$ \\
\hline
\end{tabular}


Table 2.3: Estimated bedrock depth and velocity using MASW for some sites located in the downtown area of the city of Ottawa.

\begin{tabular}{|l|l|l|}
\hline MASW Site Name & Detected bedrock depth (m) & Detected bedrock velocity (m/sec) \\
\hline Lyon and Summerset & 4.4 & 2300 \\
\hline $\begin{array}{l}\text { Mcnaab } \\
\text { Park(Bronson/GladStone) }\end{array}$ & 4.8 & 1950 \\
\hline Bay street and Arlington & 4.7 & 2756 \\
\hline Empress/Primrose St. & Near surface $(<1 \mathrm{~m})$ & 2000 \\
\hline Rochester/Primrose St. & 5 & 2150 \\
\hline Metcalf/Mclaren St. & 10.5 & 1836 \\
\hline Frank/Robert St. & 3.7 & 2100 \\
\hline Carlyle/Downing St. & 3.3 & 1903 \\
\hline Loretta/Hickory St. & 2.6 & 2200 \\
\hline Hinton/Roskin & 1.9 & 2400 \\
\hline Anna/Carling & 3 & 2220 \\
\hline Crerar/Admiral & 6 & 2325 \\
\hline Bakervale Drive & 1.7 & 2450 \\
\hline $\begin{array}{l}\text { Trenton Ave.Off Prince } \\
\text { St. }\end{array}$ & 1.9 & 2320 \\
\hline Hamilton Ave. & 2 & 2400 \\
\hline Sweetland/Summerset & 6.2 & 1910 \\
\hline Wilbroad/Augusta St. & 12.2 & 200 \\
\hline & & 2400 \\
\hline
\end{tabular}


Table 2.4: Comparison between estimated MASW results and those of the reflection/refraction methods (GSC preliminary map, 2007) for deeper bedrock in the Orleans area.

\begin{tabular}{|l|c|c|c|}
\hline \multicolumn{1}{|c|}{ Site Name } & $\begin{array}{l}\text { Bedrock Velocity } \\
\text { (From MASW) }\end{array}$ & $\begin{array}{l}\text { Bedrock Layer } \\
\text { Depth } \\
\text { (from MASW) }\end{array}$ & $\begin{array}{l}\text { Bedrock Contour } \\
\text { Depth } \\
\text { (from Reflection/ } \\
\text { Refraction) }\end{array}$ \\
\hline Barrington Park & $3,030(\mathrm{~m} / \mathrm{sec})$ & $69-86 \mathrm{~m}$ & $60-70 \mathrm{~m}$ \\
\hline Carriere Park & $2,435(\mathrm{~m} / \mathrm{sec})$ & $43-53 \mathrm{~m}$ & $50 \mathrm{~m}$ \\
\hline Louis Perrault Park & $2,697(\mathrm{~m} / \mathrm{sec})$ & $74-92 \mathrm{~m}$ & $80-90 \mathrm{~m}$ \\
\hline Heritage Park & $2,677(\mathrm{~m} / \mathrm{sec})$ & $76-95 \mathrm{~m}$ & $80-90 \mathrm{~m}$ \\
\hline
\end{tabular}




\section{Site Response Analysis Using Modified Reflection/Transmission Method}

\subsection{Introduction}

Damage distribution in sedimentary basins during many large earthquakes (e.g. Mexico City in 1985 and Kobe in 1995), has been attributed to local site effects. Seismic amplification due to local soil conditions has been the cause of the observed structural failures and intense ground accelerations. The problem of seismic amplification has gained attention amongst geotechnical engineers and seismologists, and many studies have been conducted to investigate the site response effects in sedimentary basins using different analytical/numerical methods. Analytical/numerical methods constitute a significant part of the site response studies, especially when strong ground motion data are not available to implement empirical/semi-empirical analysis techniques. A good review of the empirical/semi-empirical methods that use earthquake records/strong motion data to delineate site amplification can be found in Safak (2001). Most of 1-D, 2D and 3-D analytical/numerical methods focus mainly on site effects that occur due to the vertical or oblique incidence of seismic waves from the underlying bedrock

Papageorgiou and Kim (1993) studied 1-D and 2-D effects for deep layers of sediments on a half-space (bedrock) for different incidence angles of seismic waves using the discrete wave number boundary element method (Kawase, 1988). Their study was for 
a relatively low shear wave velocity contrast of about 2 between the soil layer and the underlying bedrock. Zeng and Benites (1998) developed a boundary integral discrete wave number approach to study the seismic response of 2-D basins for the incidence of plane shear waves. They also considered low velocity contrasts $(<3)$ between the bedrock and its upper soil layer for their multilayer basins. Mossessian and Dravinski (1990) used an indirect boundary integral method to investigate the amplification of 2-D and 3-D valleys upon the incidence of the seismic waves. They studied valleys, again with a low velocity contrast $(<2)$ between the half-space and the overlying valley sediment.

Bard and Bouchon (1980) also examined the response of sediment-filled valleys for the incidence of seismic waves. They utilized the method of Aki and Larner (1970), which was derived from the Rayleigh's representation of the scattered wave field for the plane wave incidence. Their velocity models consist of a low contrast shear wave velocity $\left(V_{s}\right)$ model with the largest contrast ratio of 5 between the bedrock and the overlying soil sediment. Sanchez-Sesma et al. (1989) carried out research on the ground motion effects on horizontally stratified alluvial basins. They used the mentioned discrete wave number (Aki and Larner, 1970) of plane wave (SH-waves) expansion in terms of the Haskell propagator matrices (Haskell, 1953). Some of other significant studies about the analytical/numerical solutions of seismic wave incidence on sedimentary basins can be found in Khair et al. (1991), Ashford and Sitar (1997) and Sanchez-Sesma and Luzon (1995).

The geological characteristics of the near-surface sediments in the Ottawa area are quite different from those of the above-mentioned studies. The surficial geology of the city consists of very soft and very low shear wave velocity post-glacial deposits 
(Holocene age sediments) underlain by very high shear wave velocity bedrock (see Hunter et al., 2006 and Motazedian et al., 2008). As an example, according to different seismic tests carried out at a site in Barrington Park of the Orleans area located in the eastern part of the city (See Figure (3.1)), the average shear wave velocity of soil is about $146 \mathrm{~m} / \mathrm{sec}$; and, the average shear wave velocity of the underlying bedrock is about 2700 $\mathrm{m} / \mathrm{sec}$, which causes a very high shear wave contrast of 18 for this site. This unusual contrast can cause multiple internal reflections of seismic waves, leading to large seismic amplification values. Thus, suitable methods that are capable of addressing this issue should be sought for the site response modeling in the study area.

The very high shear wave velocity contrast that exists in this area was not the focus of the aforementioned studies, although they illustrate most of the features of lateral interference of seismic waves, surface topography or basin shape effect, diffraction of seismic waves and resonance modes for seismic site amplification. In addition to the low shear wave velocity contrast, the damping value has been usually assumed in the above studies. Consequently, the effect of level of shaking on variations of soil damping has not been a point of concern. Those studies mostly involve boundary integral solutions and finite element/boundary element discretization of 2-D or 3-D basins and examine the low velocity gradient cases.

In this chapter, the matrix method is used to conduct site response analysis of selected sites in the Ottawa area. This method was introduced by Thompson (1950) and Haskell (1953). Later, the method was reformulated and entitled "the generalized method of reflection/transmission (R/T) coefficients" (Kennett, 1974; and Kennett et al., 1979) that connects the layer matrices to the reflection and transmission properties of the layers. 
The R/T method accounts for all the internal reverberations inside the layers, but has not been often employed in site amplification studies. As a rare example, Shearer and Orcutt (1987) used the R/T method to study the near-surface effects of seismic waves for lowcontrast surface layers upon different angles of incidence of the seismic waves.

In this study, the generalized $\mathrm{R} / \mathrm{T}$ method was applied for three sites (Figure (3.1)) in the Ottawa region to obtain the seismic soil amplification for incident SV-waves. These sites, which have loose sediment on hard bedrock, are good representatives of the surficial geology of the eastern part of the city. The shear wave velocity variations (Hunter et al., 2010) of these sites are shown in Figures (3.2) to (3.4). In addition, to include the influence of the level of shaking (shaking intensity), I made two improvements to the $\mathrm{R} / \mathrm{T}$ method, which will described later.

1- $\mathrm{R} / \mathrm{T}$ method modified for damping; The $\mathrm{R} / \mathrm{T}$ algorithm was modified to include soil non-linearity and a damping function that is compatible with the peak ground acceleration of the simulated (artificial) ground motions for the study area was introduced.

2- R/T method modified for damping-modulus; I applied the softened shear modulus in $\mathrm{R} / \mathrm{T}$ algorithm by adjusting the shear modulus based on the developed shear strain level in soil layers.

\subsection{Matrix method for site response analysis}

Thompson (1950) introduced the matrix method to deal with the problem of incident seismic waves for a stratified medium. In this method, a general solution for the displacement that satisfies the wave equation is derived and expressed in terms of dilatation and rotation. Then, the equations of normal and shear stresses are extracted, in 
terms of the dilatation and rotation, using the theory of elasticity, which in turn leads to wave propagation and reflection inside the layers. Thus, the stress-displacement components are related to advancing and reflected waves. Based on that approach, the stress-displacements for the two ends of each layer are presented by the following matrix equation:

$\left(\xi_{\mathrm{n}}, \zeta_{\mathrm{n}}, \sigma_{\mathrm{n}}, \tau_{\mathrm{n}} / 2 \mathrm{G}\right)=[\mathrm{a}]_{4 \times 4}\left(\xi_{\mathrm{n}-1}, \zeta_{\mathrm{n}-1}, \sigma_{\mathrm{n}-1}, \tau_{\mathrm{n}-1} / 2 \mathrm{G}\right)$

where $\xi_{\mathrm{n}}, \zeta_{\mathrm{n}}, \sigma_{\mathrm{n}}$ and $\tau_{\mathrm{n}}$ denote the horizontal displacement, vertical displacement, normal stress and shear stress, respectively, for the $\mathrm{n}^{\text {th }}$ layer. $\mathrm{G}$ stands for the shear modulus. [a] is a $4 \times 4$ matrix, the components of which are the functions of the P-wave velocity, Swave velocity, density of the layers and incident angles (Thompson, 1950).

The incident angles for the reflected waves are obtained by Snell's law at the boundary interfaces of the layers, and the continuity of stresses and displacements at the layer interfaces is applied to find the total layer matrix, [A], which relates the stressdisplacement components of the $\mathrm{n}^{\text {th }}$ and the $\mathrm{m}^{\text {th }}$ layers and is obtained from the following equation:

$[A]_{4 \times 4}=\left[a_{n}\right]\left[a_{n-1}\right]\left[a_{n-2}\right] \ldots\left[a_{m+1}\right]$

Later, Haskell (1953) used Thompson's matrix formulation to obtain the phase velocity dispersion equations for the elastic surface waves on multilayered solid medium. A minor error (will be discussed in the next paragraph) was corrected by Haskell in Thompson's matrix method. Furthermore, velocity components, instead of the displacement components, were used. The equation between the stress-velocity vector of the $\mathrm{n}^{\text {th }}$ layer and those of the surface layer were exhibited in the following equation:

$$
\left(u_{n}^{\cdot} / c, w \cdot / c, \sigma_{n}, \tau_{n}\right)=\left[a_{n}\right]\left[a_{n-1}\right]\left[a_{n-2}\right] \ldots\left[a_{1}\right]\left(u_{0}^{*} / c, w \cdot{ }_{0} / c, 0,0\right)
$$


where $u^{\bullet}, w^{\bullet}, c, \sigma$ and $\tau$ indicate the horizontal velocity, vertical velocity, phase velocity, normal stress and shear stress of the corresponding layer, respectively. The components of the matrices, [a], are functions of the elastic parameters expressed by Haskell (1953).

Both of Thompson and Haskell's methods need some modifications in order to be applicable for the site response purpose in the current research. First, Thompson presented $\tau / 2 \mathrm{G}$ in the stress-displacement vector, which should be corrected to $\tau$. This change was applied by Haskell, but he presented his formulation for the velocity-stress field, instead of stress-displacement field, because he extended his algorithm to investigate the dispersion equations for surface waves. Second, in Thompson's method, the incident and reflected wave angles should be calculated inside each layer using Snell's law. These calculations can be time-consuming when more complicated schemes of reflection and transmissions occur inside the layers. Third, neither of these two matrix methods delivers a comprehensive scheme for the problem of the internal reflections and reverberations inside a layer.

All of these issues with the matrix methods were addressed in the R/T algorithm (Kennett, 1974). These issues, especially the third, can be fixed in the matrix methods using the scheme introduced by Kennett (1974) and Kennett and Kerry (1979), in which all the internal reverberations are taken into account. In the $\mathrm{R} / \mathrm{T}$ method, given that the ray parameter is constant for all layers, the interface and layer matrices can be developed. Layer matrices transfer the input motion to the target ground level. In this chapter, the transfer matrices (layer matrices) of Aki and Richard (1980) will be used to estimate the displacement at the ground level. 


\subsection{Development of the generalized reflection/transmission $(R / T)$ coefficient method for plane wave incidence on multilayered medium}

\subsubsection{Scattered plane P-SV waves: Reflection and transmission of seismic waves}

The reflection of seismic waves from a free surface and the reflection/transmission of seismic waves from a solid-solid interface have been studied by many researchers (e.g. Aki and Richard, 1980). To obtain the reflection coefficients of P-SV waves on a free surface, the dynamic boundary conditions should be satisfied, which means the traction components at the free surface should be zero. Solving the resultant equations gives the ratio of the amplitudes of the reflected displacement potential to the incident displacement potential, which is the required reflection coefficient at the free surface.

The reflection/transmission coefficients can also be obtained at the layer interfaces by considering dynamic equilibrium/compatibility conditions. For the upward propagation of P-SV waves, both reflected and transmitted $\mathrm{P}$ - and SV-waves are considered. As an example of the reflection coefficients of the upward propagation, the coefficient matrix, called the scattering matrix, can be written as:

Scattering Matrix $=\left(\begin{array}{ll}\mathrm{PP} & \mathrm{PS} \\ \mathrm{SP} & \mathrm{SS}\end{array}\right)$

where PP indicates the reflection coefficient of the reflected P-wave (second index) of the incident P-wave (first index). Other coefficients are defined in a similar fashion. 
Considering upward and downward propagations for both $\mathrm{P}$ - and SV-waves, 16 coefficients are derived; and, the total scattering matrix is a $4 \times 4$ matrix.

To construct this scattering matrix across a solid-solid interface, the continuity of the displacements and tractions are satisfied in both the horizontal and vertical directions, and all of these 16 coefficients are determined (for mathematical details, see Aki and Richard, 1980). For each interface, these coefficients are functions that are expressed in terms of the P-wave velocity, S-wave velocity, density of two media, and angles of reflection and transmission. These angles can be obtained for the given ray parameter using Snell's law.

\subsubsection{The concept of propagator matrix}

The propagator matrix, $\mathrm{P}\left(\mathrm{z}, \mathrm{z}_{0}\right)$, (Gilbert and Backus, 1966) is a fundamental matrix solution of the following matrix equation:

$\partial \mathrm{B}(\mathrm{z}) / \partial \mathrm{z}=\mathrm{A}(\mathrm{z}) \mathrm{B}(\mathrm{z})$

where $B$ is the stress-displacement vector at the depth of $z$ and $A$ is a $4 \times 4$ matrix for the case of P-SV wave and a $2 \times 2$ matrix for the case of $\mathrm{SH}$ wave.

Equation (3-5) states that the stress-strain relations and the elastic equations of motion can be reduced by transformation techniques to a set of first-order differential equations, if the elastic parameters are functions of only one coordinate (Takeuchi \& Saito, 1972). Substituting the propagator matrix in equation (3-5), we have:

$\partial \mathrm{P}\left(\mathrm{z}, \mathrm{z}_{0}\right) / \partial \mathrm{z}=\mathrm{A}(\mathrm{z}) \mathrm{P}\left(\mathrm{z}, \mathrm{z}_{0}\right)$

where $P\left(z_{0}, z_{0}\right)=I$, and $I$ is the unit matrix from any fundamental matrix, $\varphi$ of the equation (3-6): 
$\mathrm{P}\left(\mathrm{z}, \mathrm{z}_{0}\right)=\varphi(\mathrm{z}) \varphi^{-1}\left(\mathrm{z}_{0}\right)$

Hence, in terms of the propagator matrix, the stress-displacement vector is calculated as:

$\mathrm{B}(\mathrm{z})=\mathrm{P}\left(\mathrm{z}, \mathrm{z}_{0}\right) \mathrm{B}\left(\mathrm{z}_{0}\right)$

This overall propagator can be split at any intermediate level, $\mathrm{z}_{1}$ :

$\mathrm{P}\left(\mathrm{z}, \mathrm{z}_{0}\right)=\varphi(\mathrm{z}) \varphi^{-1}\left(\mathrm{z}_{1}\right) \varphi\left(\mathrm{z}_{1}\right) \varphi^{-1}\left(\mathrm{z}_{0}\right)=\mathrm{P}\left(\mathrm{z}, \mathrm{z}_{1}\right) \mathrm{P}\left(\mathrm{z}_{1}, \mathrm{z}_{0}\right)$

Equation (3-9) shows that, by knowing the propagators of soil layers, the overall propagator matrix is a matrix product of all the layer propagator matrices. These propagators accompanied by the scattering matrices constitute the main framework to develop the R/T algorithm. In Section (3.3), the application of these propagators is explained and the derivation of internal reverberation scheme of the method is fully described. In section 4 , the $\mathrm{R} / \mathrm{T}$ algorithm for the upward wave propagation is depicted using the scattering matrices and the derived internal reverberation scheme in section 3.3.

\subsubsection{Generalized method of reflection/transmission}

To develop the method of the generalized of reflection/transmissions, Kennett (1974) used the following first-order differential equation that is equation (3-5) with minor change:

$$
\partial \mathrm{B}(\mathrm{z}) / \partial \mathrm{z}=\omega \mathrm{A}(\mathrm{z}) \mathrm{B}(\mathrm{z})
$$

$\omega$ indicates the angular frequency. The following transformation to the displacementstress matrix, B, was applied:

$$
\mathrm{B}=\mathrm{D} \mathrm{V}
$$

where $\mathrm{D}$ is the eigenvector matrix for $\mathrm{A}$. In a uniform medium, the new wave vector, $\mathrm{V}$, satisfies the following equation:

$$
\partial_{\mathrm{Z}} \mathrm{V}=\omega \text { i } \Lambda \mathrm{V}
$$


where $i \Lambda$ is a diagonal matrix whose entries are the eigenvalues of $A$. The elements of $V$ are identified with the amplitudes of the upward (U) and downward (D) traveling plane waves:

$$
\mathrm{V}=\left[\mathrm{V}_{\mathrm{U}}, \mathrm{V}_{\mathrm{D}}\right]^{\mathrm{T}}
$$

To derive the reverberation scheme of the propagated waves through the layers and to better illustration of the application of propagator matrices, Kennett (1974) and Kennett and Kerry (1979) suggested the following procedure:

1- For the upper level of $z_{1}$ and lower level of $z_{3}$, the relationship between $V$ vectors (Equation (3-13)) is constructed. In order to obtain this relationship, an interface of $z_{2}$ is assumed between $z_{1}$ and $z_{3}$. With this assumption, the following equations can be written:

$$
\begin{gathered}
\left(V_{U}\left(z_{1}\right), V_{D}\left(z_{1}\right)\right)^{T}=Q_{1} \quad\left(V_{U}\left(z_{2}\right), V_{D}\left(z_{2}\right)\right)^{T} \\
\left(V_{U}\left(z_{2}\right), V_{D}\left(z_{2}\right)\right)^{T}=Q_{2}\left(V_{U}\left(z_{2}\right), V_{D}\left(z_{2}\right)\right)^{T}
\end{gathered}
$$

Vectors $V$ at two levels of $z_{1}$ and $z_{3}$ can be correlated together with the following equation:

$$
\left(V_{U}\left(z_{1}\right), V_{D}\left(z_{1}\right)\right)^{T}=Q \quad\left(V_{U}\left(z_{3}\right), V_{D}\left(z_{3}\right)\right)^{T}
$$

According to the property of propagator matrix, the matrix $Q$ is the product of $Q_{1}$ and $\mathrm{Q}_{2}$, thus:

$\mathrm{Q}=\mathrm{Q}_{1} \mathrm{Q}_{2}$

The elements of matrix $Q$ are shown here:

$$
\mathrm{Q}=\left(\begin{array}{ll}
\mathrm{Q}_{11} & \mathrm{Q}_{12} \\
\mathrm{Q}_{21} & \mathrm{Q}_{22}
\end{array}\right)
$$


2- The reflection matrix (R) and transmission matrix $(T)$ can be defined in terms of $V_{U}$ and $V_{D}$. For example, for the incident downward wave from the level $\mathrm{z}$, where $\mathrm{z}<\mathrm{z}_{1}$, we have:

$\mathrm{V}_{\mathrm{U}}\left(\mathrm{z}_{2}\right)=0, \mathrm{~V}_{\mathrm{U}}\left(\mathrm{z}_{1}\right)=\mathrm{R}_{\mathrm{D}} \mathrm{V}_{\mathrm{D}}\left(\mathrm{z}_{1}\right), \mathrm{V}_{\mathrm{D}}\left(\mathrm{z}_{2}\right)=\mathrm{T}_{\mathrm{D}} \mathrm{V}_{\mathrm{U}}\left(\mathrm{z}_{1}\right)$

All the possible equations for incident waves, similar to Equation (3-19), can be developed. Using these equations and equations (3-14) and (3-15), matrices $Q_{1}$ and $\mathrm{Q}_{2}$ are determined:

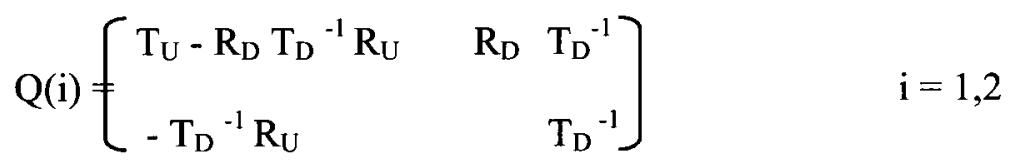

Equation (3-20) exhibits the matrices $Q_{1}$ and $Q_{2}$ in the form of reflection (R) and transmission (T) coefficients. Now, equation (3-18) can be applied to obtain the reflection/transmission matrices between the $z_{1}$ and $z_{3}$ levels. For example, for the upward wave propagation, we get:

$$
\begin{aligned}
& R^{13}{ }_{U}=R^{23}{ }_{U}+T^{23}{ }_{D} R^{12}\left[I-R_{D}^{23} R^{12}\right]^{-1} T^{23} \\
& T^{13}{ }_{U}=T^{12}\left[I-R_{D}^{23} R^{12}\right]^{-1} T^{23}{ }_{U}
\end{aligned}
$$

Equations (3-21) and (3-22) show all the internal reflections within the layer. $\mathrm{R}$ and $\mathrm{T}$ indicate the reflection and transmission matrices, respectively. $\mathrm{U}$ and $\mathrm{D}$ subscripts denote the up-going and down-going waves, respectively. These equations can be better interpreted by expanding the inverse of matrices. For a given square matrix $A$, the expansion is:

$[\mathrm{I}-\mathrm{A}]^{-1}=\mathrm{I}+\mathrm{A}+\mathrm{A}^{2}+\ldots$ 
Using equations (3-21), (3-22) and (3-23), one can obtain the reflection and transmission coefficients. For instance, the reflection coefficient for the upward wave propagation is derived in the following form:

$R^{13}{ }_{U}=R^{23}{ }_{U}+T^{23}{ }_{D} R^{12} T^{23}{ }_{U}+T^{23}{ }_{D} R^{12} R^{23}{ }_{D} R^{12} T^{23}{ }_{U}^{+}+\ldots$

All the terms in Equation (3-24) can be interpreted as in the following two examples. The first term $\left(\mathrm{R}_{\mathrm{U}}^{23}\right)$ is the reflection from the lower level (level 3). The second term $\left(\mathrm{T}^{23} \mathrm{D}^{12}{ }_{\mathrm{D}} \mathrm{T}^{23} \mathrm{U}\right)$ shows the transmission up through the lower level, reflection by the upper level and transmission down through the lower level. This internal reverberation scheme is shown in Figure (3.5).

\subsection{Seismic response of a stack of layers to the plane P-SV waves using R/T method: upward seismic wave propagation}

The generalized method of reflection/transmission $(\mathrm{R} / \mathrm{T})$ can be used to determine the seismic amplification for the upward propagation of P-SV waves. A threestep procedure used in this research is summarized here:

1- All the scattering matrices are obtained for the layer interfaces, regarding the type of the incident wave and the ray parameter. Since the ray parameter remains constant during the wave traveling to the upper layers, an algorithm can be set up to compute all the scattering matrices at the layer interfaces.

2- Equation (3-7) is a key equation that is used to transfer the incident wave to the upper layers. This equation should be combined with the layer matrices and the scattering matrices to obtain and interpret the total reflection and transmission 
matrices at the top and bottom of the layers. Kennett R/T scheme (equations such as equation (3-24)) is used to obtain the internal reflections inside the layers.

3- According to the definition of the R/T matrices, the displacement vector $\left(U_{x}, U_{z}\right)$ at the free surface is:

$$
T_{D}^{\text {top }}\left(U_{x}, U_{z}\right)-R_{U}^{\text {free }}=-R^{\text {second }}
$$

where $U_{x}, U_{z}, T_{D}^{\text {top }}, R_{U}^{\text {free }}$ and $R_{U}^{\text {second }}$ are the relative horizontal and vertical displacements, the transmission matrix for the downward wave at the top layer, the reflection matrix at the free surface and the reflection matrix on the second interface (the interface below the free surface), respectively. This relative displacement vector is the amplification ratio for the incident wave that is calculated for the corresponding excitation frequency.

\subsection{Site Response Analysis using the Equivalent Linear Method (ELM)}

The improvements proposed to include soil non-linearity effects in the $\mathrm{R} / \mathrm{T}$ algorithm require the introduction of a damping function that is compatible with the peak ground acceleration (which represents the shaking intensity) of the simulated (artificial) ground motions for the study area. In order to modify the $\mathrm{R} / \mathrm{T}$ algorithm, the relationship between PGA and damping should be derived for the Ottawa area. This was accomplished by using the Equivalent Linear Method technique for the study area.

In the equivalent linear method for site response analysis, a stack of horizontal layers are considered and the horizontal responses due to vertically propagating shear waves (SH waves) are calculated at the interfaces of the different layers. In that site response analysis method, transmission and reflection of waves at boundaries of adjacent layers are taken into account and the transfer function (frequency domain representation 
of the ratios of propagated wave amplitude to the $\mathrm{SH}$ wave amplitude on the bedrock) of the layered soil deposit is determined. To derive the transfer function, the compatibility of displacements and the continuity of the shear stresses are imposed at boundaries (interfaces) of the soil layers and also a null shear stress condition is applied at the ground surface.

To include the soil non-linearity, shear modulus reduction curves and shear strain-dependent damping curves are used for the different layers in a one dimensional model. Those curves exhibit the dependency of shear modulus and damping on the strain level or shaking intensity. For each soil layer, shear strain compatibility condition is satisfied and a proper strain compatible shear modulus and damping ratio, based on the shear strain level, are obtained (Schnabel et al., 1972; Seed and Idriss, 1969). A schematic model of ELM with the corresponding parameters for a presumptive threelayer model is shown in Figure (3.6).

\subsection{Results of $R / T$ site response analysis; Discussions}

\subsubsection{Damping relationship for target PGA}

In this section, the procedure to incorporate the damping in $\mathrm{R} / \mathrm{T}$ algorithm is explained. A solid friction model incorporating the wave attenuation (damping) can be defined mathematically, if the model velocity is considered as a complex quantity (Aki and Richards, 1980). In this approach, attenuation term, Q is included in the complex part of the velocity function, which can easily allow making of a rigorous algorithm for wave propagation in the $\mathrm{R} / \mathrm{T}$ method. $\mathrm{Q}$, in terms of damping ratio, $\mathrm{D}$, is obtained from the subsequent equation (Kramer, 1996): 
$\mathrm{Q}=1 /(2 \mathrm{D})$

To obtain a correlation between damping and PGA, first, the simulated time histories for eastern Canadian earthquakes (Atkinson and Beresnev, 1998) were used as input motions to ELM method (Schnabel et al., 1972) for layered-soil models in the region. A sample of simulated acceleration time histories is shown in Figure (3.7). Different sites in the eastern part of the city of Ottawa that represent the dominant geotechnical characteristics of the sedimentary sites in the study area were chosen. PGAs from $0.02 \mathrm{~g}$ to $0.5 \mathrm{~g}$ were used; and, the maximum effective strains $(\varepsilon)$ were obtained, as shown in Figure (3.8). The best fit linear-equation to the PGA- $\varepsilon$ data is:

$$
\varepsilon=0.4752 \text { PGA }
$$

Secondly, to account for the effect of different shaking intensities on the mobilized damping, some experimental data of damping values of clayey materials were used. These data are the damping-shear strain data for clay (from Sun et al., 1988). Figure (3.9) exhibits the mentioned data and the best-fit equation that I obtained for straindamping points as shown here:

$$
\mathrm{D}=17.308 \varepsilon^{0.2537}
$$

where $\varepsilon$ is the shear strain. Equation (3-28) shows the dependency of damping on the strain level; and, consequently, this shear strain can be related to the shaking intensity in the region. This shaking intensity will be represented by the peak ground acceleration (PGA) of the input records in this research.

Substituting Equation (3-27) in Equation (3-28), I obtained:

$$
\mathrm{D}=14.33 \mathrm{PGA}^{0.2537}
$$


It should be noted that this equation was developed using the simulated time histories for eastern Canada and gives an approximate correlation that is helpful to choose the suitable range of the damping ratio for the deposits in the study area. Then, in order to modify the $\mathrm{R} / \mathrm{T}$ algorithm, attenuation values from this equation can be used in the complex part of the velocity functions.

\subsubsection{Comparison between $\mathrm{R} / \mathrm{T}$ and ELM results}

\subsubsection{Seismic amplification results using damping modified $\mathrm{R} / \mathrm{T}$ method}

The R/T method was applied for three sites (Barrington Park, Chapel Hill site and Longleaf Park) that represent the general surficial geology of the city of Ottawa in Orleans area (See Figure (3.1)). These sites, which have loose sediments with depths of $30 \mathrm{~m}$ to $109 \mathrm{~m}$ underlain by very high velocity bedrock, are located in the eastern part of the city. The shear wave velocity profiles and other physical parameters are available from different seismic reflection/refraction and nearby borehole measurements. Shear wave velocity profiles are shown in Figures (3.2), (3.3) and (3.4) (Hunter et al., 2010). Also parameters of 3-layer models used for R/T analysis are illustrated in Tables (3.1), (3.2) and (3.3).

The given models in Tables (3.1), (3.2) and (3.3) and an appropriate damping ratio (Equation (3-29)) were used in the $\mathrm{R} / \mathrm{T}$ simulation method for the vertical incident angles of plane SV-waves; and, the horizontal amplification values were obtained. For the examined sites, the results of amplification analyses for two levels of shaking (PGAs of $0.2 \mathrm{~g}$ and $0.4 \mathrm{~g}$ ) are shown in Figures (3.10) to (3.12).

The $\mathrm{R} / \mathrm{T}$ results were compared and calibrated against the results of ProShake software (EduPro Civil Systems, Inc., 2001) which is based on the equivalent 
linear method (ELM) for the vertical propagation of S-waves. To perform a reasonable equivalent linear analysis, the multi-layered models of the target sites were analyzed; and, the horizontal amplification values were obtained using the simulated time history records for eastern Canada (Atkinson and Beresnev, 1998). Figures (3.13) to (3.18) illustrate the results of calibration of R/T method using the ELM.

The average shear wave velocity values for the Barrington Park, Chapel Hill site and Longleaf Park sites were measured as 146,171 and $131 \mathrm{~m} / \mathrm{sec}$, respectively, using different geophysical methods. The fundamental linear frequencies (equal to $V_{s} / 4 H$ ) are 0.52, 0.34 and $1.09 \mathrm{~Hz}$ for the Barrington Park, Chapel Hill site and Longleaf Park, respectively, where $V_{s}$ is the average shear wave velocity and $H$ is the depth to bedrock. These frequencies are in good agreement with those of the generalized R/T method ( see Figures (3.10) to (3.12)), which yielded 0.6, 0.4 and $1.2 \mathrm{~Hz}$ for the Barrington Park, Chapel Hill site and Longleaf Park sites, respectively.

Figures (3.13) to (3.18) show the results of the $\mathrm{R} / \mathrm{T}$ method calibration with the ELM which indicate good agreement on the fundamental frequencies of both methods. There is a slight frequency shift in the ELM results, which can be attributed to the nonlinearity effect of shear modulus softening of ELM. In addition, there is reasonable agreement on the seismic amplification values, based on both methods; and, slight differences in the seismic amplification values are probably due to the variable shear modulus in ELM.

\subsubsection{Seismic amplification results using damping-modulus modified $R / T$} method 
In addition to the mentioned damping modification in $\mathrm{R} / \mathrm{T}$ method, I modified this method by including the shear modulus softening behavior of soil material. To implement the modification, the shear wave velocity profiles were adjusted based on the expected shear modulus. The shear modulus varies with changing shear strain that has correlation with the target shaking intensity (PGA). Therefore, the finial modification would be some reduction coefficient applied on the final shear wave velocity profile (leading to lower-velocity profiles). The following steps exhibit this modification:

1-For the target shaking intensity, the average shear strain is calculated using equation (327).

2- The obtained shear strain can be correlated to the shear modulus reduction ratio $\left(\mathrm{G} / \mathrm{G}_{\max }\right)$. A sample of the strain-dependent shear modulus reduction curves for clay is shown in Figure (3.19).

3- The mentioned reduction ratio changes the velocity profile. In fact, the shear wave velocity of soil profile is adjusted for the calculated $\mathrm{G} / \mathrm{G}_{\max }$.

This three-step procedure is clarified by the following example:

Assume the time history of ground motion has the PGA of $0.2 \mathrm{~g}$ for a target site. In that case, using equation (3-27), the shear strain of $0.095 \%$ is calculated for that shaking intensity. Then, for this strain percentage, a modulus reduction curve for clays such as that from Sun et al. (1988) (see Figure (3.19)), gives $\mathrm{G} / \mathrm{G}_{\max }$ equal to 0.61. Regarding the fact that the shear wave velocity is proportional to the square root of shear modulus, the shear wave velocity values of soil profile should be corrected for the obtained shear modulus. In other words, the Vs values of soil profile should be multiplied by the square root of 0.61 which is 0.78 ( $22 \%$ softened). This new Vs profile includes the effect of 
shear modulus softening for the PGA of $0.2 \mathrm{~g}$. Figures (3.20) to (3.25) illustrate the comparison between these new results of damping-modulus modified R/T method with ELM.

\subsubsection{Comparison of damping modified $R / T$ method with damping-modulus}

\section{modified $R / T$ method}

Figures (3.26) to (3.31) show the comparison between damping modified and damping-modulus modified R/T methods. As seen in these Figures, shear modulus softening causes the fundamental frequency shifting to lower frequencies in dampingmodulus modified R/T method. For example, at the shaking intensity of $0.2 \mathrm{~g}$, Figures (3.26) to (3.28) illustrate the effect of the shear modulus softening on the fundamental frequency. Using damping modified method, the fundamental frequencies of $0.6 \mathrm{~Hz}, 0.4$ $\mathrm{Hz}$ and $1.2 \mathrm{~Hz}$ are achieved for Barrington Park, Chapel Hill site and Longleaf Park sites, respectively. On the other hand, the damping-modulus modified method gives the fundamental frequencies of $0.45 \mathrm{~Hz}, 0.35 \mathrm{~Hz}$ and $0.9 \mathrm{~Hz}$ for the mentioned sites. Hence, the frequency shift to smaller frequencies in damping-modulus modified method is more than the damping modified method.

Moreover, it is clear that the damping-modulus modified method leads to relatively greater peak amplification values (first peaks) compared to those from damping modified method. For instance, for the shaking intensity of $0.2 \mathrm{~g}$ at Longleaf Park (Figure (3.26)), the peak amplification values are 6.21 and 5.13 from the damping-modulus modified and damping modified methods respectively that shows the damping modified method gives the peak amplification value $17 \%$ less than the other method.

\subsection{Summary and conclusions}


In this chapter, the matrix method for the site response analysis was reviewed, and the algorithm of the generalized reflection/transmission $(\mathrm{R} / \mathrm{T})$ method for upward seismic wave propagation was presented and modified. There are some issues and calculation difficulties with the older matrix method of Thompson/Haskell that can be resolved and modified in the generalized $R / T$ coefficients method. The $R / T$ method was applied for three representative sites in the city of Ottawa.

Most of the city of Ottawa is covered by loose sediments underlain by very hard, high velocity bedrock; and, there is a very high shear wave velocity contrast at the boundary between the loose sediments and the bedrock. Therefore, wave trapping of seismic waves in soil layers is a serious concern. The main advantage of the $R / T$ method is a scheme that considers all internal reverberations of seismic waves, leading to a proper simulation of the wave trapping inside the soil layers.

The R/T method was modified by implementing a shaking intensity-dependent damping formulation. Furthermore, this modified $\mathrm{R} / \mathrm{T}$ method was applied for the soil profiles adjusted for the modulus softening behavior of soil materials (damping-modulus modified R/T method). In general, damping-modulus modified R/T method gives greater peak amplification values compared to those values from damping modified R/T method.

In addition, the results of the amplification values and the fundamental frequencies from the R/T method were calibrated and validated using ELM for the case of vertical incidence of shear waves. The agreement between the results of two methods was good, although different nature of two methods can cause slight differences between the amplification values or the fundamental frequencies. 
The damping modified $\mathrm{R} / \mathrm{T}$ method is recommended for the site response analysis especially in the regions without recorded strong ground motion data. In these regions, $\mathrm{R} / \mathrm{T}$ method is extremely useful if a shaking intensity-dependent damping formulation is incorporated to the method. In addition, R/T method can be developed for a long range of seismic waves (SV and $\mathrm{P}$ ) and for different angles of incidence.

In the Ottawa area, because of two major reasons, the application of modified $\mathrm{R} / \mathrm{T}$ method is justified. First the area lacks the recorded strong ground motion data and regardless of real ground motion data, the modified $\mathrm{R} / \mathrm{T}$ method predicts the seismic amplification for a target shaking intensity. Second, the surficial geology of the city highlights the possible wave trapping issue that is addressed in the reverberation scheme of the R/T method. Therefore, this method can be considered as a powerful tool for the development of the future amplification maps based on the target shaking intensity in the area.

\subsection{References}

Aki K. and Larner K.L., 1970, Surface motion of a layered medium having an irregular interface due to incident plane SH waves, Journal of Geophysical Research, 75, pp. 933-954.

Aki K. and Richards P.G., 1980, Quantitative Seismology: Theory and Methods, W. H. Freeman and Co., San Francisco, California.

Ashford S.A. and Sitar N., 1997, Analysis of topographic amplification of inclined shear waves in a steep coastal bluff, Bulletin of the Seismological Society of America, 87, pp.692-700.

Atkinson G. and Beresnev I., 1998, Compatible ground-motion time histories for new national seismic hazard maps, Canadian Journal Civil Engineering, 25, pp.305-318. 
Bard P. and Bouchon M., 1980, The seismic response of sediment-filled valleys - Part 1, The case of incident SH waves, Bulletin of the Seismological Society of America, 70, pp.1263-1286.

Bard P. and Bouchon M., 1980, The seismic response of sediment-filled valleys - Part 2, The case of incident $\mathrm{P}$ and SV waves, Bulletin of the Seismological Society of America, 70, pp.1921-1941.

Gilbert F. and Backus G.E., 1966, Propagator matrices in elastic wave and vibration problems, Geophysics, 31, 326-332.

Haskell N., 1953, The dispersion of surface waves in multilayered media, Bulletin of the Seismological Society of America, 43, pp.17-34.

Hunter J.A., Burns R.A., Good R.L., Aylsworth J.M., Pullan S.E., Perret D. and Douma , 2006, M., Borehole shear wave velocity measurements of Champlain Sea sediments in the Ottawa-Montreal region, Geological Survey of Canada Open File \#5345, in press.

Hunter, J. A., Crow, H. L., Brooks, G. R., Pyne, M., Motazedian, D., Khaheshi-Banab, K., Lamontagne, M., et al. ,2010, Seismic site classification and site period mapping in the Ottawa area using geophysical methods. Ottawa, ON: Geological Survey of Canada, Open File 6237 in publication.

Kawase H., 1988, Time-domain response of a semi-circular canyon for incident SV, P and Rayleigh waves calculated by the discrete wave number boundary element method, Bulletin of the Seismological Society of America, 78 ,pp.1415-1437.

Kennett B.L.N. and Kerry N J., 1979, Seismic waves in a stratified half space, Geophysical Journal of the Royal Astronomical Society, 57, pp.557-583.

Kennett B.L.N., Reflections, Rays and reverberations, 1974, Bulletin of the Seismological Society of America, 64, pp.1685-1696. 
Khair K.R., Datta S.K. and Shah A. H., 1991, Amplification of obliquely incident seismic waves by cylindrical alluvial valley of arbitrary cross-sectional shape; Part 2: Incident SH and Rayleigh waves, Bulletin of the Seismological Society of America, 81, pp.346-357.

Kramer S.L., 1996,Geotechnical earthquake engineering, Prentice-Hall international series in civil engineering and engineering mechanics, Upper Saddle River, New Jersey.

Mossessian T.K. and Dravinski M., 1990, Amplification of elastic waves by a three dimensional valley, Part 1, Steady state response, Earthquake Engineering and Structural Dyamics, 19, pp.667-680.

Motazedian D. and Hunter J.A., 2008, Development of a NEHRP map for the Orleans suburb of Ottawa, Ontario, Canadian Geotechnical Journal, 45, pp.1180-1188.

Papageorgiou A.S. and Kim J., 1993, Propagation and amplification of seismic waves in 2-D valleys excited by obliquely incident $P$ and SV waves, Earthquake Engineering and Structural Dynamics, 22, pp.167-182.

Proshake Software, Version 1.11, 2001, EduPro Civil Systems Inc., Sammamish, WA, USA.

Safak E., 2001, Local site effects and dynamic soil behavior, Soil Dynamics and Earthquake Engineering, 21, pp.453-458.

Sanchez-Sesma F.J., Heitz J.F. and Bravo M.A., 1989, Ground motion on stratified alluvial basins, proceeding of Fourth International Conference of Soil Dynamics and Earthquake Engineering, Mexico City, Mexico.

Sanchez-Sesma F.J. and Luzon F., 1995, Seismic response of three-dimensional alluvial valleys for incident $\mathrm{P}, \mathrm{S}$, and Rayleigh waves, Bulletin of the Seismological Society of America, 85, pp.269-284. 
Schnabel P.B., Lysmer J. and Seed H.B., 1972, SHAKE: a computer program for earthquake response analysis of horizontally layered sites, Report No. EERC72-12, University of California, Berkeley.

Seed, H.B. and Idriss, I.M.,1969, The influence of soil conditions on ground motions during earthquakes, Journal of the Soil Mechanics and Foundation Engineering Division, ASCE, No. 94, pp.93-137.

Shearer P.M. and Orcutt J. A., 1987, Surface and near- surface effects on seismic waves Theory and borehole seismometer results, Bulletin of the Seismological Society of America, 77, pp.1168-1196.

Sun J.I., Golesorkhi R. and Seed H.B., 1988, Dynamic moduli and damping ratios for cohesive soils, Report No. UCB/EERC-88/15 Earthquake Engineering Research Center, University of California, Berkeley.

Takeuchi H. and Saito M., 1971, Seismic surface waves, Methods in Computational Physics, ed. Bolt B.A., Academic Press, New York.

Thompson W.T., 1950, Transmission of elastic waves through a stratified solid, Journal of Applied Physics, 21, pp.89-93.

Zeng Y. and Benites R., 1998, Seismic response of multi-layered basins with velocity gradients upon incidence of plane shear waves, Earthquake Engineering and Structural Dynamics, 27, pp.15-28. 


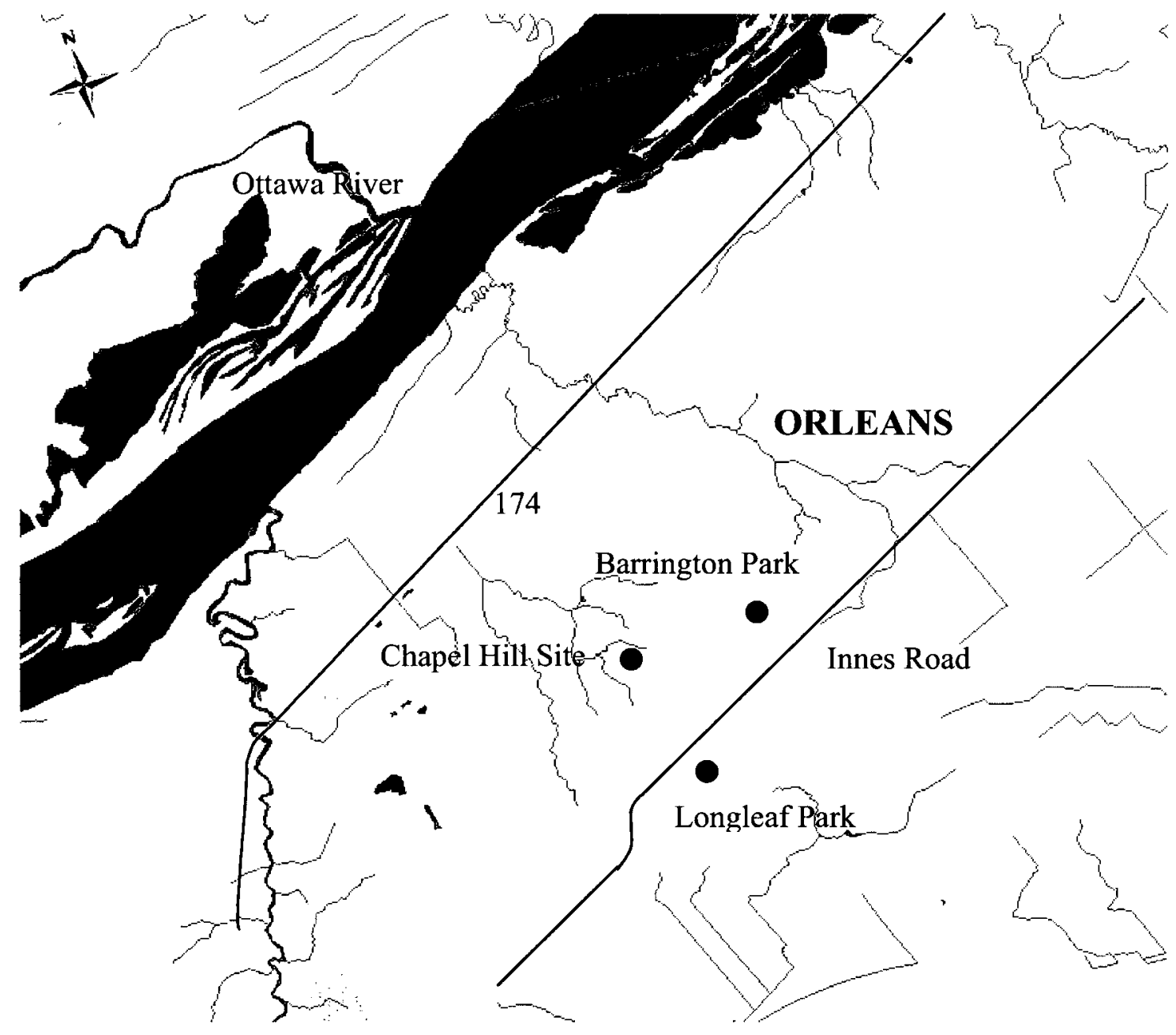

Fig. 3.1: Three examined sites in the Orleans area located in the eastern part of the city of Ottawa. 


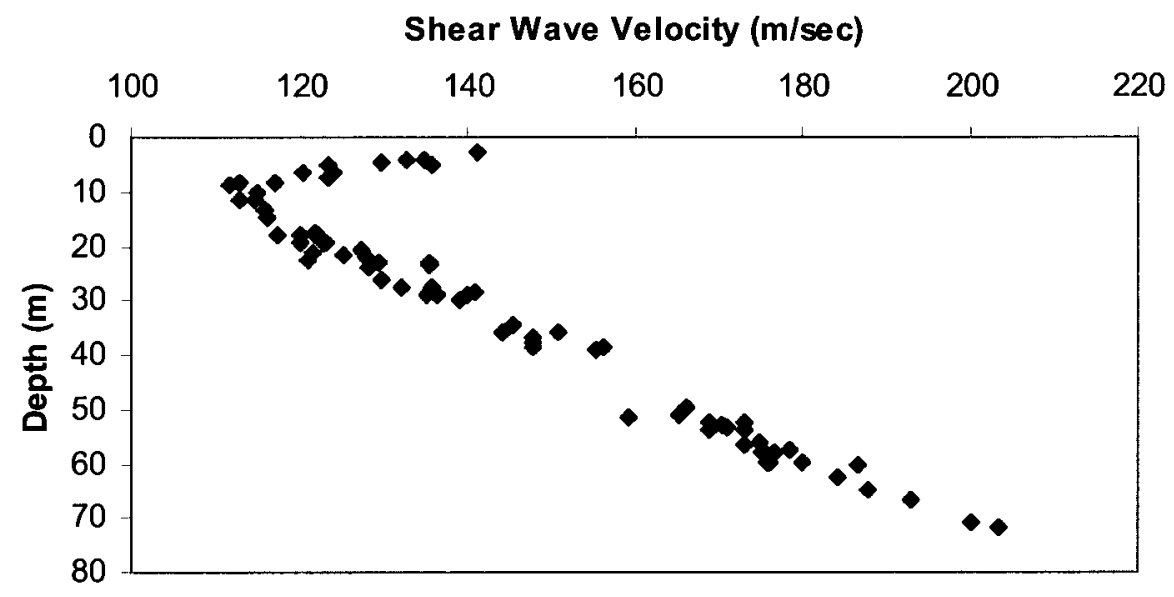

Fig. 3.2: Shear wave velocity variation for Barrington Park Site from reflection/refraction tests (Hunter et al., 2010).

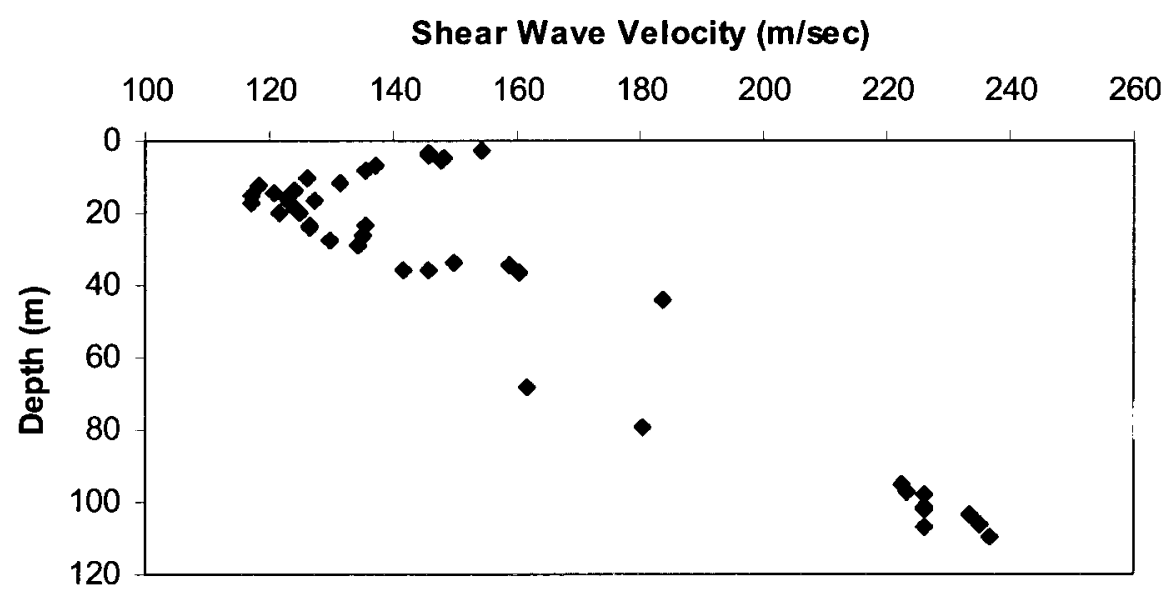

Fig. 3.3: Shear wave velocity variation for Chapel Hill site from reflection/refraction tests (Hunter et al., 2010). 


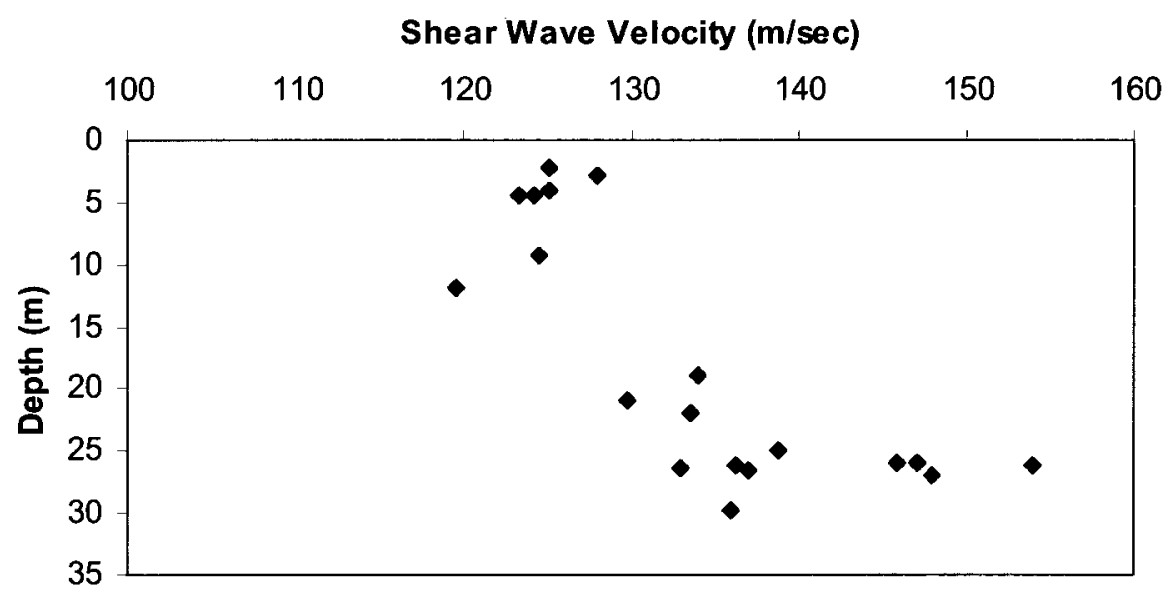

Fig. 3.4: Shear wave velocity variation for Longleaf Park Site from reflection/refraction tests (Hunter et al., 2010).

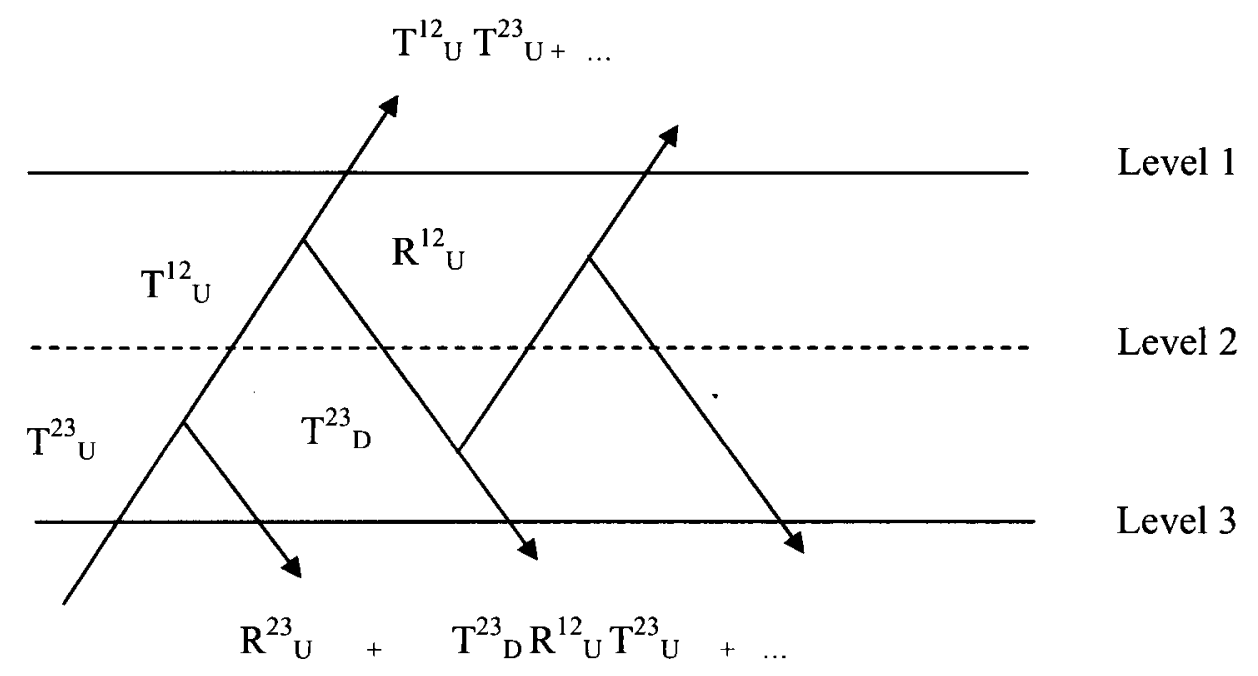

Fig. 3.5: R/T: method scheme showing the reverberations inside the soil layers for upward wave propagation. $R$ and $T$ denote the reflection and transmission matrices and $U$ and $D$ stand for the up-going and down-going waves. 


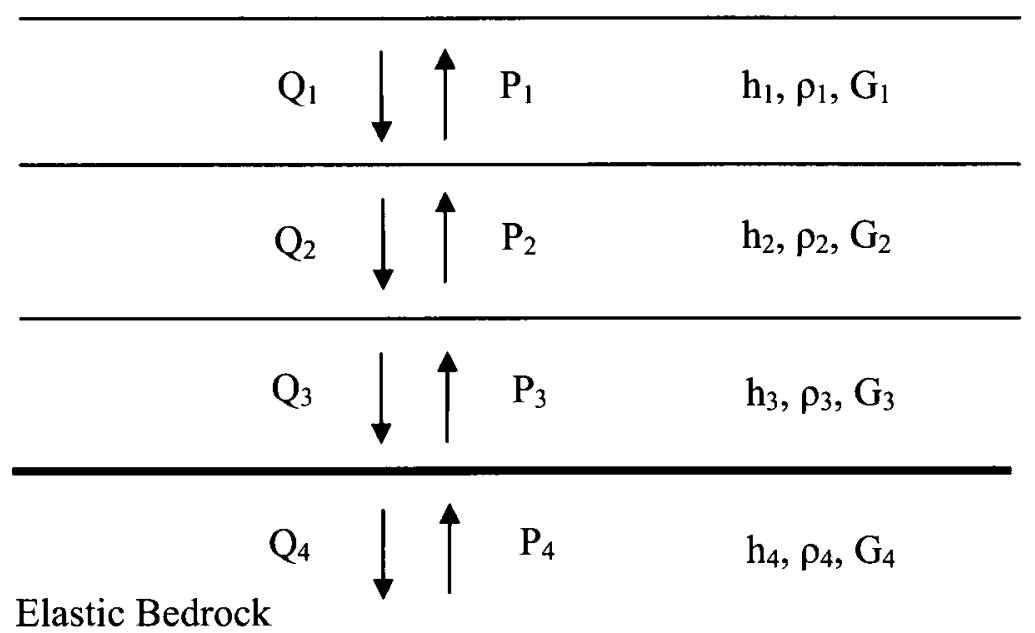

Fig. 3.6: Upward SH wave propagation scheme and the model parameters of ELM in a 3-layer model. $P$ and $Q$ show the amplitudes of the advancing and the reflected $S$-waves. $h, \rho$ and $G$ stand for the layer thickness, density and the shear modulus of the layer material respectively.

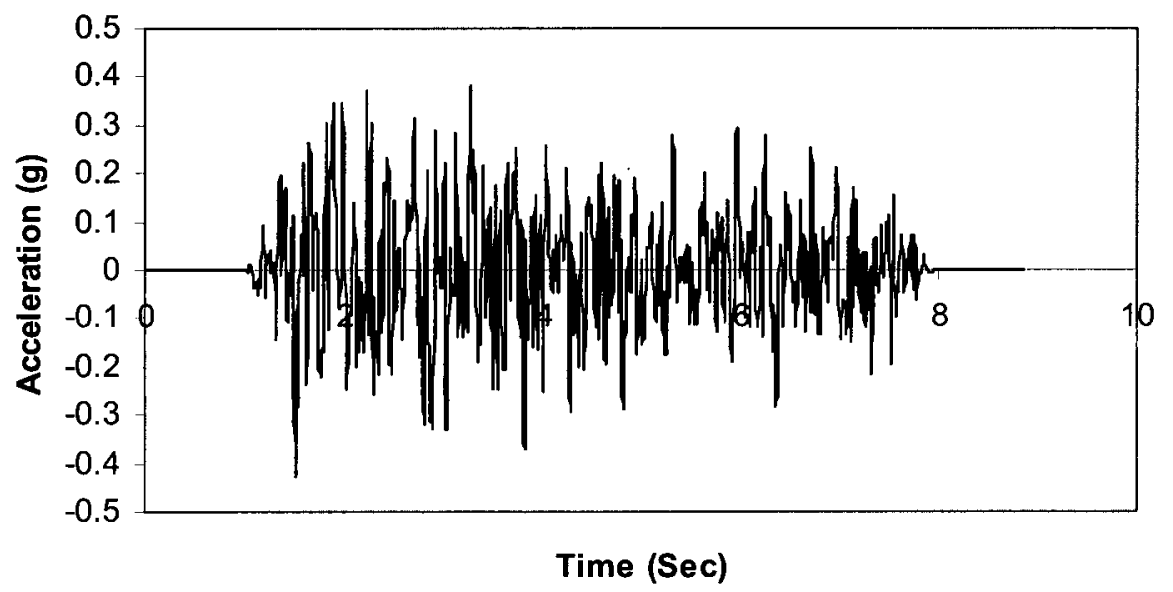

Fig. 3.7: A sample of simulated acceleration time history with the PGA of 0.4g for eastern Canadian earthquakes (Atkinson and Beresnev, 1998). 


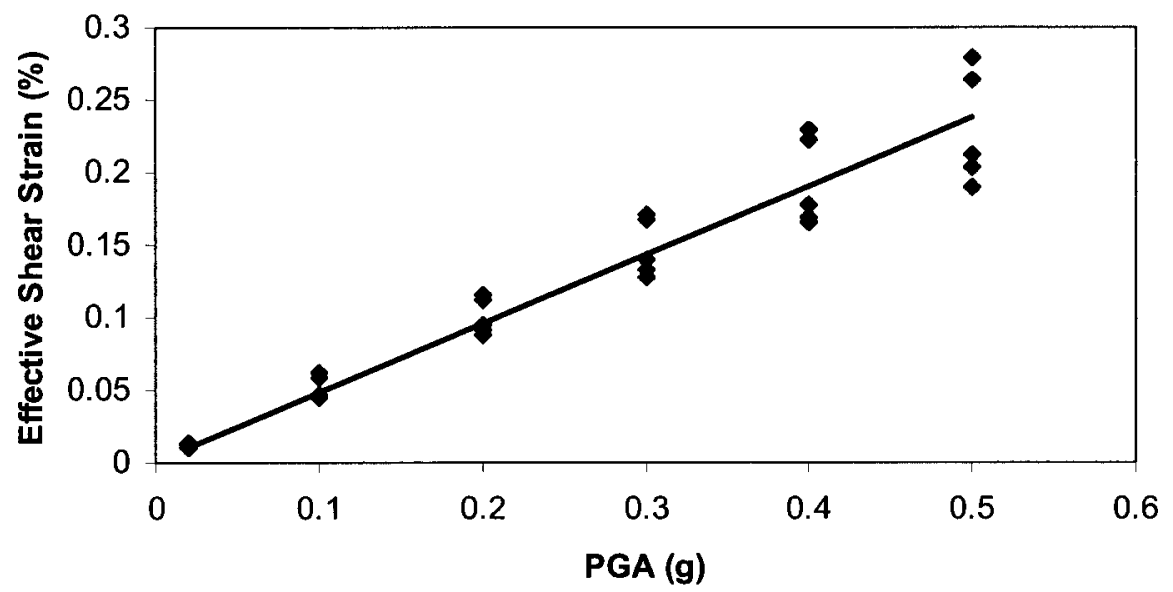

Fig. 3.8: Peak ground acceleration from simulated time histories (generated for eastern Canada) versus effective shear strain (from ProShake program). The best fit equation is $\varepsilon=0.4752 P G A\left(R^{2}=0.9289\right) . \varepsilon$ and $P G A$ are the effective shear strain and the peak ground acceleration, respectively.

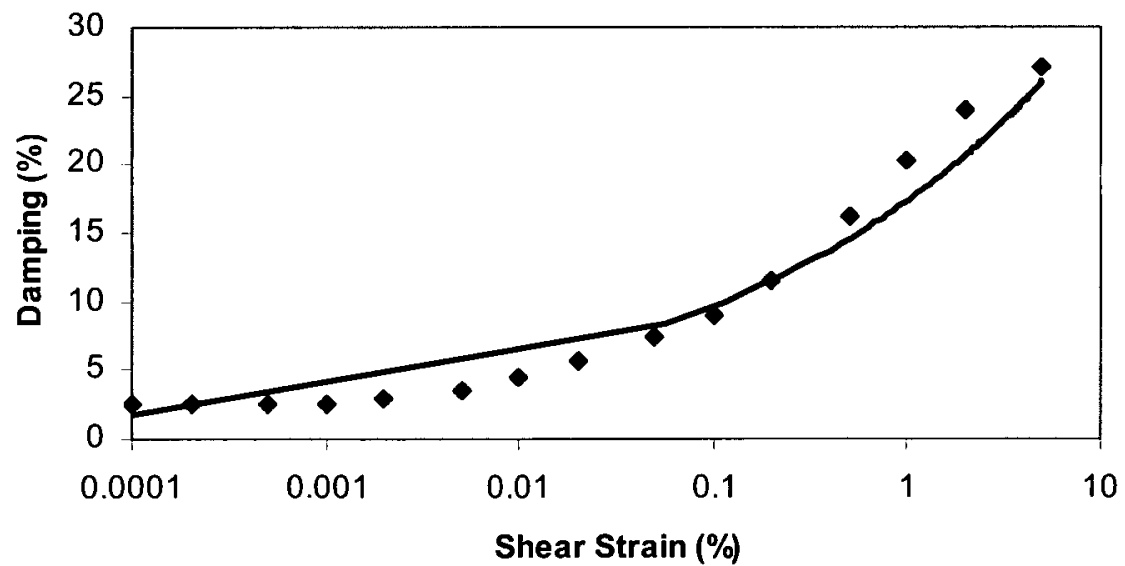

Fig. 3.9: Damping curve for clayey soil from Sun et al. (1988). The best fit equation is $D=17.308 \varepsilon^{0.2537}\left(R^{2}=0.9586\right) . D$ and $\varepsilon$ are the damping and the shear strain, respectively. 


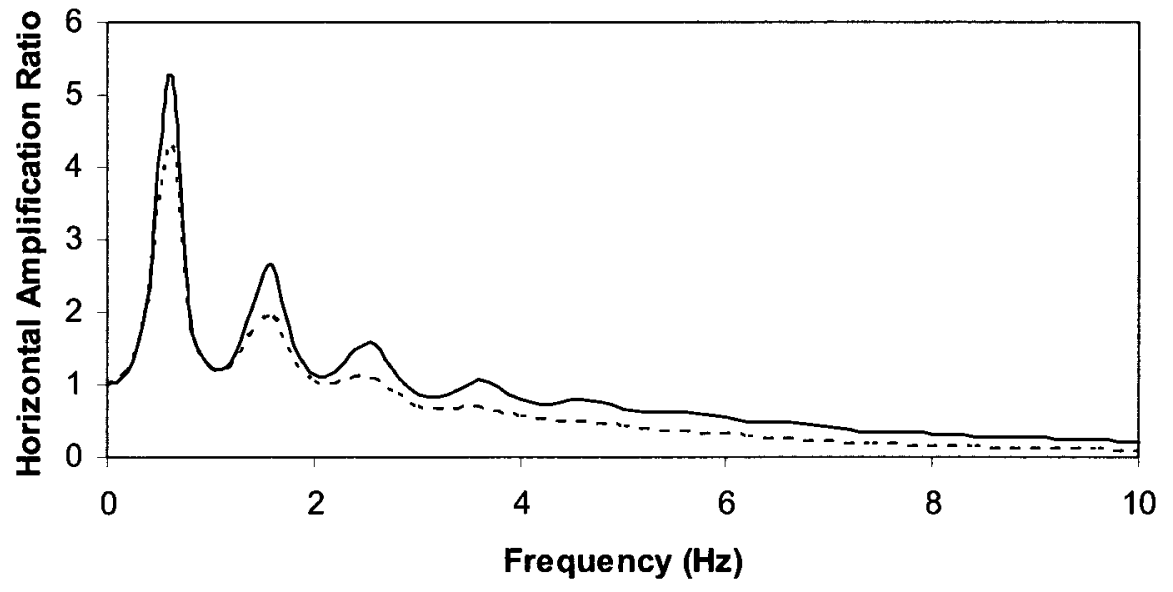

Fig. 3.10: Horizontal amplification ratios for the Barrington Park site using dampingmodified generalized $R / T$ method for the vertical incidence of the SV wave. Solid line and dashed line illustrate the amplifications for the damping ratios compatible with PGAs of $0.2 \mathrm{~g}$ and $0.4 \mathrm{~g}$ respectively.

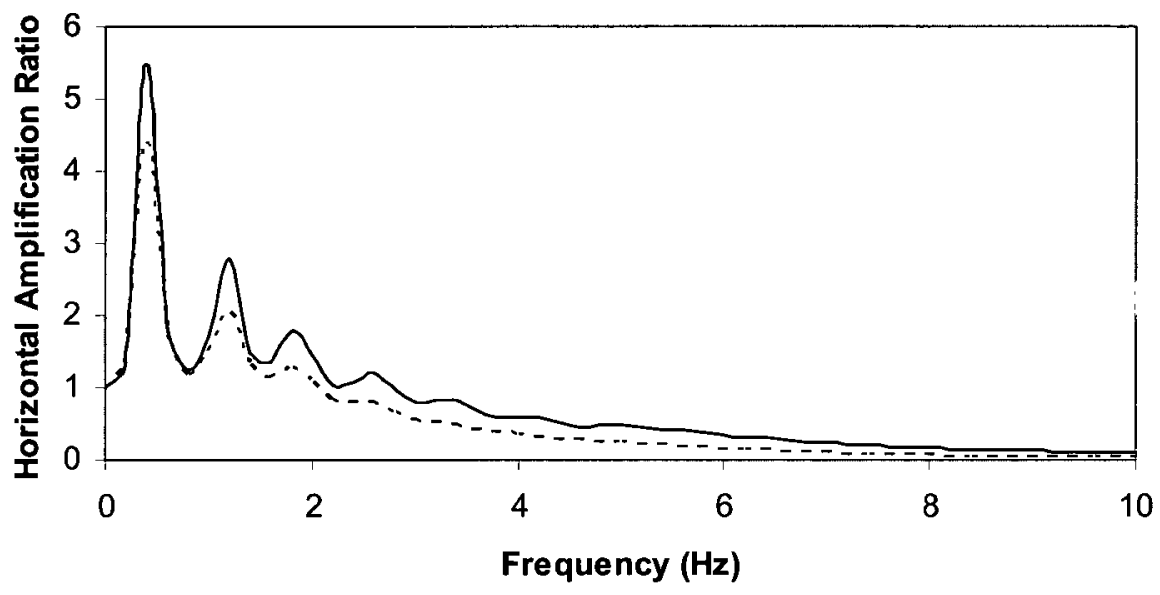

Fig. 3.11: Horizontal amplification ratios for the Chapel Hill site using dampingmodified generalized $R / T$ method for the vertical incidence of the $S V$ wave. Solid line and dashed line illustrate the amplifications for the damping ratios compatible with PGAs of $0.2 \mathrm{~g}$ and $0.4 \mathrm{~g}$ respectively. 


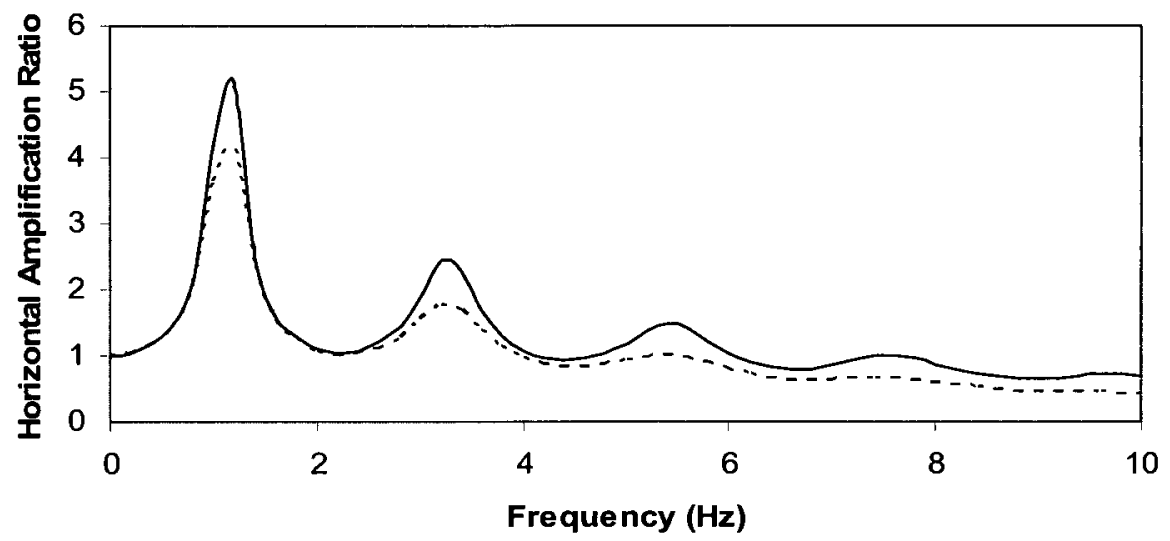

Fig. 3.12: Horizontal amplification ratios for the Longleaf Park site using dampingmodified generalized $R / T$ method for the vertical incidence of the $S V$ wave. Solid line and dashed line illustrate the amplifications for the damping ratios compatible with PGAs of $0.2 \mathrm{~g}$ and $0.4 \mathrm{~g}$ respectively.

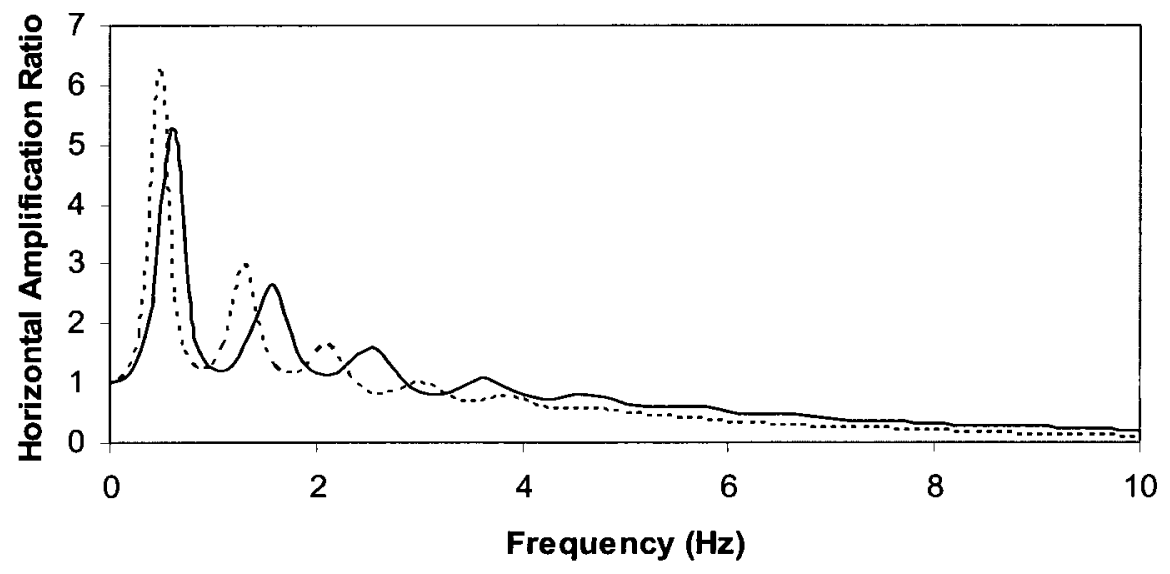

Fig. 3.13: Amplification curves for the Barrington Park site: Comparison of damping modified generalized $R / T$ method (solid line) with the equivalent linear method (dashed line). In the $R / T$ method, the vertical incidence of the $S V$ wave and the damping ratio compatible with a PGA of $0.2 \mathrm{~g}$ are considered. In the equivalent linear method, the multilayer model is subjected to a simulated strong motion for eastern Canada with a $P G A$ of $0.2 g$. 


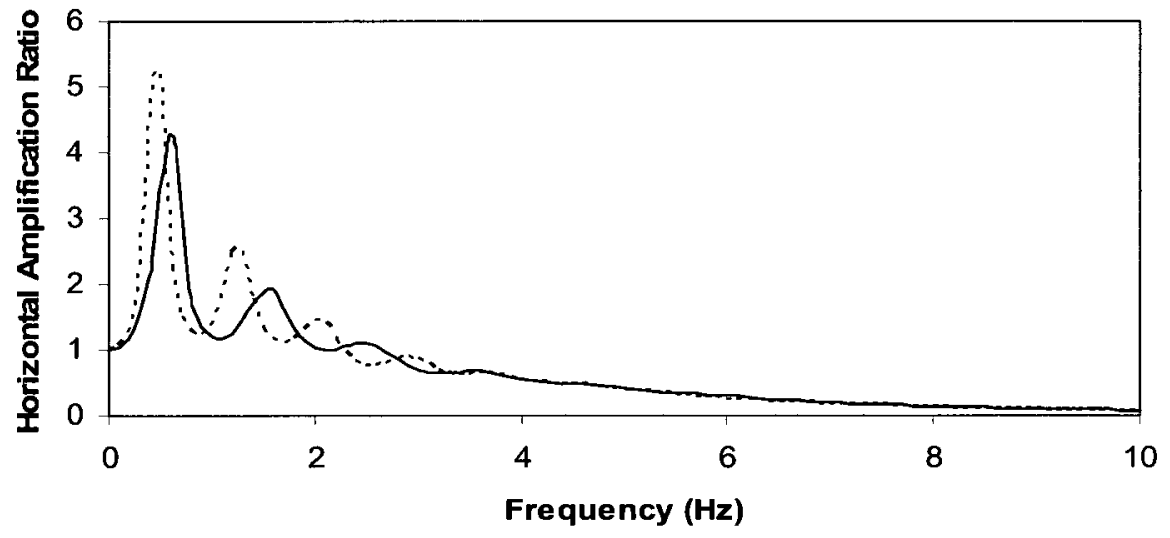

Fig. 3.14: Amplification curves for the Barrington Park site: Comparison of damping modified generalized $R / T$ method (solid line) with the equivalent linear method (dashed line). In the $R / T$ method vertical, the incidence of the $S V$ wave and the damping ratio compatible with a PGA of $0.4 \mathrm{~g}$ are considered. In the equivalent linear method, the multilayer model is subjected to a simulated strong motion for eastern Canada with a $P G A$ of $0.4 g$.

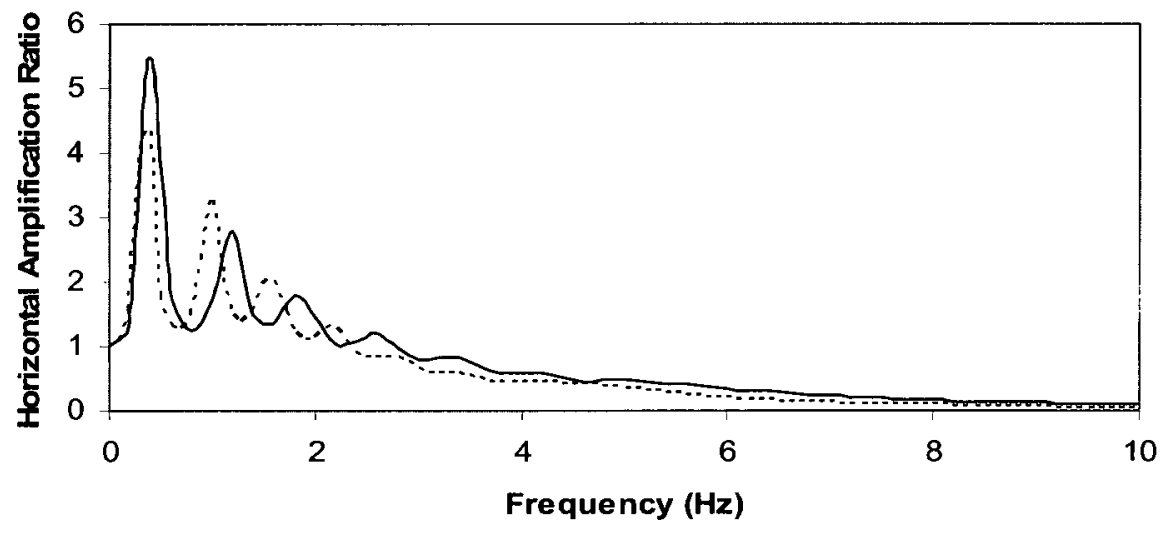

Fig. 3.15: Amplification curves for the Chapel Hill site: Comparison of damping modified generalized $R / T$ method (solid line) with the equivalent linear method (dashed line). In the $R / T$ method, the vertical incidence of the $S V$ wave and the damping ratio compatible with a PGA of $0.2 \mathrm{~g}$ are considered. In the equivalent linear method, the multilayer model is subjected to a simulated strong motion for eastern Canada with a $P G A$ of $0.2 \mathrm{~g}$. 


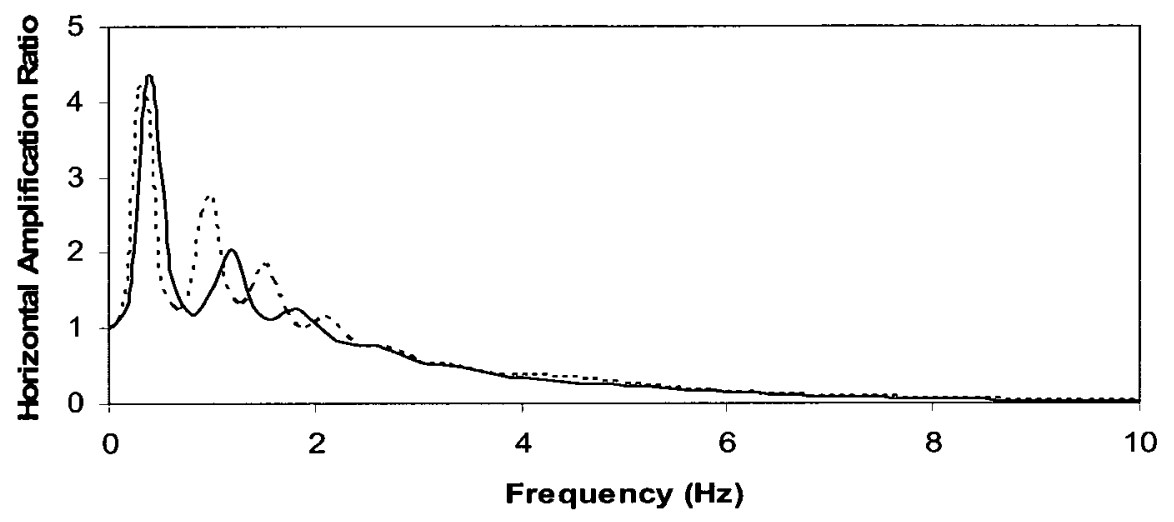

Fig. 3.16: Amplification curves for the Chapel Hill site: Comparison of damping modified generalized R/T method (solid line) with the equivalent linear method (dashed line). In the $R / T$ method, the vertical incidence of the $S V$ wave and the damping ratio compatible with a PGA of $0.4 \mathrm{~g}$ are considered. In the equivalent linear method, the multilayer model is subjected to a simulated strong motion for eastern Canada with a $P G A$ of $0.4 g$.

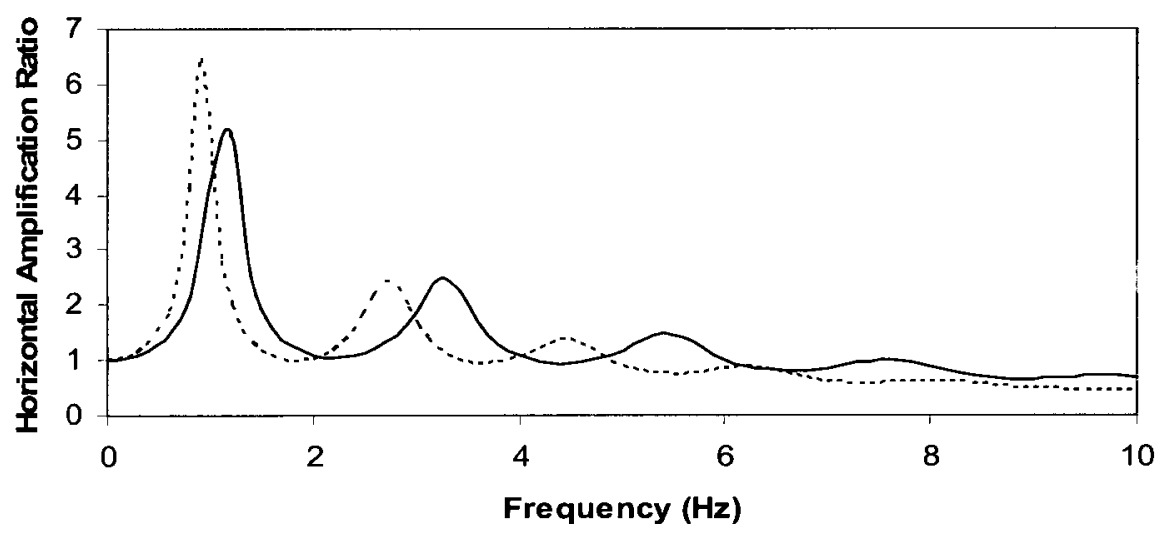

Fig. 3.17: Amplification curves for the Longleaf Park site: Comparison of damping modified generalized $R / T$ method (solid line) with the equivalent linear method (dashed line). In the $R / T$ method, the vertical incidence of the $S V$ wave and the damping ratio compatible with a PGA of $0.2 \mathrm{~g}$ are considered. In the equivalent linear method, the multilayer model is subjected to a simulated strong motion for eastern Canada with a

$$
P G A \text { of } 0.2 g \text {. }
$$




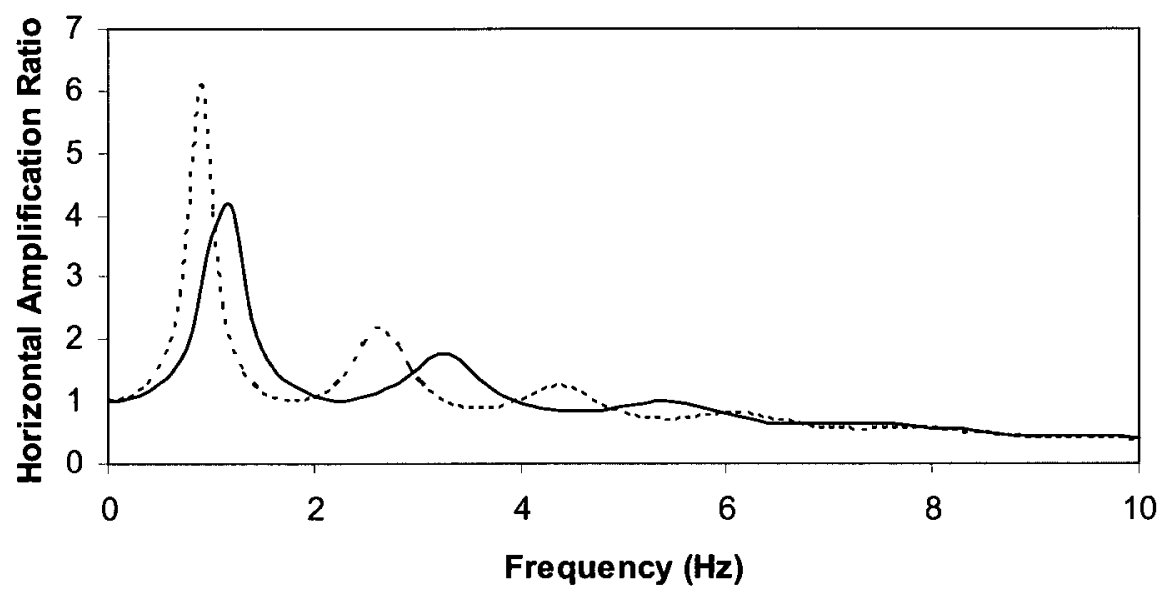

Fig. 3.18: Amplification curves for the Longleaf Park site: Comparison of damping modified generalized $R / T$ method (solid line) with the equivalent linear method (dashed line). In the $R / T$ method vertical, the incidence of the $S V$ wave and the damping ratio compatible with a PGA of $0.4 \mathrm{~g}$ are considered. In the equivalent linear method, the multilayer model is subjected to a simulated strong motion for eastern Canada with a $P G A$ of $0.4 g$.

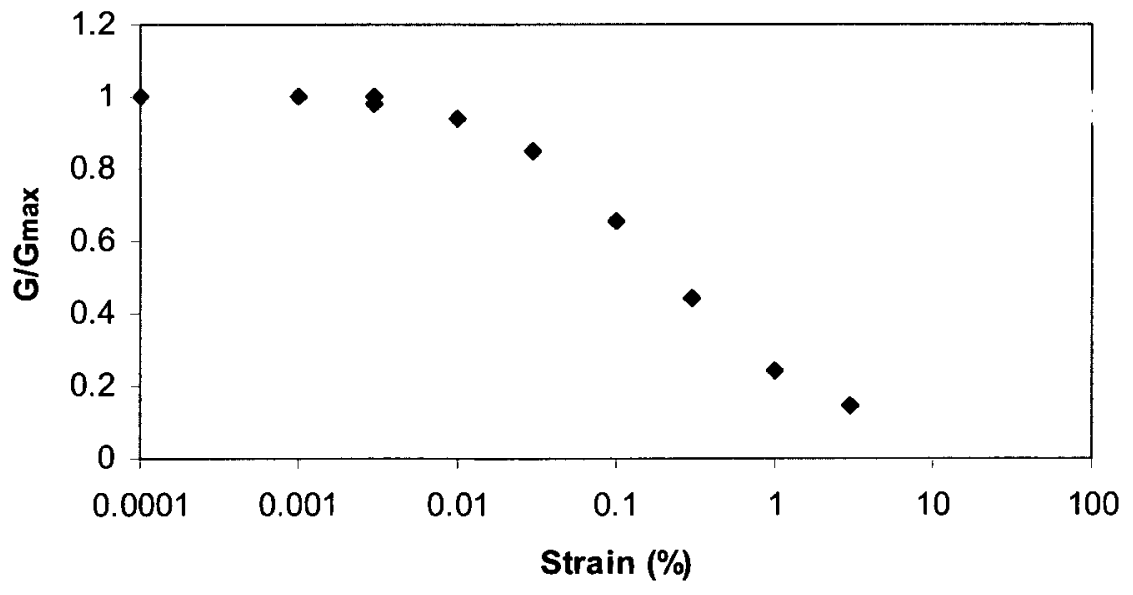

Fig. 3.19: Strain-dependent shear modulus reduction curve for clays (Sun et al., 1988). 


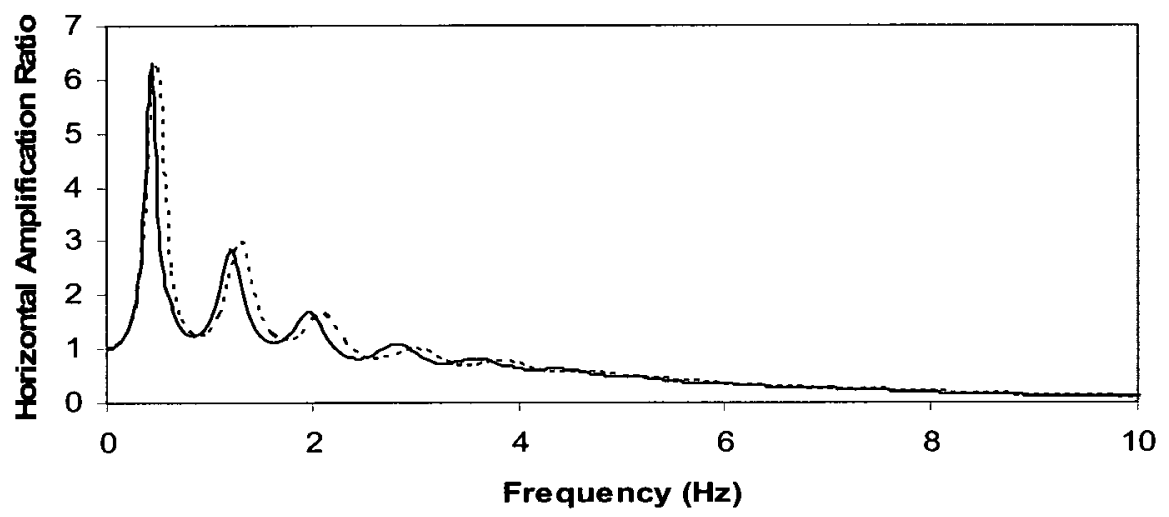

Fig. 3.20: Amplification curves for the Barrington Park site: Comparison of dampingmodulus modified generalized $R / T$ method (solid line) with the equivalent linear method (dashed line). In the R/T method, the vertical incidence of the $S V$ wave and the damping ratio compatible with a PGA of $0.2 \mathrm{~g}$ are considered. In the equivalent linear method, the multilayer model is subjected to a simulated strong motion for eastern Canada with a $P G A$ of $0.2 g$.

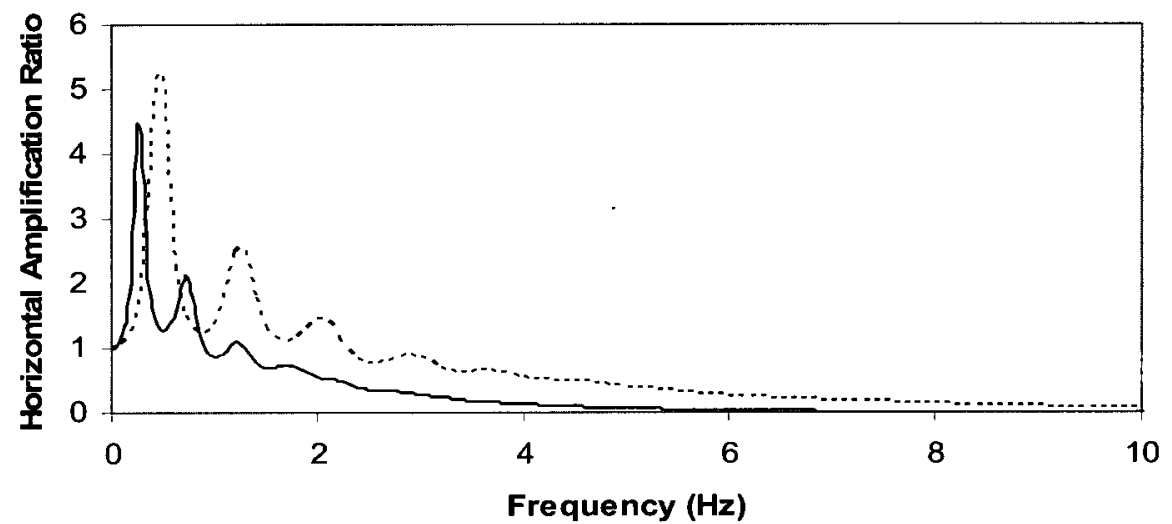

Fig. 3.21: Amplification curves for the Barrington Park site: Comparison of dampingmodulus modified generalized $R / T$ method (solid line) with the equivalent linear method (dashed line). In the R/T method vertical, the incidence of the $S V$ wave and the damping ratio compatible with a PGA of $0.4 \mathrm{~g}$ are considered. In the equivalent linear method, the multilayer model is subjected to a simulated strong motion for eastern Canada with a $P G A$ of $0.4 g$. 


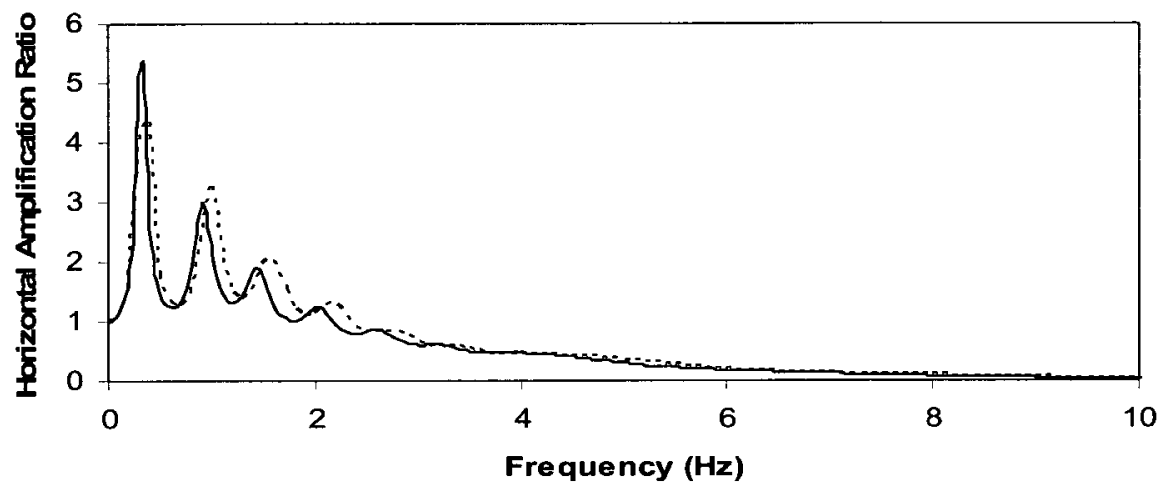

Fig. 3.22: Amplification curves for the Chapel Hill site: Comparison of dampingmodulus modified generalized $R / T$ method (solid line) with the equivalent linear method (dashed line). In the $R / T$ method, the vertical incidence of the $S V$ wave and the damping ratio compatible with a PGA of $0.2 \mathrm{~g}$ are considered. In the equivalent linear method, the multilayer model is subjected to a simulated strong motion for eastern Canada with a $P G A$ of $0.2 g$.

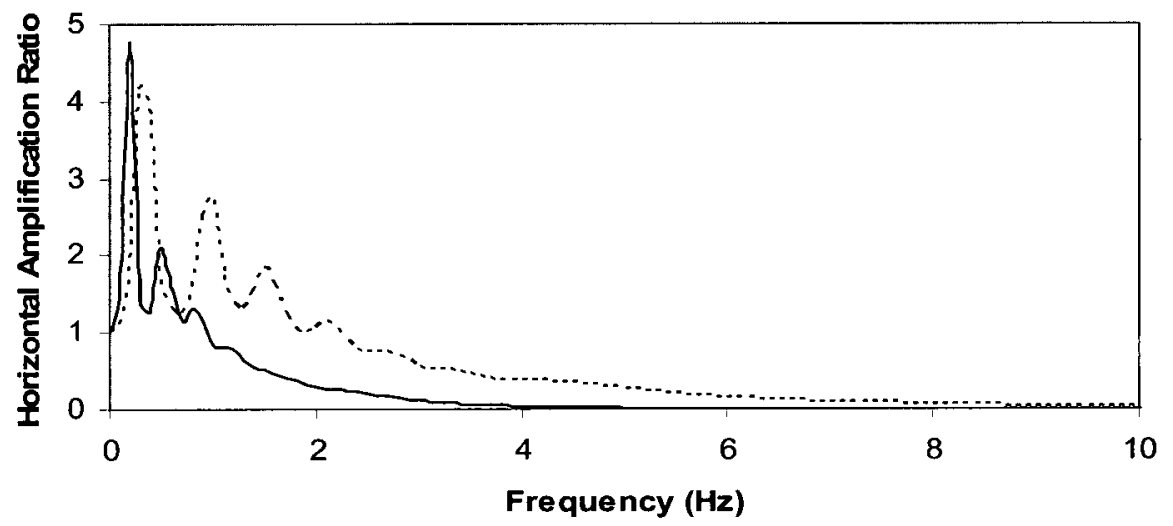

Fig. 3.23: Amplification curves for the Chapel Hill site: Comparison of dampingmodulus modified generalized $R / T$ method (solid line) with the equivalent linear method (dashed line). In the $R / T$ method, the vertical incidence of the $S V$ wave and the damping ratio compatible with a PGA of $0.4 \mathrm{~g}$ are considered. In the equivalent linear method, the multilayer model is subjected to a simulated strong motion for eastern Canada with a PGA of $0.4 \mathrm{~g}$. 


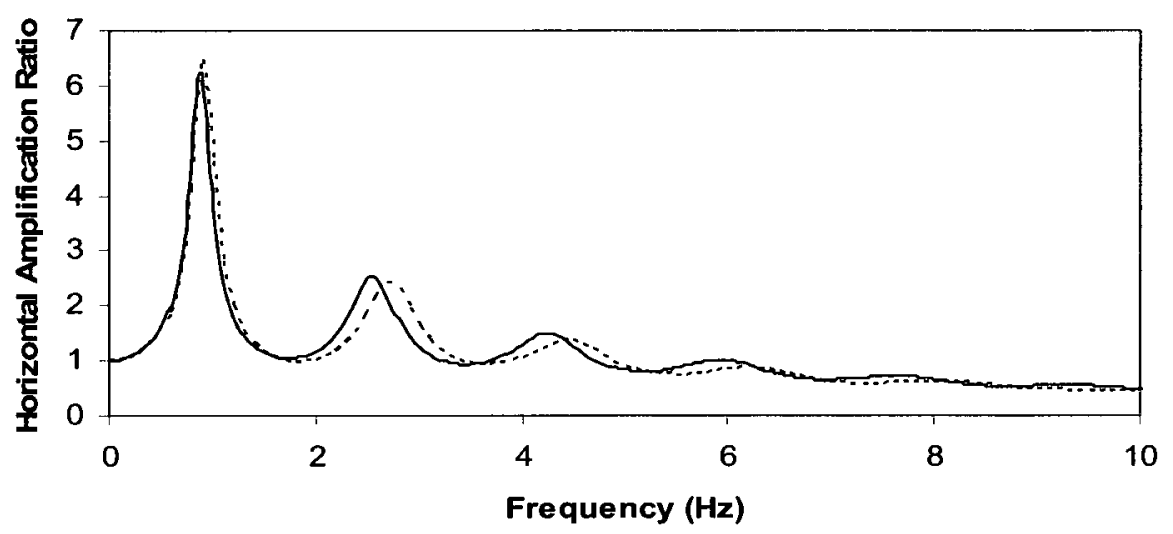

Fig. 3.24: Amplification curves for the Longleaf Park site: Comparison of dampingmodulus modified generalized $R / T$ method (solid line) with the equivalent linear method (dashed line). In the $R / T$ method, the vertical incidence of the $S V$ wave and the damping ratio compatible with a PGA of $0.2 \mathrm{~g}$ are considered. In the equivalent linear method, the multilayer model is subjected to a simulated strong motion for eastern Canada with a $P G A$ of $0.2 \mathrm{~g}$.

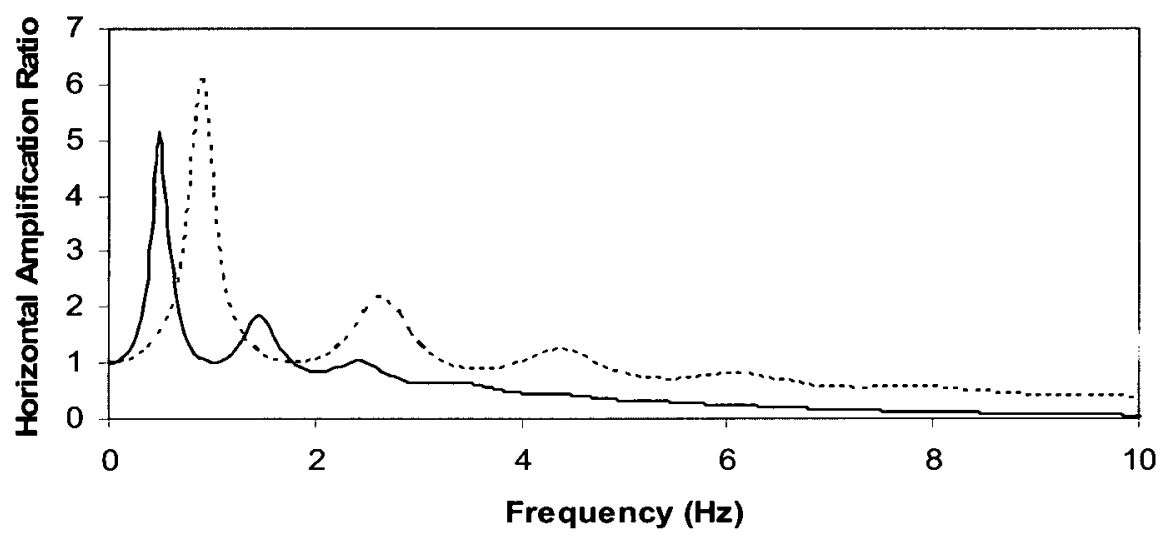

Fig. 3.25: Amplification curves for the Longleaf Park site: Comparison of dampingmodulus modified generalized $R / T$ method (solid line) with the equivalent linear method (dashed line). In the R/T method vertical, the incidence of the SV wave and the damping ratio compatible with a PGA of $0.4 \mathrm{~g}$ are considered. In the equivalent linear method, the multilayer model is subjected to a simulated strong motion for eastern Canada with a $P G A$ of $0.4 g$. 


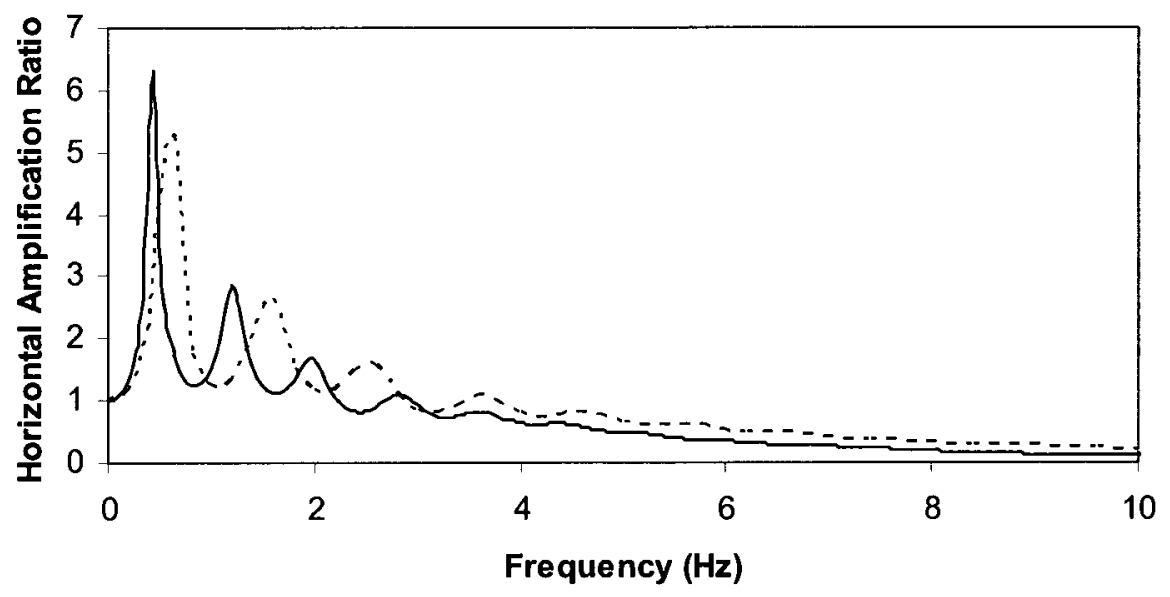

Fig. 3.26: Amplification curves for the Barrington Park site: Comparison of damping modified $R / T$ method (dashed line) with damping-modulus $R / T$ method (solid line) for the target PGA of 0.2g. The Fundamental Frequencies are obtained $0.6 \mathrm{~Hz}$ and $0.45 \mathrm{~Hz}$ from the damping modified and damping-modulus modified methods respectively.

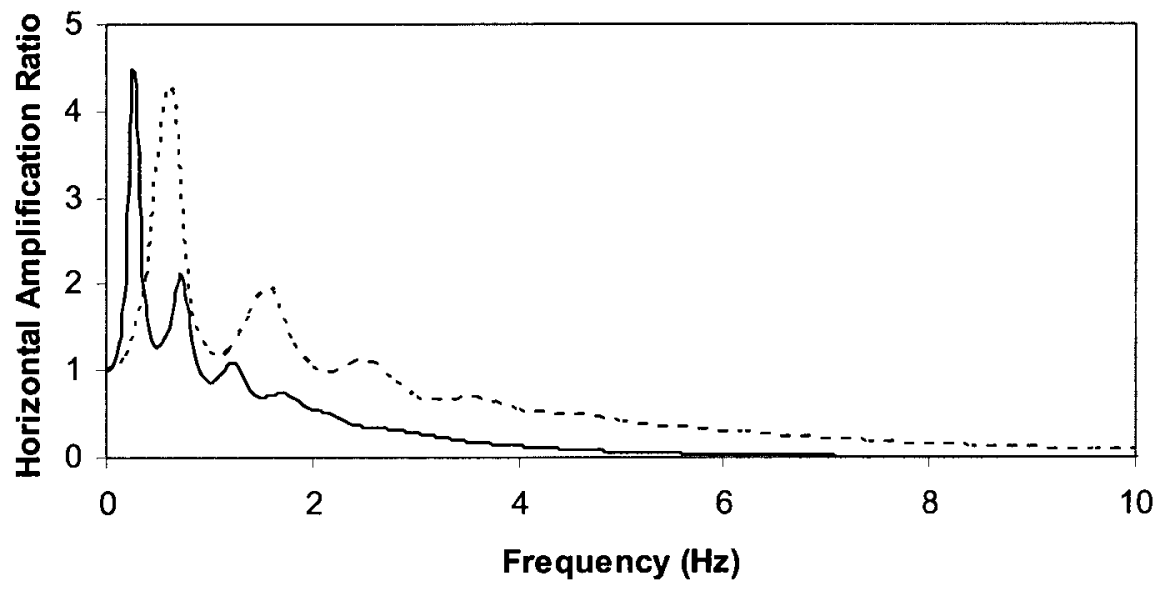

Fig. 3.27: Amplification curves for the Barrington Park site: Comparison of damping modified $R / T$ method (dashed line) with damping-modulus $R / T$ method (solid line) for the target PGA of $0.4 \mathrm{~g}$. The Fundamental Frequencies are obtained $0.6 \mathrm{~Hz}$ and $0.3 \mathrm{~Hz}$ from the damping modified and damping-modulus modified methods respectively. 


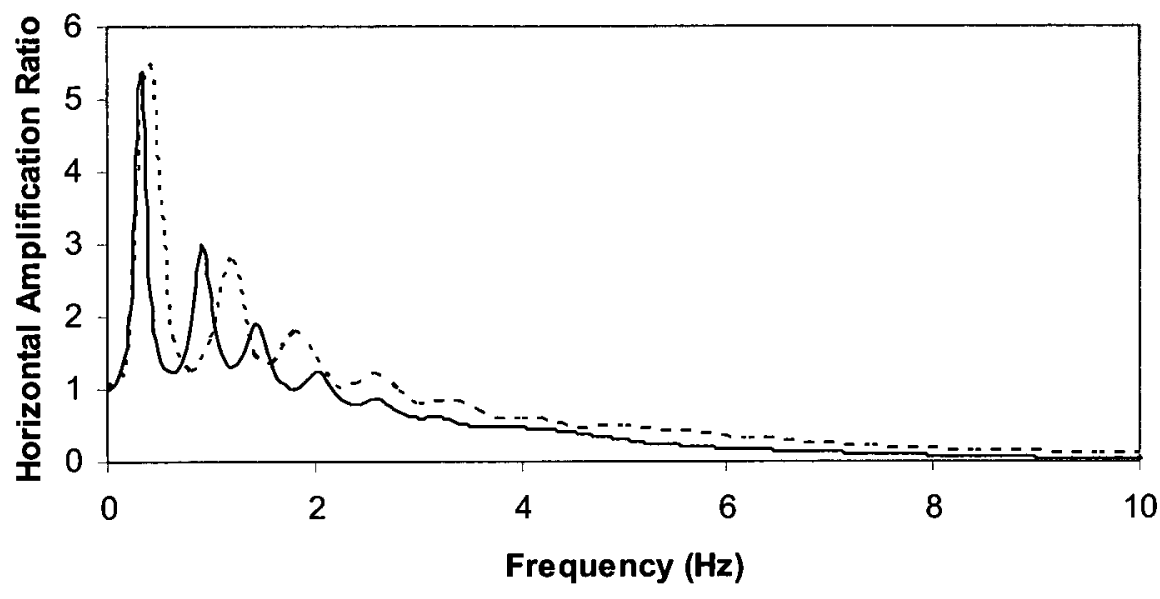

Fig. 3.28: Amplification curves for the Chapel Hill site: Comparison of damping modified $R / T$ method (dashed line) with damping-modulus $R / T$ method (solid line) for the target PGA of $0.2 \mathrm{~g}$. The Fundamental Frequencies are obtained $0.4 \mathrm{~Hz}$ and $0.35 \mathrm{~Hz}$ from the damping modified and damping-modulus modified methods respectively.

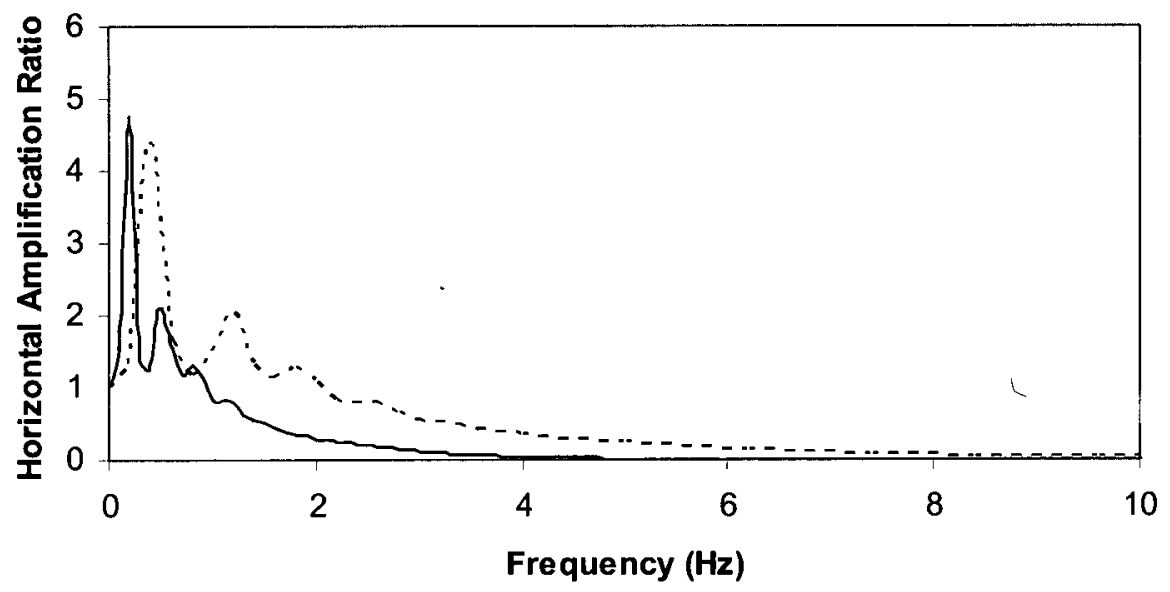

Fig. 3.29: Amplification curves for the Chapel Hill site: Comparison of damping modified $R / T$ method (dashed line) with damping-modulus $R / T$ method (solid line) for the target PGA of 0.4g. The Fundamental Frequencies are obtained $0.4 \mathrm{~Hz}$ and $0.25 \mathrm{~Hz}$ from the damping modified and damping-modulus modified methods respectively. 


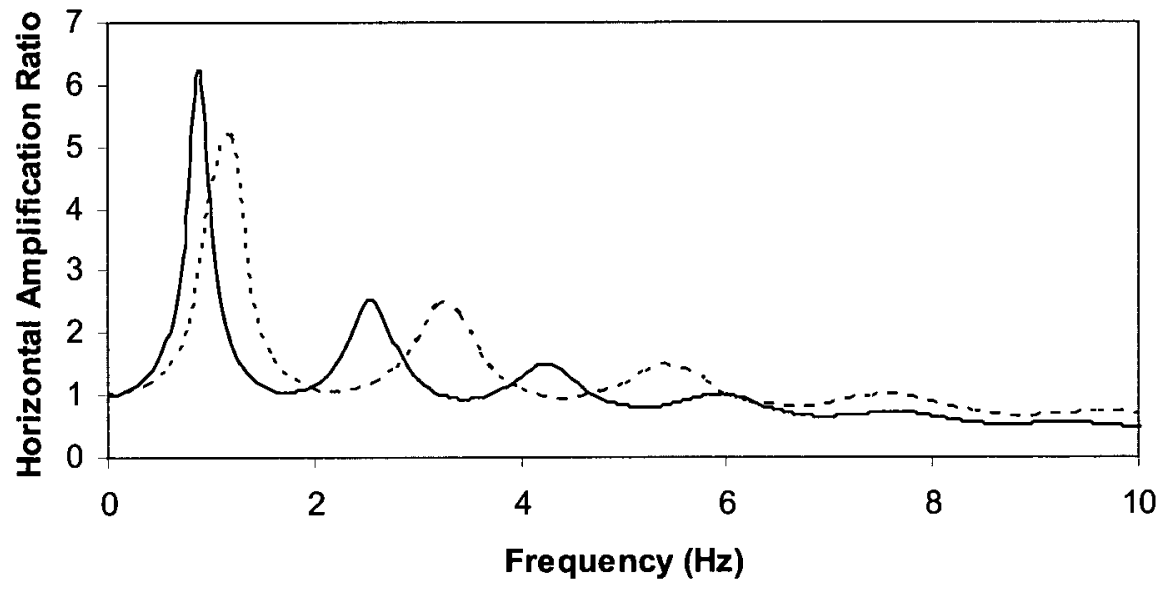

Fig. 3.30: Amplification curves for the Longleaf Park site: Comparison of damping modified $R / T$ method (dashed line) with damping-modulus $R / T$ method (solid line) for the target PGA of $0.2 \mathrm{~g}$. The Fundamental Frequencies are obtained $1.2 \mathrm{~Hz}$ and $0.9 \mathrm{~Hz}$ from the damping modified and damping-modulus modified methods respectively.

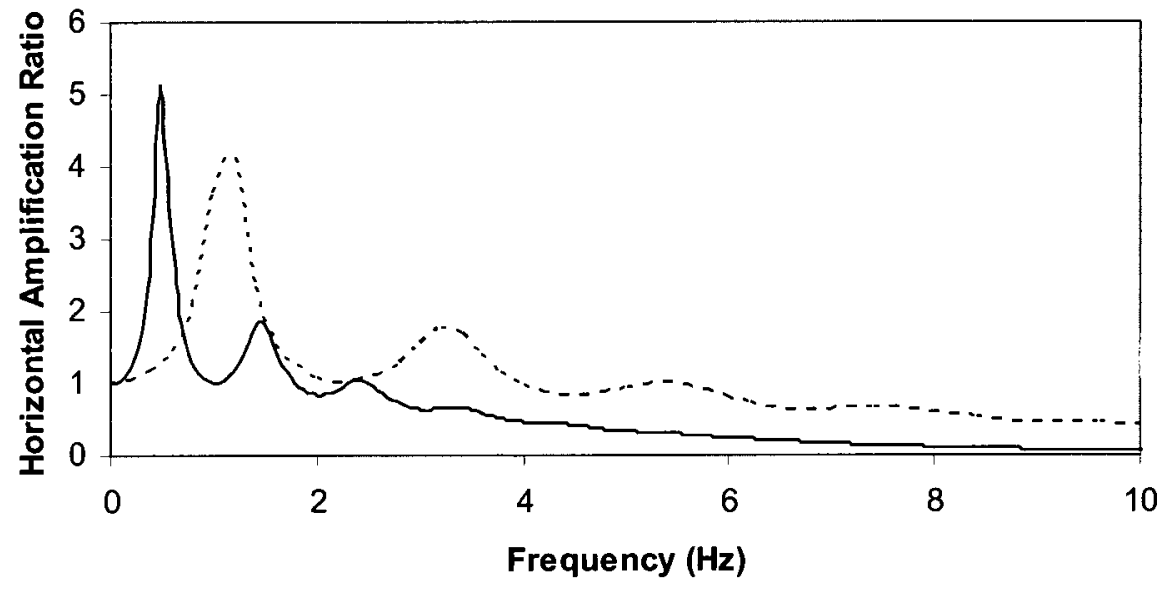

Fig. 3.31: Amplification curves for the Longleaf Park site: Comparison of damping modified $R / T$ method (dashed line) with damping-modulus $R / T$ method (solid line) for the target PGA of 0.4g. The Fundamental Frequencies are obtained $1.2 \mathrm{~Hz}$ and $0.6 \mathrm{~Hz}$ from the damping modified and damping-modulus modified methods respectively. 
Table 3.1: Physical model parameters of the Barrington Park site located in east Ottawa.

\begin{tabular}{|l|l|l|l|l|}
\hline Physical Parameter & Layer 1 & Layer 2 & Layer 3 & Half-space (Bedrock) \\
\hline S-wave velocity (m/sec) & 123 & 142 & 177 & 2700 \\
\hline P-wave velocity (m/sec) & 1230 & 1420 & 1770 & 5620 \\
\hline Thickness (m) & 23 & 23 & 24 & Not Applicable \\
\hline Unit weight $\left(\mathrm{gr} / \mathrm{cm}^{3}\right)$ & 2 & 2 & 2 & 2.5 \\
\hline
\end{tabular}

Table 3.2: Physical model parameters of the Chapel Hill site located in east Ottawa.

\begin{tabular}{|l|l|l|l|l|}
\hline Physical Parameter & Layer 1 & Layer 2 & Layer 3 & Half-space (Bedrock) \\
\hline S-wave velocity (m/sec) & 131 & 160 & 228 & 2700 \\
\hline P-wave velocity (m/sec) & 1310 & 1660 & 2280 & 5620 \\
\hline Thickness (m) & 29 & 50 & 30 & Not Applicable \\
\hline Unit weight $\left(\mathrm{gr} / \mathrm{cm}^{3}\right)$ & 2 & 2 & 2 & 2.5 \\
\hline
\end{tabular}

Table 3.3: Physical model parameters of the Longleaf Park site located in east Ottawa.

\begin{tabular}{|l|l|l|l|l|}
\hline Physical Parameter & Layer 1 & Layer 2 & Layer 3 & Half-space (Bedrock) \\
\hline S-wave velocity $(\mathrm{m} / \mathrm{sec})$ & 124 & 132 & 141 & 2700 \\
\hline P-wave velocity $(\mathrm{m} / \mathrm{sec})$ & 1240 & 1320 & 1410 & 5620 \\
\hline Thickness (m) & 12 & 10 & 8 & Not Applicable \\
\hline Unit weight $\left(\mathrm{gr} / \mathrm{cm}^{3}\right.$ & 2 & 2 & 2 & 2.5 \\
\hline
\end{tabular}




\section{Site Response Analysis using Finite Element Method}

\subsection{Introduction}

\subsubsection{Scope of the chapter}

This chapter presents the seismic site response amplification analysis of different soil profiles throughout the city of Ottawa utilizing the finite element method (see section 4.1.4) along with the application of proper boundary conditions between soil and rock (section 4.5). Seismic amplification is defined as the ratio of the ground response in frequency domain to the bedrock motion in frequency domain. This frequency domain definition of amplification is based on either the Fourier spectra or the response spectra of the acceleration time histories. Three main issues have been investigated: i) unusual seismic amplification from weak motion recordings, ii) effect of shaking intensity on seismic soil amplification and influence of soil-bedrock shear wave velocity contrast ratio on seismic soil amplification and iii) finally, developing of seismic soil amplification factors for low, high and fundamental frequencies.

\subsubsection{Analysis database}

For the above-mentioned issues, the following analysis database was used: for the weak motion amplification analysis, two broadband stations of ORHO and ORIO located at the eastern part of the city were chosen. A comprehensive record of shear wave velocity $\left(V_{s}\right)$ was obtained by Carleton University and Geological survey of Canada for 
those sites using different seismic reflection/refraction surveying and borehole data (for details, see section 4.7). The input weak motions were taken from the recordings of the earthquake on Christmas Eve, 2008, Val-des-Bois earthquake, M3.0, (Horizontal components of earthquakes recorded by Geological Survey of Canada). The earthquake occurred about $80 \mathrm{~km} \mathrm{NE}$ of Ottawa.

For the second issue, which is the combined effect of shaking intensity and soilbedrock velocity contrast on the variation of the seismic amplification ratios, three sites (Heritage Park, \#31 and \#41) with depths of 39,60 and $81 \mathrm{~m}$ were chosen. The shear wave velocity information of these sites was provided by Carleton University and Geological Survey of Canada research team for microzonation studies for the city of Ottawa. The details of the profile information of the studied sites are given in section 4.8 . The input time histories (10\% in 50 years records) are artificial time histories provided by Atkinson and Beresnev (1998).

For the third research issue, which is development of soil amplification factors for low, high and fundamental frequency, first, 19 different sites ranging from $1 \mathrm{~m}$ to $112 \mathrm{~m}$ depth were chosen. For 12 of these sites, detailed shear wave velocity equations provided by the Carleton University and GSC research team and for other sites ( 7 of them), a shear wave velocity equation (see Hunter et al., 2010) was used. Details of those profiles are explained in section 4.10. Those sites were subjected to artificial time histories ( $2 \%$ in 50 years records) for Eastern Canada. Second, 17 sites ranging from 1 to $120 \mathrm{~m}$ depth having the average shear wave velocity of soil and bedrock in the area were selected and subjected to the records having similar spectral accelerations used in the 
National Building Code of Canada (NBCC, 2005). More details are explained in section 4.11 .

\subsubsection{Amplification factors in National Building Code of Canada}

The soil amplification factor, called foundation factor $(F)$, is given for different soil categories, different levels of shaking intensity and frequencies by the National Building Code of Canada (NBCC, 2005). In this section, the two main approaches for the development of intensity and frequency-dependent foundation (amplification) factors i) Borcherdt approach $(1992,1994)$ and ii) National Earthquake Hazard Reduction Program (NEHRP, 1994) approach are discussed. The National Building Code of Canada (NBCC, 2005) adopted NEHRP (1994) provisions for site classification in Canada.

The first approach (Borcherdt, 1992 and 1994), which provides continuous foundation factors, is based on the analysis of 35 sites using records of Loma Prieta earthquake, 1989. In that approach time-averaged shear wave velocity in the top 30 meters $\left(\mathrm{Vs}_{30}\right)$ were used as a representative of site condition. $\mathrm{Vs}_{30}$ is defined as below:

$\mathrm{Vs}_{30}=30 /\left(\sum \mathrm{Vs}_{\mathrm{i}} \mathrm{h}_{\mathrm{i}}\right)$

where, $\mathrm{Vs}_{\mathrm{i}}$ and $\mathrm{h}_{\mathrm{i}}$ denote the shear wave velocity and the thickness of the $\mathrm{i}^{\text {th }}$ layer down to $30 \mathrm{~m}$ depth. Borcherdt correlated the amplification factors (F) for low and high frequency ranges to $\mathrm{Vs}_{30}$ values. Borcherdt obtained two functional forms for high $(5 \mathrm{~Hz}$ or $0.2 \mathrm{sec})$ and low frequency $(1 \mathrm{~Hz}$ or $1 \mathrm{sec})$ ranges:

$\mathrm{F}_{\mathrm{a}}=\left(1050 / \mathrm{Vs}_{30}\right)^{\mathrm{ma}}$

$\mathrm{F}_{\mathrm{v}}=\left(1050 / \mathrm{Vs}_{30}\right)^{\mathrm{mv}}$

where, $F_{a}$ and $F_{v}$ are the foundation (amplification) factors for high and low frequency ranges, respectively. $m_{a}$ and $m_{v}$ are coefficients obtained from the best fit to the observed 
data. In equations (4-2) and (4-3), 1050 (in $\mathrm{m} / \mathrm{sec}$ ) is the average shear wave velocity for bedrock (Franciscan bedrock in California).

The second approach (NEHRP, 1994) also classifies seismic sites in terms of the average shear wave velocity of top 30 meters, as well as average standard penetration resistance or the soil undrained shear strength. In NEHRP approach, similar to Borcherdt approach, low and short period ranges were defined and, for a specific shaking intensity, the amplification factors (F) were derived using real or mapped input ground motion data from the records of Loma Prieta earthquake.

The Canadian Committee on Earthquake Engineering (CANCEE) adopted NEHRP (1994) provisions for site classification in NBCC (2005). Table (4.1) shows different site classes based on NEHRP and NBCC (2005). $F_{a}$ and $F_{v}$ are also similar to NEHRP (1994) with minor modifications. The modification is that the site class C is the reference site with the amplification factor of 1 in NBCC (2005) while in NEHRP (1994) the reference site is site class B. In NBCC (2005) the foundation factor for short-period $(0.2 \mathrm{sec}$ or $5 \mathrm{~Hz})$ and long-period $(1 \mathrm{sec}$ or $1 \mathrm{~Hz})$ of spectral accelerations (indicated with $\mathrm{S}_{0.2}$ and $\mathrm{S}_{1}$, respectively) are given.

As mentioned in section (4.1.1), the amplification factor is defined based on the Fourier or the response spectra ratio of the ground motion to the bedrock motion. For the sake of consistency, in this chapter, the following symbols will represent the seismic soil amplification factors ( $\mathrm{F}$ factors):

$\left(F_{a}\right)=F$ factor for high frequency $(5 \mathrm{~Hz})$

$\left(F_{v}\right)=F$ factor for low frequency $(1 \mathrm{~Hz})$

$F_{f 0}=F$ factor for Fundamental frequency 
$\left(F_{V}\right)_{\mathrm{FFT}}=\mathrm{F}$ factor for low frequency $(1 \mathrm{~Hz})$ based on Fourier spectra analysis

$\left(F_{V}\right)_{R S}=F$ factor for low frequency $(1 \mathrm{~Hz})$ based on response spectra analysis

$\left(F_{\mathrm{a}}\right)_{\mathrm{FFT}}=\mathrm{F}$ factor for high frequency $(5 \mathrm{~Hz})$ based on Fourier spectra analysis

$\left(F_{a}\right)_{R S}=F$ factor for high frequency $(5 \mathrm{~Hz})$ based on response spectra analysis

\subsubsection{Finite element method (FEM) for site response analysis}

In the finite element method (Reddy, 2004; Bathe, 2003; Hughes et al., 2000; Zienkiewicz and Taylor, 2000 and Bathe and Wilson, 1976), the soil layer is modeled using number of elements connected at their nodes (Figure (4.1) shows the finite element mesh for a soil deposit). The following equation of motion is exploited in this method:

$[\mathrm{M}] \mathrm{u}^{*}+[\mathrm{C}] \mathrm{u}^{\bullet}+[\mathrm{K}] \mathrm{u}=\mathrm{R}$

where $[\mathrm{M}],[\mathrm{C}]$ and $[\mathrm{K}]$ are the total mass, damping and stiffness matrices, respectively, obtained from assembling of the element matrices. $R$ denotes the load vector. $u, u^{*}$ and $u^{*}$ represent the displacement, velocity and the acceleration, respectively. Equation (4-4) can be solved by different methods. For instance, Newmark-beta method expresses the displacement, velocity and the acceleration of two consequent time steps in terms of each other:

$u_{n+1}=u_{n}^{\cdot}+0.5 \Delta t\left(u^{*}{ }_{n}+u^{*}{ }_{n+1}\right)$

$\mathrm{u}_{\mathrm{n}+1}=\mathrm{u}_{\mathrm{n}}+\Delta \mathrm{t} \mathrm{u}_{\mathrm{n}}^{\cdot}+0.5(1-2 \beta) \Delta \mathrm{t}^{2} \mathrm{u}^{*{ }_{\mathrm{n}}}+\beta \Delta \mathrm{t}^{2} \mathrm{u}^{*}{ }_{\mathrm{n}+1}$

$\mathrm{n}$ and $\Delta \mathrm{t}$ denote the number of the time steps and the time interval, respectively. $\beta$ is a constant number that should be set to the values between 0 and 1 . Taking $\beta=0.25$ leads to the solution called the trapezoidal method that yields unconditional stability with no numerical damping for any frequency (Hughes, 1987). 
The analysis conducted herein considers appropriate damping for non-linearity effects in soil response. Section 4.2 gives a general overview on soil non-linearity, and models used for damping and shear modulus/stiffness reductions curves that are discussed in section 4.3. Damping and shear modulus reduction curves, which address soil non-linearity, are important when shaking intensity exceeds a threshold level. In fact, these curves change the damping and shear modulus values based on the developed shear stress level in soil material. The damping model (C) used in equation (4-4) is explained in section 4.4. Appropriate boundary conditions required for the bottom of the finite element model (shown in Figure (4.1)) are described in section 4.5.

\subsection{Non-linear behavior of soil}

Behavior of soils is fairly complex and dependent on several factors including the strain amplitude (Kwok et al., 2008; Hartzell et al., 2004; and Finn, 1991). Beyond certain level of deformation (usually shear strains greater than $10^{-5}$ or $10^{-4}$ ) soil manifests its non-linear effects. Soil behavior has often been assumed linear in the past, and such an approximation would be valid if the strains are fairly small. However, nonlinearity effects might be prominent if the intensity of the seismic loading is sufficient to develop large strains.

The relevance of non-linear soil behavior during seismic loading has been an ambiguous subject for decades (Tsuda et al., 2006; Frankel et al., 2002; Beresnev and Wen, 1996; Wen, 1994; Chin and Aki, 1991; Chang et al., 1989; and Joyner and Chen, 1975). For many years prior to the 90 s, due to the shortage of strong seismic ground motion observations, the soil non-linearity has not been generally considered in soil response during earthquakes. Earthquakes of Michoacan, Mexico (1985) and Loma 
Prieta, California (1989) provided a wide range of strong seismic motion recordings that enabled the assessment of the influence of the non-linearity of soils on the response during an earthquake. Considerable data obtained from those earthquakes was used to study the non-linear soil effects by seismologists and geotechnical engineers.

\subsubsection{Hysteretic model and the subsequent effect on soil mechanical properties}

Many cyclic loading tests, performed on numerous soil samples, proposed a hysteretic stress-strain relationship for unloading-reloading behavior (Chatterjee and Basu, 2008; Bonilla et al., 2005; Hardin and Drnevich, 1972; and Seed and Peacock, 1971). A typical hysteresis loop is shown in Figure (4.2). The hysteretic behavior consists of two main parts: 1- Initial loading curve or backbone curve 2- hysteresis loops. Numerous backbone curves have been proposed using analytical approximations. Those curves express the initial relationship between the shear stress $(\tau)$ and shear strain $(\gamma)$. Detailed models of backbone curves can be found in Erdik (1987) and Finn (1988). The following curve (equation) is widely used as the backbone curve:

$\tau=\mathrm{G}_{\max } \gamma /\left(1+\left(\mathrm{G}_{\max } \gamma\right) / \tau_{\max }\right)$

where $\tau, \tau_{\max }, \mathrm{G}_{\max }$ and $\gamma$ indicate the shear stress, maximum shear stress, maximum shear modulus and the shear strain, respectively.

To establish the reloading-unloading fractions of the hysteresis loop, as the second step of hysteretic behavior, modified Masing's rule (Masing, 1926) is usually utilized. This rule states that unloading and reloading curves can be constructed from backbone curve with the origin shifted to the reversal point at $\left(\gamma_{\text {rev }}, \tau_{\text {rev }}\right)$ and then the backbone curve should be expanded by a factor of 2 along the stress axis. As mentioned, 
$\gamma_{\mathrm{rev}}$ and $\tau_{\mathrm{rev}}$ denote the reversal point of shear strain and the reversal point of the shear stress, respectively. The extended Masing's rule is shown in Figure (4.3).

These stress-strain loops demonstrate the variation of the shear modulus (G) with different strain levels. As shown in Figure (4.2), as shear strains increase both tangent and secant shear modulus decreases. Tangent shear modulus $\left(\mathrm{G}_{\mathrm{tan}}\right)$ is obtained from the slope of the tangent line at any point of the mentioned curves. It is obvious the tangent shear modulus is variable for different points of a cycle and therefore, generally, its average value over an entire loop, called secant shear modulus $\left(G_{\text {sec }}\right)$, is used.

As explained, the shear modulus variation is a significant outcome of soil nonlinearity. This shear modulus (G) is related to the shear wave velocity (V) for small strains by the following equation:

$\mathrm{G}==\rho \mathrm{V}^{2}$

where $\rho$ is the density of the soil material.

In addition, to shear modulus variation, each hysteretic loop imposes the energy loss or damping. In general, material damping is characterized by three mechanisms: i)friction between soil particles, ii) non-linear soil behavior and iii) the strain rate effect. Generally, damping characteristics of engineering materials (soil here) is quantified by the damping ratio. Damping ratio is defined as the ratio of soil damping $(\mathrm{C})$ to the critical damping $\left(\mathrm{C}_{\mathrm{c}}\right)$ value:

$\mathrm{D}=\mathrm{C} / \mathrm{C}_{\mathrm{C}}$

In hysteretic loop, by assuming the equivalent viscous damping, the damping ratio (D) is obtained by the following equation:

$\mathrm{D}=\mathrm{W}_{\mathrm{D}} /\left(4 \pi \mathrm{W}_{\mathrm{S}}\right)$ 
where $W_{D}$ and $W_{S}$ are the dissipated and maximum stored energy in one cycle, respectively.

\subsubsection{Dependency of non-linear soil response on frequency and shaking intensity}

Some researchers (e.g. Tsuda et al., 2005; and Yu et al., 1993) have described the differences between linear and non-linear responses .Yu et al. (1993) used frequency bands to explain these differences. In the low frequency range (less than $3 \mathrm{~Hz}$ ), where the wavelength $(\lambda)$ is long, the soil stratum does not affect the waves considerably. In that range, the linear response is dominant over the non-linear response. In the intermediate range of frequencies $(3 \mathrm{~Hz}$ to $20 \mathrm{~Hz}$ ), the attenuation of seismic motion appears and the soil layers damp the amplitudes of seismic motion. In the high frequency range $(>20$ $\mathrm{Hz}$ ), because of harmonic generation (McCall, 1994), the amplification of non-linear response is dominant over the linear response.

In addition to the dependency of nonlinearity on frequency, it was notified that the strain level has a significant effect on the soil nonlinearity. A threshold shaking intensity (acceleration) is needed to trigger the nonlinearity of soil. Let us consider the following shear strain equation:

$\gamma=\partial \mathbf{u} / \partial \mathbf{z}$

where $\gamma, u$ and $z$ denote strain, the input displacement and the propagation direction, respectively. For a sinusoidal form for $\mathrm{u}$ :

$\mathrm{u}=\mathrm{u}_{0} \sin (2 \pi \mathrm{ft}-\mathrm{kz})$

where $u_{0}, f$ and $k$ (equal to $2 \pi / \lambda$ ) are the displacement amplitude, frequency and the wavenumber, respectively. Expressing $\mathrm{u}_{0}$ in terms of acceleration amplitude $\left(\mathrm{a}_{0}\right)$, we get: $\mathbf{u}_{0}=\mathbf{a}_{0} / \omega^{2}$ 
Combining the equations (4-11), (4-12) and (4-13), we will obtain the maximum shear strain for the expected acceleration level and the specific frequency:

$\operatorname{Max}(\gamma)=a_{0} /(2 \pi f V)$

Knowing the upper dominant frequency (f), velocity (V) and the desired strain level $(\gamma)$, the threshold acceleration $\left(a_{0}\right)$, which is the boundary between weak and strong motion, is calculated. Different threshold accelerations have been introduced in the literature. Beresnev and Wen (1996) consider the accelerations around 100 gal as the boundary between the linear and non-linear response. Lee et al. (2006) stated that, for their case studies in Lotung, Taiwan, non-linearity starts at the acceleration of $0.04 \mathrm{~g}$ (40 gal) and is clearly observed at the acceleration of $0.075 \mathrm{~g} \mathrm{(73} \mathrm{gal).} \mathrm{The} \mathrm{actual} \mathrm{threshold}$ acceleration will depend on the stress-strain properties of the soil deposit subjected to strong shaking.

For the loose sites in Ottawa area, reasonable parameters can be assumed in equation (4-14) to obtain $a_{0}$ for a given shear strain. For example, assuming $\gamma=10^{-4}, f=$ $5 \mathrm{~Hz}$ and $\mathrm{V}=150 \mathrm{~m} / \mathrm{sec}$, equation (4-14) gives the low threshold acceleration of $47 \mathrm{gal}$ $\left(\mathrm{cm} / \mathrm{sec}^{2}\right)$. The majority of sites in Ottawa have a low shear wave velocity (V) and equation (4-14) shows that low values of threshold accelerations are expected in the region. Figure (4.4) demonstrates the threshold acceleration for the soil layers having shear wave velocity of $150 \mathrm{~m} / \mathrm{sec}$ and the developed shear strain of $10^{-4}$.

\subsection{Variable Shear modulus and damping ratio for dynamic analysis}

The estimation of variation of shear modulus (G), and damping ratio (D) of soils is the key issue for a non-linear soil. Many researchers have carried out numerous studies to describe and characterize factors that are significant in the determination of those 
parameters (Stokoe et al., 2004; Darendeli, 2001; Sun et al., 1988; and Seed and Idriss, 1970). These studies show that the most important parameters affecting the shear modulus reduction are the level of shear strain, confining stress and the plasticity index. The less important factors are frequency of loading, over-consolidation ratio, void ratio and the degree of saturation. There is a relatively acceptable consensus in the literature that as confining stress and plasticity index increase, the degradation of shear modulus decreases.

The damping ratio is also changed by the above-mentioned parameters (the level of shear strain, confining stress, plasticity index, soil type, frequency and number of loading cycles). The confining stress increase generally causes an increase in damping. The effect of the plasticity index on the minimum material damping $\left(\mathrm{D}_{\min }\right)$ is different and is dependent on the desired strain level. In low and medium strain levels, plasticity index increase causes the damping increase while the increasing of plasticity index decreases the damping at the high levels of the shear strain (Roblee and Chiou, 2004; Stokoe et al., 2004; Vucetic et al., 1998; and Stokoe et al., 1994).

Routinely, laboratory results of resonant column tests and torsional shear tests are used to obtain and correlate the shear modulus reduction and the damping ratio relationships (Zhang et al., 2005; Hoyos and Macari, 1999; and Hwang, 1997). Shear modulus relationships have been described by hyperbolic models. One of the well-known models was proposed by Stokoe et al. (1999):

$\mathrm{G} / \mathrm{G}_{\max }=\left[1 /\left(1+\left(\gamma / \gamma_{\mathrm{r}}\right)^{\alpha}\right]\right.$

where $\gamma_{\mathrm{r}}$ and $\alpha$ are the reference strain and the curvature parameters, respectively. These parameters are determined based on the best-fit curve to the experimental data of shear 
modulus versus the shear strain. Different approaches have been introduced to model damping. One conventional approach is to correlate the damping ratio (D) to the shear modulus reduction $\left(\mathrm{G} / \mathrm{G}_{\max }\right)$. For example Ishibashi and Zhang (1993) correlated the damping to shear modulus ratio with a polynomial function. Also, Zhang et al. (2005) used the following equation:

$D=f\left(G / G_{\max }\right)+D_{\min }$

$D_{\min }$ in equation (4-16) was determined based on the experimental data using the torsional shear test. Then having (D - $D_{\min }$ ) and using $\mathrm{G} / \mathrm{G}_{\max }$ data, the best-fit curve which associates $\left(D-D_{\min }\right)$ to $\left(G / G_{\max }\right)$ is obtained. In this research, for the site response analysis, I will use the damping and shear modulus reduction data of clayey soil from Seed and Sun (1989). The damping ratio and shear modulus reduction curves are shown in Figures (4.5) and (4.6).

\subsection{Rayleigh damping}

In this section, the appropriate damping (C) needed for the equation of motion, equation (4-4), is discussed. Hysteretic damping can be approximated by the Rayleigh damping. Rayleigh damping includes mass-proportional and stiffness-proportional terms: $[\mathrm{C}]=\alpha[\mathrm{M}]+\beta[\mathrm{K}]$

where $[\mathrm{C}],[\mathrm{M}]$ and $[\mathrm{K}]$ are damping matrix, mass matrix and stiffness matrix, respectively. $\alpha$ and $\beta$ are frequency dependent factors. Hudson expression (Hudson, 1994) can be exploited to obtain these values. By using this expression, $\alpha$ and $\beta$ can be determined in such a way that the finite element model can respond to the dominant frequencies of the site and that of the input motion. $\alpha$ and $\beta$ are given by the following equations: 
$\alpha=2 \eta\left(\omega_{1} \omega_{2}\right) /\left(\omega_{1}+\omega_{2}\right)$

$\beta=2 \eta /\left(\omega_{1}+\omega_{2}\right)$

where $\eta$ and $\omega_{1}$ denote the estimated material damping ratio and the fundamental frequency of the site.

Furthermore: $\omega_{2}=\mathrm{n} \omega_{1}$

where $\mathrm{n}$ is the closest odd integer which is greater than $\omega_{\mathrm{i}} / \omega_{1}$ if $\omega_{\mathrm{i}}$ is considered the dominant frequency of the input motion. $\alpha$ and $\beta$ values obtained according to the explained procedure results in under-damping between $\omega_{1}$ and $\omega_{2}$ which in turn allows the model to respond to the dominant frequency of the input motion without experiencing a significant over-damping. After choosing the coefficients $\alpha$ and $\beta$, the frequencydependent damping curve can be established from subsequent equation (Bathe and Wilson, 1976):

$\xi_{\mathrm{i}}=0.5\left(\alpha / \omega_{\mathrm{i}}+\beta \omega_{\mathrm{i}}\right)$

Based on the coefficients $\alpha$ and $\beta$, damping ratio $\left(\xi_{\mathrm{i}}\right)$, which is $\mathrm{C} / \mathrm{C}_{\mathrm{r}}$, is determined for the corresponding angular frequency $\left(\omega_{\mathrm{i}}\right)$.

\subsection{Infinite Medium Modeling}

Boundary conditions needed for the bottom of the finite element model (Figure (4.1)) are investigated in this section. Those boundary conditions should be capable of modeling the infinite medium, which is the underlying hard bedrock. The goal of that boundary condition implementation is to achieve a perfect wave absorber. In other words, the impinging elastic waves (from the bedrock) should be absorbed quite perfectly into the finite medium (soil deposit). These boundary conditions prevent the leakage of energy through the boundaries of the finite element model. 
The boundaries at the edges of a discrete model (such as a FEM model) can be classified in three major categories: 1) elementary or fixed (non-transmitting) boundaries, 2) local (imperfect transmitting) boundaries, and 3) consistent (non-local, perfect transmitting) boundaries. Kausel and Tassoulas (1981) studied the performance of these boundaries for the problem of time-harmonic anti-plane line load on a stratum and arrived at the following three conclusions:

(i) The elementary boundaries cause strong reflections of the waves and may not be appropriate when deep strata and radiation problem are taken into account. (ii) Local boundaries have fairly good wave absorption characteristics but might fail for the case of deep deposits at low frequencies. (iii) Consistent boundaries are perfect energy absorbers but can only be used in the frequency domain formulation.

For our finite element model, a finite dynamic model that can approximate the underlying and/or surrounding infinite medium should be introduced. The idea is to propose a model, which has the maximum absorption of the wave energy at boundaries between the finite model (layered soil deposit) and the underlying infinite medium. Here, among several alternatives introduced above, viscous boundaries (as simple local boundaries) developed by Lysmer and Kuhlemeyer (1969) are used. Lysmer and Kuhlemeyer investigated the different boundary conditions at the interface between finite and infinite media and used the following stress equations at the boundary of the halfspace (infinite medium) and the finite medium:

$\sigma=\mathbf{a} \rho V_{p} w^{\prime}$

$\tau=b \rho V_{s} u^{*}$ 
where $\sigma, \tau, \mathrm{w}^{*}$ and $\mathrm{u}^{*}$ are the normal stress, shear stress, normal velocity and tangential velocity, respectively. $V_{p}, V_{s}$ and $\rho$ denote the $p$-wave velocity, s-wave velocity and the mass density respectively. $\mathrm{a}$ and $\mathrm{b}$ are constants. By considering those stress boundary conditions for the seismic incident waves on the boundaries and maximizing the ratio of the reflected wave energy to the incident energy, we obtain:

$a=b=1$

These values of $a$ and $b$ give the maximum (perfect) absorption of waves and therefore the standard viscous boundary is defined as below:

$\sigma=\rho V_{p} w$

$\tau=\rho V_{s} u^{*}$

The Lysmer-Kuhlemeyer boundary is a perfect absorber for seismic waves impinging normally (vertically) on the boundary. It can be shown that nearly perfect absorption is achieved for the angles of incidence greater than $30^{\circ}$. Equation (4-23) shows that some dashpots (dampers) should be implemented at the boundaries. To convert the stress values (equation (4-23)) to force values, the stress values should be multiplied by L, tributary width of the node in finite element model. Therefore, dashpots with coefficients of $\rho L V_{p}$ and $\rho L V_{s}$ can be implemented at the underneath boundary of the finite element model.

\subsection{Numerical seismic amplification simulation for the city of Ottawa;}

\section{Concerns}

Site amplification is a concern in geotechnical practices in the Ottawa area as about $65 \%$ of Ottawa is located on loose post-glacial sediments with very low shear wave 
velocities. In addition, those soft soil deposits overly a firm bedrock with very high shear wave velocity. The main geological units of concern consist of a very loose post-glacial soil (Vs $<150 \mathrm{~m} / \mathrm{sec}$ ) and very firm bedrock (Vs $>2300 \mathrm{~m} / \mathrm{sec})$. This large shear wave velocity contrast exhibits the high potential of the soil profiles to trap the incident seismic waves. This wave-trapping potential can be clearly confirmed if the reflected and transmitted energy coefficients are considered (Reynolds, 1997):

$\mathrm{E}_{\mathrm{R}}=\left(\mathrm{Z}_{2}-\mathrm{Z}_{1}\right)^{2} /\left(\mathrm{Z}_{1}+\mathrm{Z}_{2}\right)^{2}$

$E_{T}=\left(4 Z_{1} Z_{2}\right) /\left(Z_{1}+Z_{2}\right)^{2}$

where $E_{R}$ and $E_{T}$ denote the reflected and transmitted energy coefficients, respectively. $Z_{1}$ and $\mathrm{Z}_{2}$ stand for the acoustic impedance of the soil and the underlying bedrock, respectively. As noted earlier, acoustic impedance or contrast $(Z)$ is defined by the following formula:

$\mathrm{Z}=\rho \mathrm{V}$

where $\rho$ and $\mathrm{V}$ are the density and the shear wave velocity of the soil/bedrock layer, respectively. Furthermore, the contrast ratio is shown with $\mathrm{z}$ (lower case).

A rough calculation can verify the aforementioned wave trapping. Let us consider the density of unit weight $\mathrm{kN} / \mathrm{m}^{3}$ and the average shear wav velocity of 150 $\mathrm{m} / \mathrm{sec}$ for the loose soil sediments. Also, the unit weight and the average shear wave velocity of the firm bedrock are taken $2500 \mathrm{kN} / \mathrm{m}^{3}$ and $2700 \mathrm{~m} / \mathrm{sec}$, respectively. Using the equations (4-24) and (4-26), the reflected energy coefficient $\left(E_{R}\right)$ is obtained 0.85 . This coefficient means that the most of the traveled seismic wave $(85 \%$ of the total energy) in the upper layer (soft soil) is reflected and trapped. 
In addition to the surficial geology of the city, sparse earthquake recordings in the Ottawa area show large amplification factors for the recorded weak motions. For instance, for an earthquake near Cochrane, Ontario (Magnitude of 4.2) on Dec. 7, 2006, very large amplification factors were reported near the fundamental frequency $\left(\mathrm{f}_{0}\right)$ of the site (ORHO station). Using the above-mentioned earthquake and the spectral ratio method, the maximum amplification factor was given 143 at $0.78 \mathrm{~Hz}$, while at higher frequencies this factor is more than 20 for the horizontal components (Motazedian et al., 2007). As another example, Pugin et al. (2007) obtained high amplification values for the same site using $\mathrm{H} / \mathrm{V}$ ratio method (Nakamura technique). They achieved the maximum amplification ratio of 75 at fundamental frequency of the site. However, these are weak motion soil amplifications and the soft soil behaves linearly in this range, while we are interested in soil amplification factors for stronger level of motion.

Using the FEM for the site response analysis, the following topics are investigated in the subsequent sections:

1. Seismic amplification simulation for the weak motion recordings

2. Effect of the bedrock to soil contrast ratio or acoustic impedance/contrast ratio (z) on the expected seismic amplification ratios

3. Effect of level of shaking (shaking intensity) on the expected seismic amplification ratios

4. Combined effect of the contrast ratio ( $z$ ) and the intensity of shaking on the expected seismic amplification ratios

5. Developing of seismic amplification models/equations for, low, high and natural frequencies in the Ottawa area. 
It should be noted that the site response analysis using FEM benefits from two advantages. First, using Rayleigh damping formulation, both of the fundamental site frequency and dominant frequency of the input motions are considered and the finite element model can respond to the both of these frequencies. Second, using viscous boundary conditions, the underlying bedrock is modeled and zero/minimum energy leakage is allowed through the boundaries of the model. These advantages are not addressed properly in some of conventional site response methods such as the equivalent linear method.

\subsection{Seismic amplification simulation for the weak motion recordings}

\subsubsection{Target sites}

Considering the unusual soil amplification factors from the recent observations, numerical modeling of deep sites (especially those located in the eastern part of the city) subjected to weak motions is necessary. The two nearby sites (ORHO and ORIO seismic stations shown in Figure (4.7)), one located on thick soil and one on firm bedrock are our reference sites for the weak motion recordings and soil modeling. Such analysis is required to ensure that that amplification factors used in current design practice for strong motion are safe.

Some of local/regional earthquakes, which have been recorded by these two sites, are used for the seismic amplification modeling for the weak motion. As an example, acceleration time histories (horizontal component) of the earthquake on Christmas Eve, 2008 recorded on ORIO station was considered as an input weak motion. The recorded motions on ORIO and ORHO stations are shown in Figures (4.8) and (4.9), 
respectively. The recorded motions on ORIO were chosen as the input motion for the soil modeling of ORHO station for two main reasons: First, ORIO station is located on bedrock and second, this station is adequately close to the target ORHO station $(1.3 \mathrm{~km}$ away from ORHO), compared to the epicentral distance of earthquake which is about 80 km NE of Ottawa.

\subsubsection{Comparison of observed and modeled seismic amplification using weak motion recordings}

The seismic soil modeling for the target site (ORHO station) was carried out for two soil profiles. The first profile, profile \#1, consists of $81 \mathrm{~m}$ of Leda clay (Vs=210 \pm 10 $\mathrm{m} / \mathrm{sec}$ and unit weight $\left.\rho=1700 \mathrm{kN} / \mathrm{m}^{3}\right)$ and the bedrock $(\mathrm{Vs}=2700 \pm 680 \mathrm{~m} / \mathrm{sec}$ and the $\rho$ $=2500 \mathrm{kN} / \mathrm{m}^{3}$ ). In order to investigate the effect of relatively thin glacial till, in the second profile (profile \#2), the glacial till (a 10 meter layer of glacial till with $\mathrm{Vs}=$ $580 \pm 174 \mathrm{~m} / \mathrm{sec}$ and unit weight $=1800 \mathrm{kN} / \mathrm{m}^{3}$ ) was added to the bottom of $81 \mathrm{~m}$ Leda clay profile. All the input parameters of the finite element model are shown in Table (4.2). Comparison between a simulated acceleration time history on ORHO site with the recorded acceleration on ORIO is demonstrated in Figure (4.10).

Figures (4.11) and (4.12) illustrate the seismic soil amplification (ratio of Fourier spectra of the response to that of the input motion) for the above-mentioned weak motion using the finite element method (Program QUAD4M, Hudson et al., 1994) for profiles $\# 1$ and $\# 2$, respectively. The comparisons of these amplification values from observed data and the site response FEM models of the soil profile \#1 and \#2 are shown in Figure (4.13) and (4.14). 
As seen in these Figures, peak values of seismic amplification (at the fundamental frequency) are 83 and 99 for profiles $\# 1$ and \#2 respectively while the spectral ratios of the observed records give the peak amplification ratio of 86 for ORHO site. Therefore, the peak seismic amplification ratios from the FEM modeling and observations are in good agreement.

In addition to the agreement between amplification ratio results, the fundamental frequencies of ORHO site are obtained 0.55 and $0.7 \mathrm{~Hz}$ using the profiles \#1 and \#2 respectively. On the other hand, the observed records give the fundamental frequency of $0.75 \mathrm{~Hz}$ that is close to the fundamental frequency obtained from profile $\# 2$.

\subsection{Effect of the contrast ratio and the shaking intensity on the seismic amplification variation}

\subsubsection{Target sites and input motions}

For this part of research, three sites in the eastern part of the city were chosen. These sites include the Heritage Park site, site \# 31 and site \#41. These sites are demonstrated in Figure (4.15). All the physical parameters of these sites are shown in Table (4.3). These sites were subjected to seven time histories demonstrated in the Figures $(4.16 \mathrm{a}, 4.16 \mathrm{~b}, 4.16 \mathrm{c}, 4.16 \mathrm{~d}, 4.17 \mathrm{a}, 4.17 \mathrm{~b}$ and $4.17 \mathrm{c})$. These acceleration time histories were selected from the artificial time histories that are $10 \%$ in 50 years records (records generated by Atkinson and Beresnev, 1998). Peak ground acceleration (PGA) of these records varies from $23 \mathrm{gal}\left(\mathrm{cm} / \mathrm{sec}^{2}\right)$ to $349 \mathrm{gal}$.

To cover a broad range of bedrock to soil acoustic impedance ratios, in addition to the real $V_{s}$ profiles of the mentioned three sites, three more shear wave velocity 
profiles were generated for each site. The goal was to reach the contrast ratios (z) of 4,8 and 12 using the following equation:

$\mathrm{z}=\left(\rho_{\mathrm{b}} \mathrm{V}_{\mathrm{b}}\right) /\left(\rho_{\mathrm{s}} \mathrm{V}_{\mathrm{s}}\right)$

where $\rho_{b}, V_{b}, \rho_{s}$ and $V_{s}$ denote the bedrock density, bedrock shear wave velocity, soil density and the soil shear wave velocity, respectively. Taking the constant shear wave velocity for the underlying bedrock, $2700 \mathrm{~m} / \mathrm{sec}$, having $\rho_{\mathrm{s}}$ equal to $1700 \mathrm{kN} / \mathrm{m}^{3}$ and $\rho_{\mathrm{b}}$ equal to $2500 \mathrm{kN} / \mathrm{m}^{3}$, shear wave velocity $\left(\mathrm{V}_{\mathrm{s}}\right)$ of the target models were calculated for each contrast ratio, $\mathrm{z}$.

Some of the obtained acceleration time histories on the ground surface are shown in Figures $(4.18 \mathrm{a}, 4.18 \mathrm{~b}, 4.18 \mathrm{c}$ and $4.18 \mathrm{~d})$. Furthermore, the amplification curves for Heritage Park site (obtained from the ratio of Fourier spectra) are demonstrated in Figures (4.19) to (4.25). These amplification curves are separately shown in Appendix A.

\subsubsection{Variation of the seismic amplification ratio with the shaking intensity (level of shaking)}

Many researchers have investigated the effect of shaking intensity on the nonlinear behavior of soils during earthquakes. For instance, Jarpe et al. (1989) studied the seismic amplification of some sites in San Francisco Bay from the weak and strong motion recordings of Loma Prieta earthquake, 1989. Their study on that earthquake and the following aftershocks exhibited a significant reduction of the amplification ratios with the increased level of shaking.

Beresnev et al. (1994) carried out research on the nonlinear behavior of soils during large earthquakes. They analyzed the recorded acceleration data from two strong motion arrays in Taiwan. That study gave significant evidences on the role of shaking 
intensity on seismic soil response that was debated by the seismologists for a long time due to the lack of compelling observed data. In one of the examined data arrays, the events having peak ground acceleration (PGA) less than $30 \mathrm{~cm} / \mathrm{sec}^{2}$ and PGAs greater than $100 \mathrm{~cm} / \mathrm{sec}^{2}$ were attributed to the weak and strong motion data, respectively. In the next array, the events having PGAs less than $13 \mathrm{~cm} / \mathrm{sec}^{2}$ and PGAs greater than 100 $\mathrm{cm} / \mathrm{sec}^{2}$ were categorized in the weak and strong motion ranges, respectively. Then, using the spectral ratio method, soil amplification functions were obtained for the variety of events. The results of Beresnev et al. (1994) showed that the amplification ratios from strong motion lie below those from weak motion recordings for a wide range of frequencies. Furthermore, they demonstrated that when the ground motion amplitude turns into an adequately strong level, the soil amplification potential is drastically diminished or lost.

To quantify the strong motion effect on the amplification ratio, numerous studies have been performed. For example, Beresnev et al. (1998) derived the following equation for the ratio of weak to strong motion amplification $\left(a_{w} / a_{s}\right)$ :

$\mathrm{a}_{\mathrm{w}} / \mathrm{a}_{\mathrm{s}}=\left\{\left(\mathrm{PGA}_{\mathrm{w}}+\mathrm{c}_{5}\right) /\left(\mathrm{PGA}_{\mathrm{s}}+\mathrm{c}_{5}\right)\right\}_{11}^{\mathrm{a}}$

where $\mathrm{PGA}_{w}$ and $\mathrm{PGA}_{\mathrm{s}}$ stand for the PGA on rock for weak and strong motions, respectively. $c_{5}$ and $a_{11}$ are the empirical coefficients.

In the current amplification study of the Ottawa area, the PGA as the shaking intensity indicator is taken into account and its effect on the variation of seismic soil amplification is investigated for a variety of sites in Ottawa area. As mentioned previously, the input motion recordings encompass the seismograms with PGAs ranging 
from $23 \mathrm{~cm} / \mathrm{sec}^{2}$ to $349 \mathrm{~cm} / \mathrm{sec}^{2}$ (23 gal, $41 \mathrm{gal}, 70 \mathrm{gal}, 81 \mathrm{gal}, 147 \mathrm{gal}, 208 \mathrm{gal}$, and 349 gal).

Furthermore, it is important to investigate the effect of shaking intensity on the fundamental site frequency. For a single-layer soil deposit underlain by elastic bedrock, the resonance frequency (fundamental frequency) is defined as below:

$$
\mathrm{f}=\mathrm{V} /(4 \mathrm{H})
$$

where $\mathrm{f}, \mathrm{V}$ and $\mathrm{H}$ represent the fundamental frequency, shear wave velocity and the thickness of the soil layer, respectively. Equation (4-29) was derived by Okamoto (1973) for the case of shear wave propagating vertically through the bedrock. For linear behavior of soil layer (no damping taken into account), Okamoto showed that the vibration of the ground surface $\left(\mathrm{u}_{\mathrm{s}}\right)$ is obtained from the following equation:

$\mathrm{u}_{\mathrm{s}}=2 /\left\{\cos ^{2}\left(\mathrm{H} \omega / \mathrm{V}_{\mathrm{sl}}\right)+\kappa^{2} \sin ^{2}\left(\mathrm{H} \omega / \mathrm{V}_{\mathrm{s} 1}\right)\right\}^{0.5}$

$\kappa=\rho_{1} V_{s 1} / \rho_{2} V_{s 2}$

where $H, \rho_{1}, \rho_{2}, \omega V_{s 1}, V_{s 2}$ and $\kappa$ denote the single-layer thickness, soil density (unit weight), bedrock density (unit weight),angular frequency, soil layer velocity, bedrock velocity, and the acoustic impedance contrast, respectively. The function shown in equation (4-31) will reach its maximum value when:

$\mathrm{H} \omega / \mathrm{V}_{\mathrm{sl}}=\pi / 2 \quad$ or $\quad \mathrm{H}\left(2 \pi \mathrm{f} / \mathrm{V}_{\mathrm{sl}}\right)=\pi / 2$

Therefore, equation (4-32) gives the frequency at which the maximum response occurs as:

$\mathbf{f}=\mathrm{V}_{\mathrm{s} 1} / 4 \mathrm{H}$

It was noted that the increased shear strains leads to the reduction of shear modulus and consequently the reduction of the shear wave velocity. Therefore, the 
fundamental frequency will shift to lower frequencies as larger strains develop. Figures (4.26) to (4.28) illustrate the variation of fundamental site frequencies for different peak ground accelerations. These Figures clearly exhibit the dependency of the fundamental frequency on the shaking intensity. Having a rough divisions for the weak and strong motion based on PGA and considering the records with (PGA $>80$ gal) as the strong motion data, the effect of strong shaking on the frequency shift is clear. Figures (4.26) to (4.28) demonstrate that as the shaking intensity exceeds the PGA of 80 gal, the fundamental frequency shifts to lower frequencies compared to the frequencies obtained from average shear wave velocity of the soil deposit. It is clear that $f_{0}$ remains constant at lower level of shaking while the PGA is less than 80 gal because the soil behaves linearly. The effect of nonlinearity is observed for PGAs more than $80 \mathrm{Gal}$. The following equations of the fundamental site frequency $\left(f_{0}\right)$ are derived for three examined sites for the nonlinear part of the curves shown in Figures (4.26) to (4.28):

$\mathbf{f}_{0}=0.89 \mathrm{PGA}^{-0.04} \quad$ site $\# 31$

$\mathrm{f}_{0}=0.87 \mathrm{PGA}^{-0.03} \quad$ site $\# 41$

$\mathrm{f}_{0}=0.86 \mathrm{PGA}^{-0.08} \quad$ Heritage Park site

In the above equations, $\mathrm{PGA}$ and $\mathrm{f}_{0}$ are expressed in gal and $\mathrm{Hz}$ respectively. Equations (4-33) to (4-35) along with Figures (4.26) to (4.28) show the fundamental frequency shift compared to the fundamental frequency calculated based on the average shear wave velocity, given by Equation (4-29).

\subsubsection{Variation of the seismic amplification ratio with the contrast ratio}

Considering the theoretical basis of seismic amplification, the large shear wave velocity contrast ratio at the boundary between soil and bedrock in Ottawa has a direct 
effect on the amplification Having a single layer for a soil (damped soil on the elastic bedrock), the amplification factor $(\mathrm{F})$ is:

$\mathrm{F}=2 /\left(2 \mathrm{z}^{-1}+\alpha \pi\right)$

where $\alpha$ is the critical damping ratio of the soil layer (Okamoto, 1973; and Finn and Wightman, 2003). Equation (4-36) shows that enhancing the contrast ratio will increase the expected amplification factor. Furthermore, the effect of contrast ratio on the expected seismic amplification can be evaluated using equation (4-24):

$\mathrm{E}_{\mathrm{R}}=\left(\mathrm{Z}_{2}-\mathrm{Z}_{1}\right)^{2} /\left(\mathrm{Z}_{1}+\mathrm{Z}_{2}\right)^{2}$

This equation can be expressed in terms of the contrast ratio $(\mathrm{z})$ :

$\mathrm{E}_{\mathrm{R}}=(\mathrm{z}-1)^{2} /(\mathrm{z}+1)^{2}$

Plugging a range of high contrast ratio values from 15 to 25 (which is the contrast range for most of the available profiles throughout the city) in equation (4-37), the effect of contrast ratio $(z)$ variation on the percentage of the reflected energy $\left(E_{R}\right)$ can be assessed. Figure (4.29) demonstrates this variation for the contrast ratio ranging from 5 to 30 . This Figure shows that for the contrast ratios of 15 to 25 , about $76 \%$ to $85 \%$ of the energy of the propagated seismic wave is reflected and trapped in the upper soil layer, and lead to large ground surface motions. These values imply that the existing soilbedrock profiles in the city of Ottawa are susceptible to have large seismic amplifications during earthquakes. Therefore, due to the importance of this surficial geology, in this study, the contrast ratio is considered as a major parameter and the seismic amplification variation is monitored for a broad range of contrast ratios. The detailed discussion on the numerical analysis of contrast ratio effect on the seismic amplification variation for Ottawa area is presented in section 4.8.4.1. 
As mentioned previously, numerical seismic amplification modeling of target sites in Ottawa area were performed for different scenarios to study the effect of contrast ratio on seismic soil amplification, using input parameters given in Table (4.3). Four different contrast ratios (the real contrast ratio $(\geq 20)$ of the site plus three more contrasts ratios of 4,8 and 12) were applied for each examined site in the area and the resulting shear wave velocity profiles (from equation (4-27)) were used in the seismic response analysis.

Figures (4.30) to (4.32) show the variation of the peak amplification factor $\left(F_{f 0}\right)$ for the pair of contrast ratio (z) and PGA. These Figures demonstrate that there is a partial saturation of amplification factors $\left(\mathrm{F}_{\mathrm{f} 0}\right)$ versus contrast ratio $(\mathrm{z})$. According to these Figures, for the most of PGAs, the $F_{f 0}$ values get saturated when the contrast ratio, $z$, mostly exceeds the value of 12 . As some examples, for each shaking intensity (PGA) ,these peak amplification factors of Heritage Park site are separately illustrated in Appendix $B$ that show the partial saturation of $F_{f 0}$ versus contrast ratio (z).

\subsubsection{Mathematical models for peak amplification ratio $\left(F_{\mathfrak{f}}\right)$ variation}

In this section, mathematical models that can reasonably correlate the peak amplification ratio at the fundamental frequency $\left(\mathrm{F}_{\mathrm{fo}}\right)$ to the variations of the contrast ratio and the peak ground acceleration are sought. Based on aforementioned input parameters, seven input time histories, and four contrast ratios (one real and three contrast ratios of 4, 8 and 12), amplification curves for three sites were obtained which in total give 84 peak amplification values ( 28 amplification values for each site) as shown in Figures (4.30) to (4.32) (Amplification curves are defined as the ratio of Fourier spectra of the ground response acceleration record to that of the input motion). As shown in 
those Figures, it is clear that the lowest peak amplification values $\left(\mathrm{F}_{\mathrm{f} 0}\right)$ correspond to the lower contrast ratios cases $(\mathrm{z} \leq 8)$ subjected to high intensity of shaking (PGA $\geq 208$ gal). In addition, the highest peak amplification ratios occur for the soil profiles having contrast ratios greater than 12 and subjected to the records with low PGA values.

Figures (4.30) to (4.32) show the trends observed in this regard and relationships are sought between (i) the amplification factor and impedance contrast, (ii) the amplification factor and peak ground acceleration, and (iii) the amplification factor and impedance contrast, and peak ground acceleration.

\subsubsection{Accounting for the contrast ratio effect on the peak amplification} variation

Analyses reported above indicate that the variation of amplification ratio $F_{f 0}$ which is fairly small at low impedance contrast values, reaches the peak essentially asymptotically. In reality, the concluded amplification saturation can be justified by the shear strength of the soil deposits. Shear strength of soil puts limitation on the transferred ground motion on the ground surface because the induced shear stresses in soil layers can not be greater than the soil shear capacity. Finn and Wightman (2003) have a similar conclusion on the limitation of the ground surface acceleration resulting from the strong shaking intensities

The nature of the change in amplification ratio in the range of typical impedance contrast can be described by a logarithmic model of the contrast ratio $\left(\log { }_{10}(z)\right)$ fairly closely.

\subsubsection{Accounting for the shaking intensity effect on the peak amplification} variation 
After proposing a logarithmic function for the contrast ratio effect, the effect of second parameter, PGA, on $F_{\mathrm{f} 0}$ variation is studied. It was noted that peak amplification factor tends to decrease as PGA increases. This behavior is obvious in Figures (4.30) to (4.32). To simulate this decreasing effect of increased shaking intensity (PGA) on the $F_{f 0}$ variation, the linear function of ( $a-b$ PGA) is taken into account. $a$ and $b$ are constants. This linear function along with the previously introduced logarithmic function are the bases for the determining of the correlation between the peak amplification ratios and two parameters of $\mathrm{z}$ and PGA.

\subsubsection{Proposed model for combined effect of contrast ratio-shaking intensity on peak amplification variation}

In reality, both PGA and $\mathrm{z}$ would change, and hence a correlation combining the effects of both on amplification would be useful. According to sections (4.8.4.1) and (4.8.4.2) the indicator function of (a-b PGA) $\left(\log _{10}(z)\right)$ is chosen as the representative of the combined effect of PGA and contrast ratio (z) on the variation of peak amplification ratios. Then, using a multivariate least square method, for $\left(\mathrm{F}_{\mathrm{f} 0}, \mathrm{z}\right.$, PGA) data (84 pairs of (z, PGA)) the coefficients of $a$ and $b$ are determined:

$F_{\mathrm{fo}}=(7.812-6.992$ PGA $) \log _{10}(\mathrm{z}) \quad\left(\mathrm{R}^{2}=0.969\right)$

where: $4 \leq \mathrm{z} \leq 36 \quad 23$ gal $\leq \mathrm{PGA} \leq 349$ gal

PGA is expressed in $\mathrm{g}$ (gravitational acceleration). Furthermore, the residual plot is shown in Figure (4.33) .Equation (4-38) can be used to relate the peak $F_{f 0}$ values to the combination of $z$ and PGA values.

\subsubsection{Validation of the proposed models for $F_{\mathrm{f} 0}$ using scaled records}


Input time series of Eastern Canada (Atkinson and Beresnev, 1998) for FEM modeling, which was used in previous sections, have different frequency contents and provide different input motion to the bottom of the soil. In order to avoid the different frequency content of different earthquake, as a simplified approach in this section, just one record is selected (the record with PGA of 23 gal, Figure (4.16a)) and it is scaled in time domain to obtain different PGAs. The results are used to test Logarithmic-linear model in the equation (4-38). As explained, the record with PGA of 23 gal (Figure (4.16a)) was scaled to the PGAs up to $349 \mathrm{gal}$ and the new scaled records ( 7 time history records) were considered in the verification analysis. These input records were applied to site \#31. The obtained amplification curves are shown in Appendix C. These peak amplification ratios for each pair of contrast ratio and peak ground acceleration (z, PGA) are demonstrated in Table (4.4). Figure (4.34) illustrates the variation of $F_{f 0}$ with the shaking intensity for different contrast ratios. Furthermore, the residual plot (for simulated results and equation (4-38)) is shown in Figure (4.35)

Figure (4.34) clearly confirms the tendency of $F_{f o}$ values to saturate for a constant contrast ratio. This Figure shows that $F_{f 0}$ reaches an upper limit when contrast ratio values exceed certain values (mostly when contrast ratio of 12 is exceeded). Table (4.5) illustrates the calculated $F_{f 0}$ values based on the proposed model in the previous section. Comparison of Table (4.4) with Table (4.5) gives the following conclusions on the efficiency of the introduced model for $F_{f 0}$ in previous section: Careful examining of Table (4.5) shows the model is capable of predicting the peak amplification ratios compared to those calculated from the FEM seismic response analysis. For instance, at the contrast ratio of 23.42 , two highest peak $F_{f 0}$ values are 11.4 and 10.8 from the FEM 
analysis of site \#31 (see Table (4.4)) whereas the introduced model gives the $F_{f}$ values of 10.47 and 10.29; (see Tables (4.5)), These $F_{f o}$ values show that the introduced models predict the highest $F_{f 0}$ values with the maximum difference of $8 \%$ relative to corresponding values obtained from the numerical FEM analysis. On the other hand, at the lowest contrast ratio of 4 , two lowest peak $F_{\text {fo }}$ values for are 3.7 and 3.79 from the FEM analysis of site \#31 (see Table (4.4)) while the models gives the $F_{f o}$ values of 3.2 and 3.81 (see Tables (4.5) ). The maximum difference is $13 \%$ between the model and FEM analysis.

As the last assessment, the $\mathrm{F}_{\mathrm{f} 0}$ values corresponding to two intermediate contrast ratios ( 8 and 12) can be examined. For contrast ratios of 8 and 12, FEM seismic response analysis gives the highest $F_{f o}$ values of 7.58 and 9.62 (see Table (4.4)). On the other hand, for the contrast ratios of 8 and 12 , the highest $F_{f 0}$ values associated with the model are obtained 6.9 and 8.25 . The maximum difference of $14 \%$ is observed between two $F_{f 0}$ values of 9.62 and 8.25 . Similarly, the lowest $F_{f 0}$ values related to the contrast ratios of 8 and 12 can be compared. These $F_{f o}$ values are obtained 5.56 and 6.61 (see Table (4.4)) from the FEM method while the model gives $F_{f o}$ values of 4.8 and 5.74 (see Table (4.5)). For these values, the maximum difference occurs between 5.56 (from FEM method) and 4.8 which shows the difference of $13 \%$.

The results above generally confirm the ability of the introduced model to predict the peak seismic amplification values based on the target contrast ratio and peak ground acceleration. For the most of combinations of contrast ratio and PGA, $\mathrm{F}_{\mathrm{fo}}$ values from the introduced models (equation (4-38)) are adequately close to those given by FEM 
analysis using the scaled records. The difference occurred is mostly between $8 \%$ and $13 \%$.

\subsection{Verification of the applied site response analysis method (by FEM) for recommended amplification factors of NEHRP, 1994}

\subsubsection{Generating of Depth-velocity configurations}

In this section, the capability of one-dimensional FEM used in this study is confirmed by regenerating NEHRP (1994) soil amplification factors. FEM is applied to perform the site response analysis of depth-velocity configurations similar to those used as the source profiles of NEHRP (1994) and then, the results of amplification ratios (factor of F) are compared with the given amplification factors of NEHRP (1994). The shear wave velocity of Franciscan bedrock in California is about $1000 \mathrm{~m} / \mathrm{sec}$. Seven soilbedrock configurations are considered for different average shear wave velocity of soil ranging from $100 \mathrm{~m} / \mathrm{sec}$ to $700 \mathrm{~m} / \mathrm{sec}$. These values of soil shear wave velocity along with the mentioned bedrock velocity were used to generate five site categories ranging from class A to class E. This can be easily done if the average shear wave velocity in top $30 \mathrm{~m}\left(\mathrm{~V}_{\mathrm{s} 30}\right)$ of soil is taken into account that is the expansion of equation (4-1):

$\mathrm{V}_{\mathrm{s} 30}=30 /\left(\mathrm{h}_{\mathrm{s}} / \mathrm{V}_{\mathrm{s}}+\left(30-\mathrm{h}_{\mathrm{s}}\right) / \mathrm{V}_{\mathrm{b}}\right)$

In equation (4-39), $V_{s}$ and $V_{b}$ denote the average shear wave velocity of the soil (shown in Table (4.6)) and shear wave velocity of the bedrock respectively. $V_{530}$ can be set to the shear wave velocity limits of NEHRP (1994) (shown in Table (4.6)) and therefore, soil deposit thickness $\left(\mathrm{h}_{\mathrm{s}}\right)$ is obtained. Because of the range of chosen velocities for soil, site classes $\mathrm{D}$ and $\mathrm{E}$ can not be generated for some configurations and 
consequently two more configurations of Config.8 and Config.9 (see Table (4.6)) are added to the depth-velocity profiles in Table (4.6). Moreover, we need to have bedrocks with higher shear wave velocities than $1000 \mathrm{~m} / \mathrm{sec}$, which is the average shear wave velocity of the Californian bedrock, to reach the $\mathrm{Vs}_{30}$ for site class $A$. Thus, for class $A$, the bedrock velocity of $2000 \mathrm{~m} / \mathrm{sec}$ is considered. This modification should also be applied in equation (4-39) if class $\mathrm{A}$ is assigned for the target site.

These generated profiles were subjected to the ground motions scaled to the exact peak ground accelerations (PGA) used by NEHRP (1994) (PGAs from 0.1g to $0.5 \mathrm{~g}$ ). Finally, the amplification curves were obtained using the response spectra ratio of ground response to the bedrock motion (for damping ratio of 5\%). Some samples of amplification curves of the mentioned profile configurations for different site categories and shaking intensities are demonstrated in Appendix D.

\subsubsection{Comparison of the obtained amplification factors with NEHRP 1994 recommendations}

In this section low and high frequency amplification curves are defined and extracted from the obtained amplification curves in previous section. According to the mentioned procedures in previous section, 175 amplification curves were obtained. In NEHRP 1994, the low and high frequency ranges of seismic amplification were attributed to the frequencies of $1 \mathrm{~Hz}$ and $3.3 \mathrm{~Hz}$, respectively. Similarly, the same frequency limits were used for the obtained amplification curves and the average amplification values between 0.8 and 1.2 and between 3 and $3.6 \mathrm{~Hz}$ were calculated as the low and high frequency amplification values, respectively. Figures (4.36) to (4.45) demonstrate the comparison between the extracted amplification factors and the 
amplification factors given by NEHRP (1994). In Figures (4.46) to (4.55), the average amplification values of each shaking intensity are compared with the amplification factors of NEHRP (1994) .Amplification factors of NEHRP, 1994 are shown in Tables (4.7) and (4.8). Based on the average amplification factors in Figures (4.46) to (4.55), the following conclusions can be drawn:

1- Amplification results of NEHRP 1994 for class A, show more deamplifications than those obtained from FEM. For FEM, The largest average deamplifications happen for the shaking intensity level of $0.5 \mathrm{~g}$ that is $11 \%$ greater than the corresponding value of NEHRP 1994.

2- Average amplification ratio results of site class B from FEM and NEHRP 1994 are in good agreement. In high and low frequency ranges, the maximum differences of $2 \%$ and $5 \%$ are observed, respectively.

3- For site class $\mathrm{C}$, high frequency amplification ratios from FEM were overestimated compared to NEHRP recommendations. In contrary, there was a slight underestimation for low frequency amplification values from FEM. The maximum $10 \%$ underestimation occurred for the shaking intensity of $0.3 \mathrm{~g}$.

4- For site class $\mathrm{D}$, the maximum difference between the average low frequency amplification ratios was $5 \%$. For high frequency amplification ratios, this difference reached the maximum percentage of $11 \%$.

5- For site class E, the average amplification ratios of FEM and NEHRP are close together. At the shaking intensity of $0.4 \mathrm{~g}$, the maximum differences occurred that are $8 \%$ and $15 \%$ for the low and high frequency amplification values, respectively. 
To conclude, these results exhibit the difference of $2 \%$ to $15 \%$ between the amplification factors of NEHRP, 1994 and the average amplification factors obtained from FEM site response analysis. This reasonable difference suggests that FEM site response analysis can be applied for the determination of low and high frequency amplification factors comparable to NBCC, 2005 that is based on the results of NEHRP, 1994. The subsequent sections deal with the developing of high and low frequency amplification factors for different soil classes in Ottawa area using FEM site response analysis.

\subsection{Development of high and low frequency amplification}

\section{factors/equations for different soil classes in Ottawa area}

In this section, using FEM, an extensive seismic amplification analysis is carried out to develop high and low frequency amplification factors for different soil classes in Ottawa area.

Seismic sites: 19 sites located in Ottawa area were considered for seismic soil modeling using FEM analysis. For sites deeper than $30 \mathrm{~m}$ the site-specific shear wave velocity equations were available from Carleton University and GSC surveying results shown in Table (4.9). For sites with depth less than $30 \mathrm{~m}$ the generic shear wave velocity equation for Leda Clay $(0.88 \mathrm{z}+123.86 \pm 20.3 \mathrm{~m} / \mathrm{sec})$ which has been established by GSC (Hunter et al., 2010) and the average shear wave velocity of $2700 \mathrm{~m} / \mathrm{sec}$ for the bedrock were considered. Their depths and shear wave velocity values (or equations) are illustrated in Table (4.10). For all 19 sites, soil density and bedrock density were taken $1700 \mathrm{kN} / \mathrm{m}^{3}$ and $2500 \mathrm{kN} / \mathrm{m}^{3}$, respectively. 
Input time histories: To comply with NBCC (2005) the artificial acceleration time histories from Atkinson and Beresnev (1998) that correspond to a $2 \%$ chance of exceedance in 50 years were applied as the input motions. Those acceleration time histories are shown in Figures (4.56a), (4.56b), (4.56c), (4.56d), (4.57a), (4.57b), (4.57c), (4.57d), (4.58a) and (4.58b). The input motions were selected in such a way that a wide range of PGAs from 181 gal to 1000 gal is covered.

Using the above-mentioned input parameters each site was subjected to different input time histories with different level of PGAs. Amplification curves were obtained for each case using two different approaches. The first approach was based on Fourier analysis, in which the ratio of the Fourier spectra of the response on the ground level, which was the output of FEM, to that of input motion was taken as the amplification ratio. The second approach was passed on response spectra, in which the $5 \%$ damping response spectra of the time history on the ground level produced by FEM to that of the input motion was obtained as the amplification ratios. Some of the obtained amplification curves from the first and second definitions are shown in Appendix E and F, respectively.

\subsubsection{Low frequency amplification factors based on Fourier spectra, $\left(F_{V}\right)_{F F T}$}

\subsubsection{Correlation of $\left(F_{v}\right)_{F F T}$ with $V s_{30}$}

Similar to NBCC (2005) the low frequency was considered at frequency of 1 Hz. In this study, the low frequency amplification factors were calculated taking the average of the amplification values between $0.9 \mathrm{~Hz}$ and $1.1 \mathrm{~Hz}$. These values are shown in Table (4.11). In this section, the traditional building code based- method of seismic amplification that correlates the amplification values to the shear wave velocity structure of the soil deposits is applied for the investigated sites in Ottawa area. In other words, the 
extracted amplification values are related to the $V_{s_{30}}$ of the examined sites using appropriate equations. Variation of low frequency amplification values versus average shear wave velocity in top $30 \mathrm{~m}$ of soil $\left(\mathrm{Vs}_{30}\right)$ are illustrated in Appendix G. Similar to the Borcherdt approach in equation (4-3), an equation in terms of $\mathrm{Vs}_{30}$ can be derived. Adding PGA as another parameter, the following equation of amplification ration is suggested:

$\left(\mathrm{F}_{\mathrm{V}}\right)_{\mathrm{FFT}}=\mathrm{a}(1 / \mathrm{PGA}){ }^{\mathrm{b}} \mathrm{Vs}_{30}{ }^{\mathrm{c}}$

Using the data in Table (4.11) (or Appendix G) and implementing the multiple regression the coefficients of $\mathrm{a}, \mathrm{b}$ and $\mathrm{c}$ are determined $20.34,0.077$ and -0.354 respectively. PGA and $\mathrm{Vs}_{30}$ are expressed in gals and $\mathrm{m} / \mathrm{sec}$ respectively. It should be noted that the site class parameter is represented by $\mathrm{Vs}_{30}$ in the above equation, and that $\mathrm{Fv}$ is dependent on the shaking intensity.

For a rough comparison with the given $\mathrm{F}_{\mathrm{v}}$ values in $\mathrm{NBCC}, 2005$, amplification values can be determined for the soil classes $A, B, C$ and $D$ with lower $\mathrm{Vs}_{30}$ limits of $1500,760,360$ and $180 \mathrm{~m} / \mathrm{sec}$ in NBCC, 2005, respectively. As an example, for PGA of 422 gal, lower limits of $\mathrm{Vs}_{30}$ can be plugged in equation (4-40):

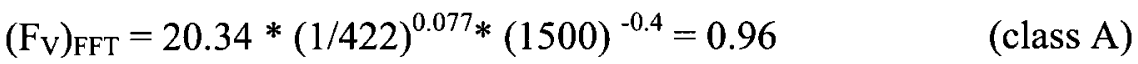

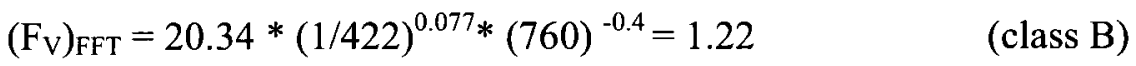

$$
\begin{aligned}
& \left(\mathrm{F}_{\mathrm{V}}\right)_{\mathrm{FFT}}=20.34 *(1 / 422)^{0.077 *(360)^{-0.4}=1.59 \quad \text { (class C) }}
\end{aligned}
$$

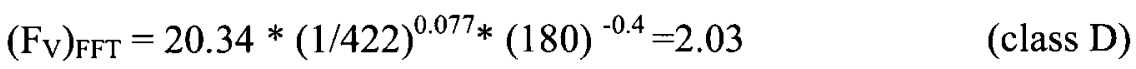

Normalizing the amplification values relative to class $C$ (class $C$ is the reference site in NBCC, 2005), the amplification values of 0.60 and $0.76,1$ and 1.27 (for PGA of 422 gal) are obtained for the site classes A, B, C and D, respectively. 
The above soil amplification factors are based on a specific PGA (422 gal in this case), which can be related to a PSA as used by NBCC (2005). For a target PGA, the spectral acceleration values (PSA) are available if the response of a single degree of freedom system is obtained at different frequencies for the corresponding input motions.

For the PGA of 422 gal in Ottawa area, PSA (pseudo acceleration) values are given by NBCC (2005) and shown in Figure (4.59). According to that Figure, the low frequency $(1 \mathrm{~Hz})$ spectral acceleration value is obtained $0.14 \mathrm{~g}$. On the other hand, the seismic soil amplification factors for PSA of $0.14 \mathrm{~g}$ given by NBCC (2005) (see Table (4.12)) are $0.5,0.64,1$ and 1.36 for the site classes of A, B, C and D, respectively. These values are close to the values of $0.6,0.76,1$ and 1.27 for the site classes $A, B, C$ and $D$, respectively, as given by equation (4-40).

Equation (4-40) shows the dependency of the amplification ratio on $\mathrm{Vs}_{30}$ but it is worth to study its dependency on fundamental frequency, which may have a significant effect on the seismic site response. This issue will be examined in the next section.

\subsubsection{Multi-parameter models for $\left(F_{\mathrm{V}}\right)_{\mathrm{FFT}}$}

In the previous section, some equations were obtained that correlate the seismic amplification values to $\mathrm{Vs}_{30}$. In this section, the dependency of seismic amplification values to other parameters will be sought. $V s_{30}$ is kept as one of the key influential parameters. The correlation of amplification ratio with $\mathrm{Vs}_{30}$ cannot be ignored and a group of studies found in the literature support the correlation of seismic amplification ratio and $\mathrm{Vs}_{30}$ (e.g. NEHRP, 1994; Borcherdt, 1994). As well, the amplification results of the current study confirm that, as seen in Table (4.11), by increasing $\mathrm{Vs}_{30}$, generally seismic amplification factors are decreased and vise versa. 
As the second parameter, the fundamental frequency $\left(f_{n}\right)$ obtained from average shear wave velocity is considered as below:

$f_{n}=\left(V_{s}\right)_{\text {average }} /(4 H)$

where $\left(V_{s}\right)_{\text {average }}$ and $H$ are the average shear wave velocity and the thickness of the soil deposit.

Fundamental frequency and amplification values for $1 \mathrm{~Hz}$ of all 19 study sites are shown in Table (4.11). Therefore, for each level of shaking (PGA), 19 pair of depth (thickness of the examined site) and amplification at $1 \mathrm{~Hz}$ are available. For example, amplification ratio for $1 \mathrm{~Hz}$ versus depth is shown in Figure (4.60) for the shaking level of 422 gal. In this Figure, it is evident that the sites with the thicknesses of $30 \mathrm{~m}, 32 \mathrm{~m}$, $38 \mathrm{~m}$ and $41 \mathrm{~m}$ (corresponding to the natural frequencies of $1.3,0.9,0.8$ and $0.9 \mathrm{~Hz}$, respectively) have a significant seismic amplification value $\left(\mathrm{F}_{\mathrm{v}}>3.3\right)$.

As another example, Figure (4.61) exhibits the same trend for the sites having thicknesses of $30 \mathrm{~m}$ to $41 \mathrm{~m}$ at the shaking intensity of 707 gal. Thus, considering that the reference low frequency is $1 \mathrm{~Hz}$ in our analysis, it is clear that high amplification values are obtained for sites with fundamental frequencies close to the reference frequency, $1 \mathrm{~Hz}$.

This finding leads us to choose the divergence from the fundamental frequency $\left(f_{n}-1\right)$ as another parameter that controls the amplification ratios. Thus, I chose two parameters of $\mathrm{Vs}_{30}$ and $\left|\mathrm{f}_{\mathrm{n}}-1\right|$ for linear regression and the following amplification equations were obtained:

$\left(\mathrm{F}_{\mathrm{V}}\right)_{\mathrm{FFT}(\mathrm{PGA}=a)}=\mathrm{a}+\mathrm{bVs}_{30}+\mathrm{c}\left|\mathrm{f}_{\mathrm{n}}-1\right|^{-1}$

where $\left|f_{n}-1\right| \geq 0.1 \mathrm{~Hz}$ and $V_{s_{30}}$ is in $\mathrm{km} / \mathrm{sec}$. In equation above, values of $a, b$ and $c$ are given in Table (4.13) for different shaking intensities, $\alpha$. The lowest frequency difference 
$\left(\left|f_{n}-1\right|\right)$ was limited to $0.1 \mathrm{~Hz}$ due to the accuracy of the frequency data. As an example at the PGA of 422 gal, low frequency amplification values (using equation (4-42)) are shown in Figure (4.62) for some selected $f_{n}$ values.

\subsubsection{High frequency amplification factors based on Fourier spectra $\left(F_{a}\right)_{F F T}$}

I did the same procedures that were explained in previous section for low frequency, for high frequency $(5 \mathrm{~Hz})$, using the mentioned sites, input parameters and time histories. The extracted high frequency amplification factors based on Fourier spectra $\left(\mathrm{F}_{\mathrm{a}}\right)_{\mathrm{FFT}}$ are shown in Table (4.14) (see also Appendix H) . NBCC (2005) also used $5 \mathrm{~Hz}$ as a representative of high frequencies for soil amplification values. For the PGAs less than $422 \mathrm{gal},\left(\mathrm{F}_{\mathrm{a}}\right)_{\mathrm{FFT}}$ can be attributed to the variation of $\mathrm{Vs}_{30}$ by power functions $\left(\mathrm{R}^{2}\right.$ $\geq 0.75$ ) as below:

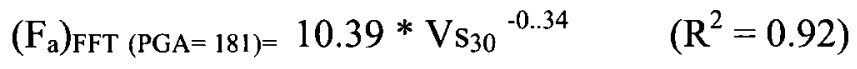

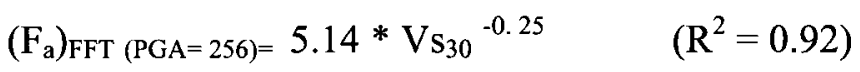

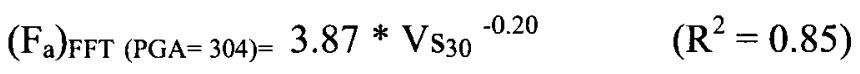

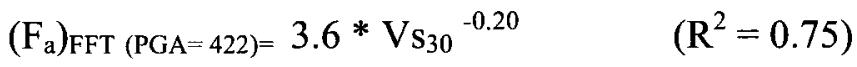

The increase of PGAs shows different behavior of the seismic response where the power equation is not a good fit to $\left(\mathrm{Vs}_{30}, \mathrm{~F}_{\mathrm{a}}\right)$ data. Not only power functions for high shaking intensities yield low $R^{2}$ values $\left(R^{2}<0.7\right)$ but also $V s_{30}$ increase does not necessarily cause the amplification ratio to decrease For example, Table (4.14) exhibits that for high shaking intensities (PGA> 422 gal), the high frequency amplification ratios of site class $E\left(\mathrm{Vs}_{30}<180 \mathrm{~m} / \mathrm{sec}\right)$ are smaller than those of site class $\mathrm{C}$ or $\mathrm{B}$, due to the non-elastic behavior of soil structure. This trend is also observed in NBCC (2005) for $F_{a}$ values of NBCC, 2005 (see Table (4.15)). Table (4.15) shows that, for $\mathrm{S}_{\mathrm{a}(0.2)}=1 \mathrm{~g}$ and $\mathrm{S}_{\mathrm{a}}$ 
$(0.2)=1.25 \mathrm{~g}$, the NEHRP site classes of $\mathrm{B}$ or $\mathrm{C}$ have the amplification ratios more than that of class $\mathrm{E}$.

As mentioned that reverse effect of $\mathrm{Vs}_{30}$ on $\mathrm{F}_{\mathrm{a}}$ values at high shaking intensities occurs due to the non-elastic behavior of soil structure. As shaking intensity exceeds a certain level, due to non-elastic behavior of soil structure, the looser deposits with lower $\mathrm{Vs}_{30}$ (site classes D and E) transfer less motion compared to stiffer deposits, hence, the expected ground motion of loose site class E, is quite less than the expected motions of the site classes $\mathrm{D}$ and $\mathrm{C}$.

\subsubsection{Low frequency amplification factors based on response spectra $\left(F_{V}\right)_{R S}$}

Similar to Fourier spectrum analysis, low frequency amplification for response spectrum was defined at the frequency of $1 \mathrm{~Hz}$ (the average values between 0.9 and 1.1 $\mathrm{Hz}$ ). Table (4.16) illustrates the obtained values. That Table clearly verifies the effect of $\mathrm{Vs}_{30}$ on the amplification value. As seen in that Table, for a constant PGA, when $\mathrm{Vs}_{30}$ decreases the amplification value increases. For example for the input motion having PGA of 181 gal, when $V_{s} 3$ is decreased from $1970(\mathrm{~m} / \mathrm{sec})$ to $96(\mathrm{~m} / \mathrm{sec})$, the amplification ratio increases from 0.8 to 3.6. Based on $\left(\mathrm{F}_{\mathrm{V}}\right)_{\mathrm{RS}}$ values in Table (4.16) (shown in Figures 4.63a, 4.63b, 4.63c, 4.63d, 4.64a, 4.64b, 4.64c, 4.64d, 4.65a and $4.65 b)$, the following form of power equation was obtained that correlates $\left(F_{V}\right)_{R S}$ to $V_{s_{30}}$ and PGA :

$\left(\mathrm{F}_{\mathrm{V}}\right)_{\mathrm{RS}(\mathrm{PGA}=\alpha)}=\mathrm{a}(1 / \mathrm{PGA})^{\mathrm{b}} \mathrm{Vs}_{30}{ }^{\mathrm{c}}$

By implementing the multiple regression, the coefficients of $a, b$ and $c$ are determined $39,0.239$ and -0.303 respectively $\left(R^{2}=0.8\right)$. PGA and $\mathrm{Vs}_{30}$ are expressed in gals and $\mathrm{m} / \mathrm{sec}$ respectively. 
Similar to section (4.10.1.1), amplification values can be determined for the soil classes $\mathrm{A}, \mathrm{B}, \mathrm{C}$ and $\mathrm{D}$ having lower $\mathrm{Vs}_{30}$ limits of $1500,760,360$ and $180 \mathrm{~m} / \mathrm{sec}$ in NBCC, 2005, respectively. As an example, for PGA of 422 gal, lower limits of $\mathrm{Vs}_{30}$ can be plugged in equation (4-47):

$$
\begin{array}{ll}
\left(\mathrm{F}_{\mathrm{V}}\right)_{\mathrm{RS}}=39 *(1 / 422)^{0.239} *(1500)^{-0.303}=1 & \text { (class A) } \\
\left(\mathrm{F}_{\mathrm{V}}\right)_{\mathrm{RS}}=39 *(1 / 422)^{0.239} *(760)^{-0.303}=1.23 & \text { (class B) } \\
\left(\mathrm{F}_{\mathrm{V}}\right)_{\mathrm{RS}}=39 *(1 / 422)^{0.239 *(360)^{-0.303}=1.54} & \text { (class C) } \\
\left(\mathrm{F}_{\mathrm{V}}\right)_{\mathrm{RS}}=39 *(1 / 422)^{0.239} *(180)^{-0.303}=1.9 & \text { (class D) }
\end{array}
$$

Normalizing the amplification values relative to class $C$ (class $C$ is the reference site in $\mathrm{NBCC}(2005)$, the $\left(\mathrm{F}_{\mathrm{V}}\right)_{\mathrm{RS}}$ values of 0.64 and $0.80,1$ and 1.23 are obtained for the site classes $A, B, C$ and $D$ respectively. On the other hand, according to PSA (pseudo acceleration) values (Figure 4.59), the low frequency $(1 \mathrm{~Hz})$ spectral acceleration value for the mentioned PGA level is $0.14 \mathrm{~g}$. For this spectral acceleration, NBCC (2005) (see Table (4.12)) suggests the amplification factors of $0.5,0.64,1$ and 1.36 for the site classes of A, B, C and D, respectively. These amplification values are close to the values obtained from equation (4-47).

\subsubsection{High frequency amplification factors based on response spectra $\left(F_{\mathrm{a}}\right)_{\mathrm{RS}}$}

Similar to NBCC, 2005, High frequency amplification values $\left(\left(\mathrm{F}_{\mathrm{a}}\right)_{\mathrm{RS}}\right)$ were defined at the frequency of $5 \mathrm{~Hz}$. The results are shown at Table (4.17) (see also Appendix I). The following power functions were obtained for the shaking intensities less than PGA of 422 gal:

$$
\begin{array}{ll}
\left(\mathrm{F}_{\mathrm{a}}\right)_{\mathrm{RS}(\mathrm{PGA}=181)=4.39 * \mathrm{Vs}_{30}-0.22}\left(\mathrm{R}^{2}=0.78\right) \\
\left(\mathrm{F}_{\mathrm{a}}\right)_{\mathrm{RS}(\mathrm{PGA}=256)=3.84 * \mathrm{Vs}_{30}{ }^{-0.2}}\left(\mathrm{R}^{2}=0.71\right)
\end{array}
$$




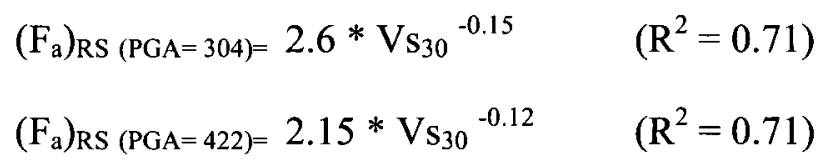

At higher shaking intensities, $\left(\mathrm{F}_{\mathrm{a}}\right)_{\mathrm{RS}}$ values, by and large, confirmed the trend mentioned in section (6.4.2). Table (4.17) shows that when shaking intensity reaches high PGAs $(\mathrm{PGA}>607 \mathrm{gal}),\left(\mathrm{F}_{\mathrm{a}}\right)_{\mathrm{RS}}$ values of site classes $\mathrm{D}$ and $\mathrm{E}$ are even smaller than those of site class $\mathrm{C}$. The reason is hidden in non-elastic behavior of soil deposits that was explained in section (4.10.2). A similar trend can be distinguished in the high frequency amplification values of NBCC, 2005 (see Table (4.15)).

\subsection{Region-specific amplification factors for Ottawa area; Foundation factors for Ottawa area in analogous format of NBCC, 2005}

\subsubsection{Developing of low and high frequency amplification values for Ottawa region for different site classes; Comparison with the foundation factors of NBCC, 2005}

In this section, different site classes in Ottawa area are subjected to different ground motions with the spectral accelerations (PSA values) given in NBCC (2005). The profiles were generated based on the average soil shear wave velocity of $150 \mathrm{~m} / \mathrm{sec}$ and the average bedrock shear wave velocity of $2700 \mathrm{~m} / \mathrm{sec}$. The examined profiles (sites) ranging from $1 \mathrm{~m}$ to $120 \mathrm{~m}$ were used and different site classes were included in the analysis procedure. The average shear wave velocities of these sites in top $30 \mathrm{~m}$ (Vs30) are shown in Table (4.18). For example, site having $\mathrm{Vs}_{30}$ of $405 \mathrm{~m} / \mathrm{sec}$ and $219 \mathrm{~m} / \mathrm{sec}$ are categorized in site class $\mathrm{C}$ and site class $\mathrm{D}$ respectively. Two sets of input motions were chosen for each level of spectral accelerations (PSA values) from Eastern Canadian 
Earthquakes and amplification ratios (based on response spectra definition) were obtained for different configurations of site classes. Some samples of these amplification curves are shown in Figures (4.66a) to (4.66f). Tables (4.19) and (4.20) illustrate the amplification ratios for two configurations of site classes $\mathrm{A}$ and $\mathrm{B}$ and four configurations of site classes $\mathrm{C}, \mathrm{D}$ and $\mathrm{E}$ at low frequency range of $1 \mathrm{~Hz}$ and high frequency range of 5 Hz.

All the low and high frequency amplification values were rounded off to 0.05 . The average values of these amplification curves of different configurations of each site class are demonstrated in Tables (4.21) and (4.22). To comply with NBCC (2005) the amplification ratios are rounded off to 0.1. In Tables (4.23) and (4.24) the amplification values are normalized to the amplification factors of site class $\mathrm{C}$ as the reference site class of NBCC (2005). Comparing these two Tables with the low and high frequency amplification values of NBCC (2005) (Tables (4.120 and (4.15)), the following recommendations are suggested for Ottawa area:

1-The obtained low frequency amplification values are greater than those of NBCC, 2005 for site classes D and E. These amplification factors exhibit the increase of about $20 \%$ to $30 \%$ compared to the recommended values in NBCC (2005). This statement is valid if class $C$ is taken as reference. Otherwise if the amplification values of classes D and E are compared with those of class A, NBCC (2005) is still conservative. Due to the low shear wave velocity of the examined sites, the fundamental site frequency of these site categories lie in the low frequency range that can justify the mentioned increase in amplification values. 
2-Based on the average low frequency amplification results, NBCC (2005) proposes more deamplifications for site classes A and B.

3-In high frequency range, NBCC (2005) is more conservative for site classes D and $\mathrm{E}$ and suggests larger values for amplification factors. For instance, NBCC (2005) recommends the amplification factor of 2.1 for the site class $\mathrm{E}$ at the spectral acceleration of $0.25 \mathrm{~g}$ and less that is $10 \%$ larger than the average amplification value for Ottawa region.

4-The deamplifications (for site classes A and B) are, by and large, the same for NBCC (2005) and the average results for Ottawa area.

5-Finally, a trend similar to that of NBCC (2005) was confirmed for high frequency amplification values. Based on this trend, as shaking intensity exceeded the PSA of $1.25 \mathrm{~g}$, the amplification values of site classes D and E are less than those of site classes $\mathrm{C}$ and $\mathrm{B}$ in Ottawa area.

\subsubsection{Peak amplification values for a target fundamental frequency}

In this section, peak amplification values of a variety of sites were obtained for target fundamental frequencies. These target frequencies were chosen the same ones used by Atkinson and Boore (2006) for the determination of the coefficients of soil response. The spectral acceleration ranging from $0.1 \mathrm{~g}$ to $1 \mathrm{~g}$ were taken into account and the average peak amplification ratios were extracted for a the site having the target fundamental frequency. These average peak amplification values are illustrated in Table (4.25). Based on these values, the followings conclusions can be drawn:

1-Due to the high contrast ratio in the region, large seismic amplification factors are obtained at the target frequencies. Although, for high frequencies of $8 \mathrm{~Hz}$ and $10 \mathrm{~Hz}$ 
the amplification ratios are high but these values are not in engineering design range of interest.

2- Peak amplification ratios at the frequencies of $1 \mathrm{~Hz}$ and $5 \mathrm{~Hz}$, exhibits the highest amplification ratios of more than 5 (at the shaking intensity of $0.1 \mathrm{~g}$ ). These large amplification values explicitly show the potential hazard if the fundamental frequencies coincide with the low and high frequency ranges $(1 \mathrm{~Hz}$ and $5 \mathrm{~Hz})$ of Building Code.

3- The amplification ratio decays with the increase of the shaking intensity verify the significant effect of level of shaking even for the peak amplification ratios. For instance, at the frequency of $5 \mathrm{~Hz}$, the amplification ratios decrease from 7 to 3.5 as the shaking intensity reaches from $0.1 \mathrm{~g}$ to $1 \mathrm{~g}$.

\subsection{Concluding remarks on the obtained low and high frequency amplification factors for the city of Ottawa}

In section 4.10.1 to 4.10 .4 , low and high frequency amplification values for the city of Ottawa were studied. The results of the site response analysis of 19 sites subjected to the variety of ground motions were used to extract the amplification ratios. For low frequency (at $1 \mathrm{~Hz}$ ) amplification values, $F_{v}$ values were correlated to $V_{s_{30}}$ and fundamental frequency of the target site obtained from the average shear wave velocity $\left(f_{n}\right)$.These correlations were based on the best-fit curve to $\left(V_{s_{30}}, F_{v}\right)$ data or the multiple linear regression that associates $F_{v}$ values to $V_{s_{30}}$ and $f_{n}$. These two parameters are obtained having the shear wave velocity profiles of the target site. For high frequency (at $5 \mathrm{~Hz}), \mathrm{F}_{\mathrm{a}}$ values were also related to $\mathrm{Vs}_{30}$ for the shaking intensities less than $422 \mathrm{gal}$ using best-fit curve to $\left(\mathrm{Vs}_{30}, \mathrm{~F}_{\mathrm{v}}\right)$ data. For high shaking intensities, the reverse effect of 
$\mathrm{Vs}_{30}$ was observed that is quite in accordance with the trend of $F_{v}$ values in NBCC (2005). Based on this trend, when shaking intensities reach high values, sites having lower $\mathrm{Vs}_{30}$ values exhibit smaller $\mathrm{F}_{\mathrm{v}}$ values compared to the sites with higher $\mathrm{Vs}_{30}$ values. Both of the amplification ratio definitions (Fourier and response spectra ratio definitions) were used in the seismic amplification analysis. Both of these definitions confirmed the strong correlations between the amplification values and the significant characteristics of the examined sites such as $\mathrm{Vs}_{30}$.

Finally, in section (4.11) region-specific amplification ratios were developed for Ottawa region in the same format of NBCC (2005). The results show that although the suggested values of NBCC (2005) are more conservative in the high-frequency range but the obtained low-frequency values for Ottawa region exhibit the increase of about $20 \%$ for the site classes of D and E compared to the recommended values of NBCC (2005). On the other hand, if these low-frequency amplification values of site classes D and $\mathrm{E}$ are compared with those of site class A (instead of site class C as reference in NBCC, 2005), NBCC (2005) is still conservative. Furthermore, peak amplification values of a variety of sites were obtained for target fundamental frequencies in Ottawa area and large amplification ratios (up to the ratio of 6 and 7) were obtained for some target frequencies. These high amplification ratios can be explained by the large contrast ratio in the region.

\subsection{Summary and conclusions}

In this chapter, extensive site response analysis was carried out for different sites located throughout the city of Ottawa. The utilized method was based on the finite element solution of the equation of motion and the soil non-linearity was simulated using the strain-dependent shear modulus and damping ratio. The analysis method benefits 
from two main advantages: First, coefficients of Rayleigh damping formulation are used in such a way that the finite element model responds to the dominant frequency of the site and that of the input motion. Second, using the boundary condition of Lysmer and Kuhlemeyer (1969) nearly perfect absorption of the wave is obtained at the soil-bedrock boundary. The following research steps were taken:

1- Due to the reported large seismic amplification values in Ottawa area from - some sparse earthquakes, the seismic response analysis of ORHO station located in the eastern part of the city was performed. As the input motion, the horizontal component of the earthquake (weak motion) of the Christmas Eve, 2008 recorded on a nearby rocky site, ORIO station, was used and the seismic amplification was obtained at different frequencies. The outcomes of the analysis confirmed the observed large amplification values occurred around the fundamental site frequency at ORHO station. The obtained fundamental frequency was $0.7 \mathrm{~Hz}$ for the Leda clay-glacial till model and was close to the observed fundamental frequency of $0.75 \mathrm{~Hz}$.

2- Three target sites in the eastern part of the city were subjected to the artificial acceleration time histories for eastern Canada ( $10 \%$ in 50 years records). The selected sites cover the depths from $30 \mathrm{~m}$ to $80 \mathrm{~m}$ and the chosen records have the peak ground accelerations (PGA) ranging from $23 \mathrm{gal}(0.02 \mathrm{~g})$ to $349 \mathrm{gal}(0.35 \mathrm{~g})$. In addition to the real shear wave velocity profiles of the target sites, more profiles were generated at the target sites to reach the contrast ratios of 4,8 and 12 . The seismic amplification analysis of all real and generated profiles was performed and the variation of the peak seismic amplification $\left(\mathrm{F}_{\mathrm{fo}}\right)$ versus two parameters of contrast ratio $(\mathrm{z})$ and PGA was assessed. According to the variation pattern of amplification ratio with PGA and $\mathrm{z}$, a mathematical 
function was proposed for the modeling of the combined effect of $\mathrm{z}$ and PGA on the peak amplification ratio. The combined function is:

$F_{f 0}=(7.812-6.992$ PGA $) \log _{10}(z) \quad\left(R^{2}=0.969\right)$

This function was achieved based on the following rationales: Most of the obtained amplification ratios get, somewhat, saturated and reach upper limits as the contrast ratio exceeds some high values. Therefore, a logarithmic function of the contrast ratio $(\log z)$ was proposed because the large increments of the contrast ratio cause little increase of the logarithmic function when $\mathrm{z}$ values pass a certain limit. Then, by incorporating the effect of shaking intensity as a linear function, multivariate least square analysis was done for $\left(\mathrm{F}_{\mathrm{f}}, \mathrm{z}, \mathrm{PGA}\right)$ data and the above-mentioned equation was determined. To validate the introduced model (equation), the target sites subjected to 10 scaled records were reanalyzed using FEM and the new $F_{f o}$ values were compared against those obtained from the introduced model. The results of this verification test were acceptable because the $F_{\mathrm{f} 0}$ values from the model and scaled record-based FEM analysis were close together (mostly different by $8 \%$ to $13 \%$ ).

3- To confirm the utilized site response analysis method, this method was applied to the soil-bedrock shear wave velocity configurations of NEHRP (1994) using different input motions. Then, the average low and high frequency amplifications ratios $\left(F_{v}\right.$ and $F_{a}$ ) were extracted and compared to those given by NEHRP (1994). The results of comparison for five site classes (A, B, C, D and E) exhibited the maximum differences ranging from $2 \%$ to $15 \%$.

4- Low and high frequency seismic response analysis was carried out at nineteen sites, ranging from 1 meter to 112 meter depth, using artificial time histories of 
eastern Canada ( $2 \%$ in 50 years records). The PGAs of the selected input motions cover the range of 181 gal to 1000 gal. The amplification curves were determined based on Fourier spectra ratio and response spectra ratio and then, the low and high frequency amplification values were extracted from the amplification curves. Then, mathematical models for low and high frequency amplification values were developed separately. For different shaking intensities those amplification ratios were correlated to average shear wave velocity in top 30 meter of soil deposit $\left(\mathrm{Vs}_{30}\right)$ using the best-fit curve to $\left(\mathrm{Vs}_{30}, \mathrm{~F}\right)$ data. In some cases, a strong correlation between the fundamental frequency obtained from average shear wave velocity $\left(f_{n}\right)$ and amplification ratio of the examined sites were recognized and therefore, using multiple linear regression alternative equations were proposed that correlate the amplification ratios to both of the parameters $\mathrm{Vs}_{30}$ and $\mathrm{f}_{\mathrm{n}}$. For the high frequency amplification values, the similar trend of NBCC, 2005 was verified where low velocity site classes (site classes D and E) compared to high velocity classes delivered smaller high amplification ratios as the shaking intensity passed a certain level.

5- Finally, region-specific amplification ratios were obtained for Ottawa area for the same spectral accelerations of NBCC, 2005. The results show somehow lower high frequency amplification values (on average 10\%) and larger low frequency amplification values of site classes $\mathrm{D}$ and $\mathrm{E}$ (on average 20\%) compared to the suggested values of NBCC, 2005. It should be noted that NBCC, 2005 is still conservative if these lowfrequency amplification values of site classes D and E are compared with those of site class A (instead of site class C).

\subsection{References}


Atkinson G.M. and Beresnev I.A., 1998, Compatible ground-motion time histories for new national seismic hazard maps, Canadian Journal of Civil Engineering, 25, pp.305-318.

Atkinson G.M. and Boore D.M., 2006, Earthquake Ground-Motion Prediction Equations for Eastern North America, BSSA, (96), pp.2181-2205.

Bathe K.J., 1984, Finite element procedures in engineering analysis, Prentice-Hall

Bathe K.J., 2003, Finite element procedures, Prentice Hall; $7^{\text {th }}$ edition.

Bathe K.I. and Wilson E.L., 1976, Numerical Methods in Finite Element Analysis, Prentice-Hall, Englewood Cliffs.

Beresnev I.A., Wen K.L and Yeh Y.T., 1994, seismological evidence for nonlinear elastic ground behavior during large earthquakes, Soil Dynamics and Earthquake Engineering, 14, pp.103-114.

Beresnev I.A., Atkinson G.M., Johnson P.A., and Field E.H. , 1998, Stochastic finitefault modeling of ground motions from the 1994 Northridge, California, earthquake. II. Widespread Nonlinear response at soil sites, Bulletin of the Seismological Society of America, 88, pp.1402-1410.

Beresnev I.A. and Wen K.L., 1996, Nonlinear soil response - a reality? , Bulletin of the Seismological Society of America, 86, pp.1964-1978.

Bonilla L.F.,Archuleta R.J. and Lavallée D., 2005, Hysteretic and Dilatant Behavior of Cohesionless Soils and Their Effects on Nonlinear Site Response:Field Data Observations and Modeling, BSSA, 95, pp.2373 - 2395.

Borcherdt R.D., 1992.Simplified site classes and empirical amplification factors for sitedependent code provisions. In Proceedings of the NCEER, SEAOC, BSSC Workshop on Site Response During Earthquakes and Seismic Code Provisions, 1820 Nov.1992, University of Southern California, Los Angeles, California, Edited by G.R. Martin. 
Borcherdt R.D., 1994, Estimates of site-dependent response spectra for design (methodology and justification), Earthquake Spectra, 10(4), pp.617-653.

Chang C.Y. ,Power M.S., Tang Y.K. and Mok C.M. , 1989, Evidence of nonlinear soil response during a moderate earthquake, Proc. of the 12th International Conference on Soil Mechanics and Foundation Engineering, Rio de Janeiro, Brazil, 3, pp.1-4.

Chatterjee P. and Basu B. , 2008,Some analytical results on lateral dynamic stiffness for footings supported on hysteretic soil medium, Soil Dynamics and Earthquake Engineering, 28(1), pp. 36-43.

Chin B.H. and Aki K. ,1991, Simultaneous study of the source, path, and site effects on strong ground motion during the 1989 Loma Prieta earthquake: a preliminary result on pervasive nonlinear site effects, Bulletin of the seismological society of America, 81,pp.1859-1884.

Darendeli M., 2001, Development of a new family of normalized modulus reduction and material damping curves, Ph.D. Thesis, University of Texas.

Erdik M., 1987, Site response analysis, in Strong Ground Motion Seismology, Erdik M. O. Toksöz M. N., (Editors) D. Reidel Publishing Company, Dordrecht, Netherlands, pp.479-534.

Finn W.D.L. ,1991, Geotechnical engineering aspects of microzonation, proceedings of the fourth international conference of seismic zonation, Stanford, California,1, pp.199-259.

Finn, W. D. L. ,1988, Dynamic analysis in geotechnical engineering, Proceedings, Earthquake Engineering and Soil Dynamics II - Recent Advances in Ground Motion Evaluations. Geotechnical Special Publication ,ASCE, 20, pp.523-591.

Finn W.D.L. and Wightman A., 2003, Ground motion amplification factors for the proposed 2005 edition of the National Building Code of Canada ,Canadian Journal of Civil Engineering, 30, pp. 272-278. 
Frankel A.D., Carver D.L., and Williams R.A., 2002, Nonlinear and Linear Site Response and Basin Effects in Seattle for the M 6.8 Nisqually, Washington, Earthquake Bulletin of the Seismological Society of America, 92, pp.2090 - 2109.

Hardin, B.O. and Drnevich V.P., 1972, Shear modulus and damping in soils: Design equations and curves," Journal of Soil Mechanics and Foundation Engineering Division, ASCE, 98(7), pp.667-692.

Hartzell S., Bonilla L.F., and Williams R.A., 2004, Prediction of Nonlinear Soil Effects Bulletin of the Seismological Society of America, 94, pp.1609-1629.

Hoyos L.J. and Macari E.J., 1999, Influence of In Situ Factors on Dynamic Response of Piedmont Residual Soils, Journal of Geotechnical and Geoenvironmental Engineering, 125(4), pp. 271-279.

Hudson M.B., 1994, Behavior of slopes and earth dams during earthquakes, Doctoral thesis, University of California, Davis.

Hudson M., Idriss I.M. and Beikae M., 1994, QUAD4M program to evaluate the seismic response of the soil structures using finite element procedures and incorporating a compliant base, University of California, Davis.

Hughes, T. J.R., 1987, The finite element method, London, Prentice Hall.

Hunter J. A., Crow, H. L., Brooks, G. R., Pyne, M., Motazedian, D., Khaheshi-Banab, K., Lamontagne, M., et al. ,2010, Seismic site classification and site period mapping in the Ottawa area using geophysical methods. Ottawa, ON: Geological Survey of Canada, Open File 6237 in publication.

Hwang S.K., 1997, Dynamic properties of natural soils, PhD dissertation, The University of Texas at Austin.

Ishibashi, I., and X. Zhang, 1993, Unified dynamic shear moduli and damping ratios of sand and clay, Soils Foundations, 33(1), pp.182-191. 
Jarpe S., Hutchings L., Hauk T., and Shakal A., 1989, Selected strong- and weak-motion data from the Loma Prieta earthquake sequence, Seismological Research Letters, 60, pp.167-176.

Joyner W.B., Chen A.T.F., 1975, Calculation of nonlinear ground response in earthquakes, Bulletin of Seismological Society of America, 65, pp.1315-1336.

Kausel E. and Tassoulas J.L., 1981, Transmitting boundaries: a closed-form comparison, Bulletin of the Seismological Society of America (BSSA), 71, pp.143-159.

Kramer S.L., 1996,Geotechnical earthquake engineering, Prentice-Hall international series in civil engineering and engineering mechanics, Upper Saddle River, New Jersey.

Kwok A.O.L, Stewart J.P. and Hashash Y.M., 2008, Nonlinear Ground-Response Analysis of Turkey Flat Shallow Stiff-Soil Site to Strong Ground Motion, Bulletin of the Seismological Society of America (BSSA), 98, pp.331-343.

Lee C-P., Tsai Y-B. and Wen K-L., 2006, Analysis of nonlinear site response using the LSST downhole accelerometer array data, Soil Dynamics and Earthquake Engineering, 26(5), pp.435-460.

Lysmer J. and Kuhlemeyer, R. L., 1969, Finite dynamic model for infinite media, Journal of the Engineering Mechanics Division (J. Eng. Mech. Div. ),ASCE 92, PP.65-91.

Masing G., 1926, Eigenspannungen und Vertfestigung beim Messing, In: Proceedings of the second international congress of applied mechanics, Zurich, Switzerland, pp. 332-335 [in German].

McCall K.R., 1994, Theoretical study of non-linear elastic wave propagation, Journal of Geophysical Research, 99 (B2), pp.2591-2600. 
Motazedian D., Hunter J.A. and Khaheshi Banab K., 2007, Using a railway train as a seismic source to observe trapped waves in a low Vs soil layer overlying a high Vs bedrock, submitted to Bulletin of the Seismological Society of America.

NEHRP (1994), 1994, Recommended provisions for seismic regulations of new buildings: Part 1, provisions. FEMA 222A, National Earthquake Hazard Reduction Program, Federal Emergency Management Agency, Washington, D.C.

Okamoto S., 1973, Introduction to earthquake engineering, University of Tokyo Press, Tokyo, Japan.

Pugin A., Hunter, J.A., Motazedian, D., and Khaheshi Banab, K. , 2007, An application of shear wave reflection landstreamer technology for soil response evaluation of earthquake shaking in an urban area, Ottawa, Ontario, Proceedings of a Symposium on the Application of Geophysics to Engineering and Environmental Problems (SAGEEP), Denver, CO.

Reynolds J., 1997, an introduction to applied and environmental geophysics, John Wiley and Sons Ltd.

Reddy J.N., 2004, An introduction to the Finite Element Method.

Roblee C. and Ciou B. , 2004, A proposed geoindex model for design selection of nonlinear properties for site response analysis." Prop., NSF/PEER Int. Workshop on Uncertainties in Nonlinear Soil Properties and their Impact on Modeling Dynamic Soil Response, University of California at Berkeley, Berkeley, California.

Seed H.B. and Idriss I.M., 1970, Report No. EERC 70-10, Soil Moduli and Damping Factors for Dynamic Response Analyses, Earthquake Engineering Research Center, University of California at Berkeley, Berkeley, California.

Seed H.B. and Peacock W.H., 1971, Test procedures for measuring soil liquefaction characteristics, Journal of Soil Mechanics and Foundation Division, ASCE, 97 (8), pp.1099-1119. 
Seed, H.B. and Sun, J.H. , 1989, Implication of site effects in the Mexico City earthquake of September 19, 1985 for Earthquake-Resistant Design Criteria in the San Francisco Bay Area of California, Report No. UCB/EERC-89/03, Earthquake Engineering Research Center, University of California, Berkeley.

Stokoe K. H. , Darendeli M.B. and Gilbert R.B,. 2004, Development of a new family of normalized modulus reduction and material damping curves, Prop., NSF/PEER Int. Workshop on Uncertainties in Nonlinear Soil Properties and their Impact on Modeling Dynamic Soil Response, University of California at Berkeley, Berkeley, California.

Stokoe K.H., Hwang S.K., Lee J.N.K. and Andrus R.D., 1994, Effects of various parameters on stiffness and damping of soils to medium strains, In Proceedings, International Symposium on Pre-failure Deformation Characteristics of Geomaterials (Japanese Society of Soil Mechanics and Foundation Engineering), Sapporo, Japan, pp.785-816.

Stokoe K.H., Danendeli M.B., Andrus R.D. and Brown L.T., 1999, Dynamic soil properties: Laboratory, field and correlation studies; Proc. 2nd Int. Conf. Earthquake Geotech. Engg., Lisboa, Portugal, pp.811-846.

Sun J.I., Golesorkhi R. and Seed H.B., 1988, Dynamic moduli and damping ratios for cohesive soils, Report No. UCB/EERC-88/15.

Tsuda K., Archuleta R. and Steidl J. , 2005, Nonlinear site response: case study from 2003 and 2005 Miyagi-Oki Earthquakes, in International Workshop on Strong Ground Motion Prediction and Earthquake Tectonics in Urban Areas, pp.115-118.

Tsuda K., Steidl J., Archuleta R. and Assimaki D., 2006, Site-Response Estimation for the 2003 Miyagi-Oki Earthquake Sequence Considering Nonlinear Site Response, Bulletin of the Seismological Society of America, 96, pp.1474-1482. 
Vucetic M., Lanzo G. and Doroudian M., 1988, Damping at small strains in cyclic simple shear test, Journal of Geotechnical Geo-environmental Engineering,ASCE, 124 (7), pp.585-594.

Wen K.L., 1994, Nonlinear soil response in ground motions, Earthquake Engineering and Structural Dynamics, 23, pp.599-608.

Yu G., Anderson J.G. and Siddharthan R., 1993, On the characteristics of non-linear soil response, Bulletin of the Seismological Society of America (BSSA), 83, pp.218-244.

Zhang J., Andrus R.D., and Juang C.H., 2005, Normalized Shear Modulus and Material Damping Ratio Relationships, Journal of Geotechnical and Geoenvironmental Engineering,ASCE, 131 (4), pp. 453-464.

Zienkiewicz O.C. and Taylor R.L., 2000, The finite element method, Published by Butterworth-Heinemann. 


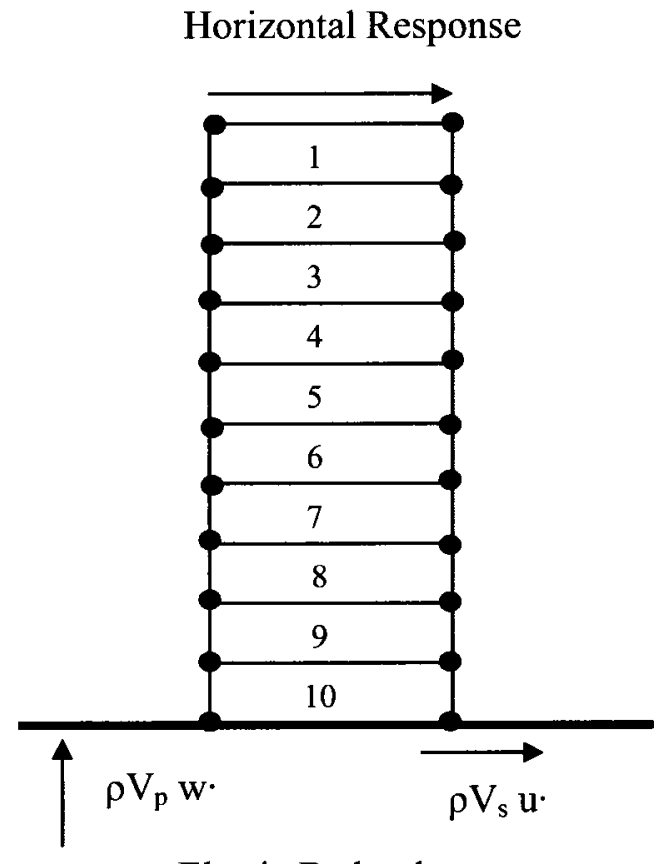

Elastic Bedrock

Fig. 4.1: Scheme of finite element mesh for site response analysis. The seismic waves propagate from elastic bedrock. Applied boundary conditions $\left(\rho V_{p} w \cdot\right.$ and $\left.\rho V_{s} u \cdot\right)$ make the infinite medium a roughly perfect absorber. These boundary conditions are explained in section 4.5 . 


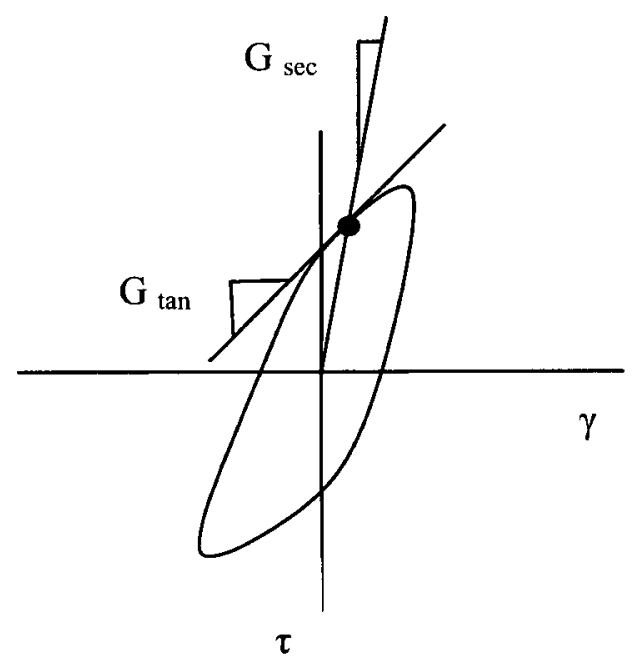

Fig. 4.2: A typical hysteresis loop that is used to describe the stress-strain $(\tau-\gamma)$ behavior of soil materials for loading-unloading during the earthquake shaking. For a point shown on the loop, secant modulus $\left(G_{\text {sec }}\right)$ and tangent modulus $\left(G_{\text {tan }}\right)$ are illustrated.

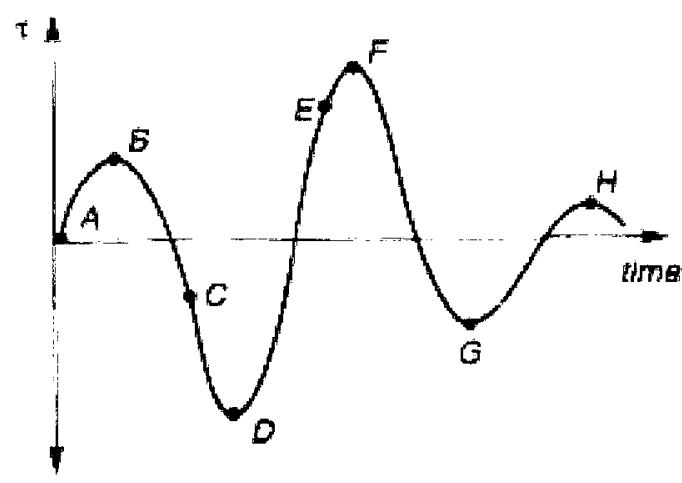

(a)

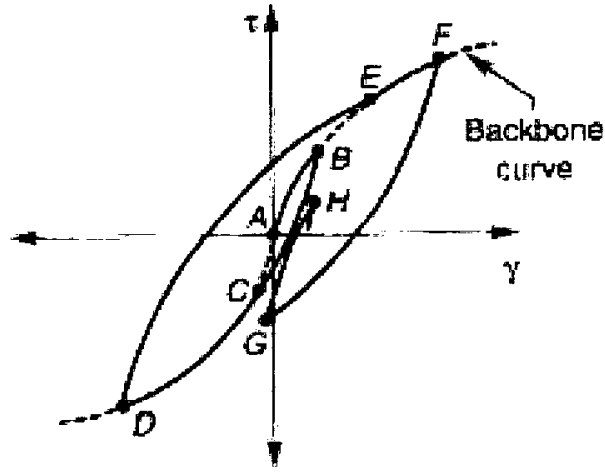

(b)

Fig. 4.3: Extended Masing's rule (a) shear stress variation with time (b)shear stressstrain behavior (from Kramer, 1996). 


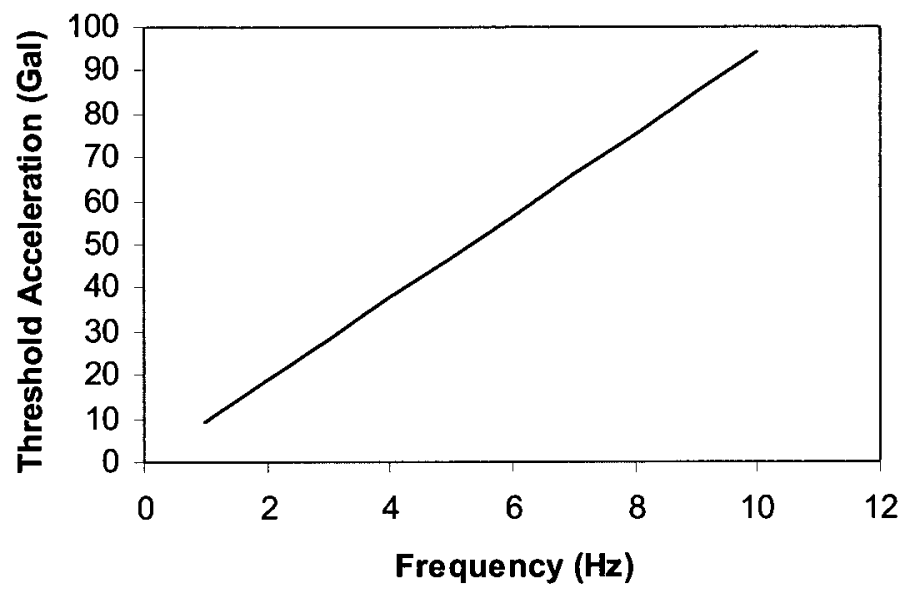

Fig. 4.4: Threshold acceleration of soil non-linearity versus frequency for a Ottawa soil with average shear wave velocity of $150 \mathrm{~m} / \mathrm{sec}$ and shear strain of $10^{-4}$.

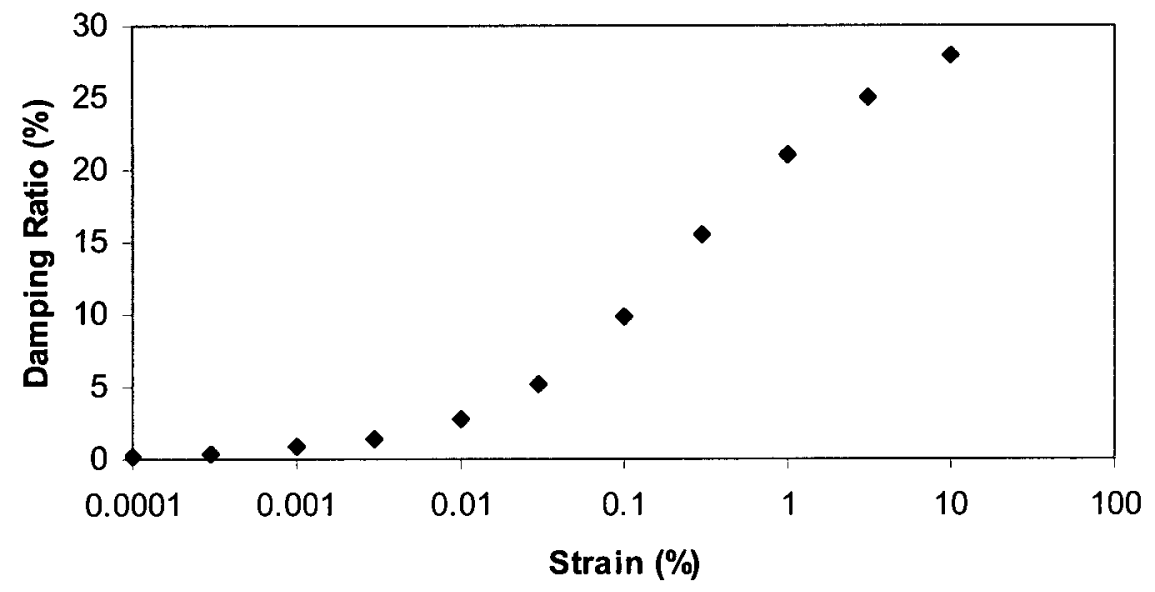

Fig. 4.5: Variation of damping ratio of clayey soil from Seed and Sun (1989). 


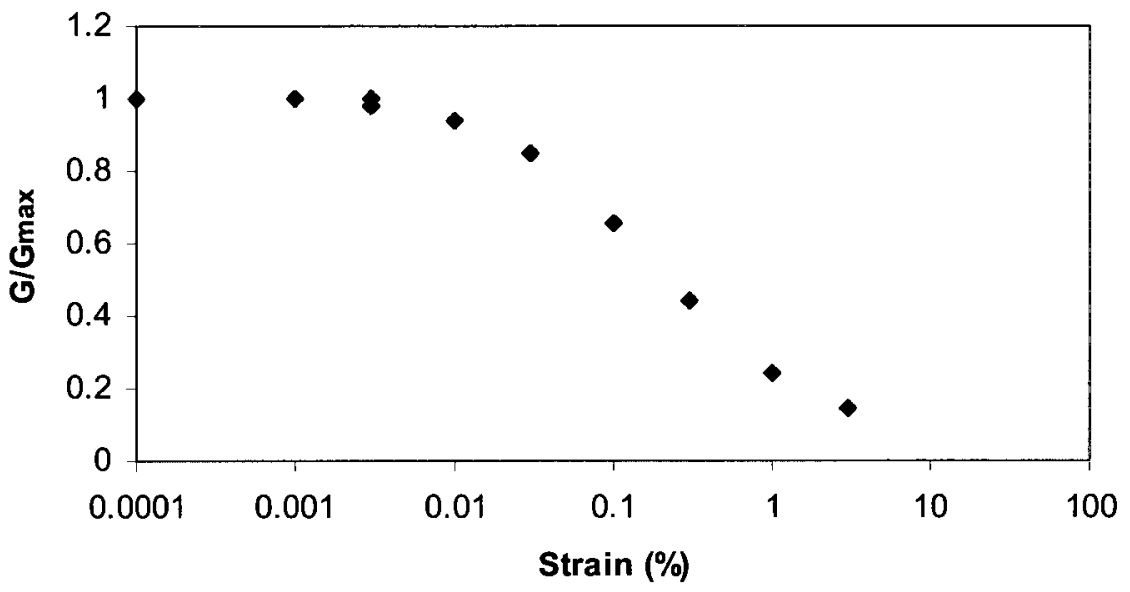

Fig. 4.6: Variation of shear modulus of clayey soil from Seed and Sun (1989). 


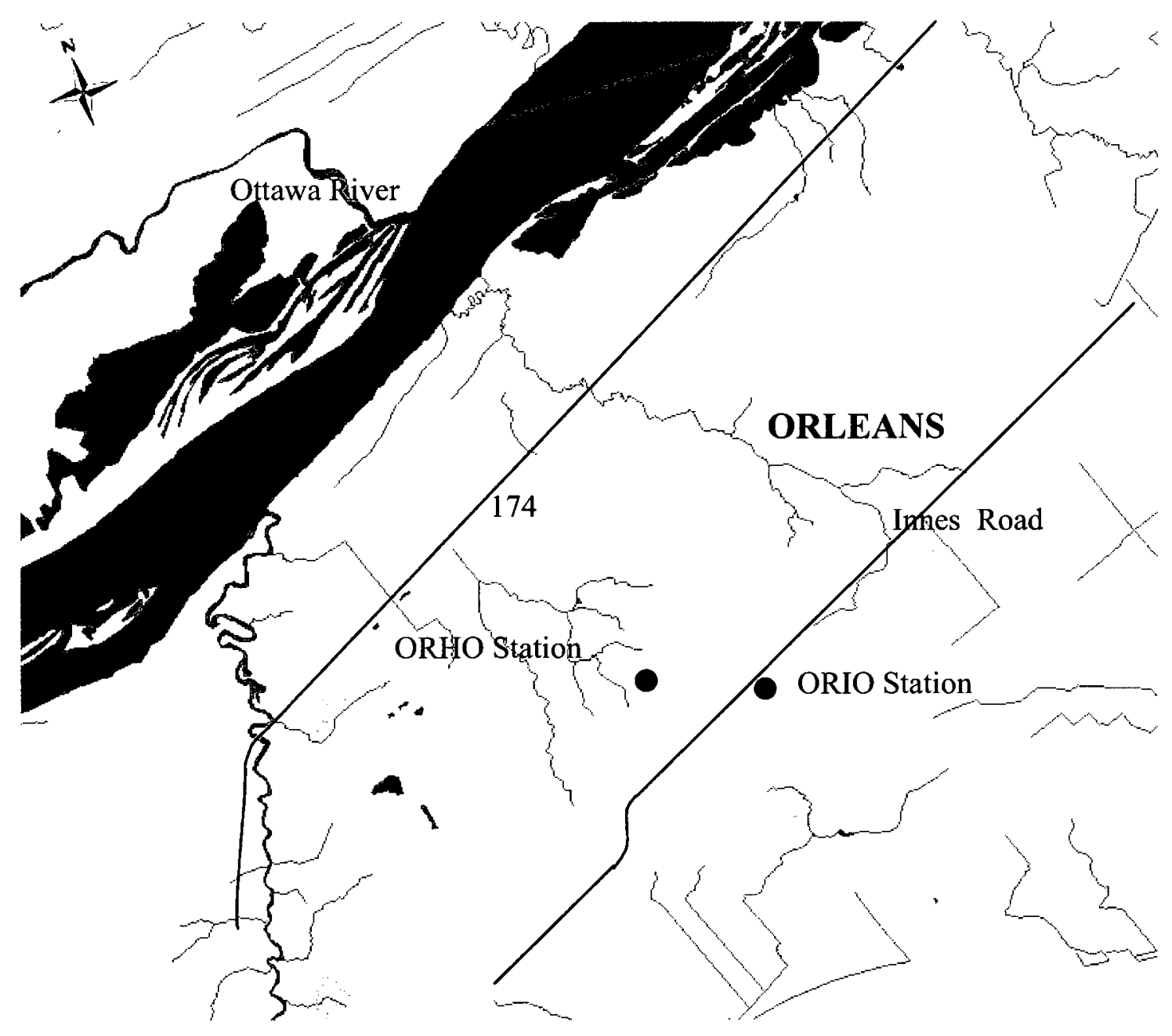

Scale

$1 \mathrm{~cm}=1271 \mathrm{~m}$

Fig. 4.7: Locations of ORHO and ORIO stations in the eastern part of the city of Ottawa. ORIO station is located on the rock and is close enough to ORHO. The stations are 1.3 $k m$ far from each other; this distance is small enough relative to the epicentral distance of recorded local and regional earthquakes. 


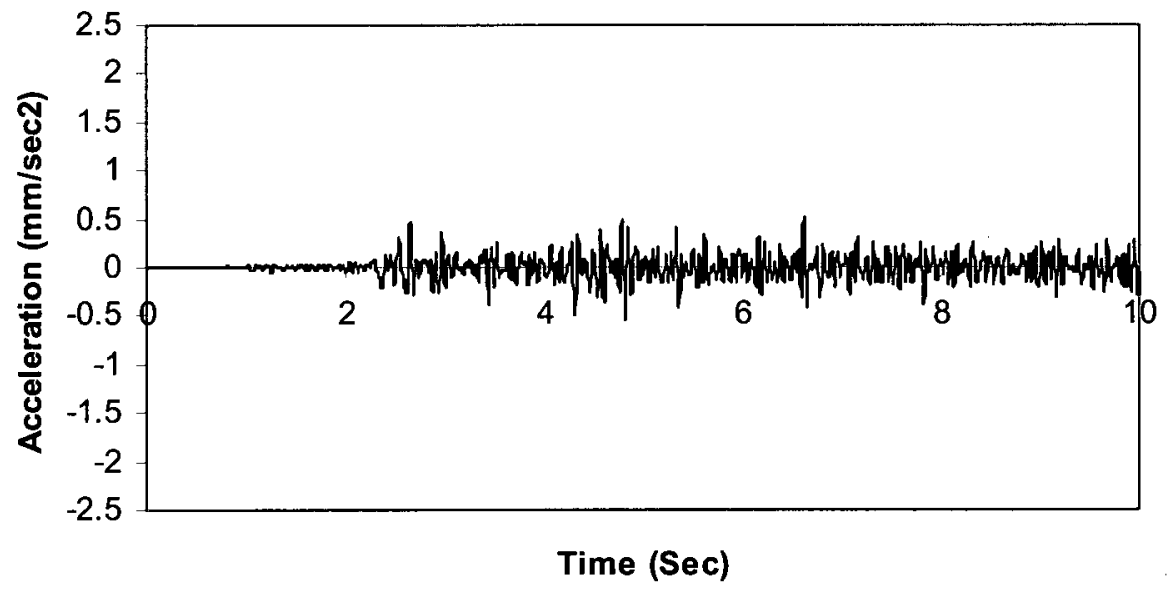

Fig. 4.8: Horizontal component of the acceleration time history recorded on ORIO station (from the earthquake of Christmas Eve, 2008).

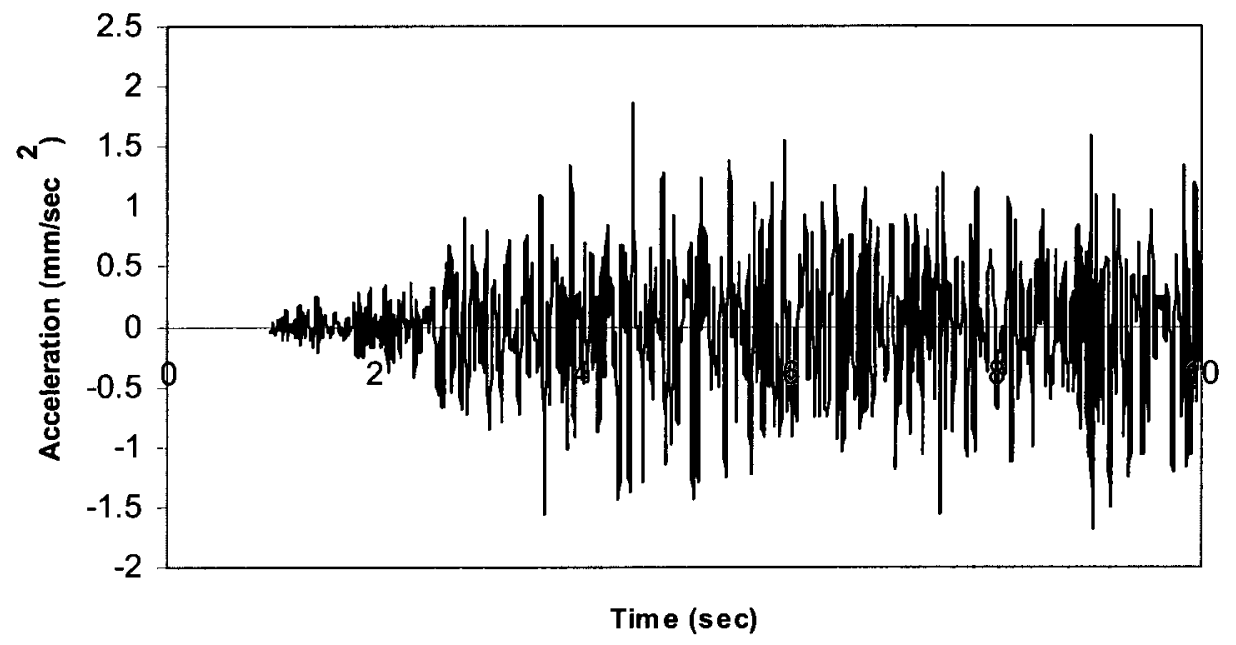

Fig. 4.9: Horizontal component of the acceleration time history recorded on ORHO station. 


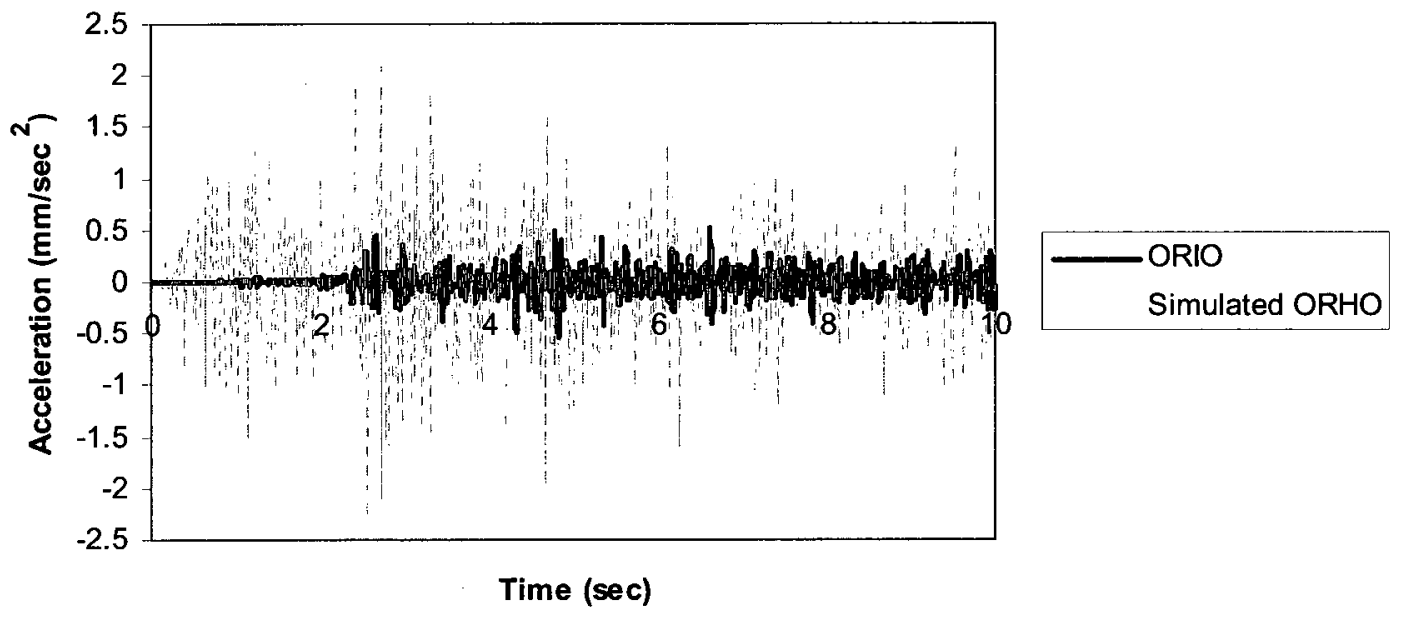

Fig. 4.10: Comparison between the simulated acceleration time history for ORHO station and the acceleration record on ORIO station.

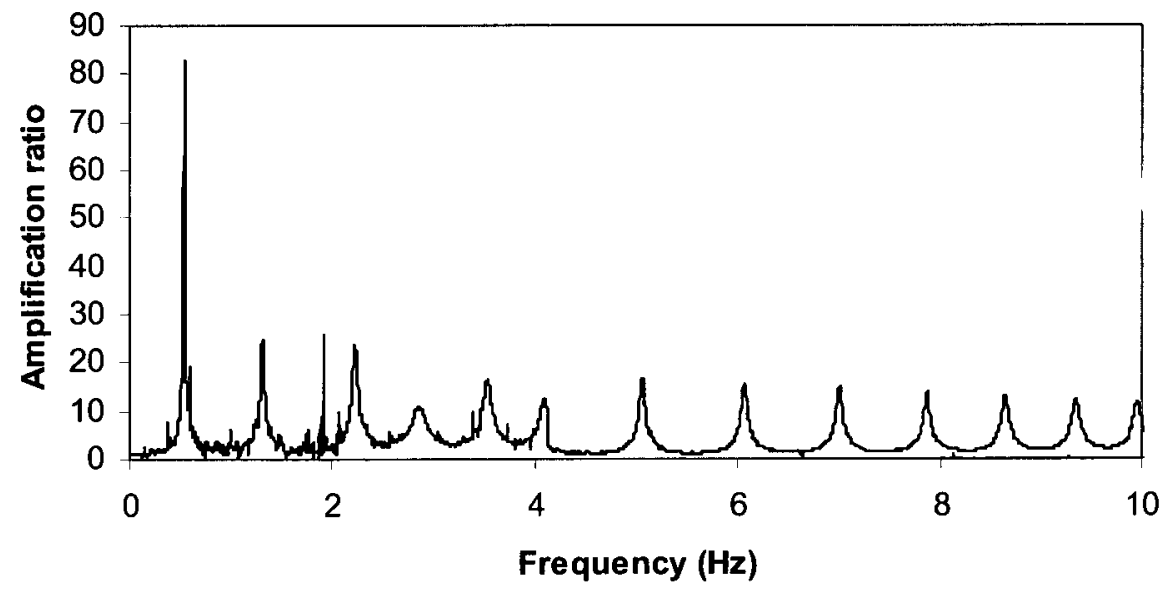

Fig. 4.11: Amplification curve on ORHO station from FEM using the weak motion recorded on ORIO station. Soil profile (profile \#1) includes loose Leda clay with the depth of $81 \mathrm{~m}$. 


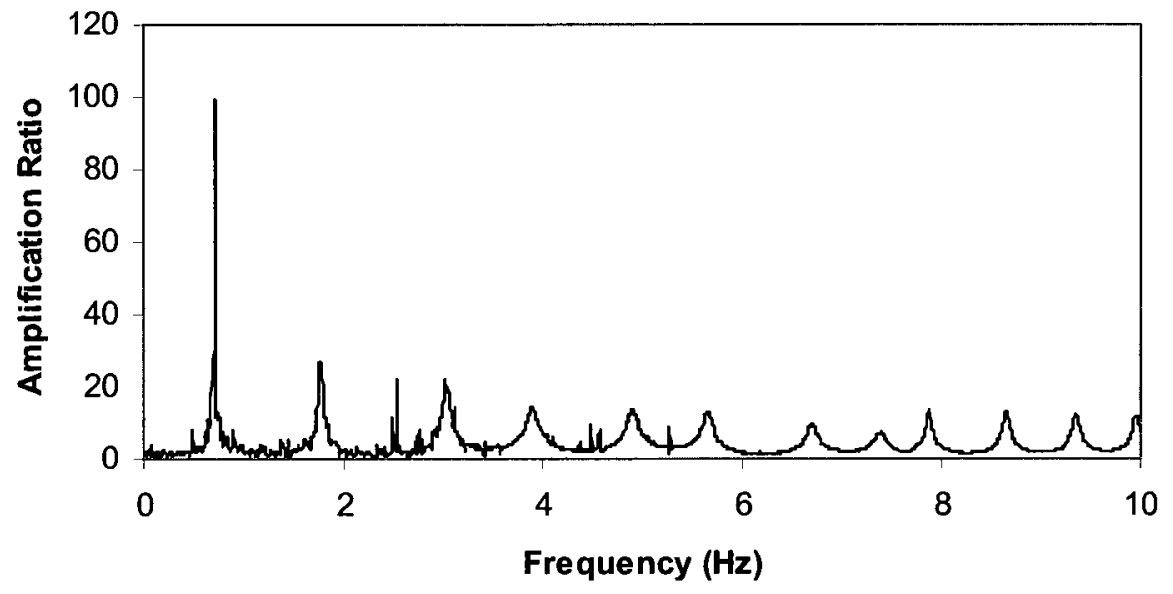

Fig. 4.12: Amplification curve on ORHO station from FEM using the weak motion recorded on ORIO station. Soil profile (profile\#2) includes the loose deposit of $81 \mathrm{~m}$, Leda clay, underlain with 10 m of glacial till.

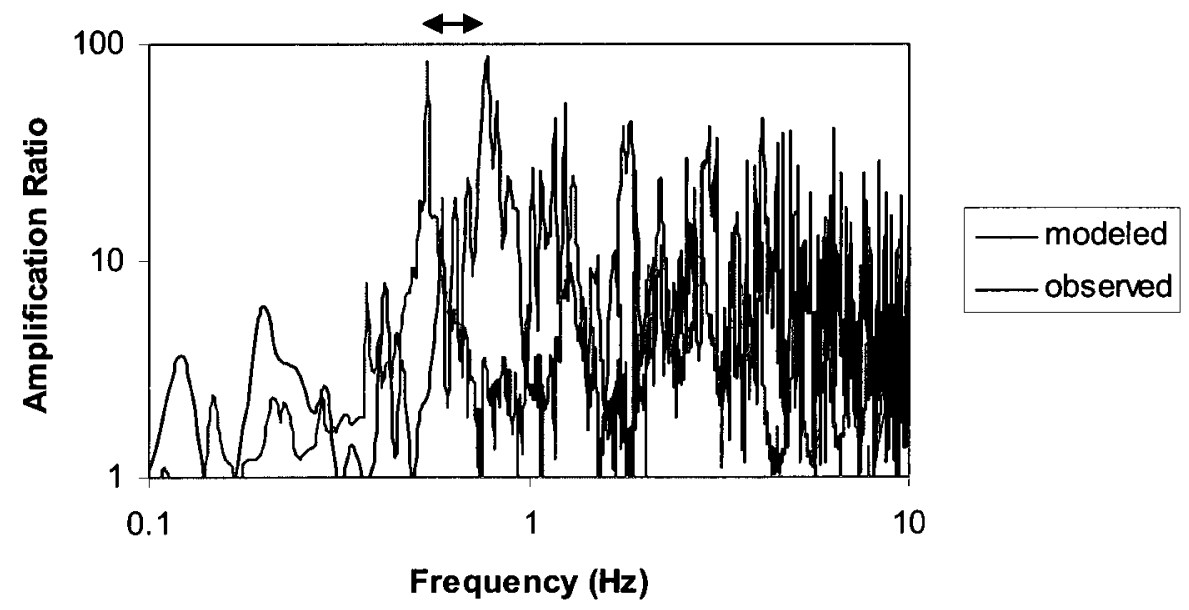

Fig. 4.13: Comparison of the observed and the modeled amplification ratios for ORHO station (profile \#1). The agreement between the peak values is satisfactory (amplification ratio of 86 from observation and 83 from modeling) although the fundamental frequency shift relative to the fundamental frequency of the site occurs (shift is shown with the arrow above the Figure). Fundamental frequencies are obtained $0.54 \mathrm{~Hz}$ and $0.75 \mathrm{~Hz}$ from the modeling and observation, respectively. 


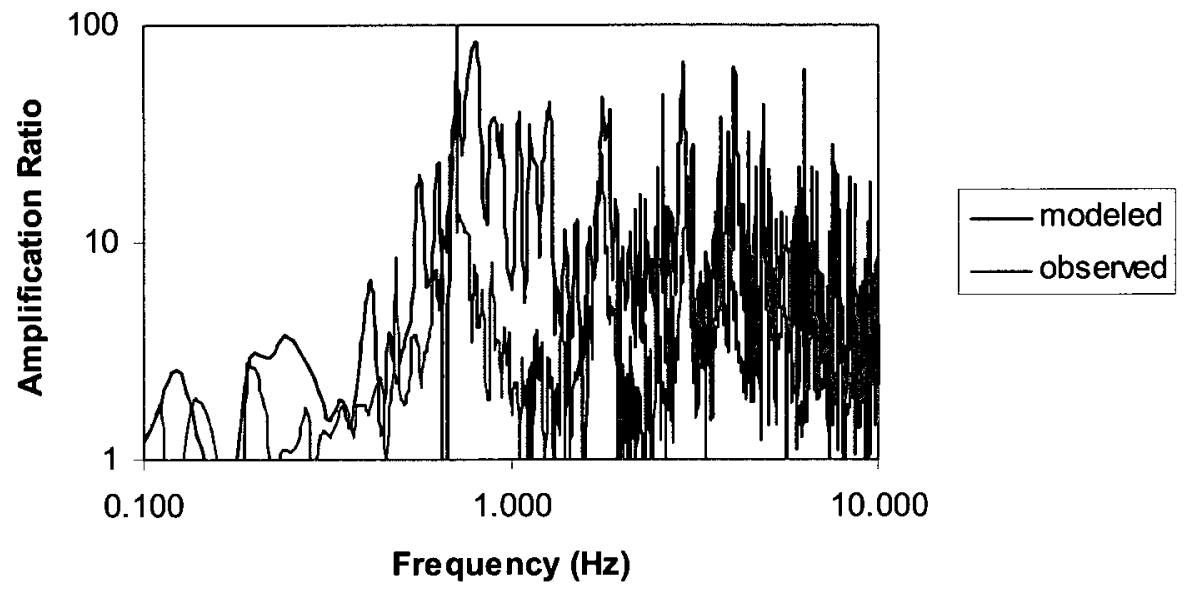

Fig. 4.14: Comparison of the observed and the modeled amplification ratios for ORHO station (profile \#2). Not only the agreement between the peak amplification ratios is good but also the fundamental frequency of modeling is obtained $0.7 \mathrm{~Hz}$ that is close to the fundamental frequency of 0.75 from observation. 


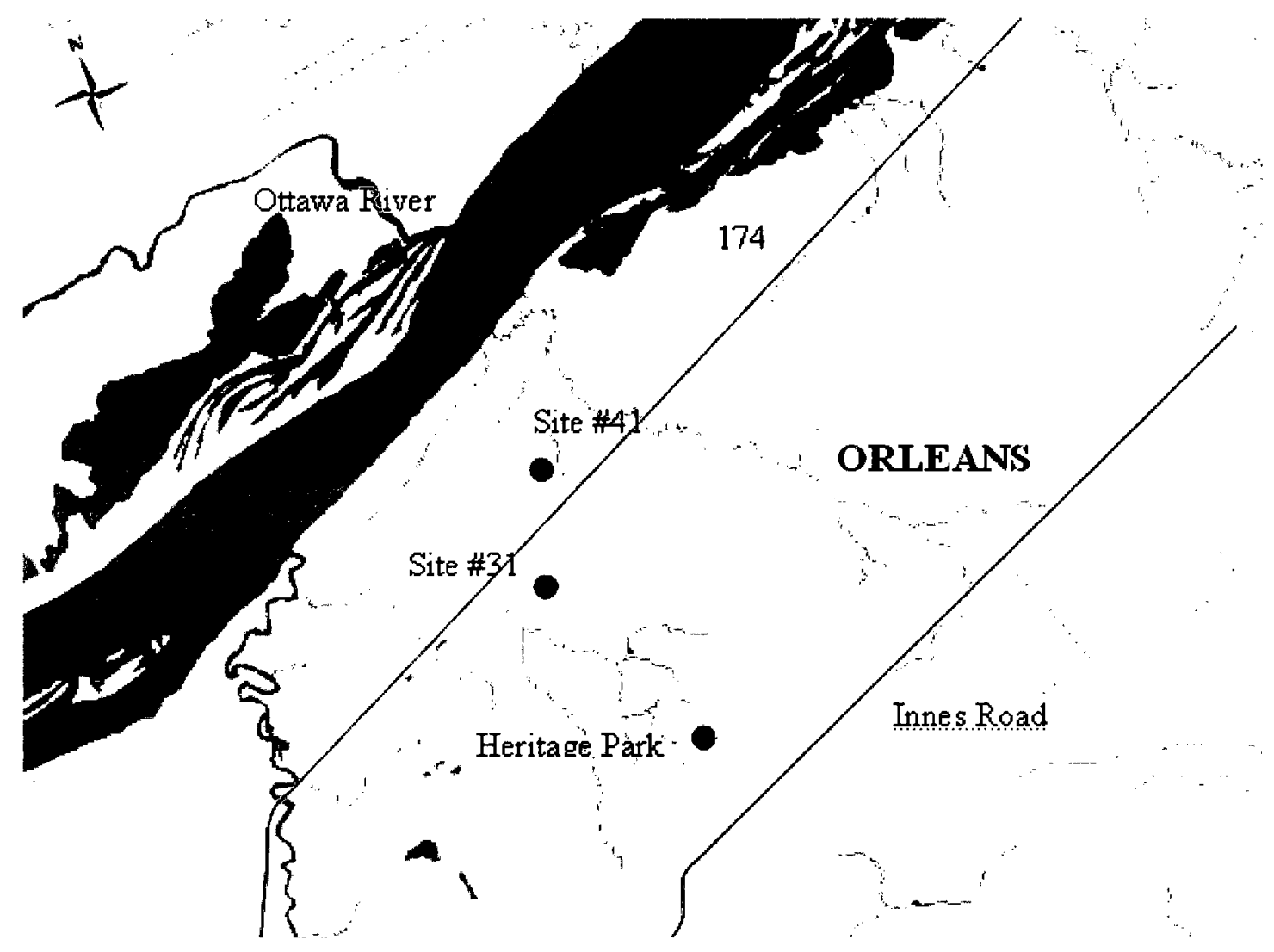

Fig. 4.15: Three investigated sites in the eastern part of the city of Ottawa. These sites were studied for the combined effect of shaking intensity and soil/bedrock contrast ratio on the seismic amplification variation. 


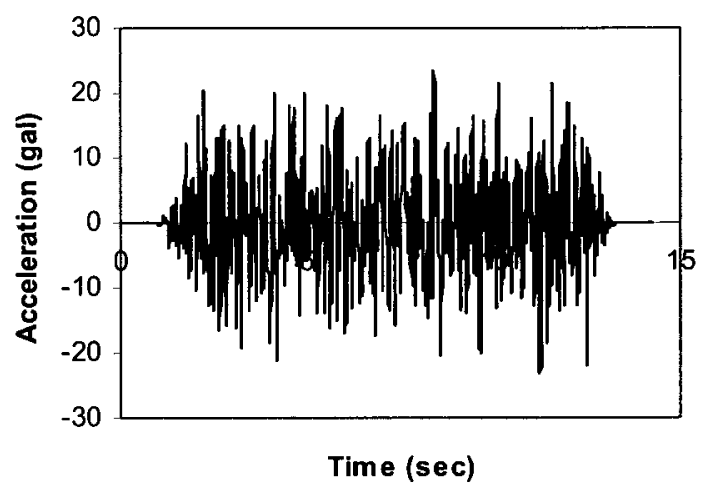

(a)

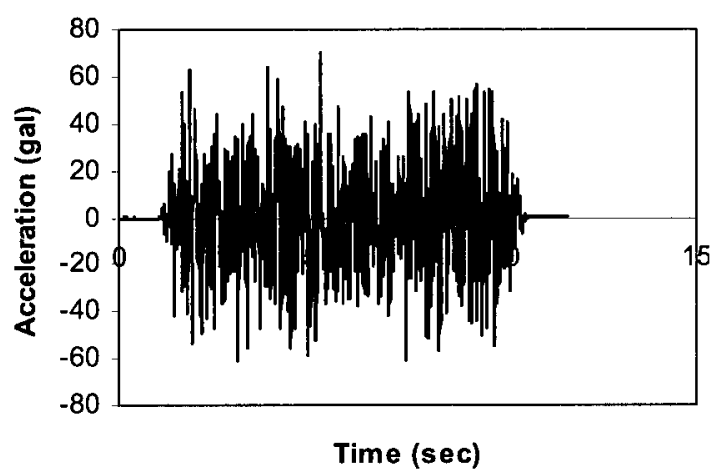

(c)

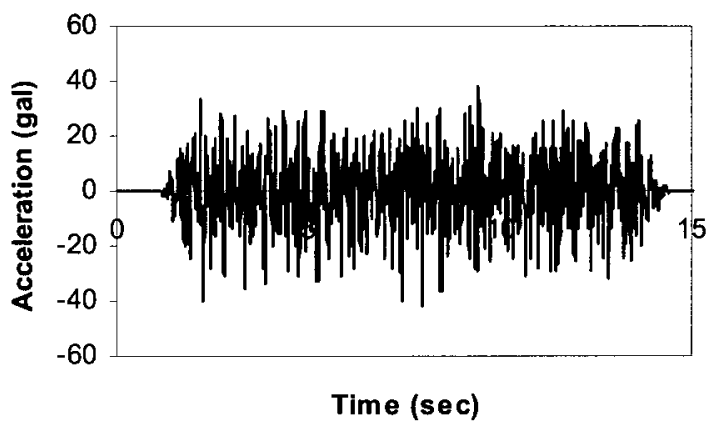

(b)

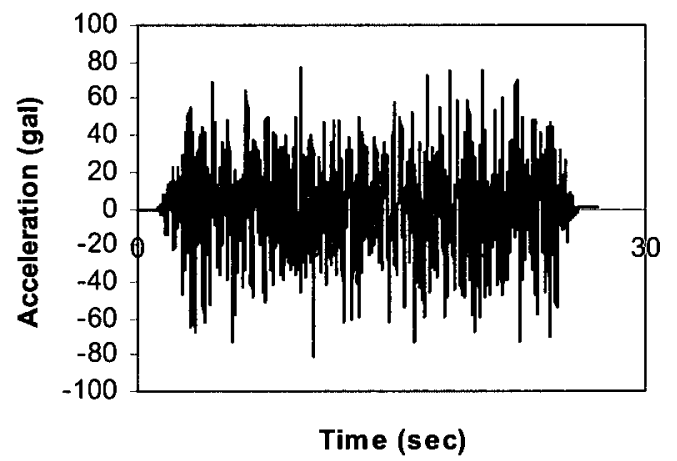

(d)

Fig. 4.16: Artificial acceleration time history of Eastern Canadian EQs (10\% in 50 years) with: (a) PGA of $23 \mathrm{gal}$; (b) PGA of $41 \mathrm{gal}$; (c) PGA of $70 \mathrm{gal}$; (d) PGA of $81 \mathrm{gal}$. 


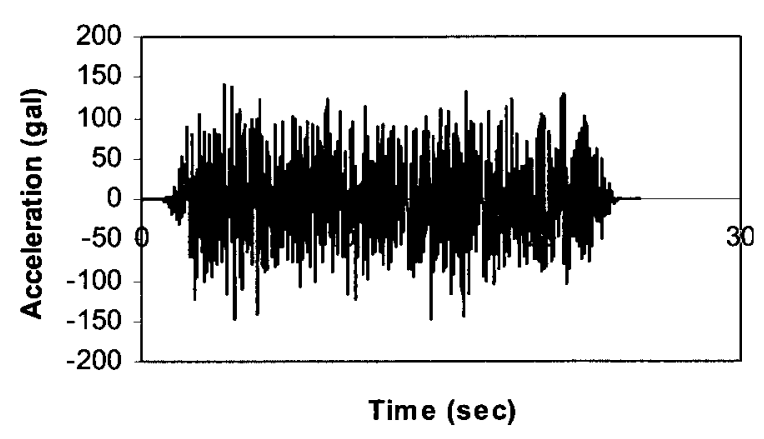

(a)

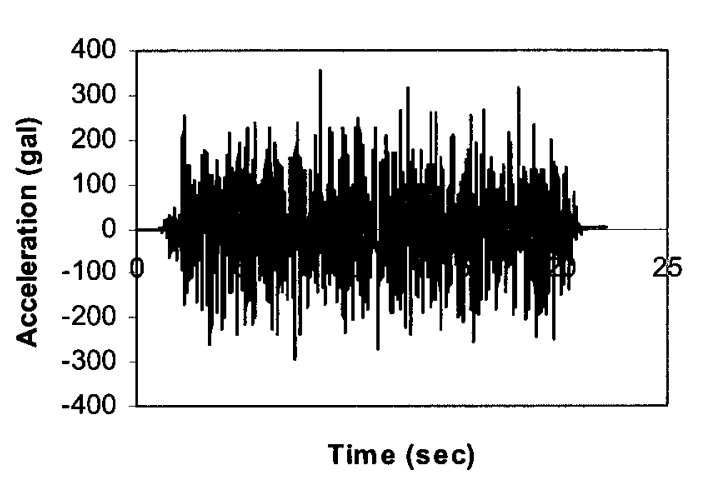

(c)

c)

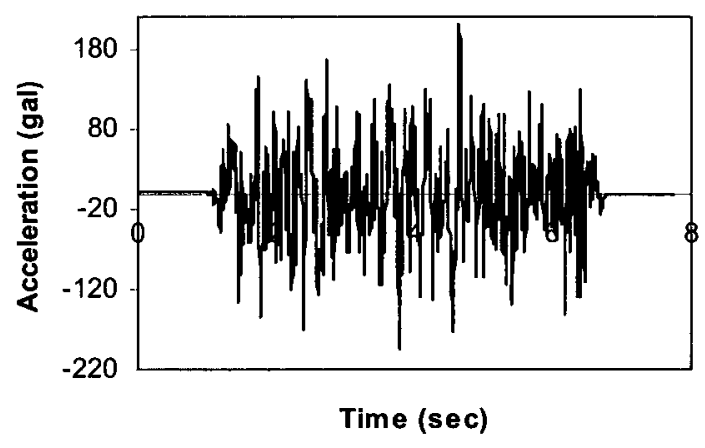

(b)

Fig. 4.17: Artificial acceleration time history of Eastern Canadian EQs (10\% in 50 years) with: (a) PGA of $147 \mathrm{gal}$; (b) PGA of $208 \mathrm{gal}$; (c) PGA of $349 \mathrm{gal}$. 


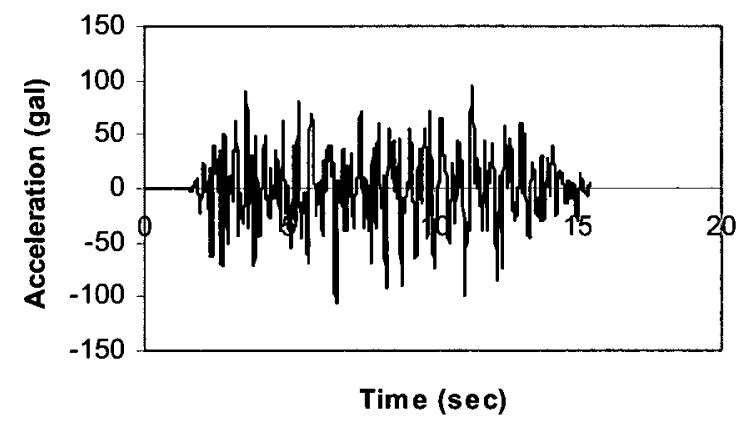

(a)

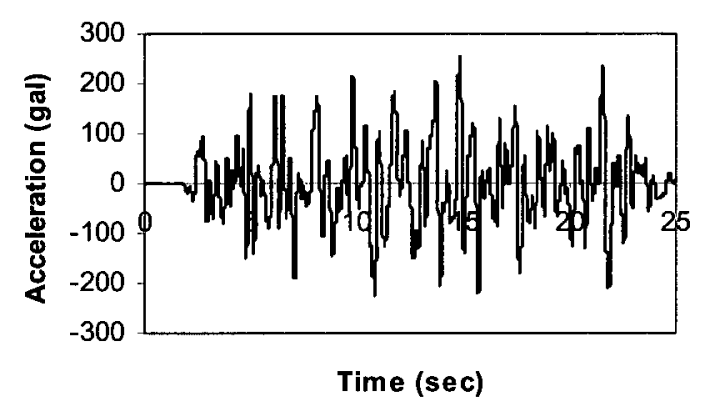

(c)

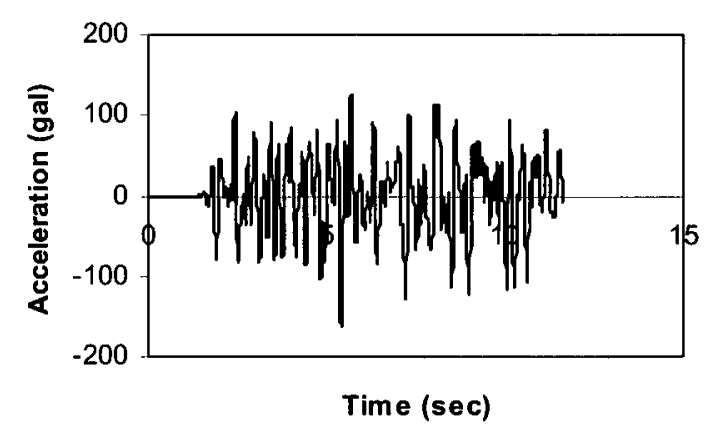

(b)

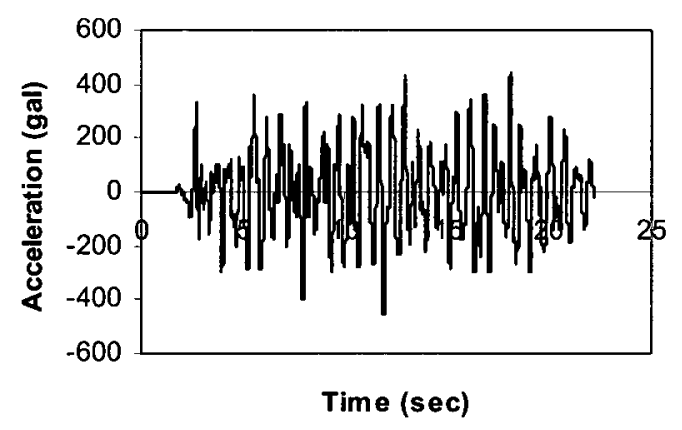

(d)

Fig. 4.18: Acceleration time history at ground level for Heritage Park site subjected to record having (a) PGA of 40 gal; (b) PGA of 70 gal; (c) PGA of 147 gal; (d) PGA of 349 gal. 


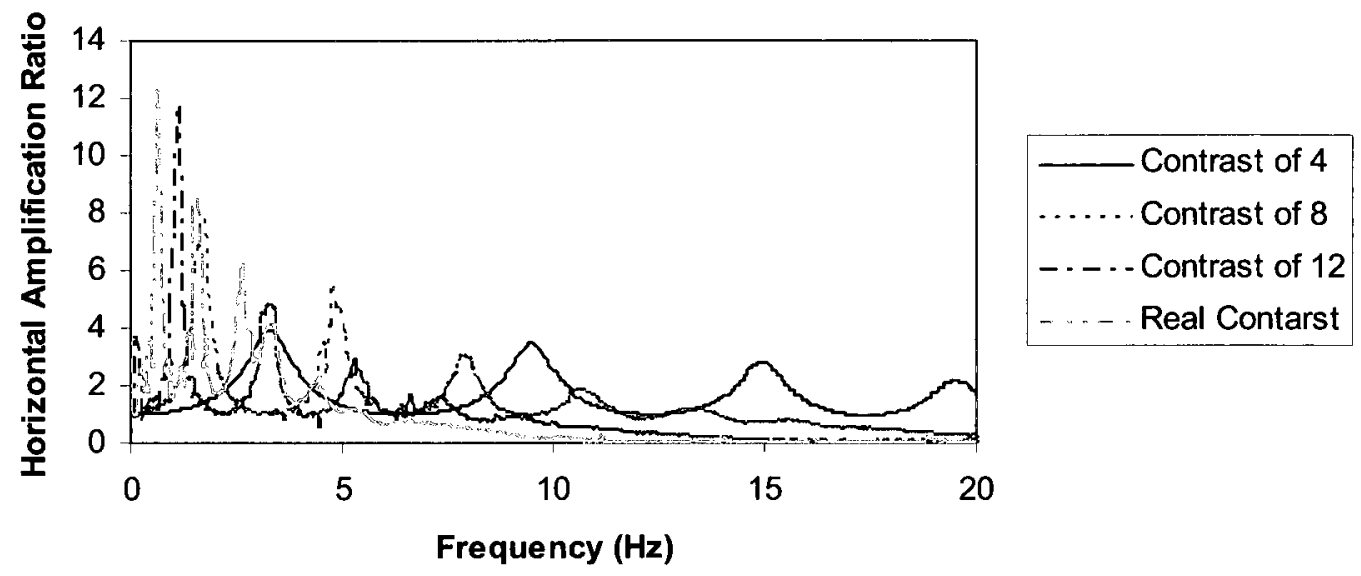

Fig. 4.19: Amplification curves at Heritage park site for different contrast ratios. The site is subjected to the acceleration time history having PGA of 23 gal.

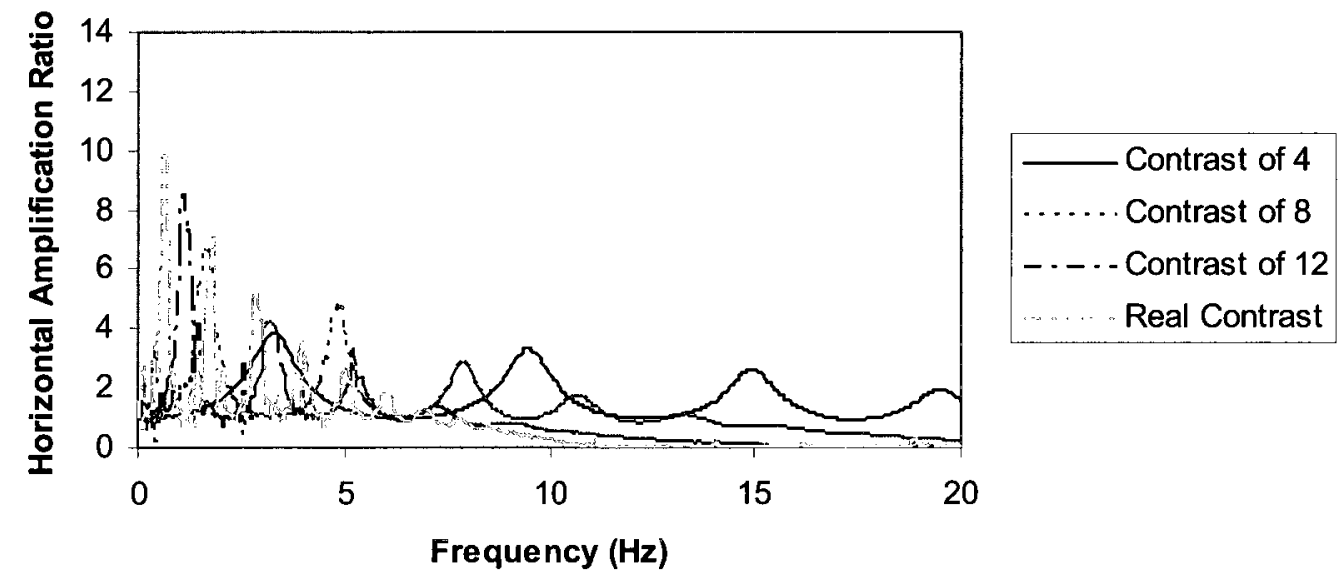

Fig. 4.20: Amplification curves at Heritage park site for different contrast ratios. The site is subjected to the acceleration time history having PGA of $41 \mathrm{gal}$. 


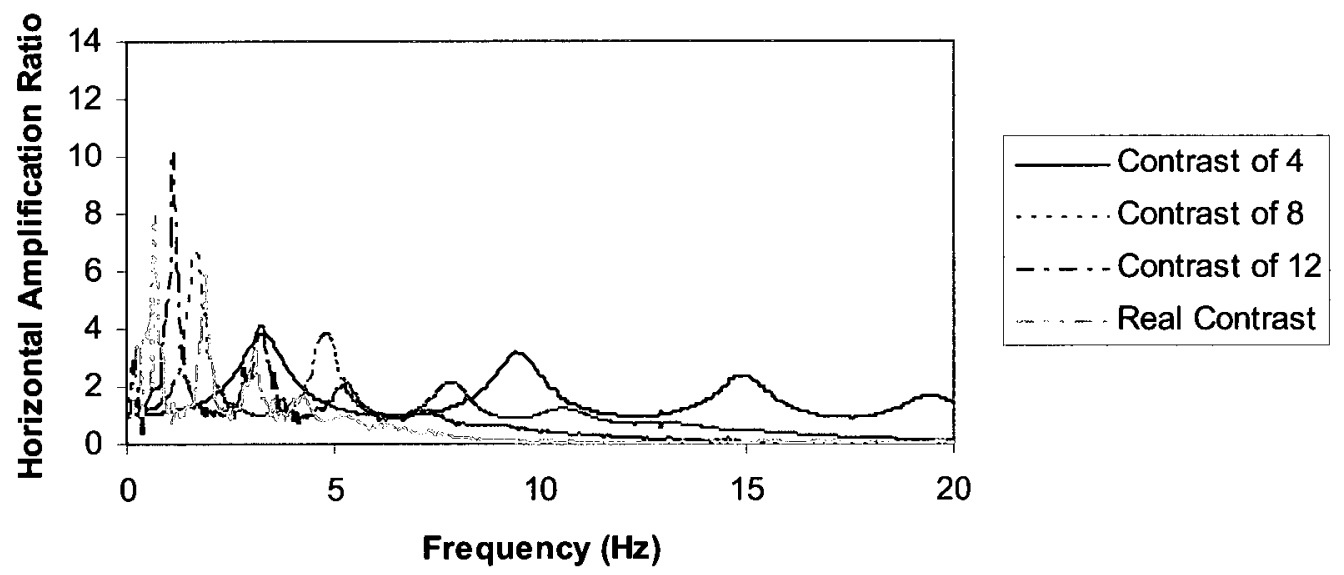

Fig. 4.21: Amplification curves at Heritage park site for different contrast ratios. The site is subjected to the acceleration time history having PGA of $70 \mathrm{gal}$.

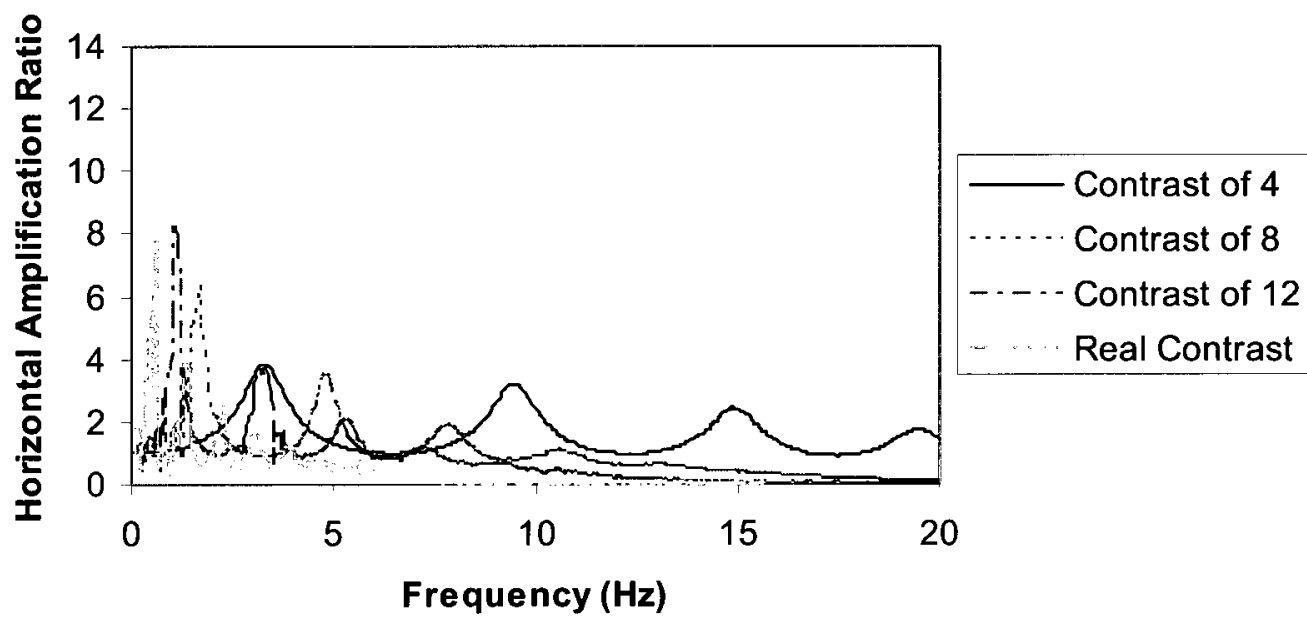

Fig. 4.22: Amplification curves at Heritage park site for different contrast ratios. The site is subjected to the acceleration time history having PGA of 81 gal. 


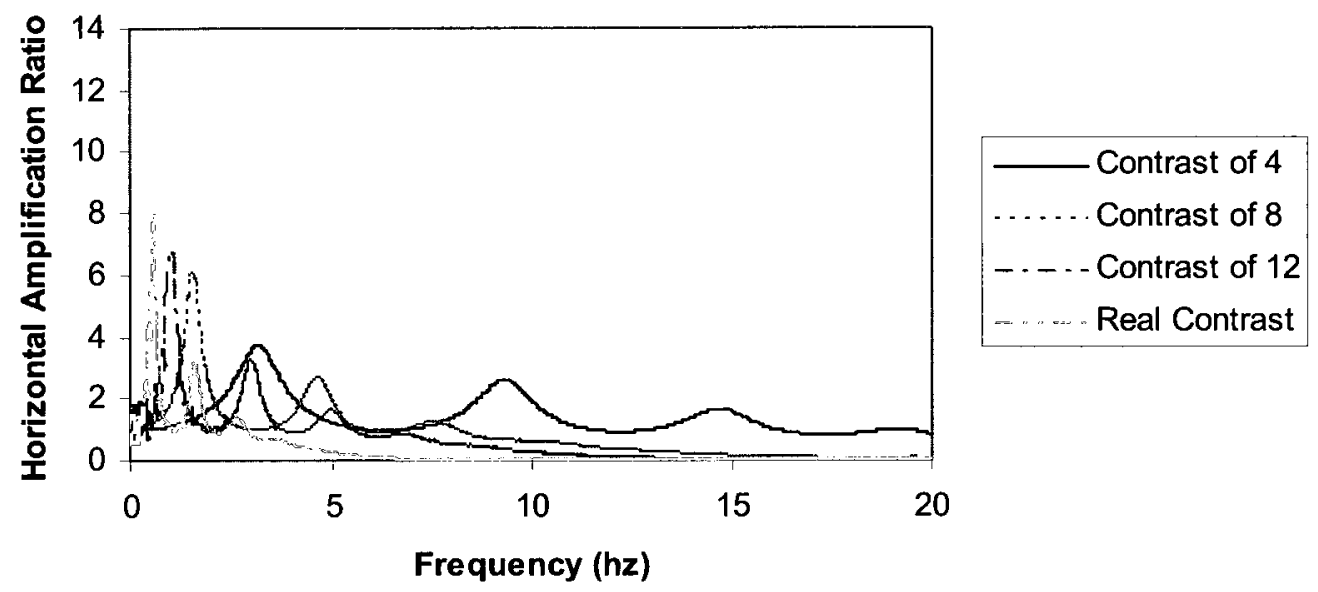

Fig. 4.23: Amplification curves at Heritage park site for different contrast ratios. The site is subjected to the acceleration time history having PGA of $147 \mathrm{gal}$.

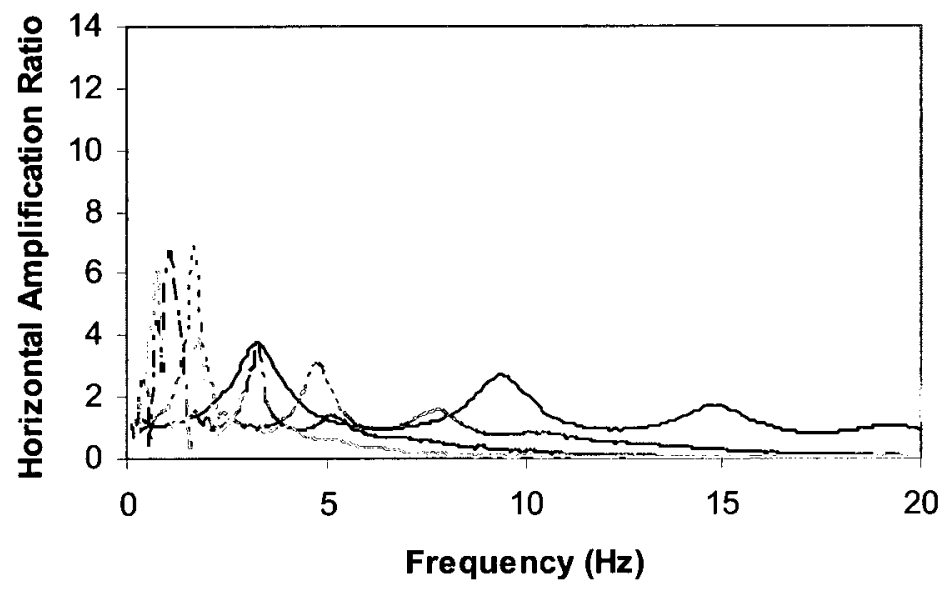

Fig. 4.24: Amplification curves at Heritage park site for different contrast ratios. The site is subjected to the acceleration time history having PGA of $208 \mathrm{gal}$. 


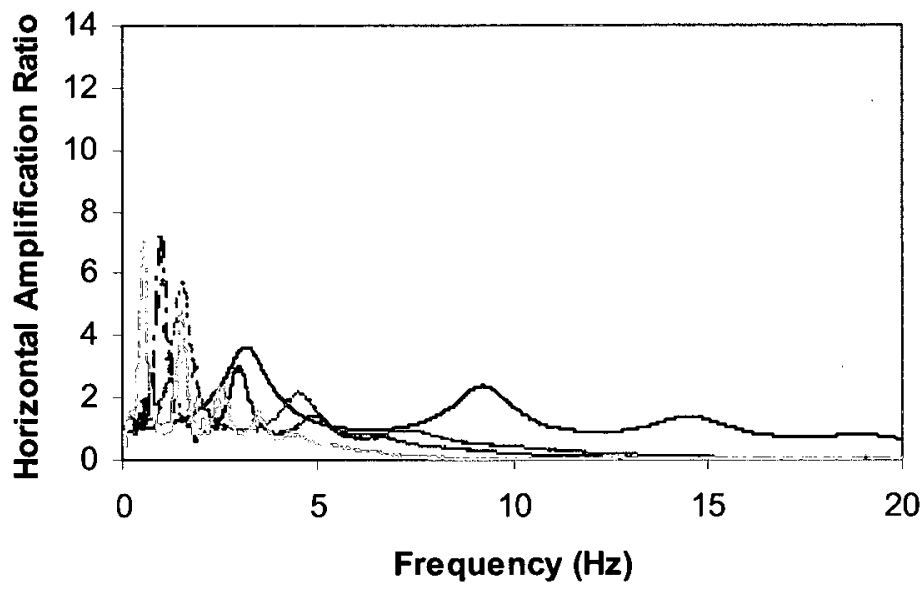

$$
\begin{aligned}
& \text { Contrast of } 4 \\
& \text {...... Contrast of } 8 \\
& \text { - - - - Contrast of } 12 \\
& \text {....... Real Contrast }
\end{aligned}
$$

Fig. 4.25: Amplification curves at Heritage park site for different contrast ratios. The site is subjected to the acceleration time history having PGA of $349 \mathrm{gal}$.

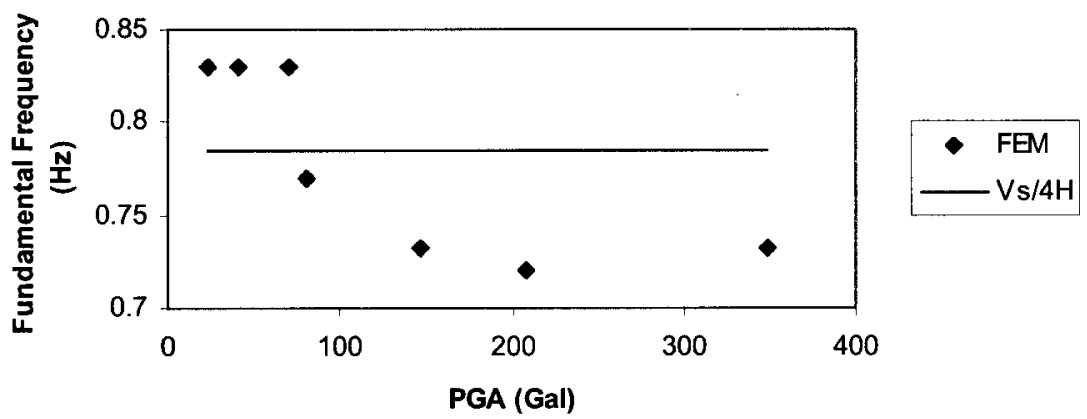

Fig. 4.26: Variation of the fundamental frequency of site \#31 versus $P G A$. The frequencies from FEM are compared with fundamental frequency of the site obtained from average shear wave velocity. The best-fit equation to non-linear part $(P G A>81$ gal) is: $f_{0}=0.89 P G A^{-0.04}$ 


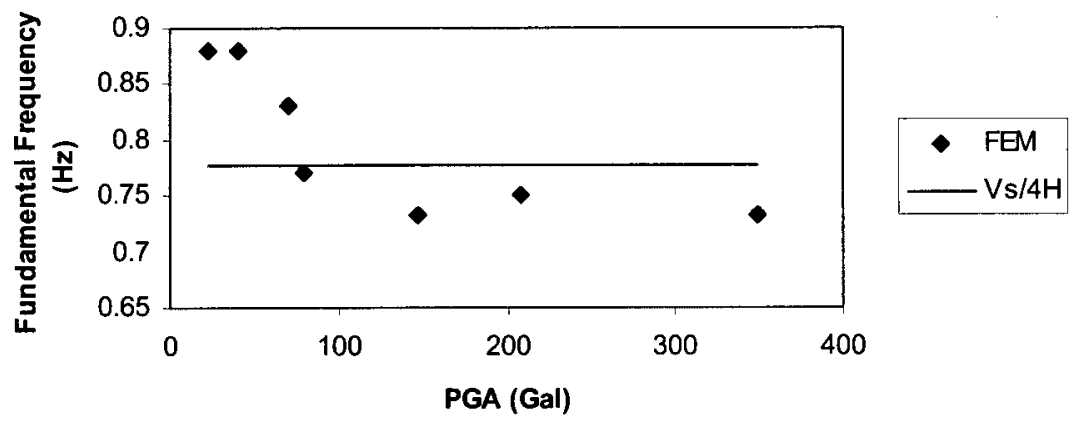

Fig. 4.27: Variation of the fundamental frequency of site $\# 41$ versus $P G A$. The frequencies from FEM are compared with fundamental frequency of the site obtained from average shear wave velocity. The best-fit equation to non-linear part ( $P G A>81$ gal) is: $f_{0}=0.87 P G A^{-0.03}$

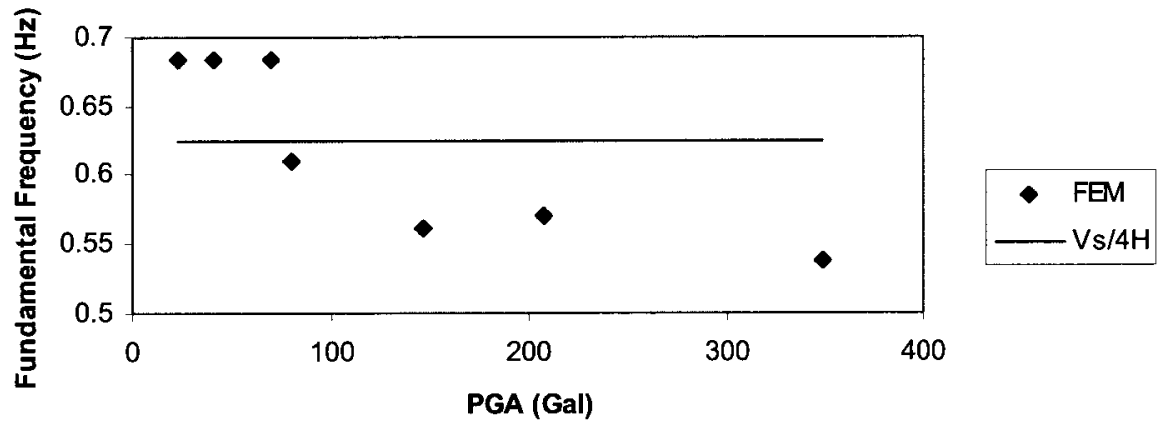

Fig. 4.28: Variation of the fundamental frequency of Heritage park site versus PGA. The frequencies from FEM are compared with fundamental frequency of the site obtained from average shear wave velocity. The best-fit equation to non-linear part $(P G A>81$ gal) is : $f_{0}=0.86 P G A^{-0.08}$ 


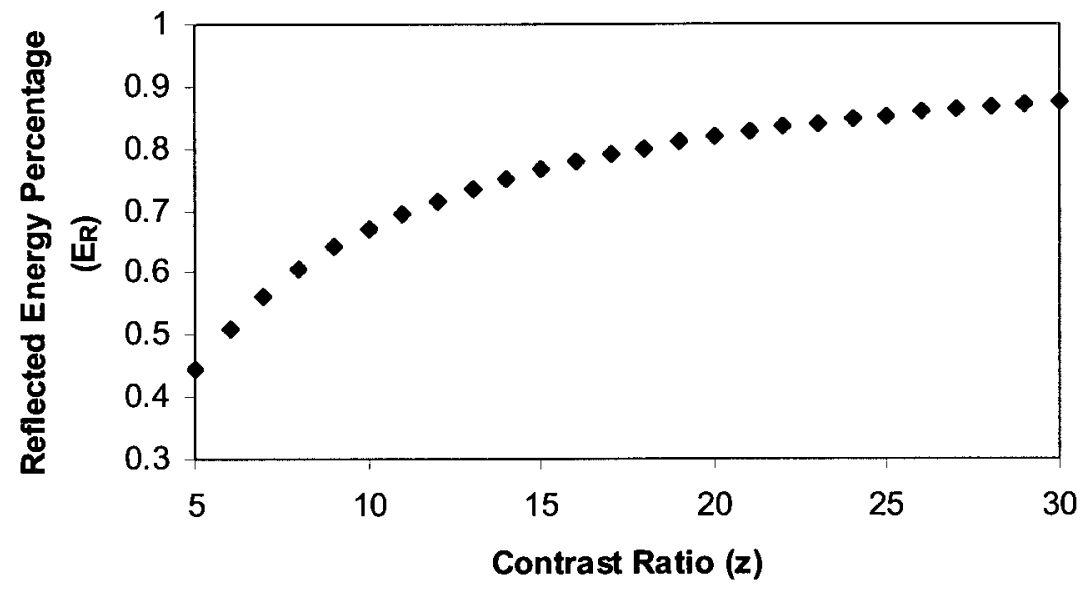

Fig. 4.29: Variation of the reflected energy percentage $\left(E_{R}\right)$ of the seismic waves with the contrast ratio of soil-bedrock formation.

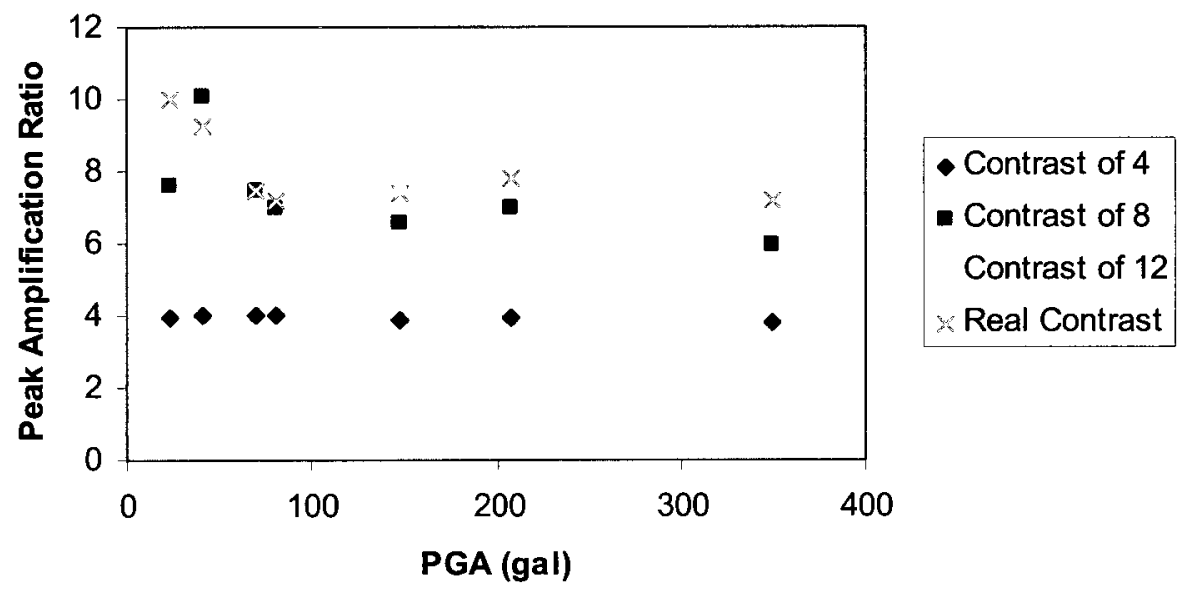

Fig. 4.30: Variation of the peak amplification ratio versus contrast ratio and PGA for site \# 31. Saturation behavior of amplification ratio (in a constant $P G A$ ) is observed when the contrast ratio exceeds high values. 


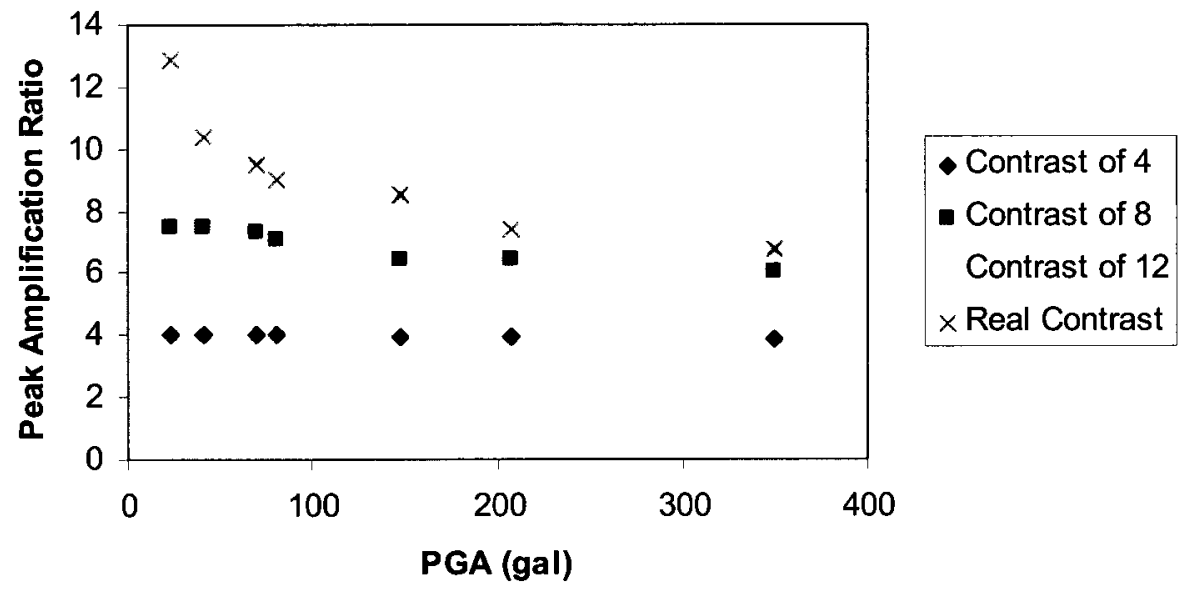

Fig. 4.31: Variation of the peak amplification ratio versus contrast ratio and PGA for site \# 41. Saturation behavior of amplification ratio (in a constant $P G A$ ) is observed when the contrast ratio exceeds high values.

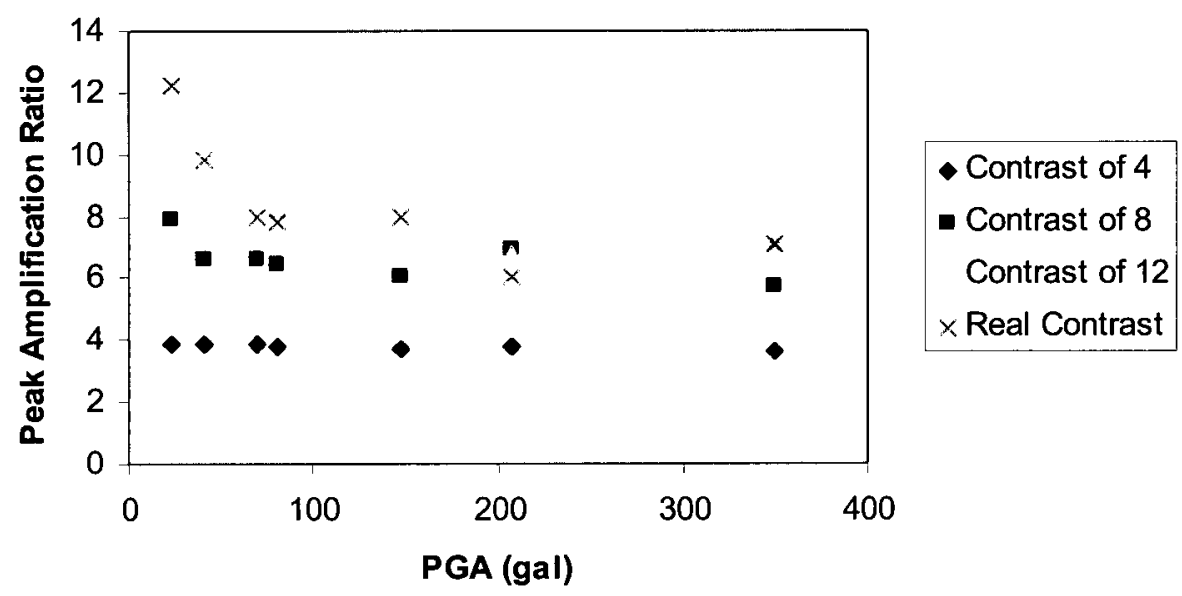

Fig. 4.32: Variation of the peak amplification ratio versus contrast ratio and PGA for Heritage Park site. Saturation behavior of amplification ratio (in a constant PGA) is observed when the contrast ratio exceeds high values. 


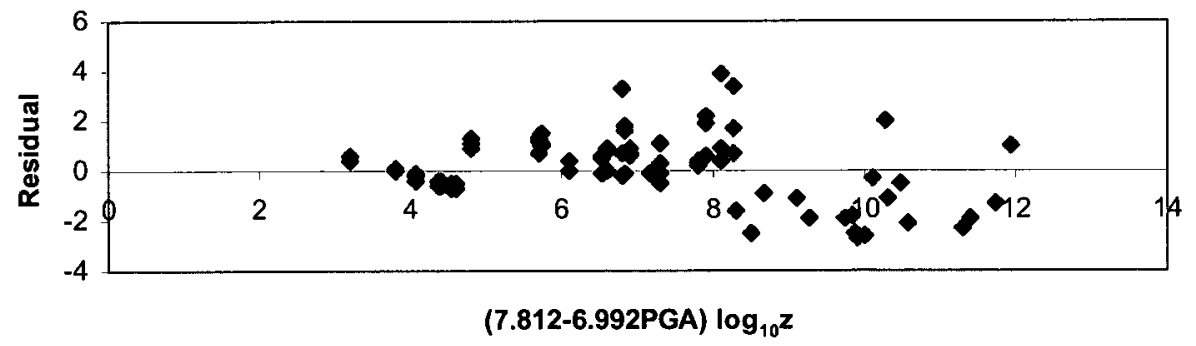

Fig. 4.33: Residual plot for the simulated $F_{f o}$ values versus equation (4-38)

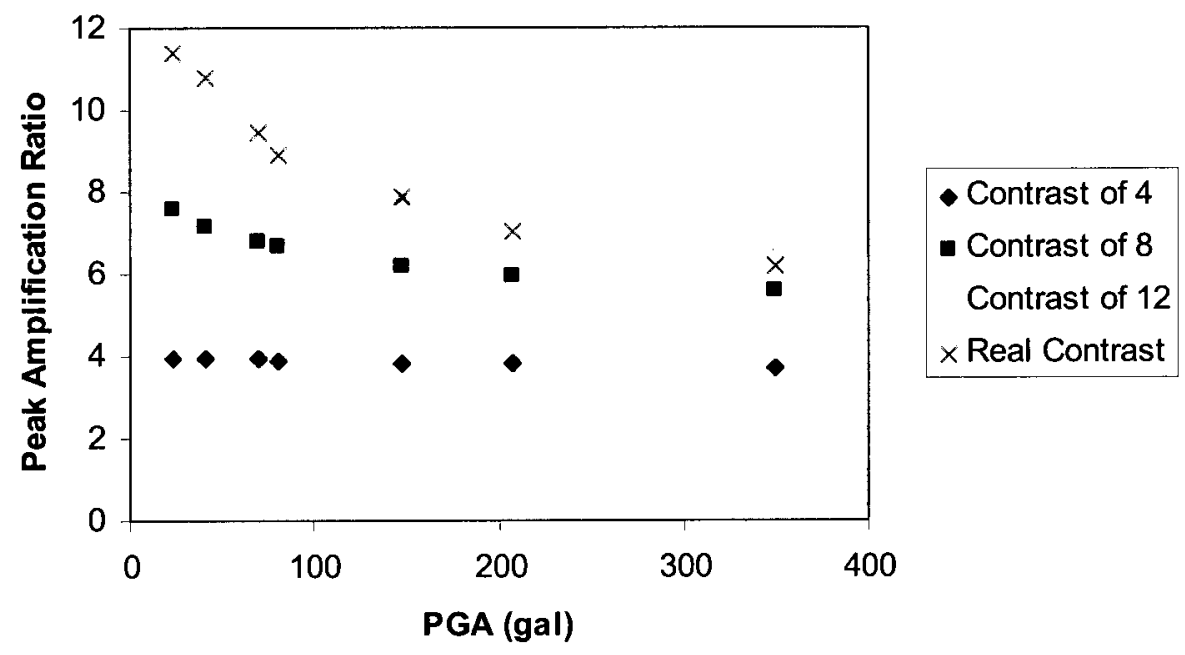

Fig. 4.34: Variation of the peak amplification ratio $\left(F_{p 0}\right)$ versus contrast ratio and $P G A$ for site \#31. The scaled records are used to obtain $F_{f o}$ for a pair of $(P G A, z)$. Similar to Figures 37 to 39 the saturation behavior of amplification ratio (in a constant $P G A$ ) is confirmed when the contrast ratio reaches exceeds high values. 


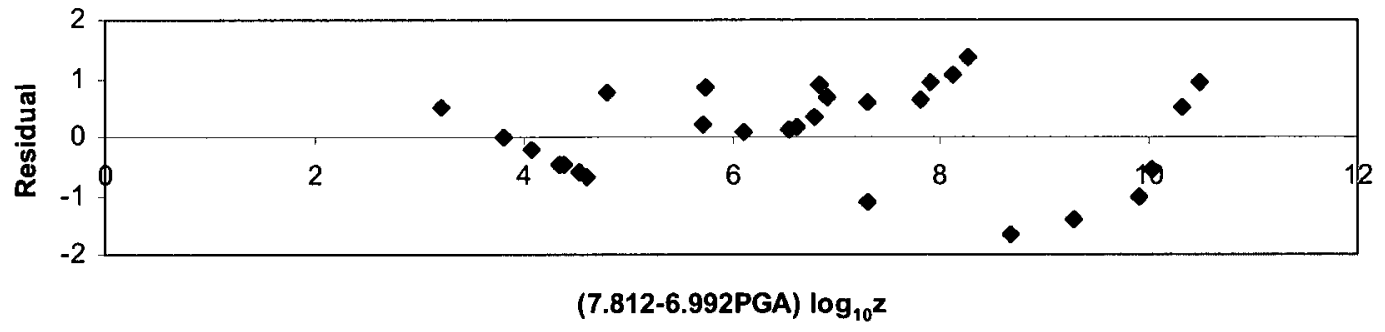

Fig. 4.35: Residual plot for the simulated $F_{f 0}$ values (using scaled records) and the equation (4-38) at site \#31.

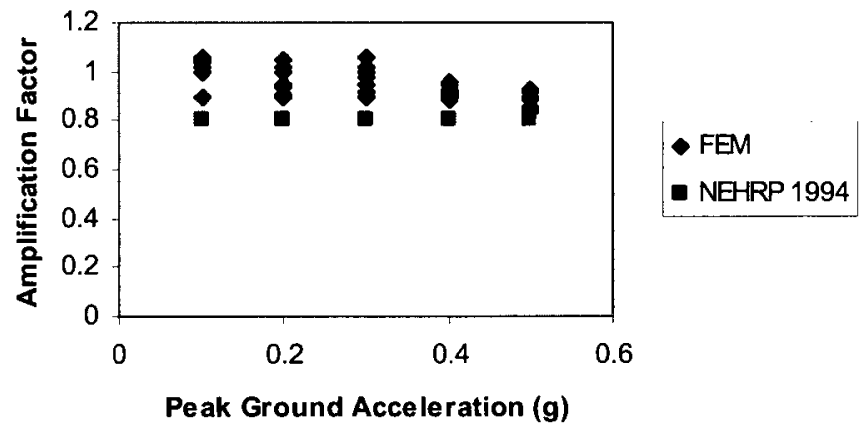

Fig. 4.36: High Frequency amplification values for class $A$ of different soil-bedrock configurations subjected to shaking intensities from $0.1 \mathrm{~g}$ to $0.5 \mathrm{~g}$.

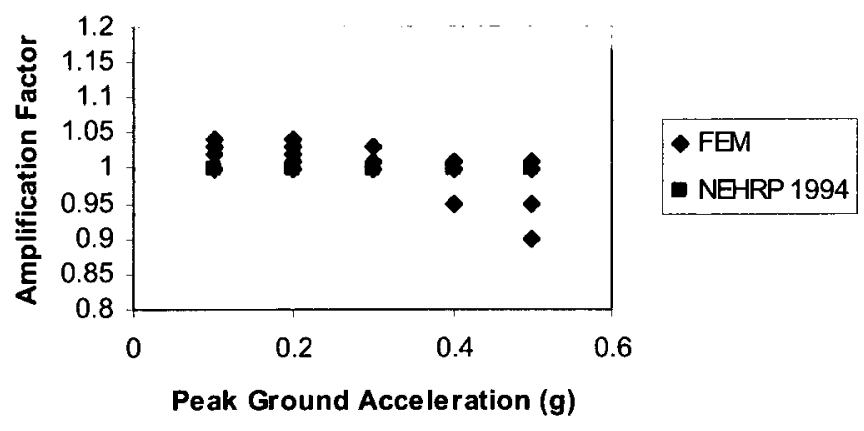

Fig. 4.37: High Frequency amplification values for class $B$ of different soil-bedrock configurations subjected to shaking intensities from $0.1 \mathrm{~g}$ to $0.5 \mathrm{~g}$. 


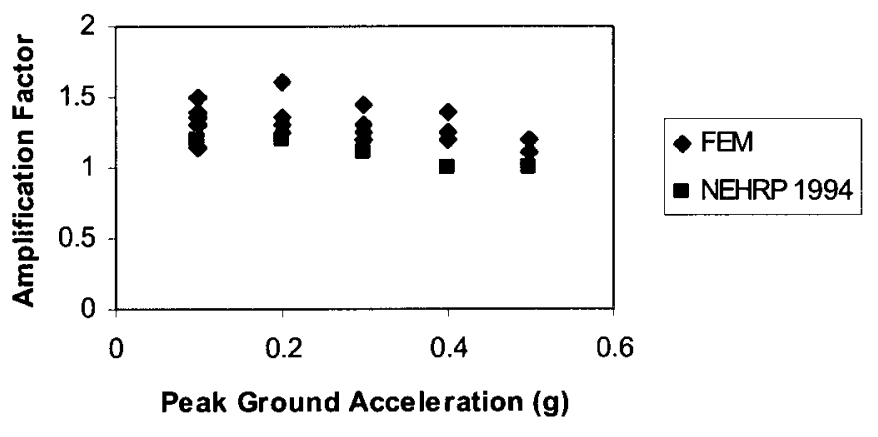

Fig. 4.38: High Frequency amplification values for class $C$ of different soil-bedrock configurations subjected to shaking intensities from $0.1 \mathrm{~g}$ to $0.5 \mathrm{~g}$.

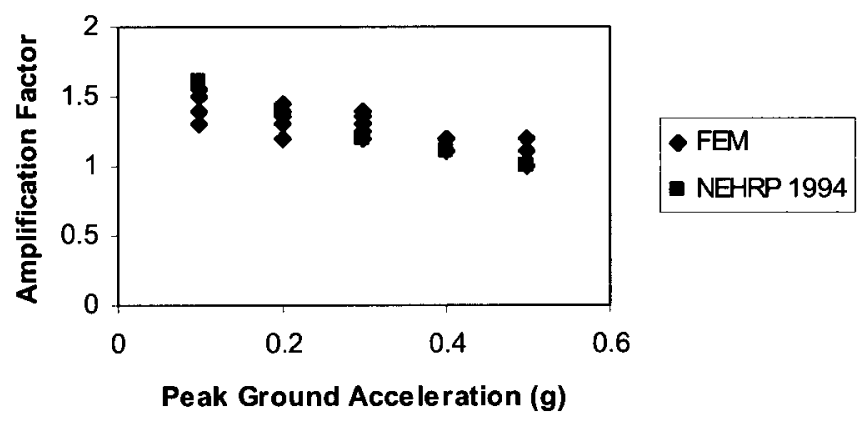

Fig. 4.39: High Frequency amplification values for class $D$ of different soil-bedrock configurations subjected to shaking intensities from $0.1 \mathrm{~g}$ to $0.5 \mathrm{~g}$. 


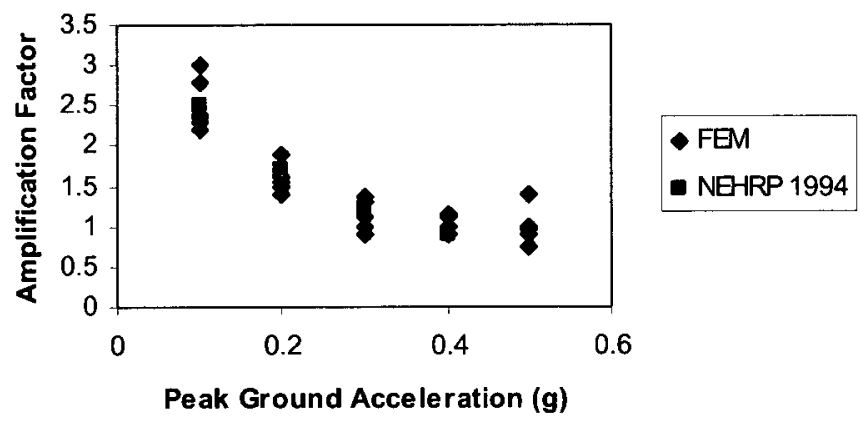

Fig. 4.40: High Frequency amplification values for class $E$ of different soil-bedrock configurations subjected to shaking intensities from $0.1 \mathrm{~g}$ to $0.5 \mathrm{~g}$.

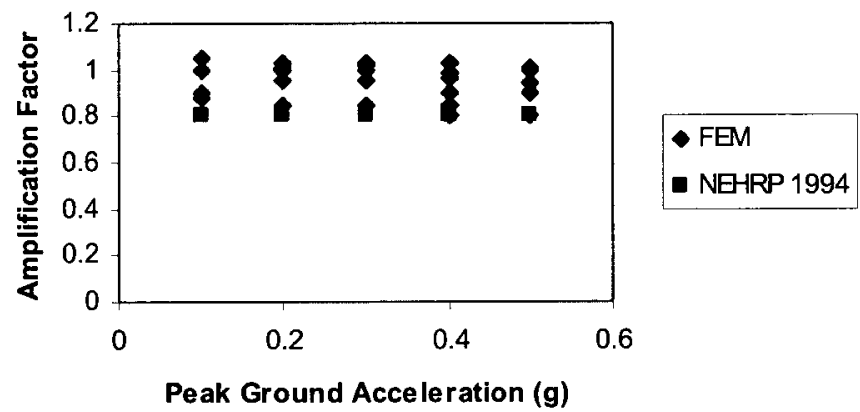

Fig. 4.41: Low Frequency amplification values for class $A$ of different soil-bedrock configurations subjected to shaking intensities from $0.1 \mathrm{~g}$ to $0.5 \mathrm{~g}$. 


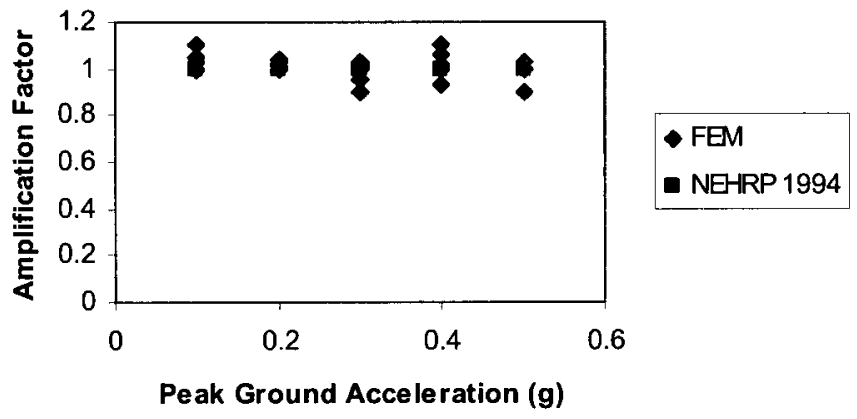

Fig. 4.42: Low Frequency amplification values for class $B$ of different soil-bedrock configurations subjected to shaking intensities from $0.1 \mathrm{~g}$ to $0.5 \mathrm{~g}$.

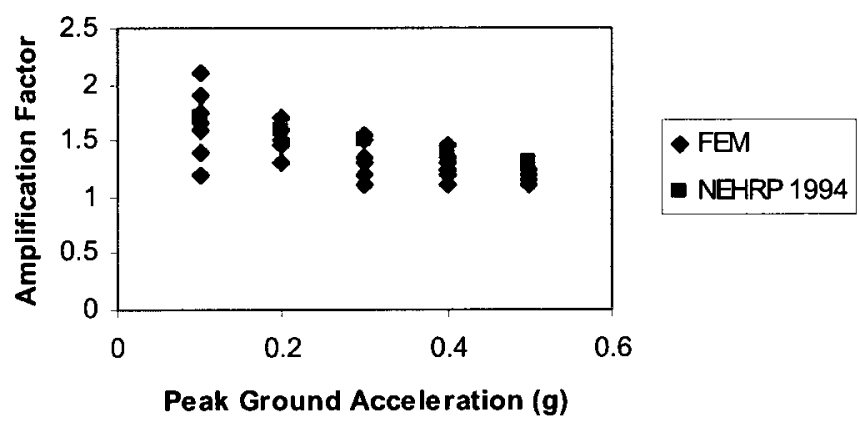

Fig. 4.43: Low Frequency amplification values for class $C$ of different soil-bedrock configurations subjected to shaking intensities from $0.1 \mathrm{~g}$ to $0.5 \mathrm{~g}$. 


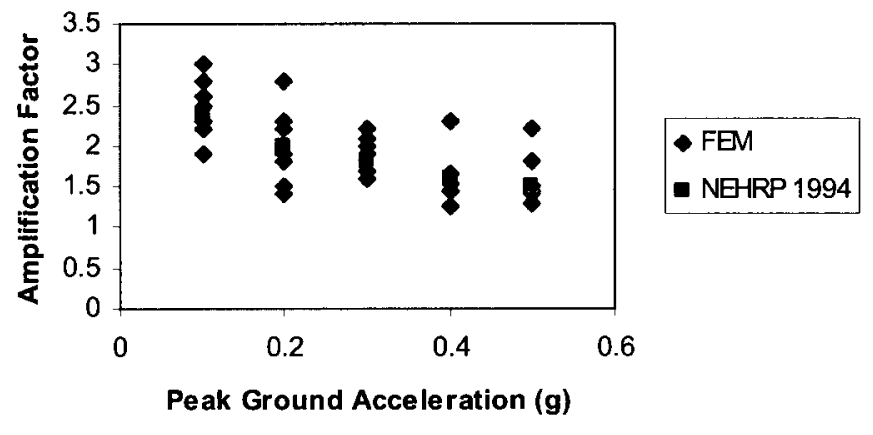

Fig. 4.44: Low Frequency amplification values for class $D$ of different soil-bedrock configurations subjected to shaking intensities from $0.1 \mathrm{~g}$ to $0.5 \mathrm{~g}$.

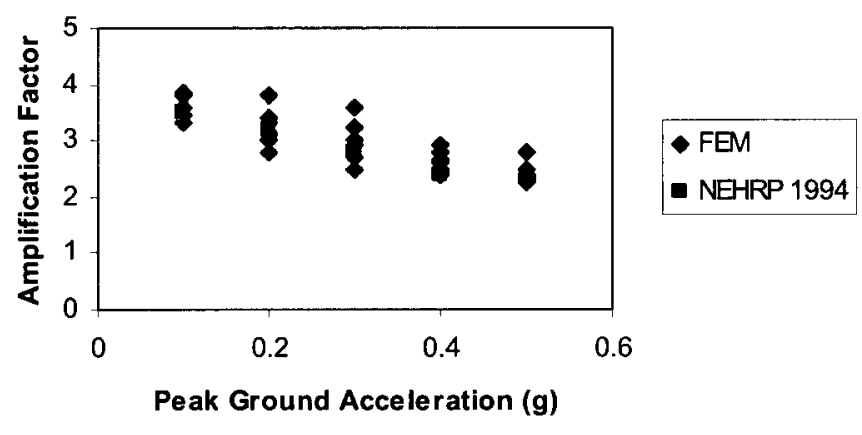

Fig. 4.45: Low Frequency amplification values for class $E$ of different soil-bedrock configurations subjected to shaking intensities from $0.1 \mathrm{~g}$ to $0.5 \mathrm{~g}$. 


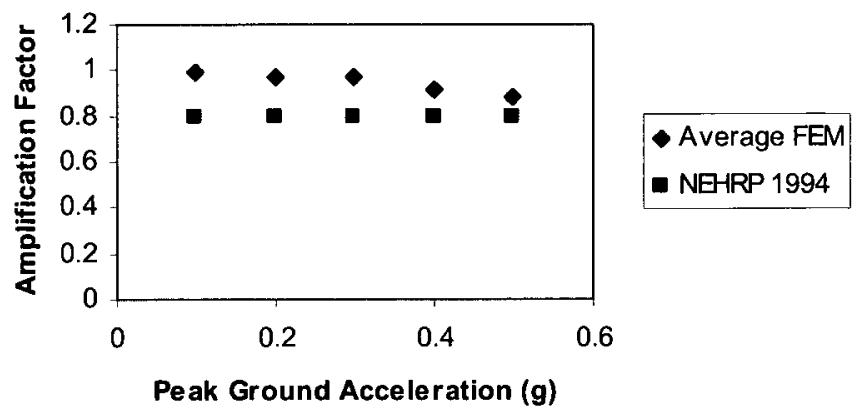

Fig. 4.46: Average high frequency amplification values for class $A$ of different soilbedrock configurations subjected to shaking intensities from $0.1 \mathrm{~g}$ to $0.5 \mathrm{~g}$.

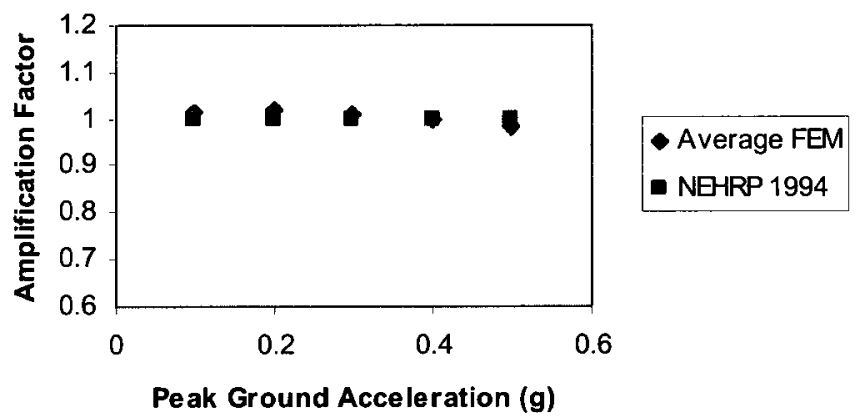

Fig. 4.47: Average high frequency amplification values for class $B$ of different soilbedrock configurations subjected to shaking intensities from $0.1 \mathrm{~g}$ to $0.5 \mathrm{~g}$. 


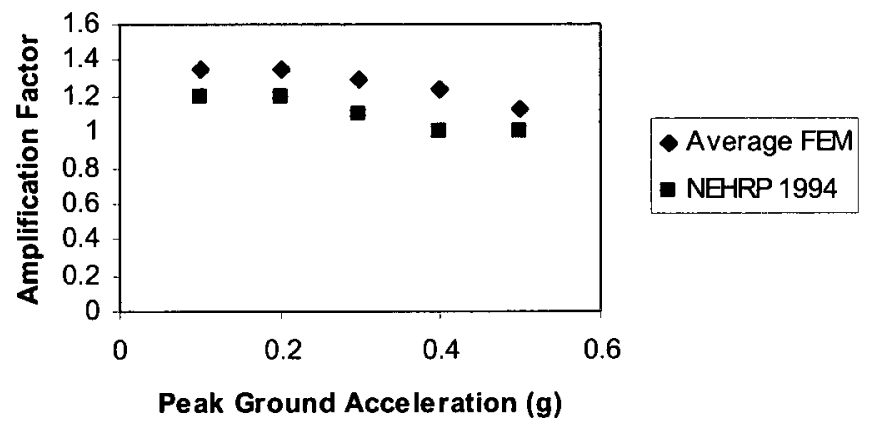

Fig. 4.48: Average high frequency amplification values for class $C$ of different soilbedrock configurations subjected to shaking intensities from $0.1 \mathrm{~g}$ to $0.5 \mathrm{~g}$.

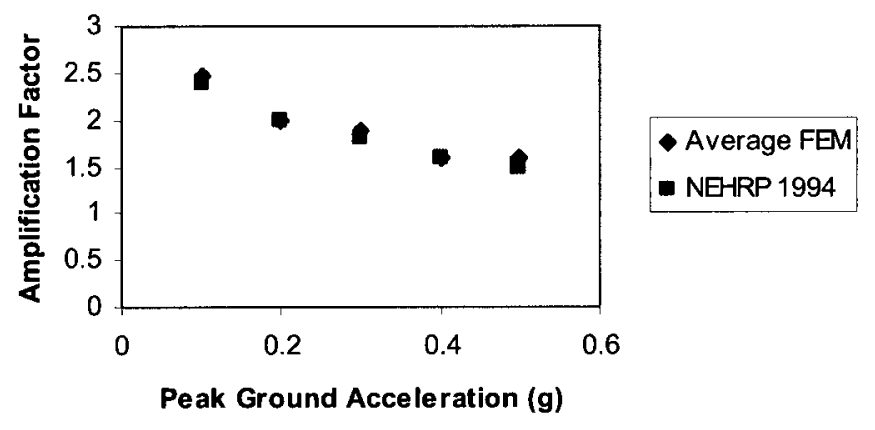

Fig. 4.49: Average high frequency amplification values for class $D$ of different soilbedrock configurations subjected to shaking intensities from $0.1 \mathrm{~g}$ to $0.5 \mathrm{~g}$. 


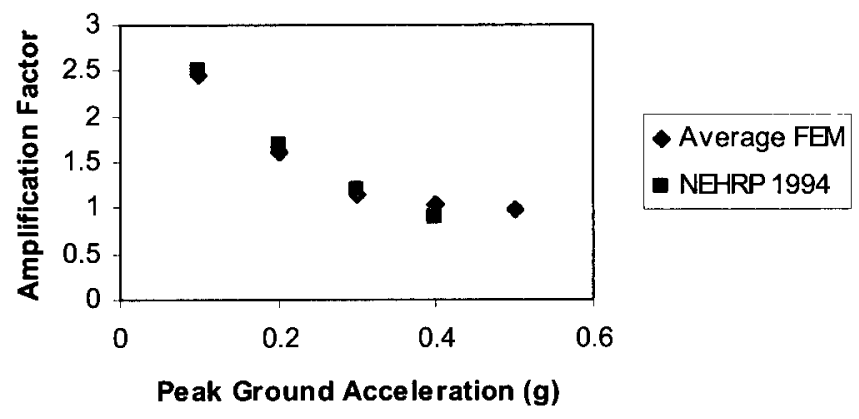

Fig. 4.50: Average high frequency amplification values for class $E$ of different soilbedrock configurations subjected to shaking intensities from $0.1 \mathrm{~g}$ to $0.5 \mathrm{~g}$.

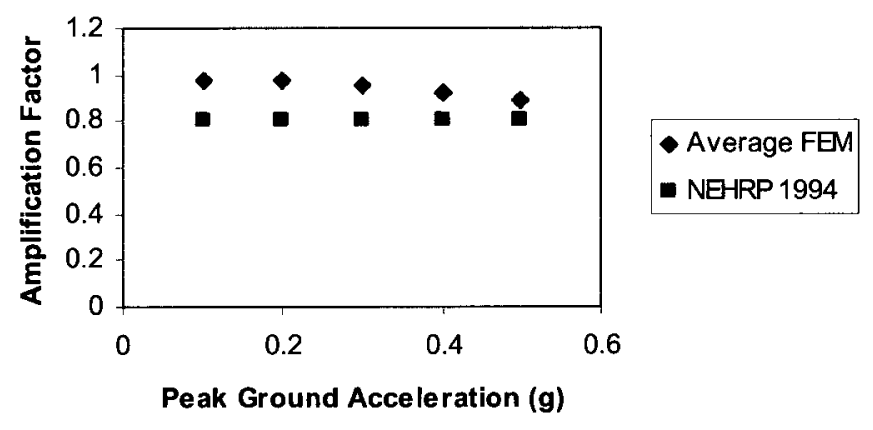

Fig. 4.51: Average low frequency amplification values for class A of different soilbedrock configurations subjected to shaking intensities from $0.1 \mathrm{~g}$ to $0.5 \mathrm{~g}$. 


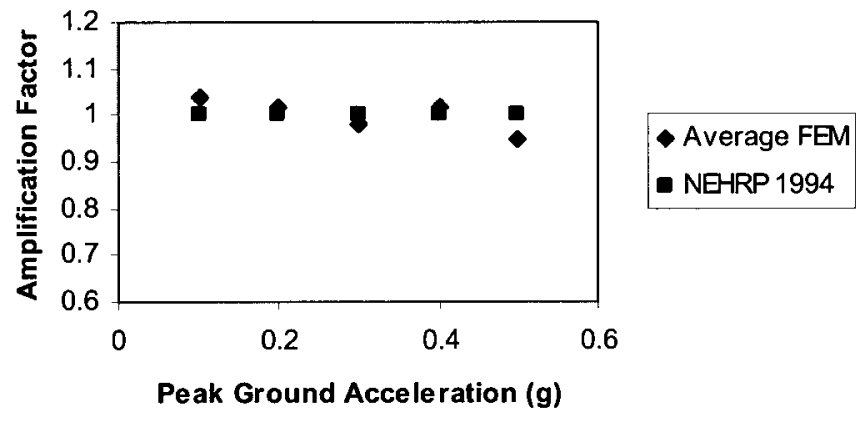

Fig. 4.52: Average low frequency amplification values for class $B$ of different soilbedrock configurations subjected to shaking intensities from $0.1 \mathrm{~g}$ to $0.5 \mathrm{~g}$.

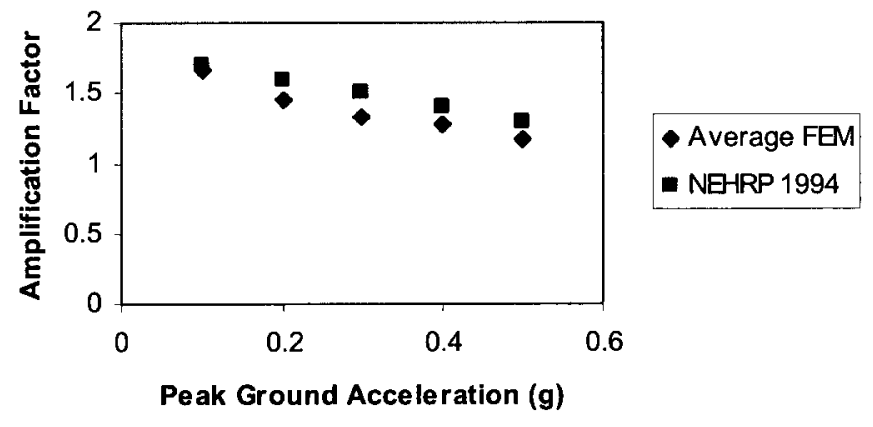

Fig. 4.53: Average low frequency amplification values for class $C$ of different soilbedrock configurations subjected to shaking intensities from $0.1 \mathrm{~g}$ to $0.5 \mathrm{~g}$. 


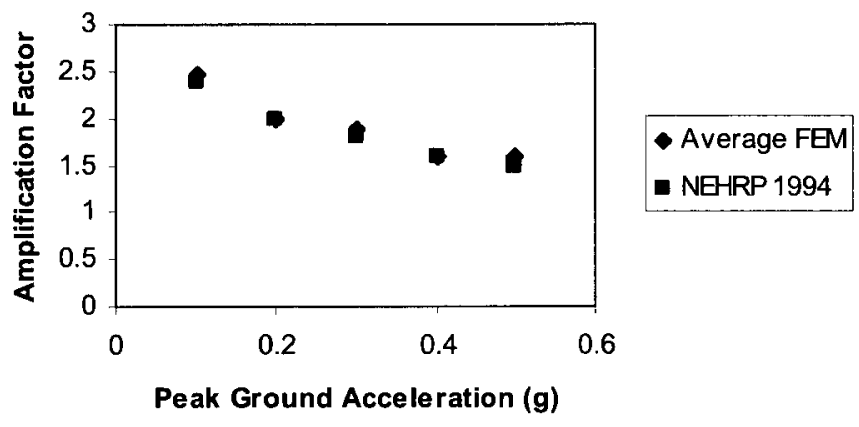

Fig. 4.54: Average low frequency amplification values for class $D$ of different soilbedrock configurations subjected to shaking intensities from $0.1 \mathrm{~g}$ to $0.5 \mathrm{~g}$.

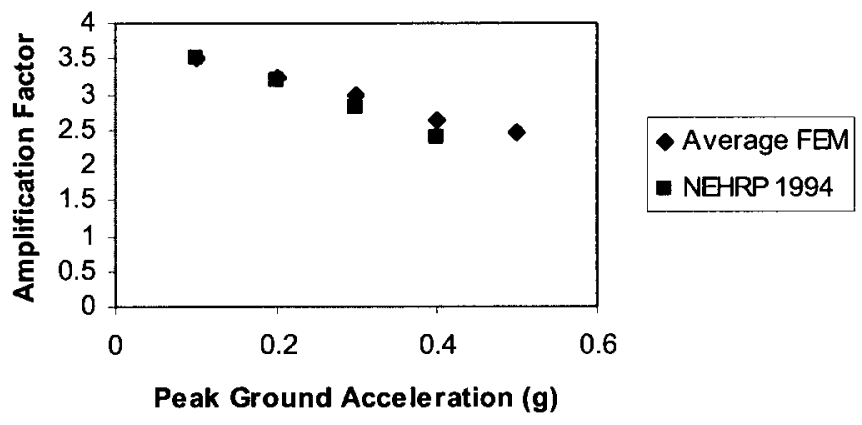

Fig. 4.55: Average low frequency amplification values for class $E$ of different soilbedrock configurations subjected to shaking intensities from $0.1 \mathrm{~g}$ to $0.5 \mathrm{~g}$. 


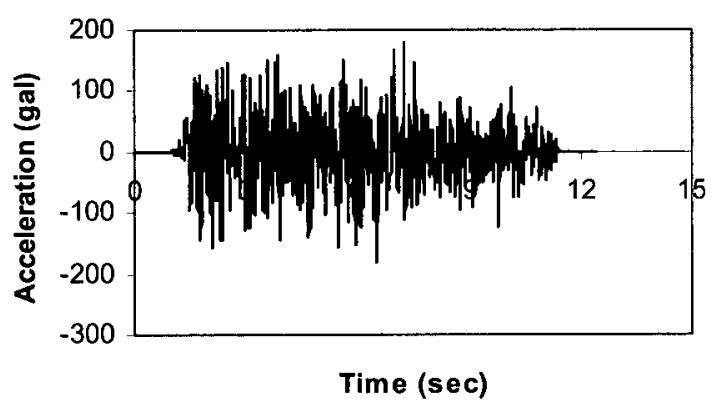

(a)

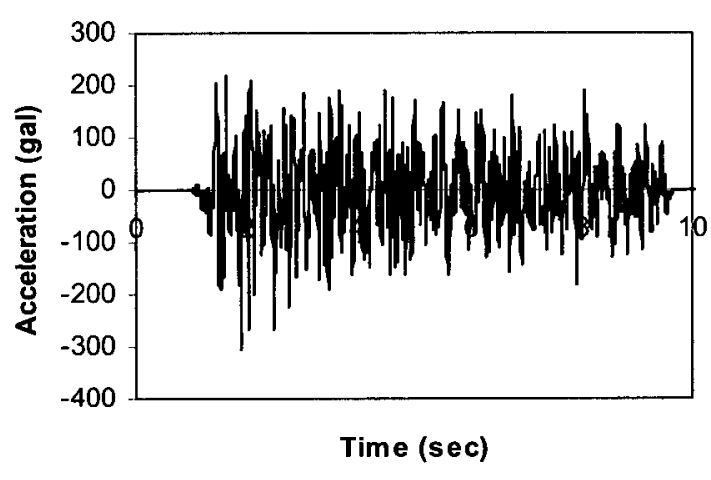

(c)

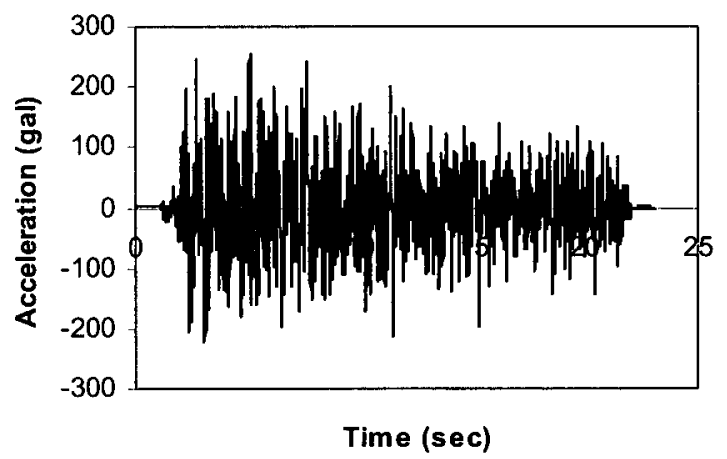

(b)

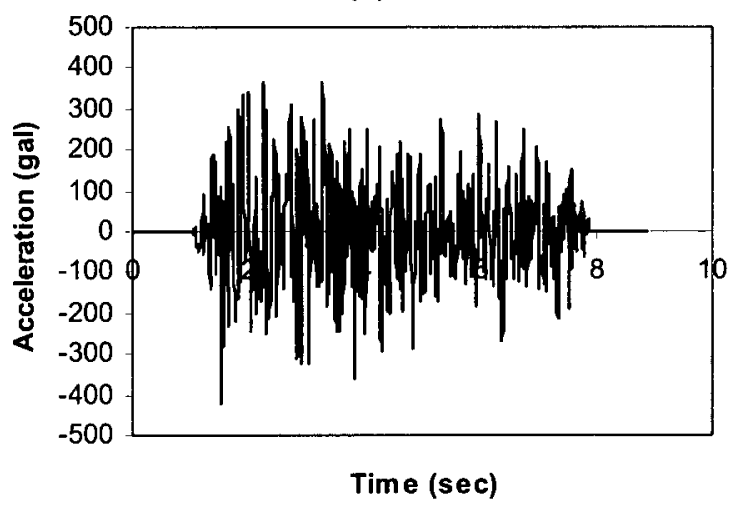

(d)

Fig. 4.56: Artificial acceleration time history of Eastern Canadian EQs ( $2 \%$ in 50 years) with: (a) PGA of $181 \mathrm{gal}$; (b) PGA of $256 \mathrm{gal}$; (c) PGA of $304 \mathrm{gal}$; (d) PGA of $422 \mathrm{gal}$. 


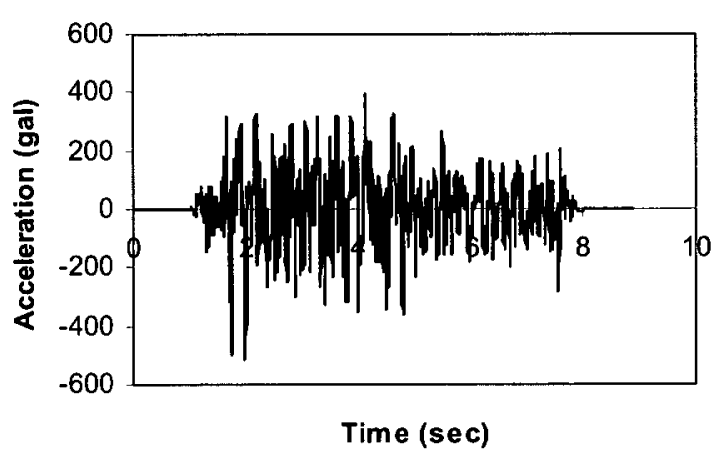

(a)

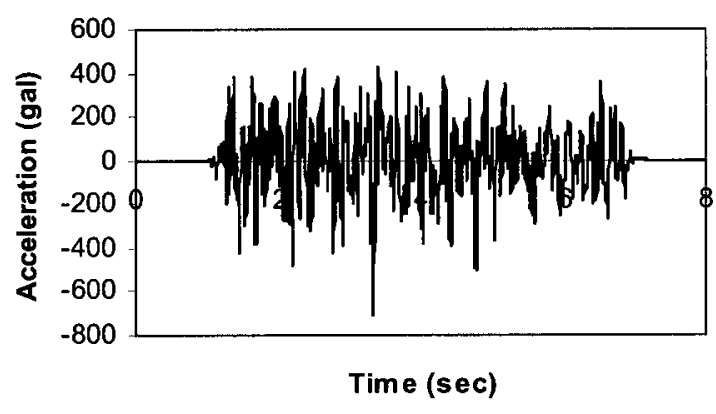

(c)

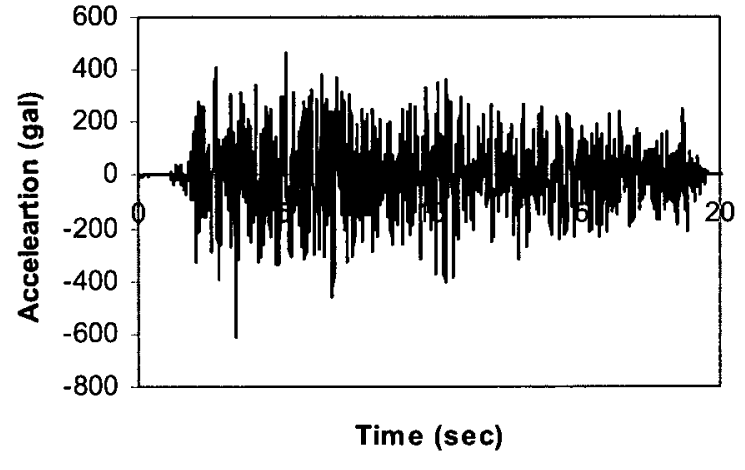

(b)

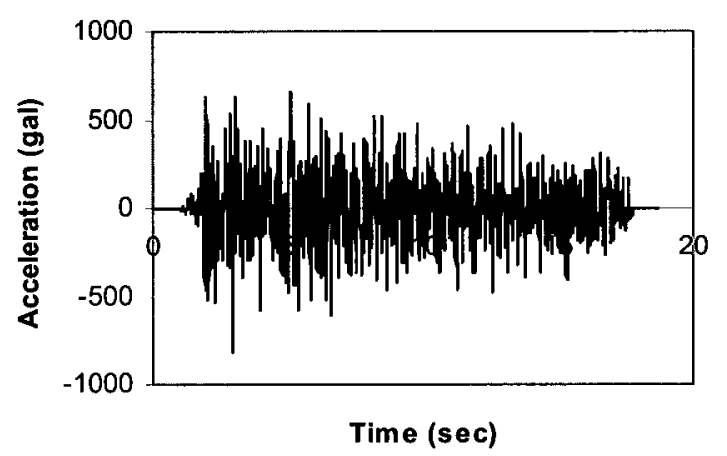

(d)

Fig. 4.57: Artificial acceleration time history of Eastern Canadian EQs ( $2 \%$ in 50 years) with: (a) PGA of 512 gal; (b) PGA of $607 \mathrm{gal}$; (c) PGA of $707 \mathrm{gal}$; (d) PGA of $813 \mathrm{gal}$. 


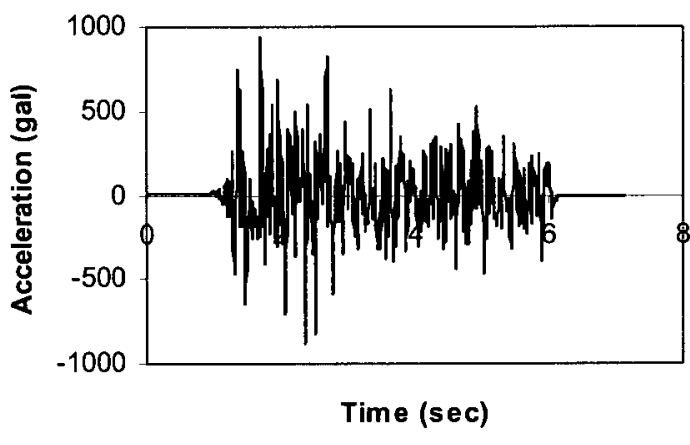

(a)

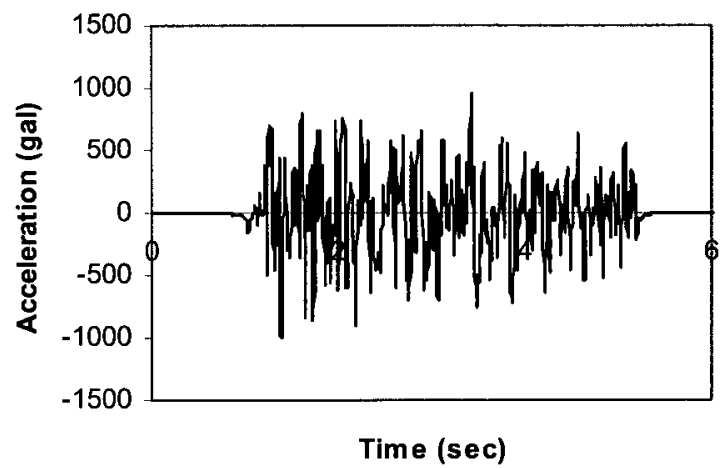

(b)

Fig. 4.58: Artificial acceleration time history of Eastern Canadian EQs (2\% in 50 years) with: (a) PGA of 942 gal; (b) PGA of 1000 gal.

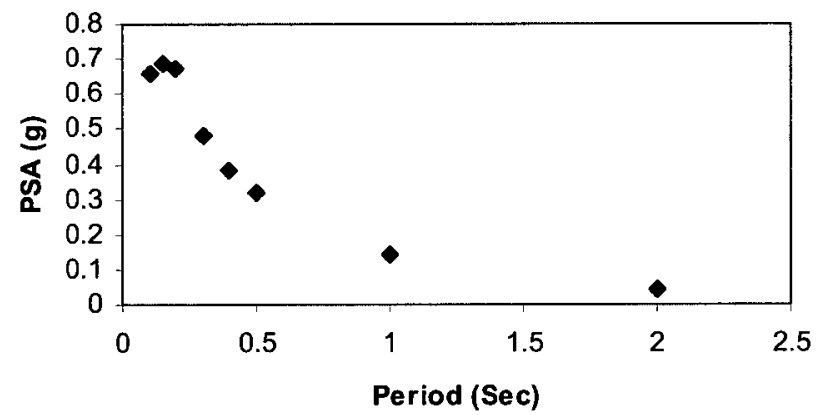

Fig. 4.59: Pseudo-acceleration (PSA) values for the target PGA of 0.42g in Ottawa area. (Probability of $2 \%$ in 50 years). A similar Table is given at NBCC, 2005.This graph was based on values given in the Appendix of NBCC (2005). 


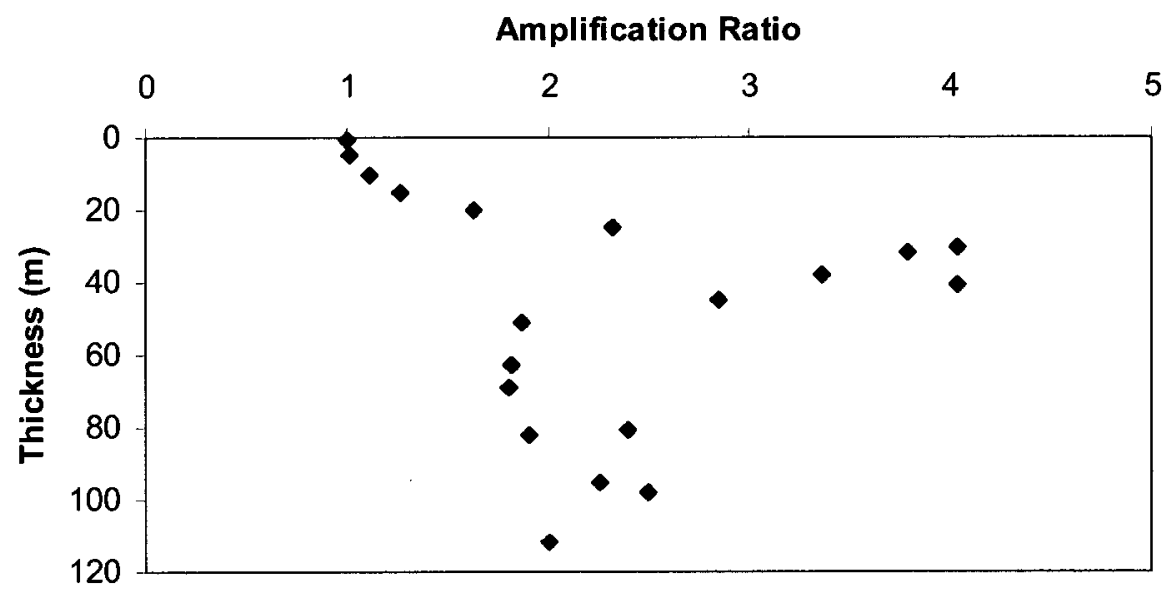

Fig. 4.60: Variation of low frequency amplification ratios in terms of the thickness of the examined sites in Ottawa area subjected to the input motion having PGA of $422 \mathrm{gal}$. The large amplification ratios $\left(F_{v}>3.3\right)$ are observed for the sites having depths from $30 \mathrm{~m}$ to $41 \mathrm{~m}$ which have natural frequencies ranging from $0.8 \mathrm{~Hz}$ to $1.3 \mathrm{~Hz}$.

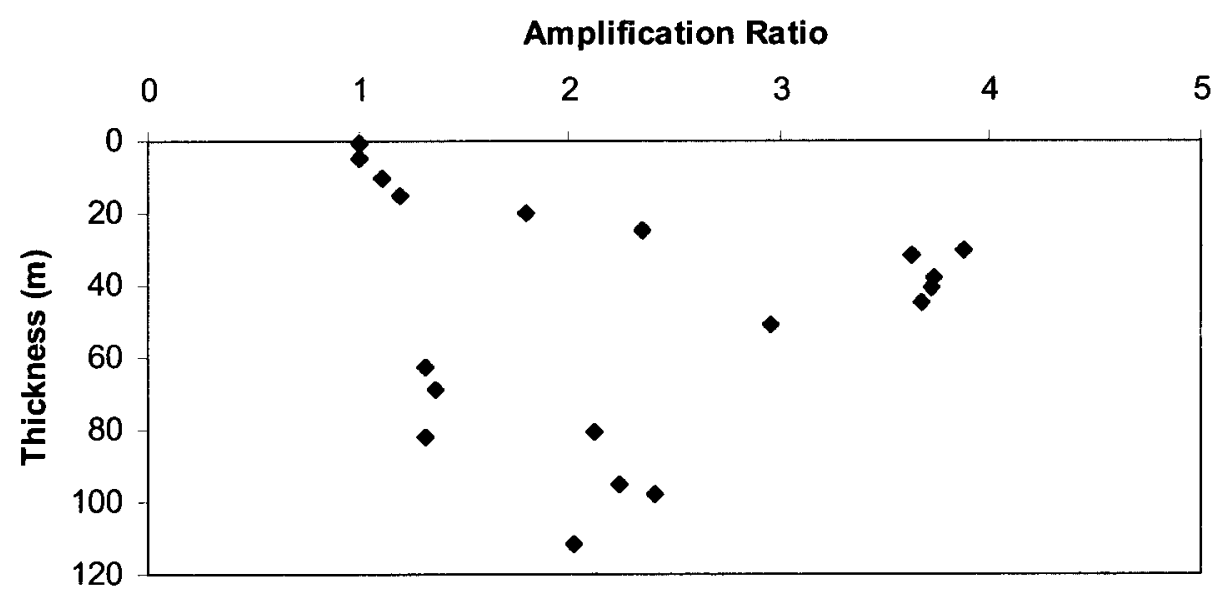

Fig. 4.61: Variation of low frequency amplification ratios in terms of thickness of the examined sites in Ottawa area subjected to the input motion having PGA of $707 \mathrm{gal}$. The large amplification ratios $\left(F_{v}>3.5\right)$ are observed for the sites having depths from $30 \mathrm{~m}$ to $41 \mathrm{~m}$ which have natural frequencies ranging from $0.8 \mathrm{~Hz}$ to $1.3 \mathrm{~Hz}$. 


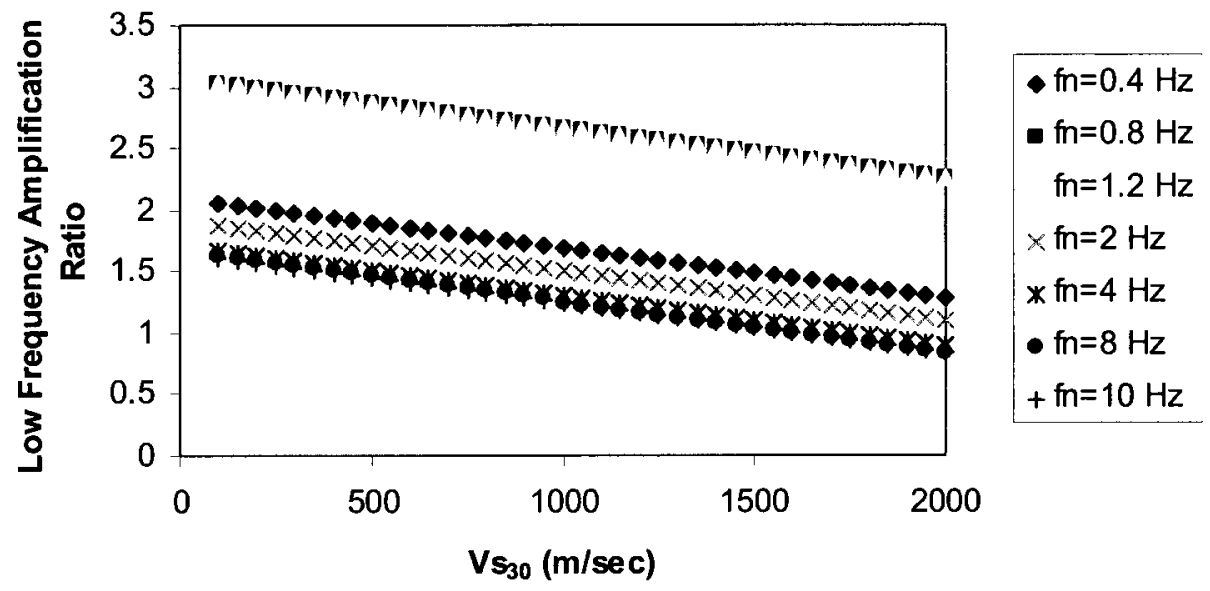

Fig. 4.62: Low frequency amplification values at the PGA of 422 gal for different $f_{n}$ values using equation (4-42).

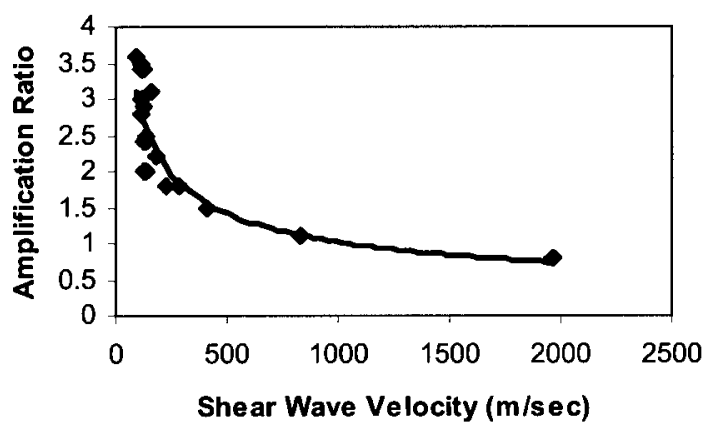

(a)

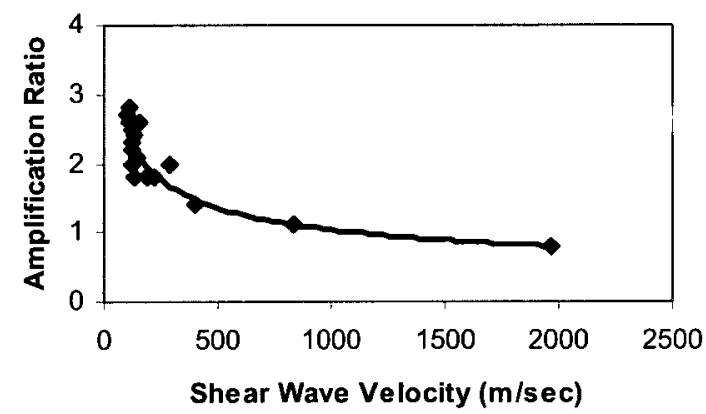

(c)

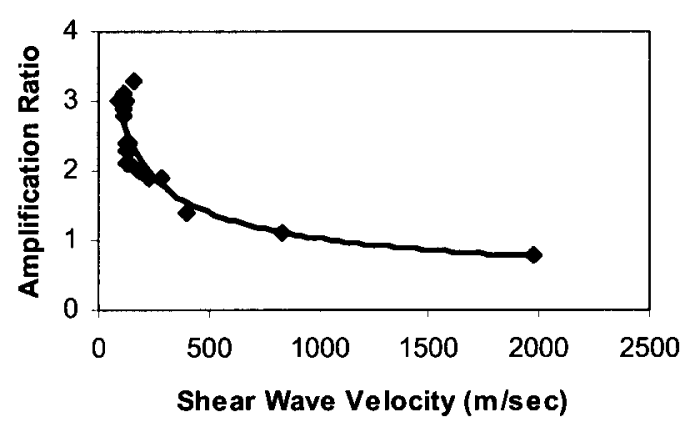

(b)

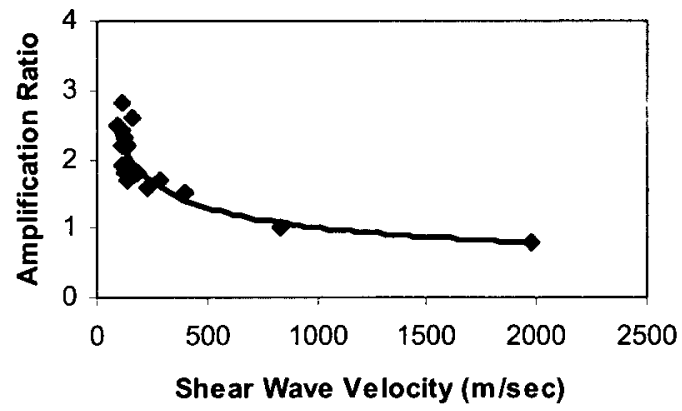

(d)

Fig. 4.63: $\left(F_{V}\right)_{R S}$ amplification values versus average $V_{s 30}$ for 19 sites using the record having (a) PGA of $181 \mathrm{gal}$; (b) PGA of $256 \mathrm{gal}$; (c) PGA of $304 \mathrm{gal}$; (d) PGA of $422 \mathrm{gal}$. 
(a)
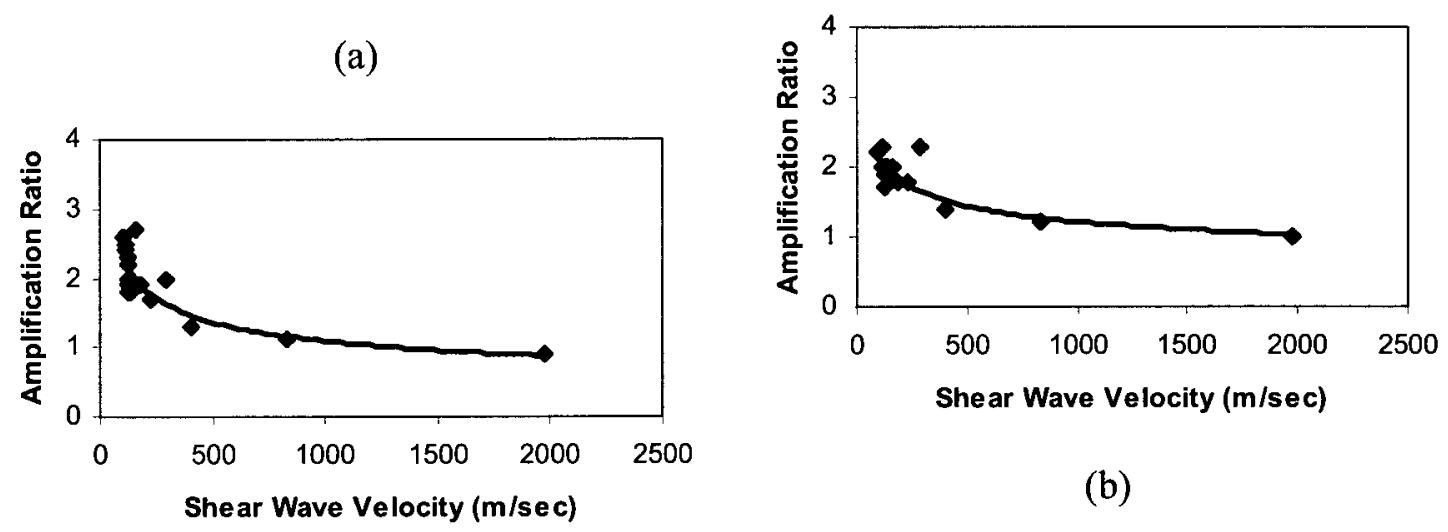

(b)
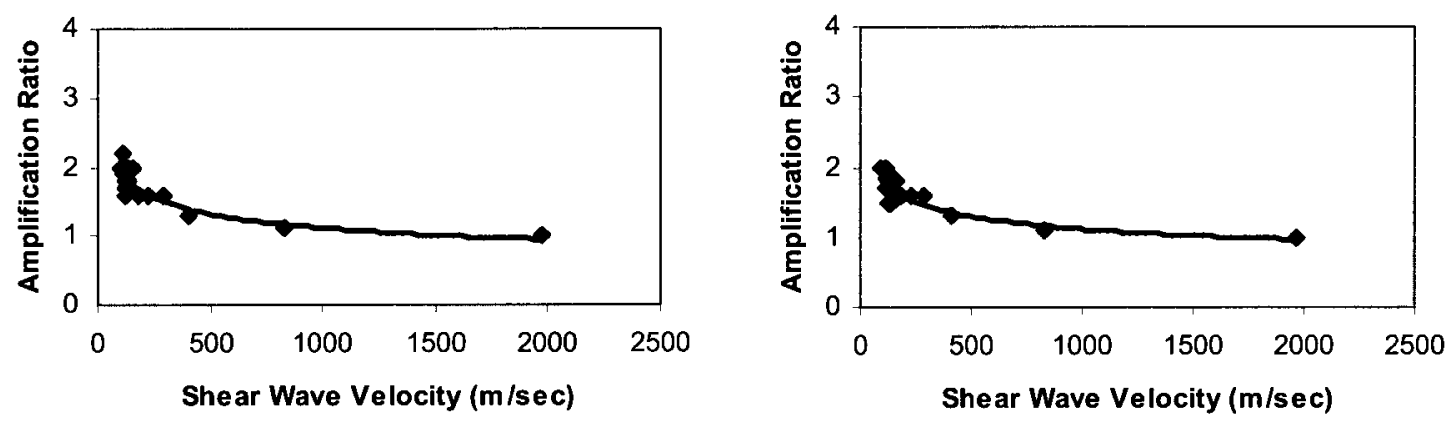

(c)

(d)

Fig. 4.64: $\left(F_{V}\right)_{R S}$ amplification values versus average $V_{s 30}$ for 19 sites using the record having (a) PGA of $1512 \mathrm{gal}$; (b) PGA of $607 \mathrm{gal}$; (c) PGA of $707 \mathrm{gal}$; (d) PGA of $813 \mathrm{gal}$. 


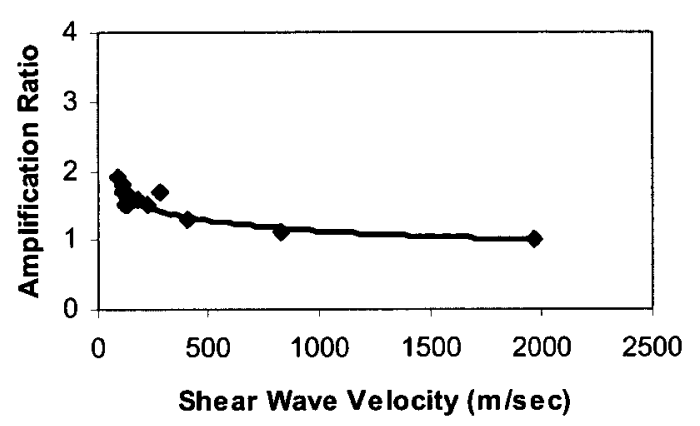

(a)

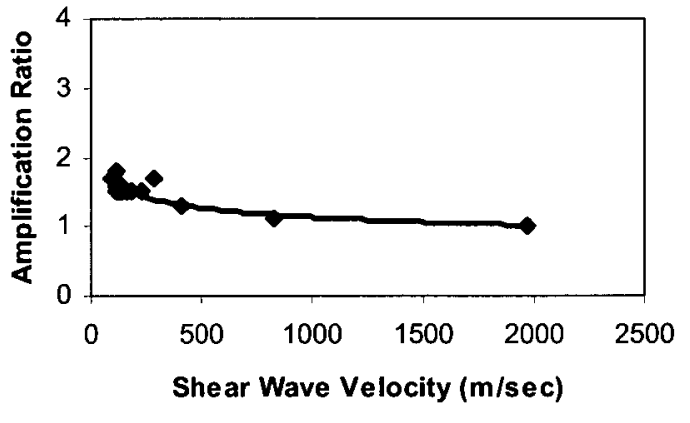

(b)

Fig. 4.65: $\left(F_{V}\right)_{R S}$ amplification values versus average $V_{s 30}$ for 19 sites using the record having (a) PGA of $942 \mathrm{gal}$; (b) PGA of $1000 \mathrm{gal}$. 


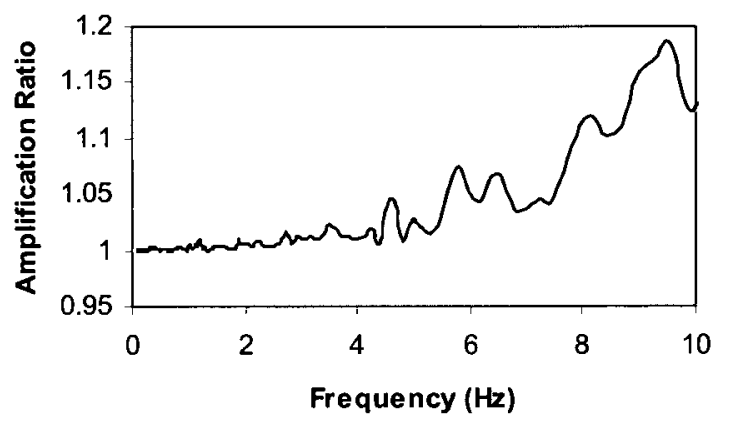

(a)

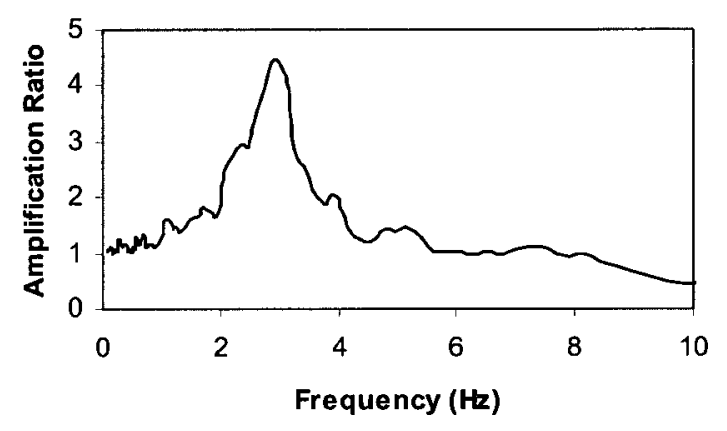

(c)

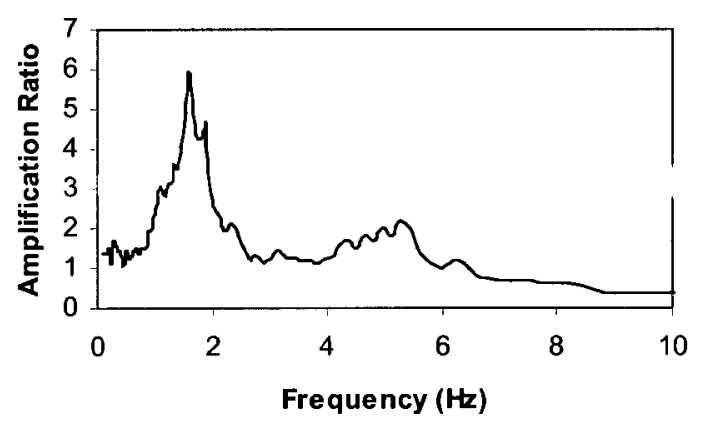

(e)

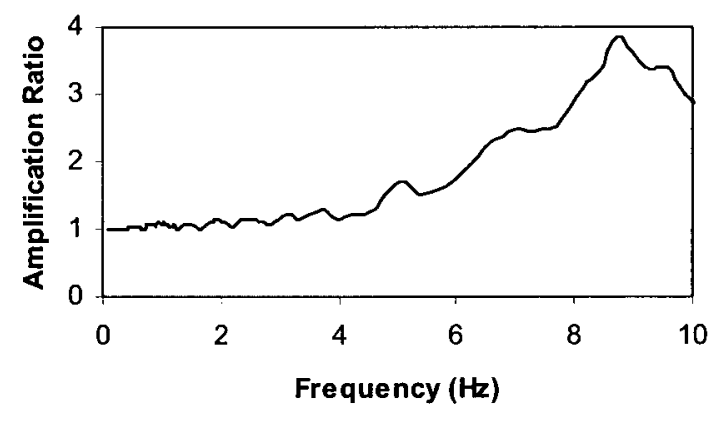

(b)

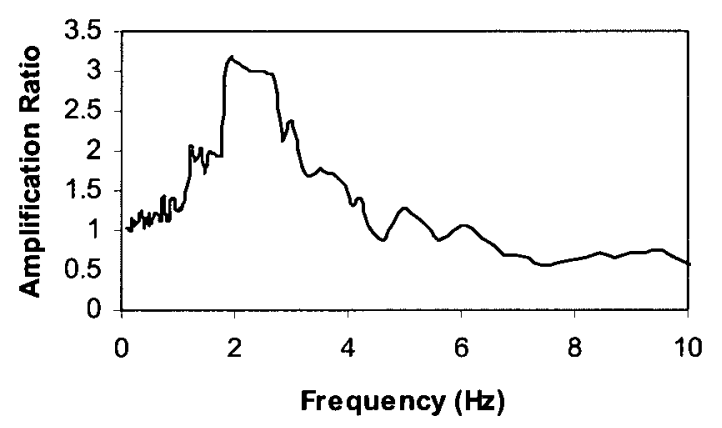

(d)

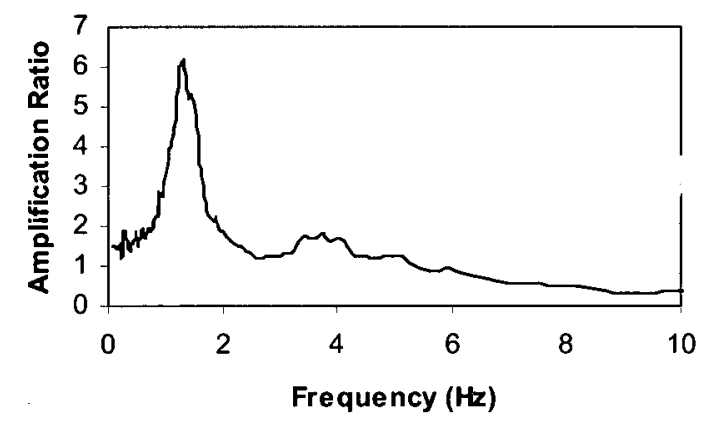

(f)

Fig. 4.66: Amplification curves for different site classes and spectral accelerations in Ottawa area (a) site class A subjected to PSA of $0.5 \mathrm{~g}$; (b) site class B subjected to PSA of $0.2 \mathrm{~g}$; (c) site class $C$ subjected to PSA of $0.75 \mathrm{~g}$;(d) site class $C$ subjected to PSA of $0.4 \mathrm{~g}$;(e) site class D subjected to PSA of 0.25g;(f) site class E subjected to PSA of $1.25 \mathrm{~g}$. 
Table 4.1: Site Categories in NEHRP Provisions and NBCC, 2005

\begin{tabular}{|c|c|c|c|}
\hline \multirow{2}{*}{$\begin{array}{l}\text { Site Profile } \\
\text { Name }\end{array}$} & \multicolumn{3}{|c|}{ Average Properties in Top $30 \mathrm{~m}$} \\
\hline & $\begin{array}{l}\text { Shear Wave Average } \\
\text { Velocity, } \mathrm{V}_{\mathrm{s}}(\mathrm{m} / \mathrm{sec})\end{array}$ & $\begin{array}{l}\text { Standard Penetration } \\
\text { Resistance, } \mathrm{N}_{60}\end{array}$ & $\begin{array}{l}\text { Soil Undrained shear } \\
\text { strength } \mathrm{S}_{\mathrm{u}}\end{array}$ \\
\hline Hard Rock & $1500<V_{s}$ & Not applicable & Not applicable \\
\hline Rock & $760<V_{s}<1500$ & Not applicable & Not applicable \\
\hline $\begin{array}{l}\text { Very Dense } \\
\text { Soil and soft } \\
\text { rock }\end{array}$ & $360<V_{s}<760$ & $50<\mathrm{N}_{60}$ & $100 \mathrm{kPa}^{2}<\mathrm{S}_{\mathrm{u}}$ \\
\hline $\begin{array}{l}\text { Stiff } \\
\text { Soil }\end{array}$ & $180<V_{s}<360$ & $15<\mathrm{N}_{60}<50$ & $\begin{array}{l}50<\mathrm{S}_{\mathrm{u}}<100 \\
\mathrm{kPa}\end{array}$ \\
\hline Soft & $\mathrm{V}_{\mathrm{s}}<180$ & $\mathrm{~N}_{60}<15$ & $\mathrm{~S}_{\mathrm{u}}<50 \mathrm{kPa}$ \\
\hline Soil & \multicolumn{3}{|c|}{$\begin{array}{l}\text { Or any profile with more than } 3 \mathrm{~m} \text { of soil with the following } \\
\text { characteristics: } \\
\text { - Plastic index } \mathrm{PI}>20 \\
\text { - Moisture content }>=40 \% \text { and } \\
\text { - Undrained shear strength } \mathrm{S}_{\mathrm{u}}<25 \mathrm{kPa}\end{array}$} \\
\hline $\begin{array}{l}(1) \\
\text { Others }\end{array}$ & \multicolumn{3}{|c|}{ Site Specific Evaluation Required } \\
\hline
\end{tabular}


1) Others include:

a) Liquefaction soils, Sensitive clays, and other soils susceptible to failure or collapse under seismic loading.

b) Peat and/or highly organic clays greater than $3 \mathrm{~m}$ in thickness

c) Highly plastic clays, with thickness greater than $8 \mathrm{~m}$.

d) Soft to medium stiff clays with thickness greater than $30 \mathrm{~m}$. 
Table 4.2: Input parameters of the finite element model for the profile in ORHO station (weak motion modeling).

\begin{tabular}{|l|l|}
\hline Leda clay shear wave velocity & $210 \pm 10(\mathrm{~m} / \mathrm{sec})$ \\
\hline Leda clay unit weight & $1700\left(\mathrm{kN} / \mathrm{m}^{3}\right)$ \\
\hline Glacial till shear wave velocity & $580 \pm 174(\mathrm{~m} / \mathrm{sec})$ \\
\hline Glacial till unit weight & $1800\left(\mathrm{kN} / \mathrm{m}^{3}\right)$ \\
\hline Bedrock shear wave velocity & $2700 \pm 680(\mathrm{~m} / \mathrm{sec})$ \\
\hline Bedrock unit weight & $2500\left(\mathrm{kN} / \mathrm{m}^{3}\right)$ \\
\hline Thickness of Leda Clay & $81(\mathrm{~m})$ \\
\hline Thickness of Glacial till & $10(\mathrm{~m})$ \\
\hline Shear modulus reduction data & Seed and Sun, 1989 \\
\hline Strain-dependent Damping data & Seed and Sun, 1989 \\
\hline
\end{tabular}


Table 4.3: Physical parameters of three sites in the eastern part of the city of Ottawa.

\begin{tabular}{|l|l|l|l|}
\hline Site \# / Name & Heritage Park & $\# 31$ & $\# 41$ \\
\hline $\begin{array}{l}\text { Average soil velocity } \\
\text { velopth-dependent (d) }\end{array}$ & $210(\mathrm{~m} / \mathrm{sec})$ & $1.37 \mathrm{~d}+147.2$ & $1.51 \mathrm{~d}+91.9$ \\
\hline $\begin{array}{l}\text { Average bedrock } \\
\text { velocity (m/sec) }\end{array}$ & 2700 & 2700 & \\
\hline $\begin{array}{l}\text { Average soil unit } \\
\left.\text { weight (kN/m } \mathrm{m}^{3}\right)\end{array}$ & 1700 & 1700 & 2700 \\
\hline Average bedrock unit \\
weight $\left(\mathrm{kN} / \mathrm{m}^{3}\right)$
\end{tabular}


Table 4.4: Peak amplification factors at Site \#31 using the FEM seismic response analysis and the scaled records.

\begin{tabular}{|l|l|l|l|l|}
\hline \multicolumn{1}{|c|}{ Contrast } & 4 & 8 & 12 & Real = \\
\hline 23 & & & & 23.42 \\
\hline 41 & 3.92 & 7.58 & 9.62 & 11.4 \\
\hline 70 & 3.95 & 7.14 & 9.19 & 10.8 \\
\hline 81 & 3.93 & 6.76 & 8.81 & 9.47 \\
\hline 147 & 3.9 & 6.65 & 8.43 & 8.9 \\
\hline 208 & 3.84 & 6.18 & 7.89 & 7.86 \\
\hline 349 & 3.79 & 5.94 & 7.73 & 7.01 \\
\hline
\end{tabular}


Table 4.5: Application of Logarithmic-Linear model (equation (4-38)) to (z, PGA) data at site \#31. Peak amplification factors are calculated for site \#31 using different contrast ratios and peak ground accelerations.

\begin{tabular}{|c|c|c|c|c|}
\hline PGA & 4 & 8 & 12 & $\begin{array}{l}\text { Real }= \\
23.42\end{array}$ \\
\hline 23 & 4.60 & 6.90 & 8.25 & 10.47 \\
\hline 41 & 4.52 & 6.79 & 8.11 & 10.29 \\
\hline 70 & 4.40 & 6.60 & 7.89 & 10.01 \\
\hline 81 & 4.35 & 6.53 & 7.80 & 9.90 \\
\hline 147 & 4.07 & 6.10 & 7.29 & 9.26 \\
\hline 208 & 3.81 & 5.71 & 6.83 & 8.66 \\
\hline 349 & 3.20 & 4.80 & 5.74 & 7.29 \\
\hline
\end{tabular}


Table 4.6: Shear wave velocity ranges of soil and the underlying bedrock for nine different profile configurations. These configurations are used to generate NEHRP, 1994 velocity profiles.

\begin{tabular}{|c|c|c|c|}
\hline Configuration \# & $\begin{array}{l}\text { Average Soil } \\
\text { Velocity }(\mathrm{m} / \mathrm{sec})\end{array}$ & $\begin{array}{l}\text { Bedrock } \\
\text { Velocity for class } \\
\text { A }(\mathrm{m} / \mathrm{sec})\end{array}$ & $\begin{array}{l}\text { Bedrock Velocity } \\
\text { for all the classes } \\
\text { except class A } \\
(\mathrm{m} / \mathrm{sec})\end{array}$ \\
\hline Config. 1 & 100 & 2000 & 1000 \\
\hline Config. 2 & 200 & 2000 & 1000 \\
\hline Config. 3 & 300 & 2000 & 1000 \\
\hline Config.4 & 400 & 2000 & 1000 \\
\hline Config.5 & 500 & 2000 & 1000 \\
\hline Config.6 & 600 & 2000 & 1000 \\
\hline Config.7 & 700 & 2000 & 1000 \\
\hline Config. 8 & $240-260-280-340$ & NA & 1000 \\
\hline Config.9 & $\begin{array}{l}110-120-130- \\
140-150-160\end{array}$ & NA & 1000 \\
\hline
\end{tabular}


Table 4.7: Low frequency amplification factors $\left(F_{v}\right)$ from NEHRP 1994. $S_{I}$ is the spectral acceleration at the frequency of $1 \mathrm{~Hz}$.

\begin{tabular}{|c|c|c|c|c|c|}
\hline $\mathrm{S}_{1}$ & & & & & \\
\hline Site Class & $0.1 \mathrm{~g}$ & $0.2 \mathrm{~g}$ & $0.3 \mathrm{~g}$ & $0.4 \mathrm{~g}$ & $0.5 \mathrm{~g}$ \\
\hline $\mathrm{A}$ & 0.8 & 0.8 & 0.8 & 0.8 & 0.8 \\
\hline B & 1 & 1 & 1 & 1 & 1 \\
\hline C & 1.7 & 1.6 & 1.5 & 1.4 & 1.3 \\
\hline D & 2.4 & 2 & 1.8 & 1.6 & 1.5 \\
\hline$E$ & 3.5 & 3.2 & 2.8 & 2.4 & $*$ \\
\hline $\bar{F}$ & $*$ & $*$ & * & $*$ & $*$ \\
\hline
\end{tabular}


Table 4.8: High frequency amplification factors $\left(F_{a}\right)$ from NEHRP 1994. $S_{0.2}$ is the spectral acceleration at the frequency of $3 \mathrm{~Hz}$.

\begin{tabular}{|c|c|c|c|c|c|}
\hline $\mathrm{S}_{0.33}$ & & & & & \\
\hline Site Class & $0.1 \mathrm{~g}$ & $0.2 \mathrm{~g}$ & $0.3 \mathrm{~g}$ & $0.4 \mathrm{~g}$ & $0.5 \mathrm{~g}$ \\
\hline $\mathrm{A}$ & 0.8 & 0.8 & 0.8 & 0.8 & 0.8 \\
\hline B & 1 & 1 & 1 & 1 & 1 \\
\hline $\bar{C}$ & 1.2 & 1.2 & 1 & 1 & 1 \\
\hline $\mathrm{D}$ & 1.6 & 1.4 & 1.2 & 1.1 & 1 \\
\hline $\mathrm{E}$ & 2.5 & 1.7 & 1.2 & 0.9 & * \\
\hline $\mathrm{F}$ & $*$ & $*$ & $*$ & * & * \\
\hline
\end{tabular}


Table 4.9: GSC sites (depth > 30m) used for low and high frequency amplification analysis in Ottawa area and the corresponding depth-velocity parameters and $V s_{30}$ $(\mathrm{m} / \mathrm{sec}) . d$ is the depth of the site.

\begin{tabular}{|l|l|l|l|}
\hline Site \# & $\begin{array}{l}\text { Post-glacial } \\
\text { Thickness (m) }\end{array}$ & Vs average Equation & $\mathrm{Vs}_{30}(\mathrm{~m} / \mathrm{sec})$ \\
\hline 126 & 32.5 & $1.1 \mathrm{~d}+96.35$ & 112 \\
\hline 068 & 38 & $1.06 \mathrm{~d}+102.98$ & 118 \\
\hline 040 & 41 & $1.19 \mathrm{~d}+122.03$ & 139 \\
\hline 030 & 45 & $1.45 \mathrm{~d}+100.68$ & 122 \\
\hline 034 & 51 & $1.44 \mathrm{~d}+96.78$ & 118 \\
\hline 411 & 63 & $1.03 \mathrm{~d}+97.07$ & 112 \\
\hline $004 \mathrm{R}$ & 69 & $1.11 \mathrm{~d}+104.22$ & 120 \\
\hline 023 & 81 & $1.15 \mathrm{~d}+102.85$ & 12 \\
\hline 020 & 82.5 & $0.8 \mathrm{~d}+125.97$ & 137 \\
\hline 027 & 95 & $1.57 \mathrm{~d}+72.66$ & 96 \\
\hline 061 & 98 & $1.1 \mathrm{~d}+116.74$ & 133 \\
\hline 685 & 112 & $1.1 \mathrm{~d}+105.83$ & 122 \\
\hline
\end{tabular}


Table 4.10: Sites (depth $\leq 30 \mathrm{~m})$ used for low and high frequency amplification analysis in Ottawa area and the corresponding depth-velocity parameters and $V s_{30}(\mathrm{~m} / \mathrm{sec}) . d$ is the depth of the site.

\begin{tabular}{|l|l|l|}
\hline Site depth $(\mathrm{m})$ & $\mathrm{V}_{\mathrm{s}}$ value or equation & $\mathrm{Vs}_{30}(\mathrm{~m} / \mathrm{sec})$ \\
\hline 1 & $180 \mathrm{~m} / \mathrm{sec}$ & 1970 \\
\hline 5 & $180 \mathrm{~m} / \mathrm{sec}$ & 830 \\
\hline 10 & $0.88 \mathrm{~d}+123.86 \pm 20.3(\mathrm{~m} / \mathrm{sec})$ & 405 \\
\hline 15 & $0.88 \mathrm{~d}+123.86 \pm 20.3(\mathrm{~m} / \mathrm{sec})$ & 287 \\
\hline 20 & $0.88 \mathrm{~d}+123.86 \pm 20.3(\mathrm{~m} / \mathrm{sec})$ & 223 \\
\hline 25 & $0.88 \mathrm{~d}+123.86 \pm 20.3(\mathrm{~m} / \mathrm{sec})$ & 184 \\
\hline 30 & $0.88 \mathrm{~d}+123.86 \pm 20.3(\mathrm{~m} / \mathrm{sec})$ & 157 \\
\hline
\end{tabular}


Table 4.11: Low frequency amplification values (Fourier spectra definition) for the 19 examined sites in Ottawa area. Site depth, average shear wave velocity in top thirty meters and fundamental frequency calculated based on the average shear wave velocity are illustrated in the first, second and third columns. The amplification values are given for 10 intensities of shaking (PGA).

\begin{tabular}{|c|c|c|c|c|c|c|c|c|c|c|c|c|}
\hline \multicolumn{3}{|c|}{ PGA of Input Motion } & \multirow{2}{*}{ Gal } & \multirow{2}{*}{$\begin{array}{l}256 \\
\text { Gal }\end{array}$} & \multirow{2}{*}{$\begin{array}{l}304 \\
\text { Gal }\end{array}$} & \multirow{2}{*}{$\begin{array}{l}422 \\
\mathrm{Gal}\end{array}$} & \multirow{2}{*}{$\begin{array}{l}512 \\
\text { Gal }\end{array}$} & \multirow{2}{*}{$\begin{array}{l}607 \\
\text { Gal }\end{array}$} & \multirow{2}{*}{$\begin{array}{l}707 \\
\text { Gal }\end{array}$} & \multirow{2}{*}{$\begin{array}{l}813 \\
\text { Gal }\end{array}$} & \multirow{2}{*}{$\begin{array}{l}942 \\
\text { Gal }\end{array}$} & \multirow{2}{*}{$\begin{array}{c}1000 \\
\text { Gal }\end{array}$} \\
\hline Site Depth & $\mathrm{Vs}_{30}(\mathrm{~m} / \mathrm{sec})$ & $f_{n}(H z)$ & & & & & & & & & & \\
\hline $1 \mathrm{~m}$ & 1970 & 45 & 1 & 1 & 1 & 1 & 1 & 1 & 1 & 1 & 1 & 1 \\
\hline $5 \mathrm{~m}$ & 830 & 9 & 1 & 1 & 1 & 1 & 1 & 1 & 1 & 1 & 1 & 1 \\
\hline $10 \mathrm{~m}$ & 405 & 3.8 & 1.1 & 1.1 & 1.1 & 1.1 & 1.1 & 1.2 & 1.1 & 1.2 & 1.2 & 1.2 \\
\hline $15 \mathrm{~m}$ & 287 & 2.5 & 1.3 & 1.4 & 1.2 & 1.3 & 1.5 & 1.5 & 1.2 & 1.7 & 1.4 & 1.5 \\
\hline $20 \mathrm{~m}$ & 223 & 1.9 & 1.6 & 2 & 1.9 & 1.6 & 1.8 & 2 & 1.8 & 1.8 & 1.7 & 2 \\
\hline $25 \mathrm{~m}$ & 184 & 1.5 & 2.5 & 3.3 & 2.7 & 2.3 & 2.3 & 3.4 & 2.4 & 4 & 2.4 & 2.7 \\
\hline $30 \mathrm{~m}$ & 157 & 1.3 & 4 & 4.4 & 4.4 & 4 & 3.8 & 4.09 & 3.9 & 3.7 & 4 & 3.8 \\
\hline $32 \mathrm{~m}$ & 112 & 0.9 & 3.7 & 2.6 & 4.6 & 3.8 & 4 & 2.2 & 3.6 & 2.3 & 23 & 2.6 \\
\hline $38 \mathrm{~m}$ & 118 & 0.8 & 3.2 & 2.2 & 4.1 & 3.4 & 3.9 & 2.1 & 3.7 & 1.9 & 2.6 & 2.2 \\
\hline $41 \mathrm{~m}$ & 139 & 0.9 & 4.6 & 3.4 & 5.5 & 4 & 4.1 & 2.8 & 3.7 & 2.6 & 3.4 & 3.2 \\
\hline $45 \mathrm{~m}$ & 122 & 0.7 & 2.8 & 1.9 & 3.6 & 2.8 & 3.3 & 1.8 & 3.7 & 1.6 & 2.3 & 1.9 \\
\hline $51 \mathrm{~m}$ & 118 & 0.6 & 2.3 & 1.5 & 2.9 & 1.9 & 1.8 & 1.5 & 3 & 1.5 & 1.7 & 1.7 \\
\hline $63 \mathrm{~m}$ & 112 & 0.5 & 1.6 & 1.6 & 1.5 & 1.8 & 1.9 & 1.6 & 1.3 & 2.1 & 1.4 & 1.5 \\
\hline $69 \mathrm{~m}$ & 120 & 0.5 & 1.6 & 1.6 & 1.5 & 1.8 & 1.9 & 1.6 & 1.4 & 2.2 & 1.4 & 1.5 \\
\hline $81 \mathrm{~m}$ & 120 & 0.5 & 2.1 & 2.1 & 2.1 & 2.4 & 2.5 & 1.9 & 2.1 & 2.3 & 1.8 & 1.9 \\
\hline $82 \mathrm{~m}$ & 137 & 0.5 & 1.7 & 1.7 & 1.7 & 1.9 & 2 & 1.6 & 1.3 & 2 & 1.4 & 1.5 \\
\hline $95 \mathrm{~m}$ & 96 & 0.4 & 3.4 & 2.5 & 2.4 & 2.3 & 2.6 & 2 & 2.2 & 1.8 & 2.3 & 2.3 \\
\hline $98 \mathrm{~m}$ & 133 & 0.4 & 2.3 & 2.2 & 2.1 & 2.5 & 2.8 & 2 & 2.4 & 1.7 & 2 & 2 \\
\hline $112 \mathrm{~m}$ & 122 & 0.4 & 2.8 & 2.3 & 2 & 2 & 2.9 & 1.8 & 2 & 1.6 & 2.1 & 2 \\
\hline
\end{tabular}


Table 4.12: Values of low frequency Foundation Factors $\left(F_{v}\right)$ in NBCC, 2005.

\begin{tabular}{|c|c|c|c|c|c|}
\hline $\mathrm{S}_{1}$ & & & & & \\
\hline Site Class & $\leq 0.1 \mathrm{~g}$ & $0.2 \mathrm{~g}$ & $0.3 \mathrm{~g}$ & $0.4 \mathrm{~g}$ & $\geq 0.5 \mathrm{~g}$ \\
\hline A & 0.5 & 0.5 & 0.5 & 0.6 & 0.6 \\
\hline $\mathrm{B}$ & 0.6 & 0.7 & 0.7 & 0.8 & 0.8 \\
\hline $\mathrm{C}$ & 1 & 1 & 1 & 1 & 1 \\
\hline $\mathrm{D}$ & 1.4 & 1.3 & 1.2 & 1.1 & 1.1 \\
\hline $\mathrm{E}$ & 2.1 & 2 & 1.9 & 1.7 & 1.7 \\
\hline $\mathrm{F}$ & * & $*$ & $*$ & * & $*$ \\
\hline
\end{tabular}

$\mathrm{S}_{1}$ is the spectral acceleration at $1 \mathrm{~Hz}$

* Site specific investigation and dynamic site response analysis require 
Table 4.13: Constants of $a, b$ and $c$ in equation (4-42) for the determination of low frequency amplification values, $\left(F_{V}\right)_{F F T}$. These constants were obtained based on the multiple linear regression at the specific shaking intensity $(P G A=\alpha)$.

\begin{tabular}{|l|l|l|l|}
\hline PGA $=\alpha$ & $\mathrm{a}$ & $\mathrm{b}$ & $\mathrm{c}$ \\
\hline 181 & 1.72 & -0.49 & 0.29 \\
\hline 256 & 1.89 & -0.55 & 0.14 \\
\hline 304 & 1.36 & -0.23 & 0.45 \\
\hline 422 & 1.62 & -0.41 & 0.29 \\
\hline 512 & 1.83 & -0.55 & 0.29 \\
\hline 607 & 1.85 & -0.51 & 0.1 \\
\hline 707 & 1.6 & -0.4 & 0.29 \\
\hline 813 & 2 & -0.61 & 0.1 \\
\hline 942 & 1.56 & -0.35 & 0.2 \\
\hline 1000 & 1.71 & -0.44 & 0.15 \\
\hline
\end{tabular}


Table 4.14: High frequency amplification values (Fourier spectra definition) for 19 sites in Ottawa area. Site depth, average shear wave velocity in top thirty meters and linear fundamental frequency are illustrated in the first, second and third columns. The amplification values are given for 10 intensities of shaking (PGA).

\begin{tabular}{|c|c|c|c|c|c|c|c|c|c|c|c|c|}
\hline \multicolumn{3}{|c|}{ PGA of Input Motion } & \multirow{2}{*}{$\mid \begin{array}{l}181 \\
\text { Gal }\end{array}$} & \multirow{2}{*}{$\begin{array}{l}256 \\
\text { Gal }\end{array}$} & \multirow{2}{*}{$\begin{array}{l}304 \\
\mathrm{Gal}\end{array}$} & \multirow{2}{*}{$\begin{array}{l}422 \\
\text { Gal }\end{array}$} & \multirow{2}{*}{$\begin{array}{l}512 \\
\mathrm{Gal}\end{array}$} & \multirow{2}{*}{$\begin{array}{l}607 \\
\text { Gal }\end{array}$} & \multirow{2}{*}{$\begin{array}{l}707 \\
\text { Gal }\end{array}$} & \multirow{2}{*}{$\begin{array}{l}813 \\
\text { Gal }\end{array}$} & \multirow{2}{*}{$\begin{array}{l}942 \\
\text { Gal }\end{array}$} & \multirow{2}{*}{$\begin{array}{l}1000 \\
\mathrm{Gal}\end{array}$} \\
\hline Site Depth & $\mathrm{Vs}_{30}(\mathrm{~m} / \mathrm{sec})$ & $\mathrm{f}_{\mathrm{n}}(\mathrm{Hz})$ & & & & & & & & & & \\
\hline $1 \mathrm{~m}$ & 1970 & 45 & 0.8 & 0.8 & 0.9 & 0.9 & 1 & 1 & 1 & 1 & 1 & 1 \\
\hline $5 \mathrm{~m}$ & 830 & 9 & 0.95 & 0.9 & 0.9 & 0.9 & 1 & 1 & 1 & 1 & 1 & 1 \\
\hline $10 \mathrm{~m}$ & 405 & 3.8 & 1.2 & 1 & 1 & 1 & 0.9 & 0.8 & 0.8 & 0.8 & 0.8 & 0.8 \\
\hline $15 \mathrm{~m}$ & 287 & 2.5 & 1.6 & 1.2 & 1.2 & 1 & 0.9 & 0.8 & 0.8 & 0.8 & 0.7 & 0.6 \\
\hline $20 \mathrm{~m}$ & 223 & 1.9 & 1.8 & 1.2 & 1.2 & 0.9 & 0.9 & 0.9 & 0.9 & 0.7 & 0.7 & 0.7 \\
\hline $25 \mathrm{~m}$ & 184 & 1.5 & 1.9 & 1.5 & 1.5 & 1.3 & 1.3 & 1.1 & 0.8 & 0.8 & 0.7 & 0.6 \\
\hline $30 \mathrm{~m}$ & 157 & 1.3 & 1.95 & 1.5 & 1.4 & 1.4 & 1.3 & 1.2 & 0.8 & 0.8 & 0.8 & 0.7 \\
\hline $32 \mathrm{~m}$ & 112 & 0.9 & 2 & 1.6 & 1.4 & 1.4 & 1.5 & 1.2 & 0.9 & 0.8 & 0.7 & 0.7 \\
\hline $38 \mathrm{~m}$ & 118 & 0.8 & 1.9 & 1.6 & 1.5 & 1.5 & 1.5 & 1.3 & 0.8 & 0.9 & 0.8 & 0.6 \\
\hline $41 \mathrm{~m}$ & 139 & 0.9 & 1.8 & 1.5 & 1.4 & 1.4 & 1.3 & 1.2 & 0.9 & 0.8 & 0.7 & 0.7 \\
\hline $45 \mathrm{~m}$ & 122 & 0.7 & 1.9 & 1.4 & 1.45 & 1.5 & 1.5 & 1.2 & 1 & 0.7 & 0.7 & 0.7 \\
\hline $51 \mathrm{~m}$ & 118 & 0.6 & 1.8 & 1.6 & 1.5 & 1.5 & 1.5 & 1.1 & 1 & 0.9 & 0.8 & 0.8 \\
\hline $63 \mathrm{~m}$ & 112 & 0.5 & 2.2 & 1.6 & 1.6 & 1.5 & 1.3 & 1 & 0.8 & 0.9 & 0.7 & 0.8 \\
\hline $69 \mathrm{~m}$ & 120 & 0.5 & 2 & 1.6 & 1.5 & 1.3 & 1.3 & 1 & 0.7 & 0.7 & 0.6 & 0.6 \\
\hline $81 \mathrm{~m}$ & 120 & 0.5 & 1.9 & 1.4 & 1.4 & 1.3 & 1.2 & 0.9 & 0.8 & 0.7 & 0.6 & 0.6 \\
\hline $82 \mathrm{~m}$ & 137 & 0.5 & 1.8 & 1.4 & 1.3 & 1.3 & 1.3 & 1 & 0.9 & 0.8 & 0.9 & 0.8 \\
\hline $95 \mathrm{~m}$ & 96 & 0.4 & 2.5 & 1.7 & 1.6 & 1.5 & 1.6 & 1.2 & 1 & 0.9 & 0.6 & 0.7 \\
\hline $98 \mathrm{~m}$ & 133 & 0.4 & 1.8 & 1.4 & 1.4 & 1.4 & 1.5 & 1.1 & 0.9 & 0.8 & 0.8 & 0.8 \\
\hline $112 \mathrm{~m}$ & 122 & 0.4 & 2.1 & 1.5 & 1.3 & 1.3 & 1.3 & 1 & 0.9 & 0.8 & 0.8 & 0.6 \\
\hline
\end{tabular}


Table 4.15: Values of high frequency Foundation Factors $\left(F_{a}\right)$ in NBCC, 2005.

\begin{tabular}{|c|c|c|c|c|c|}
\hline $\mathrm{S}_{0.2}$ & & & & & \\
\hline Site Class & $\leq 0.25 \mathrm{~g}$ & $0.5 \mathrm{~g}$ & $0.75 \mathrm{~g}$ & $1.00 \mathrm{~g}$ & $\geq 1.25 \mathrm{~g}$ \\
\hline A & 0.7 & 0.7 & 0.8 & 0.8 & 0.8 \\
\hline B & 0.8 & 0.8 & 0.9 & 1 & 1 \\
\hline $\mathrm{C}$ & 1 & 1 & 1 & 1 & 1 \\
\hline $\bar{D}$ & 1.3 & 1.2 & 1.1 & 1.1 & 1 \\
\hline$E$ & 2.1 & 1.4 & 1.1 & 0.9 & 0.9 \\
\hline $\mathrm{F}$ & $*$ & $*$ & $*$ & $*$ & $*$ \\
\hline
\end{tabular}

$\mathrm{S}_{0.2}$ is the spectral acceleration at $5 \mathrm{~Hz}$

* Site specific investigation and dynamic site response analysis require 
Table 4.16: Low frequency amplification values (Response spectra definition) for the nineteen examined sites in Ottawa area. Site depth, average shear wave velocity in top thirty meters and fundamental frequency (calculated from average shear wave velocity) are illustrated in the first, second and third columns. The values are given for ten intensities of shaking (PGA).

\begin{tabular}{|c|c|c|c|c|c|c|c|c|c|c|c|c|}
\hline \multicolumn{3}{|c|}{ PGA of Input Motion } & \multirow{2}{*}{$\begin{array}{c}181 \\
\text { Gal }\end{array}$} & \multirow{2}{*}{$\begin{array}{l}256 \\
\text { Gal }\end{array}$} & \multirow{2}{*}{$\begin{array}{l}304 \\
\text { Gal }\end{array}$} & \multirow{2}{*}{$\begin{array}{l}422 \\
\text { Gal }\end{array}$} & \multirow{2}{*}{$\begin{array}{l}512 \\
\text { Gal }\end{array}$} & \multirow{2}{*}{$\begin{array}{l}607 \\
\text { Gal }\end{array}$} & \multirow{2}{*}{$\begin{array}{l}707 \\
\text { Gal }\end{array}$} & \multirow{2}{*}{$\begin{array}{l}813 \\
\text { Gal }\end{array}$} & \multirow{2}{*}{$\begin{array}{l}942 \\
\mathrm{Gal}\end{array}$} & \multirow{2}{*}{$\begin{array}{c}1000 \\
\text { Gal }\end{array}$} \\
\hline Site Depth & $\mathrm{Vs}_{30}(\mathrm{~m} / \mathrm{sec})$ & $\mathrm{f}_{\mathrm{n}}(\mathrm{Hz})$ & & & & & & & & & & \\
\hline $1 \mathrm{~m}$ & 1970 & 45 & 0.8 & 0.8 & 0.8 & 0.8 & 0.9 & 1 & 1 & 1 & 1 & 1 \\
\hline $5 \mathrm{~m}$ & 830 & 9 & 1.1 & 1.1 & 1.1 & 1 & 1.1 & 1.2 & 1.1 & 1.1 & 1.1 & 1.1 \\
\hline $10 \mathrm{~m}$ & 405 & 3.8 & 1.5 & 1.4 & 1.4 & 1.5 & 1.3 & 1.4 & 1.3 & 1.3 & 1.3 & 1.3 \\
\hline $15 \mathrm{~m}$ & 287 & 2.5 & 1.8 & 1.9 & 2 & 1.7 & 2 & 2.3 & 1.6 & 1.6 & 1.7 & 1.7 \\
\hline $20 \mathrm{~m}$ & 223 & 1.9 & 1.8 & 1.9 & 1.8 & 1.6 & 1.7 & 1.8 & 1.6 & 1.6 & 1.6 & 1.5 \\
\hline $25 \mathrm{~m}$ & 184 & 1.55 & 2.2 & 2 & 1.8 & 1.8 & 1.9 & 1.8 & 1.6 & 1.6 & 1.6 & 1.5 \\
\hline $30 \mathrm{~m}$ & 157 & 1.3 & 3.1 & 3.3 & 2.6 & 2.6 & 2.7 & 2 & 2 & 1.8 & 1.6 & 1.5 \\
\hline $32 \mathrm{~m}$ & 112 & 0.9 & 3.4 & 3 & 2.6 & 2.2 & 2.4 & 2.3 & 2.2 & 2 & 1.8 & 1.8 \\
\hline $38 \mathrm{~m}$ & 118 & 0.8 & 3 & 2.8 & 2.3 & 2.4 & 2 & 2 & 1.9 & 1.7 & 1.7 & 1.5 \\
\hline $41 \mathrm{~m}$ & 139 & 0.9 & 2.4 & 2.4 & 2.1 & 2.2 & 1.8 & 1.9 & 2 & 1.7 & 1.6 & 1.6 \\
\hline $45 \mathrm{~m}$ & 122 & 0.7 & 2.9 & 3 & 2.5 & 2.3 & 2 & 1.9 & 1.8 & 1.8 & 1.5 & 1.5 \\
\hline $51 \mathrm{~m}$ & 118 & 0.6 & 2.8 & 2.9 & 2.3 & 1.9 & 1.8 & 2 & 1.7 & 1.7 & 1.7 & 1.6 \\
\hline $63 \mathrm{~m}$ & 112 & 0.5 & 3.5 & 3.1 & 2.8 & 2.8 & 2.5 & 2.2 & 1.9 & 2 & 1.7 & 1.6 \\
\hline $69 \mathrm{~m}$ & 120 & 0.5 & 2.4 & 2.1 & 2.2 & 1.8 & 1.9 & 2 & 1.6 & \begin{tabular}{|l|}
1.5 \\
\end{tabular} & 1.5 & 1.6 \\
\hline $81 \mathrm{~m}$ & 120 & 0.5 & 2 & 2.3 & 2 & 1.9 & 2.3 & 1.9 & 2 & 1.9 & 2.2 & 1.5 \\
\hline $82 \mathrm{~m}$ & 137 & 0.5 & 2 & 2.1 & 1.8 & 1.7 & 1.9 & 2 & 1.7 & 1.5 & 1.6 & 1.5 \\
\hline $95 \mathrm{~m}$ & 96 & 0.4 & 3.6 & 3 & 2.7 & 2.5 & 2.6 & 2.5 & 2 & 2 & 2.2 & 1.7 \\
\hline $98 \mathrm{~m}$ & 133 & 0.4 & 2.5 & 2.3 & 2.4 & 1.9 & 2 & 1.9 & 1.8 & 1.5 & 1.4 & 1.5 \\
\hline $112 \mathrm{~m}$ & 122 & 0.4 & 3.4 & 2.4 & 2.2 & 2.3 & 2.2 & 2 & 1.8 & 1.7 & 1.5 & 1.6 \\
\hline
\end{tabular}


Table 4.17: High frequency amplification values (Response spectra definition) for nineteen sites in Ottawa area. Site depth, average shear wave velocity in top thirty meters and linear fundamental frequency are illustrated in the first, second and third columns.

The values are given for ten intensities of shaking ( $P G A)$.

\begin{tabular}{|c|c|c|c|c|c|c|c|c|c|c|c|c|}
\hline \multicolumn{3}{|c|}{ PGA of Input Motion } & \multirow{2}{*}{$\begin{array}{l}181 \\
\text { Gal }\end{array}$} & \multirow{2}{*}{$\begin{array}{l}256 \\
\mathrm{Gal}\end{array}$} & \multirow{2}{*}{$\begin{array}{l}304 \\
\mathrm{Gal}\end{array}$} & \multirow{2}{*}{$\begin{array}{l}422 \\
\mathrm{Gal}\end{array}$} & \multirow{2}{*}{$\begin{array}{c}512 \\
\mathrm{Gal}\end{array}$} & \multirow{2}{*}{$\begin{array}{l}607 \\
\text { Gal }\end{array}$} & \multirow{2}{*}{$\begin{array}{l}707 \\
\mathrm{Gal}\end{array}$} & \multirow{2}{*}{$\begin{array}{l}813 \\
\text { Gal }\end{array}$} & \multirow{2}{*}{$\begin{array}{l}942 \\
\text { Gal }\end{array}$} & \multirow{2}{*}{$\begin{array}{l}1000 \\
\mathrm{Gal}\end{array}$} \\
\hline Site Depth & $\mathrm{Vs}_{30}(\mathrm{~m} / \mathrm{sec})$ & $f_{n}(H z)$ & & & & & & & & & & \\
\hline $1 \mathrm{~m}$ & 1970 & 45 & 0.9 & 0.9 & 0.9 & 0.9 & 0.9 & 0.9 & 0.9 & 0.9 & 0.9 & 0.9 \\
\hline $5 \mathrm{~m}$ & 830 & 9 & 1 & 1 & 1 & 1 & 1 & 1 & 1.1 & 1.1 & 1.1 & 1.1 \\
\hline $10 \mathrm{~m}$ & 405 & 3.8 & 1.1 & 1.1 & 1.1 & 1.1 & 1.1 & 1.1 & 1 & 0.9 & 0.9 & 0.9 \\
\hline $15 \mathrm{~m}$ & 287 & 2.5 & 1.4 & 1.1 & 1.2 & 1.1 & 1 & 1.1 & 1.2 & 0.9 & 0.9 & 0.8 \\
\hline $20 \mathrm{~m}$ & 223 & 1.9 & 1.3 & 1.3 & 1.1 & 1.1 & 1 & 1 & 1 & 1 & 0.8 & 0.7 \\
\hline $25 \mathrm{~m}$ & 184 & 1.55 & 1.4 & 1.4 & 1.1 & 1.1 & 0.9 & 0.9 & 0.9 & 0.8 & 0.8 & 0.7 \\
\hline $30 \mathrm{~m}$ & 157 & 1.3 & 1.5 & 1.4 & 1.2 & 1.1 & 1 & 0.9 & 0.8 & 0.8 & 0.7 & 0.6 \\
\hline $32 \mathrm{~m}$ & 112 & 0.9 & 1.6 & 1.7 & 1.5 & 1.2 & 1 & 1 & 0.9 & 0.7 & 0.8 & 0.8 \\
\hline $38 \mathrm{~m}$ & 118 & 0.8 & 1.6 & 1.6 & 1.3 & 1.2 & 1.2 & 1 & 0.9 & 0.8 & 0.8 & 0.8 \\
\hline $41 \mathrm{~m}$ & 139 & 0.9 & 1.5 & 1.5 & 1.2 & 1.2 & 0.9 & 1 & 0.8 & 0.9 & 0.7 & 0.7 \\
\hline $45 \mathrm{~m}$ & 122 & 0.7 & 1.5 & 1.5 & 1.3 & 1.2 & 1 & 1.1 & 1 & 0.8 & 0.7 & 0.7 \\
\hline $51 \mathrm{~m}$ & 118 & 0.6 & 1.6 & 1.5 & 1.3 & 1.3 & 1.1 & 1.1 & 0.9 & 0.9 & 0.9 & 0.9 \\
\hline $63 \mathrm{~m}$ & 112 & 0.5 & 1.6 & 1.5 & 1.5 & 1.3 & 1.1 & 1.2 & 1 & 0.8 & 0.7 & 0.8 \\
\hline $69 \mathrm{~m}$ & 120 & 0.5 & 1.5 & 1.6 & 1.2 & 1.2 & 1 & 0.9 & 0.9 & 0.8 & 0.7 & 0.6 \\
\hline $81 \mathrm{~m}$ & 120 & 0.5 & 1.2 & 1.1 & 1.2 & 1.1 & 0.9 & 0.8 & 0.8 & 0.7 & 0.6 & 0.5 \\
\hline $82 \mathrm{~m}$ & 137 & 0.5 & 1.5 & 1.5 & 1.2 & 1.1 & 1 & 0.8 & 0.8 & 0.8 & 0.7 & 0.5 \\
\hline $95 \mathrm{~m}$ & 96 & 0.4 & 2.1 & 1.7 & 1.5 & 1.5 & 1.2 & 1 & 1 & 1 & 0.8 & 0.5 \\
\hline $98 \mathrm{~m}$ & 133 & 0.4 & 1.5 & 1.2 & 1.2 & 1.2 & 1 & 0.9 & 1 & 0.9 & 0.8 & 0.7 \\
\hline $112 \mathrm{~m}$ & 122 & 0.4 & 1.6 & 1.5 & 1.3 & 1.3 & 1 & 0.9 & 0.8 & 0.8 & 0.7 & 0.5 \\
\hline
\end{tabular}


Table 4.18: Depth and average shear wave velocity values in top $30 \mathrm{~m}$ for the examined sites in Ottawa area. These sites provided the source profiles to obtain the low and high frequency amplification values similar to those given in NBCC, 2005.

\begin{tabular}{|c|c|}
\hline Depth $(\mathrm{m})$ & Vs30 (m/sec) \\
\hline 1 & 1723 \\
\hline 3 & 1000 \\
\hline 5 & 704 \\
\hline 10 & 405 \\
\hline 15 & 284 \\
\hline 20 & 219 \\
\hline 25 & 178 \\
\hline 30 & 150 \\
\hline 40 & 150 \\
\hline 50 & 150 \\
\hline 60 & 150 \\
\hline 70 & 150 \\
\hline 80 & 150 \\
\hline 90 & 150 \\
\hline 100 & 150 \\
\hline 110 & 150 \\
\hline 120 & 150 \\
\hline
\end{tabular}

Table 4.19: Low frequency amplification values for Ottawa area for different configurations of site classes.

\begin{tabular}{|c|c|c|c|c|c|}
\hline $\mathrm{S}_{1}$ & & & & & \\
\hline Site Class & $\leq 0.1 \mathrm{~g}$ & $0.2 \mathrm{~g}$ & $0.3 \mathrm{~g}$ & $0.4 \mathrm{~g}$ & $\geq 0.5 \mathrm{~g}$ \\
\hline$\overline{A 1}$ & 1 & 1 & 1 & 1 & 1 \\
\hline A2 & 1 & 1 & 1 & 1 & 1 \\
\hline $\mathrm{B} 1$ & 1.15 & 1.05 & 1.1 & 1.1 & 1.1 \\
\hline B2 & 1.05 & 1.05 & 1.05 & 1.1 & 1.1 \\
\hline $\mathrm{Cl}$ & 1.2 & 1.15 & 1.2 & 1.1 & 1.1 \\
\hline $\mathrm{C} 2$ & 1.2 & 1.2 & 1.1 & 1.1 & 1.1 \\
\hline $\mathrm{C} 3$ & 1.5 & 1.6 & 1.3 & 1.35 & 1.35 \\
\hline $\mathrm{C} 4$ & 1.45 & 1.4 & 1.35 & 1.3 & 1.3 \\
\hline D1 & 2.1 & 1.85 & 1.9 & 1.7 & 1.65 \\
\hline D2 & 2 & 2.1 & 1.85 & 1.75 & 1.8 \\
\hline D3 & 2.85 & 2.7 & 2.55 & 2.4 & 2.4 \\
\hline D4 & 2.8 & 2.85 & 2.6 & 2.3 & 2.3 \\
\hline El & 3.5 & 3.4 & 3.1 & 2.7 & 2.6 \\
\hline $\mathrm{E} 2$ & 3.4 & 3.3 & 3.1 & 2.9 & 2.5 \\
\hline E3 & 3.7 & 3.5 & 3 & 2.7 & 2.4 \\
\hline E4 & 3.55 & 3.3 & 3.15 & 2.75 & 2.8 \\
\hline
\end{tabular}


Table 4.20: High frequency amplification values for Ottawa area for different configurations of site classes

\begin{tabular}{|l|l|l|l|l|l|}
\cline { 1 - 1 } $\mathrm{S}_{0.2}$ & \multirow{2}{*}{$\leq 0.25 \mathrm{~g}$} & $0.5 \mathrm{~g}$ & $0.75 \mathrm{~g}$ & $1.00 \mathrm{~g}$ & $\geq 1.25 \mathrm{~g}$ \\
\cline { 1 - 5 } Site Class & & & & & \\
\hline $\mathrm{A} 1$ & 1 & 1 & 1 & 1 & 1 \\
\hline $\mathrm{A} 2$ & 1 & 1 & 1 & 1 & 1 \\
\hline $\mathrm{B} 1$ & 1.1 & 1.1 & 1.2 & 1.2 & 1.2 \\
\hline $\mathrm{B} 2$ & 1.15 & 1.15 & 1.2 & 1.2 & 1.1 \\
\hline $\mathrm{C} 1$ & 1.4 & 1.25 & 1.25 & 1.1 & 1.15 \\
\hline $\mathrm{C} 2$ & 1.4 & 1.2 & 1.2 & 1.2 & 1.15 \\
\hline $\mathrm{C} 3$ & 1.7 & 1.5 & 1.45 & 1.3 & 1.2 \\
\hline $\mathrm{C} 4$ & 1.55 & 1.35 & 1.3 & 1.2 & 1.2 \\
\hline $\mathrm{D} 1$ & 1.9 & 1.5 & 1.4 & 1.2 & 1 \\
\hline $\mathrm{D} 2$ & 1.85 & 1.6 & 1.4 & 1.3 & 1.1 \\
\hline $\mathrm{D} 3$ & 2 & 1.45 & 1.35 & 1.2 & 1 \\
\hline $\mathrm{D} 4$ & 1.8 & 1.55 & 1.45 & 1.25 & 1 \\
\hline E1 & 2.7 & 1.8 & 1.3 & 1.1 & 0.9 \\
\hline E2 & 2.8 & 1.9 & 1.45 & 1.1 & 0.8 \\
\hline E3 & 3 & 2 & 1.4 & 1.15 & 1 \\
\hline E4 & 2.8 & 1.85 & 1.3 & 1.2 & 0.95 \\
\hline
\end{tabular}

Table 4.21: Average Low frequency amplification values for Ottawa area.

\begin{tabular}{|l|l|l|l|l|l|}
\cline { 1 - 5 } $\mathrm{S}_{1}$ & \multirow{2}{*}{$\leq 0.1 \mathrm{~g}$} & $0.2 \mathrm{~g}$ & $0.3 \mathrm{~g}$ & $0.4 \mathrm{~g}$ & $\geq 0.5 \mathrm{~g}$ \\
\cline { 1 - 5 } Site Class & 1 & 1 & 1 & 1 & 1 \\
\hline $\mathrm{A}$ & 1 & 1 & 1 & 1.1 & 1.1 \\
\hline $\mathrm{B}$ & 1.3 & 1.3 & 1.2 & 1.2 & 1.2 \\
\hline $\mathrm{D}$ & 2.4 & 2.4 & 2.2 & 2 & 2 \\
\hline $\mathrm{E}$ & 3.5 & 3.4 & 3.1 & 2.8 & 2.6 \\
\hline
\end{tabular}


Table 4.22: Average high frequency amplification values for Ottawa area.

\begin{tabular}{|l|l|l|l|l|l|}
\cline { 1 - 2 } $\mathrm{S}_{0.2}$ & \multirow{2}{*}{$\leq 0.25 \mathrm{~g}$} & $0.5 \mathrm{~g}$ & $0.75 \mathrm{~g}$ & $1.00 \mathrm{~g}$ & $\geq 1.25 \mathrm{~g}$ \\
\cline { 1 - 5 } Site Class & 1 & 1 & 1 & 1 & 1 \\
\hline $\mathrm{A}$ & 1.1 & 1.1 & 1.2 & 1.2 & 1.2 \\
\hline $\mathrm{B}$ & 1.5 & 1.3 & 1.3 & 1.2 & 1.2 \\
\hline $\mathrm{D}$ & 1.9 & 1.5 & 1.4 & 1.2 & 1 \\
\hline $\mathrm{E}$ & 2.8 & 1.9 & 1.4 & 1.2 & 0.9 \\
\hline
\end{tabular}

Table 4.23: Proposed average low frequency amplification values for Ottawa area. The amplification values were normalized to the values of site class $C$.

\begin{tabular}{|l|l|l|l|l|l|}
\cline { 1 - 1 } $\mathrm{S}_{1}$ & \multirow{2}{*}{$\leq 0.1 \mathrm{~g}$} & $0.2 \mathrm{~g}$ & $0.3 \mathrm{~g}$ & $0.4 \mathrm{~g}$ & $\geq 0.5 \mathrm{~g}$ \\
\cline { 1 - 5 } Site Class & \multicolumn{1}{|l|}{0.8} & 0.8 & 0.8 & 0.8 & 0.8 \\
\hline $\mathrm{A}$ & 0.8 & 0.8 & 0.8 & 0.9 & 0.9 \\
\hline B & 1 & 1 & 1 & 1 & 1 \\
\hline D & 1.8 & 1.8 & 1.8 & 1.7 & 1.7 \\
\hline E & 2.7 & 2.6 & 2.6 & 2.3 & 2.2 \\
\hline
\end{tabular}


Table 4.24: Proposed average high frequency amplification values for Ottawa area. The amplification values were normalized to the values of site class $C$.

\begin{tabular}{|c|c|c|c|c|c|}
\hline $\mathrm{S}_{0.2}$ & & & & & \\
\hline Site Class & $\leq 0.25 \mathrm{~g}$ & $0.5 \mathrm{~g}$ & $0.75 \mathrm{~g}$ & $1.00 \mathrm{~g}$ & $\geq 1.25 \mathrm{~g}$ \\
\hline $\mathrm{A}$ & 0.7 & 0.8 & 0.8 & 0.8 & 0.8 \\
\hline $\mathrm{B}$ & 0.7 & 0.8 & 0.9 & 1 & 1 \\
\hline $\mathrm{C}$ & 1 & 1 & 1 & 1 & 1 \\
\hline $\mathrm{D}$ & 1.3 & 1.2 & 1.1 & 1 & 0.8 \\
\hline$E$ & 1.9 & 1.5 & 1.1 & 1 & 0.8 \\
\hline
\end{tabular}


Table 4.25: Peak amplification ratios for target fundamental frequencies in Ottawa area.

\begin{tabular}{|l|l|l|l|l|l|l|l|}
\cline { 1 - 5 } \multicolumn{1}{|c|}{$\mathrm{S}_{\mathrm{f} 0}$} & & & & & & & \\
\cline { 1 - 6 } $\begin{array}{c}\text { Fundamental } \\
\text { Frequency (Hz) }\end{array}$ & $0.1 \mathrm{~g}$ & $0.2 \mathrm{~g}$ & $0.3 \mathrm{~g}$ & $0.4 \mathrm{~g}$ & $0.5 \mathrm{~g}$ & $0.75 \mathrm{~g}$ & $1 \mathrm{~g}$ \\
\hline 0.32 & 4 & 3.9 & 3.5 & 3.3 & 3.2 & 2.8 & 2.3 \\
\hline 0.5 & 4.5 & 4.3 & 4. & 2.7 & 2.6 & 2.3 & 2.2 \\
\hline 0.63 & 5 & 4.2 & 4.2 & 3.7 & 2.6 & 2.4 & 2.6 \\
\hline 1 & 5.2 & 5.1 & 4.6 & 3.9 & 3.5 & 3.2 & 2.7 \\
\hline 1.3 & 5.6 & 5.2 & 4.8 & 4.3 & 4.1 & 3.7 & 3.4 \\
\hline 1.6 & 6.1 & 5.9 & 5.6 & 4.5 & 4.2 & 4 & 3.4 \\
\hline 2 & 6.3 & 6 & 5.9 & 4.6 & 4.5 & 4.2 & 3.5 \\
\hline 2.5 & 6.2 & 6.1 & 5.7 & 4.7 & 4.5 & 4.3 & 3.4 \\
\hline 3.2 & 6.9 & 6.3 & 5.9 & 4.8 & 4.9 & 4.7 & 3.6 \\
\hline 4 & 7 & 6.3 & 6 & 4.9 & 4.8 & 4.6 & 3.7 \\
\hline 5 & 7 & 6.5 & 5.9 & 5 & 4.9 & 4.8 & 3.6 \\
\hline 6.3 & 7.2 & 6.9 & 6.1 & 6. & 5.8 & 5.1 & 4.2 \\
\hline 8 & 8 & 7 & 6.8 & 6.3 & 6 & 5.4 & 4.2 \\
\hline 10 & 8.1 & 7.3 & 7 & 6.6 & 6.2 & 5.9 & 5 \\
\hline
\end{tabular}




\section{Two-dimensional site response analysis using explicit finite difference method}

\subsection{Introduction}

This chapter is dedicated to two-dimensional site response analysis of a loosesediment in a buried valley located in the eastern part of the city of Ottawa (Motazedian and Hunter, 2008). As shown in Figure (5.1), the borehole information indicated that a substantial bedrock depression exists although there was no indication of it from the surface topography. Our shear wave sites were strategically placed to fill in spaces in the borehole distribution and provided information for two transverse (AB) and longitudinal (CD) cross sections. From combined borehole and seismic information, the resultant overburden thickness for these two cross sections is shown in Figure (5.2) indicating an elongate valley with very steep sides.

The objective of this chapter is to assess the seismic amplification values obtained from finite difference analysis of the mentioned buried valley subjected to different levels of shaking. The results of this two-dimensional analysis will be compared against a nearby one-dimensional site. This comparison will provide the implications for the expected seismic amplification values from two-dimensional analysis. The theoretical bases for the mentioned finite difference solution and the formulation of the utilized program FLAC (version 5, Itasca Consulting Group Inc., 2005) are briefly explained in sections 5.2 and 5.3. Section 5.4 is assigned to the stress-strain constitutive models, as 
significant part of the calculation cycle in FLAC program, and specifically the modified Cam-Clay (MCC) model is elaborated in details. In Section 5.5 the geotechnical properties of Leda clay are reviewed and afterwards, the mentioned MCC model is verified using the available experimental data in section 5.6. Infinite medium modeling and implementation of Rayleigh damping for two-dimensional models are discussed in sections 5.7 and 5.8, respectively. Sections 5.9 and 5.10 provide the details of final twodimensional model and the obtained seismic amplification results.

\subsection{Dynamic relaxation technique for the solution of finite difference formulation in elasticity problems}

Dynamic relaxation (DR) technique is a numerical technique that is used to solve the elasticity equations of second to fourth order (Otter et al., 1966). When these equations are expressed in finite difference formulation, dynamic relaxation technique can be applied in an iterative manner. In other words, in dynamic relaxation technique, a critically damped wave equation having initial boundary conditions is solved using the finite difference method. For a two dimensional problem in DR technique, Forsythe and Wasow (1960) showed that the stability criterion of each time step of iteration $(\Delta t)$ is:

$\Delta \mathrm{t} \leq 1 / \mathrm{C}\left\{\left(1 /(\Delta \mathrm{x})^{2}+1 /(\Delta \mathrm{y})^{2}\right\}^{-0.5}\right.$

Where $C, \Delta x$ and $\Delta y$ denote the wave velocity, mesh length of two dimensional space in $\mathrm{x}$ and $\mathrm{y}$ directions, respectively. The mathematical basis of Dynamic Relaxation can be summarized here:

1-Laplace equation in two-dimensional space is expressed by the following equation for the displacement function $(u)$ : 


$$
\mathrm{F}=\partial^{2} \mathrm{u} / \partial \mathrm{x}^{2}+\partial^{2} \mathrm{u} / \partial \mathrm{y}^{2}
$$

2-The damped wave equation can be written as follows:

$$
C^{2}\left(\partial^{2} \mathrm{u} / \partial \mathrm{x}^{2}+\partial^{2} \mathrm{u} / \partial \mathrm{x}^{2}\right)-\mathrm{D} / \Delta \mathrm{t}(\partial \mathrm{u} / \partial \mathrm{t})-\partial^{2} \mathrm{u} / \partial \mathrm{t}^{2}=0
$$

In which $\mathrm{D}$ and $\mathrm{t}$ indicate the viscous damping factor and time, respectively.

Furthermore, $\partial \mathrm{u} / \partial \mathrm{t}$ and $\delta \mathrm{u}$ can be replaced by the following terms:

$$
\begin{aligned}
& \partial \mathrm{u} / \partial \mathrm{t}=\mathrm{u} \\
& \delta \mathrm{u}=\mathrm{u} \quad \Delta \mathrm{t}
\end{aligned}
$$

3- Equal mesh lengths are assumed in $\mathrm{x}$ and $\mathrm{y}$ directions $(\Delta \mathrm{x}=\Delta \mathrm{y})$ and the time increment is taken the maximum value shown in equation (5-1). Then equation (5-2) is written in finite difference form:

$\partial^{2} \mathrm{u} / \partial \mathrm{x}^{2}+\partial^{2} \mathrm{u} / \partial \mathrm{y}^{2}=\delta \mathrm{u}^{(\mathrm{r})}{ }_{(\mathrm{i}, \mathrm{j})}+0.5 \mathrm{u}_{(\mathrm{i}+1, \mathrm{j})}^{(\mathrm{r})}+\mathrm{u}_{(\mathrm{i}-\mathrm{i}, \mathrm{j})}^{(\mathrm{r})}+\mathrm{u}_{(\mathrm{i}, \mathrm{j}+1)}^{(\mathrm{r})}+\mathrm{u}^{(\mathrm{r})}{ }_{(\mathrm{i}, \mathrm{j}-1)}-4 \mathrm{u}^{(\mathrm{r})}{ }_{(\mathrm{i}, \mathrm{j})}$

$i$ and $j$ denote the number of row and column in the finite difference grid respectively.

4- Using equations (5-2), (5-4), (5-5) and (5-6), equation (5-3) is simplified and gives the displacement increment equation $(\delta \mathrm{u})$ for two successive iteration steps ( $\mathrm{r}$ and $\mathrm{r}+1)$ in a two dimensional finite difference mesh:

$\delta u^{(r+1)}{ }_{(i, j)}=\left\{(1-D / 2) \delta u^{(r)}{ }_{(i, j)}+0.5 u^{(r)}{ }_{(i+1, j)}+u^{(r)}{ }_{(i-1, j)}+u^{(r)}{ }_{(i, j+1)}+u^{(r)}{ }_{(i, j-1}-4 u^{(r)}{ }_{(i, j)}\right\} /(1+D / 2)$

The final displacement $(u)$ can be determined from the following equation:

$$
\mathrm{u}^{(\mathrm{r}+1)}{ }_{(\mathrm{i}, \mathrm{j})}=\mathrm{u}^{(\mathrm{r})}(\mathrm{i}, \mathrm{j})+\delta \mathrm{u}^{(\mathrm{r}+1)}(\mathrm{i}, \mathrm{j})
$$

\subsection{FLAC (Fast Lagrangian Analysis of Continua) program}

\subsubsection{Formulation}


Concept of the formulation of program "FLAC" (version 5, Itasca Consulting Group Inc., 2005), is comparable to that of dynamic relaxation mentioned in previous section. The distinctions between them are in the implementation of arbitrary grid, damping formulation and the large strains in the formulation of FLAC. In the explicit finite difference analysis by FLAC, Lagrangian formulation is used that is in contrast with Eulerian formulation. In Lagrangian approach instead of a fixed grid, the finite difference grid of the physical domain moves and the increments of the displacements are added to the coordinates. In this program, a finite difference mesh is established in the solid body medium using the quadrilateral elements subdivided into two overlaid triangles. Then, for each node of the elements displacement and velocity are obtained from the dynamic equation of motion. This equation of motion uses grid-point masses from the density of the surrounding zones. Having this mesh structure, finite difference equation is developed for the mentioned triangles as follows:

1- Gauss Divergence theorem is written for a triangular area using the nodal velocities:

$\partial \dot{u}_{\mathrm{i}} / \partial \mathrm{x}_{\mathrm{j}} \approx 1 /(2 \mathrm{~A}) \Sigma\left(\dot{\mathrm{u}}\left(\dot{a}^{\mathrm{i}} \mathrm{i}+\dot{\mathrm{u}}_{(\mathrm{b}) \mathrm{i}}\right) \mathrm{n}_{\mathrm{j}} \Delta \mathrm{s}\right.$

In equation (5-9), $\mathrm{u}^{\cdot}$ (a) and $\mathrm{u}^{\cdot}$ (b) are the nodal velocities of two consecutive nodes on the side of the triangle. $\mathrm{A}, \mathrm{n}_{\mathrm{j}}$ and $\Delta \mathrm{s}$ denote the triangle area, unit vector normal to the side of the triangle and the side length of the triangle.

2- Strain rates $\left(\mathrm{e}_{\mathrm{ij}}\right)$ is derived for a triangular zone from the following equation:

$\mathrm{e}_{\mathrm{ij}}=0.5\left(\partial \mathrm{u}_{\mathrm{i}} / \partial \mathrm{x}_{\mathrm{j}}+\partial \mathrm{u}_{\mathrm{j}} / \partial \mathrm{x}_{\mathrm{i}}\right)$

Using equation (5-9) and the similar equation for $\left(\partial \mathrm{u}_{\mathrm{j}} / \partial \mathrm{x}_{\mathrm{i}}\right)$, the strain rate of the zone is determined. 
3- The calculated strain rate (equation (5-10)) is exploited in constitutive law (see section 5.3) to evaluate the stress values. Then, the nodal forces are obtained from the stress values. Since each node receives the forces from the overlaid quadrilateral elements, the forces are summed up and averaged to give the final nodal forces.

\subsubsection{Calculation cycle of the program}

FlAC has a calculation sequence: First, the equation of motion is exploited to obtain velocities and displacements from stress and force values. In the next step, strain rates are derived from velocities and, finally the new stress values are obtained from strain rates (using an appropriate stress-strain constitutive law). In the new cycle, the derived stress values are set into the equation of the motion and the cycles continue similarly. It should be noted that when stress values are obtained from strains, the idea of frozen velocities is used that means the new stress values do not influence the velocities. The mentioned idea is justifiable when a small time-step (cycle period) is chosen because the neighboring elements of model will not affect one another during the time step. Using the frozen velocity concept, there is no need to use an iterative process to derive the stresses from strain values but a small time step is critical that usually leads to large number of calculation steps.

To have an appropriate wave transmission through the model, Kuhlemeyer and Lysmer (1973) showed that the element size should be one-tenth to one-eighth of the wavelength of highest frequency of excitation. Therefore, the element size should satisfy this condition of wave transmission. Knowing this element size, the time step of calculation procedure should be chosen less than the wave propagation time through the 
elements of model. In other words, the time step should be set in such a way that the wave propagation speed falls behind the calculation speed.

\subsection{Constitutive law/model for stress-strain relationship; Modified Cam-Clay Model (MCC)}

\subsubsection{Introduction}

As mentioned in section (5.3.2), a constitutive model/law that correlates the strain and stress values is required. This model should reasonably represent the stressstrain behavior of clayey soil in the study area .Furthermore; this constitutive model should give the satisfactory description of the elastic properties, yield function and the hardening rule of the soil in post-elastic strains. In this research, the hardening/softening elasto-plastic model of modified Cam-Clay (Roscoe and Burland, 1968) will be applied. Using this model, soil characteristics such as shear resistance and effect of volume change on the bulk properties of soil can be taken into account. Three important aspects of soil behavior are addressed in this elasto- plastic model:

1-shear strength,

2- Change of volume which leads to compression or dilatancy,

3- Critical state that represents the state in which ultimate deformation occurs in soil with no change in volume or the stress level.

\subsubsection{Critical state mechanics; General concepts}


Modified Cam-Clay is a critical state constitutive model. In critical state mechanics, three parameters describe the state of soil: effective mean stress $\left(\mathrm{p}^{\prime}\right)$, deviatoric stress $\left(q^{\prime}\right)$ and the specific volume $(v) . p^{\prime}$ and $q^{\prime}$ are defined as below:

$\mathrm{p}^{\prime}=\left(\sigma_{1}^{\prime}+\sigma_{2}^{\prime}+\sigma_{3}^{\prime}\right) / 3$

$q^{\prime}=\left\{0.5\left\{\left(\sigma_{1}^{\prime}-\sigma_{2}^{\prime}\right)^{2}+\left(\sigma_{2}^{\prime}-\sigma_{3}^{\prime}\right)^{2}+\left(\sigma_{1}^{\prime}-\sigma_{3}^{\prime}\right)^{2}\right\}\right\}^{0.5}$

$\sigma_{1}^{\prime}, \sigma_{2}^{\prime}$ and $\sigma_{3}^{\prime}$ denote the principal stresses.

Using the mentioned parameters, soil behavior is described by two spaces of ( $\ln$ $\left.p^{\prime}-v\right)$ and $\left(p^{\prime}-q^{\prime}\right)$. In (ln $\left.p^{\prime}-v\right)$ space, normal compression (or virgin consolidation) line and the swelling line are used to delineate the loading and unloading behavior of soil (clay) samples. Normal compression line and the swelling line are defined by the equations (5-13) and (5-14) and respectively:

$v=v_{0}-\lambda \ln p^{\prime}$

$v=v_{s}-\kappa \ln p^{\prime}$

In which, $v_{0}, \kappa$ and $\lambda$ are specific volume of virgin consolidation line at unit pressure, slope of virgin consolidation line and the slope of the swelling line respectively. As mentioned before, critical state describes the condition at which the soil is distorting without any change in stress or volume. This state can be characterized by a line parallel to the normal compression line at (ln $\left.p^{\prime}-v\right)$ space (See Figure (5.3)). In this Figure, $v_{\Gamma}$ is the specific volume of the critical state line (CSL) at unit pressure and can be expressed in terms of $v_{0}, \kappa$ and $\lambda$ :

$v_{\Gamma}=v_{0^{-}}(\lambda-\kappa) \ln 2$ 
The other space is the ( $\left.\mathrm{p}^{\prime}-\mathrm{q}^{\prime}\right)$ in which the stress path regarding the loading history on soil is considered. Furthermore, the yield surface is defined in this space. Details of yield surface are given in section (5.4.3).

\subsubsection{Constitutive law of plasticity}

Two main theories of plasticity are deformation theory and flow (incremental) theory. In deformation theory, the plastic strains are directly related to the stresses whereas in flow theory the strain increments are related to stresses and the stress state. In other words, in incremental theory plastic strains are expressed as the function of strain increments, stress increments and the current stress values. In both theories the material behavior is assumed elastic until the stresses reach the yield point, at which state the plastic behavior commences. Some limitations and inconsistencies were shown for deformation theory (e.g. Hill, 1998). For example, deformation theory does not consider any history dependency of previous stress and strain values. On the contrary, the flow theory does not suffer from any major disadvantages and the history dependency is taken into account by incorporating the stresses, strains and their increments in this theory. In Modified Cam Clay (MCC) model, the flow theory is exploited. In this model, yield surface in $\left(p^{\prime}-q^{\prime}\right)$ space is:

$\mathrm{q}^{2} / \mathrm{p}^{\prime 2}+\mathrm{M}^{2}\left(1-\mathrm{p}_{0}^{\prime} / \mathrm{p}^{\prime}\right)=0$

$\mathrm{p}_{0}^{\prime}$ denotes the preconsolidation pressure. $\mathrm{M}$ is the slope of critical state line (CSL) and this CSL intersects the yield curve at the maximum value of $\mathrm{q}$. When yielding occurs to the right of this intersection point (called wet or subcritical side), hardening behavior, along with compression appears. On the contrary, when yielding occurs to the left of this 
intersection point (called dry or supercritical side), the softening behavior accompanied by dilatancy is exhibited by the soil materials.

\subsubsection{Parameters of modified Cam-Clay (MCC) model}

According to the aforementioned sections, the determinations of the following parameters are required in a MCC model:

1- Maximum Bulk modulus (K), one of the parameters of shear modulus $(\mathrm{G})$ or Poisson's ratio $(\mu)$. Initial value of the bulk modulus is obtained from the following equation:

$\mathrm{K}=\left(\mathrm{v}_{0} \mathrm{p}_{0}\right) / \kappa$

where $v_{0}$ and $p_{0}$ denote the initial specific volume and the initial pressure, respectively.

2- Slope of CSL that can be obtained from the triaxial compression test as follows:

$M=6 \sin \varphi /(3-\sin \varphi)$

In which $\varphi$ is the friction angle at critical state.

3- Slopes of the normal compression line and the swelling line can be obtained from compression index $\left(\mathrm{C}_{\mathrm{c}}\right)$ and the swelling coefficient $\left(\mathrm{C}_{\mathrm{s}}\right)$ :

$\lambda=\mathrm{C}_{\mathrm{c}} / \ln 10$

$\kappa \approx \mathrm{C}_{\mathrm{s}} / \ln 10$

4- Preconsolidation pressure or the ratio of preconsolidation pressure to the current pressure (OCR).

5- Reference pressure and its corresponding specific volume on (ln $p^{\prime}-v$ ) space. 


\subsection{Leda Clay; General and geotechnical properties}

In this section, some geotechnical properties of Leda clay will be reviewed. Because of the variety of clay parameters in MCC model, a thorough description of geotechnical properties of Leda Clay is needed. As mentioned in previous chapters, in the Ottawa area, a usual borehole log would exhibit hard bedrock overlain by glacial till and the deposit of marine soft clay. This formation is usually accompanied by thin layers of sand on the top of the soft clayey layer. The mentioned marine clay is the dominant part of soil formation. It is a sensitive clay with remarkable thixotropic properties that means it might be liquefied when agitated or triggered. The sensitivity of clay is defined as the ratio of undisturbed shear strength (usually from the unconfined compression test) to remolded strength of clay in the laboratory.

As mentioned, Leda clay, which is abundant in the St Lawrence and Ottawa valleys, is sensitive. Crawford (1963) has confirmed the huge difference between the undisturbed and the remolded strengths of sensitive clay samples even if two samples contain the same water content. Furthermore, numerous studies (e.g. Bjerrum, 1954) show that this sensitivity is controlled by salt concentration and liquidity index.

Geotechnical characteristics of Leda clay deposits have been studied by many researchers. Quigley et al. (1983) investigated the geological and geotechnical characteristics of Leda clay in the Ottawa Valley near Hawkesbury, Ontario. Their study is based on the results obtained from a long-term project during the years 1975 to 1976 and 1978 to 1980 . According to those results, the clay minerals mainly contained three major parts: 1- illite (majority part) 2-chlorite 3-vermiculite and/or smectite . In addition, in-situ unit weight varying from about $15 \mathrm{kN} / \mathrm{m}^{3}$ to $17 \mathrm{kN} / \mathrm{m}^{3}$ was reported for clayey 
materials. This mineralogical composition has been confirmed by Karrow (1961) and Gillott (1971). The followings were highlighted in their study:

1-Using some geological predictions, preconsolidation pressures in the area were related to the removal (erosion) of the deltaic sand layers overlying the clayey layer. This assumption provides the bases to establish the drainage boundaries of the clayey layer that is used to obtain the coefficient of consolidation. Finally, coefficient of consolidation having average value of $0.61 \mathrm{~m}^{2} /$ year was suggested Quigley et al. (1983).

2-Different sensitivities for the clay material ranging from 5 to 25 were reported.

3- Detailed description of the in-situ void ratio plots, shear strength plots, Atterberg limits and salinity variations with depth was given. Two margins for shear strength of clay were suggested:

$\mathrm{C}_{\mathrm{u}} / \sigma_{\mathrm{p}}^{\prime}=0.5 \quad$ (for normally consolidated clays)

$\mathrm{C}_{\mathrm{u}} / \sigma_{\mathrm{p}}^{\prime}=0.3 \quad$ (for highly overconsolidated clays)

where $C_{u}$ and $\sigma_{p}^{\prime}$ stand for the undrained shear strength and the preconsolidation pressure respectively.

In another study, geotechnical properties of Leda clay in the Ottawa Area were discussed by Eden and Crawford (1957). The values reported from the borings of that research showed that the sensitivity of Leda clay exceeds 20 and even reaches up to 100 or greater values. According to that study, preconsolidation appears to depend on the previously existing overburden. They conclude that the field vane tests give more consistent results for shear strength than do laboratory tests due to potential sample disturbance. Although it is mentioned that the laboratory results can be improved by more 
refined sampling but the extreme sensitivity and fissuring cause the discrepancy in the strength results.

The preconsolidation pressure of Leda clay deposits in the Ottawa area has been investigated by many researchers. Morin et al. (1983) gave a detailed description for the in-situ determination of the preconsolidation pressures of Champlain (Leda) clays. They concluded that the Leda clay in the studied area of Eastern Canada is generally slightly overconsolidated. For instance, the overconsolidation ratio (OCR) of 1.7 was suggested for the Gloucester site in Ottawa (sample taken from a few meters depth).

Bozozuk (1963) suggested the Poisson's ratio of 0.4 or slightly less for Leda Clay from the measurements of the bottom heave in the large excavations of a construction procedure in the Ottawa Sewer Plant. Selvadurai et al. (1980) developed the screw plate test for the determination of the deformability characteristics of the cohesive soils at the depths of $2 \mathrm{~m}$ and $4 \mathrm{~m}$. They estimated the undrained shear strength $\left(\mathrm{C}_{\mathrm{u}}\right)$ from the following correlation:

$9<\mathrm{P}_{\mathrm{ult}} / \mathrm{C}_{\mathrm{u}}<11.35$

Where $\mathrm{P}_{\mathrm{ult}}$ denotes the ultimate failure load recorded in the screw plate test. Also for the elastic modulus $\left(E_{u}\right)$, the following range in terms of the undrained shear strength was recommended:

$630 c_{u}<E_{u}<$ to1070 $c_{u}$

In addition to aforementioned studies, numerous researches have been performed on strength/failure pattern of Leda Clays. Crawford (1963) showed that the strength of the highly sensitive clays does not depend on the void ratio but is largely controlled by the soil structure. Furthermore, several microstructural studies concentrate 
on the failure of Leda clay. For instance, Pusch (1970) investigated the microstructural change of the sensitive clays at failure using a transmission electronic microscope. In an other microstructural research on Leda Clay, Quigley and Thomson (1966) used x-ray diffraction technique to examine the fabric change of soil samples subjected to external pressure and consolidated to different vertical pressures. The results showed that there is negligible particle reorientation at pressures up to preconsolidation pressure and at higher pressures, breaking down of the soil structure commences.

\subsection{Verification of modified Cam-Clay model using the results of drained triaxial test}

In this section, the explained modified Cam-Clay (MCC) model is implemented in the modeling procedure of a drained triaxial test on a Leda Clay sample. The reference data are related to the experimental work by Wong (1972). That work provides a comprehensive database to study the stress-strain behavior of Leda Clay in Ottawa area. All the soil samples of the mentioned research were taken from a site in Ottawa at the depth of about $18 \mathrm{ft}$. The prepared samples in Laboratory are cylindrical and have the dimensions of $10 \mathrm{~cm}$ height and $5 \mathrm{~cm}$ diameter for the strain-controlled drained triaxial tests. In strain-controlled deformation tests, the strain rate was set to $6 \times 10^{-4} \mathrm{~mm} / \mathrm{min}$ $\left(0.1 \times 10^{-7} \mathrm{~m} / \mathrm{sec}\right)$ and the allowable strain rate was limited to the value of $0.1 \%$ per day.

The mentioned data of Leda Clay samples were used to verify the applicability of MCC model on the stress-strain behavior of Leda Clay. To carry out this verification, using the explicit finite difference method, a drained triaxial test was simulated for a $5 \mathrm{~cm}$ $\times 10 \mathrm{~cm}$ soil sample subjected to different cell pressures. The configuration of the 
rectangular model of soil sample is shown in Figure (5.4). The implemented MCC has the following parameters:

Poisson's ratio $(\mu)=0.35$

Density of soil $(\rho)=1732 \mathrm{~kg} / \mathrm{m}^{3}$

Modulus of elasticity $(\mathrm{E})=16.7 \mathrm{MPa}$

Slope of the critical state line $(\mathrm{M})=1.1$

Slope of normal consolidation line $(\lambda)=0.28$

Slope of elastic swelling line $(\kappa)=0.056$

Preconsolidation pressure $\mathrm{P}_{\mathrm{c} 0}=101 \mathrm{kPa}$

Two cell pressures of $0.8 \mathrm{~kg} / \mathrm{cm}^{2}$ and $0.2 \mathrm{~kg} / \mathrm{cm}^{2}$ was applied on the model (Figure (5.4)) and the variation of the deviatoric stress with axial strain was obtained. The comparisons of the modeling results with the experimental results are shown in Figures (5.5a) and (5.5b). As seen in Figure (5.5a), the agreement between the Cam-Clay model and the experimental results is acceptable. This Figure shows that MCC satisfactorily predicts the stress-strain behavior of the slightly overconsolidated clay $(\mathrm{OCR}=1.03 / 0.8$ $=1.28$ ). In Figure (5.5b), some discrepancies appear between the MCC and experimental results for the elastic range of the highly overconsolidated sample $(\mathrm{OCR}=1.03 / 0.2=5.15)$. Because the majority of the Leda Clay sites in Ottawa in this research including the studied valley (see section 5.8) are slightly overconsolidated, this discrepancy is not the point of concern.

\subsection{Infinite Medium Modeling}

As mentioned in chapter 4 , the infinite medium should be modeled to have roughly perfect wave absorption for seismic waves impinging on the model boundaries. 
In two dimensional models such as deep two dimensional valleys surrounded by infinite medium, infinite medium (bedrock) existing in the bottom and side boundaries of model should be taken into account. Similar to chapter 4, quiet (viscous) boundaries will be applied for two dimensional finite difference model using dashpots introduced by Lysmer and Kuhlemeyer (1969).

\subsection{Implementation of Rayleigh damping in two dimensional models}

As mentioned in Chapter 4, Rayleigh damping uses mass and stiffness proportional formulation (see equation 4-17). Based on this equation, Bathe and Wilson (1976) proposed equation (4-21) for the determination of critical damping $\left(\xi_{i}\right)$ in terms of the angular frequency $\left(\omega_{\mathrm{i}}\right)$ of a multi-degree of freedom system. This equation can be shown with a curve that has the following minimum points:

$\xi_{\min }=(\alpha \beta)^{0.5}, \quad \omega_{\min }=(\alpha / \beta)^{0.5}$

In which, $\alpha$ and $\beta$ are frequency dependent factors. By setting appropriate values for $\xi_{\min }$ and $\omega_{\min }$, frequency-independent damping values are obtained. For instance, $\omega_{\min }$ can be a combination of important frequencies such as dominant frequency of input motion and fundamental frequency of the examined site obtained from the average shear wave velocity. As an example, Table (5.1) shows the mentioned minimum frequency $\left(f_{\min }\right)$ for the site with dominant frequency (obtained from the average shear wave velocity) of $0.75 \mathrm{~Hz}$ and subjected to some artificial Eastern Canadian input motions having different dominant frequencies. In this Table, minimum frequency is taken as the average of the mentioned frequencies. The critical damping is chosen from the shaking-intensity damping equation introduced in chapter 3 :

$\xi=14.33 \mathrm{PGA}^{0.2537}$ 
Therefore, in order to specify the damping functions, pairs of $\left(\omega_{\min }, \xi_{\min }\right)$ can be implemented for different locations of two-dimensional model. As mentioned, these pairs are obtained based on the depth of each section of two dimensional model, shaking intensity and dominant frequency of the input motion.

\subsection{Modeling of buried valley in Orleans area}

In this section, a deep valley located in Orleans area (eastern part of the city) is modeled using the finite difference formulation (FLAC program, version 5, Itasca Consulting Group, 2005). The simplified valley is shown in Figure (5.6). According to section 5.4, the parameters of modified CAM-Clay model were set for different locations of valley at different depths. In addition, the wave transmission condition was satisfied by setting the quadrilateral element size to $1 \mathrm{~m}$. This element size is satisfactory for the seismic wave propagation with the wavelength $(\lambda)$ of $10 \mathrm{~m}$ (element size of one-tenth of wavelength). Considering the relation between the wavelength $(\lambda)$, velocity (V) and frequency (f), $\lambda=V / f$, the average velocity of $150 \mathrm{~m} / \mathrm{sec}$ will give the frequency of $15 \mathrm{~Hz}$. This means that the chosen element size of $1 \mathrm{~m}$ can accurately simulate the frequencies up to $15 \mathrm{~Hz}$. The Rayleigh damping was used based on the dominant frequency of input motions and the fundamental frequency of soil column at each location of valley (see Table (5.1) as an example). Furthermore, the input motions were selected from the artificial acceleration time histories of Eastern Canada ( $2 \%$ in 50 years records) that include ten acceleration time histories ranging from 181 gal to 1000 gal. These records were shown in chapter 4 . Finally, the amplification curves were obtained at the deepest part of the valley. In Figures (5.7) to (5.16), these curves are demonstrated and compared with the amplification curves (obtained from FEM site response analysis) of an adjacent 
one-dimensional site (site with $81 \mathrm{~m}$ depth shown in Table 4.9) having the depth of $81 \mathrm{~m}$. Table (5.2) illustrates the fundamental frequencies of the $2 \mathrm{D}$ valley compared to those of the adjacent 1D site.

\subsection{Discussion}

In this chapter, the constitutive model of modified Cam-Clay (MCC) was applied for the seismic analysis of a deep valley located in the eastern part of the city of Ottawa. As a validation test, MCC was implemented in the simulation of a drained triaxial test and the derived deviatoric stress results were compared with those from the experimental data. The outcomes confirmed the reliability of MCC for the slightly overconsolidated clay samples that is the dominant consolidation state of Leda clay in Ottawa area. Therefore, MCC was chosen as the constitutive model for the seismic analysis of the target valley. This constitutive model deals with two spaces of $\left(\mathrm{p}^{\prime}-\mathrm{q}^{\prime}\right)$ and (lnp'-v) and thus, contains numerous parameters that should be determined cautiously. Because of these multi-parameter and calculation-intensive features of MCC, this model has been scarcely used in the site response literature and simpler models such as elastic and Mohr-Coulomb have been applied for the seismic analysis. Consequently, the application of MCC in this research is somehow distinctive that can provide promising perspective for those researchers/practicing engineers who are hesitant to use MCC in two-dimensional seismic analysis.

The mentioned MCC model along with Rayleigh damping formulation were used to establish a 2D finite difference model that satisfies the wave transmission from the soil elements. Then, this model was subjected to ten ground motions having PGAs from 181 to 1000 gals. The horizontal response of these ground motions was achieved in 
the deepest part of the valley and the amplification curves were obtained from the response spectra ratio of the response acceleration record to that of the bedrock record (for 5\% damping). These amplification curves were compared with those from a nearby one-dimensional site with similar geotechnical parameters and subjected to same ground motions. The comparisons (see Figures (5.7) to (5.16)) show that the 2D and 1D methods are in good agreement in a broad range of frequencies. Figures (5.7) to (5.16) clearly exhibit that the peak amplification values from the 1D and 2D methods are close together. Figure (5.17) illustrates the difference between soil amplification values for the fundamental frequency $\left(\mathrm{F}_{\mathrm{f} 0}\right)$ values of $1 \mathrm{D}$ and $2 \mathrm{D}$ methods which is the residual plot. According to this Figure, the obtained $\mathrm{F}_{\mathrm{fo}}$ values of $1 \mathrm{D}$ and $2 \mathrm{D}$ methods are less than $10 \%$ different for half of the applied ground motions. For the frequencies greater than 3 $\mathrm{Hz}$, relatively larger amplification values from 2D finite difference method are obtained. The reason of the large amplification values is hidden in the definition of Rayleigh damping for 1D site using the FEM. According to this definition of Rayleigh damping (as mentioned in chapter 4), the coefficients of mass and stiffness are set in such a way that the model can respond to the predominant frequency of the site and the dominant frequency of the input motion. This definition causes over-damped response outside the dominant frequency of input motion. Because most of the utilized input motions have the dominant frequency around or greater than $3 \mathrm{~Hz}$, the over-damped response and lower amplification ratios are expected in 1D method for the frequencies more than $3 \mathrm{~Hz}$.

\subsection{References}

Bjerrum L., 1954, Geotechnical properties of Norwegian marine clays, Geotechnique, 4 (2), pp.49-62. 
Bozozuk M., 1963, The modulus of elasticity of Leda clay from field measurements , Canadian Geotechnical Journal, 1, pp. 43-51.

Crawford C.B., 1963, Cohesion in an undisturbed sensitive clay, Geotechnique, 13, pp. 132-144.

Eden W.J. and Crawford C.W., 1957, Geotechnical properties of Leda clay in the Ottawa area, Fourth international Conference on Soil Mechanics and Foundation Engineering, Proc. 1: pp.22-27.

FLAC version 5, 2005, Itasca Consulting Group Inc, Mineiapolis, Minessota.

Forsythe G.E. and Wasow W.R., 1960, Finite-difference Methods for Partial Differential Equations, John Wiley and Sons, pp.381-382.

Gillott J.E. , 1971, Mineralogy of Leda clay, Canadian Mineralogist, 10, pp.797-811.

Hill R., The Mathematical Theory of Plasticity, Oxford University Press, 1998.

Karrow P.F., 1961, The Champlain Sea and its sediments. In: R.F. Legget, Editor, Soils in Canada, Roy. Soc. Can., Spec. Publ. ,3, pp.97-108.

Kuhlemeyer R.L. and Lysmer J., 1973, Finite element method accuracy for wave propagation problems, Journal of Soil Mechanics and Foundations Division, ASCE, 99 , pp.421-427.

Morin P., Leroueil, S. and Samson L., 1983, Preconsolidation pressure of Champlain clays. Part I. In-situ determination, Canadian Geotechnical Journal, 20(4): pp.782802.

Motazedian D., Hunter J.A., 2008, Development of a NEHRP map for the Orleans suburb of Ottawa, Ontario, Canadian Geotechnical Engineering Journal, 45, pp.1180-1188.

Otter J. R.H., Casssell A.C. and Hobbs R.E., 1966, Dynamic relaxation, Proceedings of the Institution of Civil Engineers, pp.633-656. 
Pusch R., 1970, Microstructural changes in soft quick clay at failure, Canadian Geotechnical Journal, 7, pp. 1-7.

Quigley R.M., Haynes J.E., Bohdanowicz A., and Gwyn Q.H.J., 1983, Leda clay from deep boreholes at Hawkesbury, Ontario. Part I: geology and geotechnique, Canadian Geotechnical Journal, 20, pp. 288-298.

Quigley R.M. and Thomson C.D., 1966, The fabric of anisotropically consolidated sensitive marine clay, Canadian Geotechnical Journal, 3(1), pp.61-73.

Roscoe K.H. and Burland J.B., 1968, On generalized stress strain behavior of wet clay, In: Engineering Plasticity (edited by Heyman and Leckie), pp.535-609.

Selvadurai A.P.S., Bauer G.E. and Nicholas T.J., 1980, Screw plate testing of a soft clay, Canadian Geotechnical Journal, 17, pp.465-472.

Wong P.K., 1972, Strength and stress-strain relations of a sensitive clay, Ph.D. thesis, Queen's University, Kingston, Canada. 


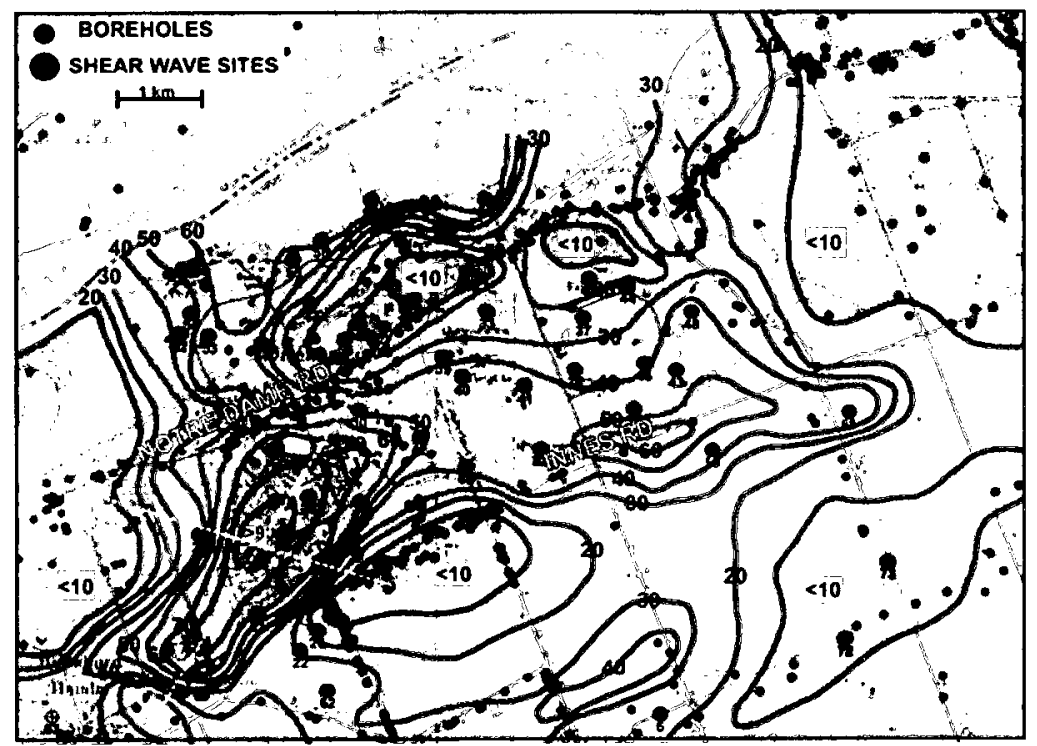

Fig. 5.1: Overburden thickness in meters in the Orleans suburb of Ottawa, based on combined borehole and shear wave seismic site measurements.

\section{A}

B
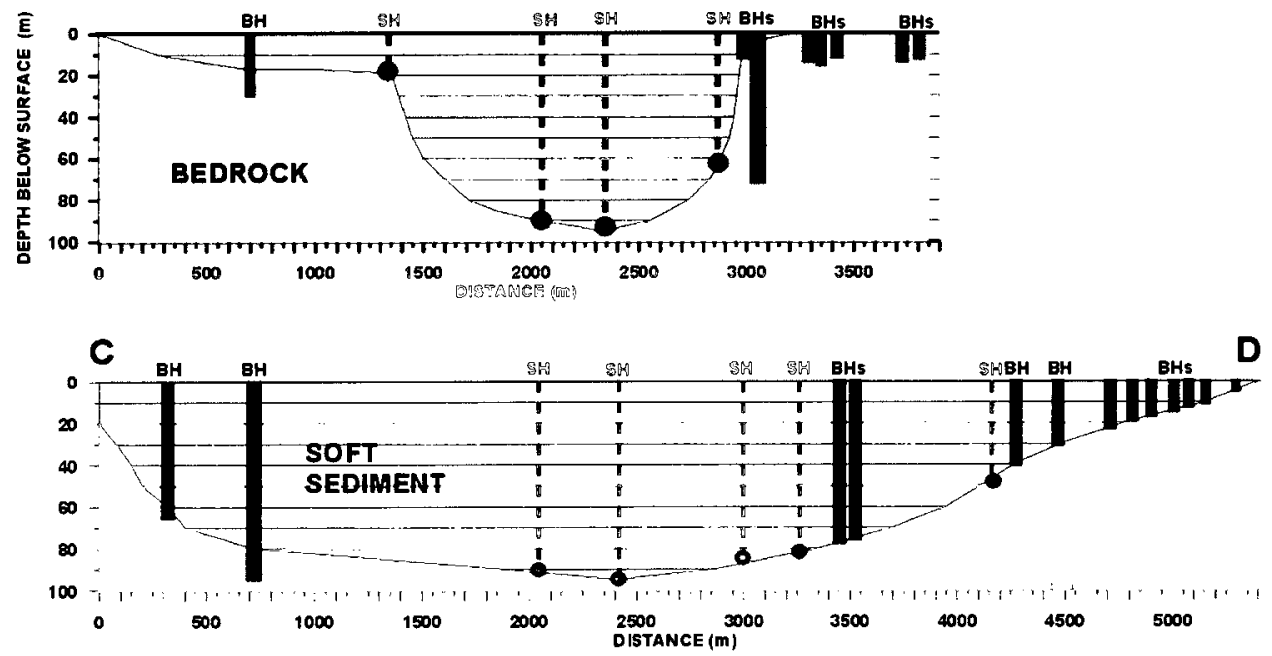

Fig. 5.2: Transverse and longitudinal cross sections of the Orleans buried valley with a vertical exaggeration of $\sim 10: 1$. (BH: borehole, SH: Seismic site). 


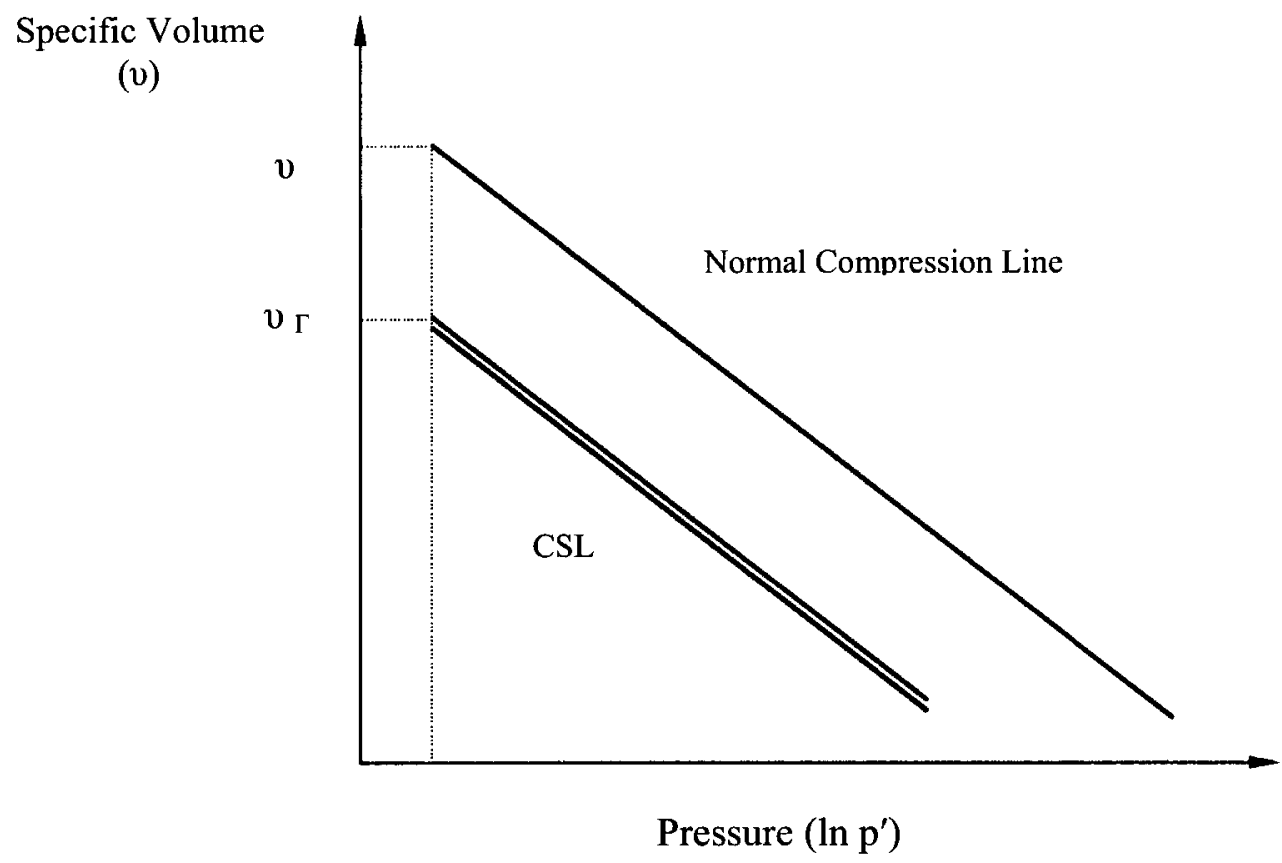

Fig. 5.3: Location of the critical state line (CSL) in the (Inp'- v) space. 


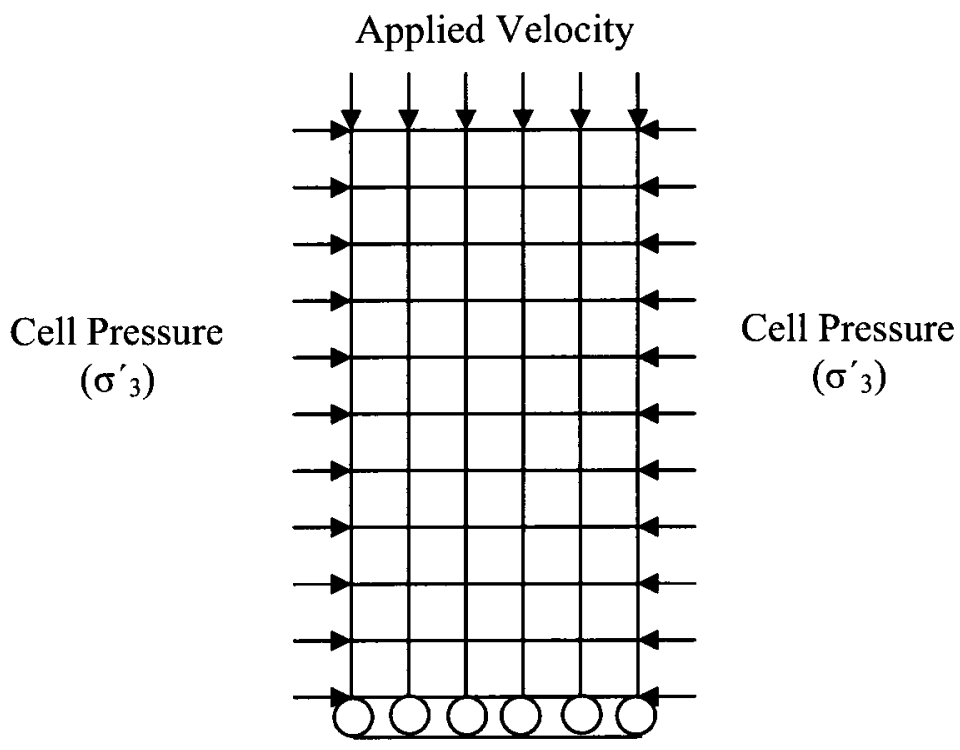

Fig. 5.4: Configuration of rectangular finite difference model for a strain-controlled drained triaxial test.

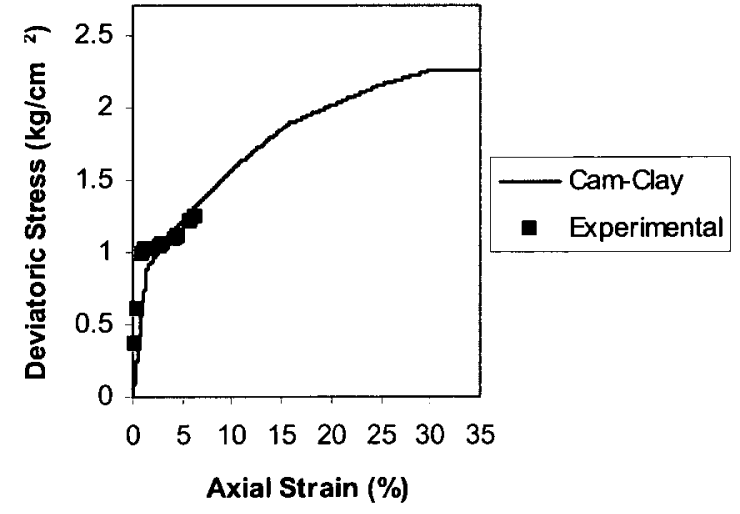

(a)

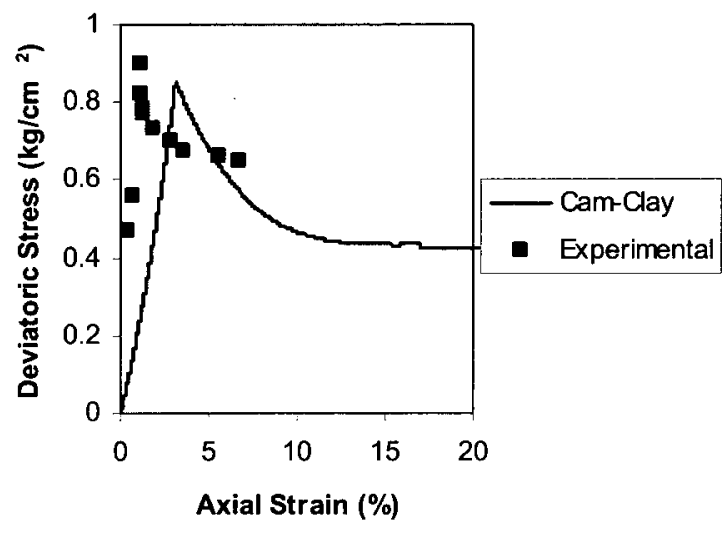

(b)

Fig. 5.5: Comparison between the results of MCC and experimental data in a drained triaxial test for (a) slightly overconsolidated sample; (b) highly overconsolidated sample. 


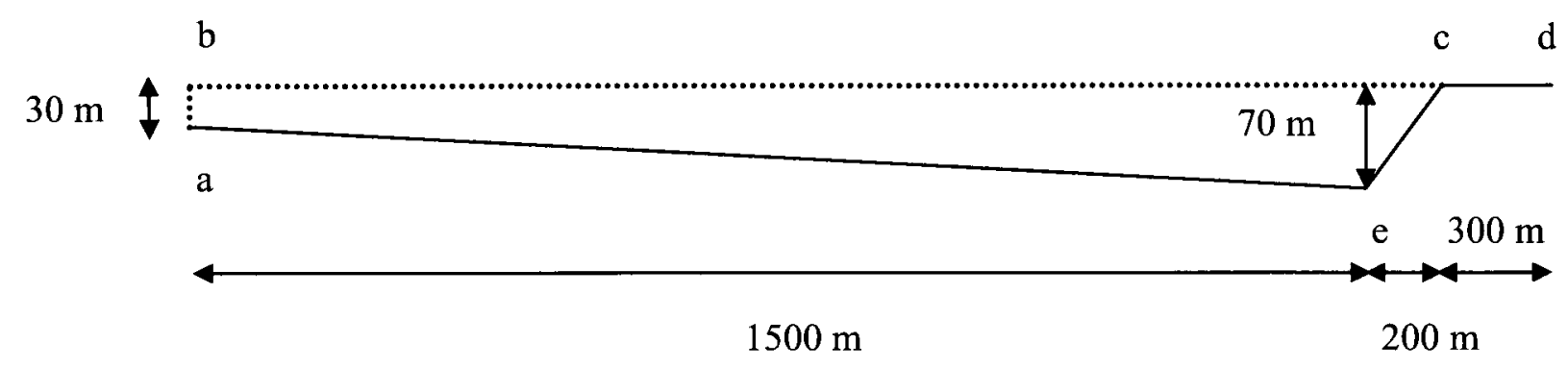

Fig. 5.6: A simplified two-dimensional non-scaled scheme of a deep valley located in the eastern part of the city of Ottawa. Lines "ae" and "ec" illustrate the boundaries between the valley sediments and the underlying bedrock. The valley has a gentle slope from points " $e$ " to " $a$ " that can be approximated by a linear boundary. 


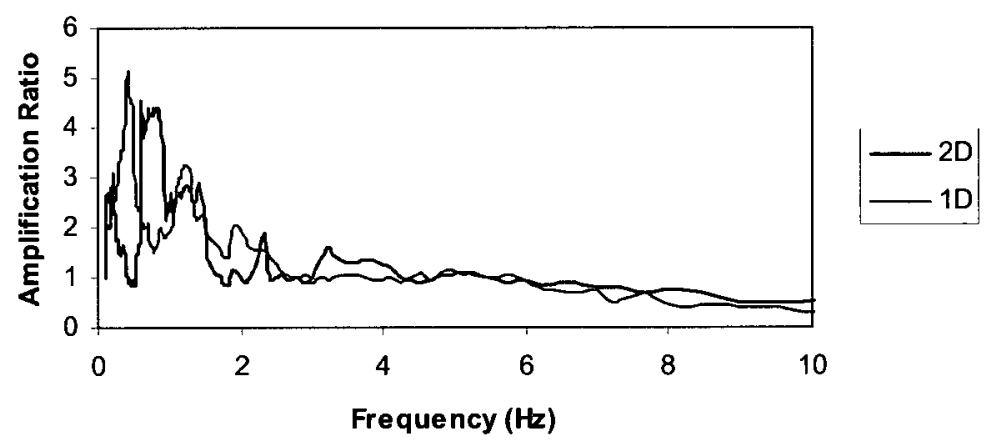

Fig. 5.7: Amplification curves for a 2D (two-dimensional) valley in Orleans area and an adjacent $1 D$ (one-dimensional) site, GSC site \#23, having depth of $81 \mathrm{~m}$. The amplification curve of $2 D$ valley was obtained at the deepest part with the depth of $70 \mathrm{~m}$.

Both sites are subjected to the same input motion having PGA of $181 \mathrm{gal}$.

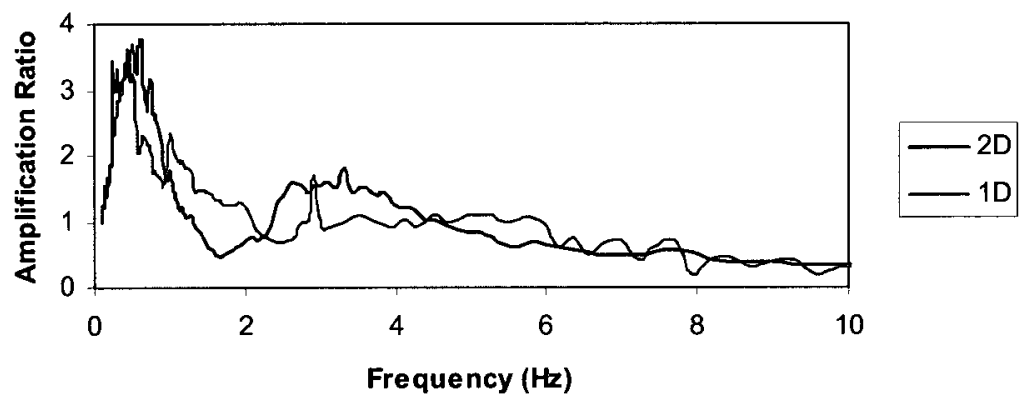

Fig. 5.8: Amplification curves for a 2D (two-dimensional) valley in Orleans area and an adjacent $1 D$ (one-dimensional) site, GSC site \#23, having depth of $81 \mathrm{~m}$. The amplification curve of $2 D$ valley was obtained at the deepest part with the depth of $70 \mathrm{~m}$.

Both sites are subjected to the same input motion having PGA of 256 gal. 


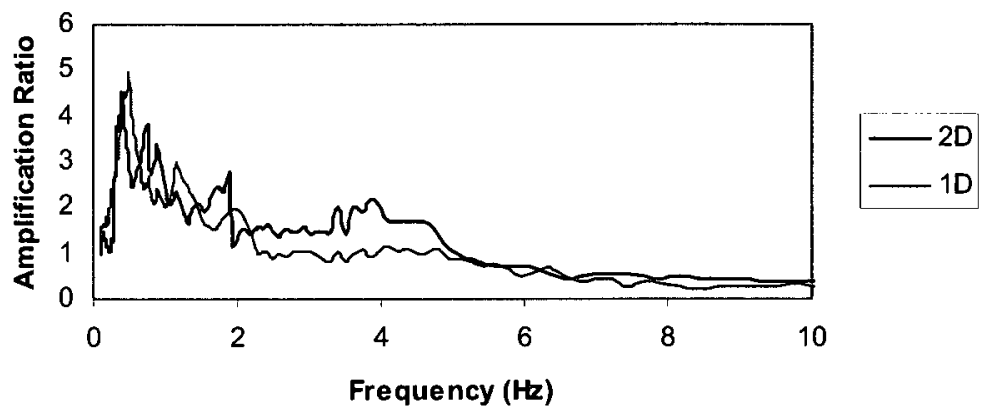

Fig. 5.9: Amplification curves for a 2D (two-dimensional) valley in Orleans area and an adjacent $1 D$ (one-dimensional) site, GSC site \# 23 , having depth of $81 \mathrm{~m}$. The amplification curve of $2 D$ valley was obtained at the deepest part with the depth of $70 \mathrm{~m}$. Both sites are subjected to the same input motion having PGA of 304 gal.

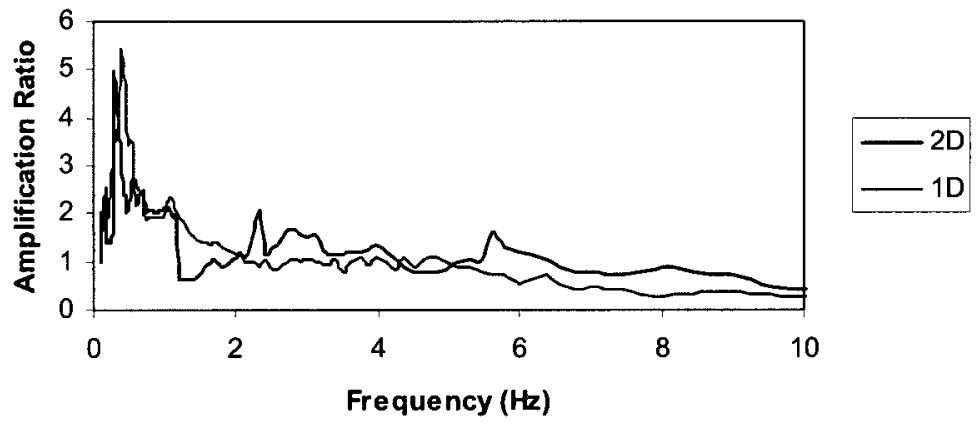

Fig. 5.10: Amplification curves for a 2D (two-dimensional) valley in Orleans area and an adjacent $1 D$ (one-dimensional) site, GSC site \# 23, having depth of $81 \mathrm{~m}$. The amplification curve of $2 D$ valley was obtained at the deepest part with the depth of $70 \mathrm{~m}$. Both sites are subjected to the same input motion having PGA of 422 gal.

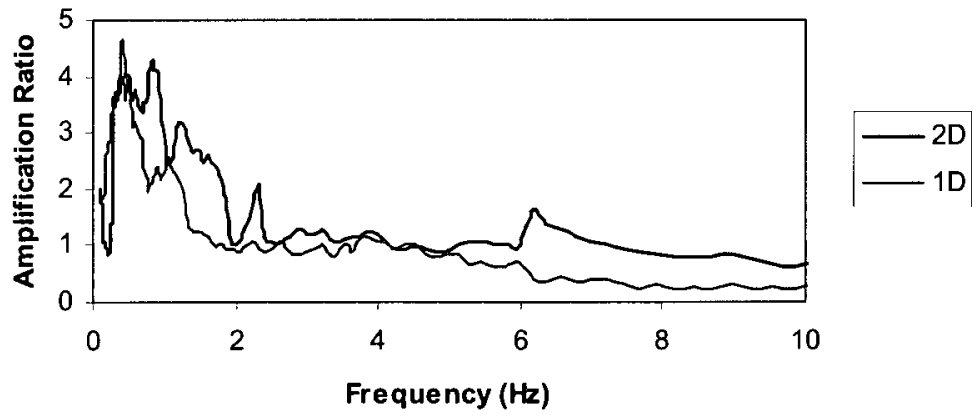


Fig. 5.11. Amplification curves for a 2D (two-dimensional) valley in Orleans area and an adjacent $1 D$ (one-dimensional) site, GSC site \#23, having depth of $81 \mathrm{~m}$. The amplification curve of $2 D$ valley was obtained at the deepest part with the depth of $70 \mathrm{~m}$.

Both sites are subjected to the same input motion having PGA of $512 \mathrm{gal}$.

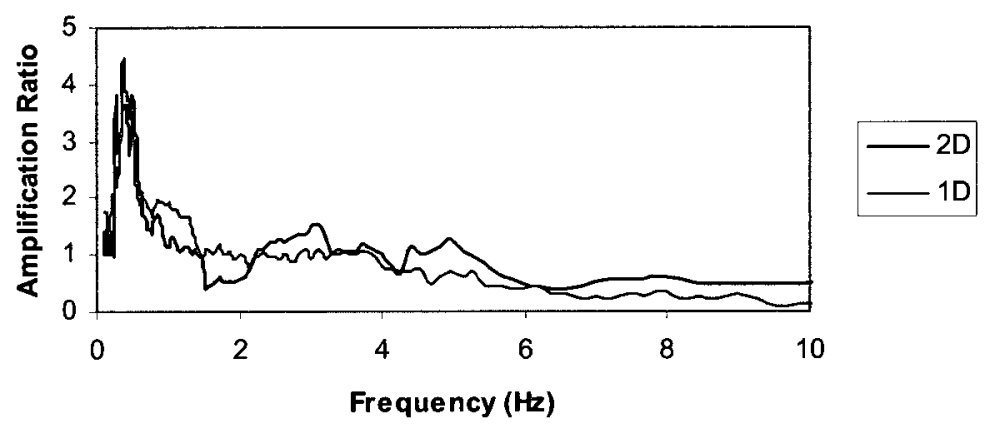

Fig. 5.12: Amplification curves for a 2D (two-dimensional) valley in Orleans area and an adjacent $1 D$ (one-dimensional) site, GSC site \#23, having depth of $81 \mathrm{~m}$. The amplification curve of $2 D$ valley was obtained at the deepest part with the depth of $70 \mathrm{~m}$.

Both sites are subjected to the same input motion having PGA of $607 \mathrm{gal}$.

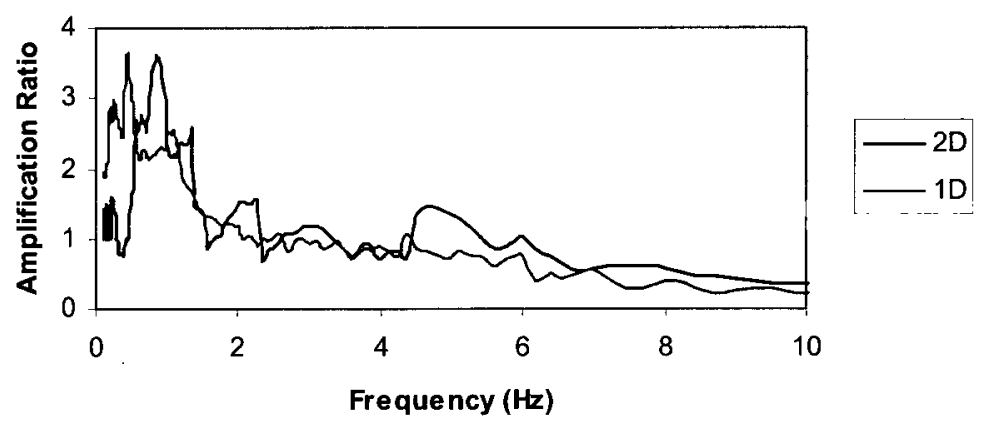

Fig. 5.13: Amplification curves for a 2D (two-dimensional) valley in Orleans area and an adjacent $1 D$ (one-dimensional) site, GSC site \# 23 , having depth of $81 \mathrm{~m}$. The amplification curve of $2 \mathrm{D}$ valley was obtained at the deepest part with the depth of $70 \mathrm{~m}$. Both sites are subjected to the same input motion having PGA of $707 \mathrm{gal}$. 


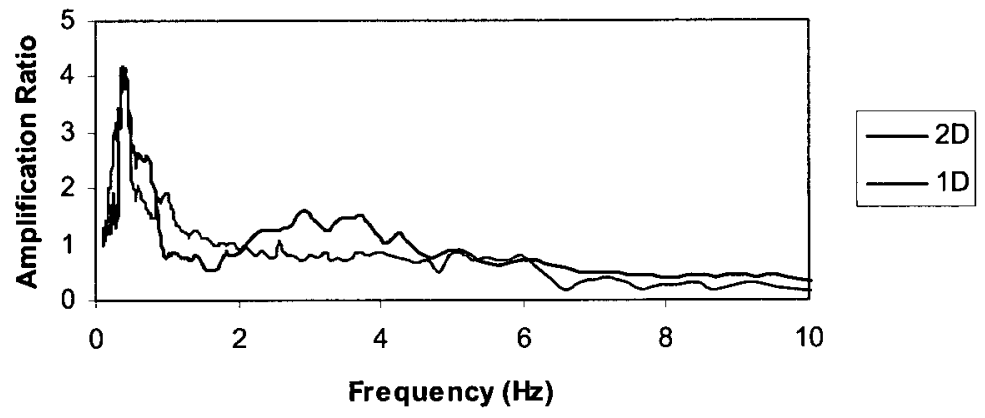

Fig. 5.14: Amplification curves for a 2D (two-dimensional) valley in Orleans area and an adjacent $1 D$ (one-dimensional) site, GSC site \# 23, having depth of $81 \mathrm{~m}$. The amplification curve of $2 D$ valley was obtained at the deepest part with the depth of $70 \mathrm{~m}$. Both sites are subjected to the same input motion having PGA of 813 gal.

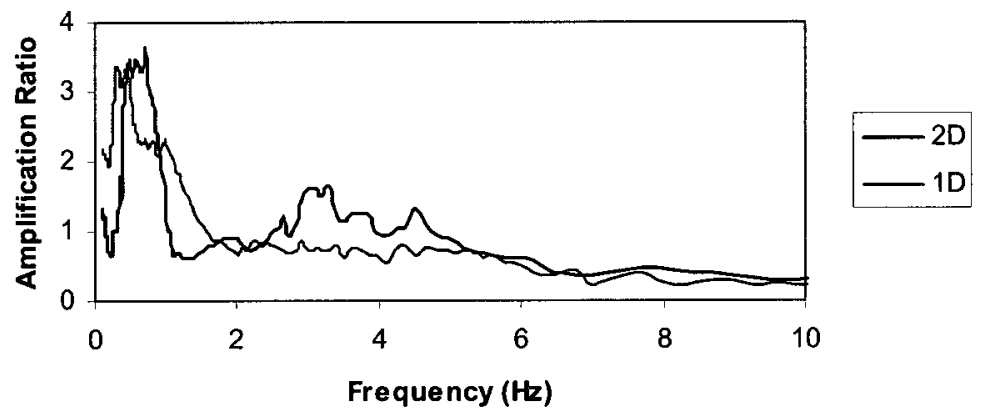

Fig. 5.15: Amplification curves for a 2D (two-dimensional) valley in Orleans area and an adjacent $1 D$ (one-dimensional) site, GSC site \# 23 , having depth of $81 \mathrm{~m}$. The amplification curve of $2 D$ valley was obtained at the deepest part with the depth of $70 \mathrm{~m}$. Both sites are subjected to the same input motion having PGA of $942 \mathrm{gal}$. 


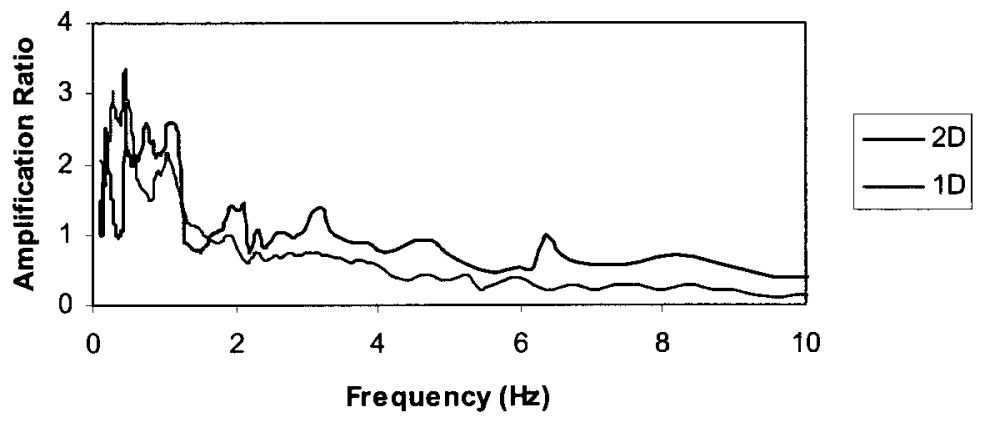

Fig. 5.16: Amplification curves for a 2D (two-dimensional) valley in Orleans area and an adjacent $1 D$ (one-dimensional) site, GSC site \# 23 , having depth of $81 \mathrm{~m}$. The amplification curve of $2 D$ valley was obtained at the deepest part with the depth of $70 \mathrm{~m}$. Both sites are subjected to the same input motion having PGA of $1000 \mathrm{gal}$.

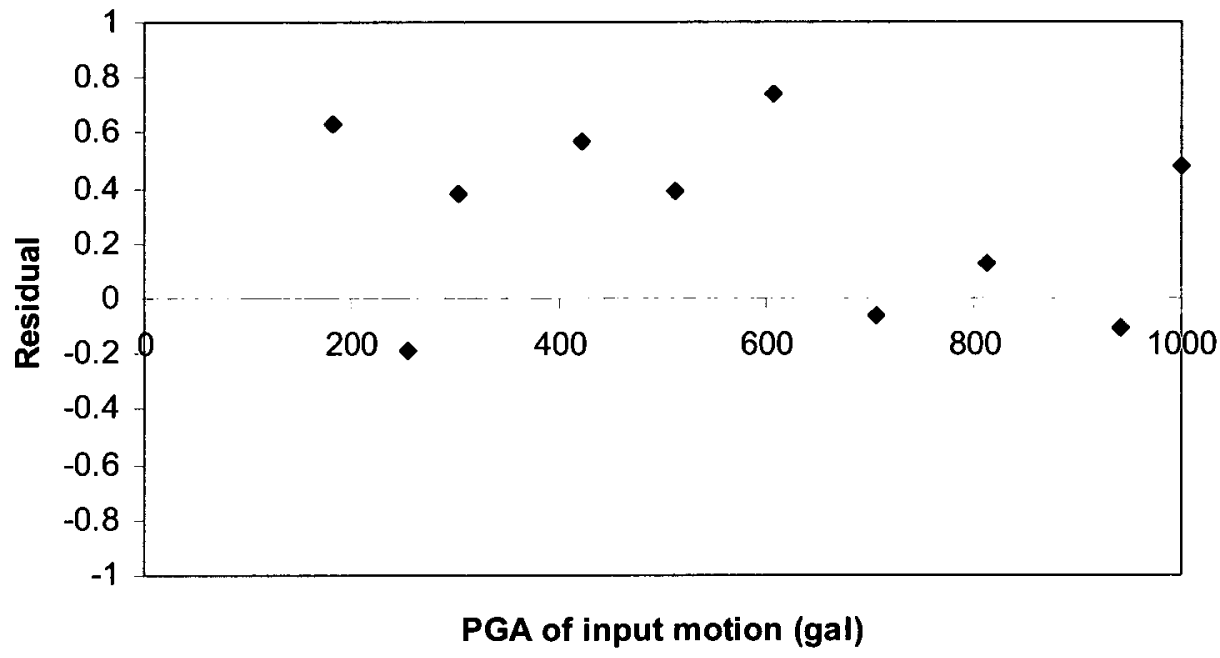

Fig. 5.17: Residual plot (Difference between the peak amplification values) for $1 D$ and $2 D$ methods for different input motions. Each input motion is represented by its peak ground acceleration (PGA). 
Table 5.1: Minimum frequency and damping values for a sites having fundamental frequency of $0.75 \mathrm{~Hz}$. Depending on the dominant frequency of input motion the minimum frequency is changed. Corresponding damping ratio of this minimum frequency is determined based on the shaking intensity of input motion.

\begin{tabular}{|l|l|l|l|}
\hline $\begin{array}{l}\text { PGA of input record } \\
\text { (gal) }\end{array}$ & $\begin{array}{l}\text { Dominant frequency } \\
\text { of input record }(\mathrm{Hz})\end{array}$ & Damping ratio & $\begin{array}{l}\text { Minimum Frequency } \\
\text { For } \mathrm{f}=0.75 \mathrm{~Hz}\end{array}$ \\
\hline 181 & 4.5 & 0.093 & 2.6 \\
\hline 256 & 1.5 & 0.101 & 1.1 \\
\hline 304 & 3.2 & 0.106 & 1.9 \\
\hline 422 & 4.1 & 0.115 & 2.4 \\
\hline 512 & 3.7 & 0.121 & 2.2 \\
\hline 607 & 2.1 & 0.126 & 1.4 \\
\hline 707 & 3.5 & 0.131 & 2.1 \\
\hline 813 & 1.6 & 0.136 & 1.1 \\
\hline 942 & 2.6 & 0.141 & 1.6 \\
\hline 1000 & 3.7 & 0.143 & 2.2 \\
\hline
\end{tabular}


Table 5.2: Fundamental frequencies of the $2 D$ valley compared to the adjacent $1 D$ site for different input motions.

\begin{tabular}{|l|l|l|}
\hline $\begin{array}{l}\text { PGA of input record } \\
\text { (gal) }\end{array}$ & Fundamental frequency & Fundamental frequency \\
\hline 181 & 0.42 & 0.49 \\
\hline 256 & 0.45 & 0.49 \\
\hline 304 & 0.5 & 0.47 \\
\hline 422 & 0.42 & 0.4 \\
\hline 512 & 0.44 & 0.48 \\
\hline 607 & 0.4 & 0.37 \\
\hline 707 & 0.42 & 0.58 \\
\hline 813 & 0.39 & 0.4 \\
\hline 942 & 0.39 & 0.45 \\
\hline 1000 & 0.39 & 0.45 \\
\hline
\end{tabular}




\section{Conclusions}

In this thesis, some issues concerning the seismic microzonation studies for the city of Ottawa were investigated that include MASW seismic surveying and seismic site response analysis of variety of sites located in Ottawa area. As the first phase of the thesis, due to the existing of high shear velocity contrast between the loose Leda clay and the underlying hard bedrock, I applied the multi-channel analysis of surface waves (MASW) method, as a seismic surveying method to delineate the shear wave velocity profiles (a primary input for site response analysis) of the investigated sites. I evaluated the efficiency of MASW method using the available data from other geophysical methods such as Borehole and seismic reflection/refraction performed by Carleton University and GSC research teams. In the second phase of thesis, due to the large seismic amplification values observed from the weak motion recordings of some sparse earthquakes in region, I carried out site response analyses for different sites located in Ottawa area. The site response analysis methods encompassed the analytical method of reflection/transmission (R/T), finite element analysis and twodimensional finite difference method. According to the findings from the above-mentioned research phases, the main conclusions of this thesis are summarized as follow:

- I calibrated the results of MASW (multi-channel analysis of surface waves) against those from the reflection/refraction method and borehole data for a broad range of sites in Ottawa area and good agreement was obtained between the inverted shear 
wave velocity profiles from the MASW and those from the other geophysical methods.

- I used combined active and passive MASW to increase the frequency range of the dispersion curves. The extracted dispersion curves clearly exhibited the efficiency of the combined method to achieve the low frequency ranges. This low frequency range contains the information of deep layers and increases the accuracy of the inversion process for the final velocity profiles.

- I applied the random search inversion method to obtain the depth and the velocity of the high-velocity bedrock from the dispersion curves. The reason was the capabilities of random search inversion that is less likely to become trapped in local minima and benefits from the flexibility to search for the best match velocity profile. According to the available data from other geophysical methods, the outcomes exhibited successful differentiation of the bedrock depth and velocity of the investigated sites.

- I analyzed the sensitivity of the initial model parameters in the random search inversion of MASW. Results indicated that, except for the case of very low contrast in the initial model, the velocity-depth data obtained from the random search inversion are in good agreement with the borehole data. MASW demonstrated partial deficiency for the detection of very deep bedrock in some loose sites. This deficiency could be resolves if more sensitive geophones and stronger sources were used.

- Due to the probable wave trapping inside the high contrast soil-bedrock profiles in Ottawa area, I applied the method of reflection/transmission $(\mathrm{R} / \mathrm{T})$ coefficients which benefits from the internal wave reverberation scheme and is a strong tool to simulate the internal reflections of seismic waves inside the soil layers. 
- I developed a shaking intensity-dependant damping formulation using artificial time history acceleration records for Eastern Canada. This formulation correlates the target peak ground acceleration to the desired damping ratio and was derived using the analysis results of equivalent linear method for numerous sites throughout the Ottawa area. The modified site response method using $\mathrm{R} / \mathrm{T}$ was proposed by implementing the damping formulation in the velocity functions of the soil profile. This modification can be followed by shear modulus adjustment for the desired level of shaking (peak ground acceleration). In the proposed damping-modulus modified R/T method for Ottawa area, only target peak ground acceleration is needed as the input excitation. This can be considered as an advantage over the equivalent linear method (ELM) in which the complete time histories are required as the input motion.

- I performed an extensive one-dimensional Finite Element Method (FEM) analysis for the numerous sites in Ottawa area. FEM analyses confirmed the large observed amplification values from the weak motion recordings. The agreement between the observations and modeling results was acceptable with minor differences in fundamental frequencies.

- I investigated the maximum seismic amplification for the variation of contrast ratios and shaking intensities using a broad range of sites and input motions. Results showed that the most of the obtained amplification ratios saturate as the contrast ratio exceeds some high values. Therefore, a logarithmic function of contrast ratio $(\log z)$ is an appropriate representative of the mentioned partial saturation. 
- Using least square multiple regression method and according to the variation pattern of amplification ratio with two parameters of PGA and $z$, the following mathematical model was proposed for the combined effect of $\mathrm{z}$ and PGA :

$$
F_{f 0}=(7.812-6.992 \text { PGA }) \log _{10}(z) \quad\left(R^{2}=0.969\right)
$$

- The results of the combined logarithmic-linear function were validated using the amplification results from some scaled records. According to this verification test, the amplification ratios from the proposed model and those from the scaled records were close together (mostly different by $8 \%$ to $13 \%$ ).

- I applied FEM to compare the high and low frequency amplification values of NEHRP(1994) with the average low and high amplification values from onedimensional FEM (Using similar depth-velocity configuration) to evaluate the capability of FEM in my studies for site response analysis. Results showed the difference of $2 \%$ to $15 \%$ between two approaches. This reasonable difference suggests that FEM site response analysis can be applied for the determination of low and high frequency amplification factors comparable to NBCC (2005) which is based on the results of NEHRP (1994).

- I obtained the correlations between amplification values and $\mathrm{V}_{\mathrm{s} 30}$ for low and high frequency amplification values for a wide range of sites in Ottawa area and a set of amplification equations were developed for high and low frequency ranges. According to that trend in NBCC (2005) for the spectral accelerations greater than 1g, high frequency amplification values of site class $E$ are smaller than those of site class C. That trend of high frequency amplification values given in NBCC (2005) was also 
obtained in the applied FEM analysis. That trend was verified for the examined sites in Ottawa area where peak ground acceleration exceeded high shaking intensities.

- The obtained region-specific amplification ratios for Ottawa area for the same spectral accelerations of NBCC (2005) showed somewhat lower high frequency amplification values (on average 10\%) and larger low frequency amplification values of site classes $\mathrm{D}$ and $\mathrm{E}$ (on average $20 \%$ ) compared to the recommended values in NBCC, 2005. It should be noted that NBCC (2005) is still conservative if these low frequency amplification values of site classes $\mathrm{D}$ and $\mathrm{E}$ are compared with those of site class A (instead of site class C).

- I applied a proper constitutive model for two-dimensional site response analysis of a buried valley in the eastern part of the city of Ottawa. By implementing the constitutive model of modified Cam-Clay (MCC), drained triaxial test was simulated and the obtained deviatoric stress values were verified using the available experimental data for the slightly-overconsolidated clay that is the dominant consolidation state in Ottawa area. Using the MCC, Rayleigh damping and a variety of ground input motions, the maximum amplification ratios of the two-dimensional (2D) valley (at deepest part of the valley) in the eastern part of the city were compared against the peak amplification ratios of an adjacent one-dimensional (1D) site and a good agreement between the peak values of 1D and 2D sites was observed. The amplifications ratios of $2 \mathrm{D}$ site response analysis method were larger than those of 1D method at the frequencies greater than $3 \mathrm{~Hz}$. The difference between amplification ratios at the frequencies larger than $3 \mathrm{~Hz}$ can be attributed to the definition of Rayleigh damping for 1D method in which the over-damped response is 
expected for the frequencies outside the range between dominant frequency of the applied input motions and the fundamental site frequency.

To sum up the outcomes, the MASW was introduced as an efficient tool to distinguish the high shear wave velocity contrast in Ottawa area. The accuracy of the inversion process of MASW depends on the captured frequency range in dispersion data that can be enhanced by using more sensitive receivers and stronger active sources combined with the passive source data.

For the site response analysis of high-contrast profiles, $\mathrm{R} / \mathrm{T}$ method improved by a proper damping scheme incorporated in the velocity profile and the adjustment of velocity profile for the shear modulus variation, provides a fast tool for the seismic amplification analysis. Having multiple reverberation schemes and being capable to respond to a target shaking intensity, modified $\mathrm{R} / \mathrm{T}$ method is a strong site response analysis algorithm for Ottawa area that lacks available strong motion data.

In addition, site response analysis using the finite element method confirmed the observed large amplification ratios from the weak motion recordings but on the other hand, exhibited the saturation behavior of amplification ratio for the shaking intensities used in geotechnical practice. In other words, when soil-bedrock velocity contrast ratio exceeds large values the peak amplification variation is trivial. In reality, this saturation of the transferred ground motion can be justified due to the limitation encountered by the shear strength of the soil.

For Ottawa area, the extracted low frequency and high frequency amplification values illustrated the strong correlation with the average shear wave velocity in top thirty meters of the site profile and by and large, the amplification values and trends in NBCC 
(2005) were verified. The peak amplification values obtained from two-dimensional site response analysis of a deep valley in the eastern part of the city were in good agreement with those obtained for a nearby one-dimensional site. Based on the amplification results, minor discrepancies occurred for the amplification values at the frequencies greater than $3 \mathrm{~Hz}$ that can be attributed to different implementation of Rayleigh damping in two-dimensional and one-dimensional site response methods. 


\section{Appendices}

\subsection{Appendix A: Amplification curves from Fourier spectra definition}

for Heritage Park site in Ottawa area. These sites (real and the generated profiles) are subjected to the artificial Eastern Canadian Earthquakes (10\% in 50 years records).

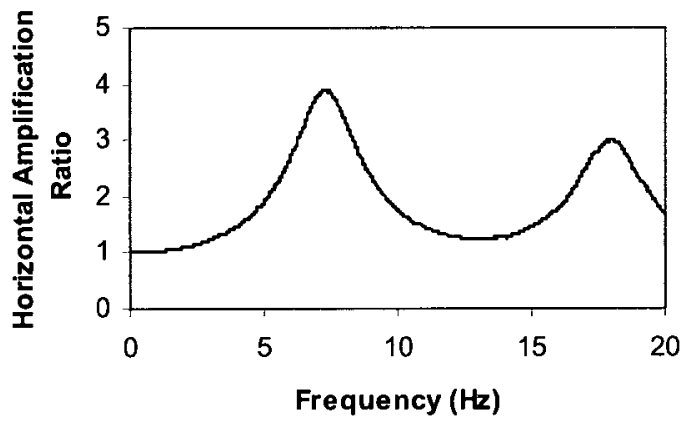

(a)

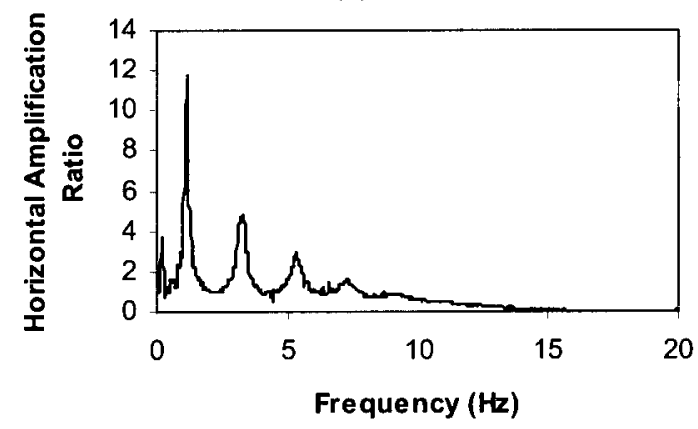

(c)

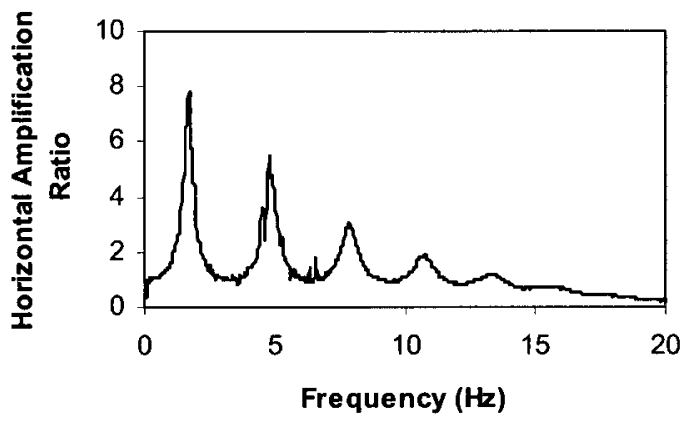

(b)

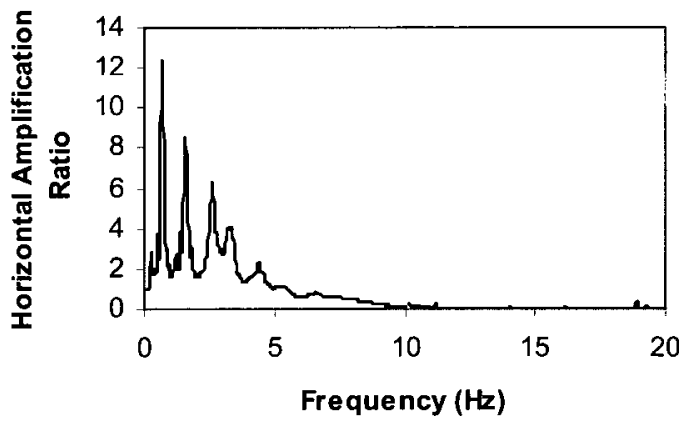

(d)

Fig. A1: Amplification Curve for Heritage Park site subjected to the record having PGA of 23 gal using: (a) contrast ratio of 4; (b) contrast ratio of 8; (c) contrast ratio of 12; (d) real contrast ratio . 


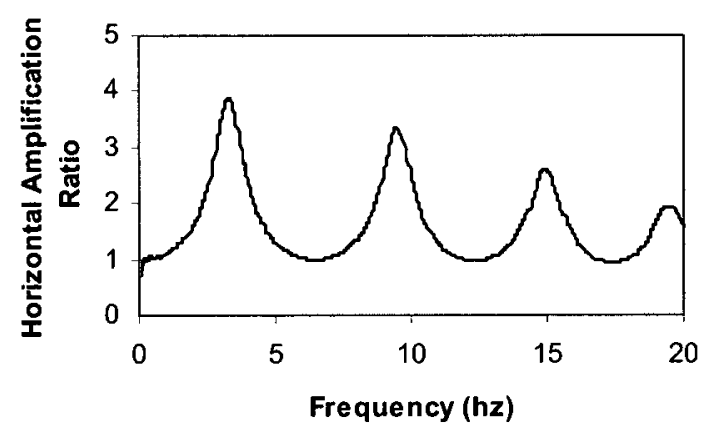

(a)

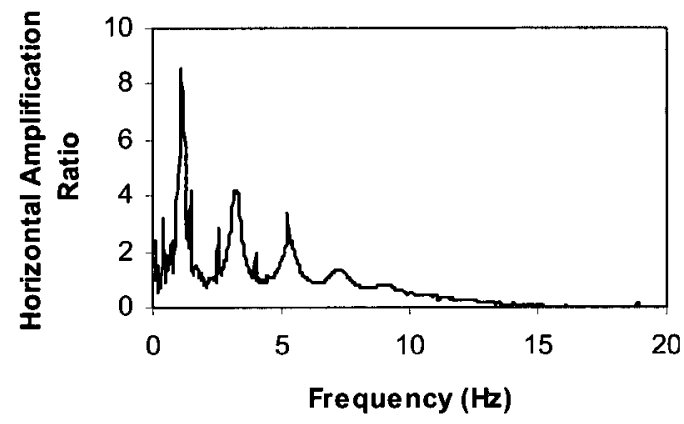

(c)

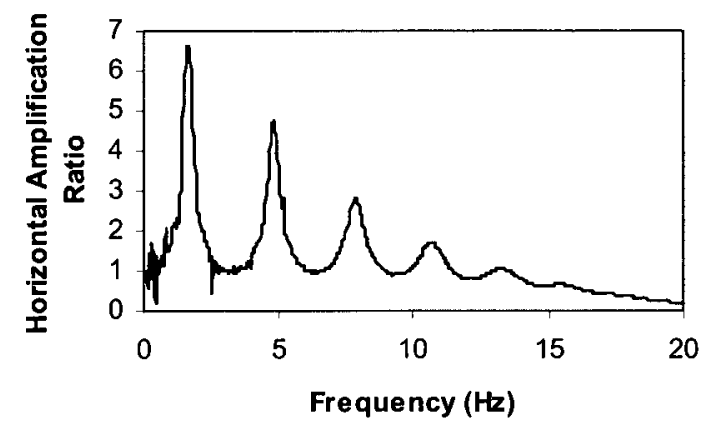

(b)

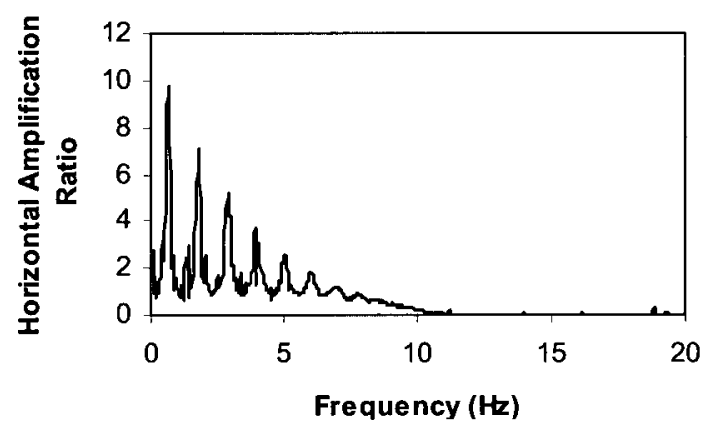

(d)

Fig. A2: Amplification Curve for Heritage Park site subjected to the record having PGA of 41 gal using: (a) contrast ratio of 4; (b) contrast ratio of 8; (c) contrast ratio of 12; (d) real contrast ratio. 


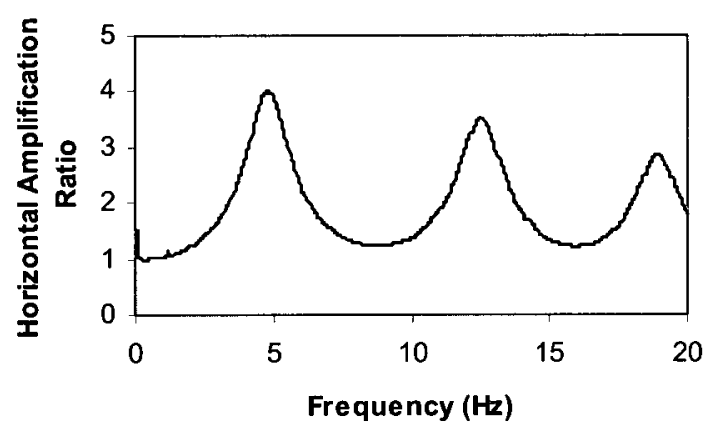

(a)

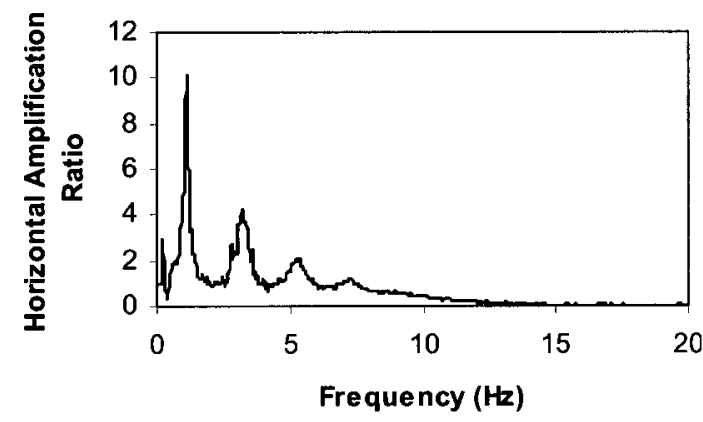

(c)

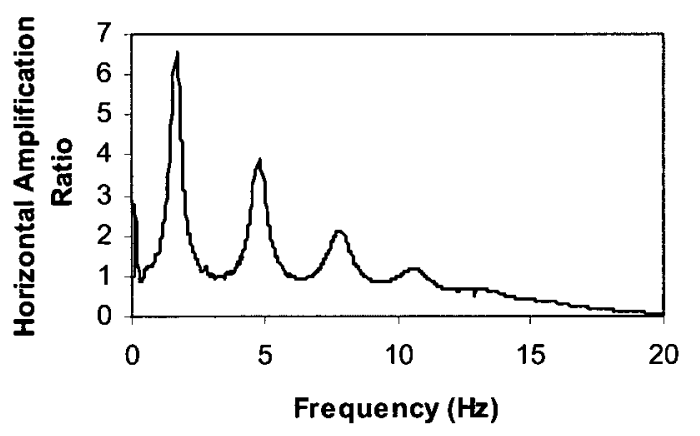

(b)

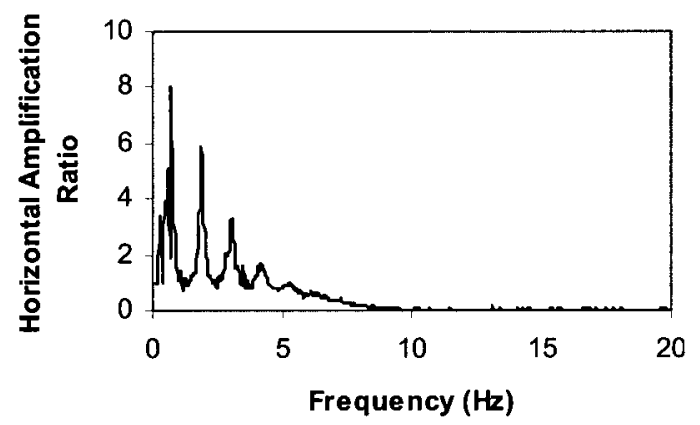

(d)

Fig. A3: Amplification Curve for Heritage Park site subjected to the record having PGA of 70 gal using: (a) contrast ratio of 4; (b) contrast ratio of 8; (c) contrast ratio of 12; (d) real contrast ratio. 


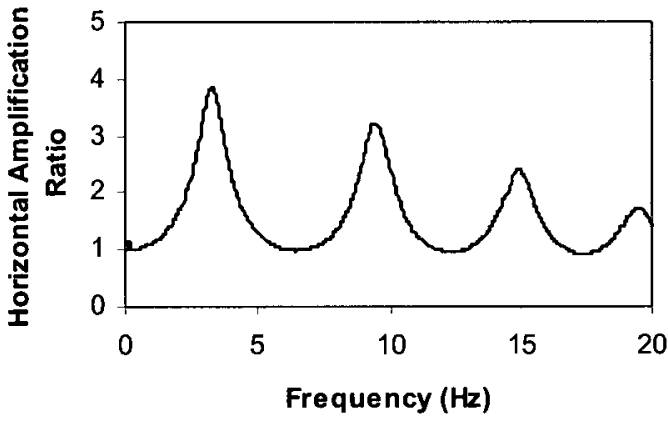

(a)

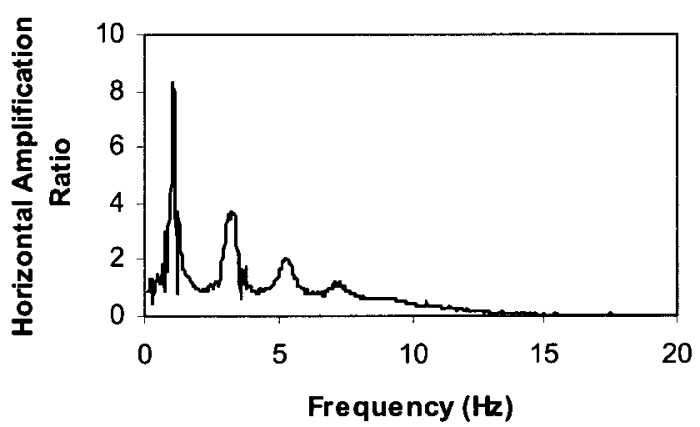

(c)

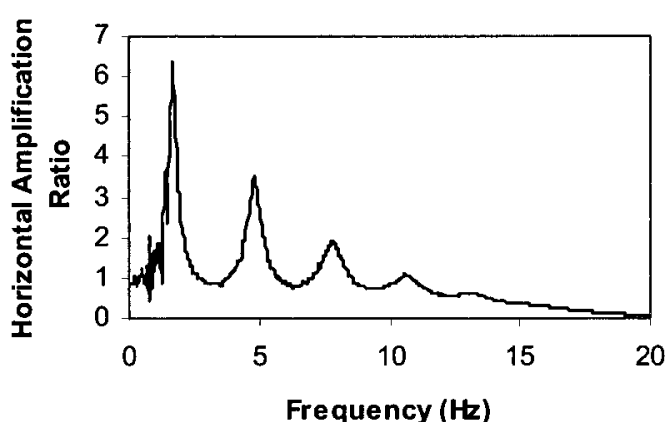

(b)

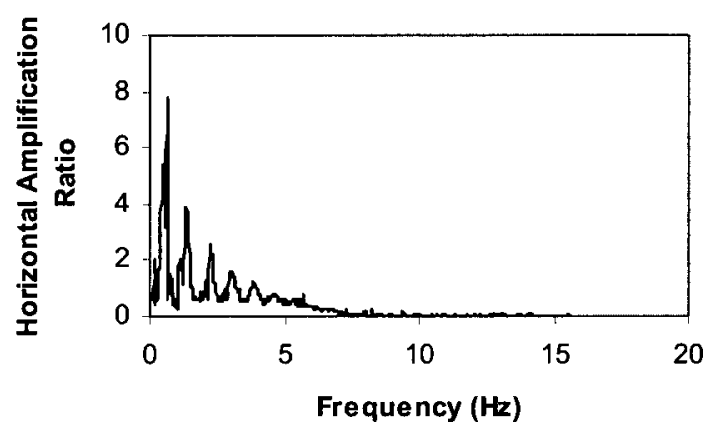

(d)

Fig. A4: Amplification Curve for Heritage Park site subjected to the record having PGA of 81 gal using: (a) contrast ratio of 4; (b) contrast ratio of 8; (c) contrast ratio of 12; (d) real contrast ratio . 


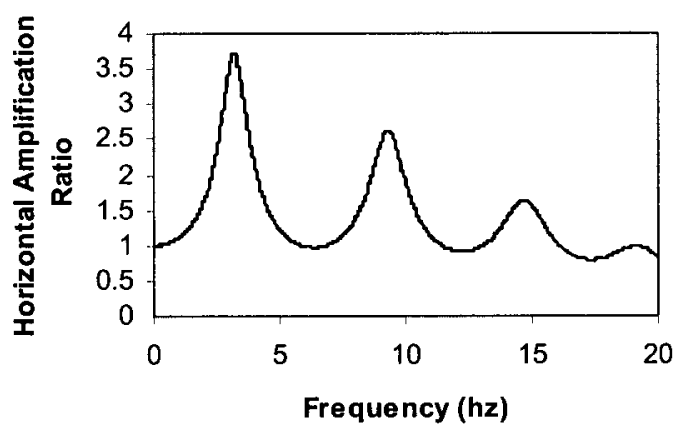

(a)

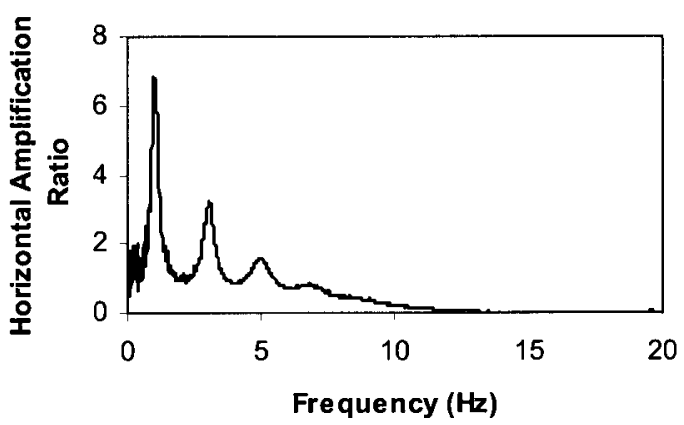

(c)

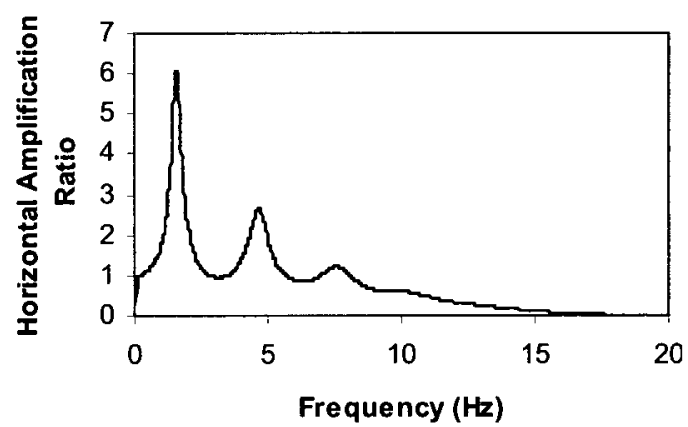

(b)

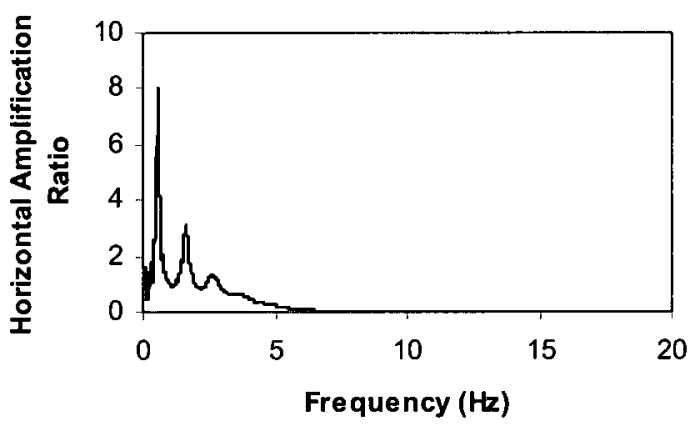

(d)

Fig. A5: Amplification Curve for Heritage Park site subjected to the record having PGA of 147 gal using: (a) contrast ratio of 4; (b) contrast ratio of 8 ; (c) contrast ratio of 12; (d) real contrast ratio . 


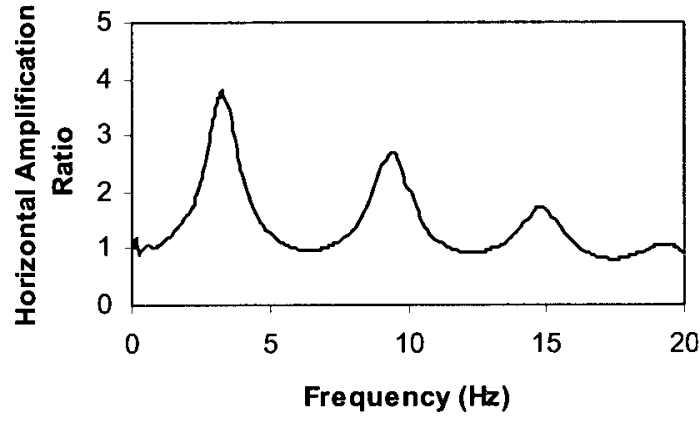

(a)

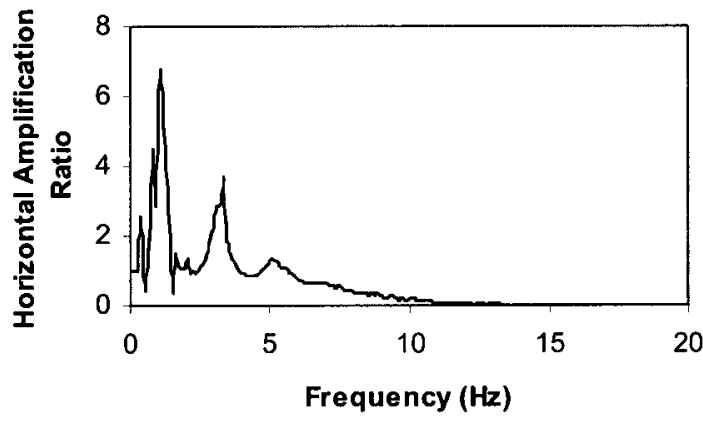

(c)

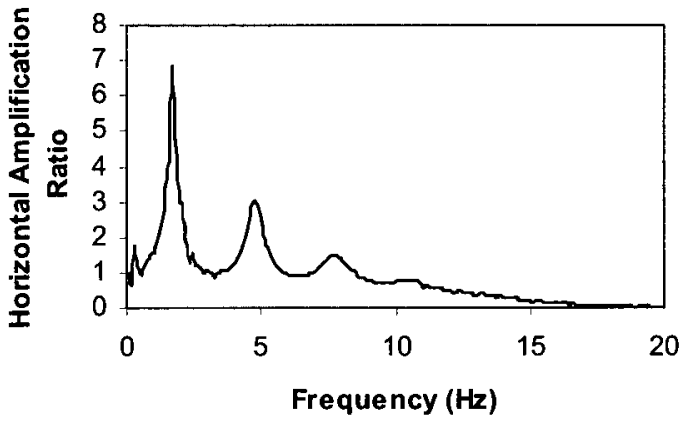

(b)

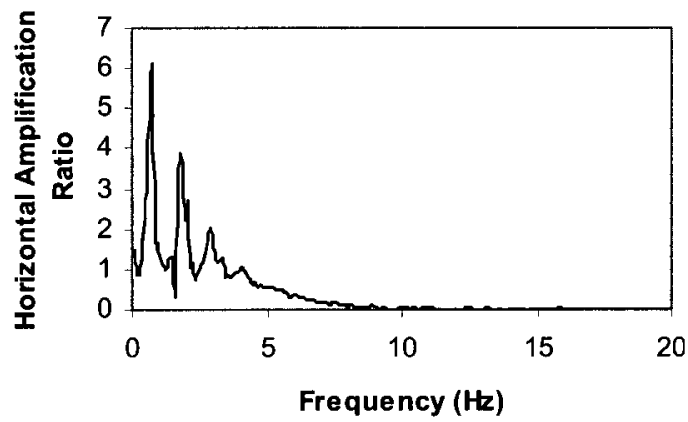

(d)

Fig. A6: Amplification Curve for Heritage Park site subjected to the record having PGA of 208 gal using: (a) contrast ratio of 4; (b) contrast ratio of 8; (c) contrast ratio of 12; (d) real contrast ratio . 


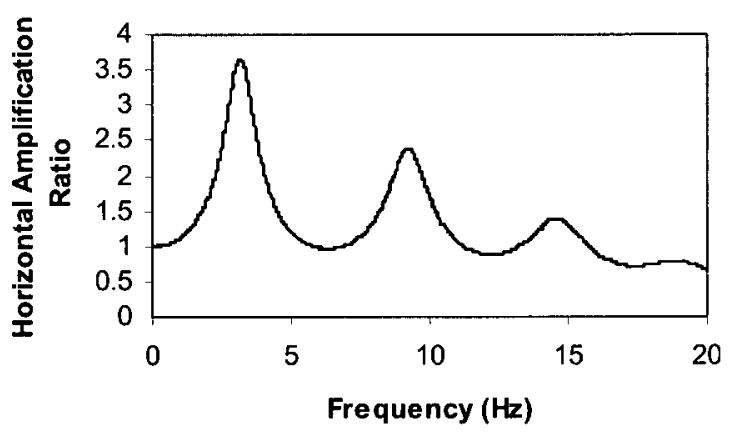

(a)

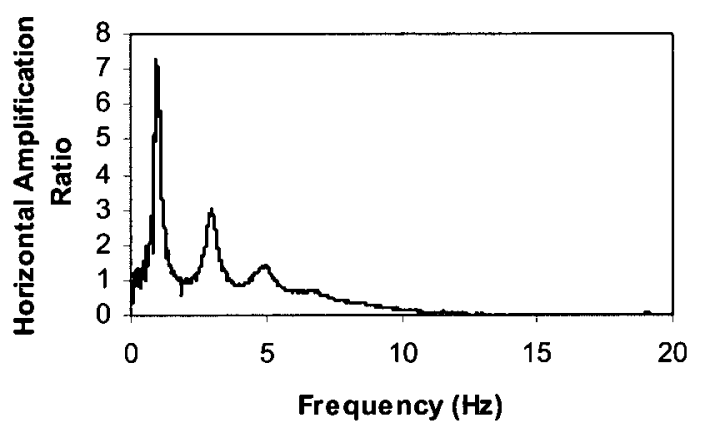

(c)

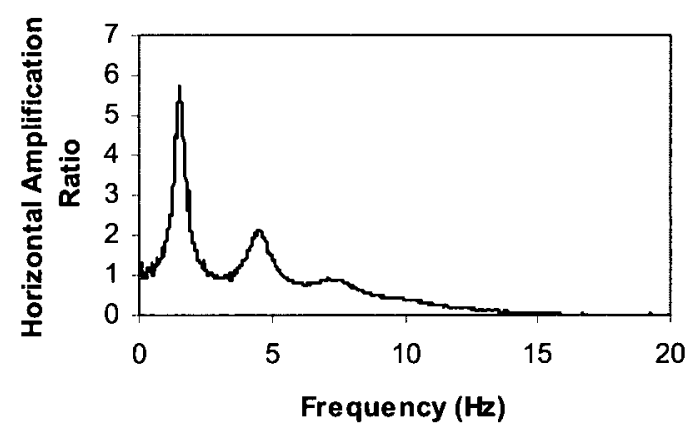

(b)

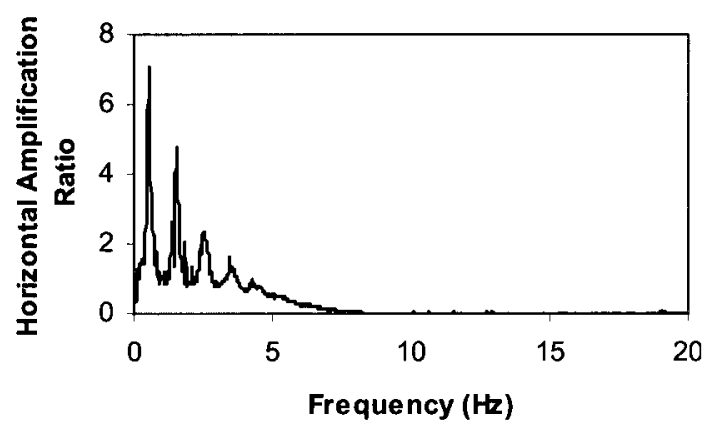

(d)

Fig. A7: Amplification Curve for Heritage Park site subjected to the record having PGA of 349 gal using: (a) contrast ratio of 4; (b) contrast ratio of 8; (c) contrast ratio of 12; (d) real contrast ratio 


\subsection{Appendix B: Peak Amplification value variation versus contrast} ratio for Heritage Park site in Ottawa area.

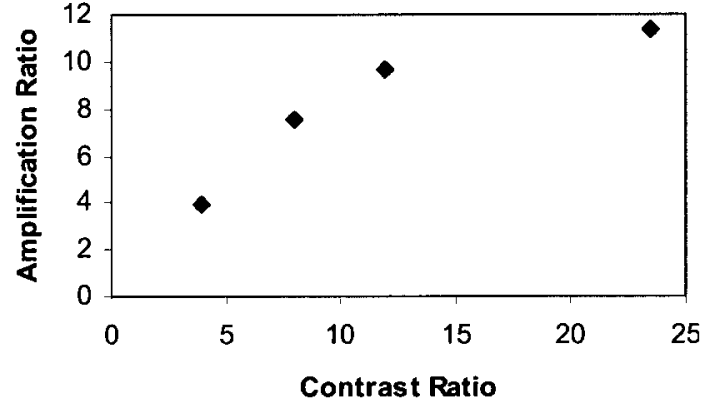

(a)

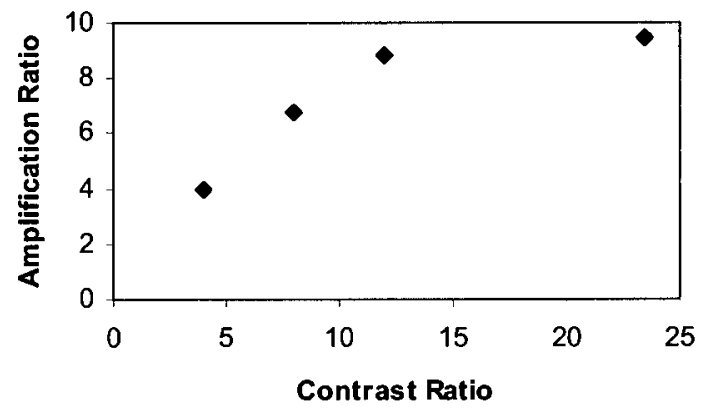

(c)

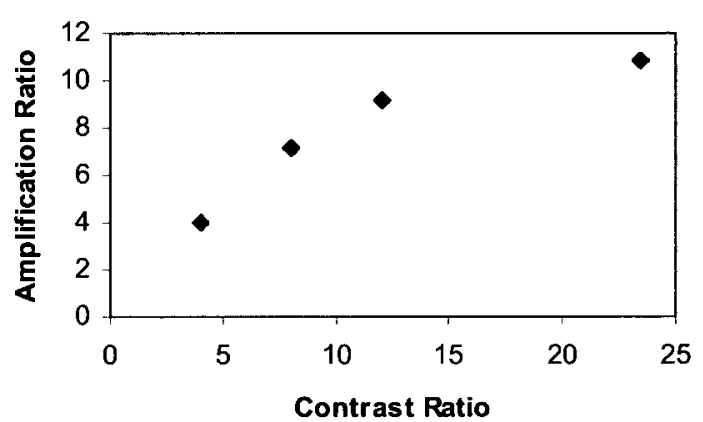

(b)

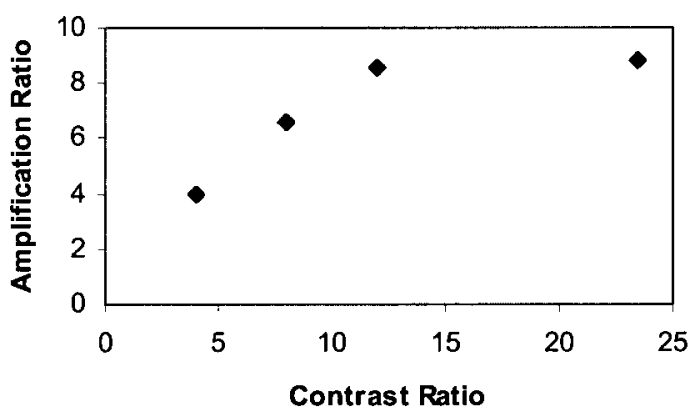

(d)

Fig. B1: Application of contrast ratios to Heritage Park site; Maximum amplification values for simulated contrast ratios using the record having: (a) PGA of 23gal; (b) PGA of 4lgal; (c) PGA of 70gal; (d) PGA of 81gal. 


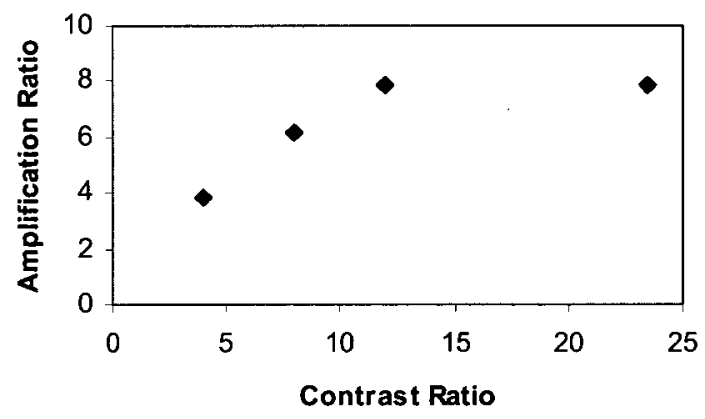

(a)

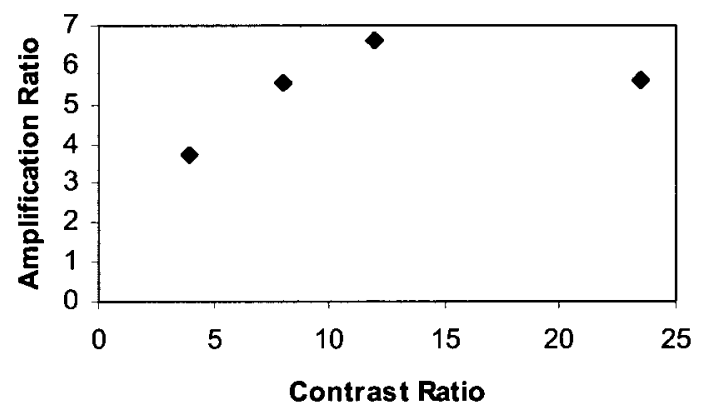

(c)

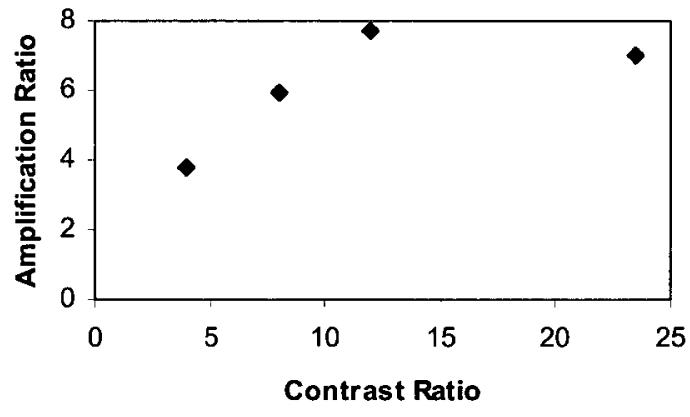

(b)

Fig. B2: Application of contrast ratios to Heritage Park site; Maximum amplification values for simulated contrast ratios using the record having: (a) PGA of 147gal; (b) PGA of $208 \mathrm{gal}$; (c) PGA of $349 \mathrm{gal}$. 


\subsection{Appendix C: Amplification curves related to site \#31 in Ottawa} area. This site (real profile and the generated ones) is subjected to the scaled records obtained from the artificial record having PGA of 23 gal.

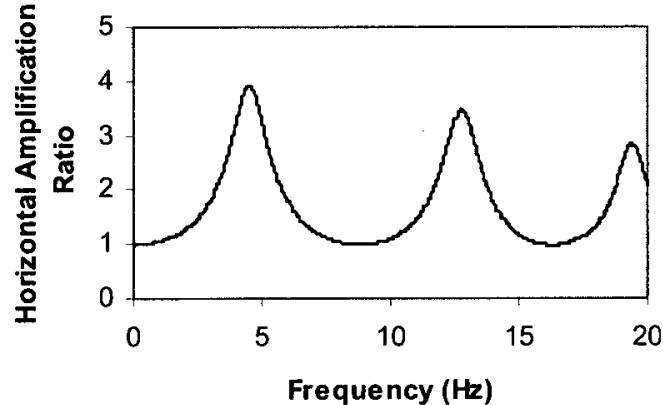

(a)

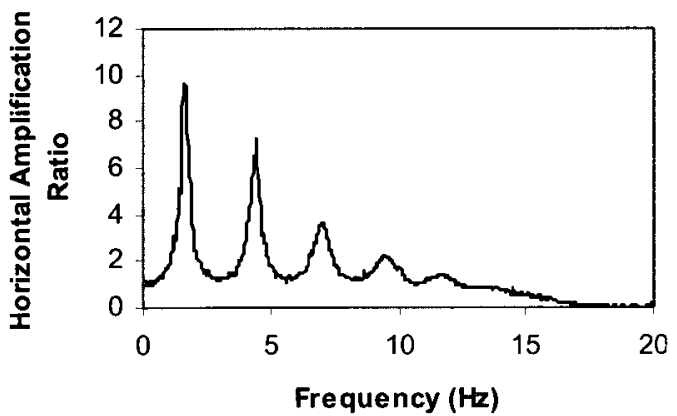

(c)

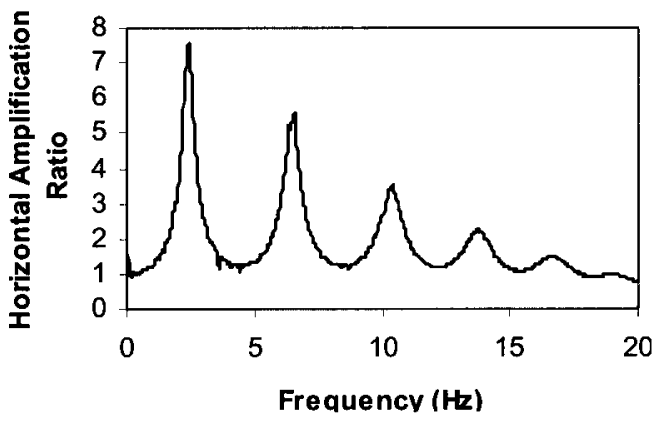

(b)

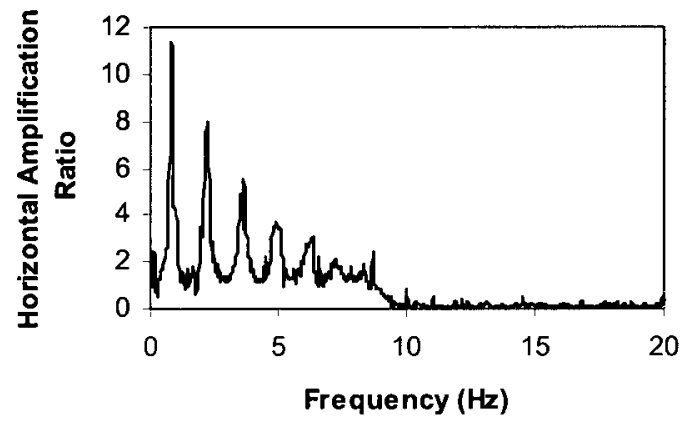

(d)

Fig. C1: Amplification Curve for site \#31 subjected to the record having PGA of 23 gal using: (a) contrast ratio of 4; (b) contrast ratio of 8; (c) contrast ratio of 12; (d) real contrast ratio . 


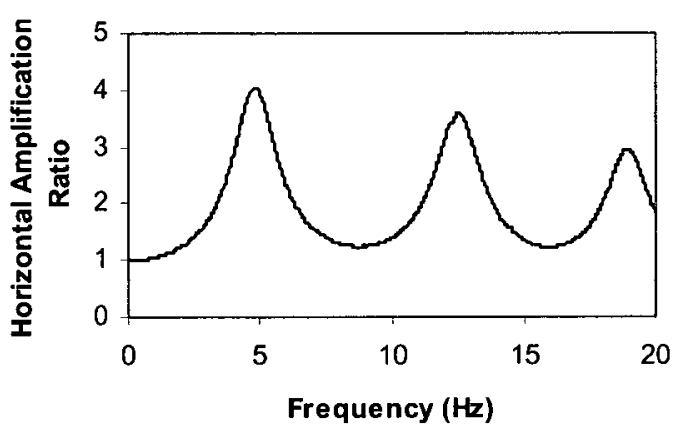

(a)

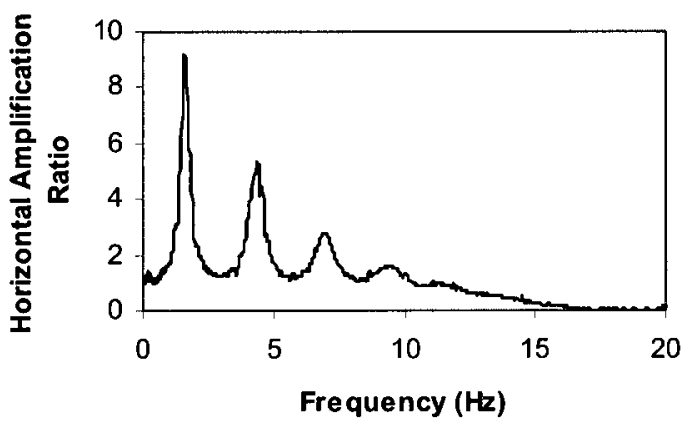

(c)

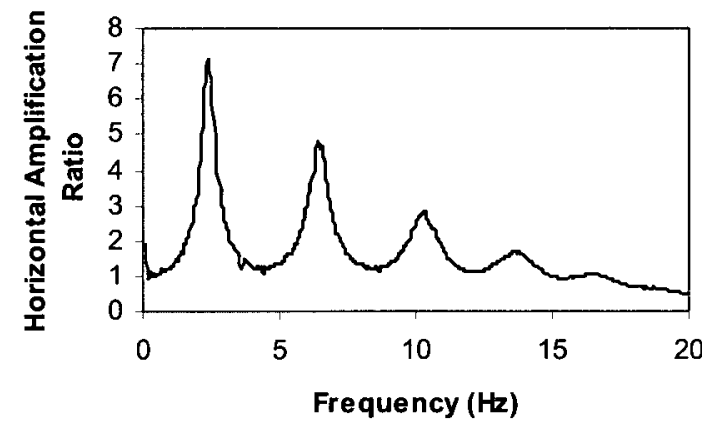

(b)

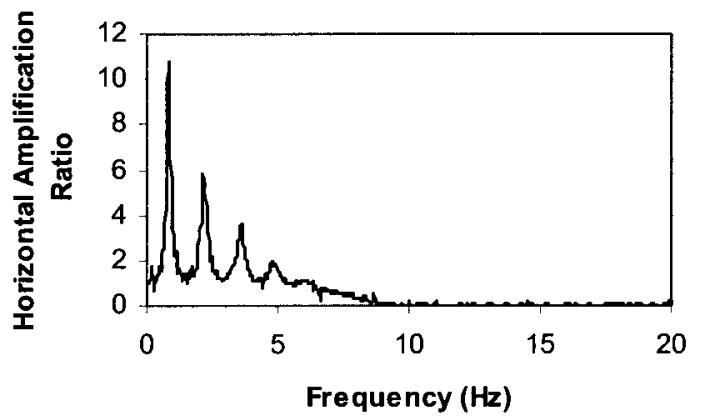

(d)

Fig. C2: Amplification Curve for site \#31 subjected to the record having PGA of 41 gal using: (a) contrast ratio of 4; (b) contrast ratio of 8 ; (c) contrast ratio of 12 ; (d) real contrast ratio . 


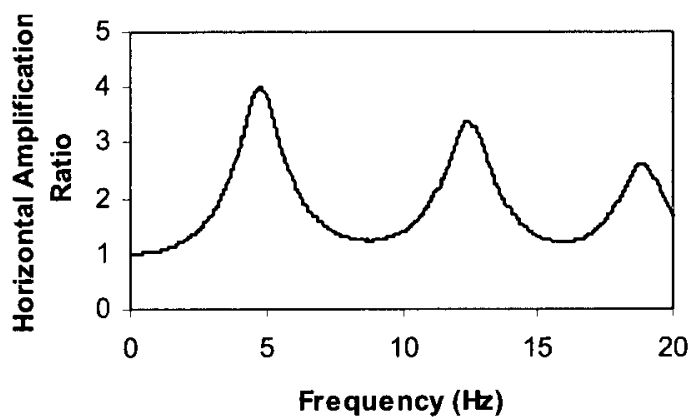

(a)

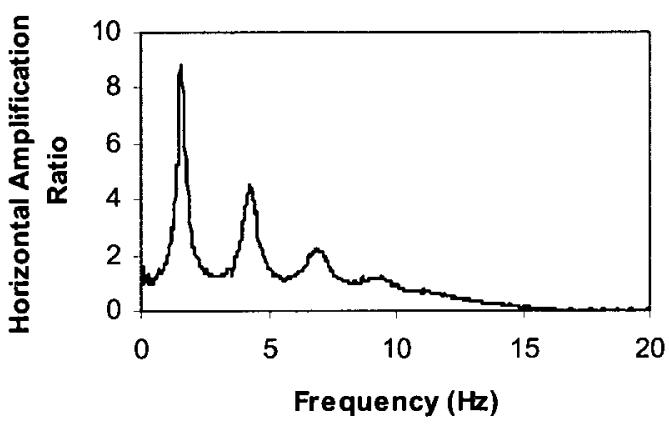

(c)

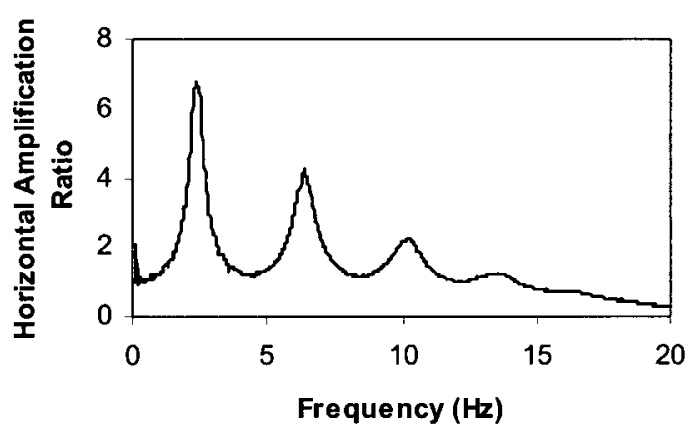

(b)

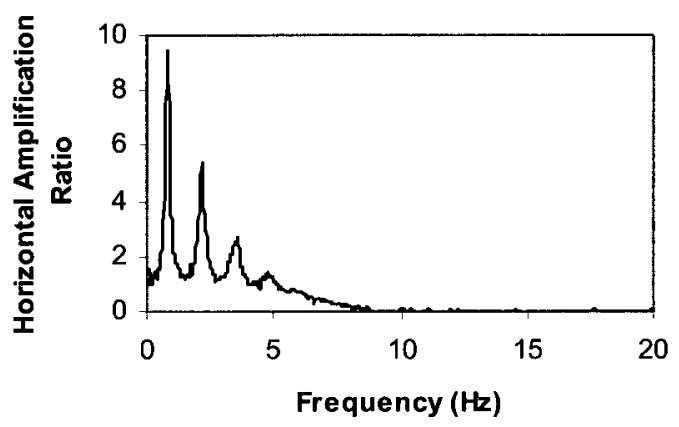

(d)

Fig. C3: Amplification Curve for site \#31 subjected to the record having PGA of $70 \mathrm{gal}$ using: (a) contrast ratio of 4; (b) contrast ratio of 8; (c) contrast ratio of 12; (d) real contrast ratio . 


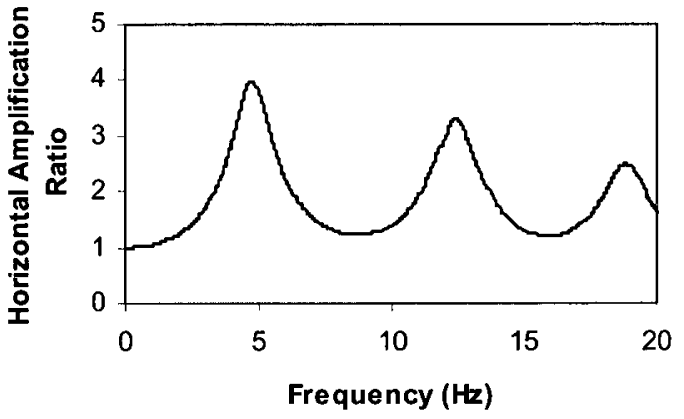

(a)

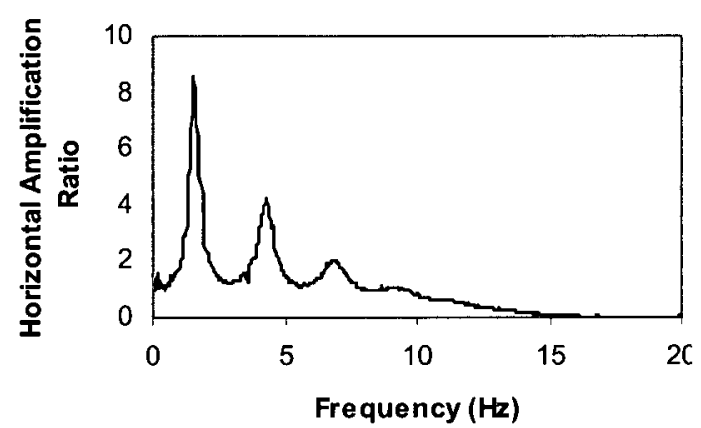

(c)

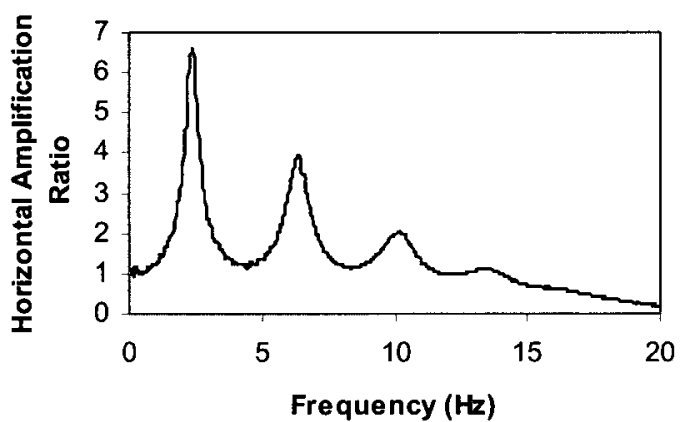

(b)

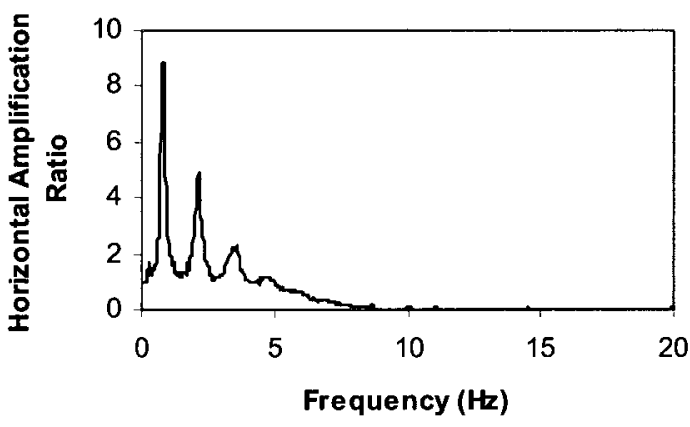

(d)

Fig. C4: Amplification Curve for site \#31 subjected to the record having PGA of 81 gal using: (a) contrast ratio of 4; (b) contrast ratio of 8 ; (c) contrast ratio of 12 ; (d) real contrast ratio . 


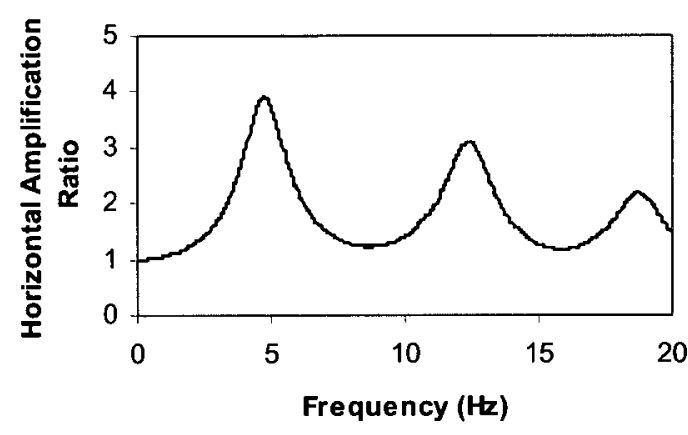

(a)

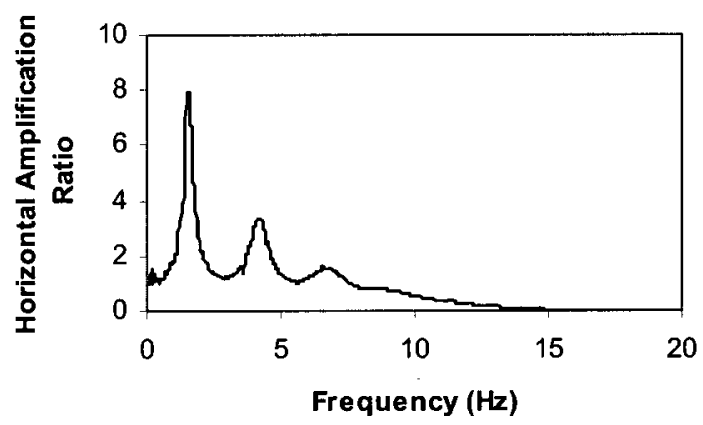

(c)

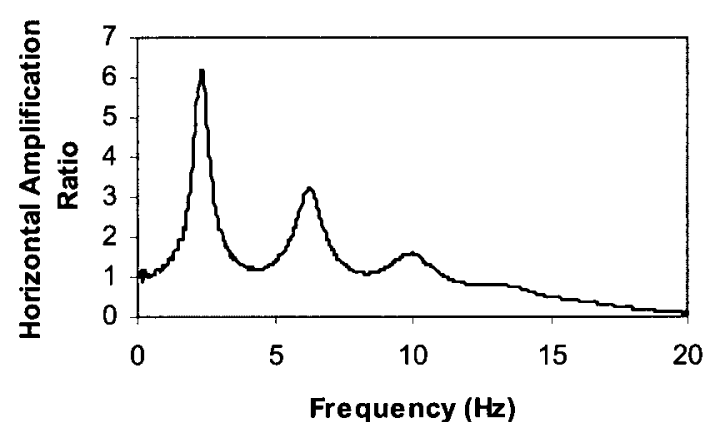

(b)

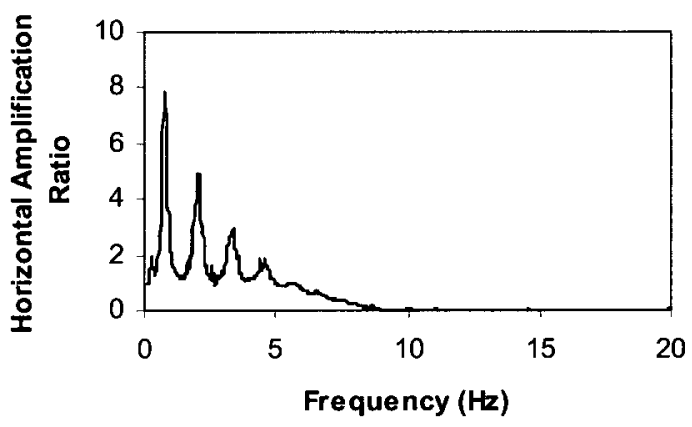

(d)

Fig. C5: Amplification Curve for site \#31 subjected to the record having PGA of $147 \mathrm{gal}$ using: (a) contrast ratio of 4; (b) contrast ratio of 8; (c) contrast ratio of 12; (d) real contrast ratio. 


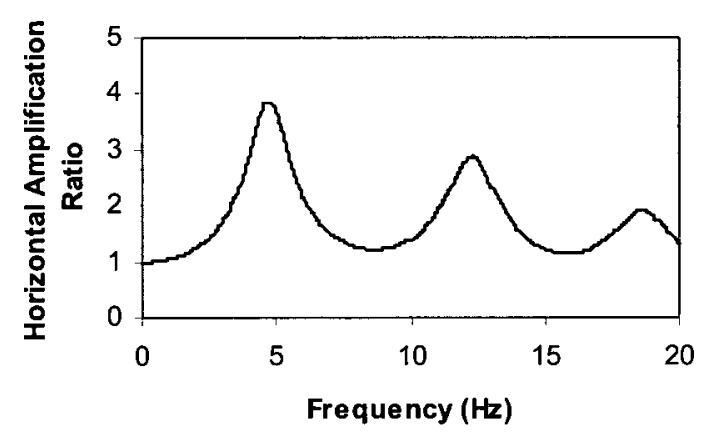

(a)

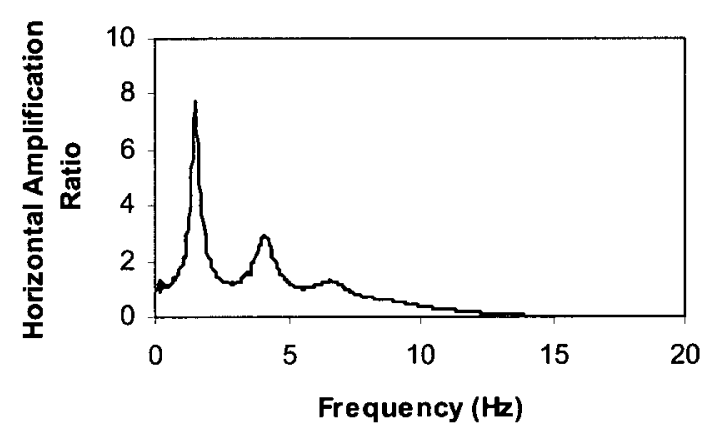

(c)

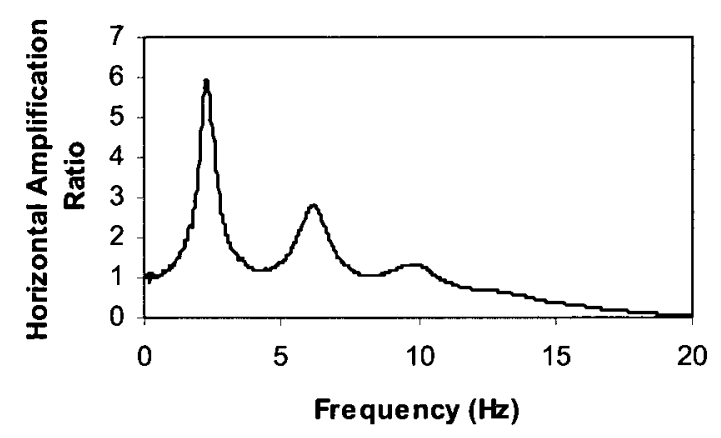

(b)

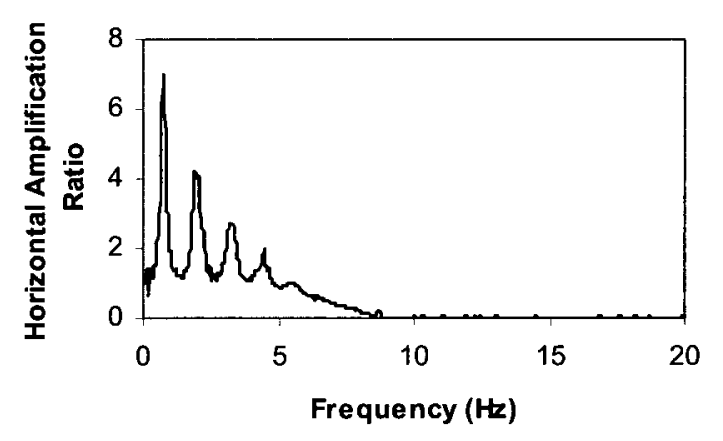

(d)

Fig. C6: Amplification Curve for site \#31 subjected to the record having PGA of 208 gal using: (a) contrast ratio of 4 ; (b) contrast ratio of 8 ; (c) contrast ratio of 12 ; (d) real contrast ratio . 


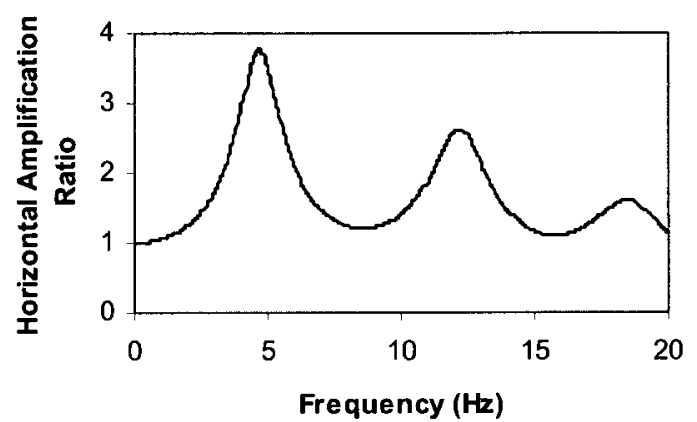

(a)

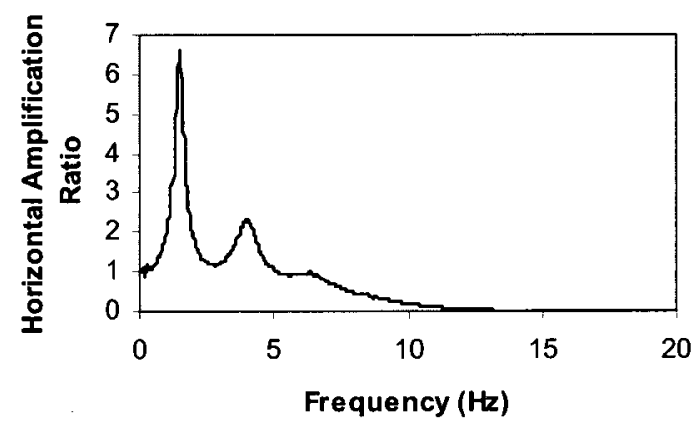

(c)

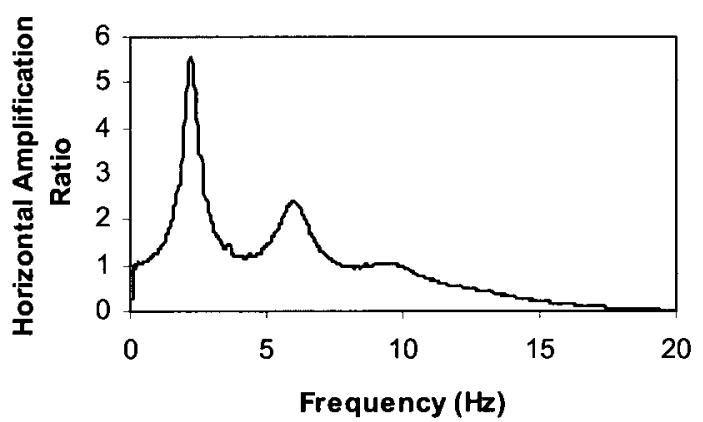

(b)

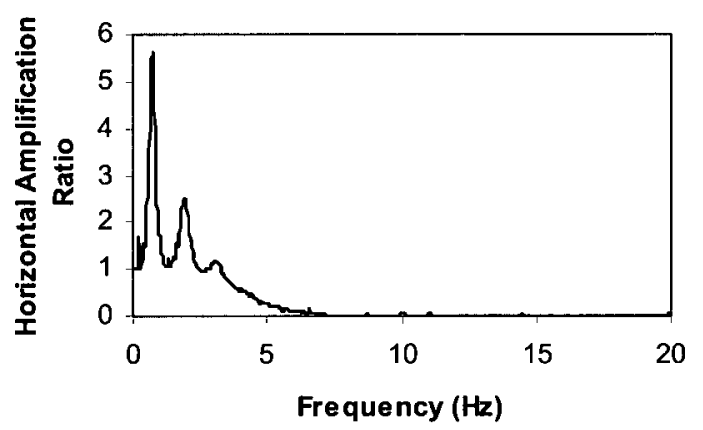

(d)

Fig. C7: Amplification Curve for site \#31 subjected to the record having PGA of $349 \mathrm{gal}$ using: (a) contrast ratio of 4; (b) contrast ratio of $8 ;$ (c) contrast ratio of $12 ;$ (d) real contrast ratio . 


\subsection{Appendix D: Samples of Amplification curves obtained from} similar depth-velocity configurations to those used by NEHRP, 1994. Each curve is shown for a specific site class subjected to the records having similar target peak ground accelerations.

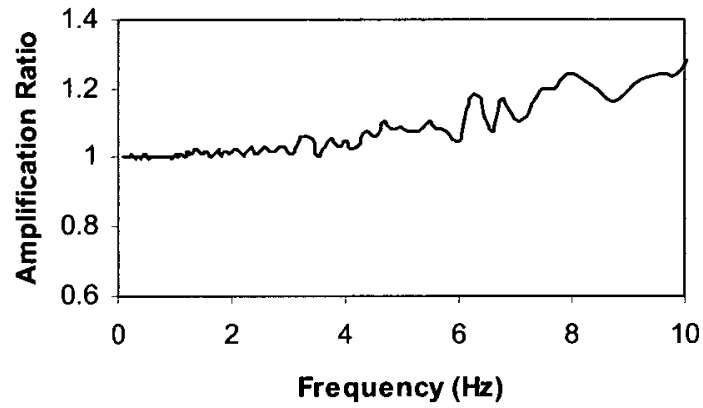

(a)

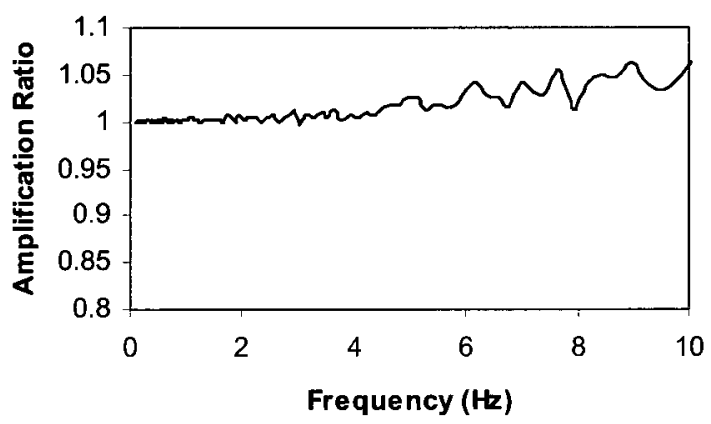

(c)

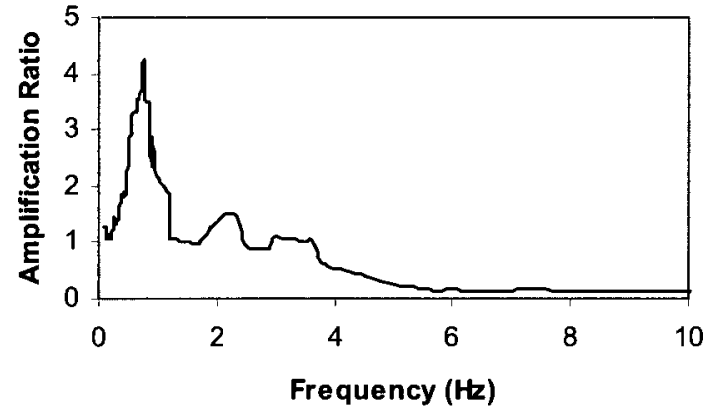

(b)

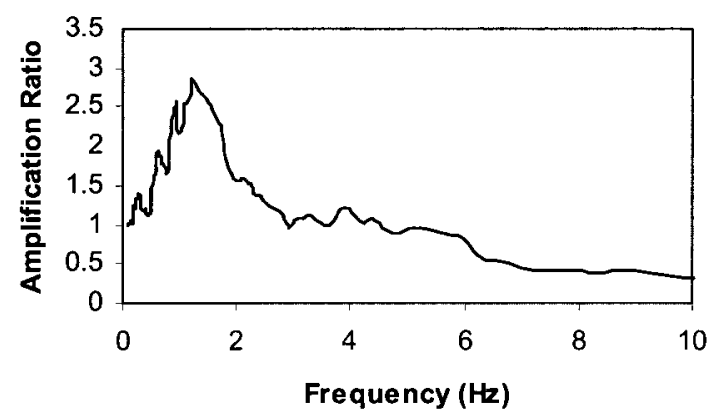

(d)

Fig. D1: Amplification Curve using different time histories;(a) for target PGA of 0.1g at site class A of Config. 1; (b) for target PGA of 0.3g at site class E of Config. 1; (c) for target PGA of $0.4 \mathrm{~g}$ at site class B of Config.2; (d) for target PGA of $0.5 \mathrm{~g}$ at site class $D$ of Config. 2. 


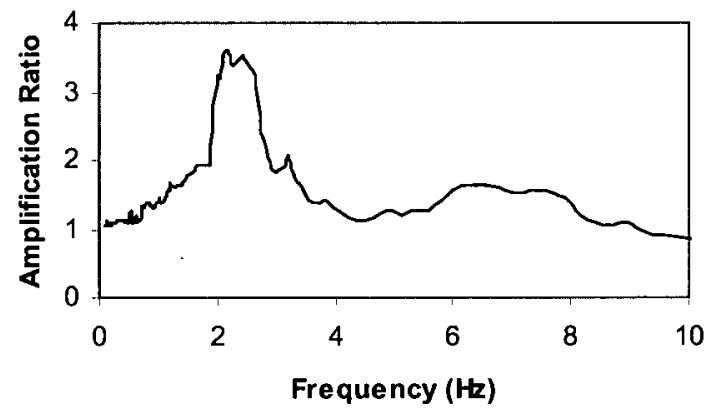

(a)

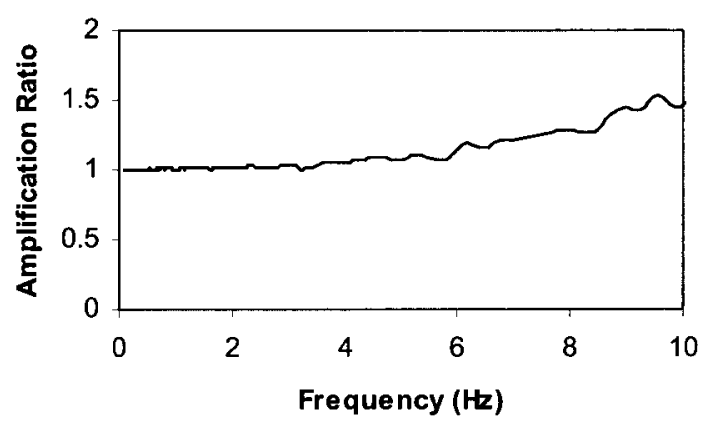

(c)

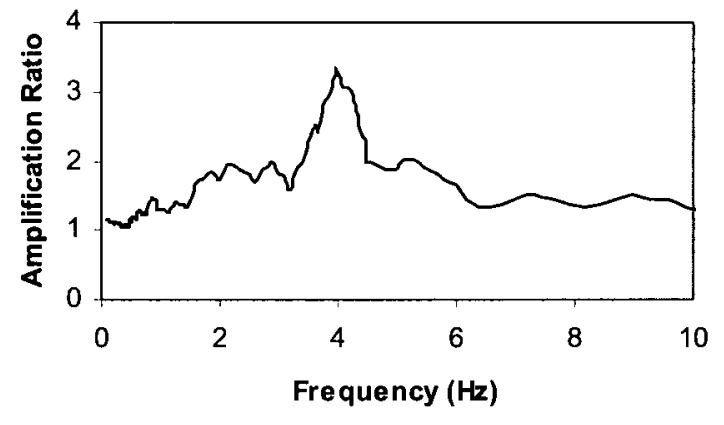

(b)

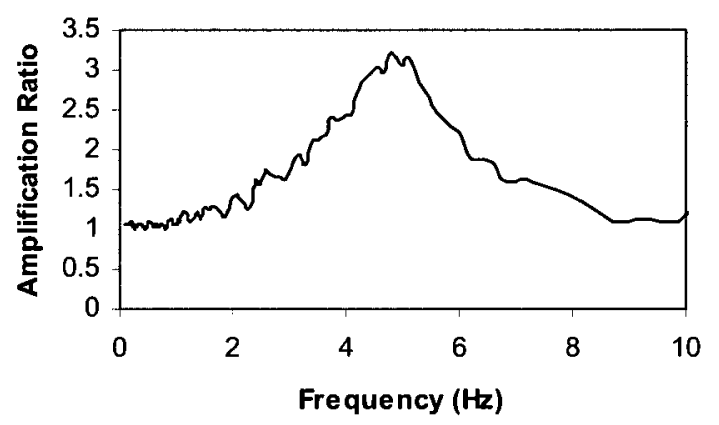

(d)

Fig. D2: Amplification Curve using different time histories;(a) for target PGA of 0.2g at site class D of Config.3; (b) for target PGA of 0.5g at site class $C$ of Config.3; (c) for target PGA of $0.5 \mathrm{~g}$ at site class B of Config.4; (d) for target PGA of $0.1 \mathrm{~g}$ at site class $C$ of Config.4. 


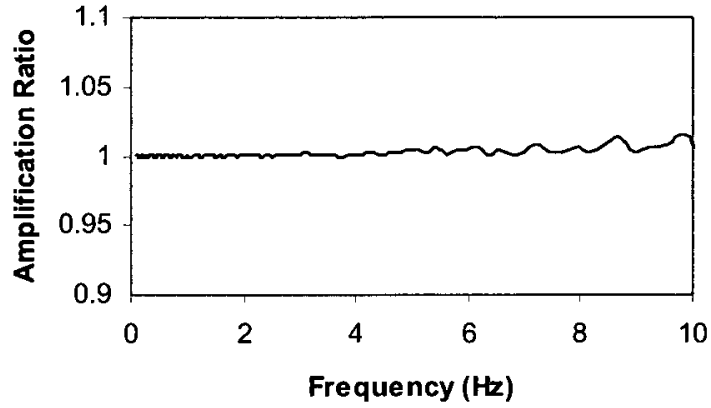

(a)

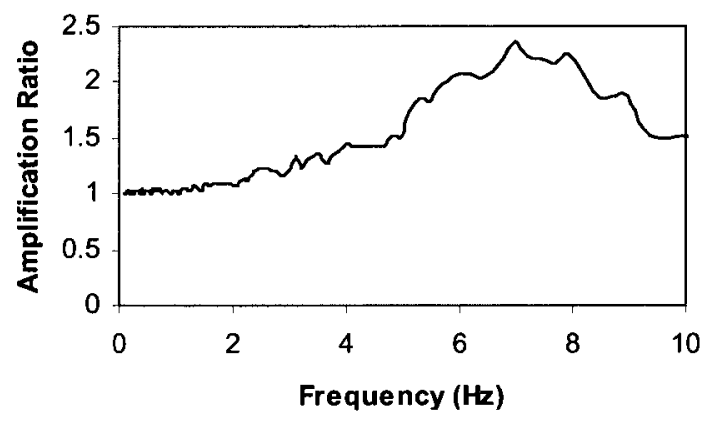

(c)

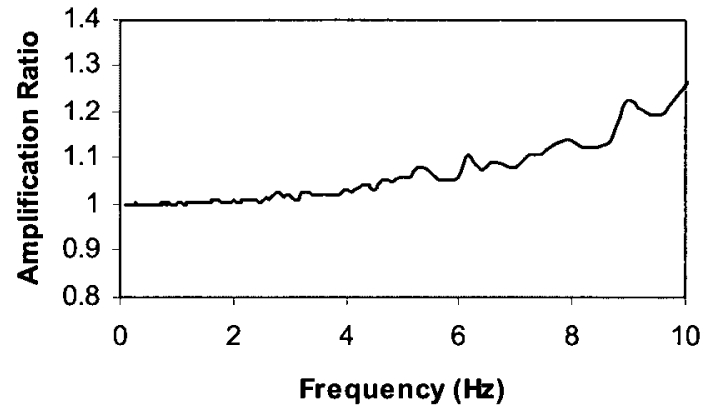

(b)

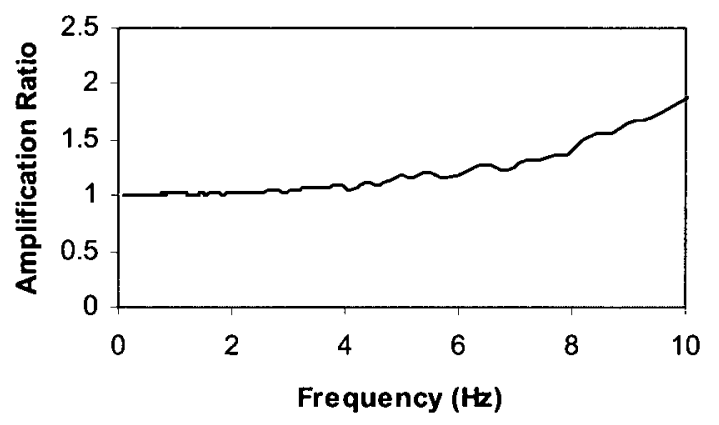

(d)

Fig. D3: Amplification Curve using different time histories;(a) for target PGA of 0.4g at site class $A$ of Config.5; (b) for target PGA of $0.2 \mathrm{~g}$ at site class $B$ of Config.5; (c) for target PGA of $0.4 \mathrm{~g}$ at site class C of Config.6; (d) for target PGA of $0.3 \mathrm{~g}$ at site class $B$ of Config. 6. 


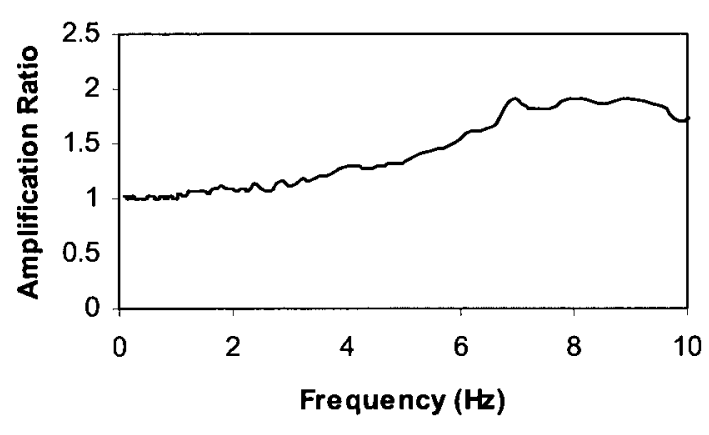

(a)

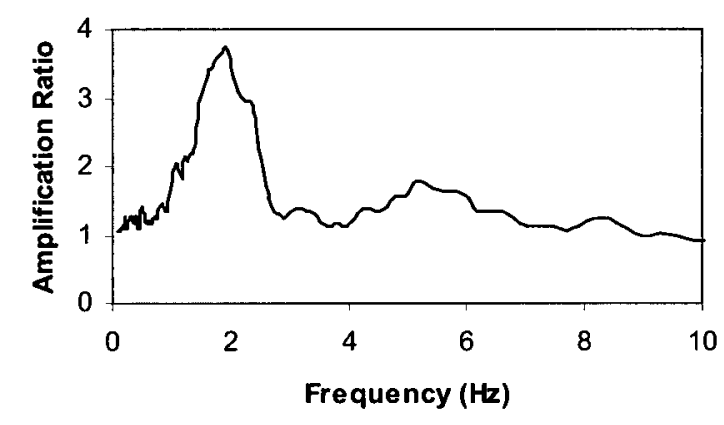

(c)

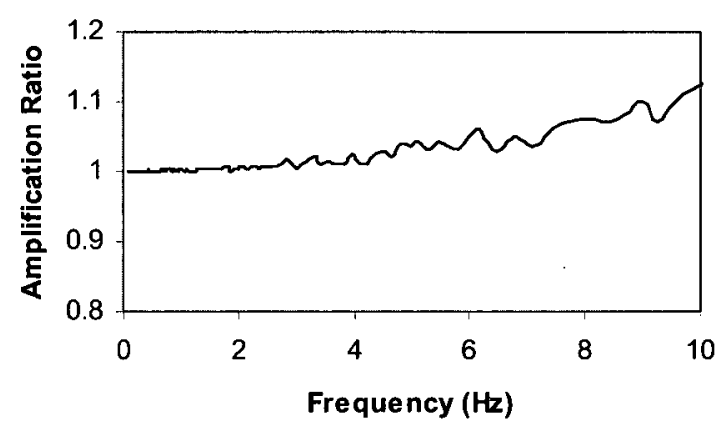

(b)

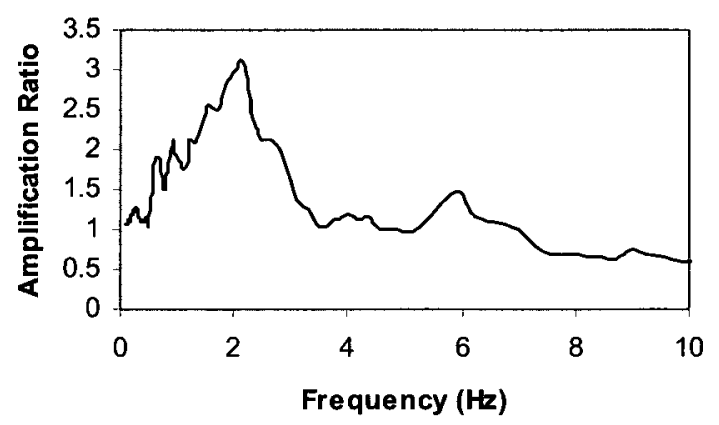

(d)

Fig. D4: Amplification Curve using different time histories;(a) for target $P G A$ of $0.5 \mathrm{~g}$ at site class B of Config.7; (b) for target PGA of 0.2g at site class $A$ of Config. 7; (c) for target PGA of $0.1 \mathrm{~g}$ at site class D of Config.8; (d) for target PGA of $0.5 \mathrm{~g}$ at site class $D$ of Config. 8 . 


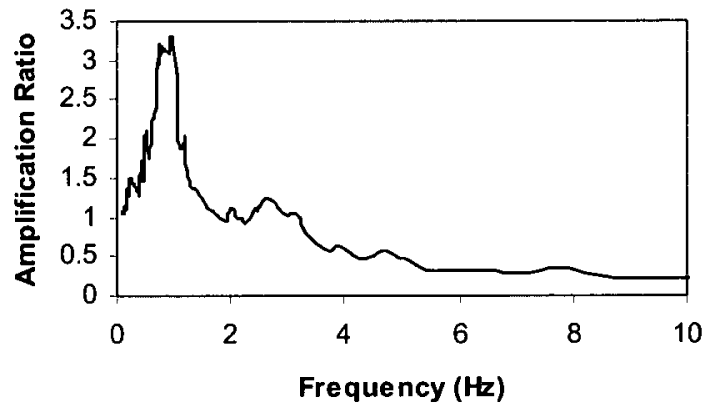

(a)

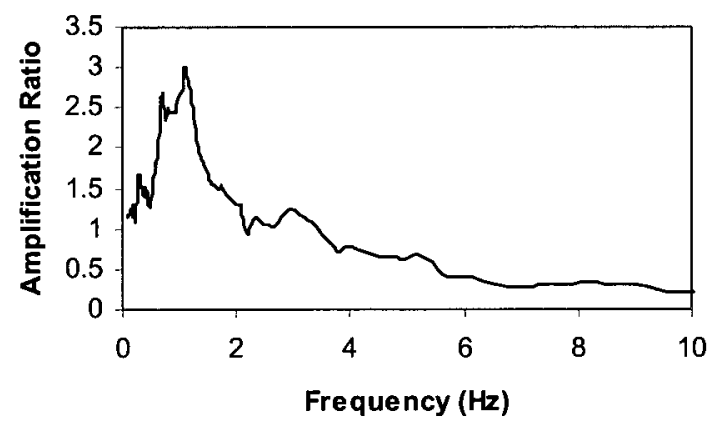

(b)

Fig. D5: Amplification Curve using different time histories;(a) for target PGA of 0.2g at site class $E$ of Config.9; (b) for target PGA of $0.4 \mathrm{~g}$ at site class $E$ of Config. 9 


\subsection{Appendix E: Sample of Amplification curves (Fourier spectra}

definition) for the sites in Ottawa area for the low and high

frequency amplification determination. The input records were chosen from the artificial Eastern Canadian Earthquakes.

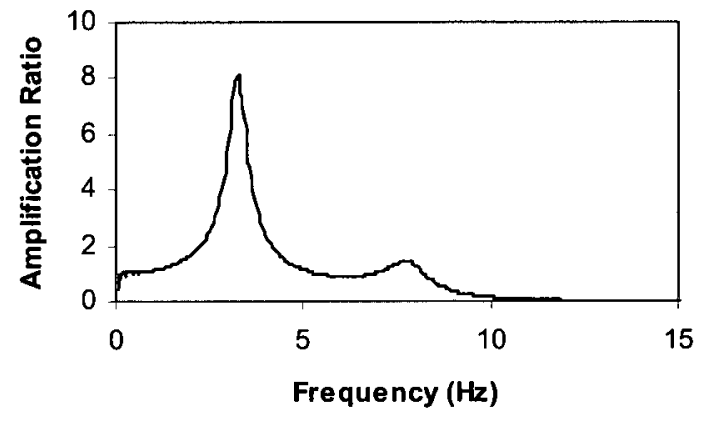

(a)

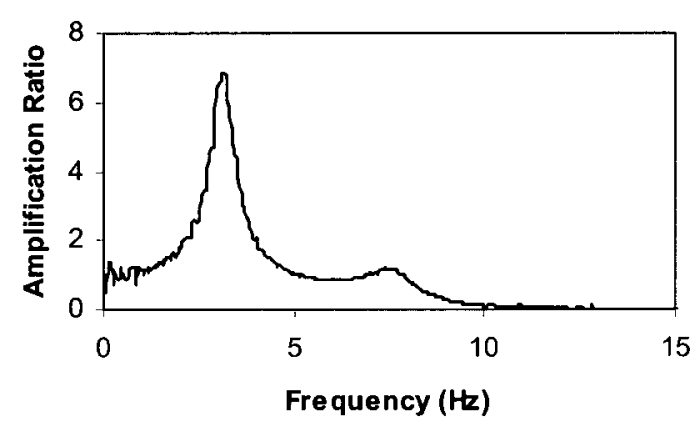

(c)

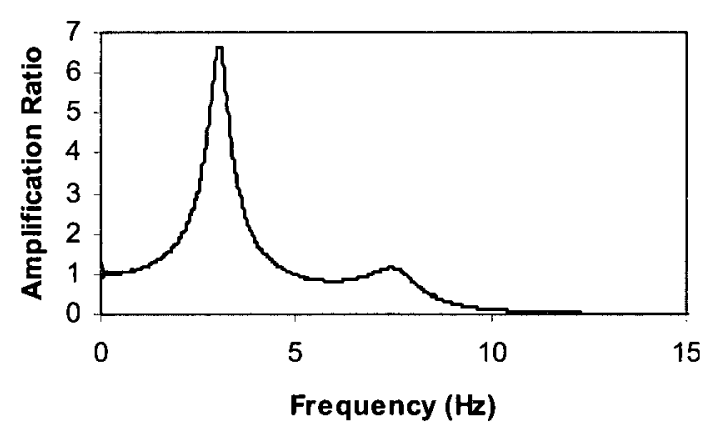

(b)

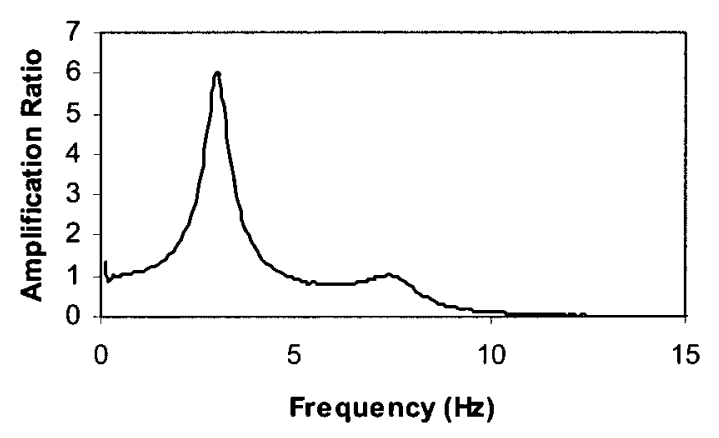

(d)

Fig. E1: Amplification Curve for site with $10 \mathrm{~m}$ deposit using the record having: (a) $P G A$ of $181 \mathrm{gal}$;; (b) PGA of $256 \mathrm{gal}$; (c) PGA of $304 \mathrm{gal}$; (d) PGA of $422 \mathrm{gal}$. 


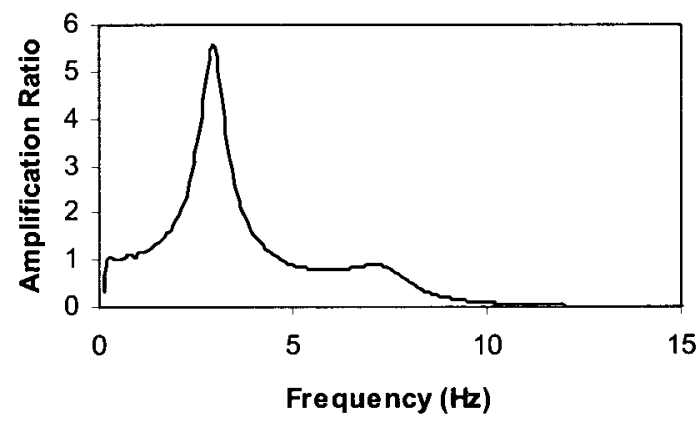

(a)

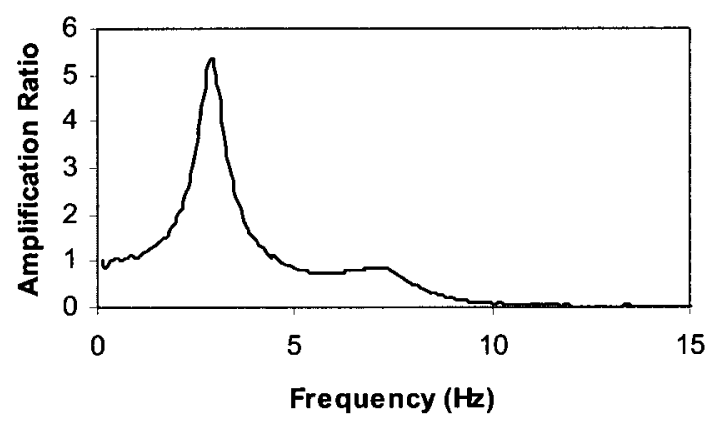

(c)

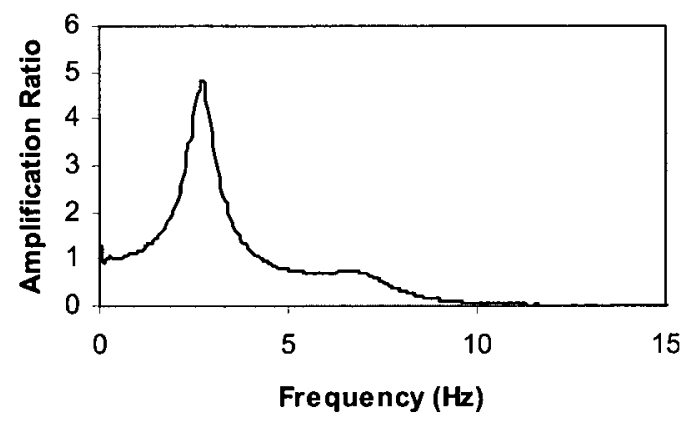

(b)

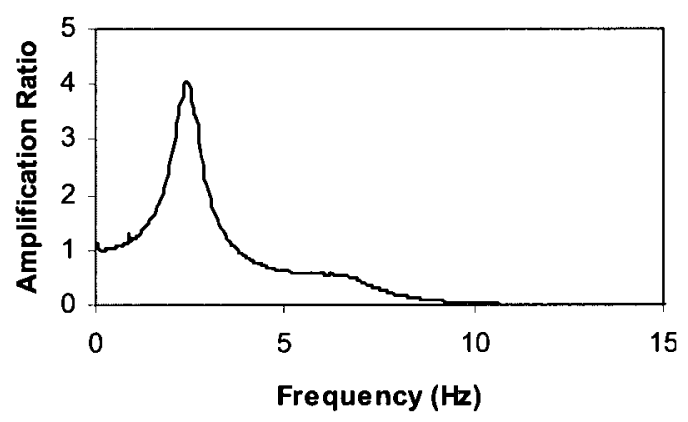

(d)

Fig. E2: Amplification Curve for site with $10 \mathrm{~m}$ deposit using the record having: (a) PGA of 512 gal.; (b) PGA of $607 \mathrm{gal}$; (c) PGA of $707 \mathrm{gal}$; (d) PGA of $812 \mathrm{gal}$. 


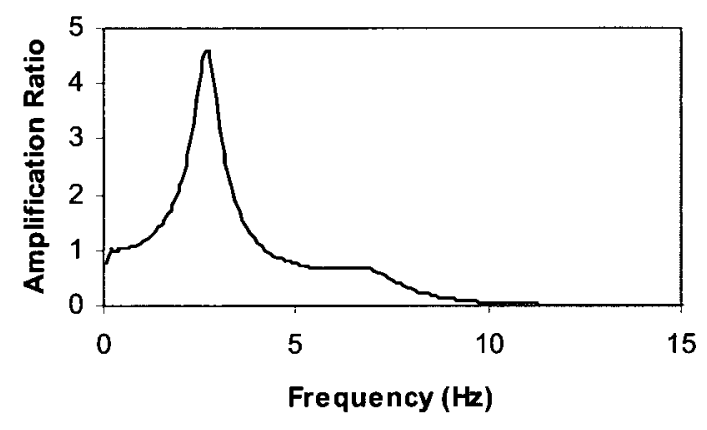

(a)

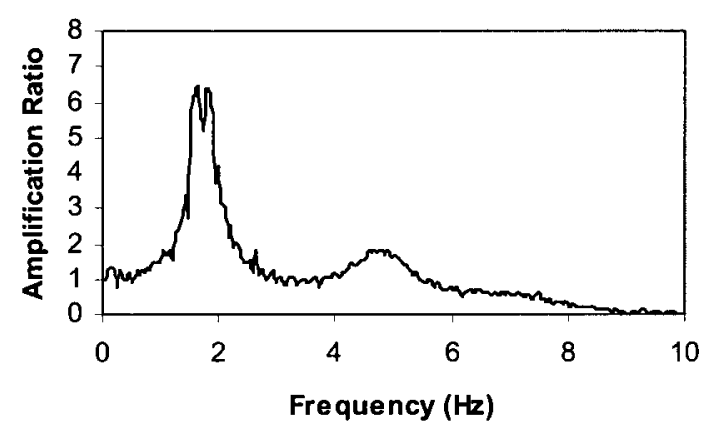

(c)

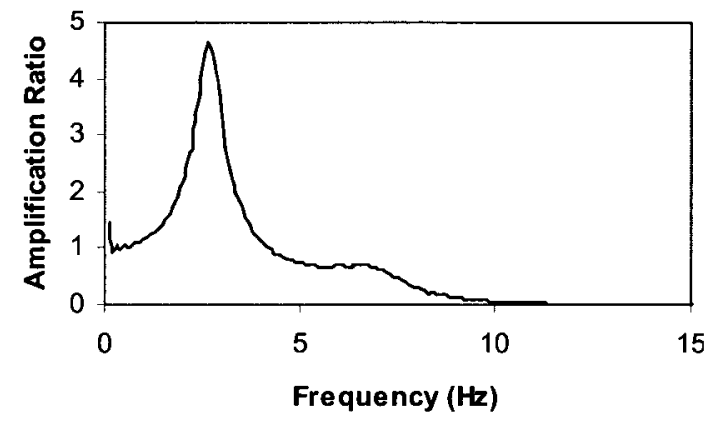

(b)

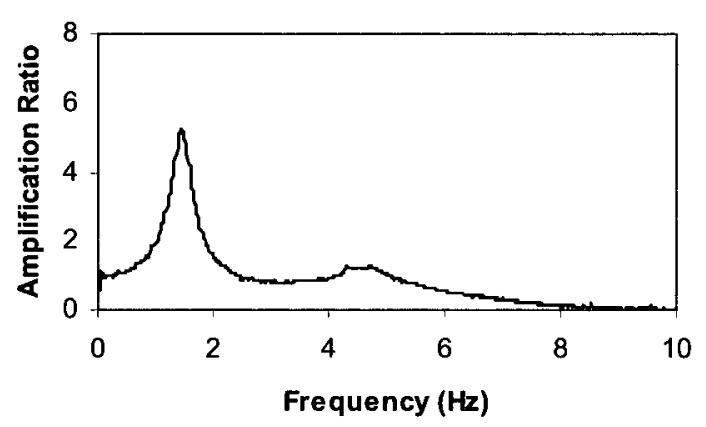

(d)

Fig. E3: Amplification Curve for the site (a) with $10 \mathrm{~m}$ deposit for target PGA of $942 \mathrm{gal}$;; (b) with $10 \mathrm{~m}$ deposit for target PGA of $1000 \mathrm{gal}$; (c) with $20 \mathrm{~m}$ deposit for target PGA of $181 \mathrm{gal}$; (d) with $20 \mathrm{~m}$ deposit for target PGA of $256 \mathrm{gal}$. 


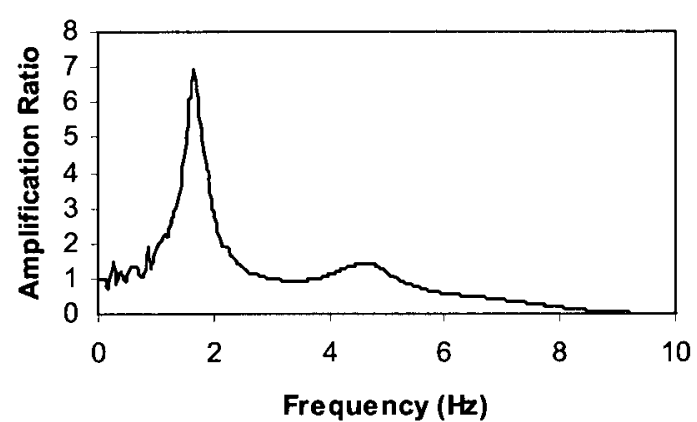

(a)

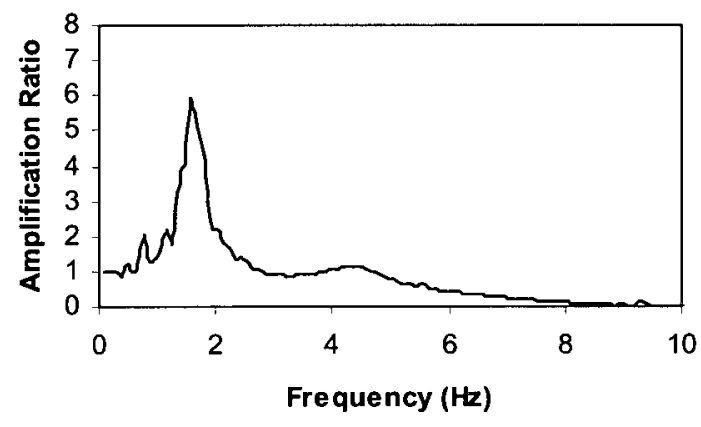

(c)

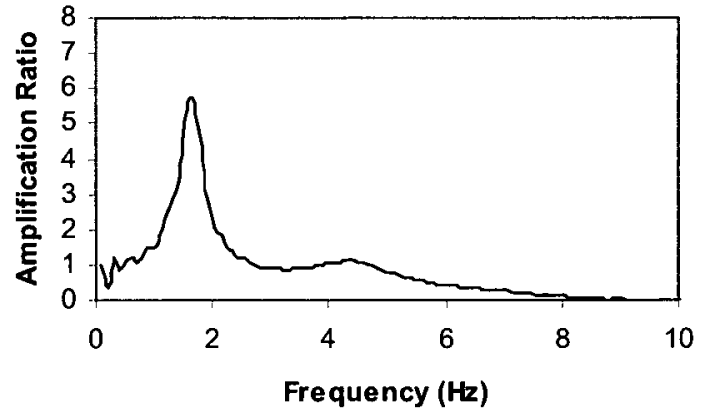

(b)

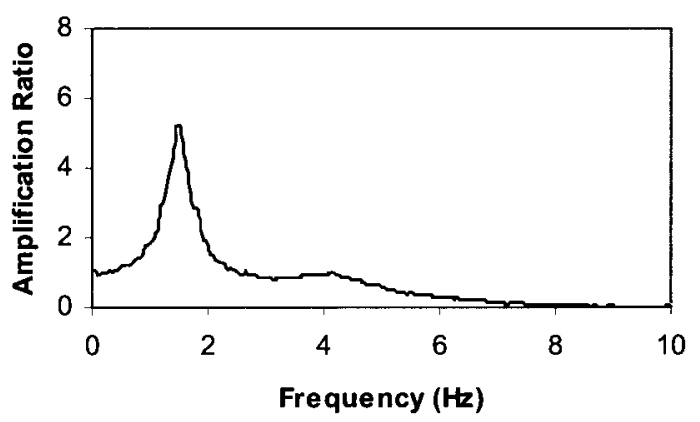

(d)

Fig. E4: Amplification Curve for site with $20 \mathrm{~m}$ deposit using the record having: (a) PGA of $304 \mathrm{gal}$.; (b) PGA of $422 \mathrm{gal}$; (c) PGA of $512 \mathrm{gal}$; (d) PGA of $607 \mathrm{gal}$. 


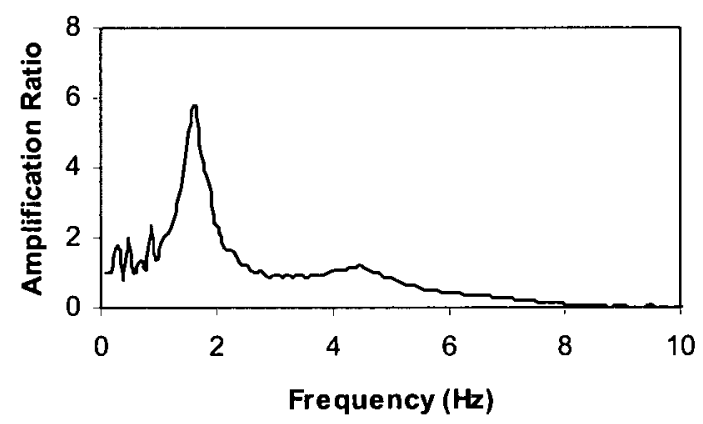

(a)

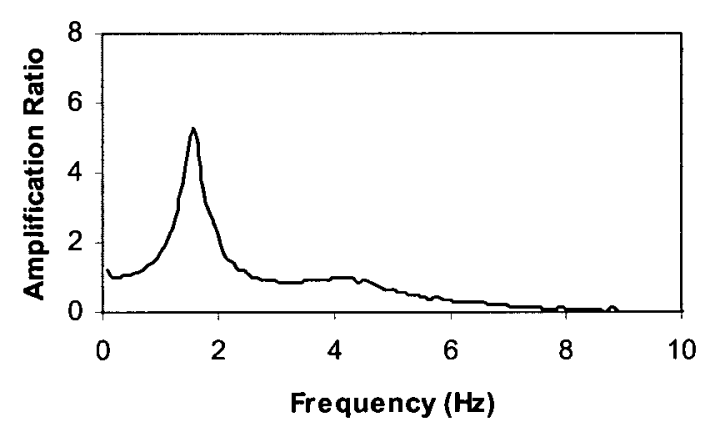

(c)

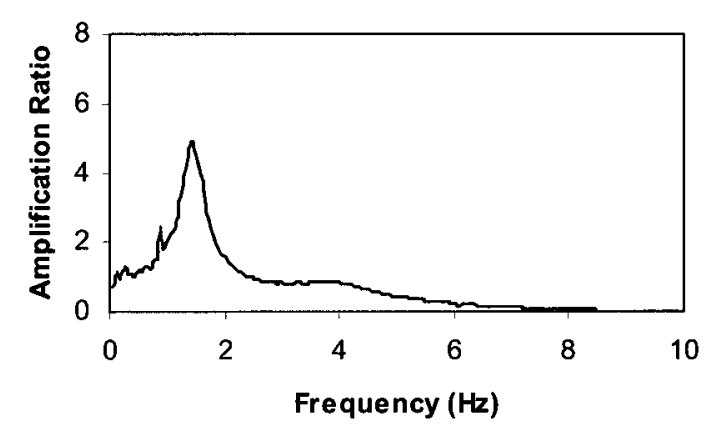

(b)

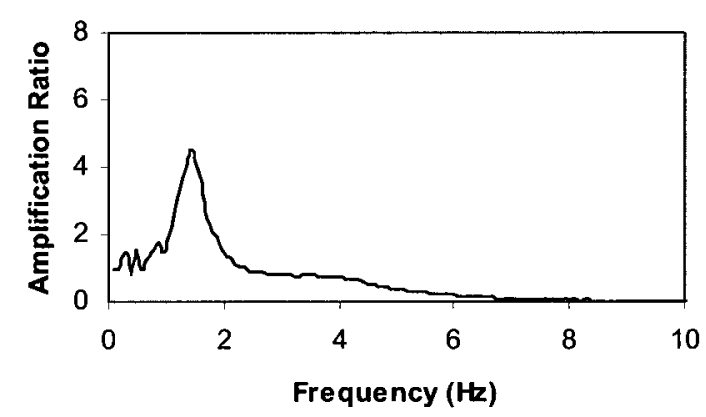

(d)

Fig. E5: Amplification Curve for site with $10 \mathrm{~m}$ deposit using the record having: (a) PGA of $707 \mathrm{gal}$; (b) PGA of $813 \mathrm{gal}$; (c) PGA of $942 \mathrm{gal}$; (d) PGA of $1000 \mathrm{gal}$. 
7.6. Appendix F: Sample of Amplification curves (response spectra definition) for the sites in Ottawa area for the low and high frequency amplification determination. The input records were chosen from the artificial Eastern Canadian Earthquakes.

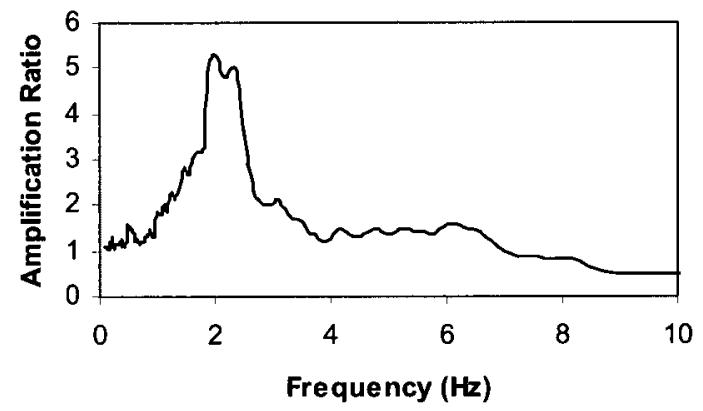

(a)

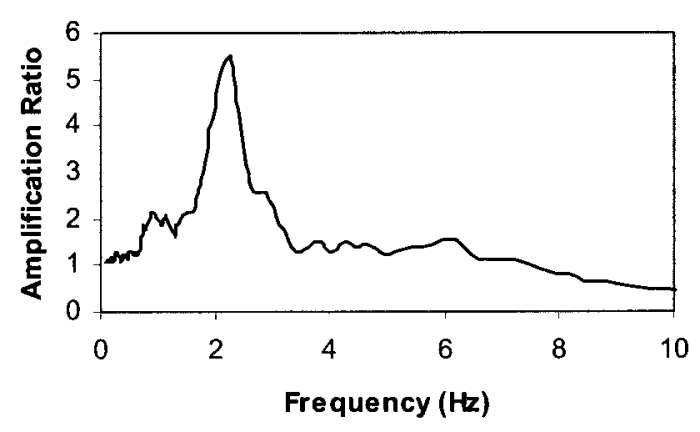

(c)

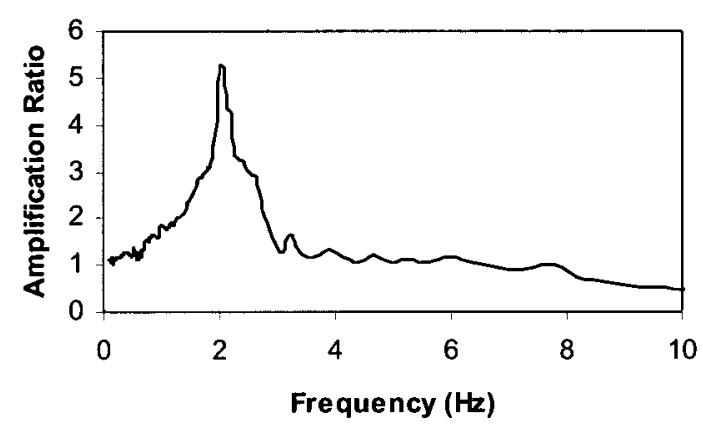

(b)

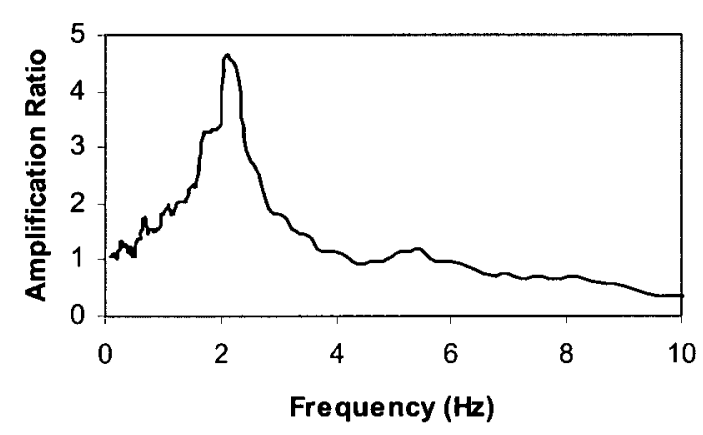

(d)

Fig. F1: Amplification Curve for site with $15 \mathrm{~m}$ deposit using the record having: (a) PGA of $181 \mathrm{gal}$;; (b) PGA of $256 \mathrm{gal}$; (c) PGA of $394 \mathrm{gal}$; (d) PGA of $422 \mathrm{gal}$. 


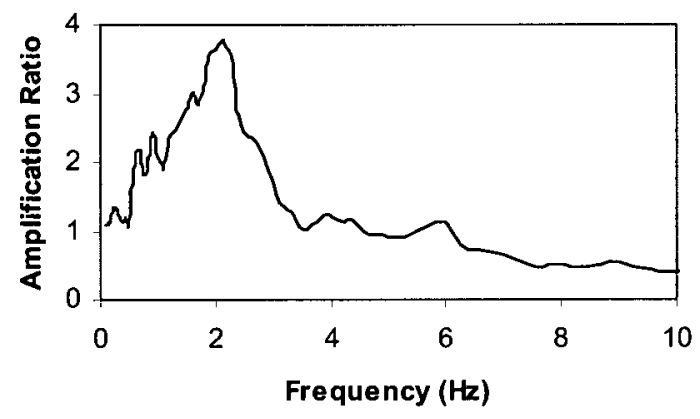

(a)

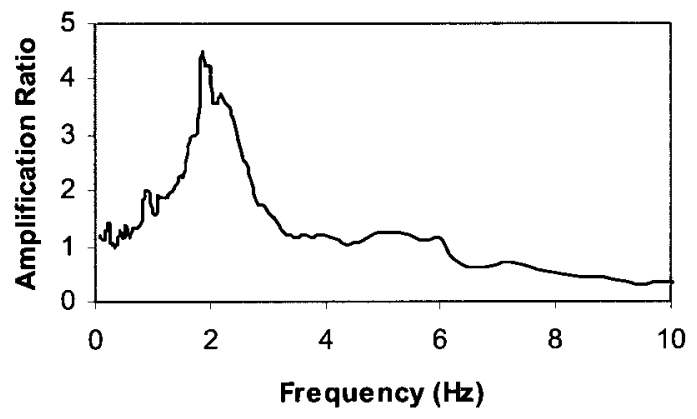

(c)

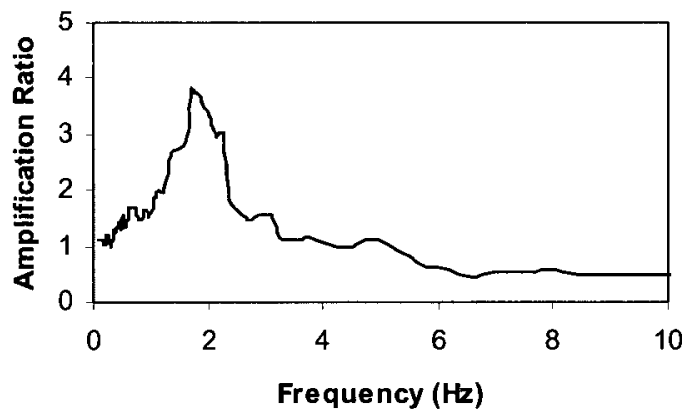

(b)

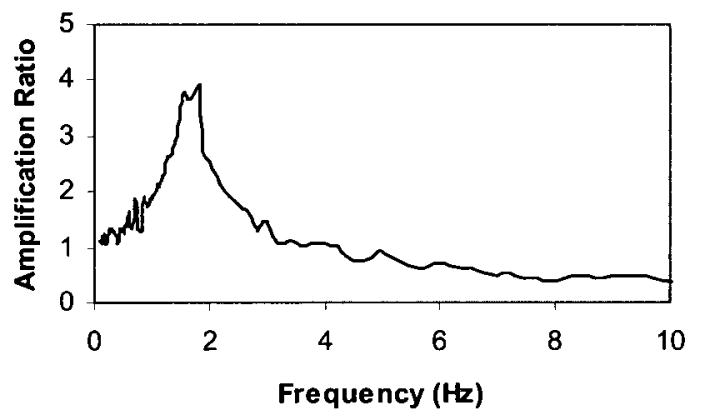

(d)

Fig. F2: Amplification Curve for site with $15 \mathrm{~m}$ deposit using the record having: (a) PGA of 512 gal.; (b) PGA of $607 \mathrm{gal}$; (c) PGA of $707 \mathrm{gal}$; (d) PGA of $812 \mathrm{gal}$. 


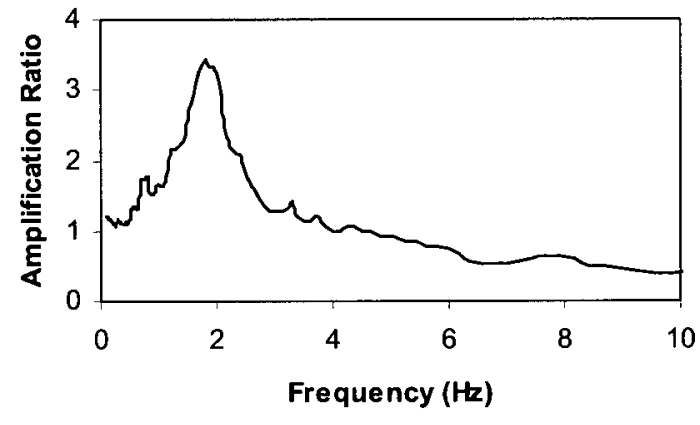

(a)

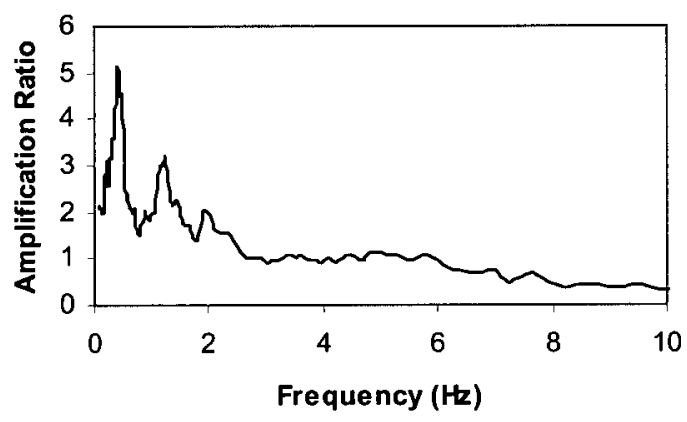

(c)

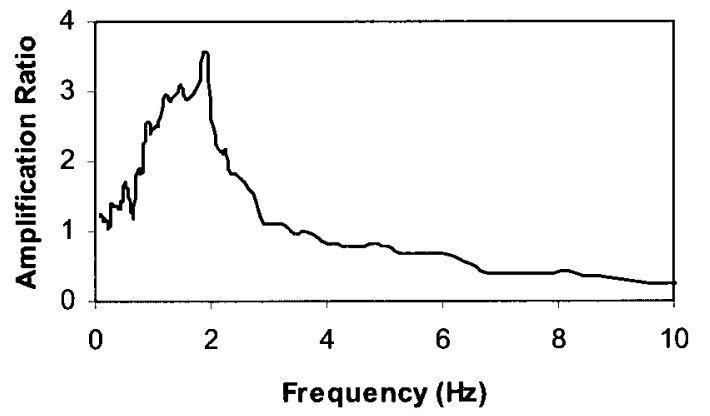

(b)

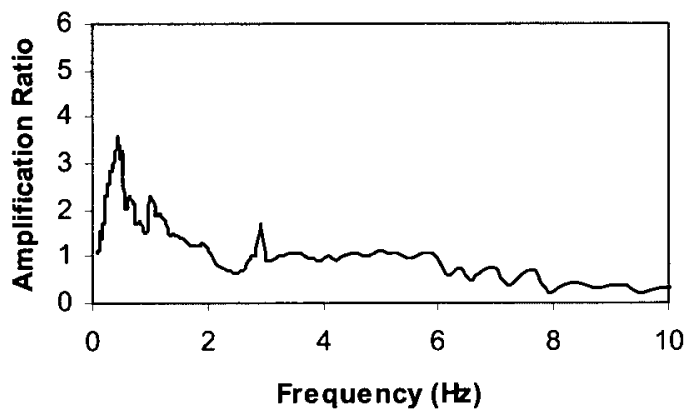

(d)

Fig. F3: Amplification Curve for the site (a) with $15 \mathrm{~m}$ deposit for target PGA of $942 \mathrm{gal}$; (b) with $15 \mathrm{~m}$ deposit for target $P G A$ of $1000 \mathrm{gal}$; (c) with $81 \mathrm{~m}$ deposit for target $P G A$ of $181 \mathrm{gal} ;$ (d) with $81 \mathrm{~m}$ deposit for target PGA of $256 \mathrm{gal}$ 


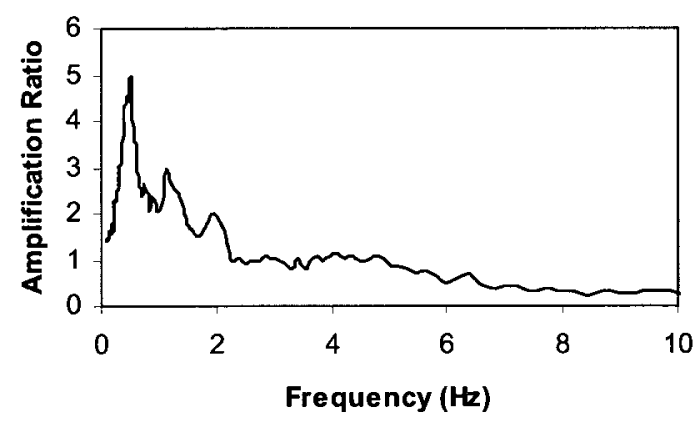

(a)

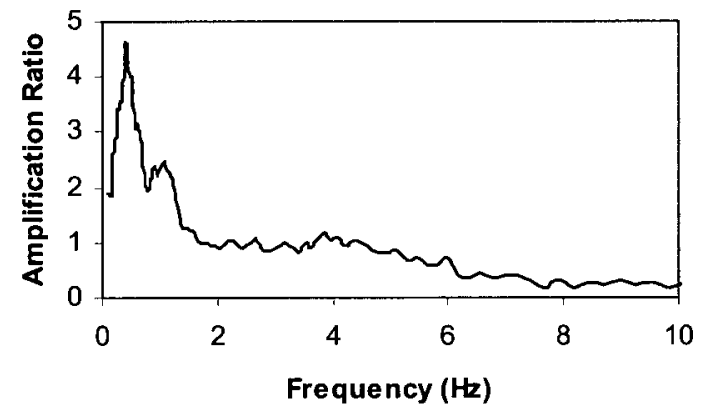

(c)

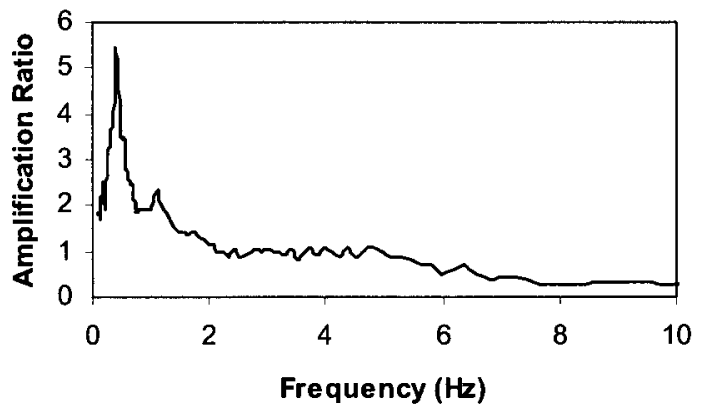

(b)

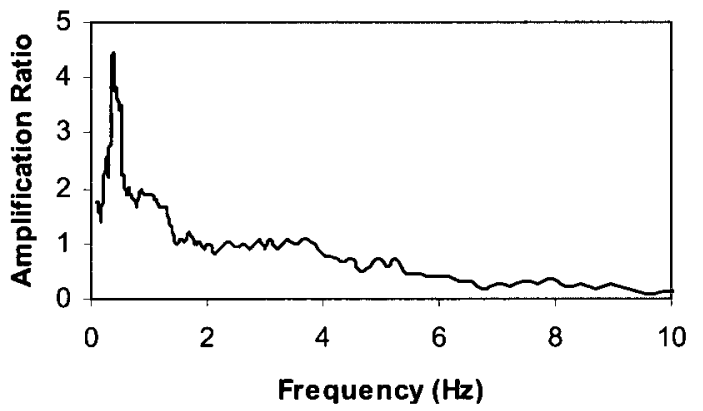

(d)

Fig. F4: Amplification Curve for site with $15 \mathrm{~m}$ deposit using the record having: (a) PGA of $304 \mathrm{gal}$; (b) PGA of $422 \mathrm{gal}$; (c) PGA of $512 \mathrm{gal}$; (d) PGA of $607 \mathrm{gal}$. 


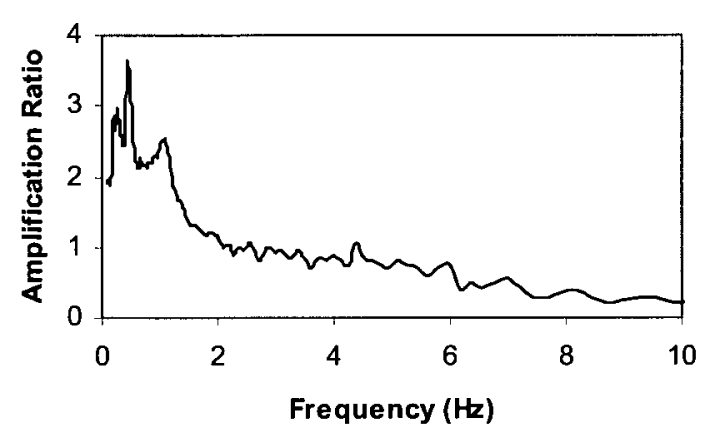

(a)

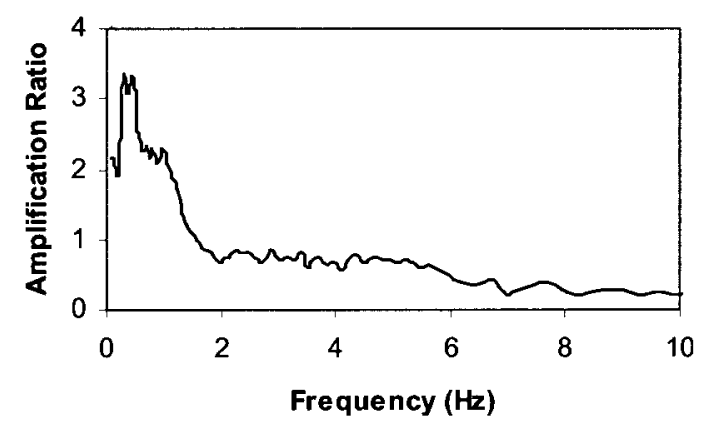

(c)

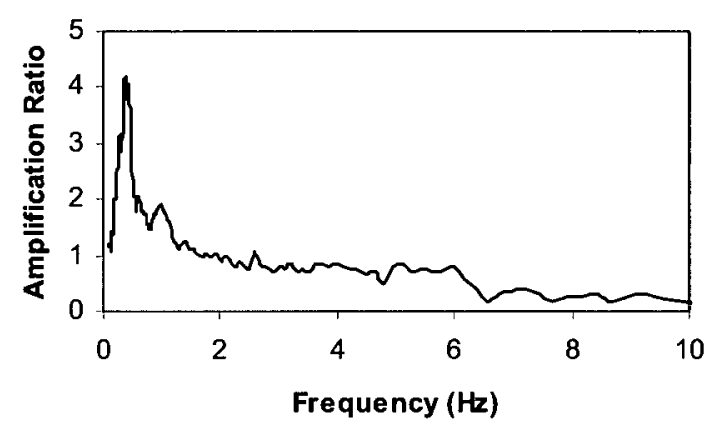

(b)

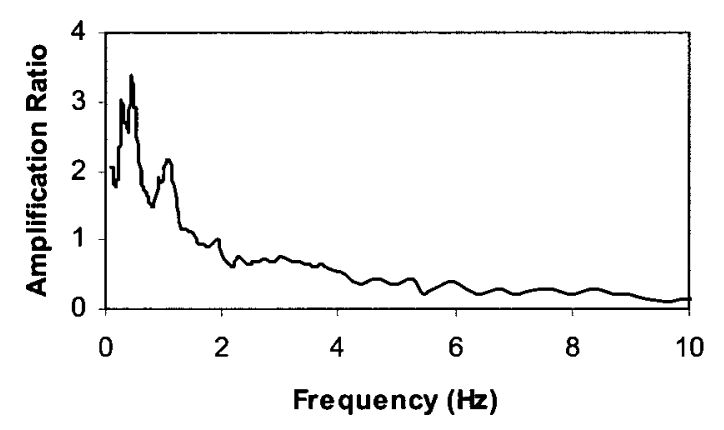

(d)

Fig. F5: Amplification Curve for site with $15 \mathrm{~m}$ deposit using the record having: (a) PGA of $707 \mathrm{gal} ;$ (b) PGA of $813 \mathrm{gal}$; (c) PGA of $942 \mathrm{gal}$; (d) PGA of $1000 \mathrm{gal}$. 
7.7. Appendix G: Extracted low frequency amplification values for $\mathbf{1 9}$ sites in Ottawa area subjected to different ground motions. Amplification values are based on the Fourier spectra definition of seismic amplification and are shown versus average $V_{\mathrm{s} 30}$ of the examined site.

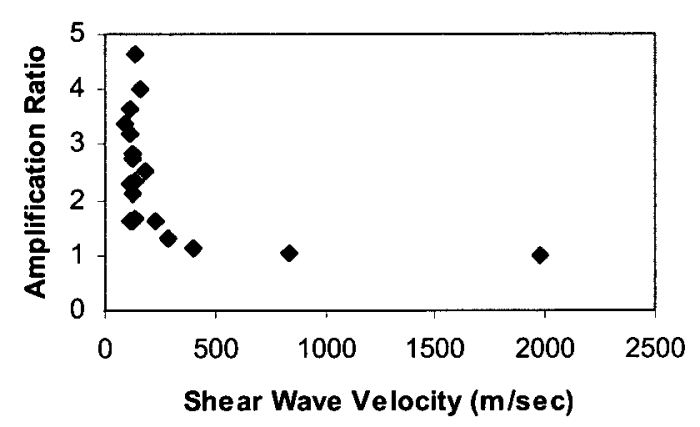

(a)

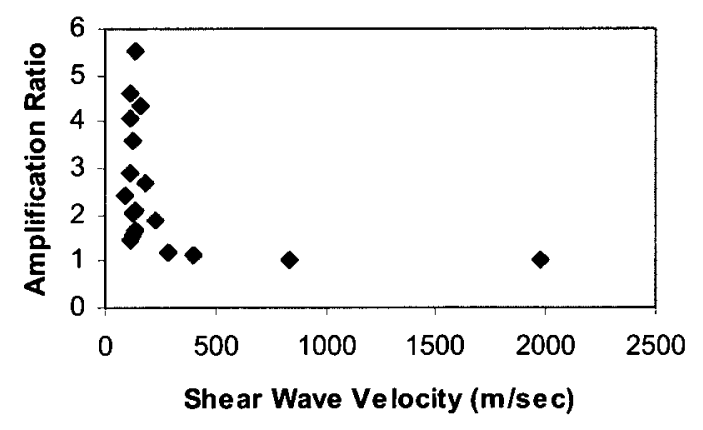

(c)

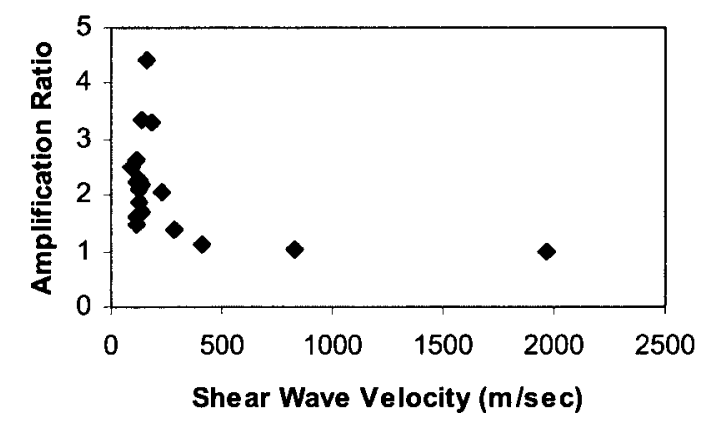

(b)

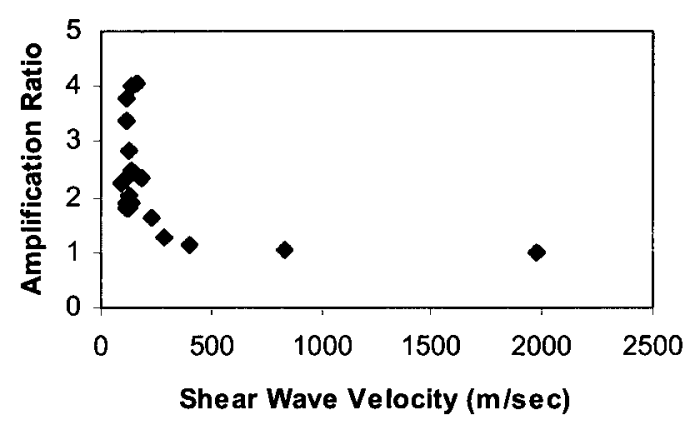

(d)

Fig. G1: Low frequency amplification values versus average $V_{s 30}$ for 19 sites using the record having: (a) PGA of $181 \mathrm{gal}$; (b) PGA of $256 \mathrm{gal}$; (c) PGA of $304 \mathrm{gal}$; (d) PGA of 422 gal. 


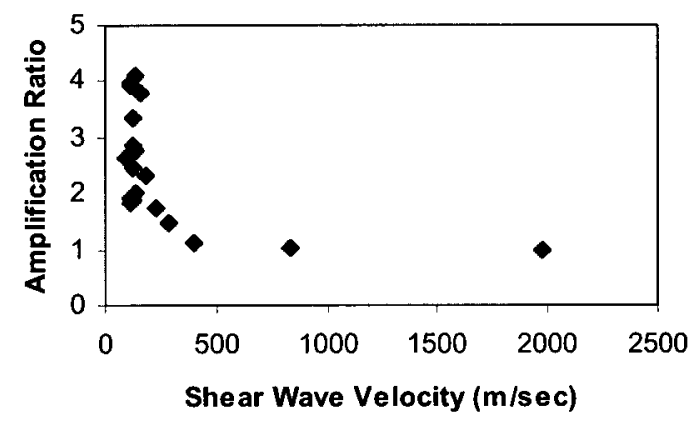

(a)

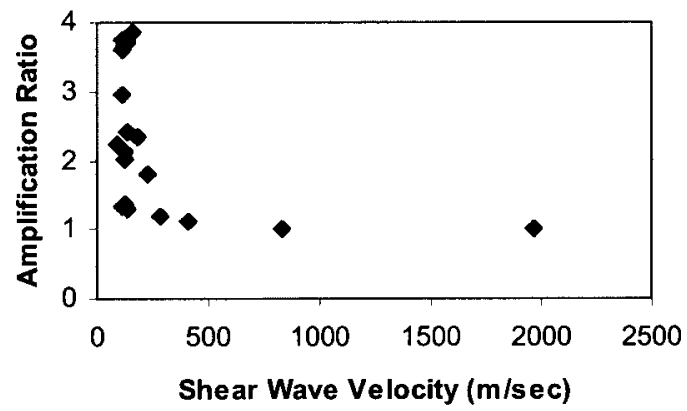

(c)

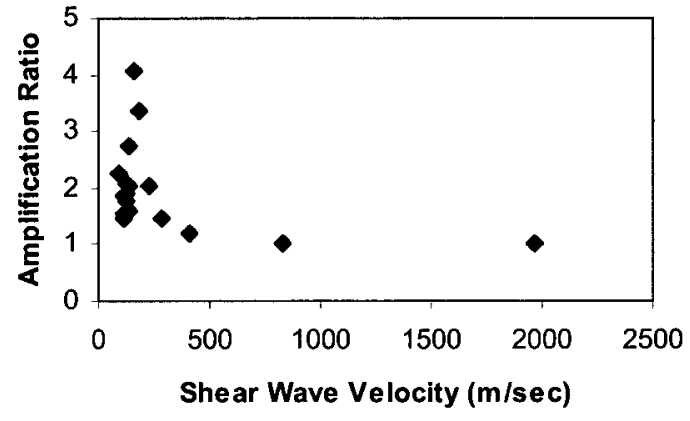

(b)

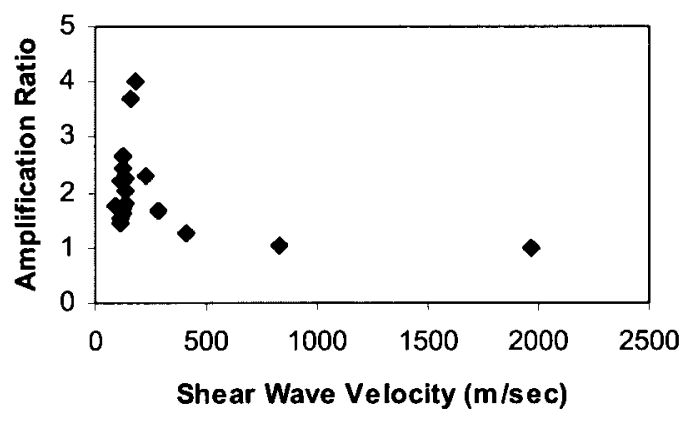

(d)

Fig. G2: Low frequency amplification values versus average $V_{s 30}$ for 19 sites using the record having: (a) PGA of 512 gal; (b) PGA of $607 \mathrm{gal}$; (c) PGA of $707 \mathrm{gal}$; (d) PGA of $813 \mathrm{gal}$. 


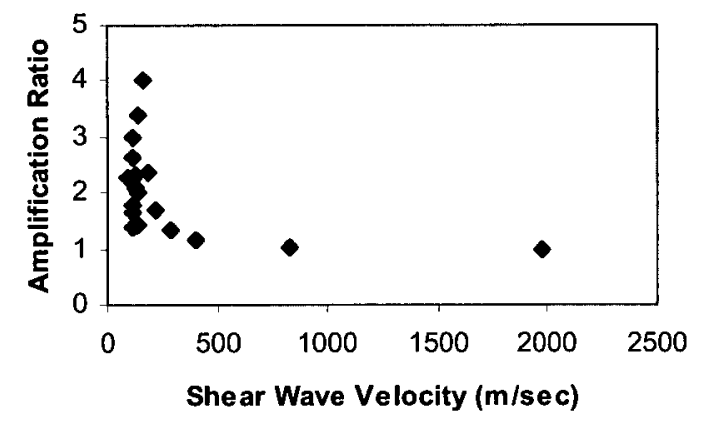

(a)

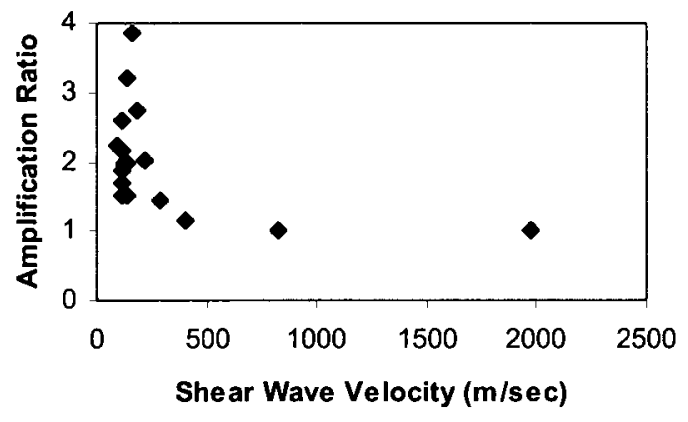

(b)

Fig. G3: Low frequency amplification values versus average $V_{s 30}$ for 19 sites using the record having: (a) PGA of 942 gal; (b) PGA of 1000 gal. 
7.8. Appendix H: Extracted high frequency amplification values for 19 sites in Ottawa area subjected to different ground motions. Amplification values are based on the Fourier spectra definition of seismic amplification and are shown versus average $V_{\mathrm{s} 30}$ of the examined site.

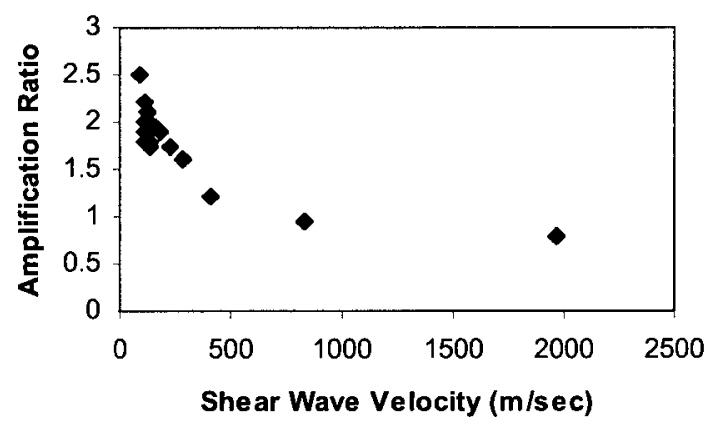

(a)

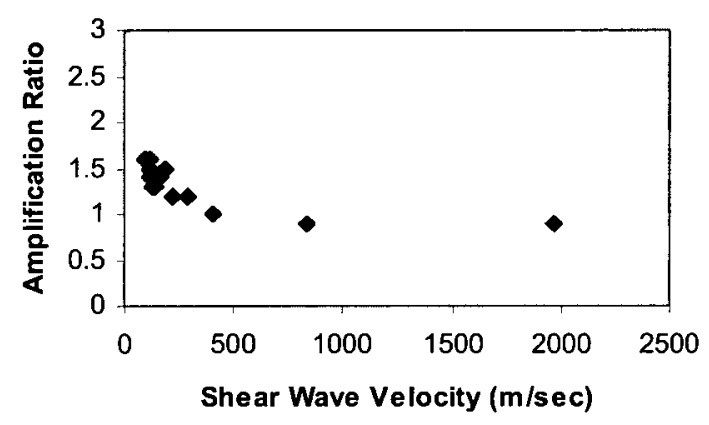

(c)

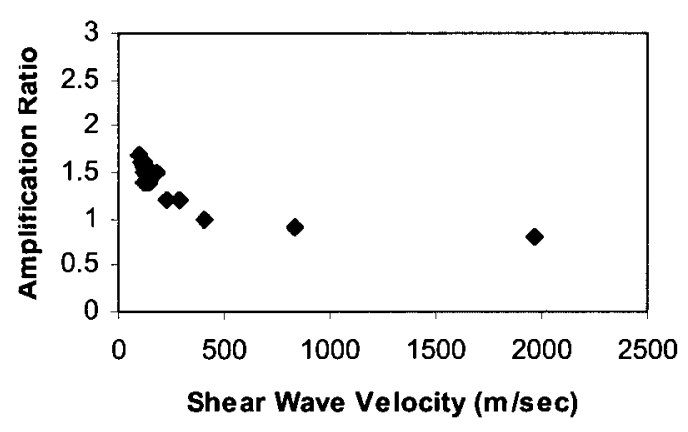

(b)

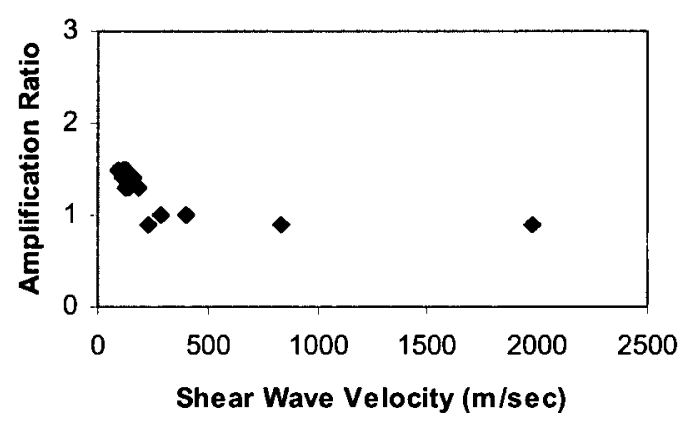

(d)

Fig. HI: High frequency amplification values versus average $V_{\text {s30 }}$ for 19 sites using the record having: (a) PGA of $181 \mathrm{gal}$; (b) PGA of $256 \mathrm{gal}$; (c) PGA of $304 \mathrm{gal}$; (d) PGA of $422 \mathrm{gal}$. 


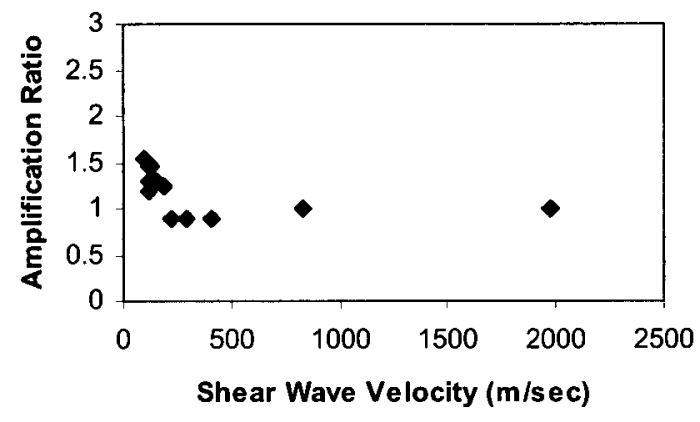

(a)

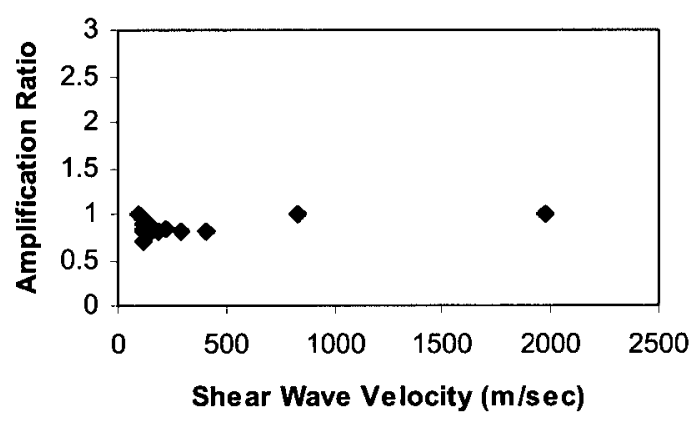

(c)

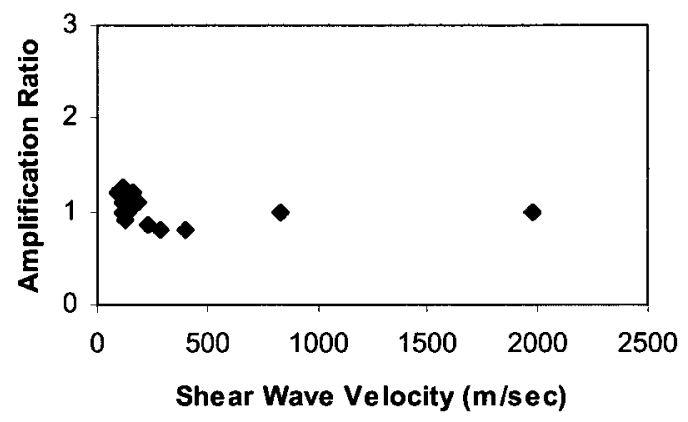

(b)

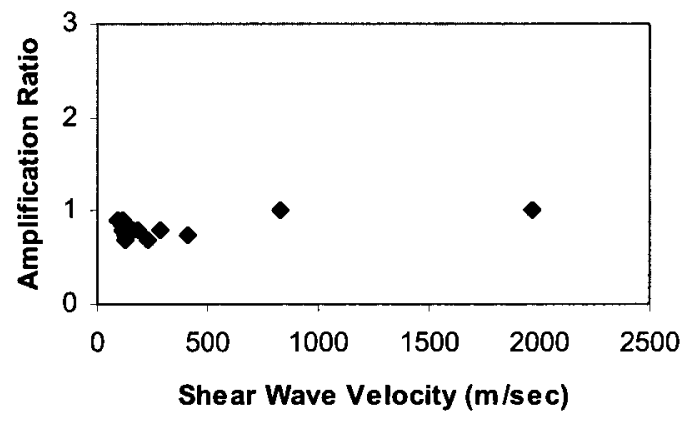

(d)

Fig. H2: High frequency amplification values versus average $V_{s 30}$ for 19 sites using the record having: (a) PGA of $512 \mathrm{gal}$;; (b) PGA of $607 \mathrm{gal}$; (c) PGA of $707 \mathrm{gal}$; (d) PGA of 813 gal. 


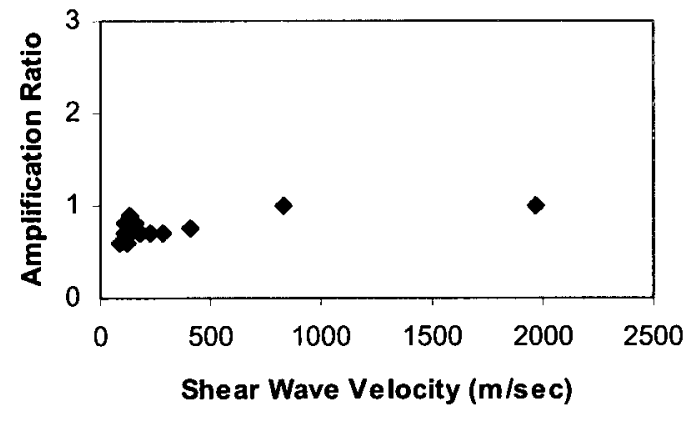

(a)

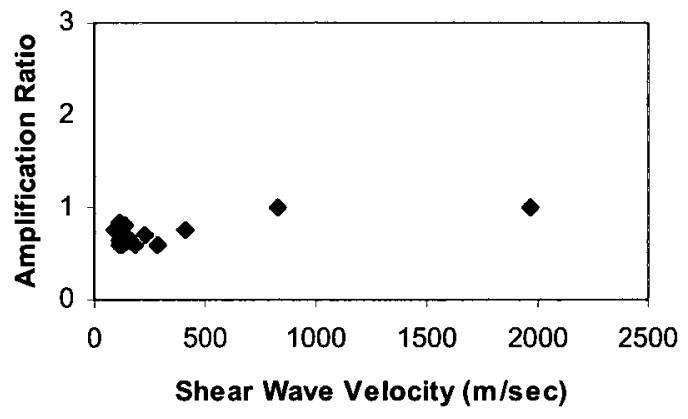

(b)

Fig. H3: High frequency amplification values versus average $V_{s 30}$ for 19 sites using the record having: (a) PGA of 942 gal.; (b) PGA of 1000 gal. 


\subsection{Appendix I: Extracted high frequency amplification values for 19} sites in Ottawa area subjected to different ground motions. Amplification values are based on the response spectra definition of seismic amplification and are shown versus average $V_{s 30}$ of the examined site.

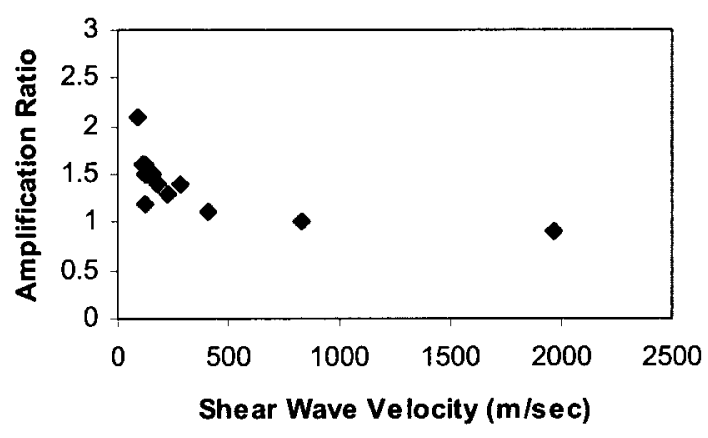

(a)

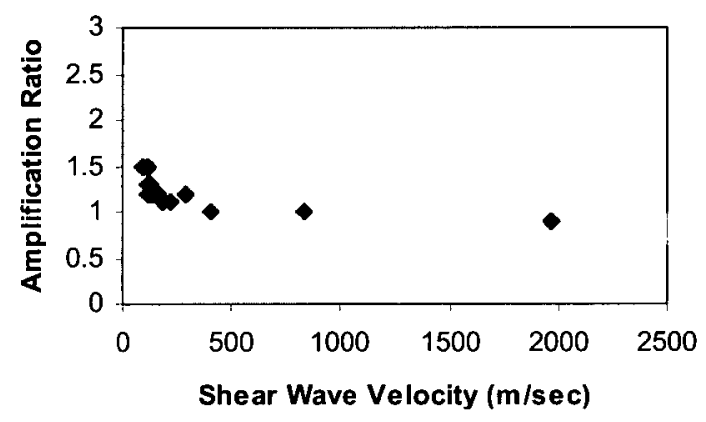

(c)

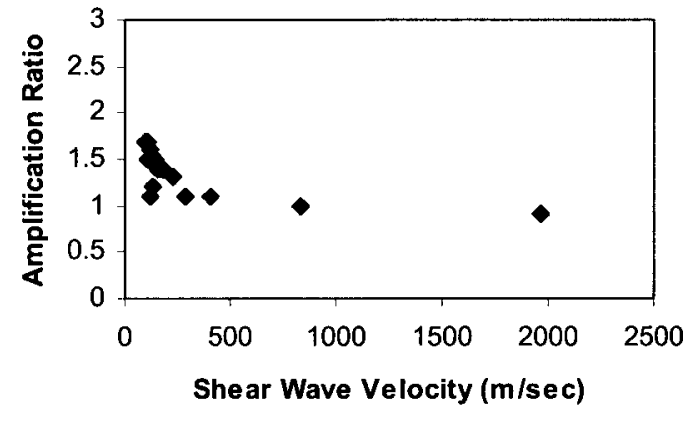

(b)

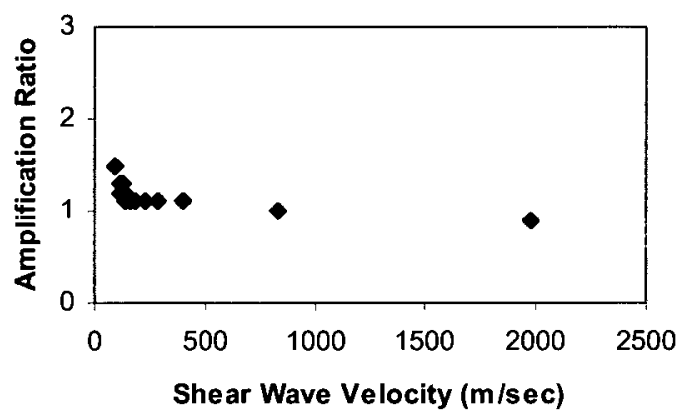

(d)

Fig. 11: High frequency amplification values (RS-based) versus average $V_{s 30}$ for 19 sites using the record having: (a) PGA of 181 gal.; (b) PGA of $256 \mathrm{gal}$; (c) PGA of $304 \mathrm{gal}$; (d) $P G A$ of $422 \mathrm{gal}$. 


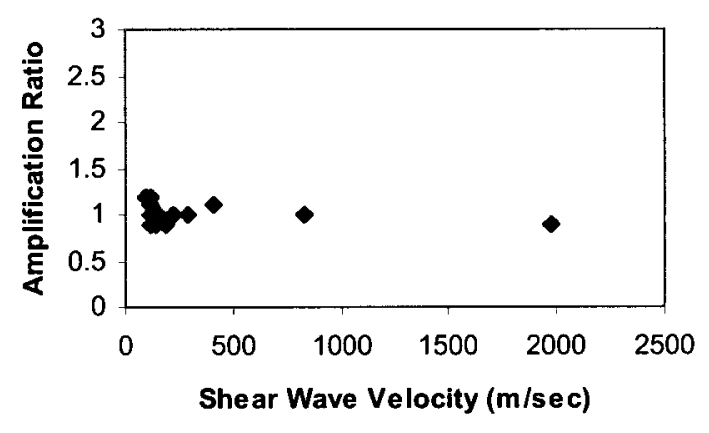

(a)

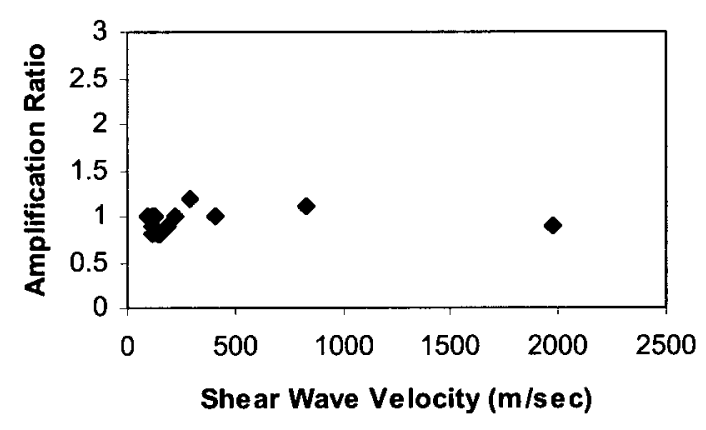

(c)

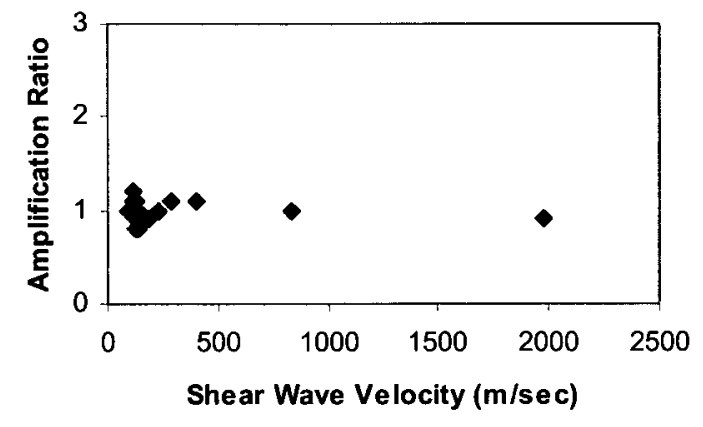

(b)

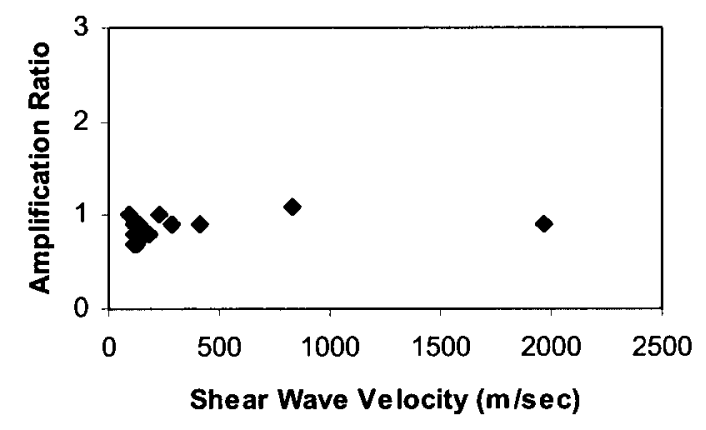

(d)

Fig. I2: High frequency amplification values (RS-based) versus average $V_{\text {s3o for }} 19$ sites using the record having: (a) PGA of $512 \mathrm{gal}$;; (b) PGA of $607 \mathrm{gal}$; (c) PGA of $707 \mathrm{gal}$; (d) PGA of $813 \mathrm{gal}$. 


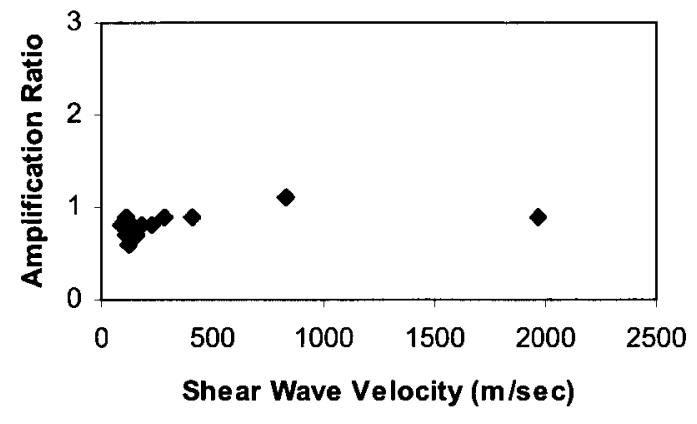

(a)

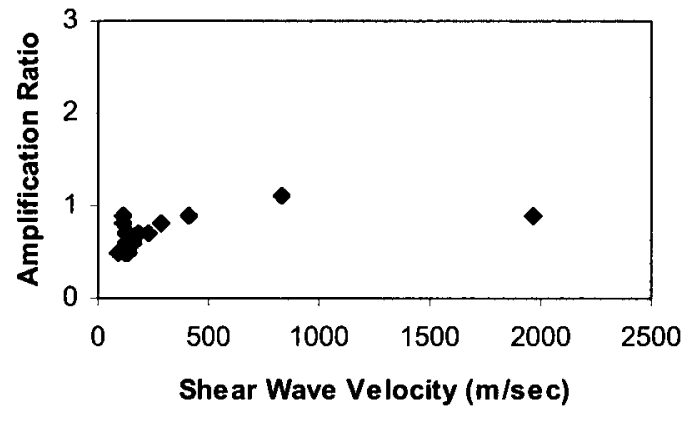

(b)

Fig. I3: High frequency amplification values (RS-based) versus average $V_{s 30}$ for 19 sites using the record having: (a) PGA of 942 gal.; (b) PGA of 1000 gal. 